\title{
Archaeology at the Alamodome: Investigations of a San Antonio Neighborhood in Transition, Volume III: Artifact and Special Studies
}

Anne A. Fox

Center for Archaeological Research

Marcie Renner

Center for Archaeological Research

Robert J. Hard

Department of Anthropology, University of Texas at San Antonio

Follow this and additional works at: https://scholarworks.sfasu.edu/ita

Part of the American Material Culture Commons, Archaeological Anthropology Commons, Environmental Studies Commons, Other American Studies Commons, Other Arts and Humanities Commons, Other History of Art, Architecture, and Archaeology Commons, and the United States History Commons

Tell us how this article helped you.

This Article is brought to you for free and open access by the Center for Regional Heritage Research at SFA ScholarWorks. It has been accepted for inclusion in Index of Texas Archaeology: Open Access Gray Literature from the Lone Star State by an authorized editor of SFA ScholarWorks. For more information, please contact cdsscholarworks@sfasu.edu. 
Archaeology at the Alamodome: Investigations of a San Antonio Neighborhood in Transition, Volume III: Artifact and Special Studies

\section{Creative Commons License}

(c) (1) (8)

This work is licensed under a Creative Commons Attribution-NonCommercial 4.0 International License 


\section{Archaeology at the Alamodome: Investigations of a San Antonio Neighborhood in Transition}

edited by Anne A. Fox, Marcie Renner, and Robert J. Hard

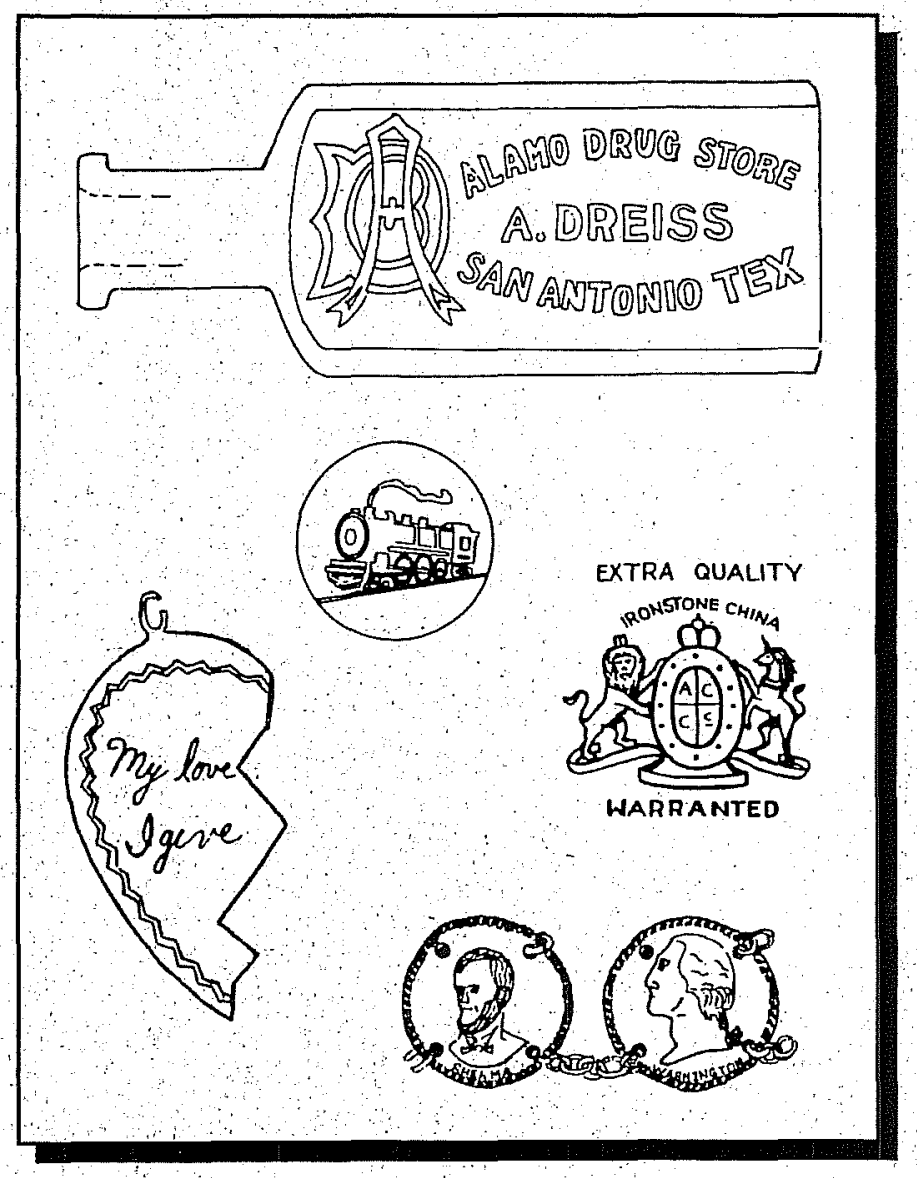

Volume III

Artifact and Special Studies

contributors:

Maureen Brown, Nora DeLaO, J. Philip Dering, Anne A. Fox, Kevin J. Gross, Johanna M. Hunziker, Barbara A. Meissner, Frank Meissner, Guillermo Mendez, René Muñoz, Cynthia L. Tennis, Mary Vaughan, and José E. Zapata

Center for Archaeological Research, The University of Texas at San Antonio Archaeological Survey Report, No. 238, 1997 



\title{
Archaeology at the Alamodome: Investigations of a San Antonio Neighborhood in Transition
}

\author{
edited by Anne A. Fox, Marcie Renner, and Robert J. Hard
}

\author{
Volume III \\ Artifact and Special Studies
}

contributors:

Maureen Brown, Nora DeLaO, J. Philip Dering, Anne A. Fox,

Kevin J. Gross, Johanna M. Hunziker, Barbara A. Meissner, Frank Meissner, Guillermo Mendez, René Muñoz, Cynthia L. Tennis, Mary Vaughan, and José E. Zapata

Robert J. Hard, Jack D. Eaton, and Anne A Fox, Principal Investigators

Texas Antiquities Committee Permit Numbers 900, 930, and 982

Ocopyright

Center for Archaeological Research

The University of Texas at San Antonio

Archaeological Survey Report, No. 238

1995 
The following information is provided in accordance with the General Rules of Practice and Procedure, Chapter 41.11 (Investigative Reports), Texas Antiquities Committee:

1. Type of investigation: Survey, testing, and mitigation

2. Project name: Alamodome

3. County: Bexar

4. Principal investigators: Robert J. Hard, Jack D. Eaton, and Anne A. Fox

5. Name and location of sponsoring agency: City of San Antonio, P.O. Box 839966, San Antonio, Texas 782833966

6. Texas Antiquities Committee Permit Nos.: 900, 932, and 982

7. Published by the Center for Archaeological Research, The University of Texas at San Antonio, San Antonio, Texas 78249-0658, 1997

A list of publications offered by the Center for Archaeological Research is available. Call (210) 458-4378; write to the Center for Archaeological Research, The University of Texas at San Antonio, 6900 N. Loop 1604 W., San Antonio, Texas 78249-0658; e-mail to car@lonestar.utsa.edu; or visit CAR's Web site at http://www.csbs.utsa.edu/research/car/index.htm. 


\section{Contents}

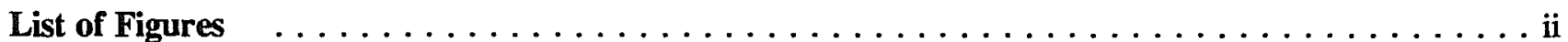

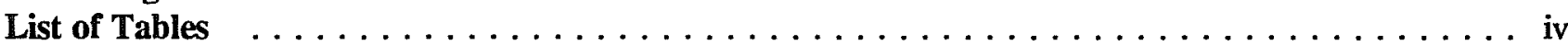

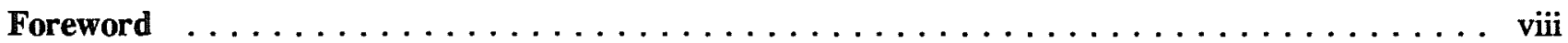

Chapter 1: Ceramic Patterns and Variations

Cynthia L. Tennis . . . . . . . . . . . . . . . . . . . . . . . 1

Chapter 2: Glass

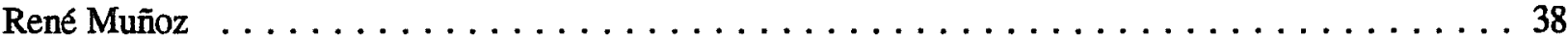

Chapter 3: Dolls, Toys, Games, and Other Diversions

Barbara A. Meissner . . . . . . . . . . . . . . . . . . . . . . . . . 57

Chapter 4: Alamodome and Abroad: A Composite Inquiry on Toy Marbles

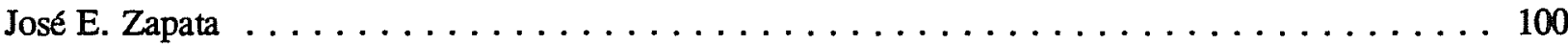

Chapter 5: Making the Man: Remains of Clothing Recovered from the Alamodome Project Barbara A. Meissner . . . . . . . . . . . . . . . . . . . . . . . . . . . . 119

Chapter 6: Matters Public and Private: Items of Personal Use from the Alamodome Project

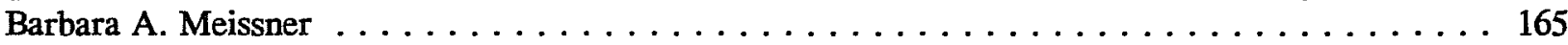

Chapter 7: Kitchen Utensils and Tablewares

Mary Vaughan .................................... 209

Chapter 8: Architectural Materials

Kevin J. Gross and Frank Meissner . . . . . . . . . . . . . . . . . . . . . . . . 229

Chapter 9: An Examination of Acequias, Wells, and Cisterns in San Antonio, Texas, ca. 1850-1930

Kevin J. Gross and Guillermo Mendez . . . . . . . . . . . . . . . . . . . 242

Chapter 10: Beneath a Crescent Moon: A Contextual and Architectural Analysis of Privies from the Alamodome Project Area

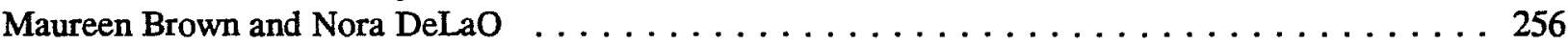

Chapter 11: Plant Remains from Historical Sites Affected by the Alamodome Project

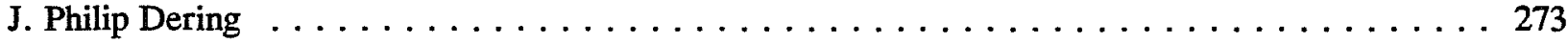

Chapter 12: Analysis of the Vertebrate Faunal Remains from the Alamodome Project Barbara A. Meissner . . . . . . . . . . . . . . . . . . . . . 286

Chapter 13: Summary

Anne A. Fox 


\section{Figures}

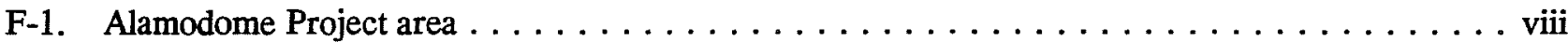

1-1. Band and line sherds.. . . . . . . . . . . . . . . . . . . . . . . 5

1-2. Edgeware, Banded Slip, and Spongeware $\ldots \ldots \ldots \ldots \ldots \ldots \ldots \ldots \ldots \ldots \ldots$

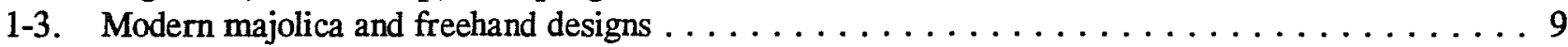

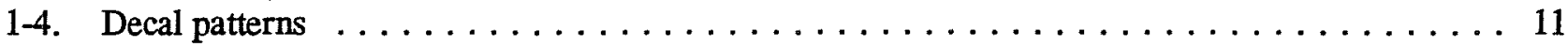

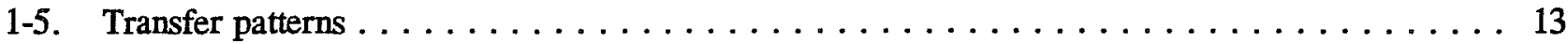

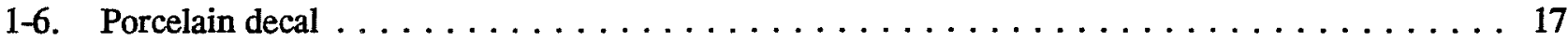

1-7. Stoneware . . . . . . . . . . . . . . . . . . . . . . . . . . . . . . . 19

2-1. Gordon's Gin bottle and base. . . . . . . . . . . . . . . . . . . . 42

2-2. Coca Cola bottle from the St. Anthony Hotel. . . . . . . . . . . . . . . . . . . . . 42

2-3. Chamberlain's Colic, Cholera, and Diarrhea Remedy. . . . . . . . . . . . . . . 43

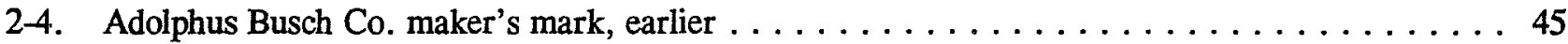

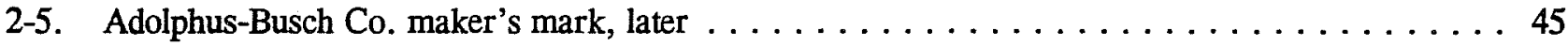

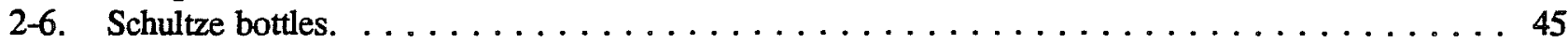

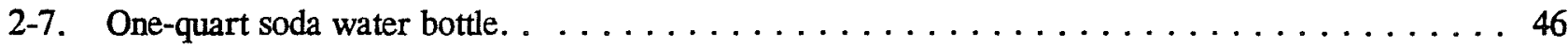

2-8. Duerler soda water bottle. . . . . . . . . . . . . . . . . . . . . . 47

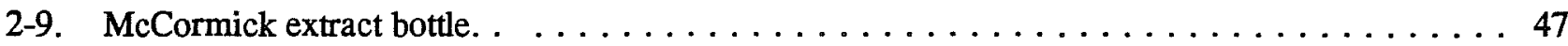

2-10. Relative frequencies of maker's marks. . . . . . . . . . . . . . . . . . . 49

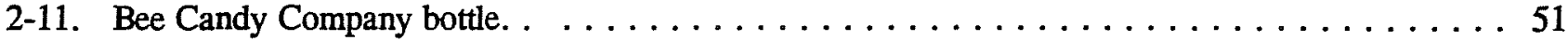

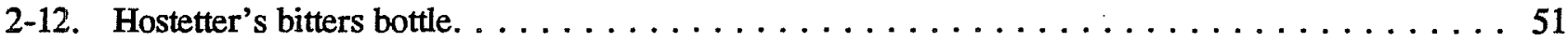

3-1. Ceramic doll fragments. . . . . . . . . . . . . . . . . . . . . . . . . 64

3-2. Ceramic doll fragments; ceramic doll dishes; glass doll bottle; and metal doll dish . . . . . . . . 66

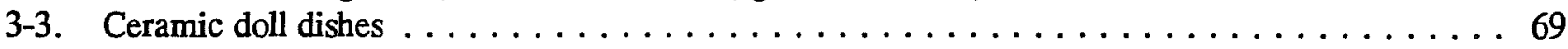

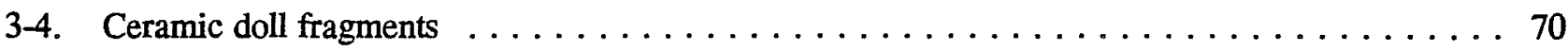

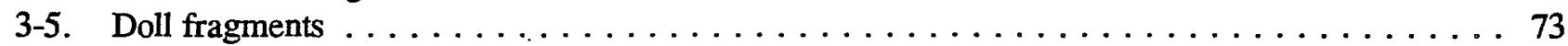

3-6. Doll back with "Alma" mark . . . . . . . . . . . . . . . . . . . . . 76

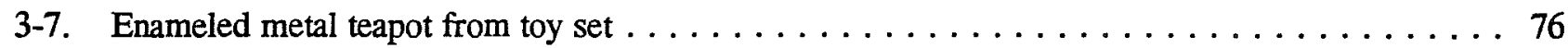

3-8. Ceramic doll dishes . . . . . . . . . . . . . . . . . . . . . . . . 77

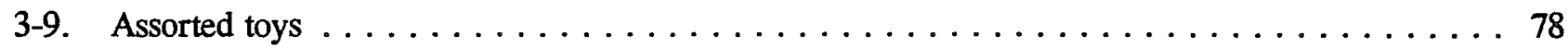

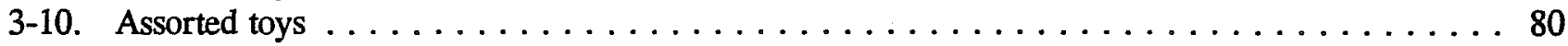

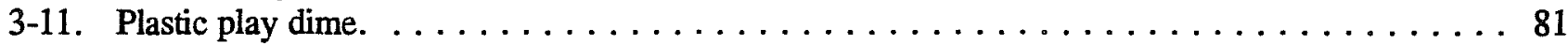

3-12. "Captain Hawks" cereal premium pre-dating $1938 \ldots \ldots \ldots \ldots \ldots \ldots \ldots$

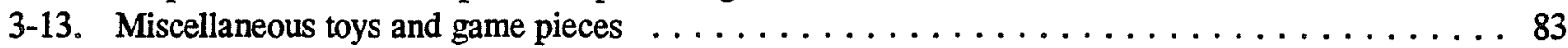

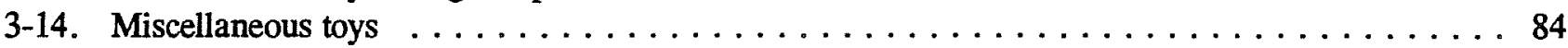

3-15. Miscellaneous items . . . . . . . . . . . . . . . . . . . . . . 93

3-16. Miscellaneous items . . . . . . . . . . . . . . . . . . . . . . . 94

4-1. Marbles from the Alamodome Project . . . . . . . . . . . . . . . . . . . . . 105

5-1. Variation in button composition across the 28 Alamodome Project sites. . . . . . . . . . . . . 124

5-2. Buttons from the Alamodome Project . . . . . . . . . . . . . . . . . . . . 143

5-3. Average button "price" for selected sites . . . . . . . . . . . . . . . . . . . 162

6-1. Miscellaneous personal items from the Alamodome Project. . . . . . . . . . . . . . . . . . 169

6-2. Miscellaneous personal items from the Alamodome Project. . . . . . . . . . . . . . . . . 171

6-3. Miscellaneous personal items from the Alamodome Project. . . . . . . . . . . . . . . . . 173

6-4. Miscellaneous personal items from the Alamodome Project. . . . . . . . . . . . . . . . . . 175

6-5. Miscellaneous personal items from the Alamodome Project . . . . . . . . . . . . . . . . 179 
6-6. Miscellaneous personal items from the Alamodome Project. . . . . . . . . . . . 182

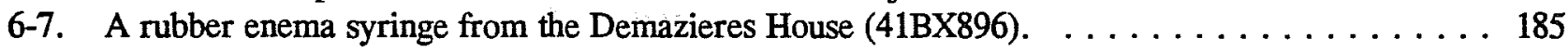

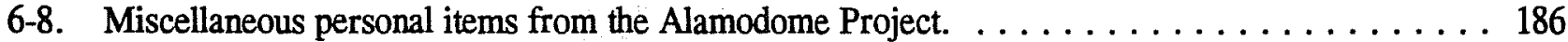

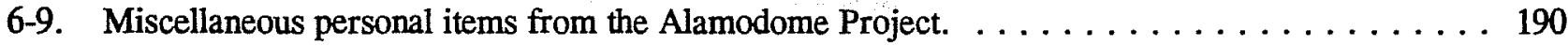

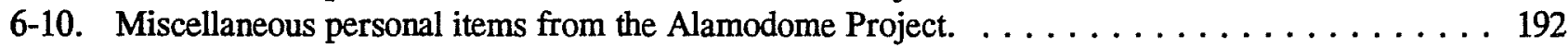

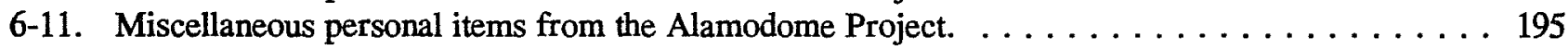

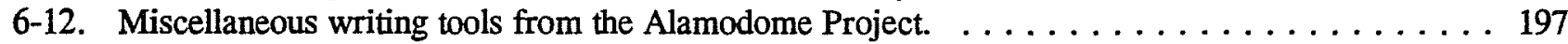

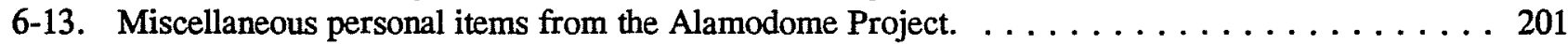

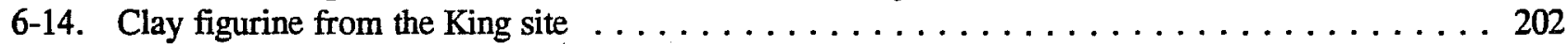

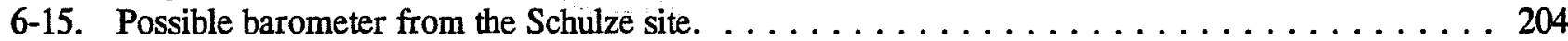

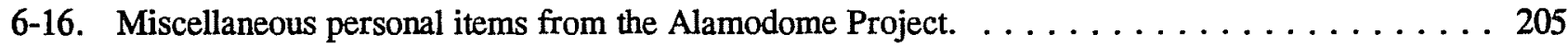

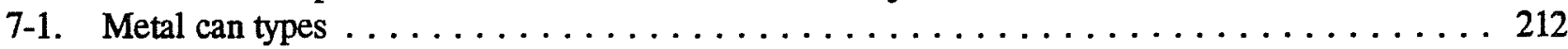

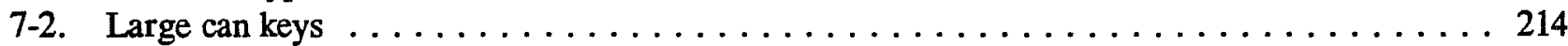

7-3. Small can keys from the Alamodome Project $\ldots \ldots \ldots \ldots \ldots \ldots \ldots \ldots \ldots \ldots \ldots \ldots \ldots$

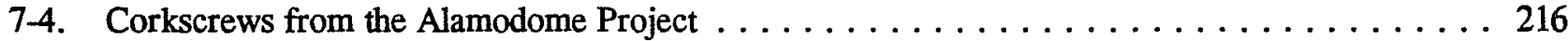

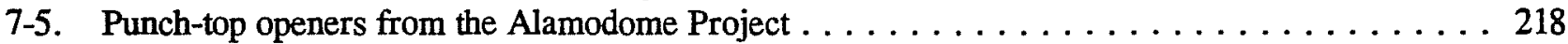

7-6. Late punch-type openers from the Alamodome Project. . . . . . . . . . . . . . . 219

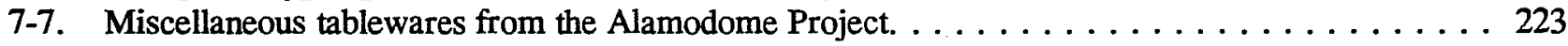

7-8. Miscellaneous tablewares from the Alamodome Project $\ldots \ldots \ldots \ldots \ldots \ldots \ldots \ldots \ldots \ldots \ldots \ldots$

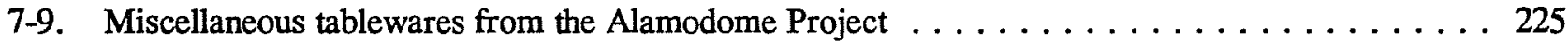

7-10. Miscellaneous tablewares from the Alamodome Project $\ldots \ldots \ldots \ldots \ldots \ldots \ldots \ldots \ldots \ldots \ldots \ldots$

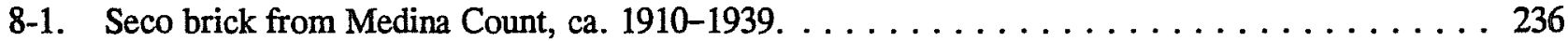

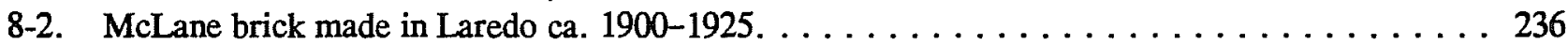

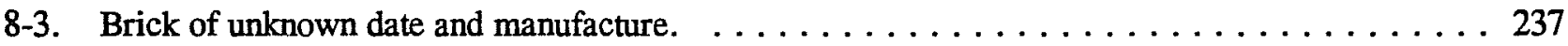

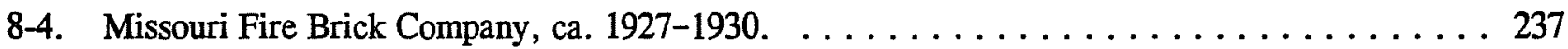

8-5. Parker and Russell Mining and Manufacturing Company of St. Louis, after 1921 . . . . . . 238

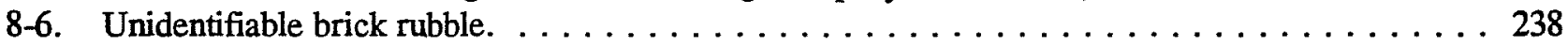

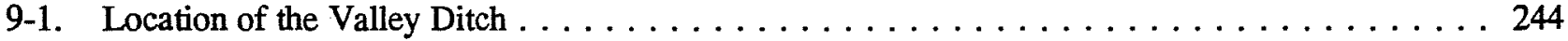

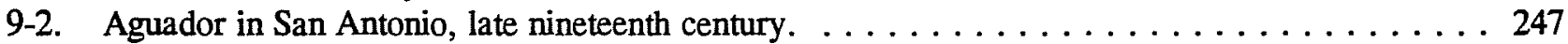

9-3. Webb well. . . . . . . . . . . . . . . . . . . . . . . . . 247

9-4. Plan map of the Pauly site. . . . . . . . . . . . . . . . . . . . . . . 249

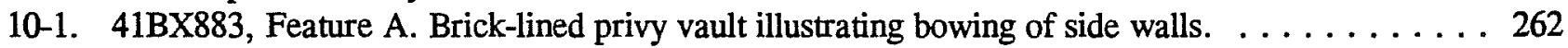

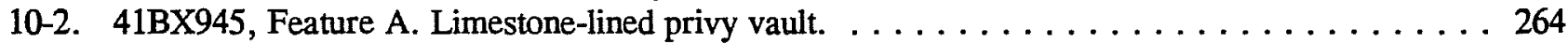

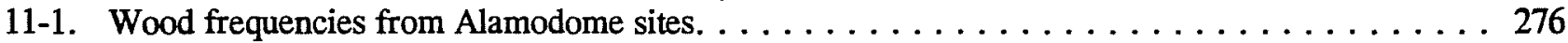

11-2. Fruits and seeds from Alamodome privies $\ldots \ldots \ldots \ldots \ldots \ldots \ldots \ldots \ldots \ldots \ldots \ldots \ldots \ldots$

12-1. Dog burial in site 41BX896 . . . . . . . . . . . . . . . . . . . . . 299

12-2. Photographs of a bullet hole in a lumbar vertebra of Bos taurus. . . . . . . . . . 330

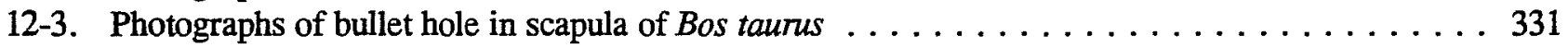

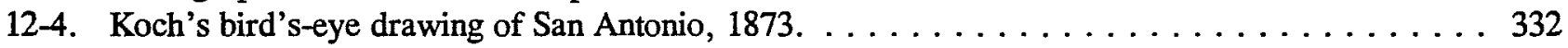

12-5. Comparison of expensive, mid-priced, and cheap meats, as a percentage of total weight purchased . . . . . . . . . . . . . . . . . . . . . . . . 339

12-6. Comparison of cost efficiency (Lyman 1987), as a percentage of total weight purchased . . . . 339 


\section{Tables}

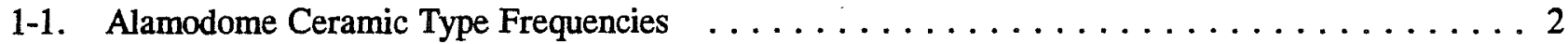

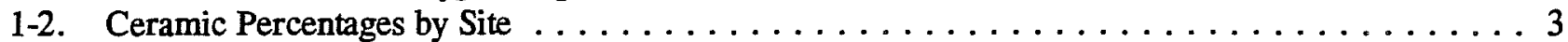

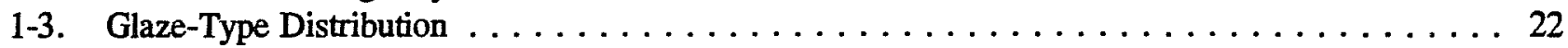

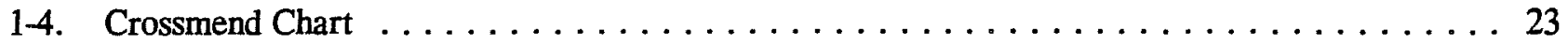

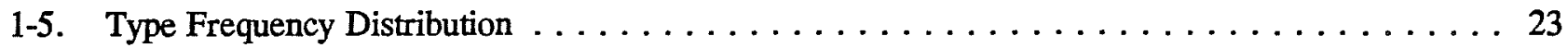

1-6. Urban and Rural Type Frequency Comparison . . . . . . . . . . . . . . . . . . . . 24

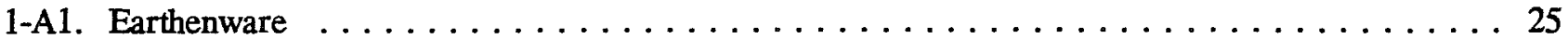

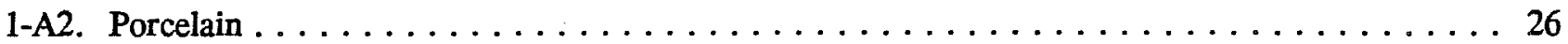

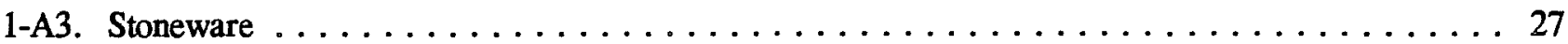

1-B1. Maker's Marks from Alamodome Sites . . . . . . . . . . . . . . . . . . 28

2-1. Dated Maker's Marks and Brand Names on Bottles Recovered from Feature A

Glass Midden, $41 B X 891 \ldots \ldots \ldots \ldots \ldots \ldots \ldots \ldots \ldots$

2-2. Dated Maker's Marks and Brand Names on Bottles Recovered from Monitored Trash Pit . . . . . 44

2-3. Dated Maker's Marks and Brand Names from the Pauley Privy . . . . . . . . . . . . . . . 48

2-4. Dated Maker's Marks and Brand Names from Beneath the Garza Store, 41BX895 . . . . . . . 50

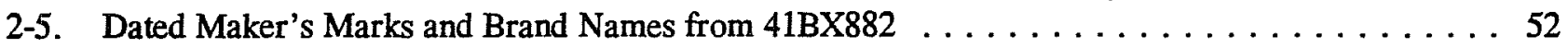

2-6 Dating of Bottles from Site 41BX883 Privy . . . . . . . . . . . . . . . 53

4-1. Significant Dates in U.S. Marble History . . . . . . . . . . . . . . . . . . . 102

4-2. U.S. Marble Companies . . . . . . . . . . . . . . . . . . . . . . 103

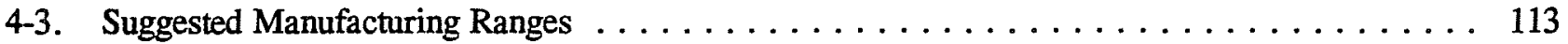

4-4. Marble Inventory, Site Specific ... . . . . . . . . . . . . . . . . . . . 114

5-1. Composition of Buttons from the Alamodome Project . . . . . . . . . . . . . . . . 123

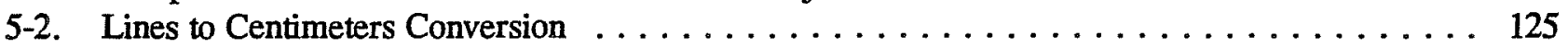

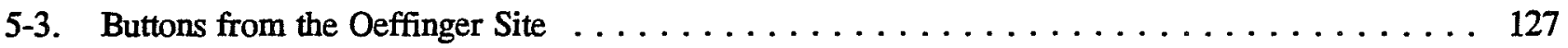

5-4. Other Clothing Items from the Oeffinger Site $\ldots \ldots \ldots \ldots \ldots \ldots \ldots \ldots \ldots \ldots$

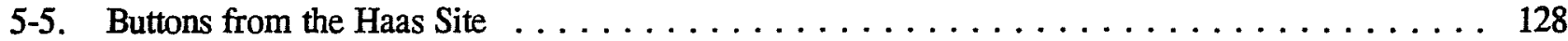

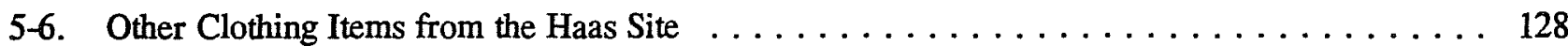

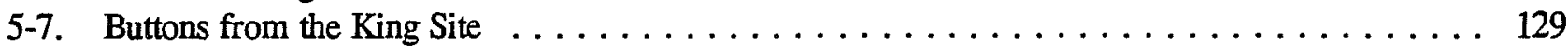

5-8. Other Clothing Items from the King Site . . . . . . . . . . . . . . . . . . . 130

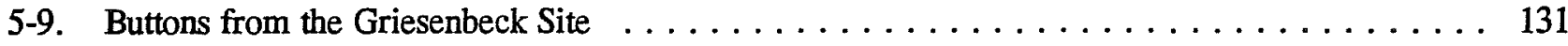

5-10. Other Clothing Items from the Oeffinger Site $\ldots \ldots \ldots \ldots \ldots \ldots \ldots \ldots \ldots$

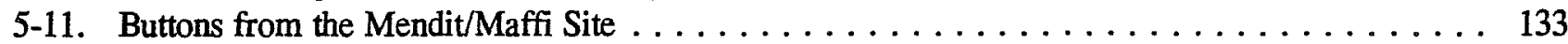

5-12. Other Clothing Items from the Mendit/Maffi Site $\ldots \ldots \ldots \ldots \ldots \ldots \ldots \ldots \ldots$

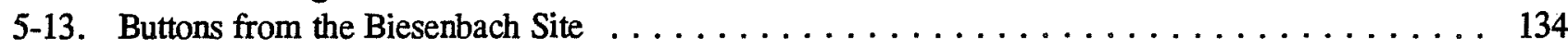

5-14. Other Clothing Items from the Biesenbach Site $\ldots \ldots \ldots \ldots \ldots \ldots \ldots \ldots$

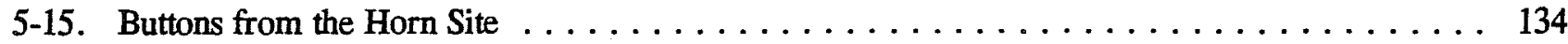

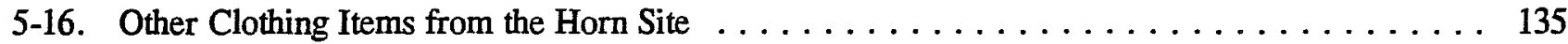

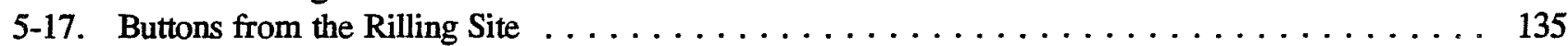

5-18. Other Clothing Items from the Rilling Site $\ldots \ldots \ldots \ldots \ldots \ldots \ldots \ldots \ldots \ldots$

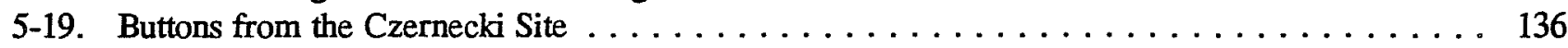

5-20. Other Clothing Items from the Czernecki Site $\ldots \ldots \ldots \ldots \ldots \ldots \ldots \ldots \ldots$

5-21. Buttons from the Czernecki Rental Site . . . . . . . . . . . . . . . . . . . 137

5-22. Other Clothing Items from the Czernecki Rental Site $\ldots \ldots \ldots \ldots \ldots \ldots \ldots$

5-23. Buttons from the Garza Store Site . . . . . . . . . . . . . . . . . . . . 138

5-24. Other Clothing Items from the Garza Store Site . . . . . . . . . . . . . . . . . . . . 139

5-25. Buttons from the Demazieres Site . . . . . . . . . . . . . . . . . . 139 
5-26. Other Clothing Items from the Demazieres Site $\ldots \ldots \ldots \ldots \ldots \ldots \ldots \ldots \ldots \ldots \ldots \ldots \ldots \ldots$

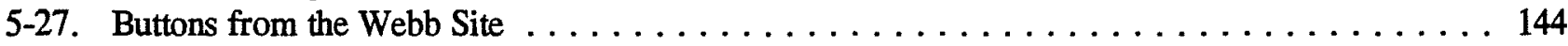

5-28. Other Clothing Items from the Webb Site $\ldots \ldots \ldots \ldots \ldots \ldots \ldots \ldots \ldots \ldots \ldots \ldots \ldots$

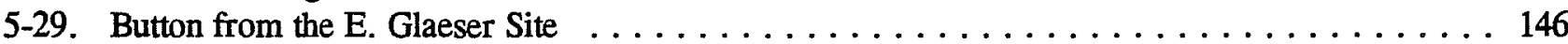

5-30. Buttons from the Gordon Site . . . . . . . . . . . . . . . . . . . . . 147

5-31. Other Clothing Items from the Gordon Site $\ldots \ldots \ldots \ldots \ldots \ldots \ldots \ldots \ldots \ldots \ldots \ldots \ldots$

5-32. Clothing Items from the Schulze Site $\ldots \ldots \ldots \ldots \ldots \ldots \ldots \ldots \ldots \ldots \ldots \ldots \ldots \ldots \ldots$

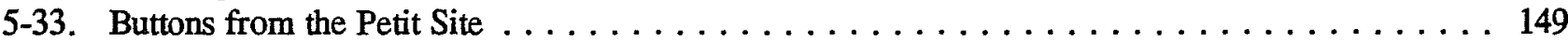

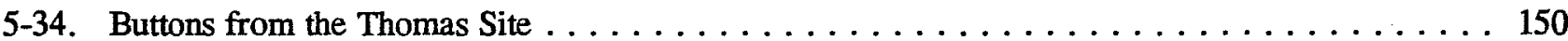

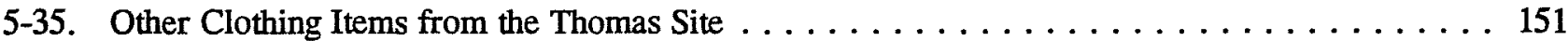

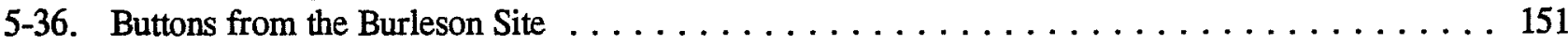

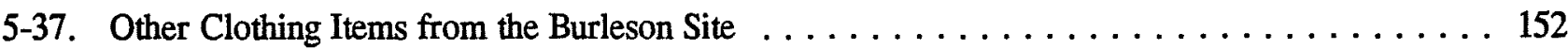

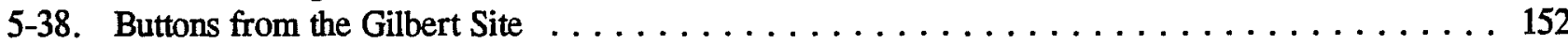

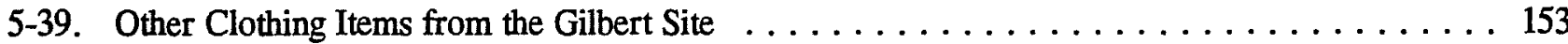

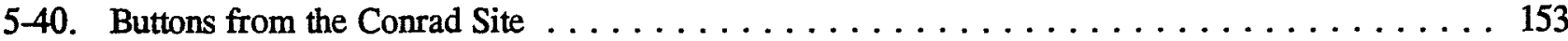

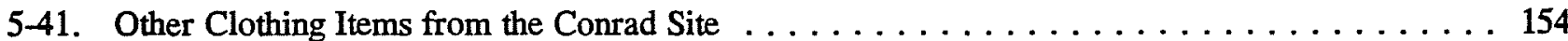

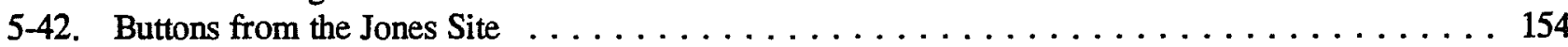

5-43. Other Clothing Items from the Jones Site $\ldots \ldots \ldots \ldots \ldots \ldots \ldots \ldots \ldots \ldots \ldots \ldots \ldots \ldots \ldots \ldots$

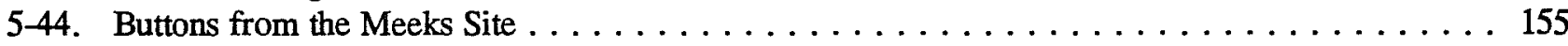

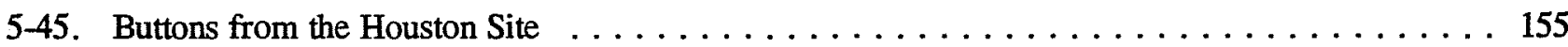

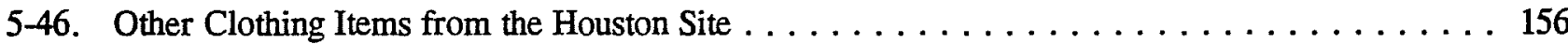

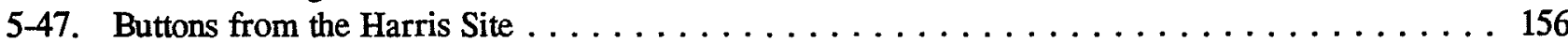

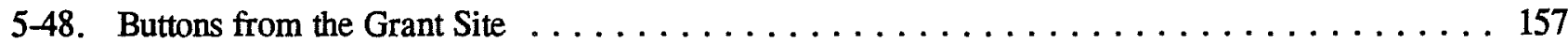

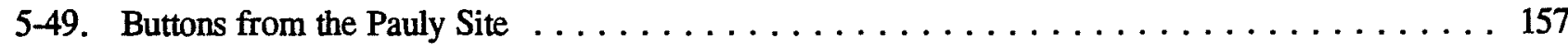

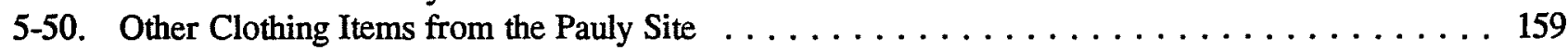

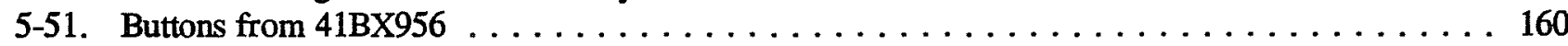

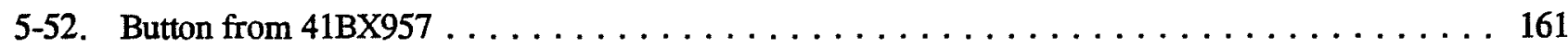

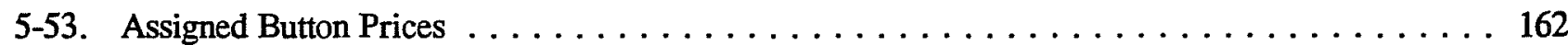

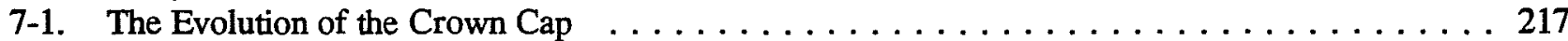

7.2. Identifiable Tablewares Recovered During the Alamodome Project $\ldots \ldots \ldots \ldots \ldots \ldots 222$

8-1. Architectural Artifacts from the Alamodome Project . . . . . . . . . . . . . . 230

8-2. San Antonio Brick Manufacturers, ca. $1860-1935 \ldots \ldots \ldots \ldots \ldots \ldots \ldots \ldots \ldots \ldots \ldots$

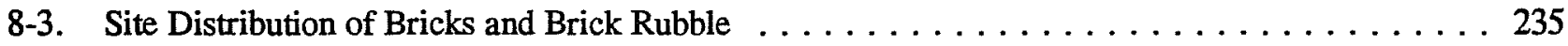

10-1. Construction information for the Las Tiendas Privy Pit Features $\ldots \ldots \ldots \ldots \ldots \ldots \ldots 258$

10-2. Location of Alamodome Privy Pit Features $\ldots \ldots \ldots \ldots \ldots \ldots \ldots \ldots \ldots \ldots \ldots \ldots \ldots \ldots \ldots \ldots$

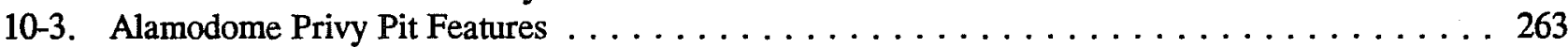

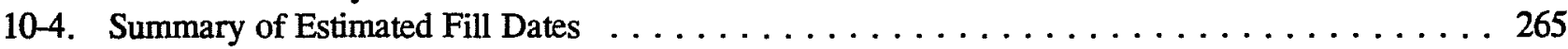

10-A1. Artifact Group Percentages for Individual Privy Pit Features . . . . . . . . . . . 271

10-A2. Artifact Count Comparisons from Three Sites and Their Respective Privy Pit Features . . . . 272

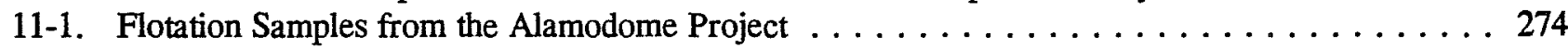

11-2. Plant Taxa Recovered from the Alamodome Samples . . . . . . . . . . . . . . . 277

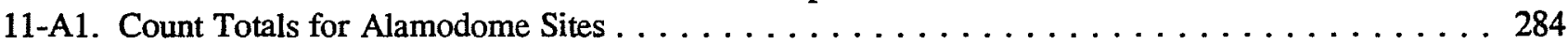

12-1. Identified Taxa . . . . . . . . . . . . . . . . . . . . . . . . . . . 287

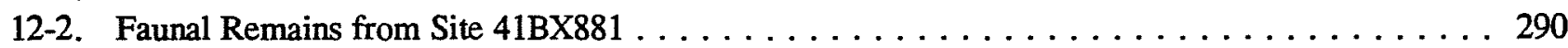

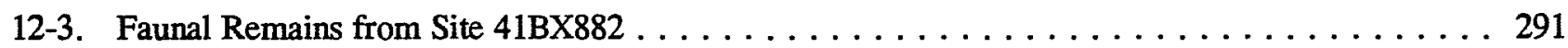

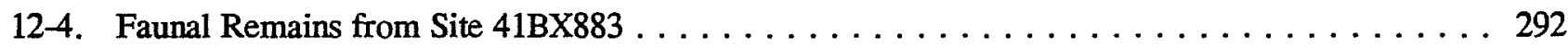

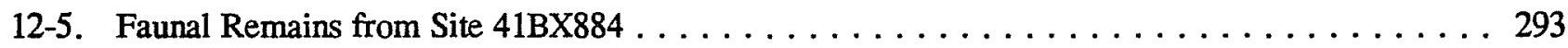

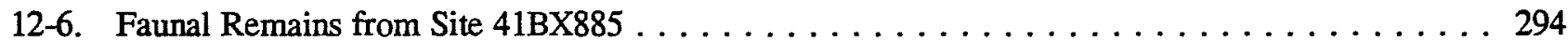

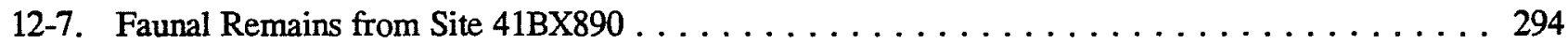


12-8. Faunal Remains from Site $41 B \times 891 \ldots \ldots \ldots \ldots \ldots \ldots \ldots \ldots \ldots$

12-9. Faunal Remains from Site $41 B X 892 \ldots \ldots \ldots \ldots \ldots \ldots \ldots$

12-10. Faunal Remains from Site $41 \mathrm{BX} 893 \ldots \ldots \ldots \ldots \ldots \ldots$. . . . . . . . . . . . . . . . . 297

12-11. Faunal Remains from Site $41 \mathrm{BX} 894 \ldots \ldots \ldots \ldots \ldots$. . . . . . . . . . . . . . . . 298

12-12. Faunal Remains from Site $41 \mathrm{BX} 895 \ldots \ldots \ldots \ldots \ldots \ldots . \ldots \ldots$

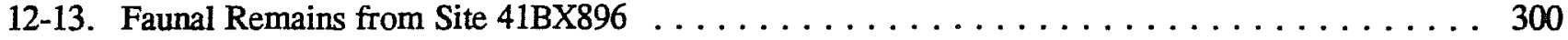

12-14. Faunal Remains from Site $41 \mathrm{BX} 897 \ldots \ldots \ldots \ldots$. . . . . . . . . . . . . . . . . . . 302

12-15. Faunal Remains from Site $41 \mathrm{BX898} \ldots \ldots \ldots \ldots \ldots \ldots$

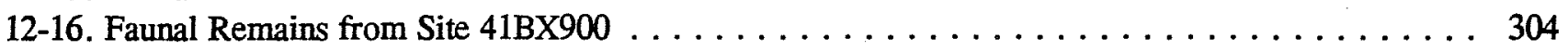

12-17. Faunal Remains from Site $41 \mathrm{BX} 926 \ldots \ldots \ldots \ldots \ldots \ldots \ldots \ldots \ldots$

12-18. Faunal Remains from Site 41BX927 . . . . . . . . . . . . . . . . . . . . . . . 305

12-19. Faunal Remains from Site $41 \mathrm{BX} 928 \ldots \ldots \ldots \ldots \ldots \ldots \ldots \ldots \ldots$

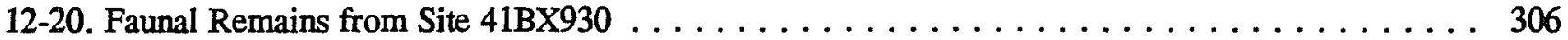

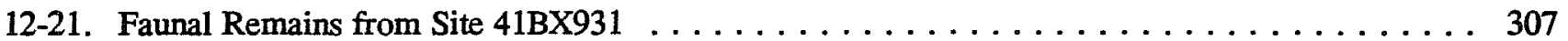

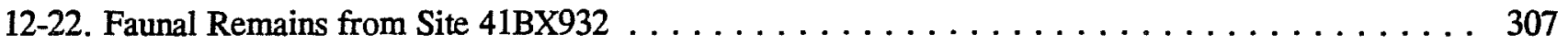

12-23. Faunal Remains from Site $41 \mathrm{BX} 936 \ldots \ldots \ldots \ldots \ldots \ldots$. . . . . . . . . . . . . . 308

12-24. Faunal Remains from Site $41 \mathrm{BX} 937 \ldots \ldots \ldots \ldots \ldots$. . . . . . . . . . . . . . . 309

12-25. Faunal Remains from Site $41 \mathrm{BX} 938 \ldots \ldots \ldots \ldots \ldots \ldots$. . . . . . . . . . . . . . . 309

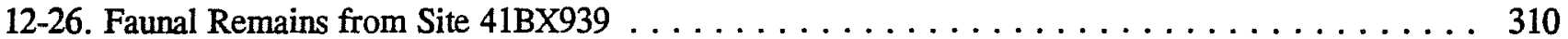

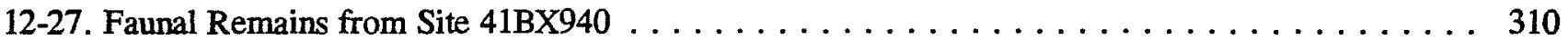

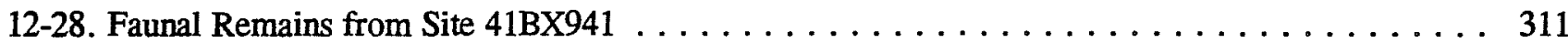

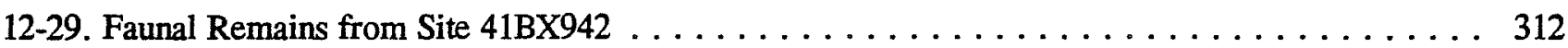

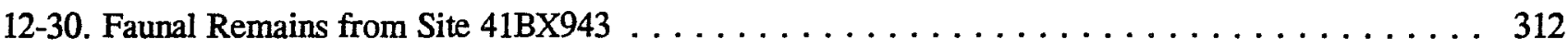

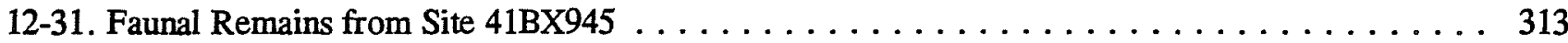

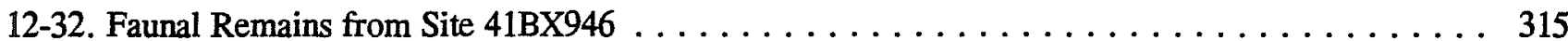

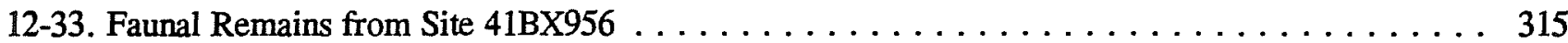

12-34. Rabbits from Three Privies, 41BX883, 41BX896, and 41BX945 . . . . . . . . . . . . . . 316

12-35. MNI of Commonly Hunted Animals (Excluding Rabbits) from Three Privies . . . . . . . . . . . 317

12-36. Percentage of Identified Bone Which Is Beef and Pork from Sites with Greater than

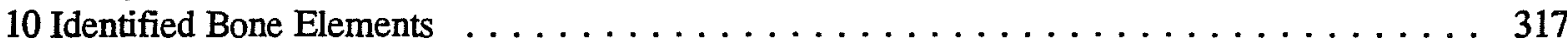

12-37. Average Counts of Cattle and Pigs per Farm in 1870 and 1880 in Counties

of West Texas with Large German Populations . . . . . . . . . . . . . . . . . . . 320

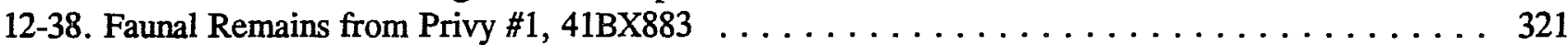

12-39. Butcher Marks on Bone from Domestic Stock in Privy \#1 . . . . . . . . . . . . . . 323

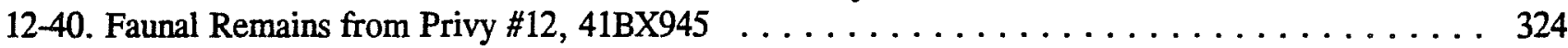

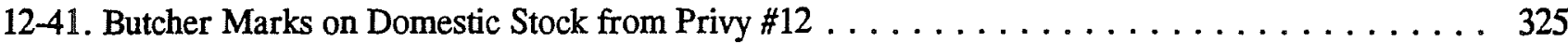

12-42. Faunal Remains from the Webb Trash Dump . . . . . . . . . . . . . . . . . . . . . . 326

12-43. Butcher Marks on Bone from Domestic Stock Animal in the Webb Trash Dump . . . . . . . . . 327

12-44. Comparison of Ranking of Meat Cuts by Cost (Schulz and Gust 1985:48) and by

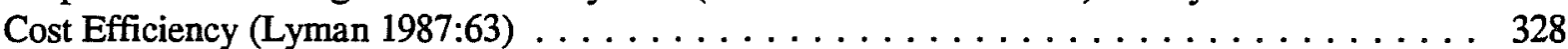

12-45. Elements Used to Define Meat Cuts During Analysis . . . . . . . . . . . . . . . . . . 335

12-46. Bos taurus Bone from Privy \#1, Classified by Meat Cut Represented . . . . . . . . . . . . . 336

12-47. Bos taurus Bone from Privy \#12, Classified by Meat Cut Represented . . . . . . . . . . . . . 336

12-48. Bos taurus Bone from The Webb Trash Dump, Classified by Meat Cut Represented . . . . . . . 337

12-49. Calculations of Estimated Meat Represented by Bone Weight, Costs Per Pound

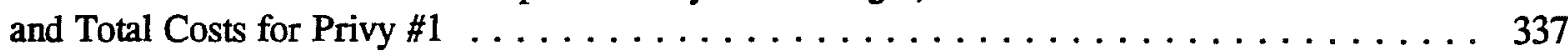

12-50. Calculations of Estimated Meat Represented by Bone Weight, Costs Per Pound and

Total Costs for Privy \#12 
12-51. Calculations of Estimated Meat Represented by Bone Weight, Costs Per Pound, and Total Costs for Webb Trash Dump . . . . . . . . . . . . . . . . 338

12-52. Comparison of Percentages of Estimated Total Meat Purchased in the Midand Low-Priced Categories . . . . . . . . . . . . . . . . . . . . . . . . . . 339

12-53. Comparison of Percentages by Cost and by Weight, of High Efficiency and Moderate Efficiency Meats 


\section{Foreword}

On March 15, 1990, the Center for Archaeological Research (CAR) of The University of Texas at San Antonio entered into a contract with the City of San Antonio's Multipurpose Domed Stadium Development Advisory Committee and Via Metropolitan Transit Authority to undertake cultural resource investigations of a 17-square-block (65 acre) area in downtown San Antonio, Texas (Figure F-1).

From mid-March to early July 1990 , and periodically thereafter, intensive archival and historical research on the entire project area was carried out by CAR staff members. Architectural recording and assessment of all standing buildings was done by Andrew Perez and Associates. Thirteen oral history interviews with residents, former residents, and officers and employees of business establishments in the general area were recorded and transcribed by E. L. Fly and Associates. This was the first phase of a multiple-phase project that also included archaeological test excavations during 1991 and 1992 to verify or identify the locations of sites and features within the project area, and detailed investigations of a selected sample of those sites and features. The project was conducted under Texas Antiquities Committee permit numbers 900,932 , and 982 . The artifacts recovered from the investigations were processed, cataloged, and sorted into categories for identification and analysis. Then followed over a year of intensive study of the products of the research and excavations.

Because of the tremendous scope of the archaeological work and the associated analysis and write-up, the results of the Alamodome Project are presented in three volumes. Volume I contains the background research results, including chapters on the historical setting, the architecture present before demolition was begun, the oral history, a study of the African-

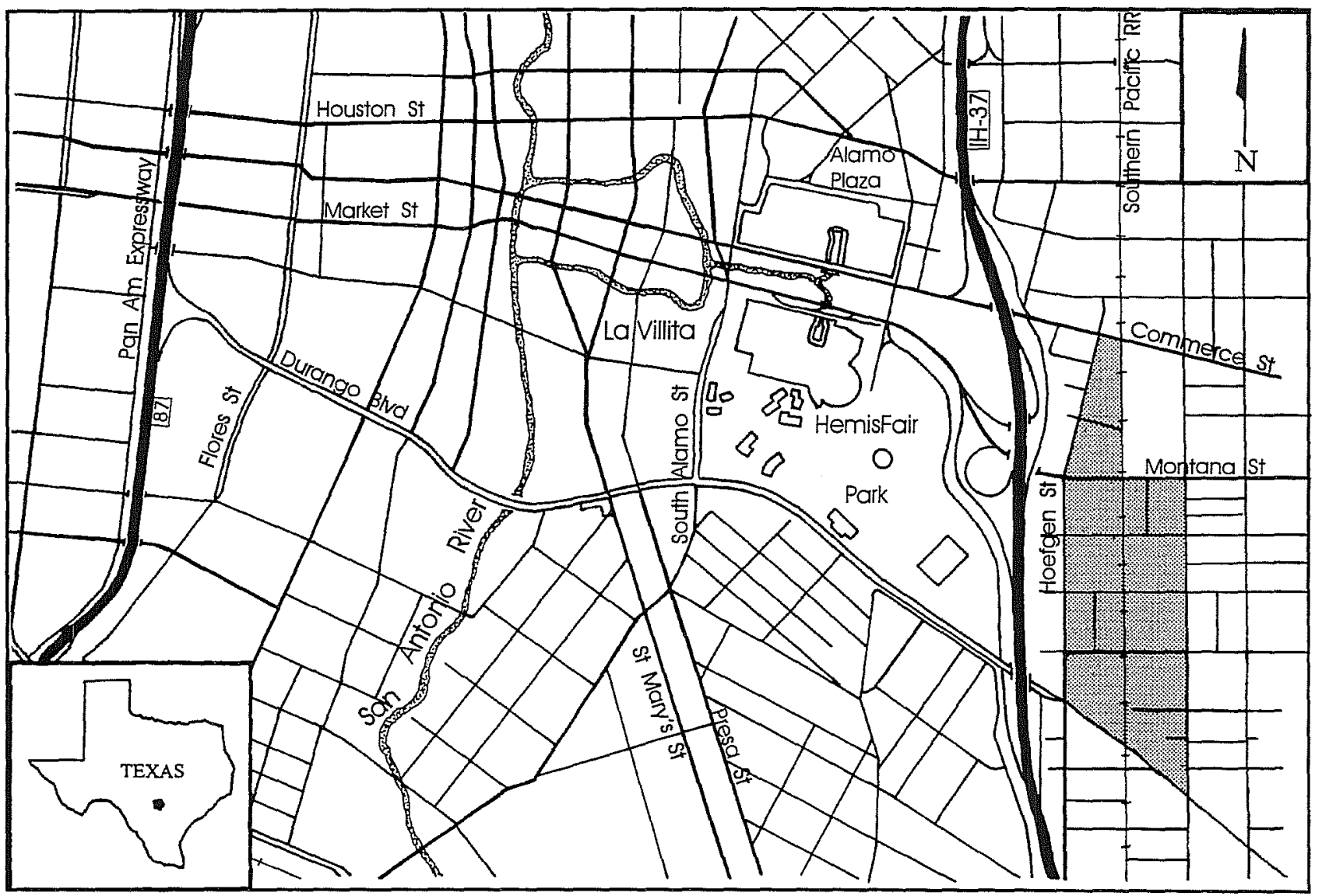

Figure F-1. Alamodome Project area. 
American community, and a summary of the structural evolution of the area. Volume II contains a complete description of the archaeological excavations and a distributional analysis of the results, written by the archaeologist who was in charge of the field work on the project. Included are numerous maps, drawings, and photographs of the work in progress. Also included in Volume II are a study of the site formation processes, undertaken by Kevin Gross, and a geomorphic description of the project area, by Michael Collins.

This volume, the last of the series, is comprised of individual reports on the description and analysis of various types of arifactual materials recovered during the project, including ceramics, glass, kitchen and tablewares, dolls and toys, marbles, clothing and personal items, and building materials. Also included in this volume are descriptions and discussions of excavated wells, cisterns, acequias, and privies, and an analysis of the faunal materials.

The temporal scope of these studies is the 100-year period from 1850 to 1950 . This time frame encompasses the period directly after the end of Spanish/Mexican control and the gradual rise of Anglo/German control of the local economy and sociopolitical structure. It is also the time during which the first wave of the Industrial Revolution arrived in Texas, seriously impacting the history of San Antonio. One goal of the project was to study this impact on the economic and cultural life of one small sector of the city.

\section{Scope of Volume III}

This volume presents the results of research by CAR staff members into the developmental history of the numerous types of artifacts used to analyze and date deposits on the archaeological sites investigated during the Alamodome Project. Comparatively little research has been done on artifacts of the post- 1900 period in Texas. Authors have spent hours of patient research in sometimes obscure publications and long distance phone calls to chase down and interview manufacturers wherever possible. We hope this volume will be a resource to others doing the same sort of research. As the years pass and 1900 recedes farther into the past, more and more archaeologists and historians will be looking for this sort of information.

The chapters on ceramics by Cynthia Tennis and glass by René Muñoz are based on commonly known dating sources for the nineteenth century, but in each case expand our knowledge into the twentieth century as well. This has required additional research into contemporary publications and the recent work of other archaeologists venturing into twentieth century archaeology.

The chapter on dolls and toys by Barbara Meissner attacks the problems of identification and dating, first from the historical point of view, and then with a detailed and illustrated accounting of the artifacts recovered during the project. The changes in fabrication of these objects brought about by the late nineteenth century inventions of the industrial revolution are particularly apparent in the toys of children of the era. This collection is also important in that it illustrates the types of toys available to lower middle class families in San Antonio during the $\mathbf{1 8 5 0}$ to 1950 period.

In the chapter on marbles, Jose Zapata has tackled the problems of identification and dating of these ubiquitous childhood toys by researching in detail the different methods of their manufacture through time. The fact that $\mathbf{2 3 5}$ marbles were recovered during this project presented a challenge to find ways to use these objects in the dating of archaeological sites. Zapata has built on the research of several other archaeologists and added his own keen ability to observe manufacturing techniques to produce a useful descriptive typology.

Meissner has undertaken in the next chapter to trace the history of buttons and other clothing details. Her descriptions of the items recovered from each site present an interesting picture of the individual inhabitants and her descriptive notes provide sidelights on their life and times.

In the following chapter, Meissner describes and dates personal items recovered form the Alamodome sites, including jewelry, beads, hair ornaments, items of personal hygiene, and items carried on the person such as watches, pocket knives, things related to tobacco use, and writing materials. She demonstrates the use of 
these objects both for dating and for estimating their social implications.

For the chapter on kitchen and tablewares, Mary Vaughan has branched out into untapped subjects. She has braved long distance calls to national corporate executives for unpublished details on the evolution of everyday objects such as can and bottle openers, bottle caps, and tablewares. She has searched for clues in their evolution that will aid in dating changes in technology, including advances in design and materials. Many of her findings will prove increasingly helpful as we do more work in post-World War II sites.

In a chapter on architectural materials, Kevin Gross and Frank Meissner deal briefly with the usual building materials and hardware present on Alamodome sites. They also discuss brick making in some detail, both in San Antonio and in Texas as a whole, then narrow the discussion to brick construction in the project area. There follows a discussion on the possible use of window glass for dating of structures. Gross and Meissner demonstrate the use of a regression equation for dating the relationship between glass thickness and the initial date of construction of a dwelling.

Following this is a chapter by Gross and Guillermo Mendez on acequias, wells, and cisterns found in the Alamodome project area. They describe and date the various types of water systems and relate them to the history of the area. Included also is a history of the San Antonio water works and its impact on the area residents.

Maureen Brown and Nora DeLaO have done a considerable study of San Antonio ordinances concerning privy construction, location, and upkeep. They also trace the history of sewage disposal in relation to the project area. Included in their discussion is an analysis of privy contents and fill dates for individual sites investigated, based on mean ceramic and glass dates, makers' marks, and other datable artifacts.

Phil Dering of the Palynology Laboratory at Texas A\&M University contributes an analysis of plant remains derived from privies and trash pits. His analysis of the light fractions from 20 flotation samples from 13 sites has identified fruits, nuts, and seeds. He also discusses the evidence of plant remains from individual features, and what they may imply about use and filling of those features.

Meissner and Johanna Hunziker have analyzed the animal bone recovered from the Alamodome Project. In this chapter, they enumerate the various species present, discuss them on a site- by-site basis, and relate meat cut frequencies to socioeconomic status.

The last chapter, written by Anne Fox, is a summary of the project, discussing the research design and how it was carried out, various questions we had hoped to answer by our research, and the final results. 


\title{
Chapter 1 \\ Ceramic Patterns and Variations
}

\author{
Cynthia L. Tennis
}

\section{Introduction}

Over 6,000 ceramic sherds were recovered from all phases of investigation at the 36 sites comprising the Alamodome Project area. As discussed earlier in this publication, the sites in the study area date from 1855 forward, in some instances up to the present decade. During this time span, but especially during the last quarter of the nineteenth and first quarter of the twentieth centuries, our 17-block area was part of an urban upwelling that saw a burst of industrialization, the coming of the railroad, and population figures that multiplied 20 -fold in six decades. This ceramic analysis, then, is focused to gauge the effects of the major social change from a rural to an urban environment on the everyday life of the people who experienced it.

\section{Methodology}

Classification of ceramic sherds for this analysis was based on distinctions between paste types and colors and the visible extent of vitrification created during firing. Based on these criteria, three broad categories were defined: earthenware, porcelain, and stoneware. These categories were then further defined into sub-categories based on the types of glazes and decorations.

Initially, sherds from features, privies, trash dumps, and excavation units were sorted into these major categories. A preliminary analysis was performed on independent collections, comparing percentages of major categories represented from sites containing these varied areas of origination. As no consistent pattern of over- or under-representation of types could be discerned, we decided that analysis would give the most complete representation of the area when viewed by entire site.

Once the basic methodology for the analysis was established, sherds from all areas of each of the 36 sites were sorted into the three broad categories (earthenware, porcelain, and stoneware) and then further sorted into appropriate sub-categories based on manufacture techniques and decoration. Corrections and clarifications of previous identification errors during the catalogue stage were amended in the computer records. The breakdown of the Alamodome Project ceramic assemblage appears in Appendix 1-A. Ceramic type frequencies for the entire assemblage are shown in Table 1-1, frequencies recovered from each site are given in Table 1-2.

\section{Category Definitions}

\section{Earthenware}

\section{Unrefined (Soft Paste)}

The term soft paste/unrefined was chosen to describe the hand-made or wheel-thrown, low-fired vessel sherds in the assemblages. Sherds of this category were found in small quantities $(n=78)$ at fewer than 50 percent of the Alamodome sites (Tables 1-1 and 1-2). 
Table 1-1. Alamodome Ceramic Type Frequencies

\begin{tabular}{|c|c|c|c|c|}
\hline Type & \# Sherds & \% of Type & & Total \\
\hline Unrefined & 78 & $100 \%$ & & $1 \%$ \\
\hline \multicolumn{5}{|l|}{ Refined } \\
\hline Undecorated Whiteware & 3,169 & 70 & 51 & \\
\hline Decorated Whiteware & 1,365 & 30 & 22 & \\
\hline TOTAL & 4,534 & $100 \%$ & & 73\% \\
\hline \multicolumn{5}{|l|}{ Porcelain } \\
\hline Undecorated & 468 & 55 & 8 & \\
\hline Decorated & 378 & 45 & 6 & \\
\hline TOTAL & 846 & $100 \%$ & & $14 \%$ \\
\hline \multicolumn{5}{|l|}{ Other } \\
\hline Yellowware & 110 & 14 & 2 & \\
\hline Stoneware & 650 & 86 & 10 & \\
\hline TOTAL & 760 & $100 \%$ & & $12 \%$ \\
\hline GRAND TOTAL & 6,218 & & & $100 \%$ \\
\hline
\end{tabular}

They have been divided into two sub-categories: lead glaze and in glaze. These ceramic types have been made in Mexico and brought into Texas since the 1750s (Ivey and Fox 1982). Sherds in this collection are quite fragmented and limited in number. They do serve, however, to reflect the continuing material and cultural interchanges between San Antonio and its Mexican neighbors.

\section{Lead-glazed (69 total)}

Sherds in this subcategory have orange to reddish brown paste. The glaze is commonly unevenly applied, sometimes covering the entire vessel, sometimes found only on the upper half and interior of the vessel. Most frequently used decorations include green, brown, or cream leaves, lines, and dots. An estimated 20 vessels of this description are represented here, of which 9 small jars or pots and 2 shallow bowls or saucers can be identified. Pottery with this type of decoration is identified as Galera ware.

Tin-glazed ( 9 total)

Examples of in-glazed sherds in this collection are limited. They consist of small fragments with pinkish colored pastes and opaque colored glaze on one side and white opaque on the other. The colored glazes include green, yellow, turquoise, and black, some having accent designs in contrasting colors.

\section{Refined (Hard Paste)}

As seen in Table 1-1, hard paste/refined earthenwares make up a large majority ( 73 percent) of the ceramics recovered from the study area. Hard-paste earthenware, defined as the end product of highly fired refined clays with vitreous glazes and varied decoration style (Stothert et al. 1992) have an evolutionary history that begins in the last half of the eighteenth century in England. Through various stages of development-from the early cream-colored wares of the 1760 s and the blue-tinted pearlwares of the 1780 s-British potters arrived at whiteware in the 1830 s and, in the 1850 s, at the granite or ironstone which is still produced today (Miller 1991). 
Table 1-2. Ceramic Percentages by Site

\begin{tabular}{|c|c|c|c|c|c|c|c|c|c|c|}
\hline Site \# & Occ. Date & \multicolumn{2}{|c|}{ Unrefined } & \multicolumn{2}{|c|}{ Refined } & \multicolumn{2}{|c|}{ Porcelain } & \multicolumn{2}{|c|}{ Stoneware } & \multirow[t]{2}{*}{ TOTAL } \\
\hline & & $\mathbf{n}$ & $\%$ & $\mathbf{n}$ & $\%$ & $\mathbf{n}$ & $\%$ & $\mathbf{n}$ & $\%$ & \\
\hline $41 \mathrm{BX} 881$ & 1893-1922 & 7 & 0.04 & 125 & 0.68 & 28 & 0.15 & 23 & 0.13 & 183 \\
\hline $41 \mathrm{BX} 882$ & $1900-1970$ & 8 & 0.04 & 114 & 0.59 & 45 & 0.23 & 27 & 0.14 & 194 \\
\hline 41BX883 & $1884-1987$ & 13 & 0.02 & 700 & 0.82 & 104 & 0.12 & 35 & 0.04 & 852 \\
\hline 41BX884 & 1883-recent & 6 & 0.09 & 51 & 0.74 & 3 & 0.04 & 9 & 0.13 & 69 \\
\hline 41BX885 & 1892 -recent & 11 & 0.17 & 25 & 0.40 & 8 & 0.13 & 19 & 0.30 & 63 \\
\hline $41 \mathrm{BX} 890$ & $1858-1925$ & 1 & 0.01 & 100 & 0.74 & 12 & 0.09 & 23 & 0.17 & 136 \\
\hline 41BX891 & $1857-1925$ & 0 & 0.00 & 67 & 0.50 & 11 & 0.08 & 55 & 0.41 & 133 \\
\hline 41BX892 & $1855-1926$ & 0 & 0.00 & 174 & 0.54 & 19 & 0.06 & 127 & 0.40 & 320 \\
\hline 41BX893 & $1899-1990$ & 0 & 0.00 & 84 & 0.79 & 11 & 0.10 & 11 & 0.10 & 106 \\
\hline 41BX894 & $1910-1990$ & 0 & 0.00 & 21 & 0.81 & 2 & 0.08 & 3 & 0.12 & 26 \\
\hline $41 \mathrm{BX} 895$ & $1889-1990$ & 2 & 0.08 & 14 & 0.54 & 9 & 0.35 & 1 & 0.04 & 26 \\
\hline 41BX896 & 1856-recent & 9 & 0.02 & 336 & 0.67 & 79 & 0.16 & 76 & 0.15 & 500 \\
\hline $41 \mathrm{BX} 897$ & 1866-1989 & 1 & 0.00 & 577 & 0.77 & 126 & 0.17 & 42 & 0.06 & 746 \\
\hline 41BX898 & 1856-recent & 0 & 0.00 & 5 & 1.00 & 0 & 0.00 & 0 & 0.00 & 5 \\
\hline 41BX899 & $1855-1925$ & 0 & 0.00 & 6 & 0.75 & 1 & 0.13 & 1 & 0.13 & 8 \\
\hline $41 \mathrm{BX} 900$ & $1858-1926$ & 2 & 0.00 & 634 & 0.76 & 108 & 0.13 & 93 & 0.11 & 837 \\
\hline $41 \mathrm{BX} 926$ & $1885-1920$ & 5 & 0.63 & 0 & 0.00 & 0 & 0.00 & 3 & 0.38 & 8 \\
\hline 41BX927 & $1870-1910$ & 0 & 0.00 & 46 & 1.00 & 0 & 0.00 & 0 & 0.00 & 46 \\
\hline 41BX928 & $1880-1910$ & 0 & 0.00 & 136 & 0.93 & 4 & 0.03 & 6 & 0.04 & 146 \\
\hline 41BX929 & $1890-1920$ & 0 & 0.00 & 0 & 0.00 & 0 & 0.00 & 2 & 1.00 & 2 \\
\hline 41BX930 & $1880-1920$ & 0 & 0.00 & 0 & 0.00 & 7 & 1.00 & 0 & 0.00 & 7 \\
\hline 41BX931 & $1920-1990$ & 1 & 0.00 & 253 & 0.75 & 37 & 0.11 & 45 & 0.13 & 336 \\
\hline $41 \mathrm{BX} 932$ & $1880-1990$ & 1 & 0.01 & 70 & 0.80 & 2 & 0.02 & 15 & 0.17 & 88 \\
\hline 41BX936 & $1920-1990$ & 0 & 0.00 & 37 & 0.95 & 0 & 0.00 & 2 & 0.05 & 39 \\
\hline 41BX937 & 1880 -recent & 0 & 0.00 & 133 & 0.86 & 18 & 0.12 & 4 & 0.03 & 155 \\
\hline 41BX938 & $1890-1920$ & 8 & 0.03 & 249 & 0.79 & 43 & 0.14 & 14 & 0.04 & 314 \\
\hline 41BX939 & 1920-recent & 0 & 0.00 & 43 & 0.86 & 4 & 0.08 & 3 & 0.06 & 50 \\
\hline $41 \mathrm{BX} 940$ & $1929-1962$ & 0 & 0.00 & 14 & 1.00 & 0 & 0.00 & 0 & 0.00 & 14 \\
\hline 41BX941 & 1927-recent & 0 & 0.00 & 15 & 0.65 & 5 & 0.22 & 3 & 0.13 & 23 \\
\hline 41BX942 & 1927-recent & 0 & 0.00 & 84 & 0.88 & 9 & 0.09 & 3 & 0.03 & 96 \\
\hline $41 \mathrm{BX} 943$ & $1921-1974$ & 0 & 0.00 & 0 & 0.00 & 0 & 0.00 & 0 & 0.00 & 0 \\
\hline 41BX944 & 1929-recent & 0 & 0.00 & 0 & 0.00 & 0 & 0.00 & 0 & 0.00 & 0 \\
\hline 41BX945 & $1855-1968$ & 3 & 0.00 & 396 & 0.60 & 148 & 0.22 & 114 & 0.17 & 661 \\
\hline 41BX955 & $1877-1915$ & 0 & 0.00 & 0 & 0.00 & 0 & 0.00 & 1 & 1.00 & 1 \\
\hline 41BX956 & 1880 -recent & 0 & 0.00 & 15 & 0.83 & 3 & 0.17 & 0 & 0.00 & 18 \\
\hline 41BX957 & 1880-recent & 0 & 0.00 & 9 & 1.00 & 0 & 0.00 & 0 & 0.00 & 9 \\
\hline
\end{tabular}


Sherds in our collection are predominately of these last two varieties. Two possible exceptions may be fragments from a blue-tinted cup and teapot that lack maker's marks, and three pieces of colored-paste ironstone with maker's marks dating after 1930 . Over 70 maker's marks are present on the whiteware and ironstone pieces in this collection, with over 70 percent being from American companies located in the North and East. (See Appendix 1-B for a complete list of marks.) Refined wares are present in mid-nineteenth deposits in San Antonio (Hard et al. 1995), but became more common with the 1877 arrival of the railroad.

\section{Undecorated (3,169 total)}

All collections that contained ceramics included undecorated whiteware and/or ironstone with the exception of two sites from which undecorated wares were not surfaced collected.

\section{Molded (275 total)}

Whiteware and ironstone sherds in this category have no colored decorations, but exhibit raised or molded designs created when the clay is poured or pressed into pre-carved molds. Molded whiteware was most popular during the last quarter of the nineteenth century (Wetherbee 1980:19). This popularity is reflected in the Alamodome collection by the fact that molded-ware sherds outnumber all other decorated types. One site, 41BX896, revealed 14 different molded patterns on plates and saucers while four other sites had at least six different patterns. The minimum number of vessels of this type is estimated at 65 , second only to decal-decorated wares.

\section{Gilded ( 72 total)}

Decorations of gold lines and bands were used on porcelains as early as 1723 , but in 1836 a process was developed that made gilding practical for use on whiteware. This process allowed dissolved gold, mixed with chemicals, to be applied before firing which produce a bright finish without burnishing. By 1870 this process was in common use in British potteries (Miller 1991:10). Twelve sites in our study area contained an estimated 33 vessels with gilded decorations.

\section{Band and Line ( 33 total)}

The 21 vessels from 16 sites in the study area are examples of what Miller (1991:7) terms Band and Line wares. These are cups, saucers, bowls, and plates of ironstone with one, two, or three lines painted under the glaze around the rim. Line colors include blue, brown with gold, and green with red, all on white, as well as brown lines on tan vessels. These decorations became popular on hotelware during the last quarter of the nineteenth century and continue in some places up to the present. The tan and brown sherds both with maker's marks from Syracuse China, ca. 1930 (Lehner 1988:455), are examples of this more modern ware (Figure 1-1).

\section{Edgeware (65 total)}

Edgeware is used in this study to identify ceramics that have incised or painted shell or feather designs along their edge. This type of ware was a popular import item from Britain during the last half of the eighteenth and the first half of the nineteenth centuries. Blue edgeware was commonly available in America through the 1860s (Miller 1991:6). Only three sites in our study area produced "edged" type ware. Site 41BX900 yielded fragments of a more-modern version, one 9inch plate and one 51/2-inch bowl. The latter are from the same set and have the same maker's mark, "La Francais," which is attributed to the French China Company ca. 1900-1932 (Lehner 1988:155). The edgeware from the other two sites, 41BX883 and 41BX897, was of three different varieties that crossmended to form two 9-inch plates, one 10-inch plate, and one 8-inch plate. The three designs have been dated by Moir (1987) as follows: non-cockled crows feet, ca. 1820-1845; non-cockled incised trident, ca. 1840-1860; and non-cockled brush strokes, ca. 1870-1890 (Figure 1-2a, b, c).

Sponge ( 70 total)

The Alamodome ceramic collection contained three different types of spongeware: spatter, sponge, and cut sponge. Spatter decorations, the earliest of the sponged types, is described as dotted, powdered, or sprayed, sometimes with hand-painted central designs. Our collection had only three examples of spatterware: one blue, one red, and one green with small portions of brown hand-painted lines resembling the foot of a bird, a common central design continuing into the mid-nineteenth century (Greaser and Greaser 1967).

Traditional spongeware, created by daubing paint onto the vessel either before or after firing, is represented here by three small fragments in yellow, blue, and green. Kitchen spongeware, described by Robacker 


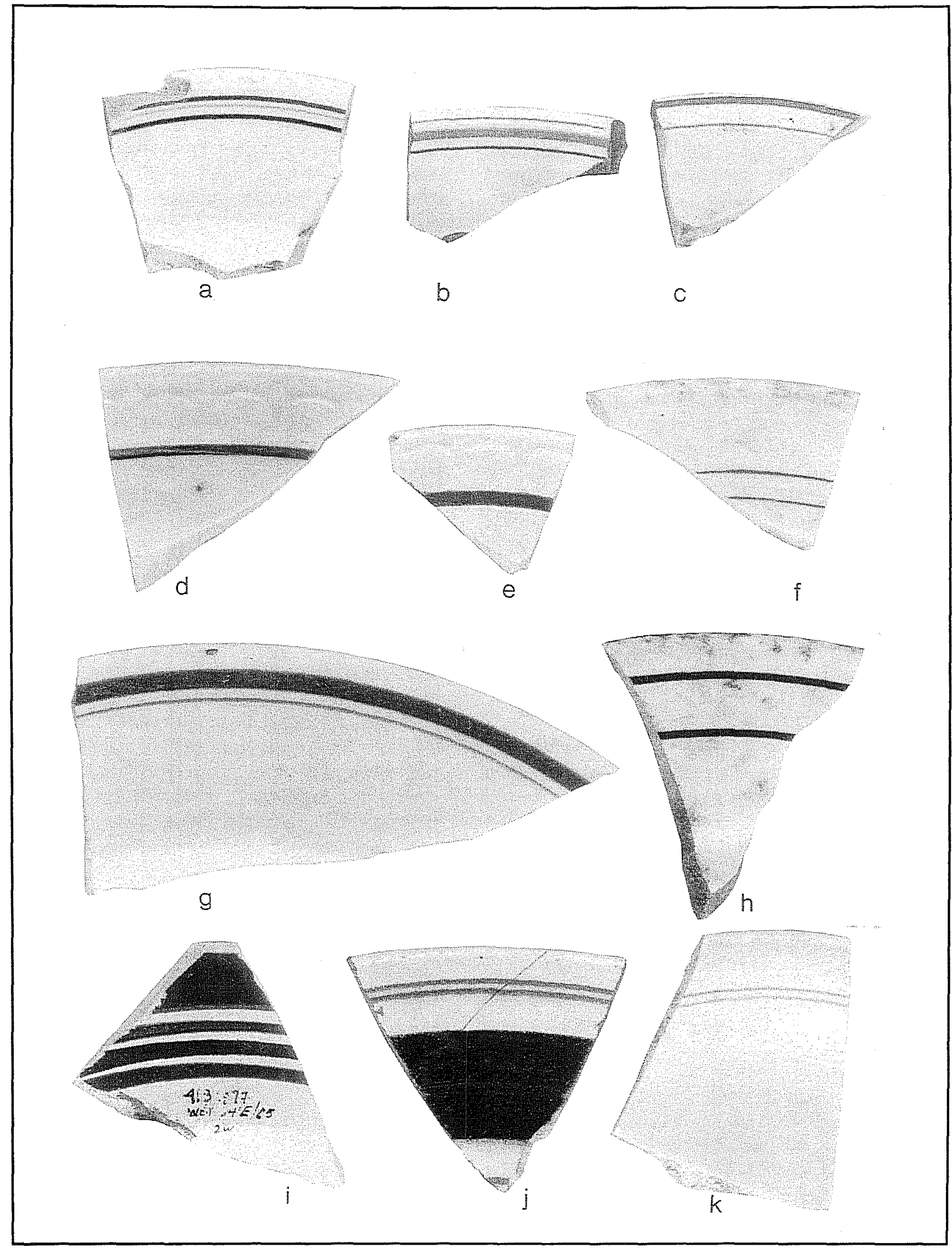

Figure 1-1. Band and line sherds. All shown actual size. 
and Robacker (1978:119) as non-uniformly decorated, heavy, porous utilitarian items, include six sherds probably from four mixing bowls and one pitcher.

Over 75 percent of the spongeware recovered was of the cut sponge variety. Designs created from the repetitive use of carved sponge stamps adorn fragments from seven plates and five cups or bowls. One 9-inch plate with a wide blue rim, thin red bands, and dark blue flowerets (Figure 1-2f) bears a maker's mark of Elsmore and Foster, potters in Tunstall, England from 1853-1871 (Godden 1964:235). Fragments from 41BX883 and 41BX897 again crossmend to form this vessel. Other pattern combinations include red with purple stamp and purple with black stamp. Many of the patterns are accented with narrow bands in contrasting colors. One other pattern, probably part of a cup, from 41BX897 displays a design in red and green with outlined crosses (Figure 1-2e), similar to those attributed by Robacker and Robacker (1978) to Villeroy and Boch, a German pottery in business in 1842 (Kovel and Kovel 1971). A seemingly more recent sponge decoration, 1890-1920 (Ketchum 1983:32), is present on several thicker pieces of whiteware. These are mottled sponge designs under a translucent yellow.glaze and appear to be on fragments from several large bowls (Figure 1-2g, h).

\section{Banded Slip (49 total)}

Sherds from 12 bowls and two cups bearing slip decoration appear in our collection. Decorations of this type are made by applying bands of colored slip to the vessel before firing. Most common in this assemblage are vessels with white bodies, wide blue bands, and thinner black bands near the rim. Also present are examples in blue and green, blue and brown, yellow and black, and green and black. Several fragments of the "cat's eye" design (Figure 1-2d) and a tiny fragment of mocha, popular before 1840, were recovered from 41BX883 and 41BX897 respectively. After 1840 only the simple blue-banded types remained popular (Miller 1991:6-7).

\section{Modern Majolica ( 9 total)}

This distinctive earthenware (Figure 1-3a-c), popular in the last half of the nineteenth century, is recognizable by its colorful lead glazes and design molded shapes (Ray 1974:129). Sherds from this collection include an unrelated green jar base and lid fragment, as well as remnants of two saucers, one with blue and green flowers, the other, also in blue, resembling a sea shell (Figure 1-3a). One unidentified maker's mark appears on a green leaf design plate.

Freehand ( 90 total)

Freehand wares are represented in this collection by 34 vessels including cups, saucers, eight plates, and four bowls. This term was chosen to describe wares that were decorated by hand painting but are late copies of the earlier wares usually called hand painted. Decorations are limited to large floral designs in pink, blue, yellow, and brown, with light and dark green leaves (Figure 1-3d, e, $f, g)$. Several have red or black accent lines around the interior and exterior of the rim (cups) and around the inside base (plates). Only 11 percent of these fragments have paint over glaze, the remainder were painted before glazing. One cup fragment appears to have a combination of a cut sponge flower with painted leaves and brush stroked petals (Figure 1-3g).

\section{Decalcomania (232 total)}

Decalcomania-decorated wares are produced by transferring a pre-colored, finished design from a sheet of tissue-like paper onto a completed vessel. This decoration technique began in the 1850 s (Durrenberger 1965:21). By the 1930s, decalcomania was exported almost exclusively from Germany (Lehner 1980:13). Second only to molded ware in decorated sherd count and leading all decorated ware in vessel count with 88, the dominant floral designs and bright colors suggest why this ceramic type was so popular. Designs are mostly floral combinations, sometimes accompanied by gilded accents (Figure 1-4). Two cups and one saucer have an entirely gilt decal design of small leaves and flowers. Decal colors tend toward pastels with the exception of one piece with a vivid maroon border. Seven decal decorated pieces, including one 8-inch bowl, one 7 -inch plate, and four $51 \frac{1}{2}$-inch saucers, bear identifiable maker's marks (Appendix 1-A). All these pieces came from American potteries which began operating in the 1890 s.

\section{Transfer-printed (227 total)}

Transfer-printed wares (Figure 1-5) were first produced in England in the 1750s and continued to be a popular export item to the United States until the 1850 s. Popularity of transfer ware increased again in the last quarter of the nineteenth century, finally to be replaced by decalcomania at the turn of the century (Miller 1991:9). This collection contains an estimated 

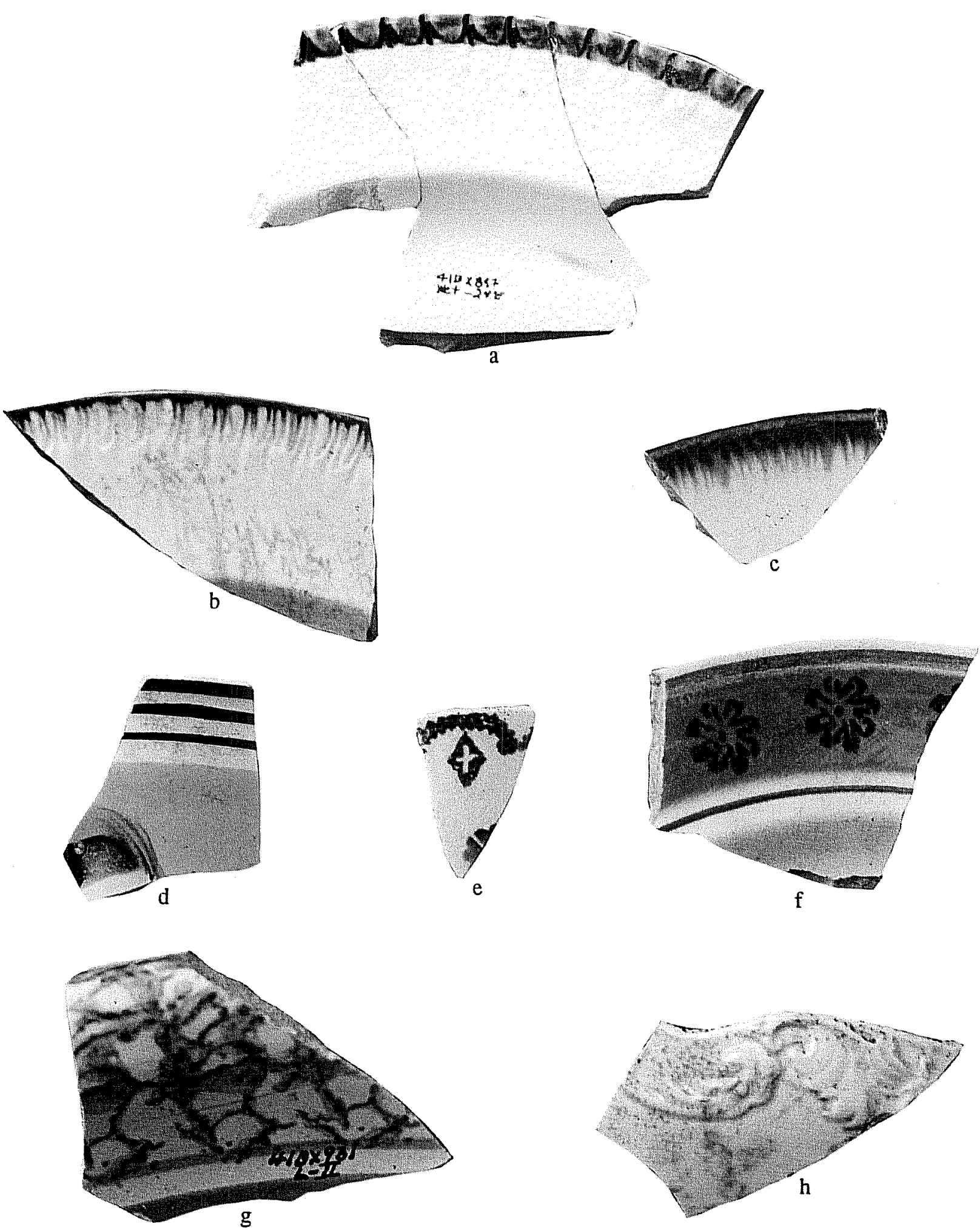

Figure 1-2. Edgeware, banded slip, and spongeware. Edgeware: a-crow's foot variant, b-lightly incised trident, c-brush-stroked pattern; banded slip: d-"cat's eye" decoration; spongeware: e-h. All shown actual size. 


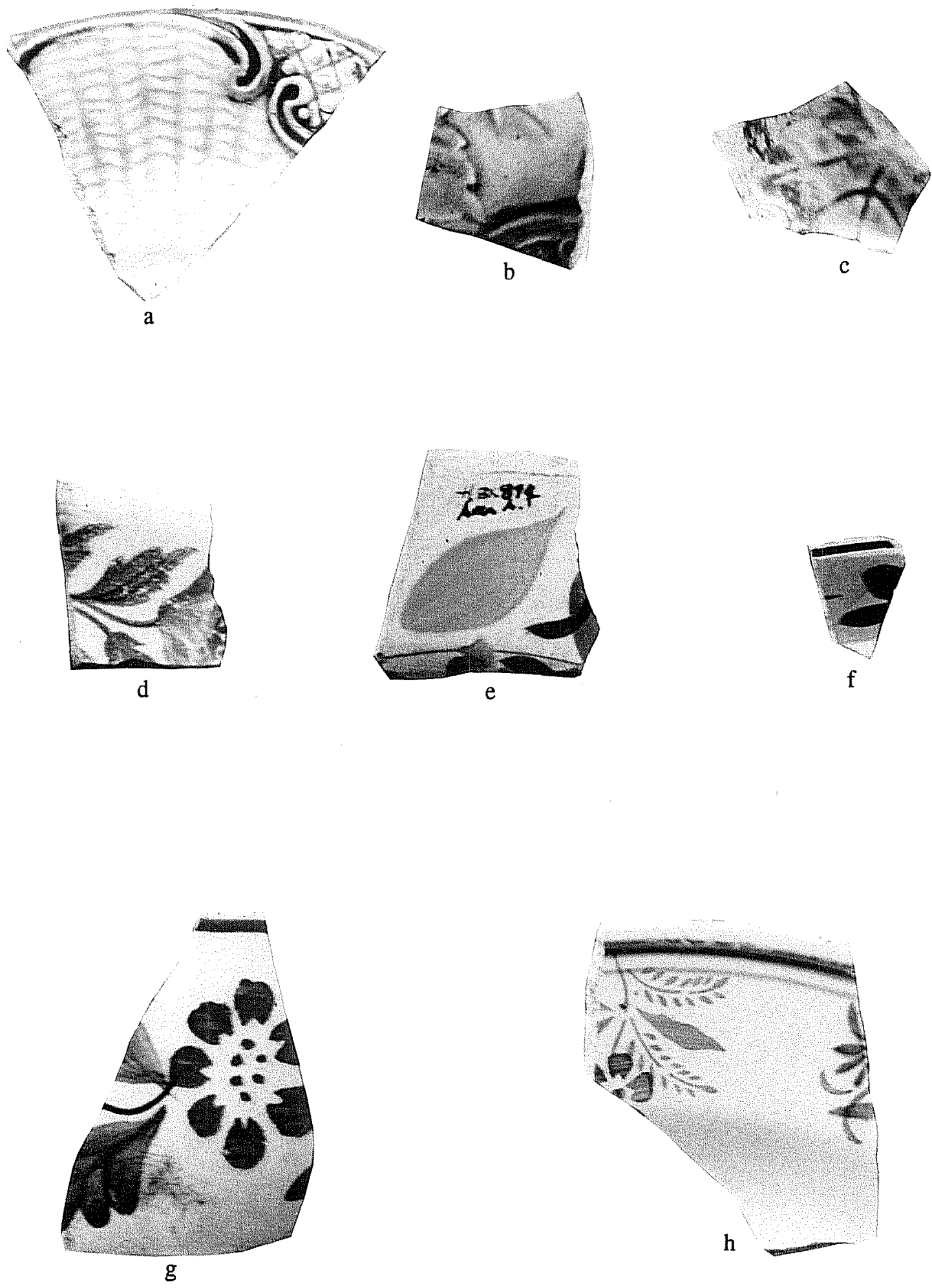

Figure 1-3. Modern majolica and freehand designs. Majolica: a-c; freehand design: $d-h$. All shown actual size. 



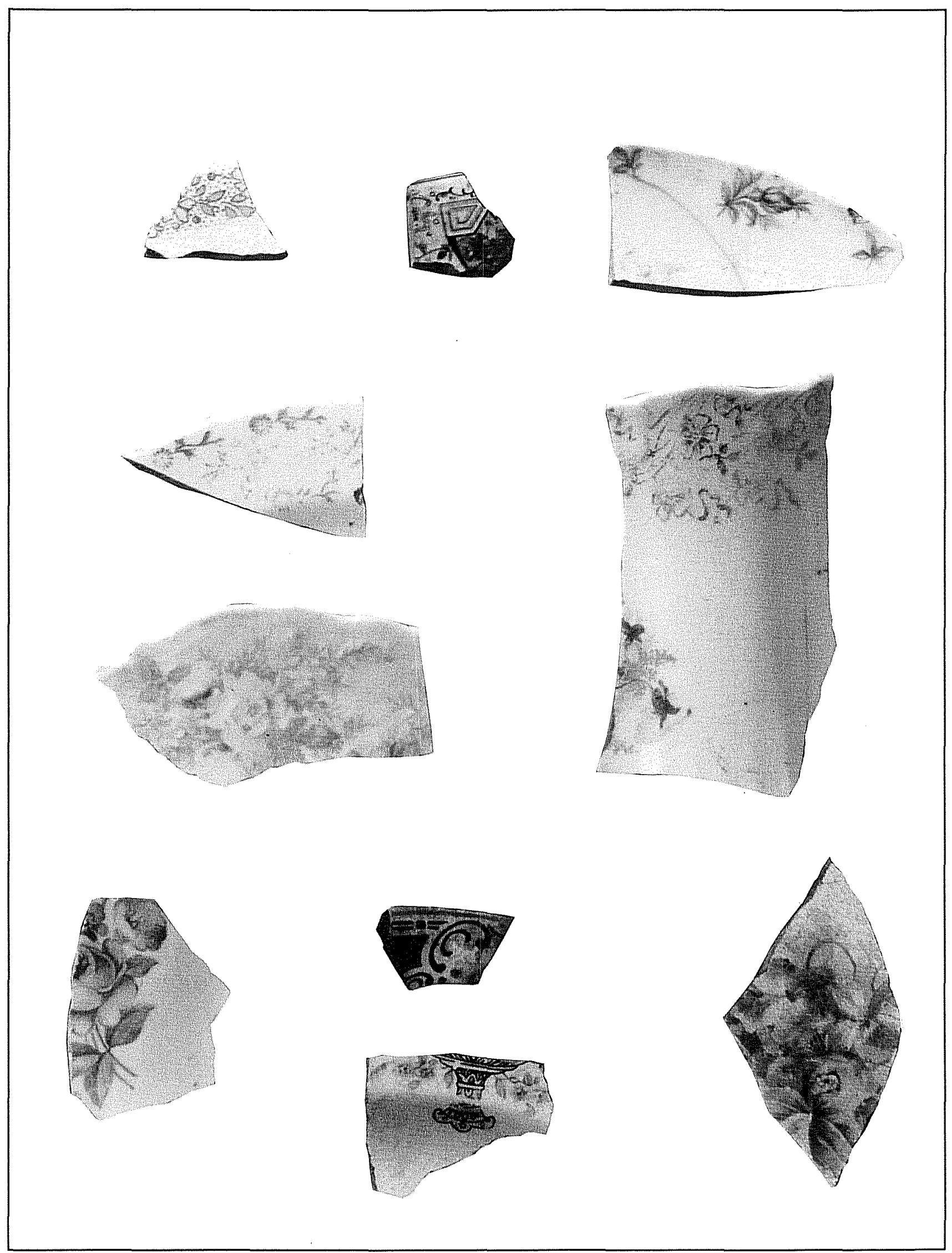

Figure 1-4. Decal patterns. All shown actual size. 



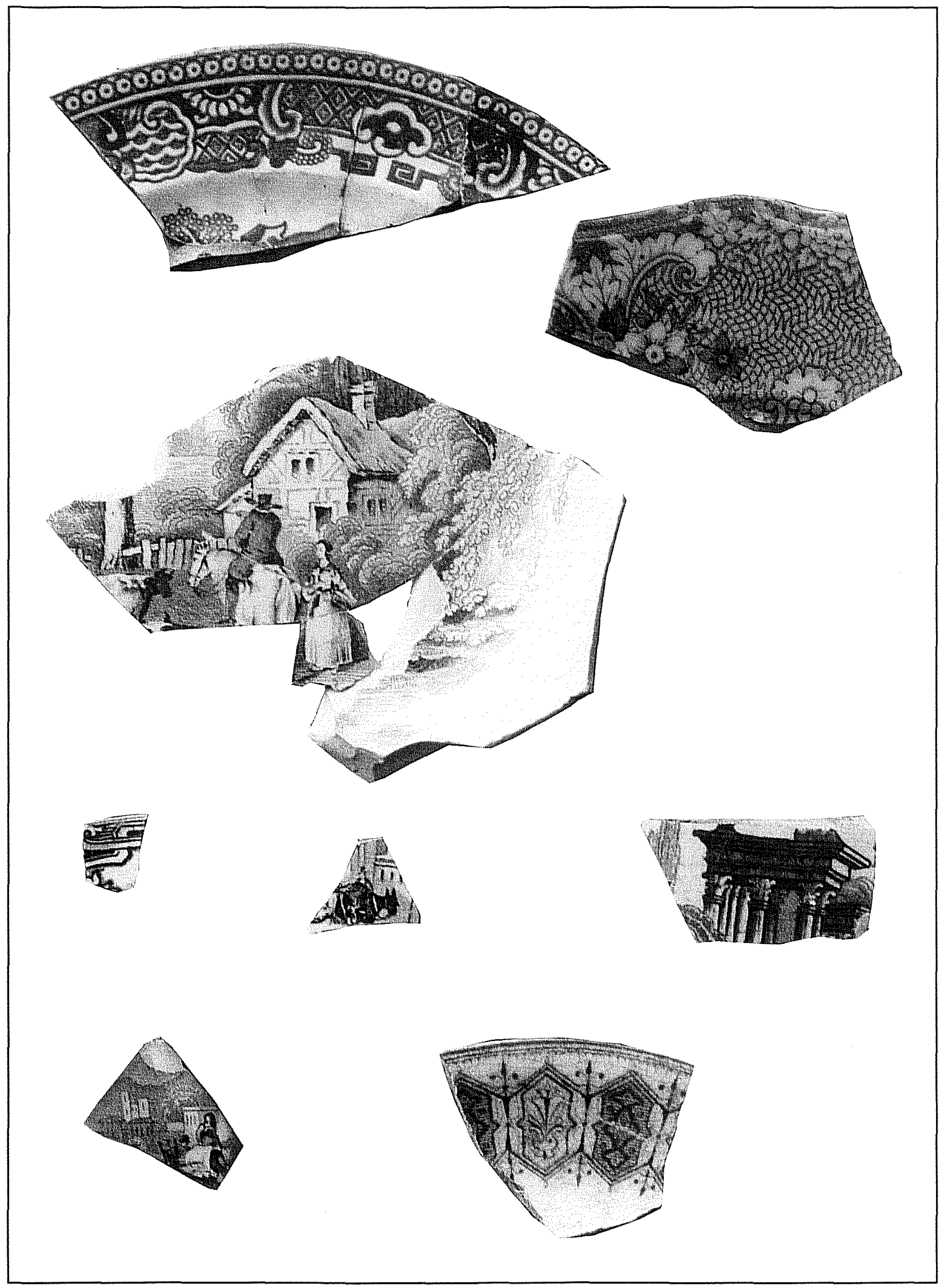

Figure 1-5. Transfer patterns. All shown actual size. 

81 transfer-decorated vessels in colors including dark and light blue, red, brown, black, green, and purple on whiteware and ironstone as well as five vessels decorated in Flow Blue. Of the eight maker's marks present, seven can be identified as European (Appendix 1-B). Dates associated with these marks fall generally between the decades of 1870 and 1890 . Two of these are found on a red "British Scenery" plate (Figure 1-5) from Davenport ca. 1852-1887 (Coysh and Henrywood 1990:35) and a blue scenery cup from Rogout \& Co. ca. 1883-1887 (Hudig 1979:55) that crossmend from 41BX883 and 41BX897. Another company, J. \& G. Meakin, Hanley, England, has a pattern name of "Concord" that is dated sometime after 1907 (Godden 1971:427). This pattern, with its bold brown flowers and leaves, appears on our only pieces identified as belonging to a set. The pieces, all from 41BX945, include two complete 6-inch saucers and part of another one, one 10 -inch dinner plate, one 10-inch serving platter with slightly scalloped rim, one cup, and one pitcher base.

Plain Colored ( 207 total)

The 18 vessels in this category are examples of the solid colored, plain tableware that was popular in the 1930s-1950s (Lehner 1988). Colors in our collection are yellow, green, maroon, pink, blue, turquoise, brown, and mustard tan. Vessel forms include plates, bowls, saucers, cups, and two decorative jars.

\section{Tea Leaf ( 6 total)}

Tea Leaf is the commonly used name that identifies ironstone with copper luster decorations in the form of rim and occasional base bands with a three-part sprig and bud design on the body. Tea Leaf decorations were manufactured in England and the United States from the 1850 s to approximately 1910 , but experienced their greatest popularity in the 1880s (Ray 1974:221). The six sherds in this assemblage represent one bowl and one pitcher.

Miscellaneous Refined Earthenware

Sherds from seven vessels recovered at separate sites have characteristics that preclude their placement in one of the established categories. These include: one splashed pink luster cup, one lamp base with a brown speckled tan glaze, and one sherd with deeply incised lines along a blue underglazed edge. The other four sites yielded sherds with blue Rockingham-like glaze over a white paste, one piece with blue and black mottled glaze, a possible pitcher with molded flowers glazed in shades of brown and yellow, and one complete plate with a blue flower decal under glaze. This last piece has a maker's mark and pattern name "Ever Yours" by Taylor, Smith and Taylor that dates to 1960-1970 (Lehner 1988:).

\section{Porcelain}

Porcelain is the end product of firing fine-grained clay mixed with Kaolin at very high temperatures. The result is a smooth, nearly translucent ceramic that rings like crystal when lightly struck. European porcelains of the type recovered at the Alamodome are rare in archaeological assemblages prior to 1859 (Miller 1991:11). Decorated porcelain is sometimes used as an economic marker as it was slightly more expensive than similarly decorated whiteware and ironstones (Miller 1991:15).

Porcelain, decorated and undecorated, makes up over 13 percent of the Alamodome assemblage. Percentages based on sherd count place undecorated porcelain at 55 percent of this total category while percentages computed on estimated vessel counts places undecorated at 30 percent of the total porcelain collection. The majority of undecorated vessel forms are cups, saucers, and plates. Of the two maker's marks present, one was used by Onondaga Pottery Company as early as 1885 (Lehner 1988:455). The other mark, from Germany, remains unidentified.

The predominate type of decoration in this porcelain assemblage is decal (Figure 1-6). An estimated 55 vessels have decorations of this kind. Designs are generally floral, some having gilded accents. Two plates from different sites are decorated with floral borders and outdoor scenes in their centers. One of these plates from the surface at $41 \mathrm{BX} 895$ bears a Bavarian maker's mark dating sometime after 1880 (Poche 1974:505). Two 8-inch plates and one 51/2-inch saucer from the privy at $41 \mathrm{BX} 945$ have a matching delicate pink floral pattern. Two 9-inch serving bowls with unidentified German maker's marks have similar large pansy-like decals on a faintly pink tinted background. Two other $7 \frac{1}{2}$-inch plates share a badly faded floral design, and several very small fragments with orange Oriental designs are also present. Transfer decorations appear on only an estimated 12 vessels in 

the porcelain assemblage. All the transfer is done in blue and appears to be Oriental, at least in inspiration. Only one very thick plate rim has a willow-like design while examples of a foliated-scroll design appear in several sites. One "Made in Japan" maker's mark remains unidentified.

Handpainted designs on porcelain are limited in this collection to painted rim bands and scenic views too small to describe.

Nine fragments of thick porcelain with solid color decorations under glaze were recovered. These include a maroon checkered design and several fragments of green and dark blue from hanging lids.

\section{Stoneware}

Stoneware (Figure 1-7) made up 12 percent of the ceramics collected during all phases of the Alamodome archaeological project. Stoneware, as discussed here, is identified as ceramics made from natural clays that have been fired at temperatures between $1200^{\circ}$ and $1400^{\circ} \mathrm{C}$, producing vitrified, nonpermeable vessels. Stoneware varies in natural color from near white to shades of brown and gray depending upon the type of clay used. While stoneware, if properly fired, requires no glaze to make it leak-proof, and some vessels in fact have no interior glaze, it became the custom in the United States by the mid-nineteenth century to glaze vessels on both the inside and outside. In this form, the attractive, impermeable, smooth, easy-to-clean ware became the preferred ceramic medium, replacing the softer, lead-glazed earthenwares for utilitarian and storage needs (Greer 1981).

Stoneware and its manufacturing techniques arrived in North America with the colonists and later immigrants; its position as a sturdy utilitarian ware was well established. Early European potters and their descendants spread westward and southward with the pioneers, establishing potteries across the frontier to supply the local needs. In Texas the earliest potteries were founded by men from Georgia and the Carolinas who centered their operations near the excellent clay outcrops of the Wilcox geological formation from Bexar, Wilson, and Guadalupe counties and into east
Texas. Nine potteries are known to have been in operation in the San Antonio area from the late $1800 \mathrm{~s}$ until the mid 1900 s. These were small, family-owned and operated- businesses that supplied most of the stoneware to the community (Greer and Black 1971).

Products including jugs, jars, bowls, pitchers, cups and churns were made by hand for use in the local community. The clay for these items was usually hand dug from local sources, then transported to the pottery where it was mixed, shaped, and fired in kilns. The "Groundhog" or "Hog" kilns that were used were small, tunnel- shaped brick structures, fueled by fires from local oak and mesquite. They operated on an updraft principle, drawing heat from the firebox at the door, through the kiln and out the short chimney on the top of the structure. The average potter could hand-turn 200 gallons of wares per day (Greer and Black 1971).

For the purpose of analysis, all stoneware vessels and sherds were sorted according to interior and exterior glaze combinations, resulting in 13 categories (Appendix 1-A). Stoneware within each category was then sorted by site for analysis of vessel form and evaluation of temporal deposition. Estimates of number of vessels represented were based on complete rim and neck, base, and shoulder sherds whenever possible. When complete diagnostics were not available, differentiation was based on sherd thickness and type. Body sherds were only included when there was clear evidence that they indeed represented a separate vessel, as from sites where the few sherds recovered included no rim, neck, base, or shoulder fragments or where glaze type was clearly different. With this exception, glaze types were not used to estimate the number of vessels as glaze appearance can vary greatly on the same vessel as a result of application, firing technique, and weathering. Reconstruction was attempted whenever possible, resulting in the completion of several vessels that support the last statement. It is also fair to note that application, firing and weathering variables could affect the glaze category placement of individual sherds as well, affording a small margin of error, especially in the Salt Exterior and Leon Slip categories. 



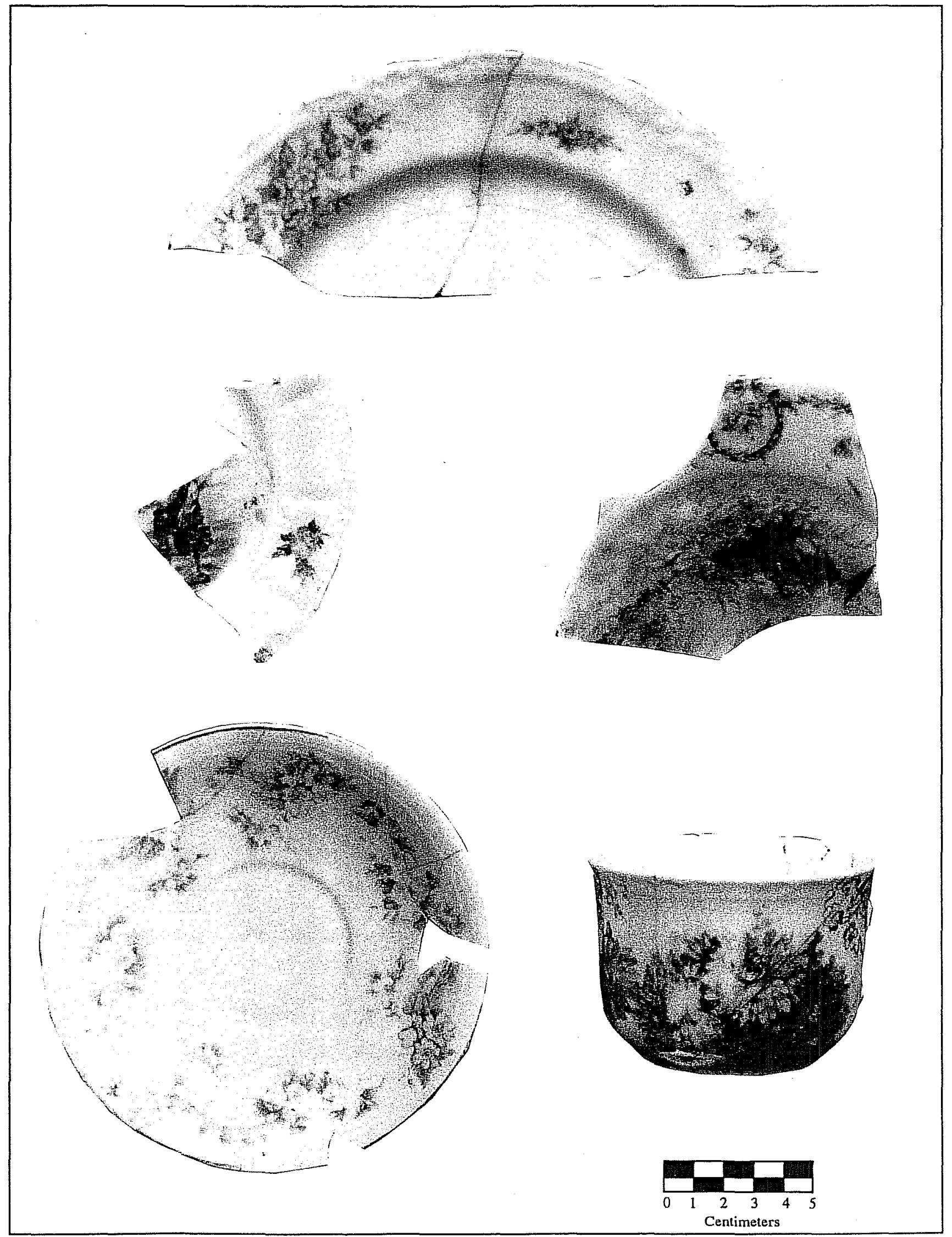

Figure 1-6. Porcelain decal. 



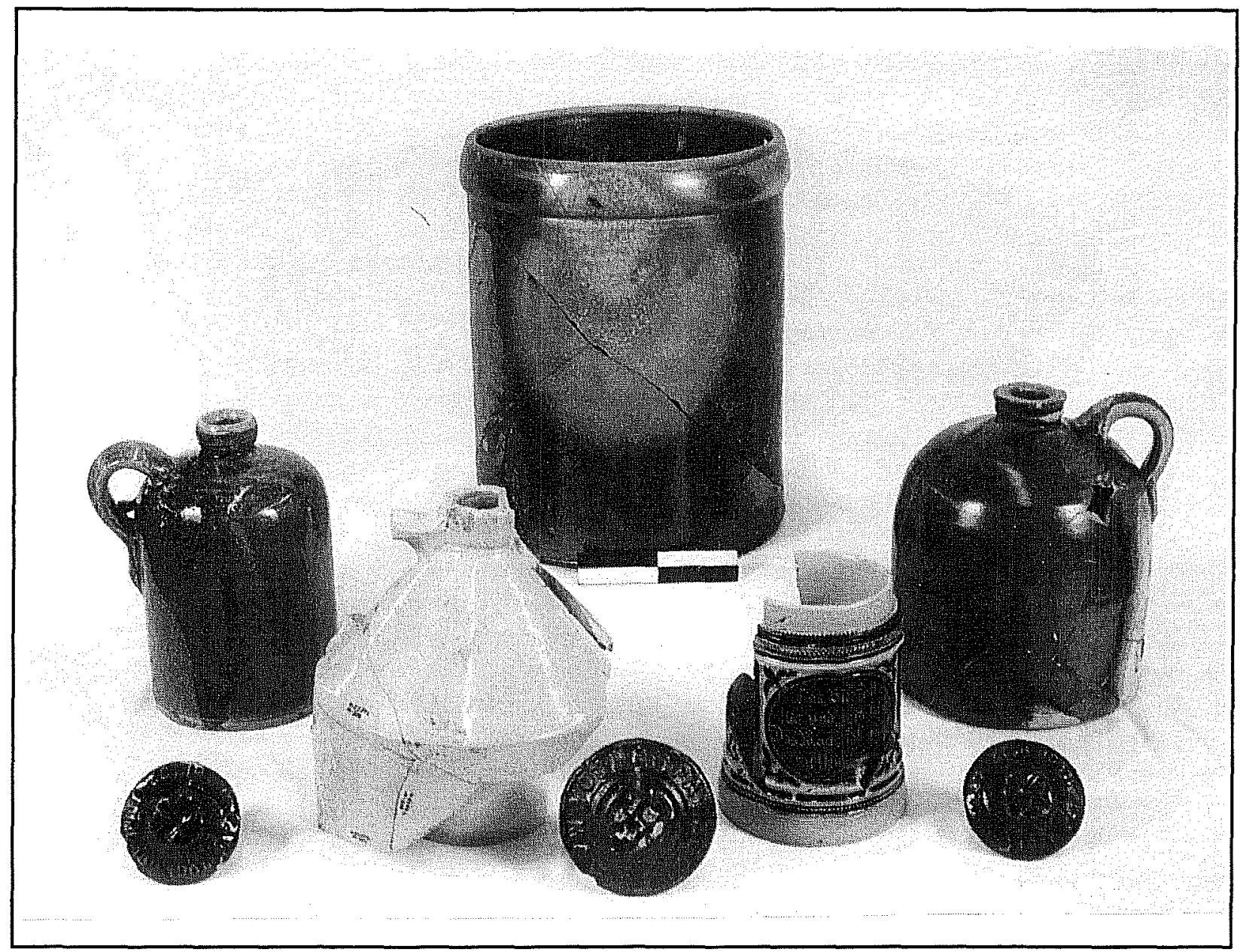

Figure 1-7. Stoneware. Top row: a-brown and gold Leon Slip crock; center row (left to right): b-alkaline glazed jug, c-Bristol glazed jug, d-German salt and cobalt mug, e-Albany Slip jug; bottom row: f-h-Albany slip preserve lids. Two smaller ones read "1901 Pat. March 1st 92. April 16." Large one (center) reads "Youngs Pat. May 27 1902." Scale is four inches long.

\section{Glaze Categories}

\section{Alkaline Glaze}

Alkaline dipping was a popular, inexpensive type of stoneware glaze used throughout the rural South and Texas during the second half of the nineteenth century. This distinctive glaze is made by combining wood ash, clay, and sand. The varieties of wood ash, clay, and sand used varies the color of the glaze immensely from cream through deep brown in an oxygen rich atmosphere to pale bluegreens, olives, and black in a reduction atmosphere. The texture of the glaze is its most noticeable feature, showing streaks and runs as the glaze seems to separate and glob (Figure 1-7b). Additionally alkaline glaze is, with very few exceptions, used on both the inside and outside of the vessel.
Sherd count of stoneware classified as alkaline glaze equaled 25 pieces. These were recovered from seven sites. All with beginning occupancy dates in the 1850 s or $1860 \mathrm{~s}$. The minimum vessel count is estimated at seven, one vessel from each site.

\section{Salt Glaze}

Salt glazing was the most popular method of glazing stoneware in the United States in the nineteenth century, but it died out slowly at the beginning of the twentieth. To produce this finish, common salt is introduced into the kiln when the vessels inside have almost reached the point of vitrification. The resulting salt vapor combines with the silica on the melted stoneware surface to form a glaze with a texture 
similar to orange peel. The glaze itself is usually colorless, so vessel color depends on the iron content of the clay itself. Prior to 1860 vessels were salt glazed on the exterior and left unglazed on the interior. Most common from 1860 to 1900 was the combination of a slip glazed interior with a salt glazed exterior (Greer 1981).

Of the salt glaze combinations, 15 sherds with unglazed interiors were recovered from five sites dating from 1900 and before. Based on distribution the minimum number of vessels has been estimated at five, but only three vessel forms are identifiable: one single process hanging lid with nob handle and two bases from cylindrical jars or churns.

Twenty sites contained fragments of stoneware with a salt exterior and Albany slip interior. Again, based on distribution, a minimum number of 20 vessels is estimated as present, but because of fragmentation, only four vessel forms can be identified: one jug top with a wide neck band and pulled strap handle attached; and three wide-mouth jars or churns, one with a flattened, rolled rim, one with an inside lid ledge, and one with inside lid ledge and blue cobalt trim under the rim.

\section{Albany Slip}

Slip glazes are prepared from watery suspensions of natural clay. The material is strained, leaving a very finely textured liquid that is used to coat the inside as well as the outside of all forms of stoneware. Slips from local clays were used by local potters, but after 1870 a dark brown slip made from an Albany, New York clay became the most common glaze of this type in the South. The popularity of Albany slip is attributed to the fact that it will produce a reliable glaze when fired at a wide range of temperatures, making it suitable for potters using different clays and firing at uneven heats. These slip glazes are smooth and untextured, firing to deep chocolate browns, blackish browns, or yellowish browns depending upon the firing temperature (Greer 1981).

Vessels and sherds assigned to this category are those that exhibit the Albany Slip on both the interior and the exterior (Figure 1-7e). An estimated 22 vessels with this type glaze were recovered from 16 of the 35 sites identified during the Alamodome Project. Of these, 12 identifiable forms were recovered from six sites.
These forms include two shallow bowls, four pulled strap handles, a tooled shoulder jug fragment and a jug top with an unusual 2-inch diameter mouth and a partial pulled strap handle attached. Also identified was one rim fragment with the edge rolled to the inside, possibly from a small mouth preserving jar, and three preserving jar lids with dates of 1901 and 1902 in raised letters on the tops (Figure 1-7f-h).

\section{Leon Slip}

Leon Slip is one of the rare, readily identifiable local stoneware glazes. It was used by the Meyer Pottery of Atascosa County between 1895 and 1944. This finish is so recognizable because of the distinctive firing characteristics of the clay used by the Meyer potters. The clay, dug exclusively by the Meyers from a small hill on Leon Creek, fires to an endless variety of colors from yellow and golden brown to numerous shades of green, sometimes all on the same vessel (Figure 1-7a). Because of the Meyer's 77 years of production in the San Antonio area (1887-1964), Leon Slip is some of the most common stoneware found in this area (Greer and Black 1971).

Vessels and fragments with this finish were recovered from 11 sites, all with pre-1900 original occupancy dates except one narrow site which is bordered on all sides by earlier sites. The minimum number of vessels is estimated at 15 . One seven-inch cylindrical jug with wide shoulders, a wide neck band, and pulled handle with distinctively attached end was recovered complete from 41BX892, the Rilling Site. One wide-mouth cylindrical jar with a full-rolled rim and one cylindrical jug with a reeded neck were reconstructed totally from 41BX945, the Pauly Site. Three additional bases, one shoulder fragment with a distinctively attached, laid on handle, one churn or jar lid, one isolated handle piece, and two wide-banded neck fragments complete the diagnostics in this category.

\section{Bristol Glaze}

In 1884 American potters introduced their version of the popular English Bristol glazed stoneware. This smooth, white, chemically produced finish was instantly popular with potters because of its consistent nature and with the buying public because of its clean, sanitary appearance. The earliest uses of the Bristol glazes were in combination with Albany slip; the darker slip used on the inside and upper portions of the vessels in imitation of the ferruginous-slipped English 
products. This combination was popular until 1915 or 1920 when it was replaced by vessels with Bristol slip on both interior and exterior (Greer 1981).

Ten sites, all, but one with pre-1900 dates, contained fragments of stoneware with the Bristol/Albany glaze combination. Bases from five separate vessels as well as four distinct jugs with tooled shoulders have been identified. A partial maker's mark was recovered from 41BX900. This mark has been traced to the Western Stoneware Company of Illinois, which was in business from 1906 to 1985 . The mark found here is most commonly associated with premiums distributed with flour products from the Sleepy Eye Milling Company (Lehner 1988).

Twelve sites contained sherds with Bristol glaze on both the interior and exterior. The minimum number of vessels has been estimated at 15, including two jar or churn lids, one small mouth preserve jar, and one tooled-shouldered jug (Figure 1-7c).

Table 1-3 shows the occurrences of sherds from these major glaze categories. Of note is the gradual decrease in stoneware in sites with beginning occupancy dates prior to the turn of the century. Stoneware production continued well past the turn of the century in the San Antonio area (Greer 1981), but seems to have been used less frequently in our study area after 1880 .

\section{German Salt Glaze}

Fragments from two beer steins in German salt glaze with cobalt decorations were recovered from two sites, 41BX882 and 41BX945 (Figure 1-7d). Both mugs have incised marks on the bottom: "Germany 372 " and "B \& D, NB2 - Germany."

\section{Miscellaneous Stoneware}

\section{Baking Dishes}

An estimated nine separate dishes with glazed interiors and unglazed exteriors were recovered from nine sites in this study area. These shallow vessels, all approximately 8-10 inches in diameter, have white, blue, or brown interiors and one has "American Cooking Ware" inscribed around the exterior edge and "Sanito" printed in the center. Lehner (1988:105-106) provides a lengthy discussion on cookware of this type but is only able to give a general production date of ca. 1900 in the Ohio area.

\section{Stoneware Bottles}

Evidence was found for at least 11 bottles, possibly as many as five from $41 \mathrm{BX892}$ and two others from 41BX891, next door. Exterior glaze varies from brown to pinkish tan salt while interior finishes include clear, tan, and pinkish mat glazes. One partial incised mark has been interpreted as "Wynand FockinkAmsterdam," probably from a cylindrical Rhenish jug manufactured in Germany for Dutch beverage exports (Greer 1981:244). Three examples of the classic British ginger beer or ale bottles were also recovered. Their characteristic tan and white glaze was a combination of Bristol on the lower half and the darker ferruginous dipped upper half.

Other stoneware items include 12 unglazed low-fired fragments, sherds from stoneware braziers from three sites, a redware tile with yellow slip glaze on one side, a blue and Bristol glazed bowl sherd, four fragments with a blue speckled glaze, and several pieces of an unglazed terra-cotta teapot with a blue and white painted floral pattern.

\section{Discussion}

\section{Crossmending}

Reconstruction of ceramic vessels from sherds found in different proveniences and at different depths is one of the main ways ceramics are used in archaeology to clarify site use and deposition patterns. The occurrences listed on the crossmend chart (Table 1-4) are examples of both horizontal and vertical crossmending. Fragments of a cup reconstructed from the privy at 41BX896 came from depths of between 20 and 45 inches. This indicates that items within these levels were deposited in the privy during a very short interval, possibly even in a single event. The horizontal crossmends between 41BX883 and 41BX897 strongly support the interactions between these two sites (see Volume II). 
Table 1-3. Glaze-Type Distribution

\begin{tabular}{|c|c|c|c|c|c|c|c|c|}
\hline Site \# & Occupation & Alkaline & Salt & Salt/Albany & Leon Slip & Albany/Albany & Bristol/Albany & Bristol/Bristol \\
\hline \multicolumn{2}{|c|}{ Popularity Sequence } & $1840-1860$ & $1840-1860$ & $1860-1900$ & $1895-1944$ & $1870-1900$ & $1900-1915$ & After 1915 \\
\hline 41BX892 & $1855-1926$ & 3 & 2 & 11 & 8 & 9 & & 13 \\
\hline 41BX899 & $1855-1925$ & & & & & & & \\
\hline 41BX945 & $1855-1968$ & 8 & 7 & 9 & 35 & 5 & 7 & 5 \\
\hline 41BX896 & 1856-recent & 1 & & 13 & 4 & 2 & 20 & 45 \\
\hline 41BX898 & |1856-recent & & & & & & & \\
\hline 41BX891 & $1857-1925$ & 1 & & 3 & 13 & 12 & 6 & 7 \\
\hline $41 B \times 890$ & $1858-1925$ & 9 & & 8 & & & & \\
\hline 41BX900 & $1858-1926$ & 3 & 6 & 22 & 2 & 9 & 19 & 3 \\
\hline 41BX897 & $1866-1989$ & 1 & & 13 & 2 & 1 & & 7 \\
\hline 41BX927 & $1870-1910$ & & & & & & & \\
\hline 41BX955 & $1877-1915$ & & & & & & & \\
\hline 41BX928 & $1880-1910$ & & & & & & & \\
\hline 41BX930 & $1880-1920$ & & & & & & & \\
\hline 41BX932 & $1880-1920$ & & & 4 & & 7 & & \\
\hline 41BX937 & 1880-recent & & & & & 5 & & \\
\hline 41BX956 & |1880-recent & & & & & & & \\
\hline 41BX957 & 1880-recent & & & & & & & \\
\hline $41 B \times 884$ & 1883-recent & & & 1 & & 1 & 7 & \\
\hline 41BX883 & $1884-1987$ & & 1 & 7 & 1 & 1 & 4 & 5 \\
\hline 41BX926 & $1885-1920$ & & & 2 & & & & 1 \\
\hline 41BX895 & 1889-1990 & & & 1 & & & & \\
\hline 41BX929 & $1890-1920$ & & & 1 & & & & \\
\hline 41BX938 & $1890-1920$ & & & 7 & & 1 & & \\
\hline 41BX885 & 1892-recent & & & 1 & & 2 & & \\
\hline 41BX881 & $1893-1922$ & & 3 & 5 & 5 & 4 & 1 & 1 \\
\hline 41BX893 & $1899-1990$ & & & 3 & 2 & & & 2 \\
\hline 41BX882 & $1900-1970$ & & & 4 & 2 & 2 & 5 & 4 \\
\hline 41BX894 & $1910-1990$ & & & & & & 3 & \\
\hline 41BX931 & $1920-1990$ & & & 3 & 3 & 7 & & 2 \\
\hline 41BX936 & $1920-1990$ & & & 1 & & & & \\
\hline 41BX939 & 1920-recent & & & & & & & \\
\hline 41BX943 & $1921-1974$ & & & & & & & \\
\hline 41BX941 & |1927-recent & & & & & & & \\
\hline
\end{tabular}




\section{Frequency Distribution}

Sites with more than 50 ceramic sherds were analyzed in ranked order based on ceramic-type frequency to look for patterns of spatial and/or ethnic similarities or differences across our study area. The results were somewhat inconclusive. When sites were ordered by percent of porcelain or whiteware present, random patterns of distribution resulted. However, one pattern did emerge as shown in Table 1-5. Sites with a higher than 10 percent stoneware frequency were predomi nately German and had beginning occupancy dates before 1900. This could be due to a combination of two factors: personal preference of German-born residents, and availability of stoneware during the earlier, transitional phases of the area.

Table 1-4. Crossmend Chart

\begin{tabular}{||l|l|l||}
\hline \multicolumn{1}{|c|}{ Crossmend Item } & \multicolumn{1}{|c|}{ Provenience } & \multicolumn{1}{c|}{ Provenience } \\
\hline Porcelain cup with decal design & $\begin{array}{l}\text { 41BX896 } \\
\text { Levels V (20-25") VI (25-30") VII (30-35") VIII (35-40") IX ( (40-45") }\end{array}$ \\
\hline Cup with blue transfer pattern & 41BX883 WET 3-W & 41BX897 WET 2-E \\
\hline Bowl with red transfer pattern & 41BX883 WET 3-W & 41BX897 WET 9-29.5 \\
\hline Plate with cut sponge design & 41BX883 WET 3-W & 41BX897 WET 3-E \\
\hline Edgeware design on 3 plates & 41BX883 WET 3-E & 41BX897 WET 6-7 and Trench E \\
\hline
\end{tabular}

Table 1-5. Type Frequency Distribution

\begin{tabular}{||c|c|c|c|c|c|c||}
\hline \multirow{2}{*}{ Site \# } & \multirow{2}{*}{ Occupation dates } & \multirow{2}{*}{ Ethnicity } & \multicolumn{3}{|c|}{$\%$} & \multirow{2}{*}{ Total Sherds } \\
\cline { 4 - 6 } & & & Stoneware & Whiteware & Porcelain & \\
\hline 41BX891 & $1857-1925$ & German & 38 & 58 & 8 & 133 \\
\hline 41BX892 & $1855-1926$ & German & 34 & 61 & 6 & 289 \\
\hline 41BX885 & $1892-$ recent & Varied & 28 & 42 & 13 & 64 \\
\hline 41BX945 & $1855-1968$ & German & 14 & 63 & 23 & 148 \\
\hline 41BX896 & $1856-$ recent & French/German & 16 & 67 & 16 & 497 \\
\hline 41BX890 & $1858-1925$ & German & 13 & 77 & 9 & 131 \\
\hline 41BX884 & $1883-$ recent & German & 13 & 73 & 5 & 67 \\
\hline 41BX881 & $1893-1922$ & German & 12 & 70 & 14 & 182 \\
\hline 41BX882 & $1900-1970$ & Varied & 12 & 61 & 23 & 195 \\
\hline 41BX932 & $1890-1990$ & Varied & 11 & 86 & 2 & 84 \\
\hline 41BX893 & $1899-1990$ & Polish & 9 & 80 & 11 & 103 \\
\hline 41BX900 & $1858-1926$ & English/German & 8 & 78 & 13 & 808 \\
\hline 41BX939 & $1920-$ recent & Black & 6 & 86 & 8 & 50 \\
\hline 41BX931 & $1920-1990$ & Black & 5 & 82 & 13 & 327 \\
\hline 41BX897 & $1866-1989$ & Black & 4 & 79 & 17 & 713 \\
\hline 41BX883 & $1884-1987$ & German & 3 & 83 & 13 & 839 \\
\hline 41BX938 & $1890-1920$ & Varied & 3 & 80 & 15 & 295 \\
\hline 41BX942 & $1927-$ recent & Black & 3 & 88 & 9 & 96 \\
\hline 41BX937 & $1890-$ recent & Varied & 1 & 88 & 11 & 158 \\
\hline
\end{tabular}




\section{Sets As Socioeconomic Markers}

It has been suggested that the presence of tableware sets and matching serving pieces may be a reliable indicator of socioeconomic status (Moir 1987; Stothert 1992). This statement appears to be supported in our study area by the fact that the one site that did yield matching ceramic pieces was the privy at 41BX945. The Muellers, owners of this site after the turn of the century, were reported by archival documents and oral histories to be among the most prosperous in the area (Brown and DeLaO, this volume). Pieces from three sets were recovered, including a plate, platter, cup, saucer, and pitcher in a brown transfer pattern; two plates and two saucers in a delicate pink floral decal on porcelain; and matching serving bowls also in a floral decal on porcelain.

\section{Assemblage Comparisons}

Initially the focus of this analysis was to see if the arrival of the urban era in San Antonio would be reflected in the ceramic assemblage recovered from the Alamodome Project area. A growing urban center should have had a wider variety of goods readily available at more moderate costs than could be found in more rural areas of the state at this time. A typefrequency comparison was made between our study area and four other historic sites. Two sites were chosen close to San Antonio. Camp Bullis (Gerstle et al. 1978) and LBJ State Park (Tunnell and Jensen 1968), are both north of the city, 10 and 50 miles respectively. Two rural sites were also chosen, Cuero I, in southwest Texas (Fox et al.1974) and Richland Creek, in east Texas (Moir 1987). Frequency comparisons are shown in Table 1-6.

In the two rural areas, stoneware retained a greater position of importance, while the use of porcelain was restricted, possibly as a result of availability, personal preference, and/or practicality. Assemblages from the Alamodome area and nearby Camp Bullis and LBJ State Park present a picture of more evenly distributed ceramic types. Stoneware is present but apparently losing popularity. Decorated whitewares are found with greater frequency in the Dome area and in LBJ Park, while porcelain consistently averages 11-14 percent of these three collections. The even distribution of ceramic types in areas near San Antonio reflects the expected increase in variety and availability in a growing urban center.

Table 1-6. Urban and Rural Type Frequency Comparison

\begin{tabular}{|l|c|c|c|c|c||}
\hline \multirow{2}{*}{ Site } & \multirow{2}{*}{$\begin{array}{c}\text { Occupation } \\
\text { Dates }\end{array}$} & Whiteware & Porcelain & $\begin{array}{c}\text { Stoneware/ } \\
\text { Yellowware }\end{array}$ & Soft Paste \\
\cline { 3 - 6 } & & & & \multicolumn{4}{|c|}{} \\
\hline Camp Bullis & $1850-1940$ & 72.7 & 10.8 & 16.5 & 0 \\
\hline LBJ Park & $1868-1940$ & 75.6 & 13.3 & 8.0 & 3.1 \\
\hline Alamodome & $\mathbf{1 8 5 5 - 1 9 9 0}$ & $\mathbf{7 3 . 7}$ & $\mathbf{1 3 . 7}$ & $\mathbf{1 1 . 3}$ & 1.3 \\
\hline Cuero I & $1830-1950$ & 83.0 & 3.5 & 13.5 & 0 \\
\hline Richland Creek & $1855-1965$ & 69.7 & 3.6 & 26.5 & .2 \\
\hline
\end{tabular}




\section{Appendix 1-A: Ceramics}

Table 1-A1. Earthenware

\begin{tabular}{|c|c|c|c|c|c|c|c|c|c|c|c|c|c|c|c|c|c|c|c|c|c|}
\hline Site \# & $\begin{array}{l}z \\
z \\
\dot{5}\end{array}$ & 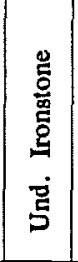 & $\begin{array}{l}\frac{\vec{d}}{0} \\
\frac{0}{2} \\
\frac{0}{2}\end{array}$ & 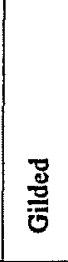 & $\begin{array}{l}\text { 总 } \\
\text { 总 } \\
\text { E }\end{array}$ & $\begin{array}{c} \pm \\
\stackrel{0}{5} \\
5 \\
5\end{array}$ & 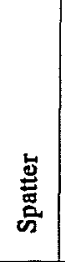 & 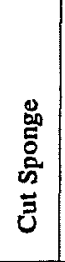 & 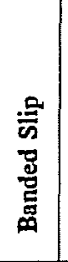 & 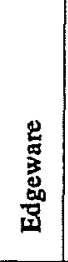 & 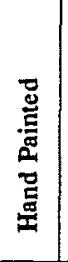 & 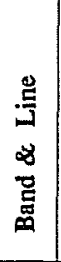 & $\begin{array}{l}\cong \\
\stackrel{\Xi}{\underline{m}} \\
\frac{\vec{z}}{a}\end{array}$ & 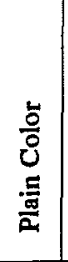 & $\begin{array}{l}\bar{\Xi} \\
\text { वूँ } \\
\end{array}$ & 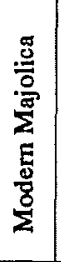 & 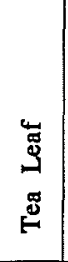 & 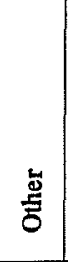 & 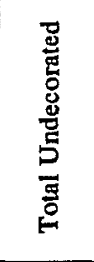 & 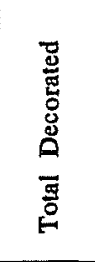 & 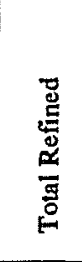 \\
\hline 41 BX881 & 76 & 8 & 3 & & 3 & & & & 1 & & 9 & 1 & & 7 & 14 & 3 & & & 84 & 41 & 125 \\
\hline 41BX882 & 52 & 20 & 13 & & 9 & 1 & & & & & 2 & 2 & & 3 & 12 & & & & 72 & 42 & 114 \\
\hline 41BX883 & 235 & 273 & 17 & 4 & 52 & 3 & & 21 & 27 & 20 & 13 & 3 & 5 & 11 & 12 & & 1 & 3 & 508 & 192 & 700 \\
\hline 41BX884 & 23 & 6 & 2 & 1 & 4 & & 1 & 1 & & & 4 & 2 & & 6 & & 1 & & & 29 & 22 & 51 \\
\hline 41BX885 & 6 & 14 & & & & & & 1 & & & 1 & & & 1 & 2 & & & & 20 & 5 & 25 \\
\hline 41BX890 & & 65 & 2 & & 3 & 1 & & & 1 & & & 2 & & 26 & & & & & 65 & 35 & 100 \\
\hline 41BX891 & 18 & 34 & 7 & & 1 & 2 & & & & & & & & & 5 & & & & 52 & 15 & 67 \\
\hline 41BX892 & 28 & 114 & 5 & & 10 & & 2 & 1 & 2 & & 3 & 2 & 2 & & 4 & 1 & & & 142 & 32 & 174 \\
\hline 41BX893 & 62 & 3 & 3 & 5 & 1 & & & & 1 & & & & & 1 & 6 & 1 & & 1 & 65 & 19 & 84 \\
\hline 41BX894 & 5 & & & & 10 & & & & & & & 1 & & 3 & 2 & & & & 5 & 16 & 21 \\
\hline 41BX895 & & 9 & & & 2 & & & & & & & 1 & & 1 & & & & 1 & 9 & 5 & 14 \\
\hline 41BX896 & 151 & 44 & 25 & 8 & 11 & & & & & & 11 & & & 47 & 36 & & & 3 & 195 & 141 & 336 \\
\hline 41BX897 & 348 & 125 & 10 & 1 & 18 & 3 & & 15 & 14 & 19 & 7 & 1 & & 4 & 12 & & & & 473 & 104 & 577 \\
\hline $41 \mathrm{BX} 898$ & 2 & & & & & & & & 2 & & 1 & & & & & & & & 2 & 3 & 5 \\
\hline 41BX899 & 5 & & & & & & & & & & 1 & & & & & & & & 5 & 1 & 6 \\
\hline 41BX900 & 372 & 118 & 56 & 12 & 17 & 6 & & 4 & 4 & 26 & 6 & 1 & & 1 & 5 & & 5 & 1 & 490 & 144 & 634 \\
\hline $41 \mathrm{BX} 926$ & & & & & & & & & & & & & & & & & & & 0 & 0 & 0 \\
\hline 41BX927 & 4 & 22 & & & 1 & & & & & & & & & & 15 & & & 4 & 26 & 20 & 46 \\
\hline 41BX928 & 42 & 42 & 21 & 16 & & & & & & & & & & & 15 & & & & 84 & 52 & 136 \\
\hline 41BX929 & & & & & & & & & & & & & & & & & & & 0 & 0 & 0 \\
\hline 41BX930 & & & & & & & & & & & & & & & & & & & 0 & 0 & 0 \\
\hline 41BX931 & 154 & 54 & 14 & & 28 & 1 & & & & & & & & 1 & 1 & & & & 208 & 45 & 253 \\
\hline 41BX932 & 32 & 36 & 1 & & & 1 & & & & & & & & & & & & & 68 & 2 & 70 \\
\hline 41BX936 & 17 & 7 & & & 6 & & & & & & & 3 & & 2 & 2 & & & & 24 & 13 & 37 \\
\hline 41BX937 & 66 & 34 & 3 & 1 & 6 & & & & & & & 2 & 3 & & 18 & & & & 100 & 33 & 133 \\
\hline 41BX938 & 90 & 27 & 9 & 17 & 9 & 1 & & & & & 17 & 7 & & 51 & 21 & & & & 117 & 132 & 249 \\
\hline 41BX939 & 25 & & 1 & & & & & & & & & 1 & & 8 & 8 & & & & 25 & 18 & 43 \\
\hline 41BX940 & 12 & & 1 & 1 & & & & & & & & & & & & & & & 12 & 2 & 14 \\
\hline 41BX941 & 3 & & 4 & & & & & & & & & 1 & & 2 & 5 & & & & 3 & 12 & 15 \\
\hline 41BX942 & 18 & 18 & 7 & & & 6 & & & & & & 1 & & 19 & 15 & & & & 36 & 48 & 84 \\
\hline $41 \mathrm{BX} 943$ & & & & & & & & & & & & & & & & & & & 0 & 0 & 0 \\
\hline 41BX944 & & & & & & & & & & & & & & & & & & & 0 & 0 & 0 \\
\hline 41BX945 & 79 & 158 & 72 & 4 & 35 & & & & & & 1 & 4 & 4 & 11 & 20 & & & 8 & 237 & 159 & 396 \\
\hline 41BX955 & & & & & & & & & & & & & & & & & & & 0 & 0 & 0 \\
\hline 41BX956 & 5 & & & 1 & 2 & & & & & & 1 & & & 2 & 4 & & & & 5 & 10 & 15 \\
\hline 41BX957 & 7 & 1 & & & & & & & & & & & & & 1 & & & & 8 & 1 & 9 \\
\hline TOTAL & 1937 & 1232 & 276 & 71 & 228 & 25 & 3 & 43 & 52 & 65 & 77 & 35 & 14 & 207 & 235 & & 6 & 21 & 3169 & 1364 & 4533 \\
\hline
\end{tabular}


Table1-A2. Porcelain

\begin{tabular}{|c|c|c|c|c|c|c|c|c|c|}
\hline Site\# & Undec & Gilded & Molded & Decal & Transfer & $\begin{array}{l}\text { Free } \\
\text { Hand }\end{array}$ & Other & $\begin{array}{l}\text { Total } \\
\text { Dec. }\end{array}$ & $\begin{array}{c}\text { Total } \\
\text { Porcelain }\end{array}$ \\
\hline $41 \mathrm{BX} 881$ & 11 & & 1 & 10 & 1 & 5 & & 17 & 28 \\
\hline $41 \mathrm{BX882}$ & 21 & 2 & 3 & 18 & 1 & & & 24 & 45 \\
\hline 41BX883 & 84 & & 11 & 9 & & & & 20 & 104 \\
\hline $41 \mathrm{BX} 884$ & 3 & & & & & & & 0 & 3 \\
\hline $41 \mathrm{BX} 885$ & 7 & 1 & & & & & & 1 & 8 \\
\hline $41 \mathrm{BX} 890$ & 9 & & 1 & & & & 2 & 3 & 12 \\
\hline $41 \mathrm{BX} 891$ & & & 10 & 1 & & & & 11 & 11 \\
\hline 41BX892 & 9 & 1 & 3 & 2 & & & 4 & 10 & 19 \\
\hline $41 \mathrm{BX} 893$ & 6 & & & 2 & & & 3 & 5 & 11 \\
\hline $41 \mathrm{BX} 894$ & & & & 1 & & & 1 & 2 & 2 \\
\hline 41BX895 & 4 & 1 & & 3 & & & 1 & 5 & 9 \\
\hline $41 \mathrm{BX} 896$ & 36 & 5 & 8 & 14 & 5 & 7 & 4 & 43 & 79 \\
\hline $41 B \times 897$ & 103 & 2 & 3 & 13 & & 2 & 3 & 23 & 126 \\
\hline 41BX898 & & & & & & & & 0 & 0 \\
\hline $41 \mathrm{BX899}$ & 1 & & & & & & & 0 & 1 \\
\hline $41 \mathrm{BX} 900$ & 89 & & 10 & 6 & 2 & 1 & & 19 & 108 \\
\hline $41 \mathrm{BX} 926$ & & & & & $\therefore$ & & & 0 & 0 \\
\hline 41BX927 & & & & & & & & 0 & 0 \\
\hline 41BX928 & 4 & & & & & & & 0 & 4 \\
\hline $41 \mathrm{BX} 929$ & & & & & & & & 0 & 0 \\
\hline $41 \mathrm{BX} 930$ & & & & 2 & 4 & 1 & & 7 & 7 \\
\hline 41BX931 & 26 & & 9 & 2 & & & & 11 & 37 \\
\hline $41 \mathrm{BX} 932$ & 1 & & 1 & & & & & 1 & 2 \\
\hline $41 \mathrm{BX} 936$ & & & & & & & & 0 & 0 \\
\hline $41 \mathrm{BX} 937$ & 5 & & 1 & 11 & 1 & & & 13 & 18 \\
\hline $41 \mathrm{BX} 938$ & 28 & 4 & 2 & 5 & 4 & & & 15 & 43 \\
\hline 41BX939 & & & & 4 & & & & 4 & 4 \\
\hline $41 \mathrm{BX} 940$ & & & & & & & & 0 & 0 \\
\hline 41BX941 & 3 & & & 1 & & & 1 & 2 & 5 \\
\hline 41BX942 & & & & 9 & & & & 9 & 9 \\
\hline $41 \mathrm{BX} 943$ & & & & & & & & 0 & 0 \\
\hline $41 \mathrm{BX} 944$ & & & & & & & & 0 & 0 \\
\hline $41 \mathrm{BX} 945$ & 18 & & 1 & 121 & & 8 & & 130 & 148 \\
\hline 41BX955 & & & & & & & & 0 & 0 \\
\hline $41 \mathrm{BX} 956$ & & & & & 3 & & & 3 & 3 \\
\hline $41 \mathrm{BX} 957$ & & & & & & & & 0 & 0 \\
\hline TOTAL & 468 & 16 & 64 & 234 & 21 & 24 & 19 & 378 & 846 \\
\hline
\end{tabular}


Table1-A3. Stoneware

\begin{tabular}{|c|c|c|c|c|c|c|c|c|c|c|c|c|c|c|c|c|c|c|c|}
\hline Site \# & 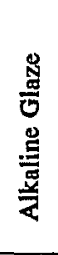 & $\begin{array}{l}\text { 嶌 } \\
\text { 离 } \\
\text { 离 }\end{array}$ & 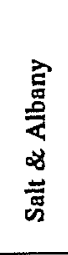 & 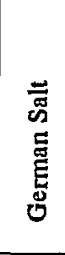 & $\begin{array}{l}\stackrel{0}{\bar{n}} \\
\vdots \\
\vdots \\
\vdots\end{array}$ & 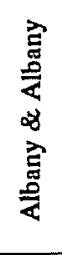 & 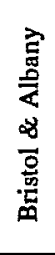 & 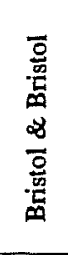 & 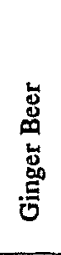 & 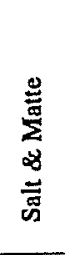 & 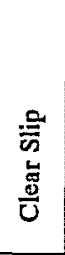 & 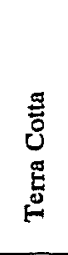 & 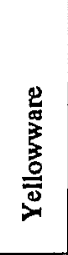 & 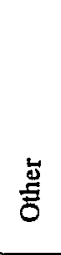 & 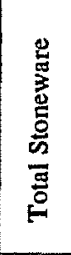 & 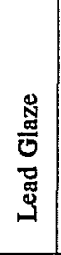 & 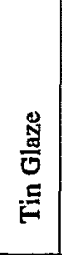 & 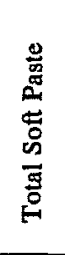 & $\begin{array}{l}\overrightarrow{\mathrm{g}} \\
\stackrel{0}{0} \\
\stackrel{0}{\omega}\end{array}$ \\
\hline 41BX881 & & 3 & 5 & & 5 & 4 & 1 & 1 & & & & 1 & 1 & 2 & 23 & 7 & & 7 & 183 \\
\hline 41BX882 & & & 4 & 2 & 2 & 2 & 5 & 4 & 4 & & & & 4 & & 27 & 7 & 1 & 8 & 194 \\
\hline $41 \mathrm{BX} 883$ & & 1 & 8 & & 1 & 1 & 4 & 5 & & & & 3 & 8 & 4 & 35 & 13 & & 13 & 852 \\
\hline 41BX884 & & & 1 & & & 1 & 7 & & & & & & & & 9 & 6 & & 6 & 69 \\
\hline 41BX885 & & & 1 & & & 2 & & & & & & 1 & & 15 & 19 & 11 & & 11 & 63 \\
\hline 41BX890 & 9 & & 8 & & & & & & & & & 2 & 3 & 1 & 23 & 1 & & 1 & 136 \\
\hline 41BX891 & 1 & & 3 & & 12 & 12 & 6 & 7 & & & 10 & & 4 & & 55 & & & 0 & 133 \\
\hline 41BX892 & 3 & 2 & 11 & & 9 & 11 & 1 & 33 & & 21 & 16 & & 20 & & 127 & & & 0 & 320 \\
\hline 41BX893 & & & 3 & & 2 & & & 2 & & 2 & & & 1 & 1 & 11 & & & 0 & 106 \\
\hline 41BX894 & & & & & & & 3 & & & & & & & & 3 & & & 0 & 26 \\
\hline 41BX895 & & & 1 & & & & & & & & & & & & 1 & 2 & & 2 & 26 \\
\hline 41BX896 & & & 13 & & 4 & 2 & 3 & 45 & & & & & 2 & 7 & 76 & 9 & & 9 & 500 \\
\hline 41BX897 & 1 & & 15 & & 2 & 1 & & 7 & & 3 & & 1 & 7 & 5 & 42 & 1 & & 1 & 746 \\
\hline 41BX898 & & & & & & & & & & & & & & & $\underline{0}$ & & & 0 & 5 \\
\hline 41BX899 & & & 1 & & & & & & & & & & & & 1 & & & 0 & 8 \\
\hline $41 \mathrm{BX} 900$ & 3 & 6 & 22 & & 2 & 10 & 19 & 3 & & 1 & & 14 & 11 & 2 & 93 & 2 & & 2 & 837 \\
\hline $41 \mathrm{BX} 926$ & & & 2 & & & & & 1 & & & & & & & 3 & 5 & & 5 & 8 \\
\hline 41BX927 & & & & & & & & & & & & & & & 0 & & & 0 & 46 \\
\hline 41BX928 & & & & & & & & & & & & & 6 & & 6 & & & 0 & 146 \\
\hline 41BX929 & & & 1 & & & & & & & & & & 1 & & 2 & & & 0 & 2 \\
\hline 41BX930 & & & & & & & & & & & & & & & 0 & & & 0 & 7 \\
\hline 41BX931 & & & 3 & & 3 & 7 & & 2 & & 2 & & 14 & 14 & & 45 & 1 & & 1 & 336 \\
\hline 41BX932 & & & 4 & & & 5 & & & & & & 4 & 2 & & 15 & 1 & & 1 & 88 \\
\hline 41BX936 & & & 1 & & & & & & & & & & & 1 & 2 & & & 0 & 39 \\
\hline 41BX937 & & & & & & 1 & & & & & & & 3 & & 4 & & & 0 & 155 \\
\hline 41BX938 & & & 7 & & & 1 & & & & & & & & 6 & 14 & & 8 & 8 & 314 \\
\hline 41BX939 & & & & & & & & & & & & & & 3 & 3 & & & 0 & 50 \\
\hline $41 \mathrm{BX} 940$ & & & & & & & & & & & & & & & 0 & & & 0 & 14 \\
\hline 41BX941 & & & & & & 3 & & & & & & & & & 3 & & & 0 & 23 \\
\hline 41BX942 & & & & & & & & & & & & & & 3 & 3 & & & 0 & 961 \\
\hline 41BX943 & & & & & & & & & & & & & & & 0 & & & 0 & 0 \\
\hline 41BX944 & & & & & & & & & & & & & & & 0 & & & 0 & 0 \\
\hline 41BX945 & 8 & 3 & 9 & 18 & 36 & 5 & 5 & 5 & & & & 2 & 23 & & 114 & 3 & & 3 & 661 \\
\hline 41BX955 & & & 1 & & & & & & & & & & & & 1 & & & 0 & 1 \\
\hline 41BX956 & & & & & & & & & & & & & & & 0 & & & 0 & 18 \\
\hline 41BX957 & & & & & & & & & & & & & & & 0 & & & 0 & 9 \\
\hline & 25 & 15 & 124 & 20 & 78 & 68 & 54 & 115 & 4 & 29 & 26 & 42 & 110 & 50 & 760 & 69 & 9 & 78 & 6217 \\
\hline
\end{tabular}




\section{Appendix 1-B: Maker's Marks}

Table 1-B1. Maker's Marks from Alamodome Sites

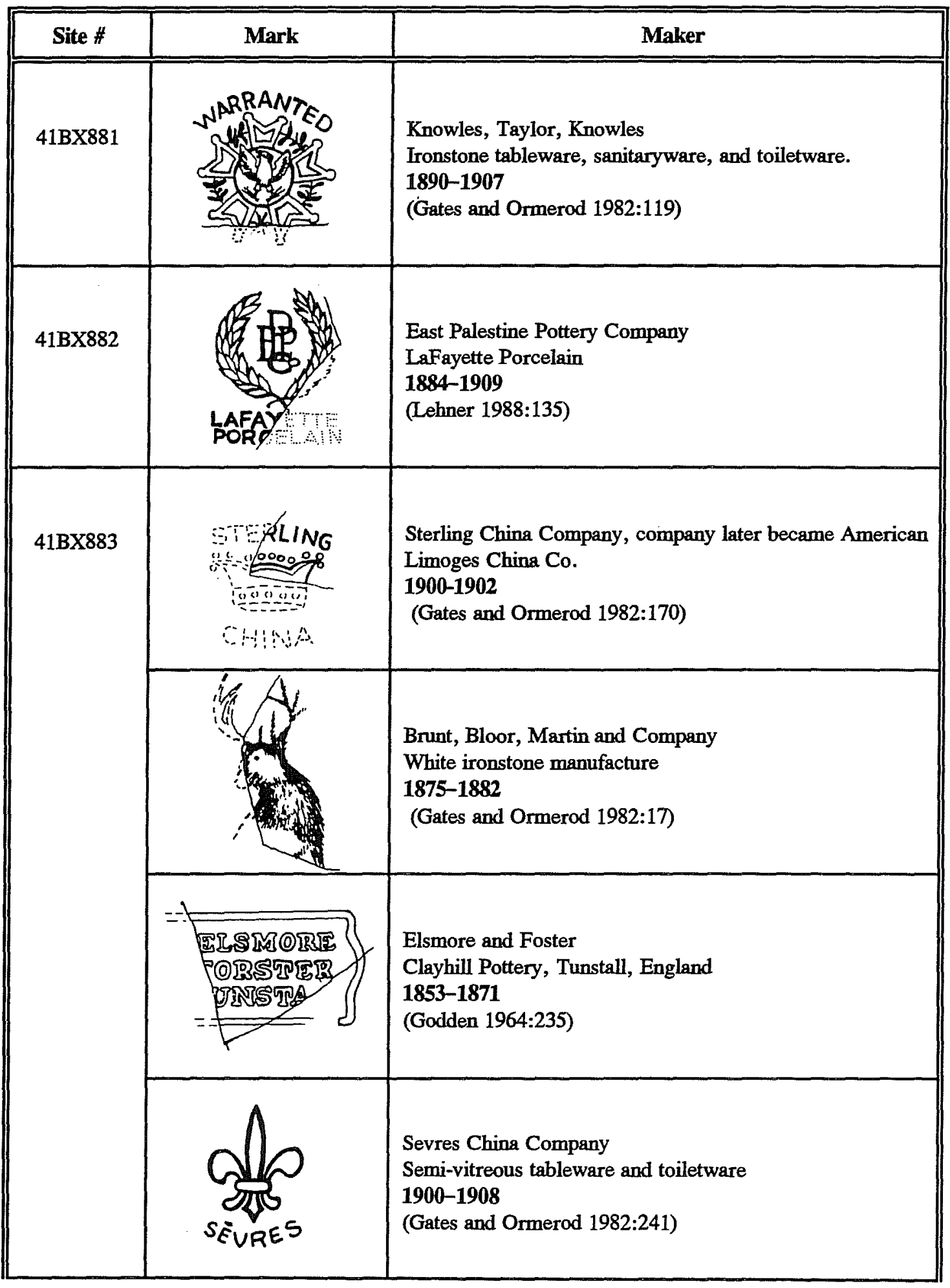


Table 1-B1. continued

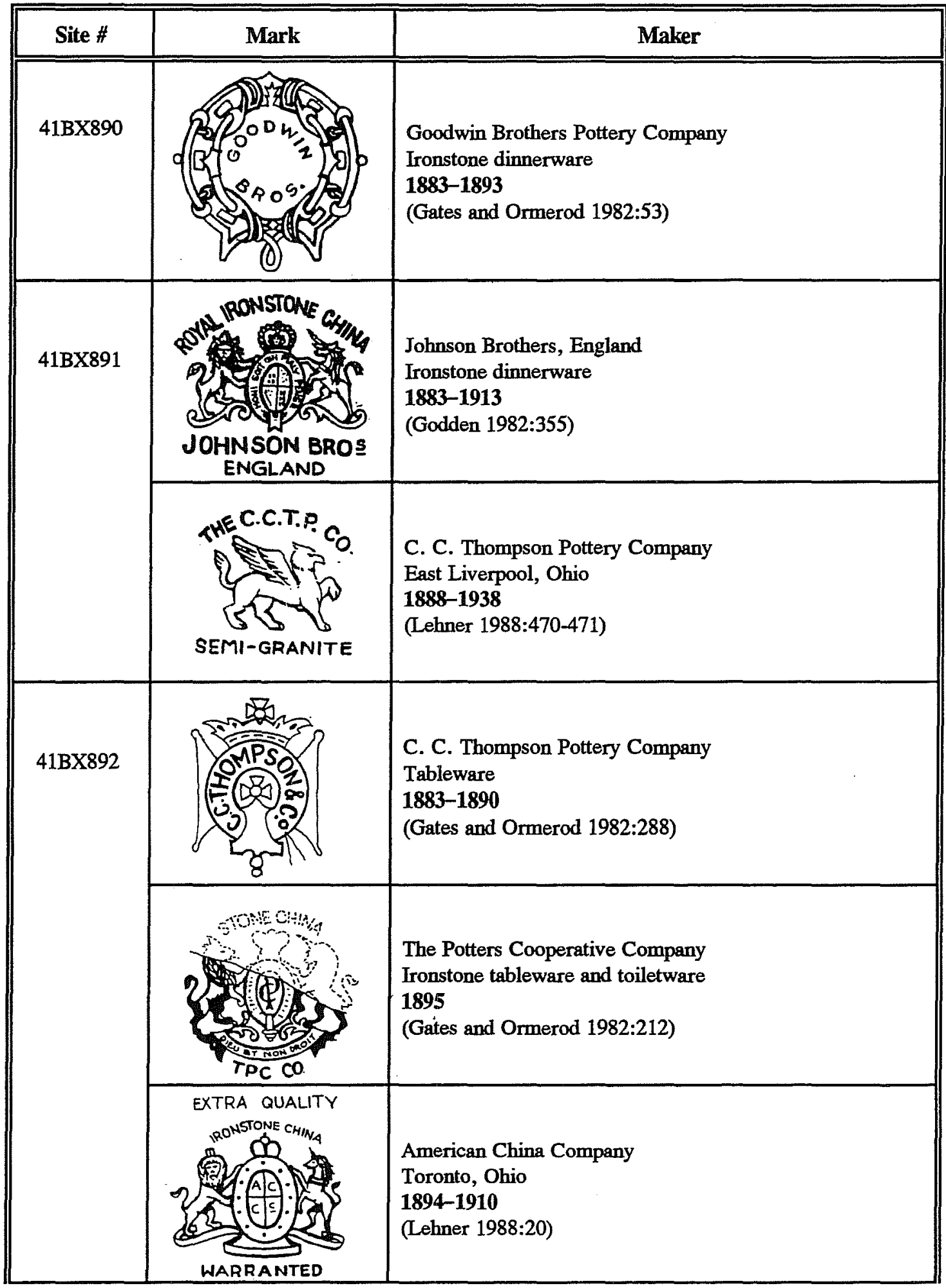


Table 1-B1. continued

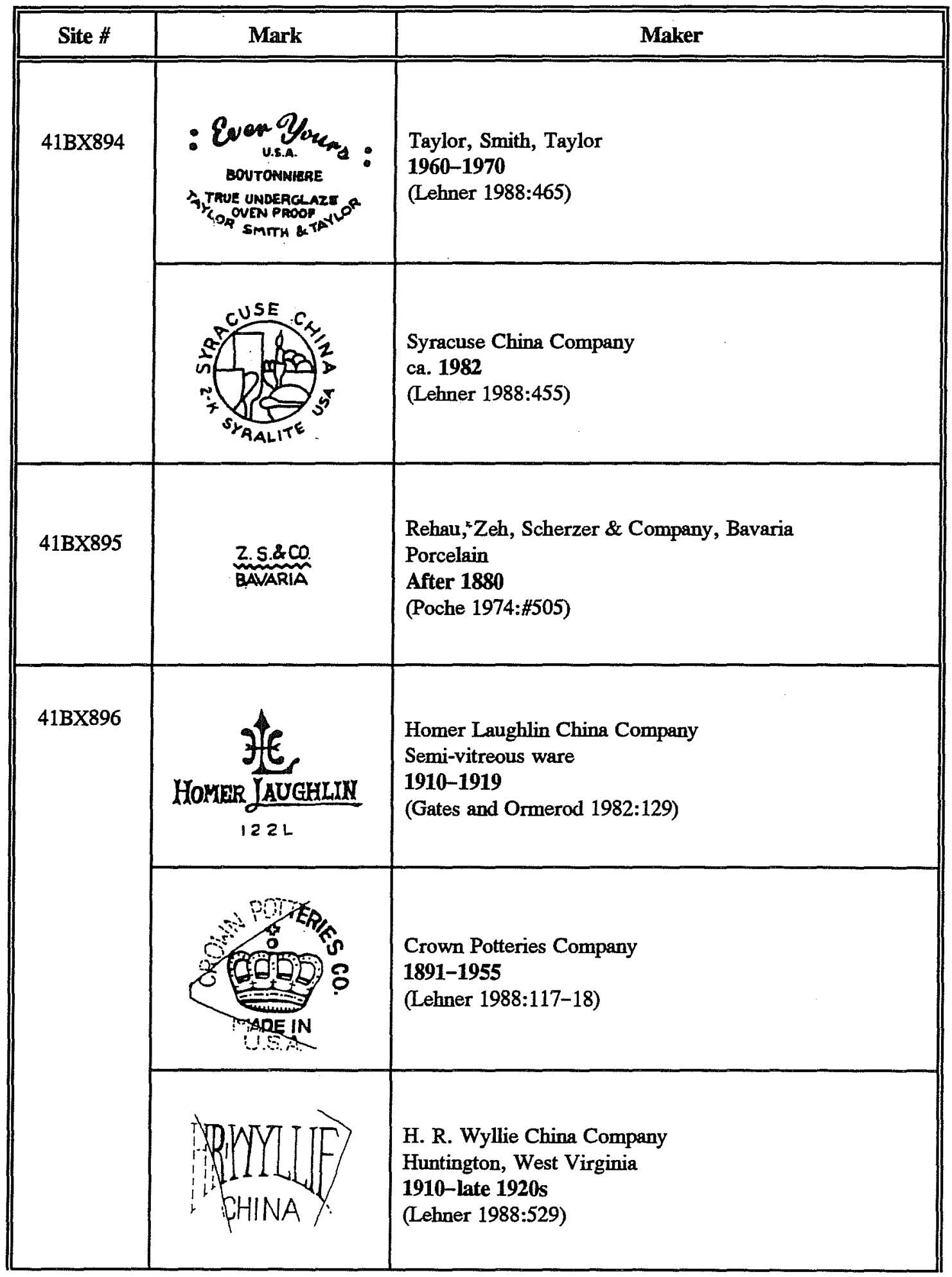


Table 1-B1. continued

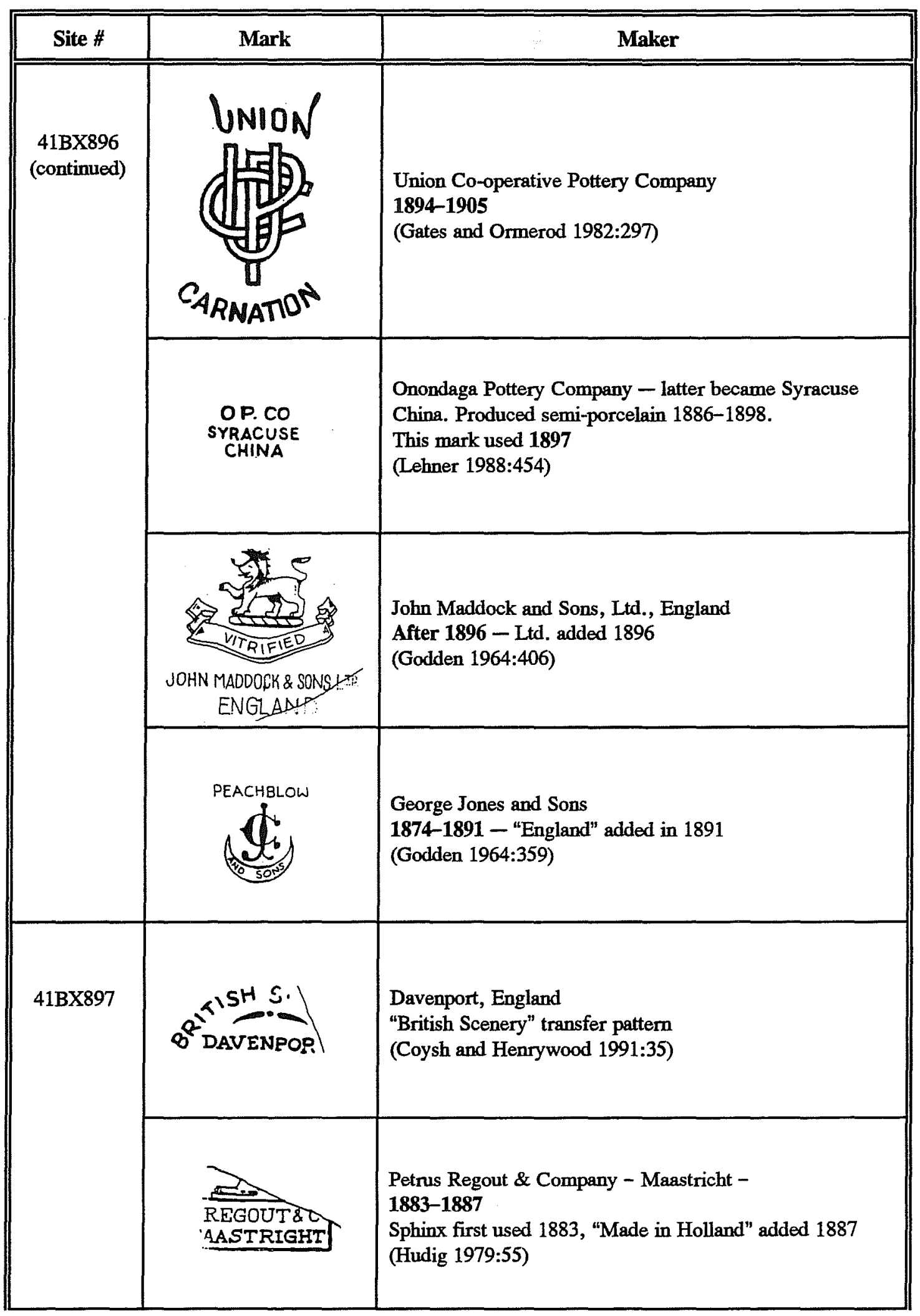


Table 1-B1. continued

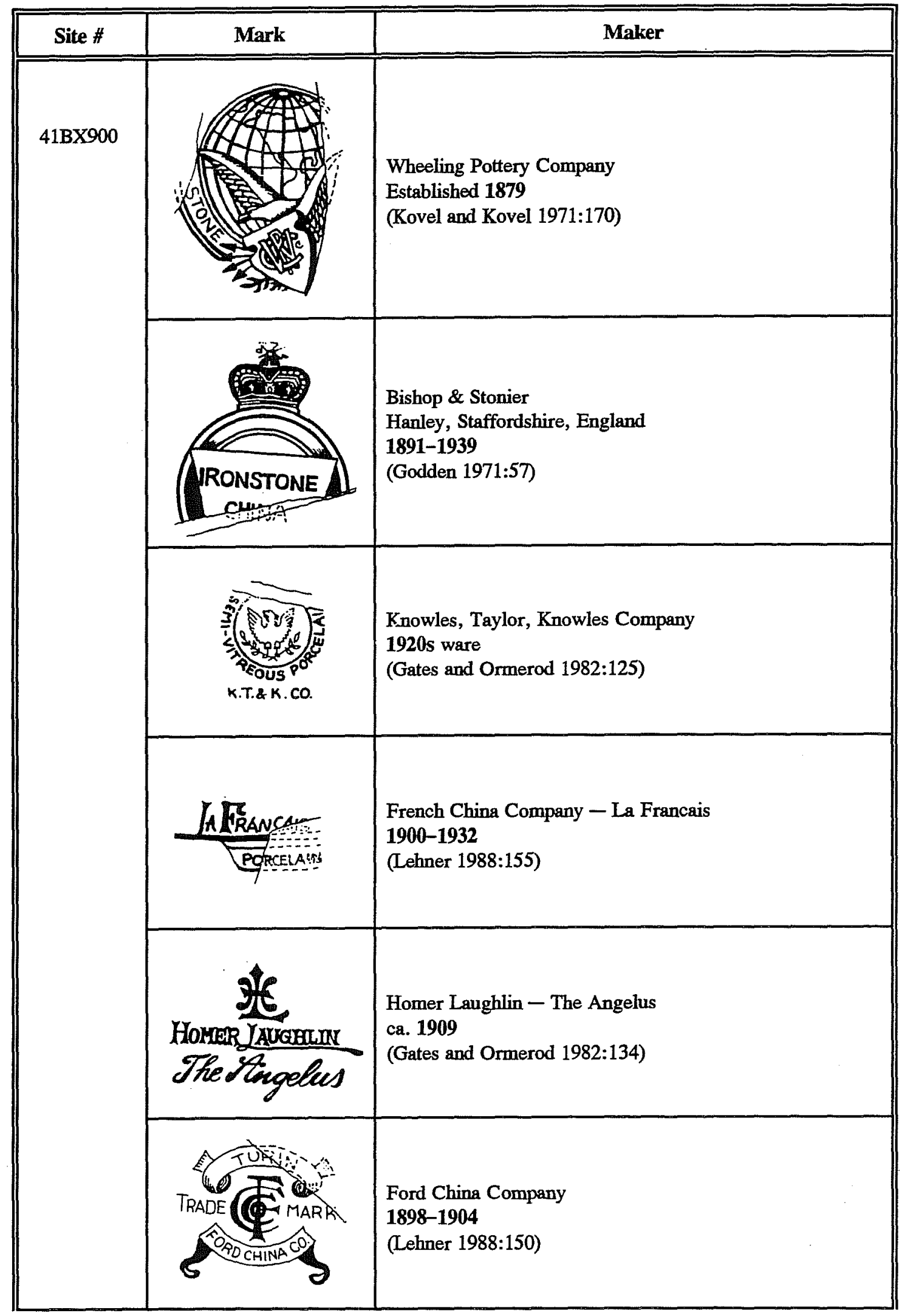


Table 1-B1. continued

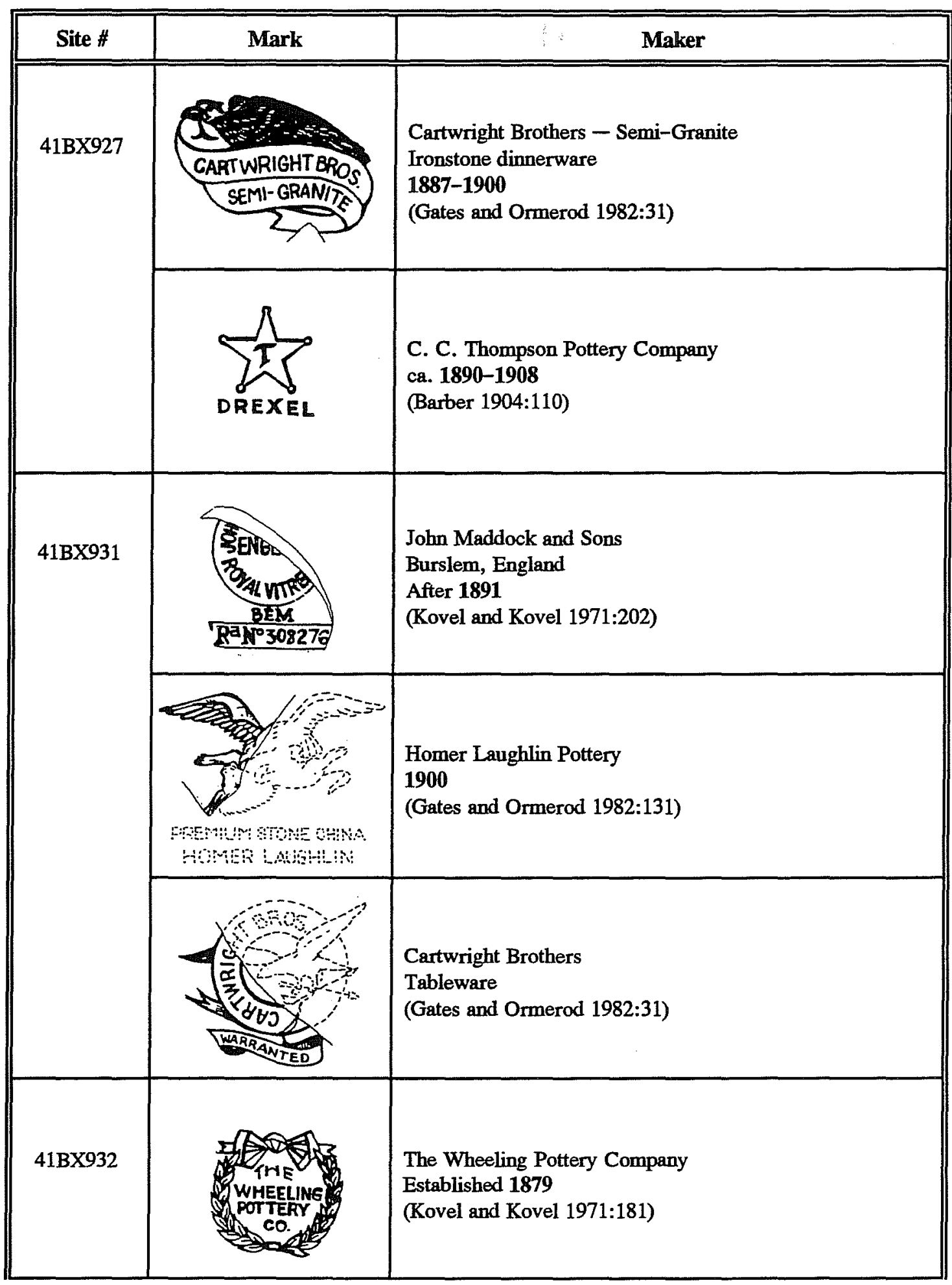


Table 1-B1. continued

\begin{tabular}{|c|c|c|}
\hline Site \# & Mark & Maker \\
\hline 41BX936 & 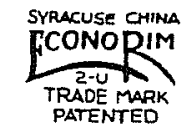 & $\begin{array}{l}\text { Syracuse China Company } \\
\text { 1930 } \\
\text { (Lehner 1988:456) }\end{array}$ \\
\hline 41BX937 & $\begin{array}{l}\text { S. P I. } \\
\text { CLINCHFIELD } \\
\text { CHINA }\end{array}$ & $\begin{array}{l}\text { Clinchfield Pottery } \\
\text { 1910-1917 } \\
\text { Becomes Southern Pottery after } 1917 \\
\text { (Lehner 1988:433) }\end{array}$ \\
\hline \multirow[t]{4}{*}{ 41BX945 } & $\begin{array}{l}\text { LIMO GES } \\
\text { CHINA }\end{array}$ & $\begin{array}{l}\text { Limoges China Company } \\
\text { Semi-porcelain dimnerware } \\
\text { 1900-1930 } \\
\text { (Lehner 1988:262) }\end{array}$ \\
\hline & MELIOR\&CO. & $\begin{array}{l}\text { Cook Pottery } \\
\text { 1893-1959 } \\
\text { (Lehner 1988:107) }\end{array}$ \\
\hline & 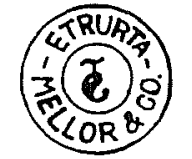 & $\begin{array}{l}\text { Cook Pottery } \\
1893-1959 \\
\text { (Lehner 1988:107) }\end{array}$ \\
\hline & 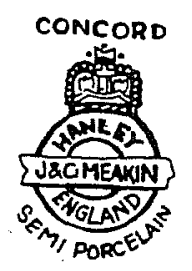 & $\begin{array}{l}\text { J \& G Meakin } \\
\text { Hanley, England } \\
\text { After 1907 } \\
\text { (Godden 1964:427) }\end{array}$ \\
\hline
\end{tabular}


Table 1-B1. continued

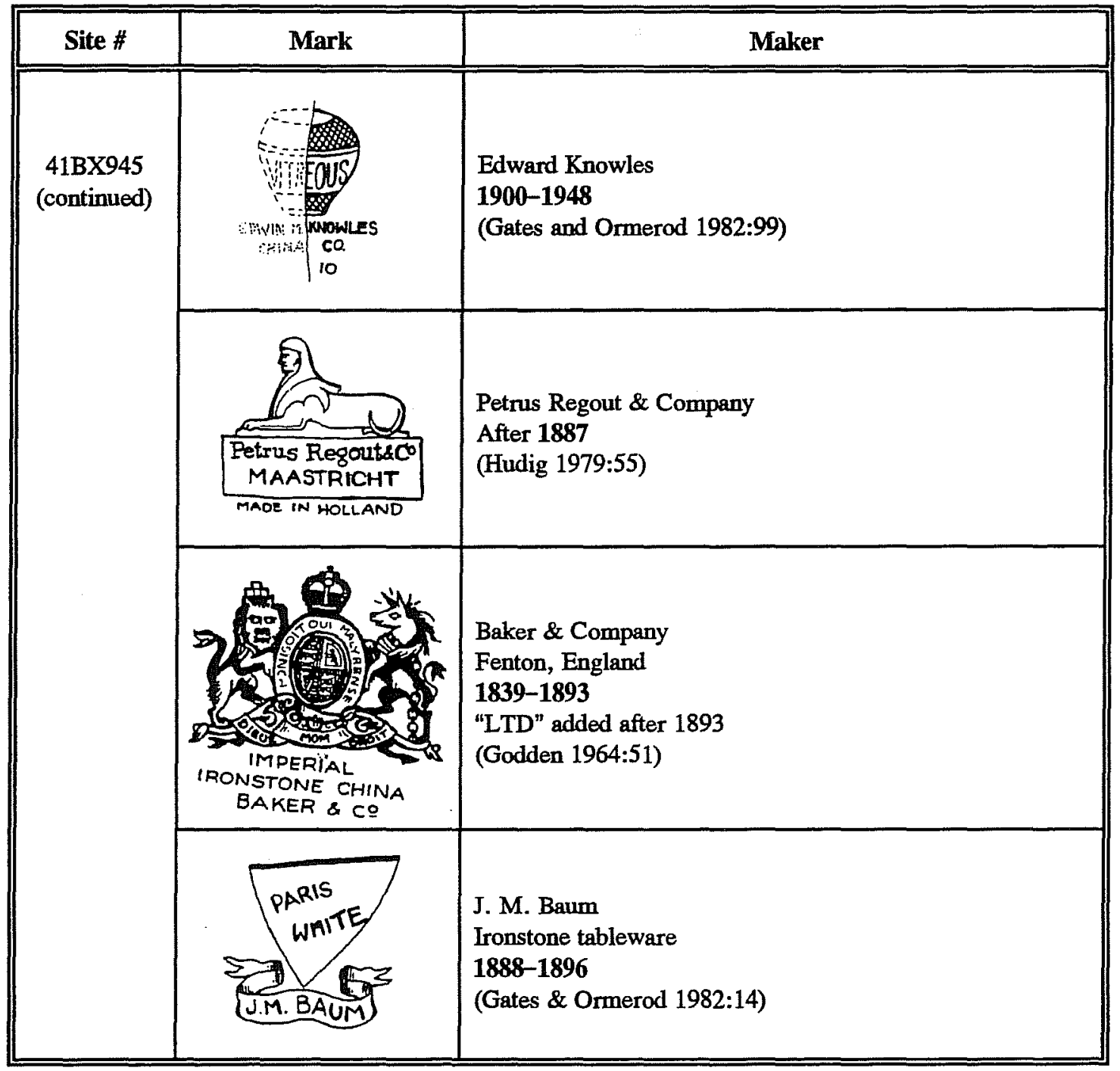




\section{References Cited}

Coysh, A. W., and R. K. Henrywood

1990 The Dictionary of Blue and White Printed Pottery 1780-1880, Volume II. Antique Collector's Club, Suffolk, England.

Durrenberger, E. P.

1965 Anderson's Mill (41TV130): A Historical Site in Travis County, Texas. Bulletin of the Texas Archeological Society 36:1-70.

Fox, D., R. Mallouf, N. O'Malley, and W. Sorrow

1974 Archeological Resources of the Proposed Cuero I Reservoir, DeWitt and Gonzales Counties, Texas. Archeological Survey Report No. 12. Texas Historical Commission and Texas Water Development Board, Austin.

Gerstle, A., T. C. Kelley, and C. Assad

1978 The Fort Sam Houston Project: An Archaeological and Historical Assessment. Archaeological Survey Report, No. 40. Center for Archaeological Research, The University of Texas at San Antonio.

Godden, G. A.

1964 Encyclopedia of British Pottery and Porcelain Marks. Bonanza, New York.

1971 The Illustrated Guide to Mason's Patent Ironstone China. Praeger, New York.

Greaser, A., and P. H. Greaser

1967 Homespun Ceramics. Third edition. Privately printed, Allentown, Pennsylvania.

Greer, G. H.

1981 American Stonewares, The Art and Craft of Utilitarian Potters. Schiffer, Exton.

Greer, G. H., and H. Black

1971 The Meyer Family: Master Potters of Texas. Trinity University Press, San Antonio.

Hard, R. J., A. A. Fox, I. W. Cox, K. J. Gross, B. A. Meissner, G. Mendez, C. L. Tennis, and J. Zapata 1995 Excavations at Mission San Jose Y Miguel de Aguayo, San Antonio, Texas. Archaeological Survey Report, No. 218. Center for Archaeological Research, The University of Texas at San Antonio.

Hudig, F. W.

1979 Maastricht Pottery Part II. In European Pottery and Porcelain, edited by P. Atterbury, pp. 51-55. Mayflower, New York.

Ivey, J. E., and A. A. Fox

1982 Archaeological Investigations at Mission Concepción and Mission Parkway, Part I: Excavations at Mission Concepcion. Archaeological Survey Report, No. 114. Center for Archaeological Research, The University of Texas at San Antonio.

Ketchum, W. C. Jr.

1983 Pottery and Porcelain, The Knopf Collector's Guides to American Antiques. Knopf, New York. 
Kovel, R. M., and T. H. Kovel

1971 Dictionary of Marks, Pottery and Porcelain. Crown, New York.

Lehner, L.

1980 Complete Book of American Kitchen and Dinner Wares. Wallace-Homestead, Des Moines.

1988 Lehner's Encyclopedia of U.S. Marks on Pottery, Porcelain and Clay. Schroeder, Paducah, Kentucky.

Miller, G. L.

1991 A Revised Set of CC Index Values for Classification and Economic Scaling of English Ceramics from 1787 to 1880 . Historical Archaeology 25:1-23.

Moir, R. W.

1987 Refined Earthenwares and Rural Ceramic Traditions. In Historic Buildings, Material Culture, and People of the Prairie Margins, Richland Creek Technical Series, vol. 5, edited by D. Jurney and R. Moir, pp. 97-120. Archaeological Research Program, Southern Methodist University, Dallas.

Poche, E.

1974 Porcelain Marks of the World. Arco, New York.

Ray, $\mathrm{M}$.

1974 Collectible Ceramics, An Encyclopedia of Pottery and Porcelain for the American Collector. Crown, New York.

Robacker, E. F., and A. F. Robacker

1978 Spatter and Sponge, Hardy Perennials of Ceramics. A. S. Barnes, London.

Tunnell, C. D., and H. P. Jensen, Jr.

1968 Archeological Excavations in Lyndon B. Johnson State Park, Summer of 1968. Report No. 17. State Building Commission Archeological Program, Austin.

Stothert, K. E., A. Fox, and K. Gross

1992 Early Nineteenth Century Settlements and Ceramics of the Tambo River, Southwest Coast of Ecuador. Paper presented at the 1992 Conference of Historical and Underwater Archaeology, Society for Historical Archaeology, Kingston, Jamaica.

Wetherbee, J.

1980 A Look at White Ironstone. Wallace-Homestead, Des Moines. 


\section{Chapter 2 Glass}

\section{René Muñoz}

Development in the Alamodome project area during the late nineteenth century and early twentieth centuries coincided with changes and innovations in glass manufacturing. Glass manufacturing techniques changed during this time in response to increased demand after 1830, when the rapid expansion of the railroads opened up new markets (Lorraine 1968:35). One of America's largest glass houses, the Illinois Glass Company, may have been producing more than one million gross of bottles annually (Illinois Glass Company 1904). In order to meet the increasing demand, manufacturers had to increase production and simplify output. The development of semi-automatic and automatic bottle-blowing machines during this era brought about standardization in bottle shapes, color, and closure types. The new mode of production soon created new patterns of bottle reuse and revolutionized food preservation and storage methods. Many of those changes are reflected in the bottles recovered from the businesses and residences in the Alamodome Project area.

Bottle glass was used to establish chronology and to reveal behavioral patterns within early San Antonio. Some of the behavioral patterns include demographics, health needs, consumer habits, and recycling and garbage disposal practices. Methods for establishing chronology and function will be discussed in the following sections.

Major technological changes in the production of glass are identified by the characteristic marks left by molds, pontils, and lipping tools. Prior to the nineteenth century, the most common manufacturing methods for producing bottles were free-blowing and mold-blowing (Baugher-Perlin 1982). Free-blown bottles are usually lopsided, have smooth shiny surfaces and exhibit pontil marks. A pontil was an iron rod dipped in molten glass and attached to the bottom of a bottle to hold it while the neck and lip were being finished (hence the term "finish" used to refer to the neck and lip of a bottle). After the glass blower had completed the bottle, the pontil was removed from the bottle, leaving a raised, circular scar on the bottom. If this scar interfered with the ability of the bottle to stand, the scar was ground down until only a smooth dimple or small circular depression remained (Lorraine 1968; Munsey 1970).

In 1857 the snapcase was introduced in the United States and, by the 1870 s, most glass houses were using it rather than the pontil (Baugher-Perlin 1982). A snap case is "essentially a pontil split down the middle for about a foot with a cup between the two split ends" (Baugher-Perlin 1982). The bottle sat in the cup and the bars of the pontil gripped it. The snap case left no scars on the base of the bottle and only occasionally left scars on the sides. No bottles manufactured with a snap case were identified among the Alamodome collection.

A variety of methods were developed for producing bottles in molds. The most common types used in the manufacture of bottles found in the Alamodome collection are the bottom-hinged, post-bottom, cup-bottom, and blow-back molds. The type of mold used in the manufacture of a bottle can be identified by close study of the number and placement of the various seams on the bottle.

Hinged-bottom molds leave seams on the base and side of the bottle. The seam on the bottom either proceeds 
directly across the bottom or forms a half-circle around the push-up. In the latter case, an embossed design such as a maker's mark is often found. The seams on the side run nearly to the lip. In this type of mold, there was no form for the lip; the bottle had to be removed and the lip applied or shaped with a tool. The use of this type of mold began around 1750 and continued until 1880 (Baugher-Perlin 1982:262).

The post-bottom mold leaves the same type of seams on the side as does the hinged-bottom mold. The bottom, however, shows a ring-shaped scar that is connected to the seams on the body and is not necessarily centered. Both this mold and the cupbottom mold below were used with the hinged-bottom molds. For that reason, there is no definite date as to their introduction.

The cup-bottom mold is common on machine-blown bottles. The vertical seams run to the top of the lip, the lip being formed in the molding process and not applied separately. The diagnostic seam encircles the base of the bottle just above the heel, where it meets the sides of the bottle. It was rarely used with hinged-bottom molds because of the difficulty in centering it.

Blow-back molds were used in the manufacture of wide-mouth jars with threaded closures such as those used for cosmetics, condiments, and pickled foods. The seams run the entire length of the bottle, from base to lip. The bottom may or may not be attached separately as in the post-bottom mold. This type of mold was used from about 1850 on (Baugher-Perlin 1982:265).

The processes described above represent a majority of the types found in the Alamodome collection. Other styles of manufacture are evident such as free-blowing and the use of three-part dip molds. These are represented by only one or two examples.

In 1903 Michael J. Owen patented his automatic bottleblowing machine. Because of this innovation bottle design became more homogenous and the number of bottles produced increased. In 1917 the first fully mechanized bottle-making factory opened and, by 1922, automatic machines accounted for 80 percent of all bottles produced. This figure jumped to 90 percent by 1924 . Because it was difficult and expensive to manufacture special-order bottles, fewer different bottle shapes were produced. The retailer of bottled products began to depend more heavily on paper labels and plate molds to identify his product. While this trend lowered the total number of bottle shapes, it also brought growing standardization to the industry. It is often possible to identify bottle function by shape.

The predominant color of a bottle collection can be used for dating. Until the mid-1800s, the color of most bottles, ranging from amber to dark green, was determined by impurities in the sand used to make them. Bottles for cosmetics, medicines, and toiletries were also colored by the addition of minerals. This changed in 1910 when Nicolas Appert developed a new method of food processing. Food could be preserved, he discovered, if it was bottled and thoroughly cooked (Lorraine 1968:38). This increased the demand for bottles. Consumers preferred clear glass so they could see the product within. In order to meet that demand, bottlers began using various additives in their glass formulas to eliminate color.

During the last quarter of the nineteenth century, clear glass was produced by the addition of small amounts of manganese to the glass recipe. Manganese was used until the start of World War I when America was cut off from Germany, its primary supplier. Selenium was found to be an adequate replacement for manganese and was used until about 1930, when arsenic became a popular decolorizer (Munsey 1970:55). Glass decolorized by any of these elements assumes distinctive colors when exposed to ultraviolet radiation. Glass decolorized by the addition of manganese turns amethyst, while glass decolorized by selenium turns amber. This fact aids in producing a rough approximation of the age of a bottle.

It is important to realize that changes in the technology of manufacture are most useful in assigning a "no earlier than," or terminus post quem, date to bottles. They are of limited utility in determining a terminal date for manufacture. This is because the glass industry did not shift from one mode of manufacture to another all at once, changes were phased in gradually. Depending on the size of the glasshouse, old methods of manufacture may have continued long after better ways had been found. A switch to more efficient systems may have been impractical in terms of capital outlay or market size. In Canada many smaller 
glasshouses kept using mold processes after the introduction of the Owens machine simply because they were unable to circumvent the licensing agreement between Dominion Glass and the Owens Company (Miller and Pacey 1985).

It is difficult to come closer than about a decade when dating bottles by studying manufacturing techniques and color. Some mold processes, for example, were in use for more than half a century. Trademarks and maker's marks provide the single most accurate date for the manufacture of bottles. Commercial marks are put on the bottles by glass manufacturers, wholesalers, and/or retailers. They were not considered to be decorative since their main function was to identify the manufacturer or bottler. The most common methods were embossing, paper labels, and applied color labels. Trademarks can be used most successfully only if their period of use was short. However, if the mark was used for many years, other factors such as storage and reuse must be taken into account. In any case, marks can provide definite starting and ending dates for the manufacture of bottles (Table 2-1). Bottle Makers and Their Marks by Julien Toulouse (1971) was my main source of information on manufacturing marks. The San Antonio City Directories [CD] from 1892 to 1909 were prime sources for local bottlers and businesses. Also used were various publications intended for the collector. These books, while generally pricing guides, do occasionally make reference to the dates of manufacture for specific items.

It is also useful to look at popular literature printed during the time the bottles under investigation were thought to be manufactured. Advertisements and the like can provide valuable information for refining dates and determining function and place of manufacture.

This report reviews the bottle glass recovered at six sites in the Alamodome project area, sites 41BX891, $892,895,945,882$, and 883 . The sites were selected because their beginning occupation dates are similar and they represent the largest and most diverse collection of bottles recovered from any of the 36 sites within the project area in terms of variety of style and contents. Also they are representative of the various contexts in which bottles were found: in privies, kitchen middens, and specialized middens or caches that contained only glass.

\section{BX891, The Horn Site}

Two trenches were placed in NCB 613 Lot 5, exposing three features. The majority of glass fragments are from Feature A. Feature A was located in Trench A placed near the boundary between lots 4 and 5 . The feature's edges were sharply defined, and there was a high percentage of glass in the excavated portion. In some units over 70 percent of the artifacts were glass. The deposits contained in excess of 3,235 pieces of glass. This represents 99.996 percent of the glass found on the site.

The lack of stratigraphy and the mixture of broken bottles with a wide range of dates supports the identification of Feature $\mathrm{A}$ as a secondary deposit. There were only six whole bottles from a very conservative estimated total of 309 . From where were the bottles moved? Why were they the object of secondary deposition? These questions must be answered before any inference concerning secondary deposit can be made. These bottles were probably deposited over a relatively short period of time after a long period of reuse postdating the exhaustion of their original contents. The bottles were discarded after they became broken or were otherwise unfit for further use. The midden is not representative of normal household refuse. Reuse can explain the high incidence of broken bottles, but it cannot explain the frequency of bottle types.

Most of the containers were originally used for the storage of alcohol or items with a high alcohol content such as bitters or other patent medicines. Very few of the bottles were intended for food or cosmetic storage. Bottles positively identified as containing alcohol include the following: 16 Gordon's Gin (Figure 2-1); six beer, six alcohol, and seven non-prescription medicines with a minimum of one, probably Lash's, bitters. While it is difficult to establish the contents of many other bottles, the presence of alcohol can be inferred from the 11 metal foil bottle covers, 33 champagne and wine finishes, and 75 brandy finishes. There were also 41 oval bases similar to those used for pint flasks.

In addition to the alcohol bottles, the following types were found: 12 food, one medicine, and one personal. One very interesting piece was recovered from this feature. It is a large bottle of heavy glass with the 
Table 2-1. Dated Maker's Marks and Brand Names on Bottles Recovered from Feature A Glass Midden, 41BX891

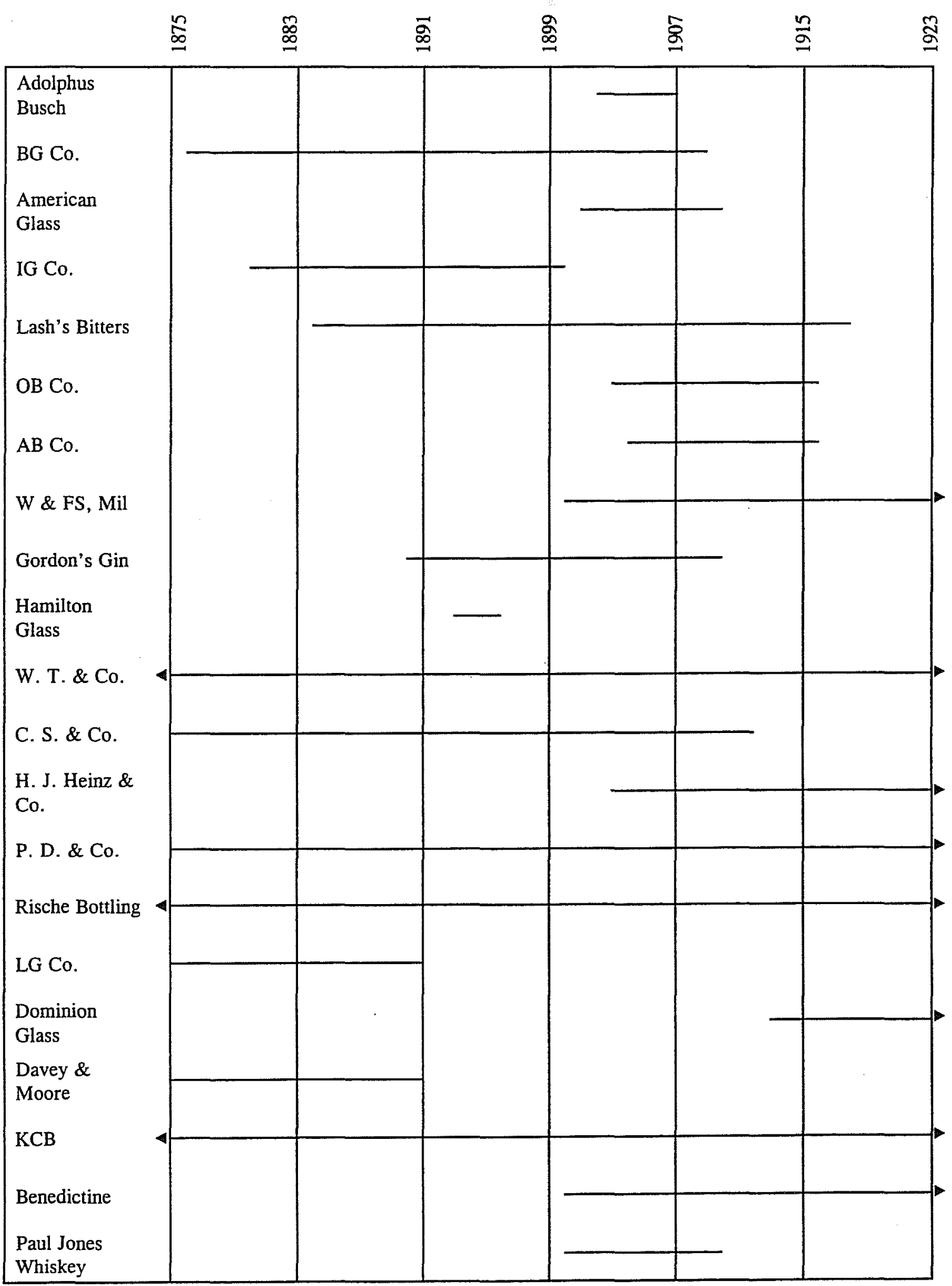




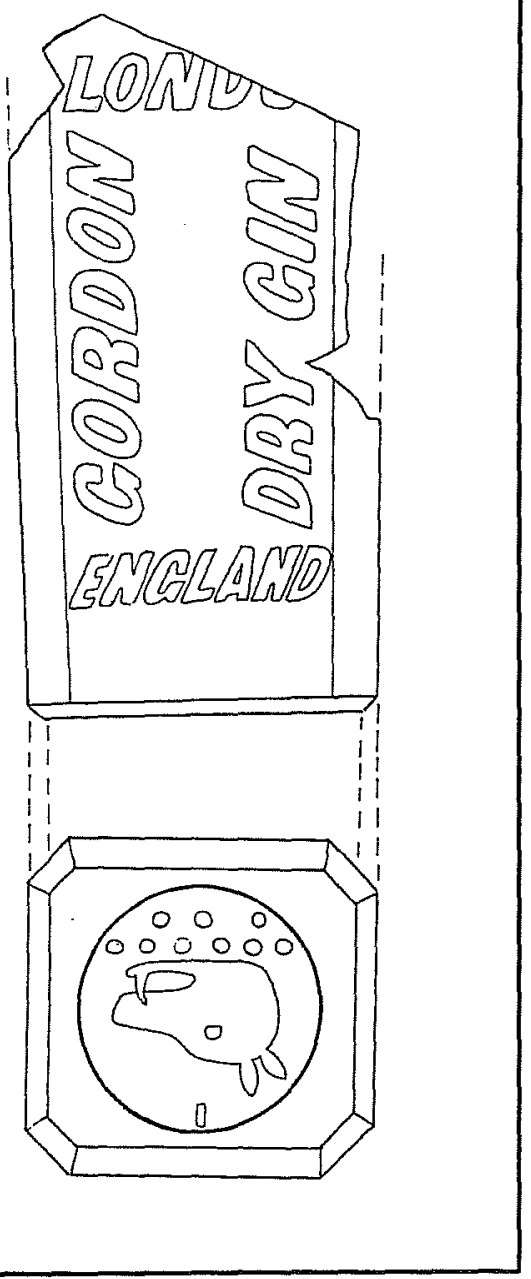

Figure 2-1. Gordon's Gin bottle and base. Shown one-half actual size.

label embossed, "Coca Cola Bottling Co. San Antonio, Tx." and "St. Anthony Hotel" (Figure 2-2). This bottle has been identified as a seltzer bottle, based on its resemblance to several pieces illustrated in the 1903-1904 Illinois Glass Company catalog (1904:49).

\section{BX892, The Rilling Site}

The bottles recovered from this site were in a context similar to that of the bottles recovered from 41BX891. Near the northeast corner of the lot a large trash pit was discovered during demolition monitoring of the Alamodome footprint area. This feature was located north of the Trench A extension, approximately $150 \mathrm{ft}$ south of Wyoming Street and $64 \mathrm{ft}$ west of Hoefgen Street. The pit was filled almost exclusively with bottle glass, containing wine, beer, and whiskey bottles. Within this collection are few bottles intended for food or cosmetic storage. By a conservative count, 146 bottles are represented. This feature was not fully excavated, but its size has been estimated to be three

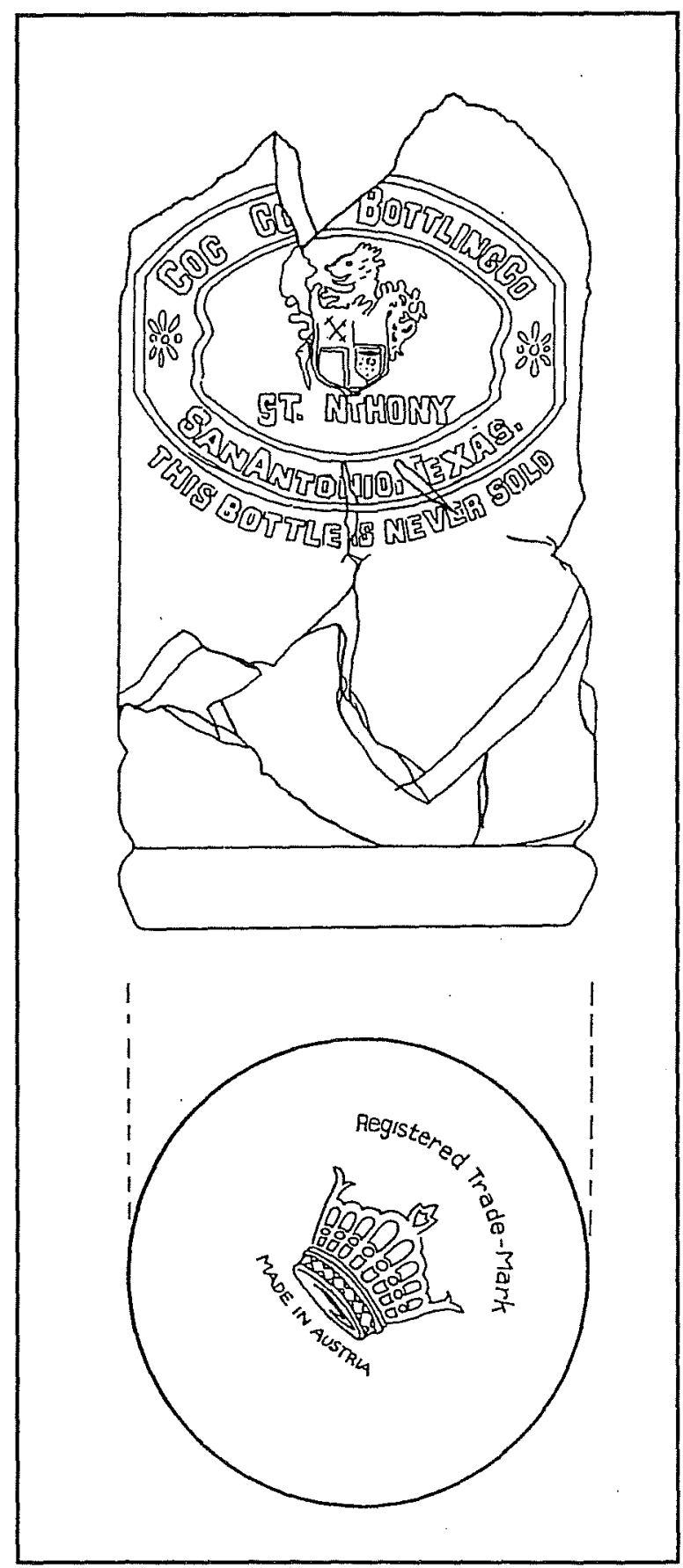

Figure 2-2. Coca Cola bottle from the St. Anthony Hotel. Shown one-half actual size. 
feet deep by five feet in diameter. More formal measurements were not taken due to time constraints.

Of the 146 bottles counted, only five are whole: three patent medicine bottles, one large condiment bottle with a screw top, and one container for an alcoholic beverage. Two of the three patent medicine bottles bear no identification. The third is embossed with "Chamberlain's Colic, Cholera and Diarrhea Remedy" (Figure 2-3). A bottle similar to the condiment one is identified as a champagne catsup bottle in the 1903-1904 Illinois Glass Company catalog (Illinois Glass Company 1904). The fifth bottle is also similar to one illustrated in the same catalog, where it is identified as a "liquer" bottle. Only the catsup bottle was machine-made. The others were produced in two-piece molds with handfinished lips. This method of manufacture dates to between 1880 and 1913 . These bottles were the only ones in this collection that were dated by method of manufacture. The other pieces were, for the most part, too fragmentary to date in this way.

Fourteen bottle fragments in the collection, primarily heels, contained information that allowed them to be dated. This information was normally comprised of maker's marks or patent information (Table 2-2).

Bottles that definitely contained alcoholic beverages composed 68.4 percent of the collection. Household items such as milk, cosmetics, medicine, and soda bottles comprise 8.2 percent of the collection. The rest of the collection, approximately 23.4 percent, is composed of bottles whose function is unknown. Identification and count was based on the identification of finish types: 34 wine/champagne, 36 brandy, 16 beer, and 14 finishes of a type unique to Gordon's Gin (Figure 2-1). The balance was composed of two milk bottle finishes and 10 prescription/extract finishes. The balance was made up of unidentifiable finishes.

The bottles in this collection were likely deposited during or just shortly after the period 1905-1907. This dating is based on the presence of several bottles bearing the Adolphus-Busch maker's mark and another bearing the mark for the A B Co.; bottles with the Adolphus-Busch mark (Figure 2-4) were produced between 1903 and 1907, bottles with the mark "A B Co." (Figure 2-5) were only produced between 1905

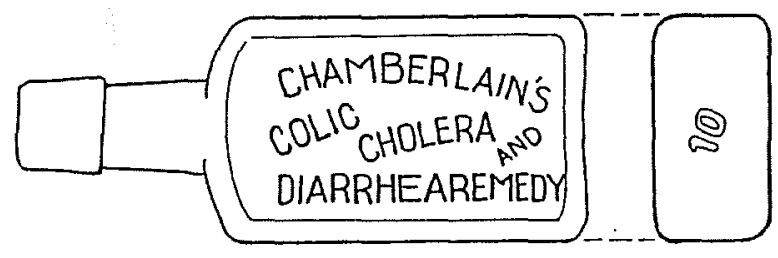

Figure 2-3. Chamberlain's Colic, Cholera, and Diarrhea Remedy. Shown one-half actual size.

and 1916 (Toulouse 1971). The manufacturers dates of all other bottles, with the exception of one, overlap completely with this time period (Table 2-2).

\section{BX945, The Pauly Site}

Site 41BX945 was continually occupied from 1855 to 1975. The major source of bottles for this site was a privy located on the west lot line. The bottles are typical of household refuse in that they represent a fairly even distribution of food, personal, and alcoholic containers. Of the 50 whole bottles recovered, 20 were related to the preparation of food or contained food. These include 10 bottles that held either condiments or other preserves, four extract bottles, and two bottles that held milk or milk products. Fourteen bottles were related to personal health or hygiene: three cosmetic bottles, 11 medicine bottles, and one possible perfume bottle. Two of the medicine bottles (Figure 2-6), virtually identical except for size, were manufactured by the W. T. Company for use by local druggist Ed Schultze who was in business between 1902 and 1935 (CD). Finally, 13 bottles contained beverages, either alcoholic or otherwise: four contained whiskey, four beer, and five soft drinks. The contents of the remaining six bottles could not be determined.

A study of the remaining diagnostic bottle fragments reveals a continuation of this pattern. An extremely conservative estimate places the number of bottles in the privy at 96 . This number was determined by adding the number of whole bottles to the number of complete or nearly complete finishes recovered. The finishes indicate a high number of milk, preserving, 
Table 2-2. Dated Maker's Marks and Brand Names on Bottles Recovered from Monitored Trash Pit

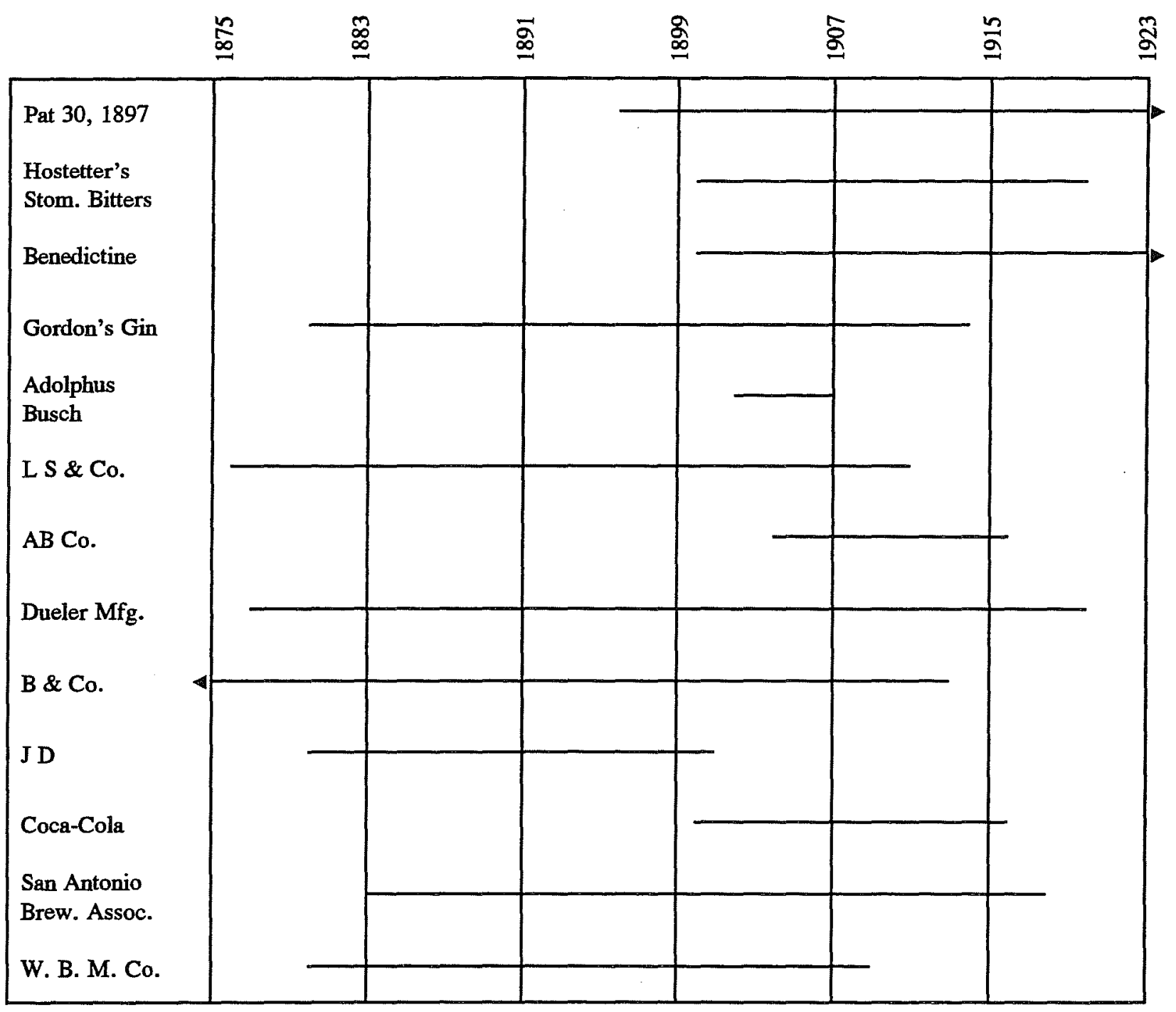




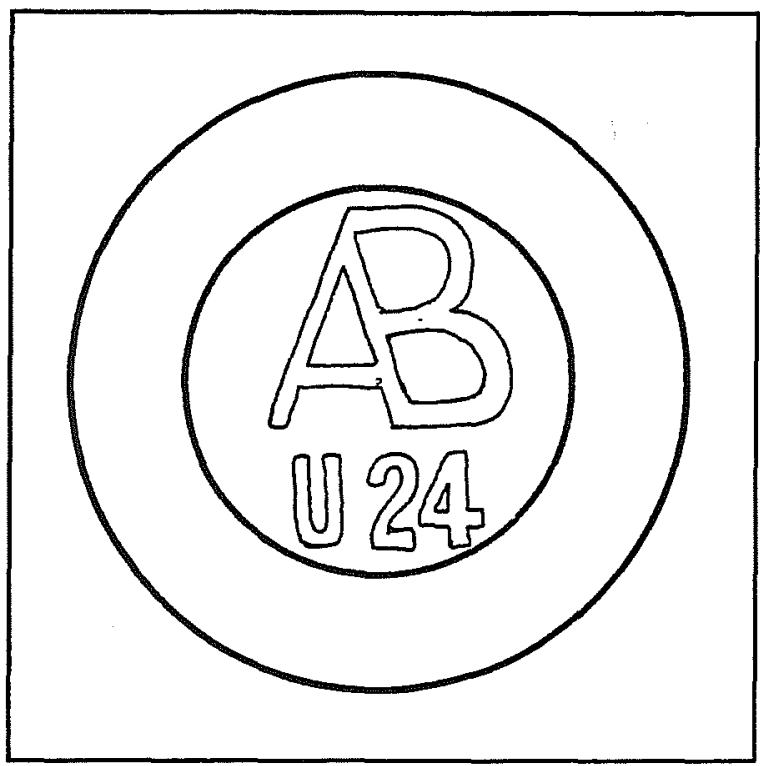

Figure 2-4. Adolphus Busch Co. maker's mark, earlier. Shown actual size

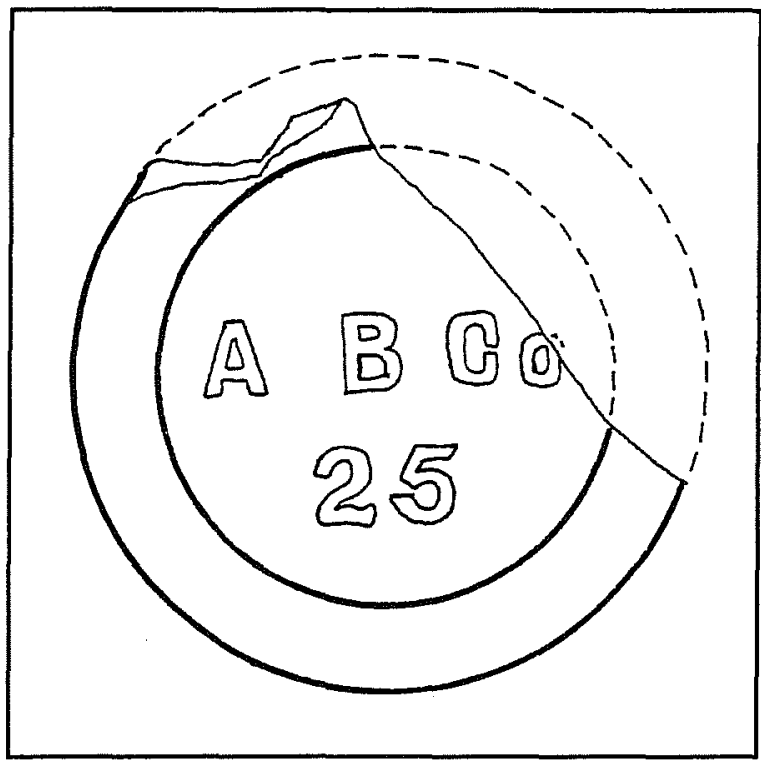

Figure 2-5. Adolphus-Busch Co. maker's mark, later. Shown actual size.
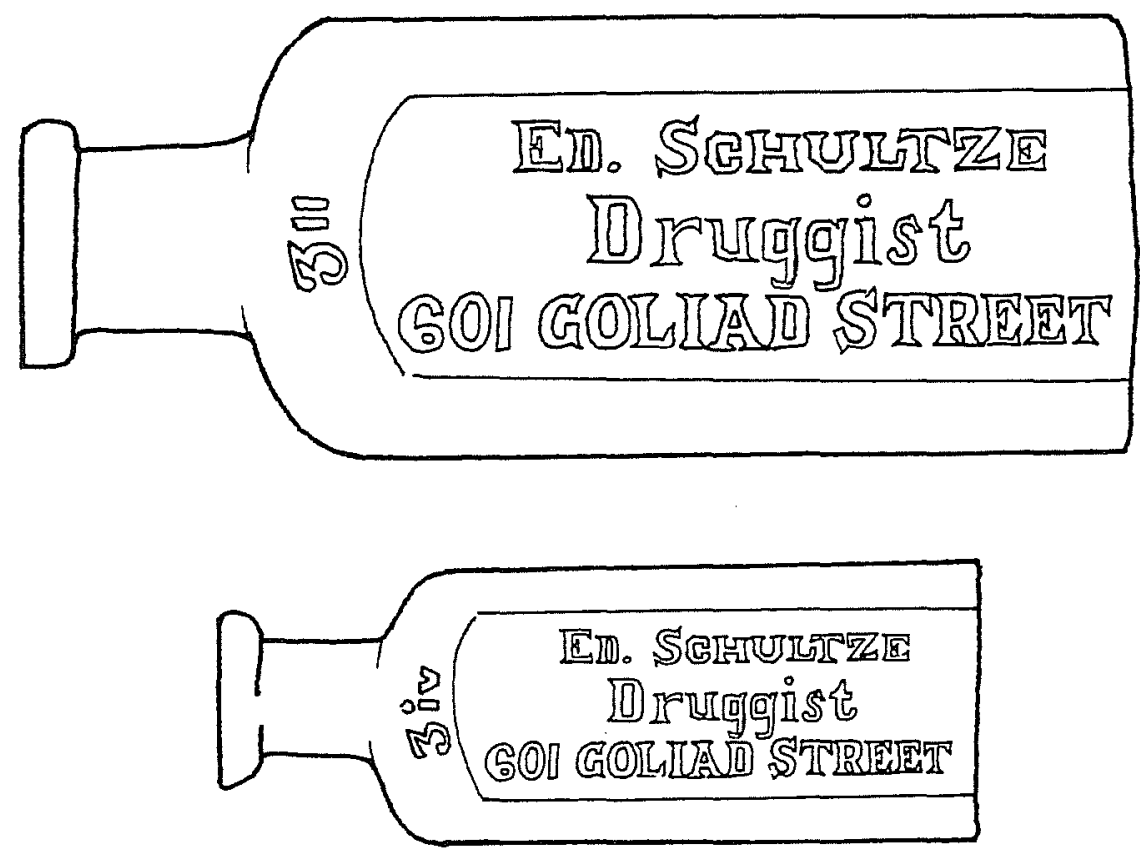

Figure 2-6. Schultze bottles. Shown actual size. 
patent medicine, and extract bottles. A great many crown finishes in both clear and brown glass were recovered. The brown glass finishes, of which there were nine, more than likely graced beer bottles. The original use of the clear finishes could not be determined. While it is probable that some may have been for soft drinks, others were attached to bottles too large to be ordinarily considered for soda water (Figure 2-7). The contents of these bottles is unknown.

Wine bottles, with their distinctive finishes and kick-up bottoms, either whole or fragmentary, occur with a conspicuously low frequency. In the entire privy collection, only one was found. This number is far exceeded by the number of whiskey and beer bottles found, although neither of these approaches the numbers recovered from 41BX891 and 41BX892. The absence of wine bottles may be correlated with the introduction of city water into the area sometime prior to 1904 and the possible reduction in the need for such bottled drinks.

In addition to the bottles found in the privy, household glasswares were also found. Two whole drinking glasses were found as were fragments of several plates including a portion of a fluted plate or serving tray. This provides further evidence for the privy being a repository for household waste as opposed to being an area of specialized disposal.

Outside the privy, bottles and bottle fragments were recovered from trenches $A, B, C, E, F$, and $G$, as well as from surface collection. The surface collection, as expected, consisted mostly of recent refuse: one Big Red soft drink bottle, one Miller High Life Beer bottle, and one Tres Flores Brilliantine bottle. Trenches A, B, C, and $F$ yielded small quantities of glass related to personal and household functions. Notable among these bottles was a small ovoid jar, machine-made of milk glass, bearing a maker's mark that read "POND'S". This jar, which would have contained cold cream, was recovered from Trench $C$. Trench $E$ yielded a portion of a bottle that had inscribed on it "ERLER" in a semi-circular pattern (Figure 2-8). This piece was probably once part of an embossed pattern that read "Duerler Mfg. Co.," a San Antonio firm active in the mid-nineteenth to early twentieth century (City Directories). The remaining trenches yielded no glass of note.
This site is unusual in that despite the large amount of glass items recovered, very few bear maker's marks that are positively identifiable. Eight were identified, all from the privy. Bottle dates alone do not provide an adequate indicator of the age of this privy (Table 2-3). Several general statements, however, can be made. The privy was most likely cleaned for the final time sometime just prior to 1900 and was used until at least 1905. This is based on the presence of bottles manufactured only prior to or after those years. For more specific information on this privy, see Brown and $\mathrm{DeLaO}$ in this volume.

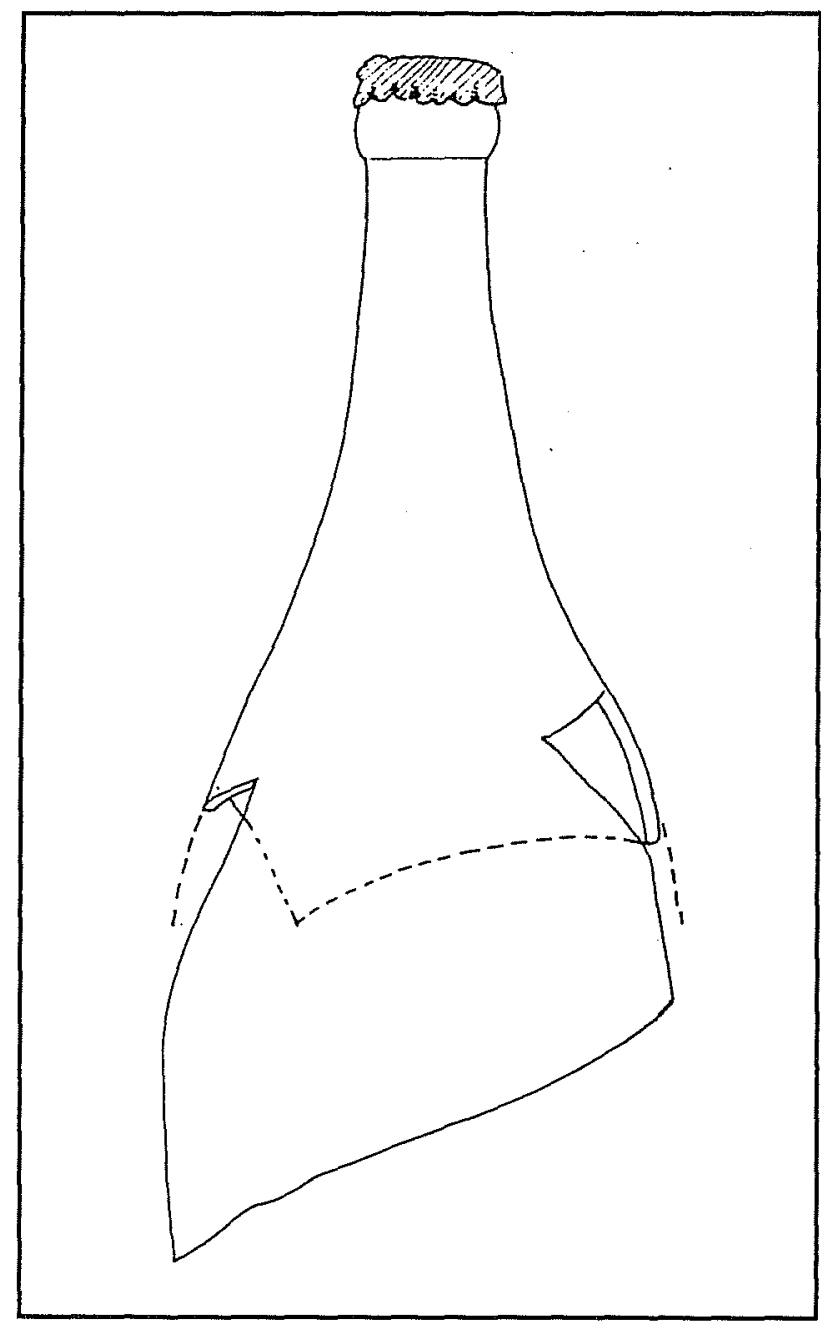

Figure 2-7. One-quart soda water bottle. Shown one-half actual size. 


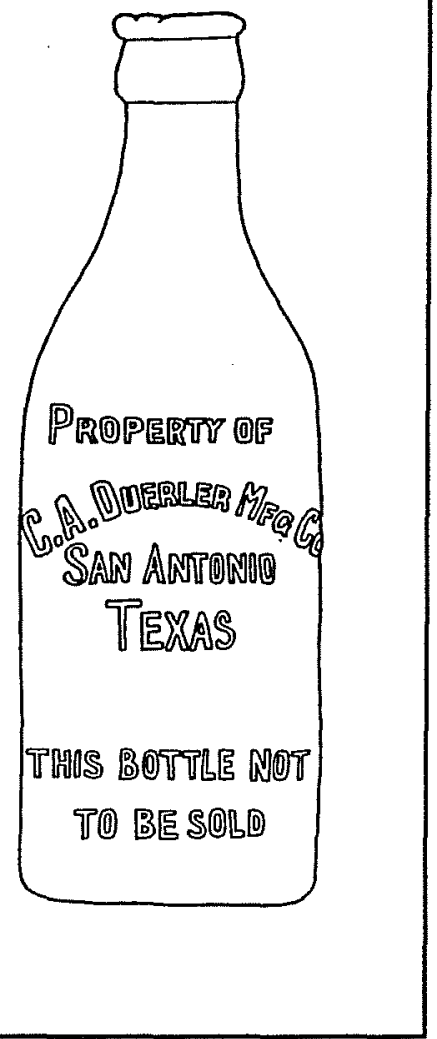

Figure 2-8. Duerler soda water bottle. Shown one-half actual size.

\section{BX895, The Garza Store}

Testing and initial excavation below the floor of the 1880s structure at site 41BX895 revealed two deposits of vanilla extract bottles, apparently intentionally cached. Also recovered, but in much lower quantities, were medicine bottles and bottles that contained alcoholic beverages. Of the 256 whole bottles recovered, 246 were extract bottles (Figure 2-9) dating to about 1929. This date, taken in the context of the bottles' primary contents, indicates that the caching of extract bottles was related to Prohibition. Because extracts generally have a high alcohol content they may have been consumed after the enactment of Prohibition laws as a legal alternative to wine, beer, whiskey, or other hard liquors. The bottles might also have served as disguised containers for illegally distilled liquors. Similar deposits have been found beneath Prohibition-era homes in the past by demolition contractors. Analysis of the residues inside the extract bottles was not done due to time constraints, but remains a viable avenue for research.

Most of the recovered extract bottles were at one time filled by a product manufactured by McCormick and Company or by Sauer's Extracts. The bottles themselves were manufactured either by Owens Glass Company, Illinois Glass Company, or the merged company of Owens-Illinois. American Glass Works (A.G.W.) and Rochester Glass Works are also represented. The four companies were identified by their distinctive maker's marks. Figure 2-10 presents the relative frequencies of each type of mark. A significant portion of all extract bottles recovered was manufactured by the Owens Company between 1911 and 1929. The second most frequently represented maker, Owens-Illinois, manufactured bottles with that mark between 1929 and 1954 (Toulouse 1971:403).

The caches of extract bottles certainly date to just after 1929. This is the earliest possible date based on the presence of the Owens-Illinois bottles. Although the majority of extract bottles were manufactured by the

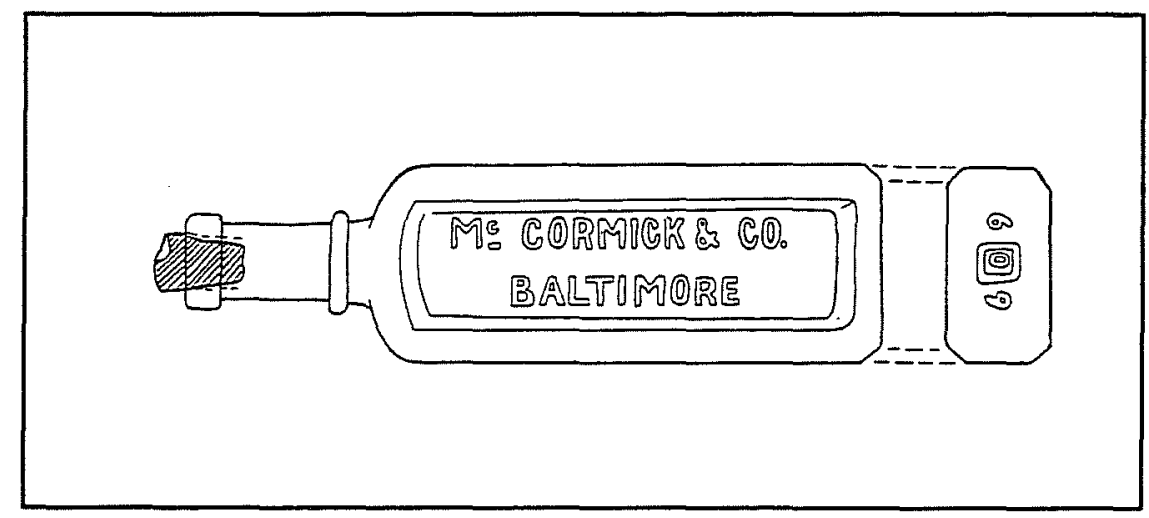

Figure 2-9. McCormick extract bottle. Shown one-half actual size. 
Table 2-3. Dated Maker's Marks and Brand Names from the Pauly Privy
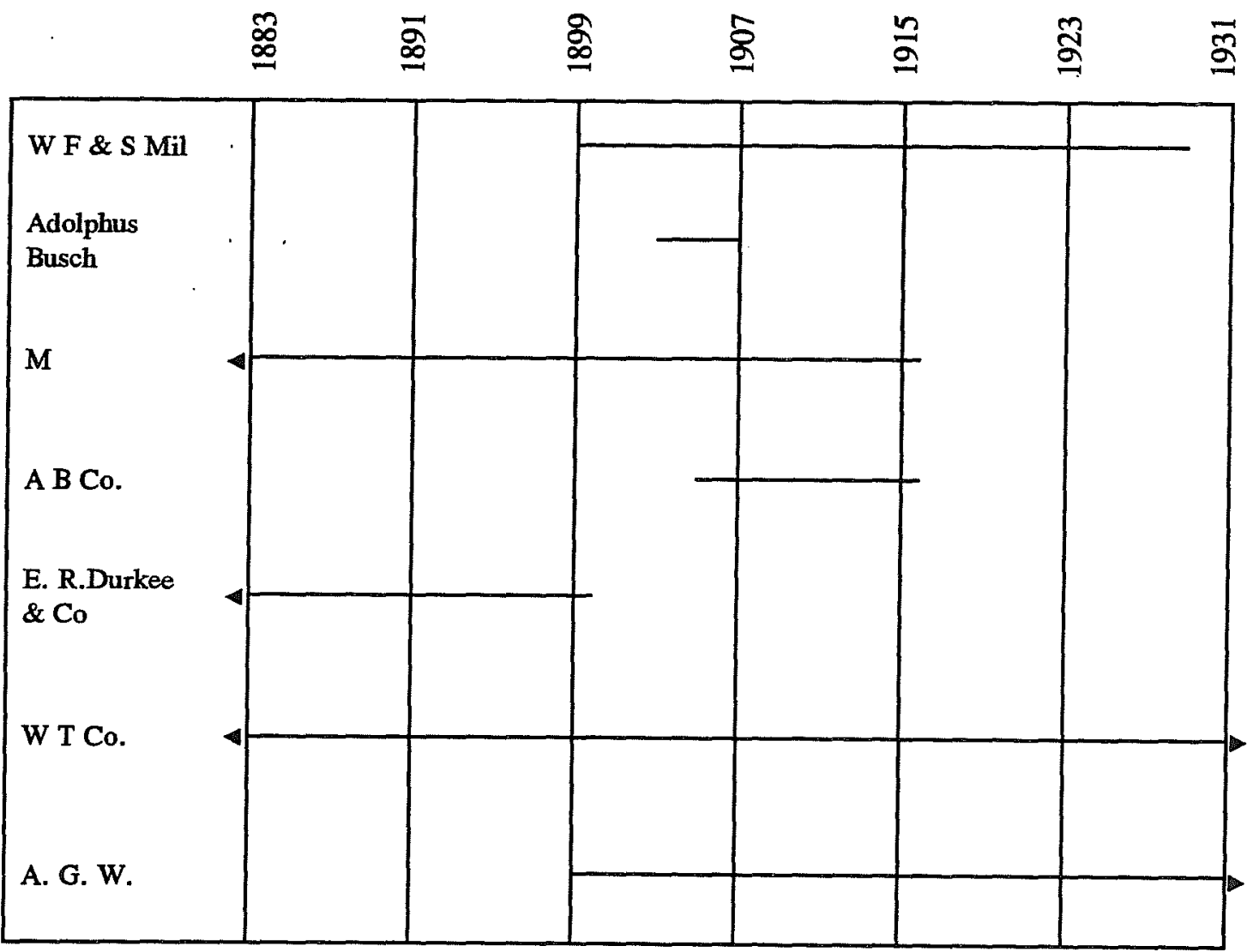

Owens company, their presence may be due to some sort of manufacture circulation lag or the purchase of a great quantity of extracts just prior to Prohibition. In any case, the Owens-Illinois bottles in question all contain numerical codes as part of their maker's marks, indicating they were manufactured between 1929 and 1954. Two numbers, one to the right of the maker's mark and the other to the left, indicate at which plant and in what year the bottle was manufactured (Toulouse 1971:403). The number on the left indicates the plant, the one on the right indicates the year. Three lines of evidence converge to provide a date that corresponds to the beginning of Prohibition.

1) Relative frequencies of bottle types differentiated by maker's marks. If the bottles were bought and deposited at a time significantly post-dating 1929, we would expect to see a larger number of Owens-Illinois bottles than either Owens or Illinois alone. Conversely, if the deposition occurred significantly before 1929, we would expect to see a large number of either Owens or Illinois bottles almost to the exclusion of Owens-Illinois bottles. Rather than either of these two options, what we see is a compromise-a large number of Owens bottles but also a significant number of Owens-Illinois bottles. This suggests that one maker's mark was being phased out while another was introduced.

2) Site occupation at this time converges nicely with the suggested date of deposition. Peter Nocker occupied the site from 1915 to 1932 . It is unlikely that the residents prior to or after Mr. Nocker would have shared the practice of consuming large quantities of vanilla and other 


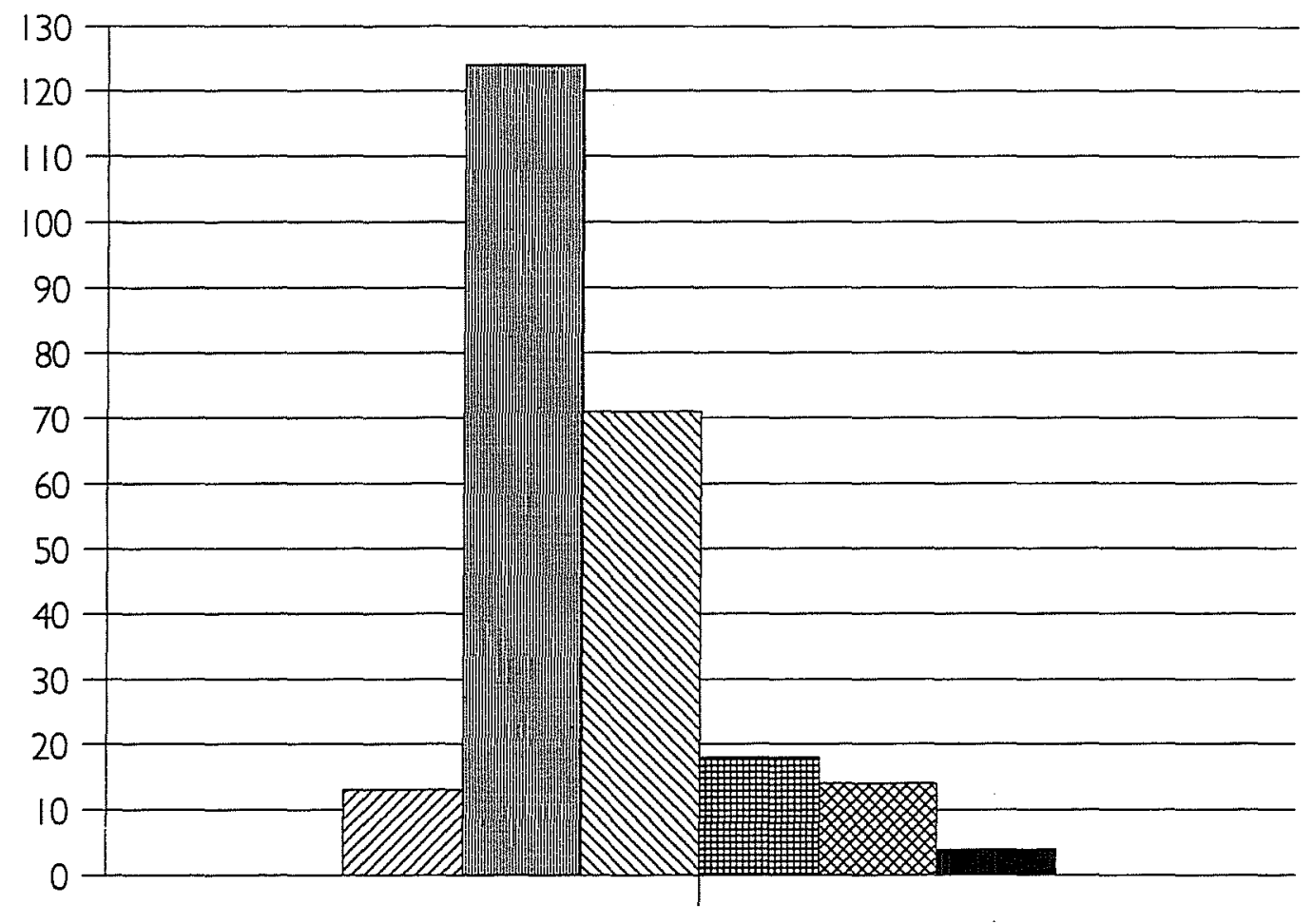

$\begin{array}{lll}\text { A.G.W. } & \text { Owens } \\ \text { Owens-Illinois } & \text { No Mark } \\ \text { Rochester } & \text { Illinois }\end{array}$

Figure 2-10. Relative frequencies of maker's marks.

extracts and caching the spent bottles beneath the floor of their home.

3) The final line of evidence is the numerical data included with the Owens-Illinois maker's mark that references it to a particular date and manufacturing plant. The dates and plants indicated by the code were in operation in 1929 and were producing this type of bottle. Furthermore, this code represents only one year's worth of production and was the only one found among the Owens-Illinois bottles. This is seemingly evidenced by the fact that only the six-nine code appears with the Owens-Illinois mark. If a later date were represented, we would expect to see a change in the number to the right of the mark.

The remaining recovered bottles from the site with maker's marks cover, chronologically, the site's recorded dates of occupation from 1889 to 1990 (Table 2-4). Included in this collection are four bottles that held soft drinks: one from the Bee Candy Company (Figure 2-11), two from Alamo Bottling Works, and one with no brand name but bearing "For your health's sake" embossed upon it. Others include one Hostetter's 
Table 2-4. Dated Maker's Marks and Brand Names from Beneath the Garza Store, 41BX895. Note that the first five manufacturers listed were all represented solely by extract bottles.

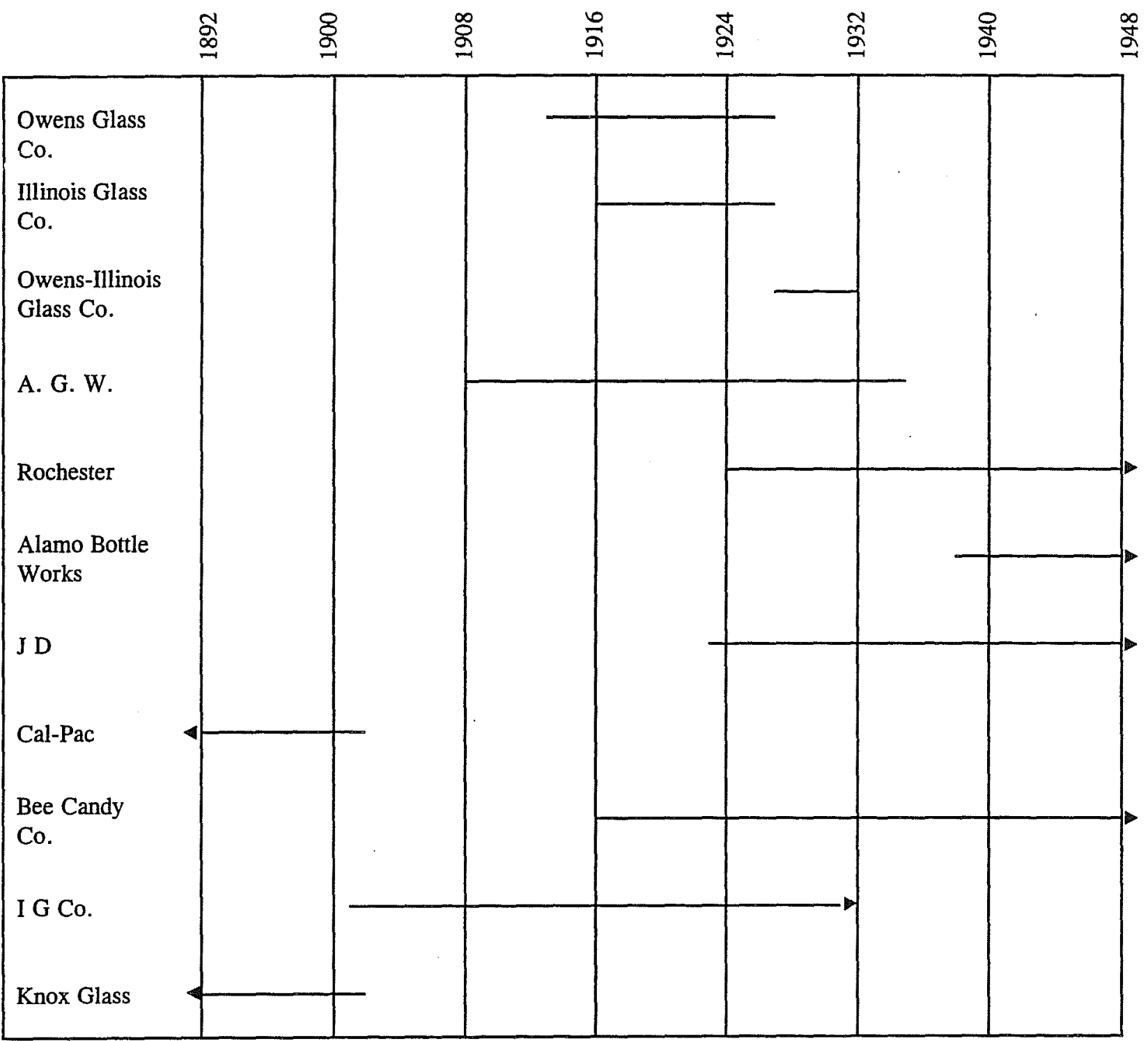

Bitters bottle (Figure 2-12), one Hoyt \& Company perfume bottle, and two condiment bottles: one manufactured for Lea \& Perrins Worcestershire sauce and the other a pickle or relish bottle manufactured by the Cal-Pac Corp. Also of interest is one large bottle with "Platt's Chloride" stamped on the bottom, a brown, quart-size whiskey flask that appears to be of fairly recent origin, and one example of the ubiquitous Cheeseborough Vaseline jar.

\section{BX882, The Haas Site}

The bottle glass recovered from this site was found throughout the site, whereas the glass from the four previous sites tended to be found only in one or two dense concentrations. In NCB 621 north (the south end was designated 41BX883) significant amounts of glass were recovered from five separate locations. The site contained a minimum number of 36 bottles, including 


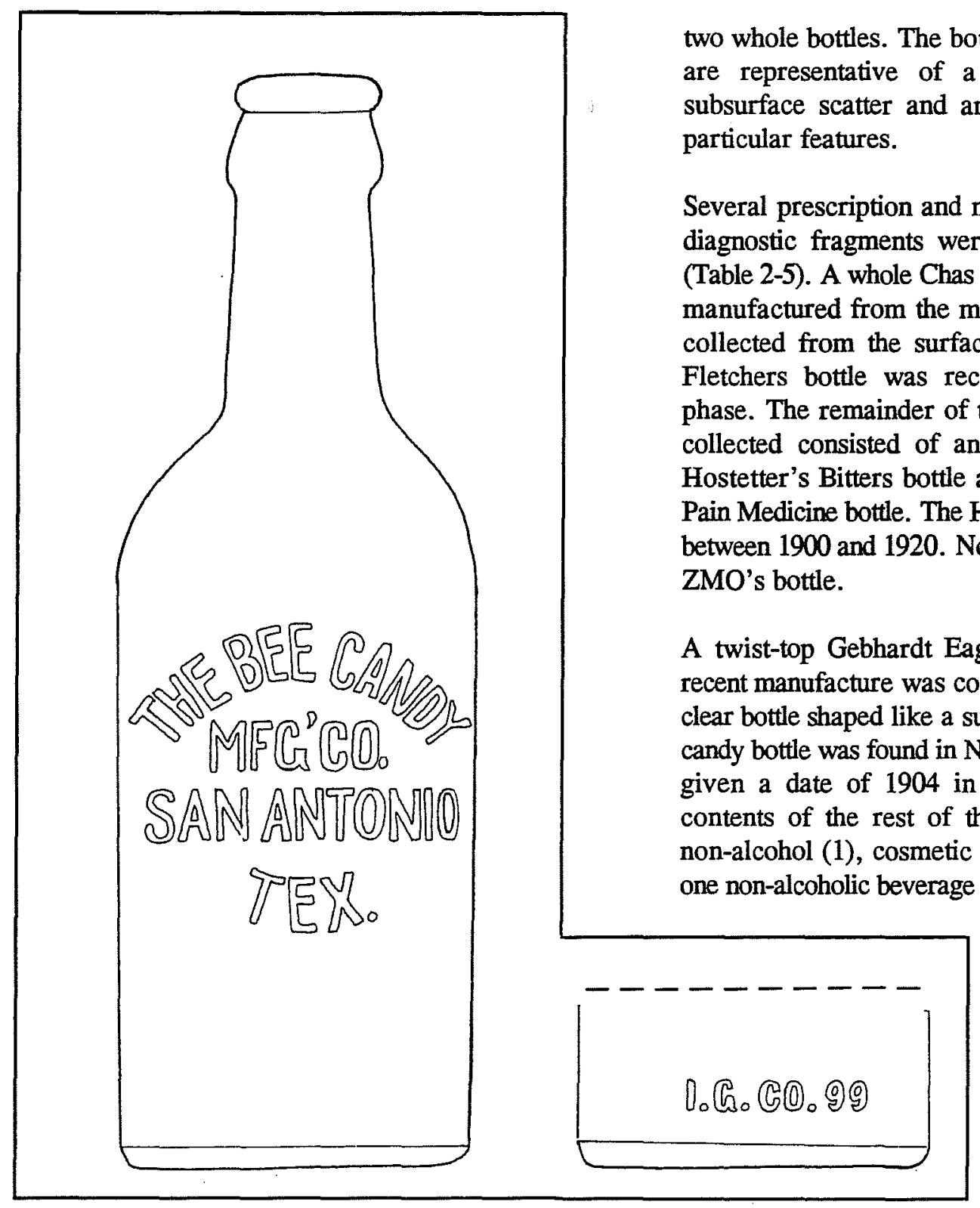

Figure 2-11. Bee Candy Company bottle. Front and back. Shown three-fourths actual size. two whole bottles. The bottles found in this collection are representative of a generalized surface and subsurface scatter and are not associated with any particular features.

Several prescription and non-prescription bottles and diagnostic fragments were recovered from the site (Table 2-5). A whole Chas A Fletchers Castoria bottle, manufactured from the mid-1800s to the 1920 s, was collected from the surface. A fragment of another Fletchers bottle was recovered during the testing phase. The remainder of the non-prescription bottles collected consisted of an embossed fragment of a Hostetter's Bitters bottle as well as a partial ZMO's Pain Medicine bottle. The Hostetter's bottle dates from between 1900 and 1920 . No date was available for the A twist-top Gebhardt Eagle Chili Powder bottle of recent manufacture was collected from the surface. A clear bottle shaped like a suitcase and probably once a candy bottle was found in N50/E88. A similar bottle is given a date of 1904 in Munsey (1970:187). The contents of the rest of the bottles are alcohol (8), non-alcohol (1), cosmetic (2), and medicine (2). The one non-alcoholic beverage container is embossed with

"THE BEE CANDY MF'G CO. SAN ANTONIO TEX." This bottle dates between approximately 1880 and 1930. This company, along with several other local bottlers, did not survive the onset of Prohibition.

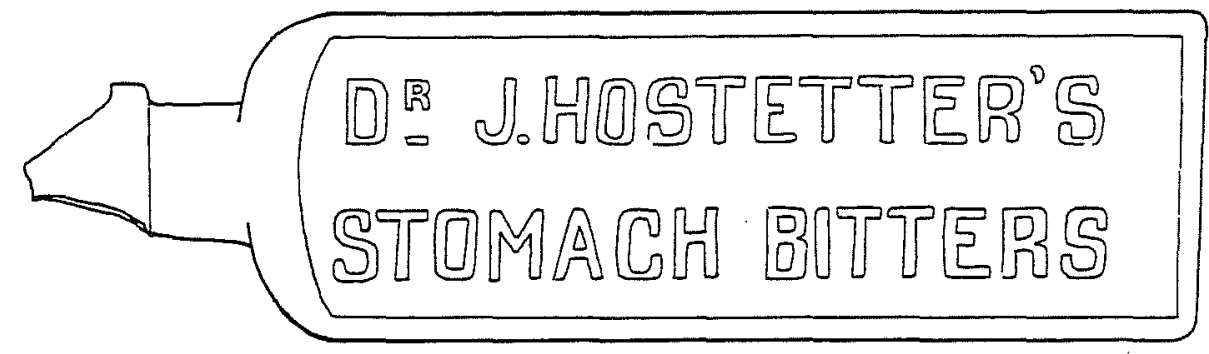

Figure 2-12. Hostetter's bitters bottle. Shown one-half actual size. 
Table 2-5. Dated Maker's Marks and Brand Names from 41BX882

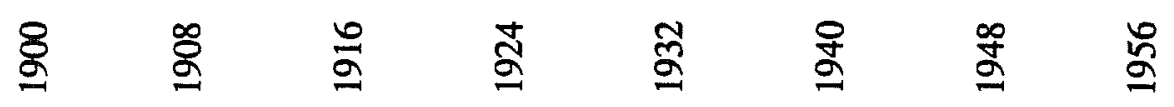

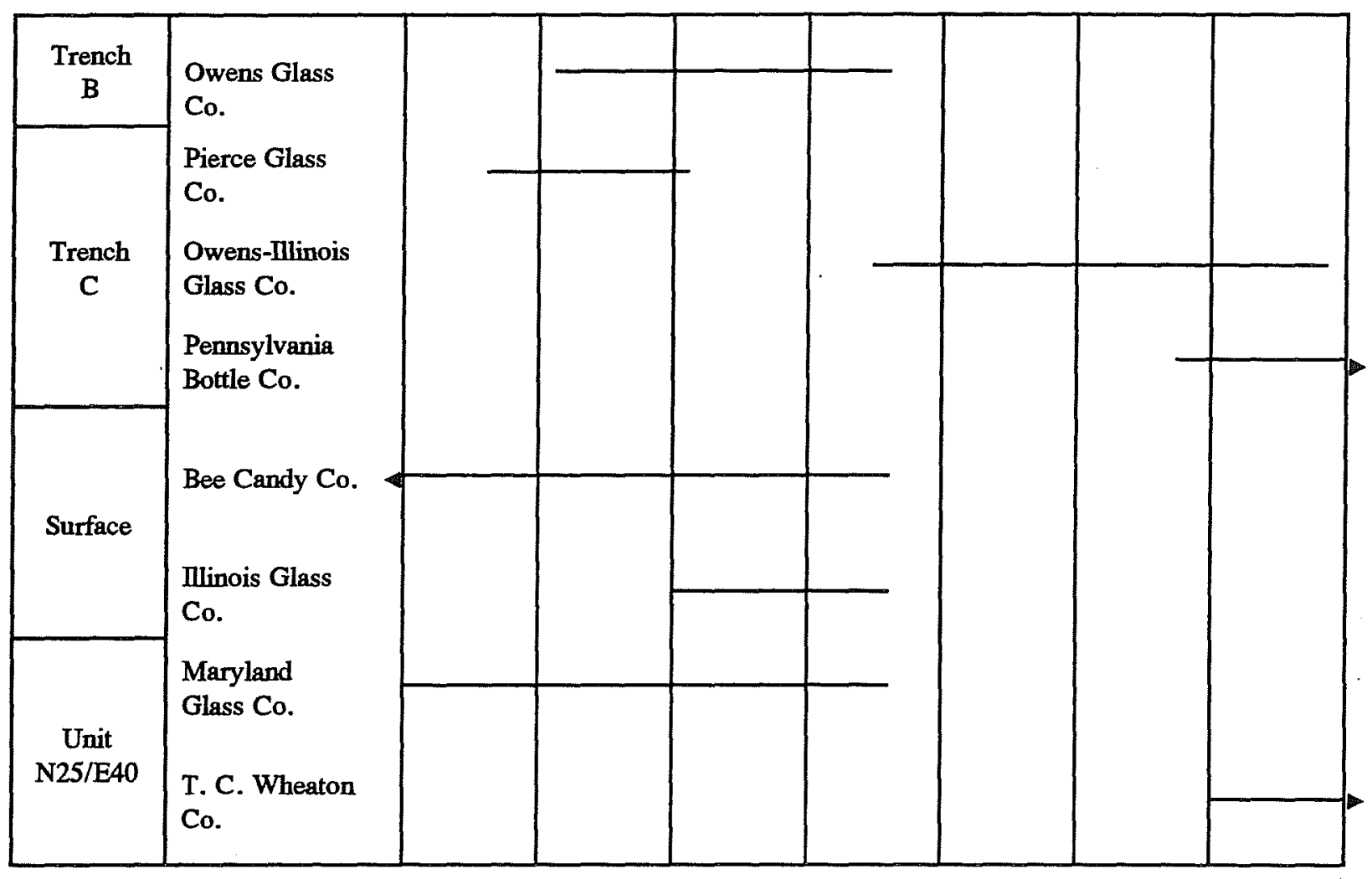

\section{BX883, The King Site}

Site 41BX883 was occupied from 1894 to 1987 . The glass recovered from this site consisted of fragments with mixed dates spread over a wide area in the northwest portion of NCB 621. At minimum, 88 bottles, including 33 whole, are represented in this collection. The scatter of glass is possibly a secondary deposit created when the site was bulldozed in 1965 . Due to the wide distribution of bottle fragments from earlier trash deposits in the northwest portion of the lot which may possibly be from the adjoining site 41BX897, the bottles and their contents are not considered representative of bottle use and distribution of the inhabitants of this site.
A privy excavated in the southeast corner of the lot, on the other hand, escaped the bulldozing and is probably the best source for resident household information. Bottle contents from the privy include food, cosmetics, prescription and non-prescription medicines and household products such as bluing.

The privy contained 22 whole bottles and an estimated minimum of 27 bottles. A bottle from a San Antonio druggist, Allen L. Swearingen, who was in business from 1901 to 1902 was excavated from the lowest level. The final cleaning of the privy, therefore, probably occurred just prior to 1901 . Confounding this, however, is the presence of two bottles that can be dated respectively to $1832-1886$ and $1810-1880$ by 
maker's marks. The presence of machine made bottles within the upper levels of the privy indicate that it was in use through at least 1903, the year of the invention of the automatic bottle making machine. This is interesting in the light of the fact that these dates correspond closely with dates estimated for the privy at site 41BX945, the Pauly site.

Only two maker's marks or datable brand names were available for this site, so no table listing maker's marks and their dates is included with this section. Instead, a table listing various manufacturing traits and their dates is presented (Table 2-6). Dates for the various techniques come from Munsey (1970), Lorraine (1968), and Newman (1970). Only whole bottles were used.

A close look at these data places the privy contents between about 1880 and the present. The ending date is based on the appearance of machine-made bottles. While they may have been manufactured as early as 1903, many pieces manufactured during the latter part of the first quarter of this century and later are virtually indistinguishable from their modern counterparts.

\section{General Discussion}

In assigning dates of deposition to the Alamodome materials, reuse and the manufacturing/deposition lag had to be considered. During and immediately after Prohibition, bottles were recycled for use either by manufacturers of illegal alcohol or by barkeeps who refilled bottles from kegs. When reuse is taken into account, the utility of bottles in adequately dating a site declines. The time lag between bottle manufacture and deposition may be as long as or longer than ten years (Hill 1982). "Absence of usable bottles in trash deposits might be linked to immigrant status; there is historical evidence that European immigrants were more accustomed than Americans to reusing bottles" (Busch 1987).

Table 2-6. Dating of Bottles from Site 41BX883 Privy

\begin{tabular}{||c|l|c|c||}
\hline Level & \multicolumn{1}{|c|}{ Key Diagnostic Features } & Frequency & Dates \\
\hline 1 & tooled lip & 2 & $1700-1920$ \\
\hline 1 & bust off and grind finish & 1 & $1858-1915$ \\
\hline 1 & machine made & 1 & $1903-$ present \\
\hline 2 & tooled lip & 1 & $1700-1920$ \\
\hline 3 & no diagnostic glass recovered & \multicolumn{2}{|l|}{} \\
\hline 4 & no diagnostic glass recovered & 1 & $1840-1870$ \\
\hline 5 & laid-on ring finish & 1 & $1860-1903$ \\
\hline 6 & hinged mold, seam to shoulder & 1 & $1880-1900$ \\
\hline 6 & seam to finish & 8 & $1700-1920$ \\
\hline 6 & tooled lip & 1 & $1845-1903$ \\
\hline 6 & post bottom mold & & \\
\hline
\end{tabular}


This provides possible explanations for the large number of broken bottles found on sites 41BX891 and 41BX892. These sites were originally the property of German settlers who bought and built on the lots in the 1850s and whose families occupied the sites until their abandonment. Both of these sites contained middens that were composed almost entirely of broken bottles. These middens were not associated with privies.

This section is concerned almost entirely with dating features from three of the six sites described above, 41BX891, 41BX892, and 41BX895. Of the remaining three sites, two (41BX945 and 41BX883) are privies and are covered in more detail by Brown and DeLaO in this volume. $41 \mathrm{BX} 882$ represents a special case. The record in terms of bottle glass from this site is so scattered and fragmentary that it is impossible to assign a date to any single feature.

Two methods of dating the features are considered here. The first is the application of Stanley South's Mean Ceramic Date (MCD) formula (South 1977). The second method is a derivation of this formula and is designed to provide clues as to the time difference between the manufacture of bottles and the time of deposition into the archaeological record (Hill 1982).

South's formula is aimed at establishing the median dates of occupation of a site. In this case, however, we already know the occupation dates of the site. What we hope to find out is the median date of deposition for the feature in question. Calculation of the MCD for the monitored trash pit at site 41BX891 yielded a date of 1900. In using bottles to date the time of deposition, factors beyond the simple date of manufacture must be considered. These factors include the time lag between manufacture, filling, and use, as well as the possibility of reuse. The time lag for various types of bottled items differs. "Fresh" drinks such as beer, soft drinks, and milk are expected to have a shorter time lag than other bottled goods such as sauces, food, or alcoholic beverages such as whiskey or other items which can have a longer period of consumption.

Hill (1982) presents a formula for calculating the time lag between manufacture and deposition for bottles. Her model, however, only works when the time of deposition is known with a fair degree of accuracy or the sites in question had a relatively short period of occupation-less than or equal to about 25 years. In the case of the Alamodome where occupation of a single site often exceeded 70 years, the formula is somewhat less useful. Applying Hill's formula to some of the Alamodome materials yields manufacture/deposition lags approaching 30 years for some sites. Time of deposition for some sites can be estimated from the presence of bottles having a short manufacturing period. The use of whole bottles to date the time of deposition is not entirely practical. These bottles must be subject to the same forces that caused the manufacture/deposition lag that acted upon the other bottles. In that case, the safest approach is to take the occupation period as the dates of deposition. Following Hill's suggestion, the terminal date of occupation is also given as the terminus ante quem of manufacture. When no date was available for the initial production of a bottle or that date preceded the initial occupation of the site, the date of initial occupation was given as a terminus post quem.

In the analysis of site 41BX891, because of the state in which the bottles were recovered, no effort was made to group them in categories based on contents. Instead, all were considered together and a figure of 1899 was reached as the mean year of production for the bottles. The use of 1925 as the date of occupation as per Hill's suggestion results in a deposition lag of 26 years. This is the maximum possible value and it is difficult to reconcile it with the archaeological evidence that indicates that these bottles were deposited within a relatively short period of time. The mean date of manufacture and the manufacture/deposition lag cannot be used to calculate the date of deposition for these bottles. Some of the bottles were manufactured only between 1903 and 1907. This provides the single most diagnostic piece of information for estimating date(s) of deposition. Had dates of manufacture been used alone, the estimate would have run from 1895 to 1903. This is based on dating such features as mold marks, glass color, and so forth. In light of the information obtained through the maker's marks, dating is much tighter.

Hill's formula is not applicable to the Alamodome materials because of the lack of definite dates for the termination of the use of a feature. In her example using the Edgewood site (Hill 1982:312-318) the midden was known to have had well established initial 
and terminal dates. Assuming that the bottles with the $A B$ maker's mark in sites $41 B \times 891$ and 892 were produced and originally used in 1905 , the middle of their production run, and given a period of reuse of 10 years, we still cannot begin to approach the manufacture/deposition lag suggested by Hill's formula. Beer and milk bottles as well as containers for other fresh drinks, were recycled, reused, and discarded faster than other types of bottles because of the deposit and return policy that was levied upon them. Other bottles such as condiment bottles or those containing items that could be stored for long periods of time without the risk of spoilage, could be expected to have a longer lag between manufacture and deposition. 


\section{References Cited}

Baugher-Perlin, S.

1982 Analyzing Glass Bottles for Chronology, Function, and Trade Networks. In Archaeology of Urban America: The Search for Pattem and Process. Edited by R. S. Dickens, Jr., pp. 258-289. Academic, New York.

Busch, J.

1987 Second Time Around: A Look at Bottle Reuse. Historical Archaeology 21(1):67-80.

Hill, S. H.

1982 An Examination of Manufacture-Deposition Lag for Glass Bottles from Late Historic Sites. In Archaeology of Urban America: The Search for Pattern and Process, edited by R. S. Dickens, Jr., pp. 290-327. Academic, New York.

Illinois Glass Company

1904 Illustrated Catalogue and Price List. Alton, Illinois.

Lorraine, D.

1968 An Archaeologist's Guide to Nineteenth Century American Glass. Historical Archaeology 2:35-44.

Miller, G. L., and A. Pacey

1985 Impact of Mechanization in the Glass Container Industry: The Dominion Glass Company of Montreal, a Case Study. Historical Archaeology 19(1):38-50.

Munsey, C.

1970 The Illustrated Guide to Collecting Bottles. Hawthorn, New York.

Newman, T. S.

1970 A Dating Key for Post-Eighteenth Century Bottles. Historical Archaeology IV:70-75.

South, S.

1977 Method and Theory in American Archaeology. Academic, New York.

Toulouse, J. H.

1971 Bottle Makers and Their Marks. Thomas Nelson, New York. 


\title{
Chapter 3 \\ Dolls, Toys, Games, and Other Diversions
}

\author{
Barbara A. Meissner
}

\section{Introduction}

During the course of the archaeological investigation of the 16-block area of San Antonio, Texas, which was affected by the construction of the Alamodome Stadium, 379 items were recovered which reflect the material remains of play, games, sports, and other diversions enjoyed by the inhabitants of the area during almost 150 years $(1850 \mathrm{~s}-1990)$. These items have, for convenience, been broken down into the loose categories of Dolls and Doll-Related Toys, Other Toys, Games, Entertainment, and Other Diversions and Activities. Marbles will be considered in a separate report (see Zapata, this volume). In some cases a particular artifact could fit into two or more categories and the assignment of such artifacts to a category is made arbitrarily.

Provenience is provided for most artifacts. Information concerning these proveniences, including site and excavation maps, are provided in Volume II. Unique or interesting items from the collection are illustrated, as are representative examples of more mundane items.

Toys have recently been defined as "the material artifacts of play" (Merken 1984:149), a distinctly modern interpretation. The word "toy" once meant a miniature version of a thing or some small thing of little value (Noël Hume 1970:313). It is easy to understand why the things with which children played were call "toys," because children's play was, in past centuries, considered a frivolous waste of time and energy. Children were considered little adults, expected to participate in adult life (Ariès 1965:368). It was not until the sixteenth and seventeenth centuries that children were given their own toys and games (Hunt 1970:34). Even after this time, however, little value was attached either to the creativity or the learning potential of play (Frost 1985:ix).

But value, like beauty, is in the eye of the beholder, and the value of play has been increasingly understood throughout this century. Various theories of play behavior have developed. The surplus energy theory, prevalent in the early part of this century, maintained that children built up excess energy that had to be dissipated with play (Wortham 1985:3). A contrasting theory in the same period held that play was recreation, i.e., that play restored energy spent in hard work (Wortham 1985:3). Another theory felt that in play, children recapitulated the various social stages through which man had passed (Wortham 1985:4).

After the 1930s, theories about play were more strongly influenced by Freud and Piaget. Freud saw play as a cathartic process in which children gain control of strong emotions by repetitively reliving through play, either directly or symbolically, the events that had sparked those emotions (Wortham 1985:5). Piaget believed that play was a vehicle for cognitive development, and that the changing kinds of play seen as children grow reflected the stages of that development (Wortham 1985:5). Therefore, far from being considered a waste of time, play is now viewed as "children's work" (Isenberg and Jacobs 1982:23), the "major vehicle through which young children learn" (Isenberg and Jacobs 1982:11). Anthropologists believe that the most important part of what children are learning in their play is the specific information they need to live in the particular culture into which they are born (Schwartzman 1978:108). 
If importance is now attached to play, there is also an increasing perception of toys as important aspects of childhood, having a life-long effect on children, for good or evil (Sutton-Smith 1986:3). Large and active organizations fight to promote the kinds of toys they consider good and to discourage or even ban the kinds they consider bad (Sutton-Smith 1986:5-7). Billions of dollars are spent in the United States to buy more than 150,000 different kinds of toys every year (SuttonSmith 1986:2).

It is important to understand that this automatic association of play with playthings is a recent product of our changing culture. In the past, and in other cultures around the world, play was as important a part of childhood as it seems to us now, but the nature of play was somewhat different. Sutton-Smith (1986:26) points out that though children in these non-modern or non-Western cultures had playthings, the focus of play was on its social aspects. The more recent ways of looking at play suggest that the reason for this is that these children were being born (and socialized) into groups where conformity of behavior and strong intragroup-especially intra-familial-relationships were the norms. The interactions and interdependency of social play taught these principles to children at a very fundamental level.

We no longer live in such a society. Changes in the technological and economic structures in which we live have had a profound effect on every aspect of our lives. During the last century, changes occurred in both the quality and the quantity of consumer demand in all areas of Western life. These changes are influenced by three historical trends: (a) the increase in per capita disposable income; (b) the continued improvement of technology, which generates a range of new products; and (c) the shortening of working hours and the accompanying increase in leisure time (Smelser 1976:136-137).

Almost every item we need, for work or play, that used to be made at home or in small local shops, is now routinely made in large factories far from most of the people who will buy them (White 1971:13-19). The recent emphasis on commercially made toys is a part of this change in society.

The idea that toys are required for play, however, is only indirectly related to the commercial availability of toys. The impact of the Industrial Revolution required changes in social organization. In order for society to function within the influence of new technologies, new methods of working, new kinds of transportation and communication, and different kinds of relationships between persons had to be established. We are now, from birth, encouraged to be individuals first and members of a group, even of our families, second (Sutton-Smith 1986:37). The change in social emphasis is seen in the way our children are being raised. They must now spend much more of their time playing alone than was ever true in the past (Sutton-Smith 1986:27). This isolation of the child begins in infancy, when the baby is placed in its own bed instead of sleeping with its mother, and continues into adulthood. At the same time, we strive to increase the sensory stimulation of our children. The infant is "physically isolated but intellectually stimulated" (Sutton-Smith 1986:36).

Sutton-Smith (1986) believes that the emphasis on toys that has developed in our society is part of this isolation training. We spend a great deal of time as parents in this society attempting to increase the intellectual abilities of our children, and we are told that toys are the way to accomplish this (Isenberg and Jacobs 1982). We buy toys and give them to our children, perhaps show the child how we think the toy should be played with, and then expect the children to go somewhere to be alone and play with the toy. We are encouraged to believe-by advertisers, if not by educators-that the more toys the better, i.e., the happier and more intelligent, the child.

However, the citizens of San Antonio who built houses in the study area during the 1850 s to 1880 s were not a part of this somewhat frenzied attempt on the part of parents to aid in the development of their children, and the openly frenzied attempts on the part of the toy industry to promote toys as necessities in the lives of children. In those early years, toys would have been homemade, improvised by the children or designed and built by adults using an oral-technical tradition as a guide (Abernethy 1989:1; Hart 1975:18). We have only a "hazy impression" (Merken 1984:151) of these toys for the most part, confined to a few collectors' delights and the continuation of those oral-technical traditions (see Abernethy 1989). For girls, rag dolls, clothespin dolls, dolls made from every imaginable natural material, including corn husks, pine cones, and flowers, were made at home by a friendly adult or by 
the child herself (Roach 1989:61). Toys for boys were made from sticks, pieces of leather or cloth, bits of metal, old inner tubes, etc., all recycled from a previous use (Abernethy 1989:3-99). Unfortunately, though we can be sure the children in the Alamodome area had some of these wonderful made-with-love playthings, they would have been made, almost without exception, either of materials that did not survive to be recovered by archaeologists, or of recycled materials not recognizable now as playthings. After all, a hoop from a wagon hub used by a child as a toy will likely be classified as "wagon parts," not "toy" in a catalog of recovered historic artifacts.

The idea of spending money on toys for children must have been alien to all but the wealthiest of these people, and this did not change significantly until the last two decades of the nineteenth century. The growing need to encourage individualism, the growing industrialization that fostered that need (Sutton-Smith 1986:245), and the growing availability of disposable income, all worked together to promote the expanding use of toys manufactured as such by companies expecting to make a profit.

It was not until the social awareness of toys as necessities had grown among the middle class, and a market for relatively cheap dolls and other toys was perceived by manufacturers, that toys began to be acknowledged as such. They are recognizable in the archaeological record because they were specifically made as toys, there were so many more of them, and they were made of more durable material. For example, though expensive bisque and porcelain dolls had been made in Germany and France since the lateeighteenth century, it was not until after the Civil War that the little all-bisque "penny babies," so common in the 1880 s and afterwards, were first manufactured (Byfield 1986a:36), and made available to any little girl who lived near a railroad and could find a penny. Before that time, only a wealthy child could expect to have a commercially made toy (White 1971:18).

The "Industrial Revolution" in toymaking was in full swing in Europe by 1860 (Remise and Fondin 1967:12) and in the United States after the Civil War. San Antonio, however, could not be a significant part of this growing toy market until the San Antonio, Harrisburg \& Galveston Railroad line reached the city in 1877 . Even after this, most toys in the study area would still have been made as they always had: of perishable or unrecognizable materials (Abernethy 1989:3).

Change eventually did reach even the fringes of the United States. Starting around 1880 and continuing to the present, it is largely true that "the majority of [commercial] toys are designed and made by grownups to appeal-that is, to sell-to other adults. Children merely provide an excuse" (Remise and Fondin 1967:14). In examining the toys found at the Alamodome site, it is important to remember that, with the exception of the very cheap items like penny dolls and gumball machine toys, most of the items listed in this report were bought by adults to give to children. In addition, the toys, game pieces, dolls, and balls recovered during excavation represent, at best, only a small fraction of the played-with objects used by these working-class families. Yet they also represent the profound changes that American society underwent in the last decades of the nineteenth and the early years of the twentieth century.

\section{Dolls And Doll-Related Toys}

There are numerous definitions of "doll," but a functional definition will be used here: a doll is a figurine in human form, intended to be actively played with. This excludes toy animals, to be discussed in the Other Toys category, and figurines intended to remain on stands, which can be considered more decorations than playthings and will be discussed in the "Personal Items" report in this volume. This definition would, of course, include paper dolls and other dolls made of perishable materials, but these dolls will obviously not survive long in an archaeological context, and none was represented in this collection.

The dating of dolls is something of a problem for the archaeologist, as it is for the doll collector. On marked dolls it is sometimes possible to establish an earliestpossible date of manufacture by identifying a particular mold number or by knowing the exact dates in which a particular company used a particular mark. Such dating is, however, usually very general. For instance, the mold \#1079 made by Simon \& Halbig was registered in 1892 (Collier 1988:165) but was probably in use until the company went out of business in 1926. Even this information is limited because the more 
expensive dolls were often carefully kept in the family for a generation or more, and because so few of the cheaper kinds of dolls had any marks on them at all. Another problem with using marks and manufacturers as dating devices is that, in the archaeological record, the marks which once existed are often either missing or fragmented.

Another method of dating which is sometimes used is to examine the hairstyle, footware style, or the size of the chest portion of a doll. Prichett and Pastron (1983) describe "typical" hairstyles from two general dates, the 1840 s to 1850 s and the 1850 s to 1870 s. They also state that "flat-soled slippers or shoes indicate a doll dating before 1860" (Prichett and Pastron 1983:328). Another fashion note is that early nineteenth-century fashions allowed deeply cut dresses and the "shoulderhead" porcelain dolls made during this period were "deep-chested" to allow a similar fashion for them (St. George 1948:101).

The trouble with the hairstyle method is that while one may be sure that an 1870 s hairstyle was unlikely to have been made before that time, there is absolutely no guarantee that they were not made after that time (Coleman 1986). The shoe and chest methods of dating may also be subject to this objection, though it is likely that they are less problematic. The "deep-chested" look was definitely not considered acceptable for dolls by the mid-nineteenth century, and even an "oldfashioned" doll made, say, in the early twentieth century, would probably not have such a deep décolletage as dolls actually made earlier. The flatsoled shoe is also likely to be a fairly good indication of age, though some twentieth-century boy dolls have flat soles, and flat soles alone are not an absolute indicator for pre-1860s dolls. A doll dated 1870 pictured in Byfield (1986a:36) has distinctly flat-soled shoes. Thus, dating dolls by their fashions can often be less than accurate.

A total of 203 fragments of dolls or doll-related toys was recovered during the Alamodome project. Before describing them in detail, it is necessary to provide a brief glossary of doll types and related terms which might be encountered in the study of dolls. The individual items will then be discussed, grouped by site.

\section{Doll Types and Related Terms}

\section{Bisque}

The word bisque is a French word which means "dry cake" (Angione 1973:26) and has many meanings, even among doll experts (Angione 1973:26-27). For the purposes of this report, the word will mean "an unglazed ceramic" used for making doll and figurine parts.

\section{Bisque Dolls}

This was a general term used for dolls with bisque heads. Bisque heads (and sometimes arms and legs) were sold separately as replacements or to be attached to homemade cloth bodies (Schroeder 1971:44, 124). Others were sold as whole dolls in large or small sizes, and sold dressed or undressed. Bodies could be composed of cloth, bisque, kid leather, paper mache, composition, celluloid, or even wood. Limbs on hardbodied dolls were often jointed at the shoulders and hips and might also be jointed at the knees, elbows, wrists and ankles. Heads could be stiff-necked or turning. Eyes could be painted, or glass, and be either fixed or "sleep" eyes.

Bisque dolls were very expensive or very cheap, depending on the characteristics listed above and their over-all quality. A doll six inches tall, with only hip and shoulder joints, turning head, wig, glass eyes, dressed in a cotton slip, was sold wholesale for $\$ .39$ a dozen in 1895 . In the same catalog, a 28-inch bisque doll with sleep eyes, composition body, mohair wig, joints at wrist and knee as well as shoulder and hip, dressed in night robe with shoes and stockings, was sold for $\$ 40.00$ a dozen (Schroeder 1971:94). But whether cheap or expensive, these dolls were a treasure to the children who received them (Roach 1989:63). 


\section{Candy Store Dolls}

Candy store dolls were a later version of the penny doll. They were fairly cheap, small, all-bisque dolls, and were usually made in Germany. They were quite popular in the years before World War I (Angione 1973:220). Pennies, dimes, and nickels were carefully saved in order to buy dolls ranging in size from tiny two-inch miniatures to about six inches (Angione 1973: 220-239), and in price from a few pennies to $\$ .29$ (Angione 1973:222).

\section{Celluloid}

This was an early type of plastic used to make dolls beginning in the late nineteenth century (Collier 1988:407). Invented in 1869 (White 1971:19), the material was highly flammable, and a hundred years later its use in toys was banned (White 1971:22).

\section{China}

This is a term used in many old toy catalogs which usually refers to glazed ceramic doll parts, but sometimes, as in China Limb Dolls (see below), the term means any kind of ceramic.

\section{China Limb Dolls}

These were dolls with bodies made of a soft material, usually fabric, with bisque or porcelain head, arms, and legs. The arms and legs have grooves in the tops where string was used to hold the limb to the soft body. This type was a compromise between the expensive "character" bisque dolls and the simplest rag doll. These dolls looked nice when dressed, yet they were quite cheap and, thus, very popular. Butler Brothers sold these dolls in 1895 for wholesale prices of from $\$ .30$ to $\$ 3.20$ a dozen (Schroeder 1971:92). The largest factor in the price deferential was the size of these dolls. Prices were also affected if ceramic parts were glazed or unglazed and had other decorations. By the beginning of World War I, these dolls had been almost entirely displaced in the toy catalogs by rubber, composition or celluloid equivalents, and can be dated roughly from the 1870 s to the 1910 s.

\section{Complexion Coat}

The complexion coat was the color added to most dolls to give them a skin-like color since the natural color of porcelain and bisque. This could be applied before or after the final firing. If applied after, it will be inclined to rub off easily.

\section{Composition}

This is a term for a pressed wood pulp mixture used to make doll bodies. This is a twentieth century term for material much like the paper maché of the nineteenth century (Collier 1988:408).

\section{Frozen Charlotte}

The Frozen Charlotte was one type of penny doll, less than four inches tall, with arms and legs "frozen" in a single position, i.e., without moving joints. The name comes from a nineteenth-century poem about a vain girl who would not cover her ballroom finery on a cold night, with fatal consequences (St. George 1948:42-45). Male versions are called frozen Charlies.

These little dolls were generally cheaply made, but some were made of glazed porcelain, decorated with gold colors or other lusters, and were " 10 cent" dolls. Most had painted shoes and faces, and many were wigged. Others had molded hair and some even had molded bonnets. They could be either solid or hollow. Dolls of this type have been insecurely dated as early as the mid-1850s (Angione 1973:83-84); however, it is safe to say that they were gladdening young hearts soon after the Civil War (St. George 1948:41), and were still being sold in the early 1930s. They sold wholesale for between $\$ .75$ and $\$ .82$ a gross in 1895 (Schroeder 1971:92).

\section{Goo-Goos}

Goo-Goo dolls were popular after the turn of the century. They had round, impish faces, large eyes which look to one side, and a "roguish" expression. Similar dolls were sometimes called "Googlies" (Byfield 1986b:109) or "Pixies" (Angione 1975:40). 


\section{Joint types}

Rag and other soft-bodied dolls had sewn joints, usually made by simply sewing a line across the stuffing of a joint area so it would bend readily at that place. More elaborate methods produced dolls whose joints moved in a very natural fashion. Doll bodies of composition or other hard material had many different, often patented, methods to create a ball-and-socket type joint.

Most string-jointed dolls have one of three types of stringing. Some very old dolls were strung with string threaded through holes in the joint areas and held in place with pegs. In the second method, wire was strung through the body and twisted into a loop on the outer surface of the limb. The older and better-quality dolls had brass wire, but cheaper dolls had iron wire that could (and did) rust. The third method was to hook rubber bands through hooks or shanks molded at the tops of arms and legs to hold them into shoulder and thigh sockets (Angione 1973:45).

\section{Paper maché}

This was mixture of paste and wood pulp pressed into molds to form doll parts. After the turn of the century, this material is usually referred to as composition (Collier 1988:412).

\section{Parian}

This term is used by doll collectors to mean a doll or figurine of untinted bisque or porcelain. While features or molded clothing may be painted, the "skin" of the figure remains white, with no complexion coat (Angione 1973:35).

\section{Penny dolls}

Penny dolls were often called "penny babies" in catalogs (Stirn 1990:10), these cheaply made, one- to four-inch little dolls became the first "store bought" doll of many little girls in the years after the Civil War (St. George 1948:39). Most were of the "frozen Charlotte" type, but others had jointed hips and/or shoulders. Generally, they were not dressed, this task was left to the little girl who bought them (St. George 1948:39). Making outfits for these tiny dolls was a good use of small scraps of material, and enhanced needleworking skills.

\section{Porcelain}

For the purposes of this report the word "porcelain" will mean a glazed ceramic, either undecorated white or painted before or after the last firing. Sometimes referred to as china in old catalogs and doll books.

\section{Pre-colored}

Pre-coloring was an economy measure in which the bisque or porcelain itself is given a pink color instead of the usual white. In this manner the complexion coat step could be skipped entirely.

\section{Shoulder head}

This is the term for a type of doll head in which the head and shoulders are molded in one piece (Collier 1988:414). Also called "stiff-necks" (Angione 1973:119).

\section{Sleep eyes}

These were doll eyes (usually glass) attached to a balance mechanism that turned them to a closed position when the doll was laid down.

\section{Socket head}

This is the term for a type of doll head which tapers at the neck to fit into a socket in the shoulders. The head was secured to the shoulders with rubber, string or wire. This method allowed the doll's head to turn (Collier 1988:414). 


\section{Alamodome Dolls}

Each diagnostic doll part is described below by provenience. Most of the diagnostic doll parts are illustrated. Each doll part is given an arbitrary number to aid in discussion.

\section{Oeffinger Site (41BX881)}

1) N40/W25. Lower lip and chin of bisque doll (Figure 3-1a). The complexion coat is good and the molding generally of good quality. The lower lip is painted, and a dimple is found in the chin.

2) N32/W48. Tiny bisque doll arm (Figure 3-1b). This arm has a poorly molded hand in a fist. The hole for wire stringing is stained with rust, indicating galvanized wire was used. This would have been a small penny baby type doll.

Two non-diagnostic pieces that were probably doll fragments were found. These doll parts come from dolls at both the lower and upper range of expense. The date range on both types is fairly wide, but it is safe to say that both were made before World War II, and probably before World War I.

\section{Haas Site (41BX882)}

3) Surface. Porcelain doll shoulder with small amount of complexion paint still present (Figure 3-1c). This doll would have been a stiff-neck.

4) N44/E71. Fragment of bisque chin with a good complexion coat and a tiny bit of the lower lip paint remaining.

5) N50/E88, Trench B. Doll's face fragment, bisque, with open mouth and four porcelain teeth applied inside the upper lip (Figure 3-1d). Eye holes are probably for "sleep eyes." It is well made, having a good complexion coat, excellent molding, and painting around the lips and eyes. The fragment appears to have been cast from mold \#1079 made by Simon and Halbig, a large German manufacturer of doll heads. They used this mold for their own doll heads and also sold the molds to other manufacturers. The mold was registered in 1892 (Collier 1988:165), but was used for many years thereafter, possibly until 1925 , when the company went out of business (MacDowell and MacDowell 1986:110). Dolls with these heads ranged from 7 to 46 inches tall (Collier 1988:165). This particular doll was a medium to small size and would have been expensive. Similar dolls are listed in the Montgomery Ward Catalog for 1903 with prices ranging from $\$ .75$ to $\$ 2.25$ (Schroeder 1971:124).

Two non-diagnostic doll fragments were also found.

The $\# 2$ and $\# 3$ dolls would have been nice little dolls, small but fairly expensive. The porcelain doll (\#3) may have been a shoulder head from a "china limb" doll, but if so, it would have been from a somewhat more expensive variety.

\section{King Site (41BX883)}

6) Trench E, Feature B. Fragment of lower brow and nose, and part of eyes, made of bisque (Figure 3-1e). The color is intense, a characteristic of some German dolls after 1910 (Angione 1973:145).

7) Trench A, Feature C (Privy \#1). Fragment of the chin and lower lip of a chubby doll (Figure 3-1f). The complexion coat is even, the chin has a dimple, and the lower lip is painted. This could be an infant doll.

8) Trench A, Feature C (Privy \#1). Doll's arm of untinted bisque (Figure 3-1g). It is poorly finished. A self loop is present at the shoulder for joining. The hand style is distinctive, with the palm almost horizontal and the fingers spread, except the middle and ring finger which are molded together. This hand style is usually seen in goo-goo dolls made by Gebruder Heubach (Angione 1973:145), but the poor quality and lack of tint suggest strongly that this is a Japanese copy (Angione 1973:149). It probably dates between World War I and 1939.

9) Well Expansion 3 East. Doll's leg, solid bisque, broken at knee and ankle, with remains of black boot painted at bottom (Figure 3-1h). This leg is identical to the solid bisque leg (\#43, Figure 3-1i) from site 41BX897, and is probably from the same doll. The flat-heel style is strongly suggestive of a pre-1870s date. A doll pictured in Byfield (1986b:36), dating to 1870 , has almost identical legs. If this early dating is 


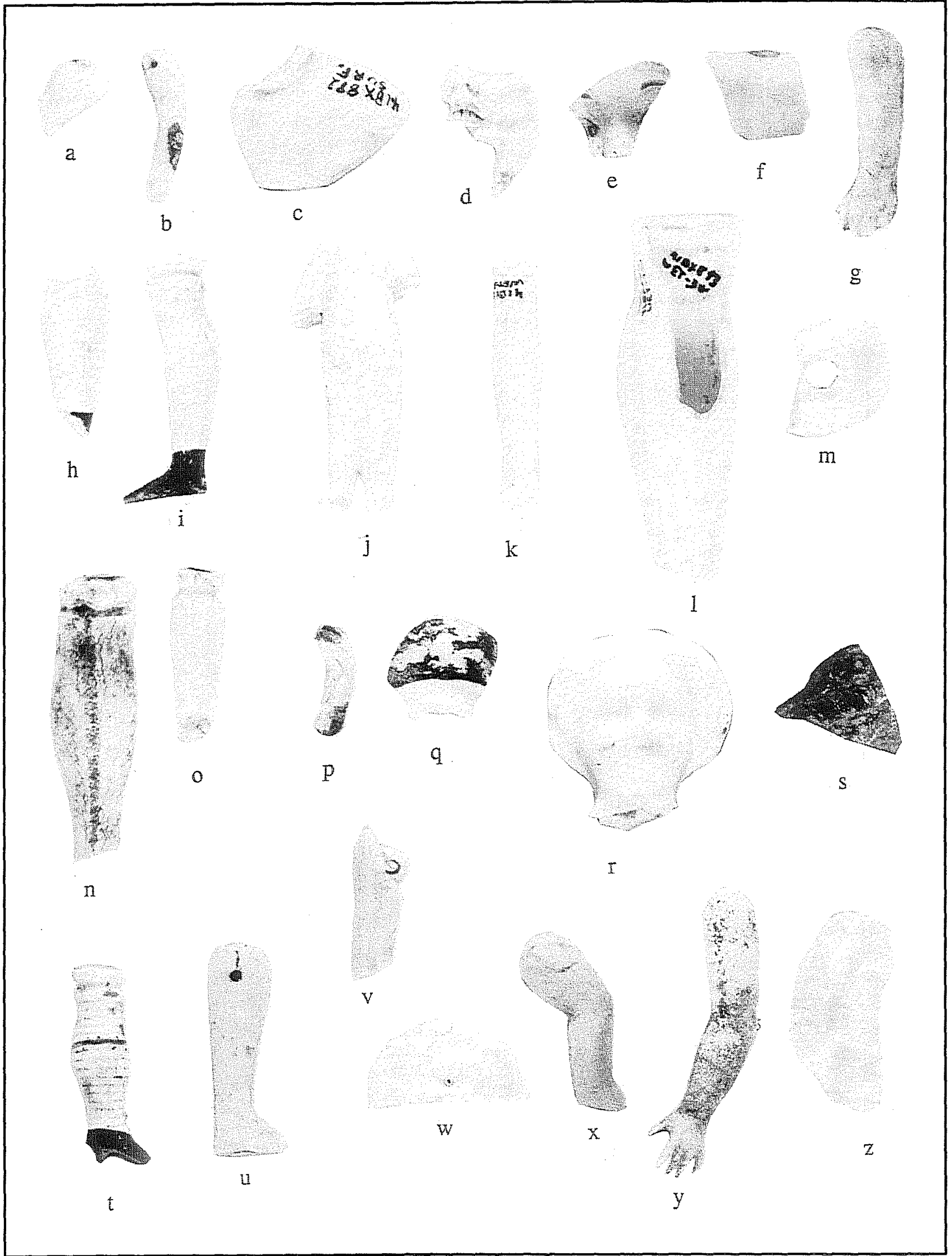

Figure 3-1. Ceramic doll fragments. See detailed descriptions in text. All shown actual size. 
valid, these two legs are probably the oldest doll parts found during the project.

10) Well Expansion 3 East. Doll body, solid bisque, with arms and head missing (Figure $3-1 \mathrm{j}$ ). It is a poorly made Frozen Charlotte. No tinting is present.

11) Well Expansion 3 East. Fragment of untinted porcelain from a shoulder head doll.

12) Well Expansion 3 West. Doll's arm, solid bisque with string groove at elbow (Figure 3-1k). The hand has fingers and thumb molded together but is fairly well modeled. This arm is from a cheap variety of a China limb doll.

13) Well Expansion 3 West. Large doll's leg, hollow porcelain with string groove at knee (Figure 3-11). The foot is gone. From a China limb doll of a large and fairly expensive variety. Dates from 1870 to 1910 .

14) Well Expansion 3 West. Tiny, untinted porcelain shoulder head with the head missing (Figure 3-1m). The smallest "china limb" dolls appear to have been 7.5 inches long (Schroeder 1971:92; Stirn 1990:10); this could certainly have been no more than that. Such a little doll, of porcelain, would have cost about $\$ .33$ a dozen wholesale in 1893 (Stirn 1990:10).

15) Well Expansion 3 West. Solid bisque doll's leg (Figure 3-1n). A string groove and the mark "VIII" are near the top. The foot is broken off. This leg is not well made.

16) Well Expansion 3 West. Very small porcelain leg fragment with a string groove at the knee (Figure 3-10). The small size, similar material, and proximity suggest that this could be a part of the doll listed above (\#14).

Three non-diagnostic doll fragments were also found.

Eleven of the 12 doll dish fragments were found in the Well Expansion Trench associated with the midden found in the next lot, site 41BX897. They represent at least three different sets. The first set includes a small, solid, undecorated whiteware lid for a tea or coffee pot, with slight indication of some embossed design on the top (Figure 3-2f); and a small, undecorated whiteware cup with solid handle (Figure $3-2 h$ ). The second set is whiteware decorated with a blue decal pattern that has largely rubbed off. The pieces include 4 cup fragments with fancy double loop handles (Figure 3-2g); and 4 plate fragments, 2 of which are shown (Figure 3-2i). The third set is represented by a single undecorated porcelain cup fragment. The single piece not found in the Well Expansion Trench was at N13/E87: a porcelain cup fragment. We also found a small glass baby bottle, about six centimeters tall. A design embossed on the bottle includes an infant holding a bottle on one side and graduated markings on the other (Figure 3-2m).

The problem of differentiating between artifacts associated with the Webb/Deman complex and the $\mathrm{King} / \mathrm{Klar}$ residence in this site has been discussed extensively in Volume II. Suffice it to say here that it is no surprise to find parts from the same doll both here and on the Webb site, which is adjacent to the King site. The confusion in the ownership and use of the outbuildings is confirmed in the doll record as well as other ceramics (see Tennis, this volume). Not only are matching doll legs (\#9 and \#43, Figure 3-1h, i) found at each site, but one of the shoulder heads (\#46) found in the Well Expansion Trench, which is listed in the Webb site, was composed of fragments from both the Webb and King sites. We can be fairly sure that the dolls and toys found here did not belong to the Klar family, as they never had any children (U.S. Census 1900).

\section{Griesenbeck Site (41BX884)}

17) N13/W65. Tiny bisque arm broken just below the shoulder (Figure 3-1p). This is probably from a penny baby.

18) N80/W32. Small fragment of bisque doll represent area of forehead between the eyes. The bisque exhibits a pale pre-coloring.

Three doll dish fragments were recovered from Trench A, Feature A: a small whiteware cup with a solid handle (Figure 3-2k), a small porcelain cup with a flower and leaf decal, and a porcelain cup fragment.

There is nothing spectacular about either doll fragment. The pre-coloring in \#18 has a nice tint and 


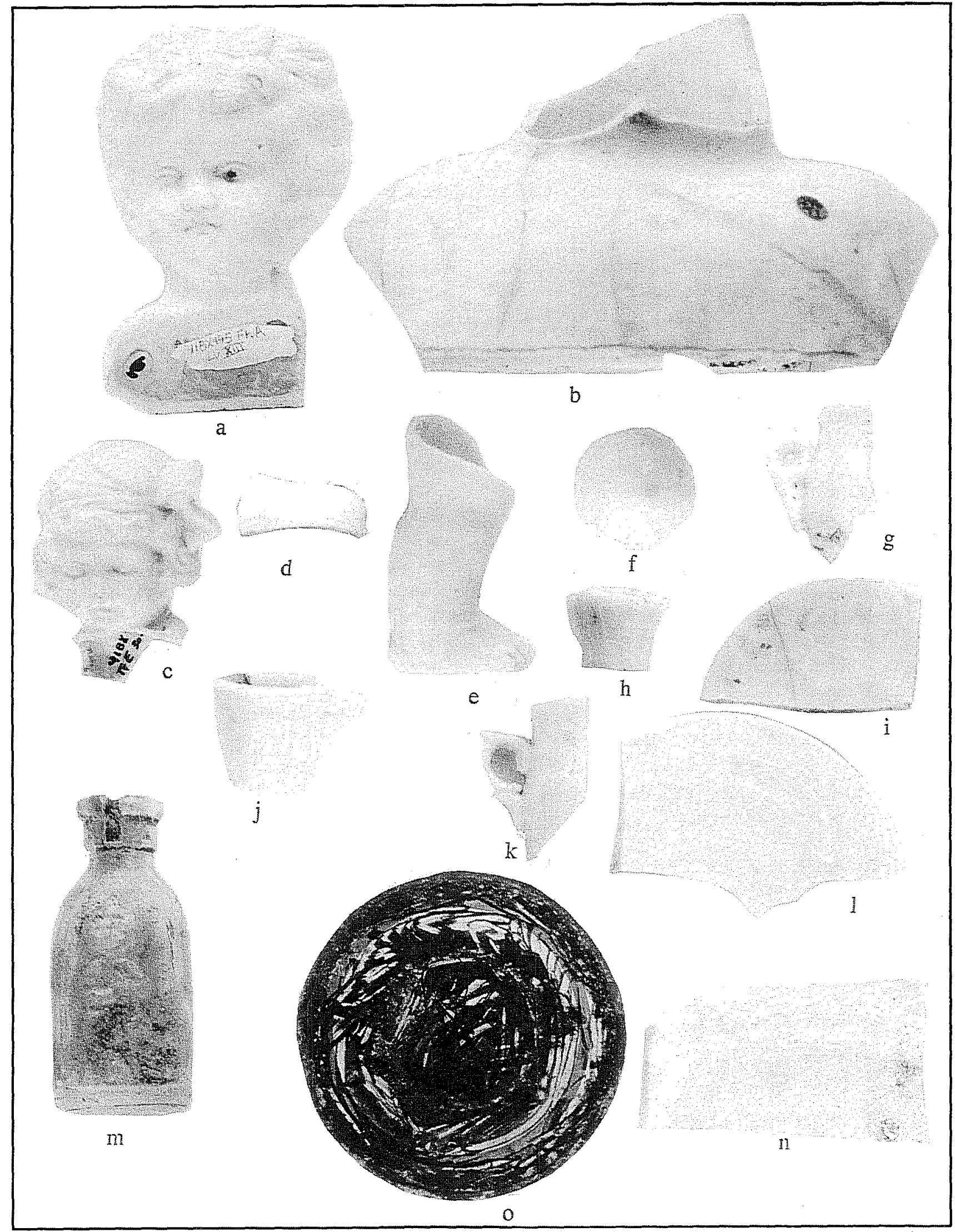

Figure 3-2. Ceramic doll fragments (a-e); ceramic doll dishes $(f-l, n) ;$ glass doll bottle $(m) ;$ and metal doll dish (o). See detailed descriptions in text. All shown actual size. 
the bisque is good quality, indicating that the doll was of fairly good quality.

\section{The Mendit/Maffi Site (41BX885)}

19) N9/W71. Two fragments of a pre-colored bisque doll. The pre-coloring is an intense and not very natural pink.

20) N13/W65. Back of small porcelain head and neck with slight molding for hair (Figure 3-1q). The hair is painted black on top of the glaze. This would have been a small stiff-necked doll.

Three doll dish fragments were found at this site. (1) N26/E39: whiteware cup fragment with ". . . 45" embossed on the bottom; (2) N13/W75: tea or coffee pot lid of undecorated whiteware; and (3) surface: large porcelain plate fragment (Figure 3-21).

\section{Biesenbach Site (41BX890)}

Only three dish fragments were found on this site. (1) Trench B, Feature A: a large porcelain cup with a fancy loop handle and a matching saucer (Figure 3-2k, 1) (2) Surface: porcelain plate fragment similar to the set represented by the other pieces.

\section{Horn Site (41BX891)}

21) $S 89 / W 116$, Level 2. A head from a parian-style porcelain doll with the remains of cheek and lip paint. The eye color is gone. The hair does not appear to have ever had coloring. The molding is not very detailed, but the hairstyle is suggestive of the 1880 s (Coleman 1986). This head is probably from a shoulder head. The poor molding and small size suggest that this was not an expensive doll (Figure 3-1r).

\section{Horn Site (41BX892)}

22) Trench A, Feature A. A fragment of a doll's head showing molded, curly hair painted black (Figure 3-1s).
23) Trench A, Extension 2, Feature A. Doll's leg of hollow bisque with glazed brown shoe with heel and glazed brown garter ribbon on calf. "China limb" dolls with identical legs are shown in the 1895 Butler Bros. catalog for $\$ .30$ to $\$ 3.30$ a dozen, depending on size and quality (Schroeder 1971:92) (Figure 3-1t). These two doll fragments could easily have come from the same doll.

\section{Rilling Site (41BX893)}

24) Trench A. Small doll's leg of solid bisque, probably from a penny doll (Figure 3-1u). A hole at the hip was for a wire-held joint. Rust stains are found around the hold, indicating that the wire was not brass; the poor finishing is also an indication for cheap quality. There is a slight indication in the mold for low shoes and a tiny amount of black coloring left. The flat sole suggests either a boy doll or a very early date (before 1870). In 1893 dolls made like this wholesaled for \$.33-\$.40 a dozen (Stirn 1990:10).

25) S29/E60. Fragment of bisque doll's arm with self shank for rubber or string held joint (Figure 3-1v). Broken at about the elbow.

Six non-diagnostic doll pieces were found on this site.

We also recovered a single metal doll dish with a lithographed picture of a long-haired blonde girl sweeping with a broom (Figure 3-20), all covered by a scribble of what appears to be marker pen. The use of lithography for designs on toys began in the $1870 \mathrm{~s}$ (White 1975:11). A 14-piece tea set of lithographed metal with saucers of exactly the same size as this piece sold for $\$ .45$ each in the 1930 Montgomery Ward Catalog (Schroeder 1971:240).

The flat sole and the general "old" appearance of the bisque on \#24 (Figure 3-1t) are strong indications of age. With \#9 and \#43, this leg is probably one of the oldest doll fragments. Since the Rilling site is one of the oldest sites in the Alamodome area, it is not surprising to find this doll here. 


\section{Czernecki Rental Site (41BX894)}

26) S18/E74. Fragment of a porcelain doll head, showing hair and eyes (Figure 3-1w). The eyes are painted blue with a black pupil. No other coloring remains.

27) Surface. Bisque leg with bent knee, done in infant style (Figure 3-1x). The large toe is raised, a characteristic of real infants shown on some dolls (Angione 1973:198). There is a self shank for string jointing. All-bisque dolls like this can be dated between about 1870 and the 1930s (Byfield 1986a:36), but this one is likely to date after World War I (see discussion).

Two doll dishes were recovered: (1) S59/E72: a large undecorated whiteware cup (Figure 3-3a); and (2) Surface: a large undecorated whiteware cup fragment.

Commercially made infant dolls like \#27 were fairly rare until after World War I, especially in the United States, where Victorianism lingered long after Victoria died in 1901 (Angione 1973:192). The reason for this seem to have been the fear that the presence of infant dolls might lead a child to ask where infants came from, and even talk of cabbage patches and storks was so embarrassing that parents preferred to avoid the topic if possible. Most infant dolls that did exist were tiny little creatures, only an inch or so tall, many of whom were sold sitting in little bathtubs (Angione 1973:193). The "babies" advertised in late-nineteenthcentury catalogs were almost exclusively "child" or "lady" dolls, not infants (Stirn 1990:10). Because so few infant dolls were made during the heyday of ceramic dolls, most existing infant dolls are made of composition material or celluloid (Remise and Fondin 1967:60), again, with the exception of the tiny "bathing" babies.

\section{Garza Store Site (41BX895)}

28) Surface. Plastic doll's arm with a broken hook at the shoulder for rubber-band stringing (Figure 3-1y). The molding is fairly good. This doll probably dates after World War II.

29) Under Garza Store. Back of porcelain doll head (Figure 3-1z). The molded hair is painted golden blonde.

\section{Demazieres Site (41BX896)}

30) S118/E143, Privy (\#5), Test (0-40 inches). Most of the face of a very well made bisque doll (Figure 34a). She has an open mouth with four teeth showing, and is well molded and beautifully painted. Eye holes suggest "sleep eyes." She is a large-sized version (probably 24-28 inches) of Simon \& Halbig's popular mold \#1079 (see Item \#5, site 41BX882). This would have been a very expensive doll, costing as much as $\$ 4.00$ or $\$ 5.00$ in 1895 (Schroeder 1971:94).

31) S118/E143, Privy (\#5), Test (0-40 inches). Bisque doll's leg with string groove at knee (Figure 3-4b). The shoe is molded, with a slight heel and the remains of some kind of glazing, although there is no tinting of any kind.

32) S118/E143, Privy \#5, Level 5. Bisque doll's leg with self loop at hip for a rubber or string joint (Figure $3-4 c)$. There is a painted black shoe with a heel and one strap and white ribbed stockings. The complexion coat on the upper leg is a pleasant pale pink. On the inside of the hip joint is the mark " $3 / 0$."

33) S118/E143, Level 6. Fragment of buttocks from an all-bisque doll (Figure 3-4d). Dating is impossible, but this doll would have been of good quality, as the bisque is good and the molding is excellent, if demure.

34) S118/E143, Level 8. A fragment of the base of a bisque shoulder head (Figure 3-4e). The quality of the bisque is excellent and the complexion coat is good.

35) S79/E124. Plastic doll's arm with a hook at shoulder for rubber band stringing (Figure 3-4f). The quality is poor. It is probably post World War II.

36) S87/E107. Fragment of a large bisque head. The complexion coat is pale but well done, and the bisque is of excellent quality.

37) S111/E119, Level 1. Pre-colored doll's arm of very poor quality bisque (Figure $3-4 \mathrm{~g}$ ). There is a self shank at the shoulder for rubber or string joining. The hand is poorly modeled with fingers and thumb barely discernable. Probably from a candy store doll, 1910-1935. 


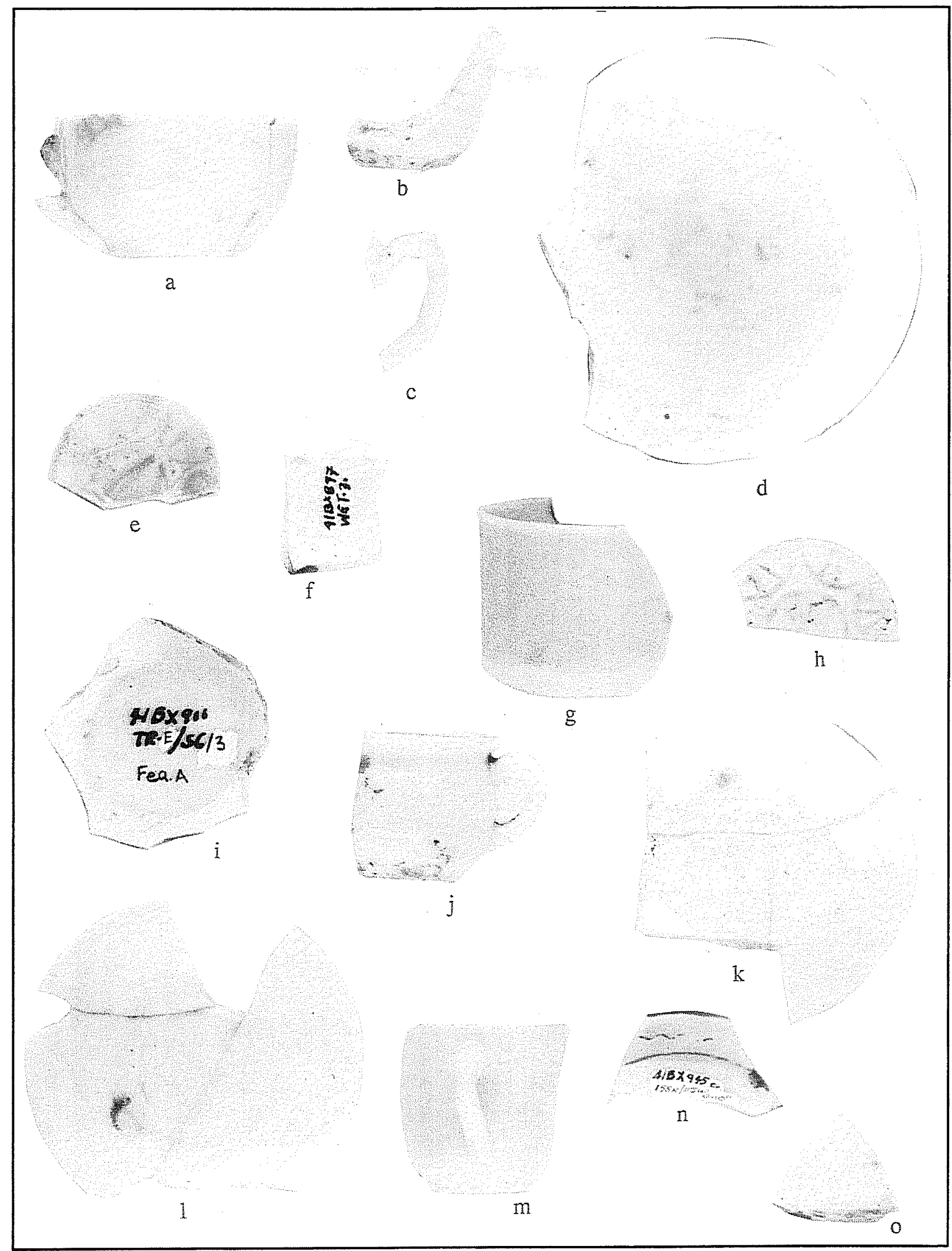

Figure 3-3. Ceramic doll dishes. See detailed descriptions in text. All shown actual size. 


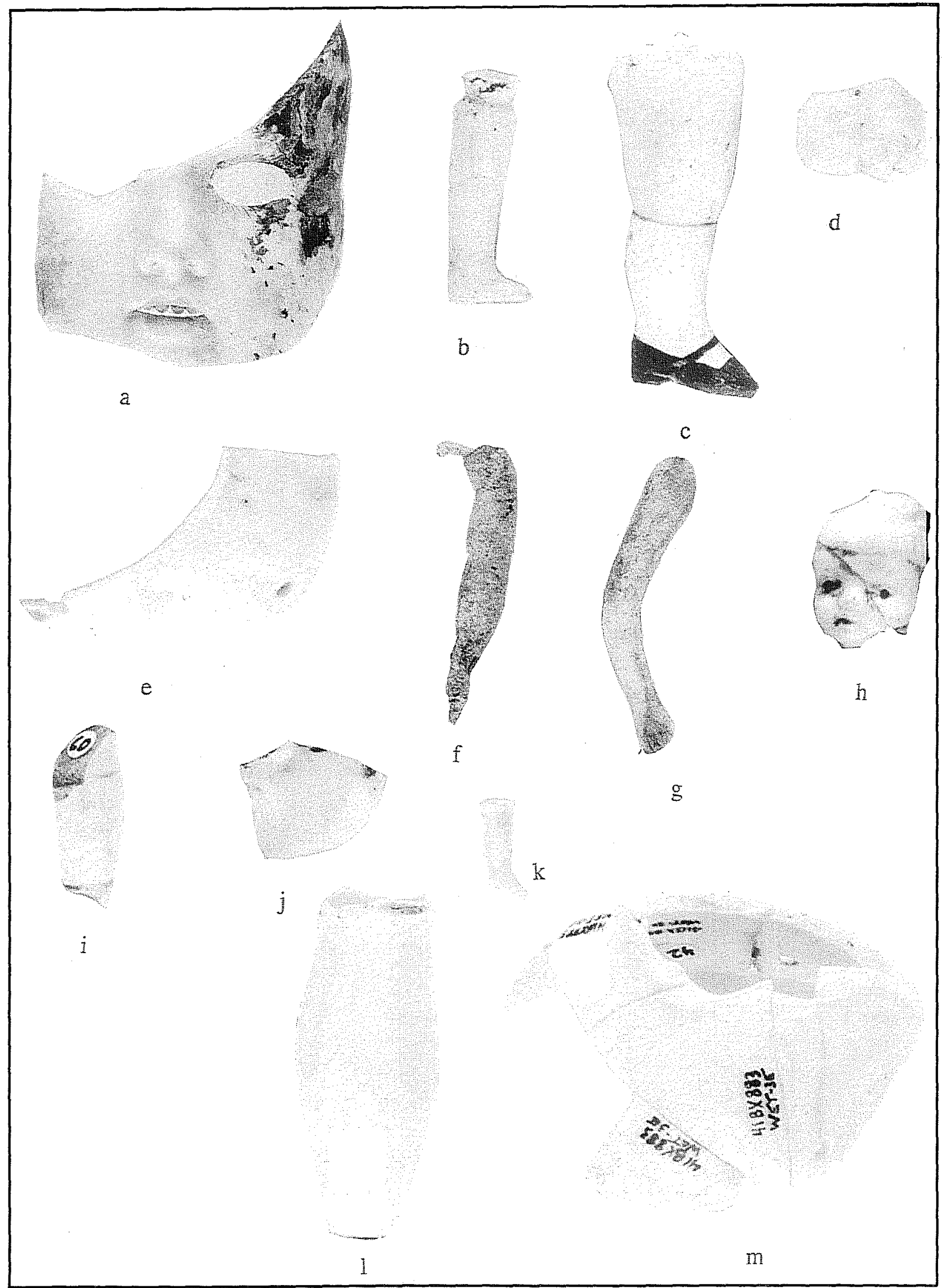

Figure 3-4. Ceramic doll fragments. See detailed descriptions in text. All shown actual size. 
38) $S 117 / E 123$. A small porcelain doll's face fragment of the Parian type (Figure 3-4h). The eyes and mouth are hand painted, but the hair was left white. The facial features suggest Japanese origins (Angione 1973:328-346). If that is the case, it probably dates to between World War I and World War II.

39) Rm. 3, Unit C1W. A fragment of a bisque doll's cheek. The bisque is excellent, with a good complexion coat and carefully hand-painted lower eye lashes. This was probably from a fairly expensive, if small, doll.

Six non-diagnostic doll pieces were found.

We recovered six doll dish fragments: (1) S118/E143 (Privy Test): a large undecorated whiteware cup fragment. (2) S107/E107: a large undecorated whiteware cup fragment; (3) wall of Trench D: a porcelain saucer of medium size with hand painted pink edges; (4) Trench E, Feature D: a fragment of a porcelain cup or bowl with a poor quality decal on it (Figure 3-3b;. (5) Trench I: a large porcelain cup handle (Figure 3-3c); and (6) a large whiteware plate with slight embossing and scalloping on the edge and the remnants of a flower decal on the face (Figure 3-3d). At least four separate sets are represented.

An unusually large number of doll parts was recovered from this site. The quality and probable dates of the dolls suggest that the fortunes of the inhabitants of the Demazieres house declined over time. We know that by World War II, the family that rented the house was quite poor; yet many of the older doll parts described above are of unusually good quality.

\section{Webb Site (41BX897)}

40) Well Expansion, 1 East. Solid porcelain doll's leg, broken at the top and bottom (Figure 3-4i). A little of the glazed yellow-brown boot color is left on the bottom, and the remains of a blue ribbon garter are seen on the calf. This leg is characteristic of a small but better-quality china limb doll.

41) Well Expansion, 1 West. Fragment of the shoulder of an untinted porcelain shoulder head (Figure 3-4j).
42) Well Expansion, 1 West. Porcelain hand, broken at the wrist, with no complexion coat. The fingers and thumb are molded in a straight, stiff position.

43) Well Expansion, 2 West. Small doll's leg, solid bisque, with string groove at knee (Figure 3-1i). The boot is painted black and has no heel. This is probably a match to \#9 listed in 41BX883. From a cheap china limb doll.

44) Tiny infant-style porcelain leg fragment, broken near the knee (Figure 3-4k). It is untinted porcelain and is less than an inch long. It is probably from a "bathing infant" (see discussion in Czernecki Rental site).

45) Well Expansion Trench 2 East. Large porcelain doll's calf, broken near the top of the boot, showing only a touch of black color there (Figure 3-41). The top is also broken, but shows remains of a string groove. This would have been a large and fairly expensive China limb doll, costing as much as $\$ 4.00$ a dozen in 1893 (Stirn 1990:10).

46) Well Expansion Trench 2 East. Part of a shoulder plate in seven pieces (Figure 3-4m). Made of untinted porcelain with sewing holes, this would have been a stiff-neck doll.

Twelve non-diagnostic doll fragments were found on this site.

We recovered nine fragments of doll dishes: (1) Well Expansion Trench 2 East: an embossed whiteware plate (Figure 3-3e), an unglazed whiteware bowl, and a milk glass cup rim; (2) Well Expansion Trench 2 West: an embossed porcelain plate (Figure 3-3f), and 2 pieces of unglazed whiteware; (3) Area A: an undecorated whiteware cup fragment; (4) Trench H, Extension E: 2 porcelain cup fragments, one with a thick pink band hand-painted around the lip.

The trash deposit uncovered in the Well Expansion Trench in both the Webb site and the King site had extensive evidence that the Webb and/or the Deman families had considerable economic resources. The Webbs, a fairly well-to-do African-American family, lived for several generations in an essentially white neighborhood. By combining the probable dates of these dolls with information from the 1870 and 1890 
censuses, we attempted to find out exactly who was playing with these particular dolls. In 1870 Margaret Webb was 19 and her sister, Charlotte, was 9 . Since most of these doll fragments probably arrived in San Antonio after the railroad came in 1877 , when Charlotte was 16 , these girls were probably too old to have played very much with these dolls. Charlotte Webb married and continued to live on the south half of the lot, but as of 1900 , she had only four sons and no daughters (U.S. Census). Who owned the dolls? We know that after Ben Deman re-purchased the northern half of Lot 7, the old William Webb house was rented out. Unfortunately, identifying any particular children living there is difficult, and in any case, many of these dolls were quite expensive. How could a black family renting a home afford such luxuries? It is possible that many of these dolls were owned by the Webb daughters, kept more as decorations or keepsakes than dolls to play with. Or perhaps other children lived on the site between census years. Whoever it was played with a number of china limb dolls, some unusually large and fine, and had several dish sets. All these dolls were white; although black dolls were available even in these early days of industrial toymaking, white, not black, children played with them (Collier 1988:348).

\section{Gordon Site (41BX900)}

47) Trench C, S9. Top of porcelain doll's leg. A string groove and horizontal ribbing are present. The leg would have been of medium size.

48) Trench D, S2. Fragment of a doll shoulder with molded necklace decorated with gilding (Figure 3-5a). This item is made of fine, thin porcelain, and would have come from one of the fancier types of shoulder head dolls, probably a china limb type. The Butler Brothers catalog of 1895 describes such a doll, with fancy print fabric as well a gold trimming, as "Our Own." They range in size from 7.5 to 19.75 inches and in price from $\$ .42$ to $\$ 3.20$ a dozen (Schroeder 1971:92).

49) Trench E, S4. Part of a very small, untinted, porcelain shoulder head doll. This doll was probably in the 7- to 9-inch size range.
50) Trench E, Feature A. Bottom of shoulder plate with sewing holes, in untinted porcelain. This doll could have been either a shoulder head or a socket head. The sewing holes indicate it was intended to go on a soft-bodied doll. By World War I, china limb dolls and replacement porcelain heads like this were no longer commonly sold because celluloid and composition took over the cheaper end of doll making (Schroeder 1971). Dating could be anywhere from ca. 1870 to 1910.

51) Trench E, Feature A. Fragment of bisque shoulder with edge for socket head. A little of the complexion coat remains. Too little of this doll is left to identify type or date, but we can say that turning-head dolls were more expensive than stiff-necked (Schroeder 1971:44).

52) Trench E, Feature A. Doll's arm of untinted bisque (Figure 3-5b). A string groove is seen at the elbow. The hand is molded in such a way that it could be used as either a right or left hand, an economy measure for china limb dolls.

53) Trench E, Feature A. A hollow bisque leg with molded horizontal ribbing, a glazed brown shoe with heel, and a string groove at the top (Figure 3-5c). The mold line was removed without care for the ribbing. China limb dolls with similar legs were being sold for about $\$ .80$ a dozen in 1895 (Schroeder 1971:92).

The doll parts listed above indicate a date prior to World War I for the trash pits with which they are associated.

Four non-diagnostic doll pieces were found.

Three recovered doll dishes include: Surface: one large porcelain cup fragment with the remains of a decal; Trench D: a small plate with a deeply embossed sun pattern (Figure 3-3h); and Feature A-an undecorated whiteware doll dish (Figure 3-3i).

\section{Doering Site (41BX926)}

54) Privy \#6. Fragment of bisque head with molded ear (Figure 3-5d). The bisque is untinted and of excellent quality. There is no sign of hair molding, so 


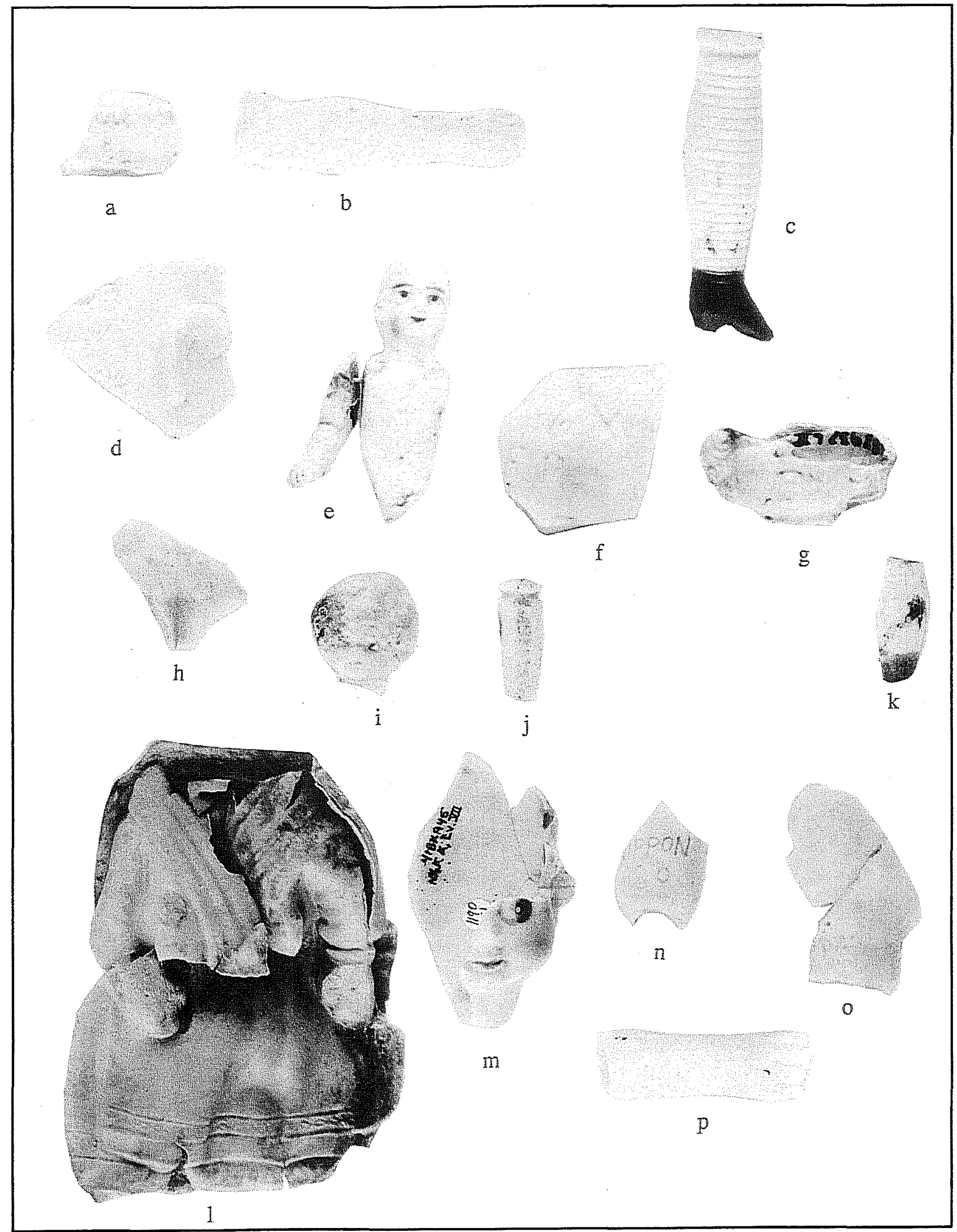

Figure 3-5. Doll fragments. 3-31 is made of cellulose; all others are ceramic. See detailed descriptions in text. All shown actual size. 
the doll was probably wigged. The doll would have been fairly large (ca. 28 inches).

Privy \#6 was monitored during its destruction in the excavation of the footing hole for the Alamodome. Monitors were only able to pick up a few samples of the artifacts seen in this privy (see Brown and DeLaO, this volume)

\section{Schulze Site (41BX927)}

55) Privy \#7. Small bisque doll missing one arm and both legs (Figure 3-5e). No complexion coat is present. Blue eyes, light brown eyebrows, red mouth and pink cheeks are painted on. The head is bald, but would have had a glued-on wig. There is an " $O$ " mark on the back. It has holes for wire jointing at the shoulders and hips, but no rust staining, implying that brass wire was used. This and the quality of the molding and painting indicate an above-average-quality doll. The arm is no longer attached to the body. It is slightly bent and the hand is in a fist, which is common in smaller dolls. Dating of this doll is difficult, because dolls this size and construction were made for 60 or 70 years, beginning at the end of the Civil War.

One doll dish was found: Monitored Privy: fine, medium sized, porcelain cup with gilt edging (Figure 3-3j).

Privy \#7 was also monitored during its destruction, as described above for Privy \#6.

\section{Eckenroth Site (41BX928)}

56) Privy \#8. Doll fragment of white bisque (Figure 35h). Appears to be the back of head, near rim where a wig would once have been glued. It is marked " $6 \mathrm{X}$ " above ". . . EP." "DEP" is both a German and French abbreviation for "registered" (Collier 1988:408). The specific mark was not identified.

A fragment of a bisque doll was also found in Privy \#8. The piece has a light pink complexion coat.

Seventeen doll dish fragments were recovered from this monitored privy, representing at least two different sets. The first set consists of three large porcelain plates, a porcelain cup fragment, and three similar fragments (Figure 3-3k, 1). The second set consists of 10 small, undecorated whiteware fragments.

Privy \#8 was a third monitored privy, similar to \#7 and $\# 6$ above. This was one of the largest number of doll dish fragments found in a single area, and when one considers the limited sampling of privy artifacts possible while bulldozers are digging, it suggests that there were actually even more doll dish fragments. See Brown and $\mathrm{DeLaO}$, this volume, for a discussion of privy contents.

\section{Petit Site (41BX931)}

Only a single porcelain cup fragment was found on the surface on this site (Figure 3-3m).

\section{Burleson Site (41BX936)}

A single opaque blue glass doll saucer fragment was recovered from this site.

\section{Gilbert Site (41BX937)}

57) Surface. Lower half of bisque doll's head. It has well-molded, fat cheeks; curly hair; and molded eyes (Figure 3-5g). No sign of tint is present. The quality, size, and workmanship of this doll suggest that \#58 may be part of the same doll.

58) N99/W140. Fragment of buttocks and upper legs from an all-bisque doll (Figure 3-5h). The molding is well done and the bisque of good quality, although untinted. This is probably from a frozen Charlotte, but the arms may have been jointed (Angione 1973:79-104). This appears to be a good quality doll and may be part of $\# 57$.

\section{Conrad Site (41BX938)}

59) Trench B, S6. Fragment of molded hair made of untinted bisque.

A single undecorated whiteware doll dish fragment was recovered on the site. 


\section{Houston Site (41BX942)}

In Trench D, S13, was a single undecorated whiteware doll plate of medium size.

\section{Pauly Site (41BX945)}

60) Pauly House Foundation. Very thin, hollow bisque head, probably of a frozen Charlotte or other penny doll (Figure 3-5i). The molding is poor, being barely discernable in some places. No complexion coat is seen. Blue eyes are painted looking sideways, and the lips have a touch of color. The hair style is too poorly molded to reveal much, but the side-looking eyes is a trait much more common after the turn of the century (Byfield 1986b).

61) Privy \#13, N1/2, Level 2. Upper arm, broken about halfway, of a small bisque doll (Figure 3-5j). The piece has a string groove at the elbow. No complexion coat is present, and the piece is poorly finished and, in general, appears to be very cheaply made. From a china limb doll.

62) Privy \#13, N1/2, Level 2. Fragment of doll face of painted porcelain, in the Parian style (Figure 3-5k). Black hair, blue eyes, and black eyebrow are painted on. The hairstyle is suggestive of the 1880s (Prichett and Pastron 1983:327).

63) Privy \#13, N1/2, Level 3. Doll's leg of bisque, broken at the top and bottom (Figure 3-51). Signs of a string groove are seen at the top, and a small amount of glazed yellow-brown color represents the top of the boot.

64) Privy \#13, N1/2, Level 3. Celluloid doll body and a few fragments of the face (Figure 3-51). The molding is minimal, with arms and hands molded to the body. The back is labeled with a cross inside a circle, and the word "Japan." This would have been a cheap little doll. Dolls much like it sold for about $\$ 2.00$ a dozen in 1914 (Schroeder 1971:162), but this doll was probably imported somewhat later, as Japan used the word "Nippon" on its exports before, during, and immediately after World War I (although the exact date of the change is unknown [Angione 1973:328]).
65) Privy \#13, N1/2, Levels. 7 and 10. About half of a small socket head, made of bisque and a wearing bluepainted, molded cap with a tassel over left ear (Figure 3-5m). The eyes are looking sideways in the "goo goo" fashion. The color of the painting is rather harsh, and the molding is of mediocre quality. Partial mark at base of neck is a "6" over the letters "NIPP. . ., " which is the word "Nippon," meaning Japan. The Japanese firm Morimura Brothers exported hundreds of thousands of cheap little copies of popular German and American Kewpies and Goo-Goo dolls much like this between the World Wars (Collier 1988:47-48). This would be from early in that period, because the Japanese started using the word "Japan" instead of "Nippon" in their later dolls (Angione 1973:328).

66) Privy \#13, N1/2, Level 10. Fragment of the neck of a socket head of untinted bisque (Figure 3-5n). It is marked ". . . IPPON/80," which suggests it is from a Japanese doll made during or shortly after the first World War (Angione 1973:328).

67) Privy \#13, N1/2, Level 10. Small fragment of the neck of a bisque socket head (Figure 3-5o). Marked ". . . 11/0 M" and ". . . ermany." Though incomplete, this mark reveals the doll was manufactured by Armand Marseilles, a large German company, and was probably a "Goo-goo" type doll dated between 1900 and 1910 (Angione 1975:140).

68) Privy \#13, S1/2, Level 13. Lower arm of good quality bisque (Figure 3-5p). The fingers are molded with separate tips and separate thumb, and are well marked, including joint folds and fingernails. The elbow does not have a string ridge, so it was probably glued to a composition or celluloid body. Marked with an "O" near the base.

69) Privy \#13, S1/2, Level 13. Bisque shoulder head of the "Parian" style, with blue eyes and black pupils, pink color above the eyes, and painted mouth and cheeks (Figure 3-2a). There is only a trace of golden blonde color left in the hair. The hair parted in the middle with curls around the face is a style indicative of the late- nineteenth century (Prichell and Pastron 1983:327), although this style was still being made into the 1930s (Coleman 1986:25-28). However, "Lady" heads which appear almost identical to this item were used on "corset-bodied" dolls patented in 1885 
(Coleman 1975:6). These dolls had cloth bodies printed to look like a lady's corset. The lower arms and legs were leather (Coleman 1975:5). The 1889 Montgomery Ward catalog sold them for $\$ .25$ each (Schroeder 1971:37).

70) N1/2, Levels 12 and 13 . Fragments of very large shoulder head with head missing (Figure 3-2b). Excellent quality bisque with good complexion coat. Marked "Alma/0" and "Germany" on back (Figure 3-6). This head was made by Armand Marseille, and was sold in the United States by George Borgfeldt and Co. Alma dates from 1900 (Bach 1985:17, 86). This is a large doll, with a neck circumference of about six inches. She

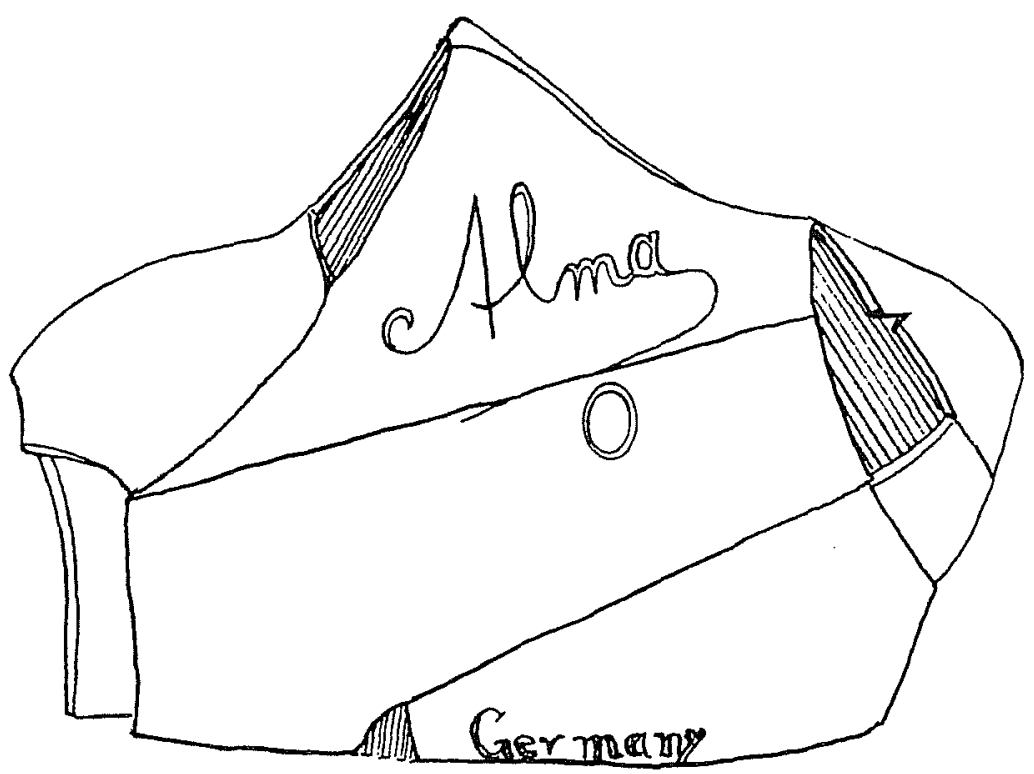
must have been at least 28 inches long, and may have cost as much as $\$ 5.00$ (Schroeder 1971:124.

71) Trench $E$, S4. Hollow bisque head of a young girl, in the Parian style, with molded bobbed hair and bow (Figure 3-2c). This could easily be from a figurine rather than a doll, as there is no sign that it was ever painted. The bobbed hair suggests a post-1920 date for the doll.

72) Trench E, S3. Pre-colored bisque fragment with part of a stamped maker's mark: "Japa . . .."

73) Feature E, NE Q, Level 5. Fragment of a bisque cheek (Figure 3-2d). The bisque and complexion coat are of excellent quality. Nicely handpainted lower lashes are seen at edge of eye hole. This would have been a medium-sized doll of excellent quality.

74) Feature E, NE Q., Level 17. Large toddler-style untinted bisque leg fragment, broken at the knee (Figure 3-2e). The foot is bare and is made to stand.

Six non-diagnostic doll fragments were found.

Twenty-two pieces of doll dish fragments were recovered. (1) N1/2 Pauly Privy, Level 1: a hand-

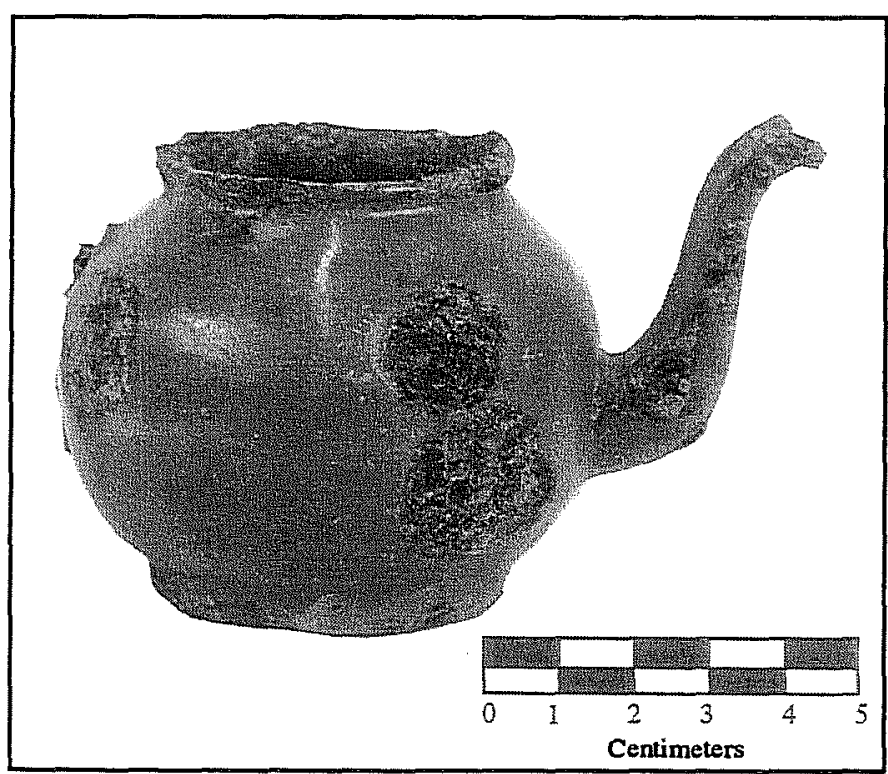

Figure 3-7. Enameled metal teapot from toy set. See detailed description in text. 
whiteware pitcher with loop handle (Figure 3-8a); (5) $S^{1 / 2}$, Level 3: 4 undecorated whiteware dish fragments; (6) $\mathrm{N} 1 / 2$ Level 4 : a large, undecorated whiteware lid for a coffee or tea pot (Figure 3-8b); (7) S1/2, Level 4: a small, embossed whiteware plate fragment; (8) $\mathrm{N}^{1 / 2}$, Level 7: an undecorated whiteware lid fragment (Figure 3-3o) and a large porcelain pitcher fragment (Figure 3-8c); (9) N1/2, Level 12: an undecorated whiteware plate fragment; (10) $S^{1 / 2}$, Level 14: a brown-glazed miniature stoneware jug, probably intended for a doll's house (Figure 3-8d); (11) Shovel Test \#33: a medium-sized porcelain teapot fragment; (12) Drain west of cistern (Feature E): a porcelain plate fragment; and (13) Feature E, NE Quad, Level 6: a large porcelain cup (Figure 3-8e).

Clearly the children who played with the toys left in the Pauly Privy were doing so between about 1890 and about 1930 . The dolls found near the top of the privy are from the $1920 \mathrm{~s}$, as are the other dateable artifacts in these upper layers (see Brown and $\mathrm{DeLaO}$, this volume).

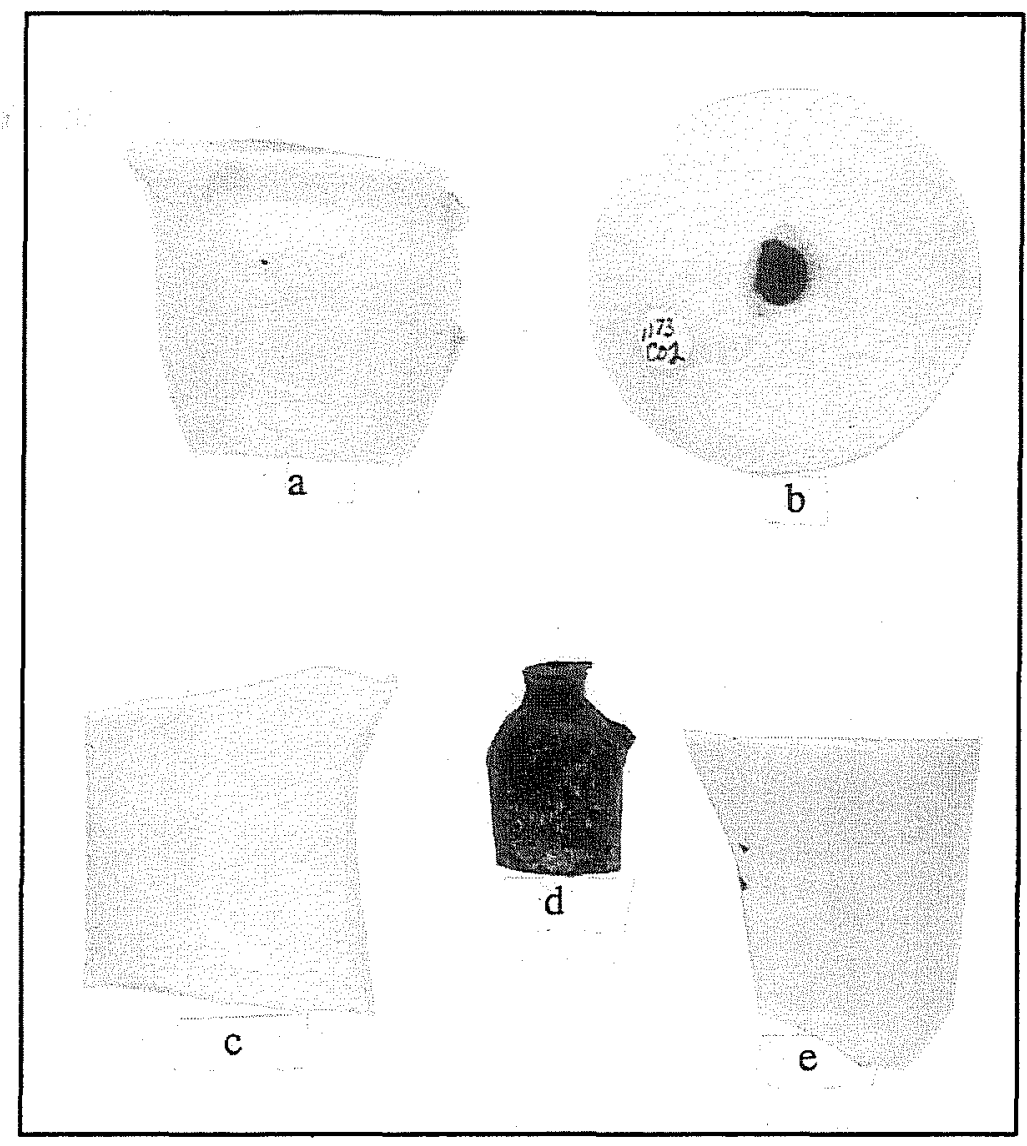

Figure 3-8. Ceramic doll dishes.
The doll parts from the lower areas are older. The supposition that Japanese dolls marked "Japan" are more recent than those marked "Nippon" (Angione 1973:328) is confirmed in the stratification in the Pauly Privy.

The Pauly Privy was probably last cleaned out around the turn of the century. The "Alma" doll in Levels 12 and 13 has a fairly concise manufacturing date of 1901 (see \#69, above). In the 1900 U.S. Census, the William Mueller family, living in the Pauly house, had three children: a son, Willie, age 4, and two daughters, Helene, age 2, and Nellie, age 4 months (in June). Most of the toys found in the lower levels of the Pauly privy probably belonged to these children.

\section{Other Toys}

Ninety-eight items representing other kinds of toys were found during the Alamodome Project. Of these, 38 were made of plastic. The word plastic has numerous meanings, but in this report it refers to the more modern types of petroleum-based long-chain polymers. These types of plastics were invented in the 1930s and began to take over the toy manufacturing industry shortly after World War II (Harpur 1982:67). Now almost all cheap toys and most other toys are made from these materials.

For this report, extensive use of toy catalogs is made to provide information about the availability, style, and price of toys. These include retail catalogs from Sears, Roebuck \& Co. for the years 1897 (Israel 1968), 1902 (Sears, Roebuck and Co. 1969), and 1927 (Mirken 1970); and a Montgomery Ward catalog from 1895 (Montgomery Ward and Company 1969). The catalog of a wholesale firm, Carl P. Stirn, for 1893 (Stirn 1990) is also used. In addition, portions of catalogs from numerous wholesale and retail firms reprinted in The Wonderful World of Toys, Games, \& Dolls: 1860-1930 (Schroeder 1971) are used extensively. 


\section{Oeffinger Site (41BX881)}

Trench A. A small, black plastic molded item. It appears to be the club-like tail of an anklosaur-type dinosaur. It is marked "Japan."

\section{Haas Site (41BX882)}

N50/E88 A metal submarine, $10.5 \mathrm{~cm}$ long, made without the lower part and set with wheels so that it will roll easily on a hard surface while looking partially submerged (Figure 3-9a). The shape is reminiscent of a World War II boat. Marked on the underside "TootsiToy[trademark]/Made in America/O . . alls." A TootsieToy wholesale catalog from 1925 (Schroeder 1971:233-239) shows a wide variety of toys, both simple and elaborate, including doll houses made of cardboard; doll furniture; water pistols; metal animals on wheeled platforms; and many kinds of cars, trucks, and airplanes. This particular toy is not listed, but since it seems to be post-World War II vintage, this is not surprising.

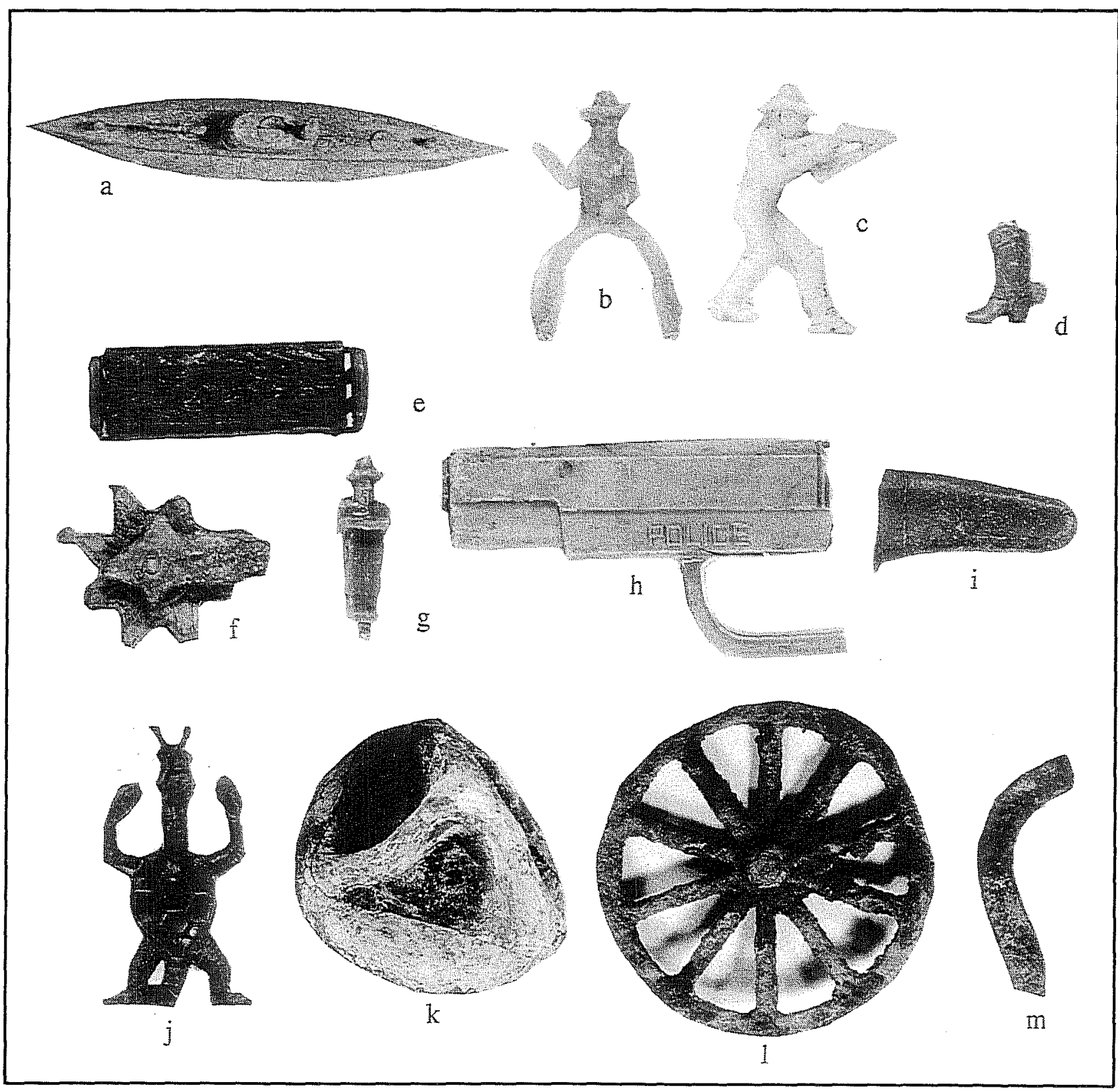

Figure 3-9. Assorted toys. b-e, g-j: plastic; k: rubber; a, 1, m: metal. All shown actual size. 


\section{King Site (41BX883)}

Test Trench D, Structure B. Small (2.2 by $1.4 \mathrm{~cm}$ ) yellow plastic window frame from a LEGO building block set.

Test Trench D, Structure B. A pink plastic ring fragment with a flat face, unmarked except for a fracture mark where something has broken off. This ring is much like those available in gumball machines since at least the 1950 s.

Test Trench D, Structure B. A small pink and white plastic whistle about $2.5 \mathrm{~cm}$ long. A star design is seen on the barrel and remnants of a self loop for a lanyard are present.

\section{Griesenbeck Site (41BX884)}

N80/W32. A fragment of a metal horse leg. Similar legs appeared on many toys in the latter-nineteenth and early twentieth centuries. Horse-drawn wagons, including fire wagons, express wagons, and numerous other vehicles, were modeled in metal. The horse or horses were set on a wheel so that the whole toy could be pulled or pushed across the floor (see Stirn 1990 for excellent drawings of examples).

N80/W42. A red plastic cowboy, about $5.4 \mathrm{~cm}$ tall, molded to sit on a horse (Figure 3-9b). One of his hands is positioned to hold the reins, the other is raised. This is a poorly molded, very poor-quality toy. A virtually identical toy was part of a "Lone Ranger Target Pistol and Targets" television premium made after 1957 (Tumbusch 1991:103).

N80/W42. A yellow plastic cowboy, $5.4 \mathrm{~cm}$ tall (Figure 3-9c). The quality of this piece is much better than the other found in the same unit. This figure is standing and aiming a rifle. The detail in the molding is better, the finishing much better.

N80/W42. A play money dime made from metal. Marked "Play Money" on one side and "10" on the other.

N80/W42. A maroon plastic "Dopey" charm (Figure 3-10a). This artifact may date as early as 1937 , when the Disney movie Snow White debuted (Wolf and Wolf
1979:170). During the late 1930s Disney characters dominated the category of "cartoon and movie character rights" (Merken 1984:155) However, it is likely to be from a much later time, as the plastic is translucent and quite modern in appearance. This is the sort of toy found in gumball machines.

N80/W42. A cowboy boot charm made of translucent brown plastic coated with a metallic copper color that has rubbed off in places (Figure 3-9d). The molding is fairly detailed, with fancy work on the boot uppers, and a spur. The remains of a self loop are seen at the top. The boot is two centimeters tall. This is also most likely from a gumball machine.

Trench A, Feature A. A tiny, fragment of a blue plastic cowboy, measuring only $1.5 \mathrm{~cm}$ (Figure 310b). The head and lower legs are missing, although the position of the legs suggests the cowboy is riding a horse. The plastic is an intense, almost dayglo blue, and the molding is quite good for such a small toy, both indicating recent manufacture.

\section{Czernecki Site (41BX893)}

Trench A. Dark brown plastic base for unknown toy item, perhaps a tree or other large plant. The top is molded to look like ground with grass on it.

Trench A. Dark brown plastic bench molded to look like wood (Figure 3-9e). The legs are missing. It looks as if it belongs with a doll house or similar set. This piece and the one above are made of plastic identical in texture and color, and are probably from the same set. This would have been fairly cheaply made.

Test I. Metal lever from a lever-action toy rifle, decorated with an embossed pattern including a swirl pattern and three stars. Total length is $22.5 \mathrm{~cm}$.

Test I. Fragment of a metal spur (Figure 3-9f). The spur, about four centimeters in diameter, is unusually well made for a toy. The wheel of the spur is set between two spokes which are broken off just above the wheel.

S126/E33. A metal jingle bell, $1.7 \mathrm{~cm}$ in diameter. These bells are made by bending thin leaves of metal into a circle, enclosing a small, loose, metal weight 


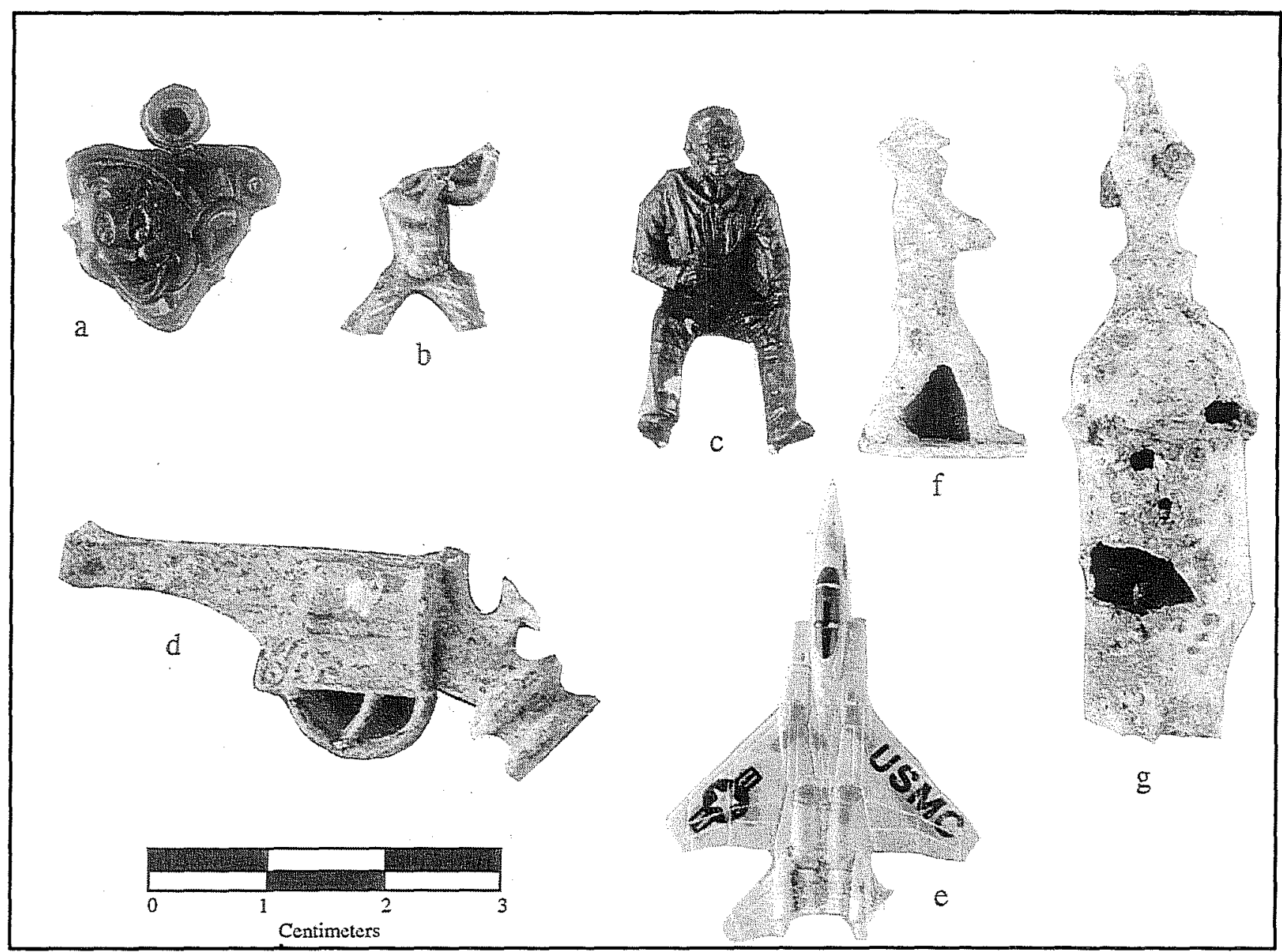

Figure 3-10. Assorted toys. a-c, e: plastic; d, f, g: metal. See detailed description in text.

which acts as a ringer. Bells like this, not uncommon in even the earliest toy catalogs, were usually found on sets of toy reins. These toys were intended to allow a child to be harnessed and driven like a horse, and were always decorated with bells. They were still so popular in 1912 the Sears, Roebuck Catalog offered four sets, ranging in price from $\$ .10$ to $\$ .39$ each (Schroeder 1971:137).

S150/E34. Dark brown plastic horse leg, with details molded only on the outside. A touch of blue paint, which may have been a factory error, is seen.

S150/E34. Blue plastic fireman (Figure 3-9g). Only minimal detail is included in the molding. There is a peg on the bottom of the feet meant to fit into a hole on a fire truck.

S152/E23 and S150/E23. Two pieces of a barrel and part of the trigger guard of a red plastic automatic pistol (Figure 3-9h). The word "Police" is embossed on the trigger guard. All pieces are sun bleached.

S177/E37. Small brown plastic worm or snake.

A distinct preference for cowboy toys of various kinds is seen on this site.

\section{Czernecki Rental Site (41BX894)}

Surface. Metal airplane wing painted red (Figure 3-9i). Slight marks in the mold represent flaps and rivets, but no engines, so it is probably a single-engine plane. The wing shape suggests a fighter from ca. World War II, but the piece could, of course, be from any time after that.

Surface. Black plastic alien (Figure 3-9j). This appears to be a cross between a biped turtle and a crayfish. It 
is six centimeters high. Alien creatures composed of miscellaneous bits of known animals are seen in some radio premiums as early as 1949 (Tumbusch 1991:37), but the type of plastic suggests a more modern toy.

Surface. Dark green plastic seated aircraft pilot (Figure 3-10c). The helmet style suggests the plane was World War II. The pilot was intended to fit into such a plane. He is two centimeters tall from seat to head. The detail in the molding is fairly good.

S18/E74. Half of black plastic wheel about $1.5 \mathrm{~cm}$ in diameter.

S18/E74. Four pieces of a light blue plastic caboose with molded stationary wheels. It is about one centimeter high and $3.5 \mathrm{~cm}$ long. This is a very cheaply made toy, but the molding exhibits considerable detail, suggesting a recent date.

S144/E56. Small head from a toy shovel. The flat blade is $11.5 \mathrm{~cm}$ long and $9 \mathrm{~cm}$ wide.

Feature A. Fragment of an orange wax crayon.

\section{Garza Store Site (41BX895)}

Surface. A grey plastic play money dime (Figure 311). It has "Uncle Sam/1950/Play Dime" in a circle around a " 10 " with a small "w" above it. On the other side is "Play Money/Falsa Pecunia."

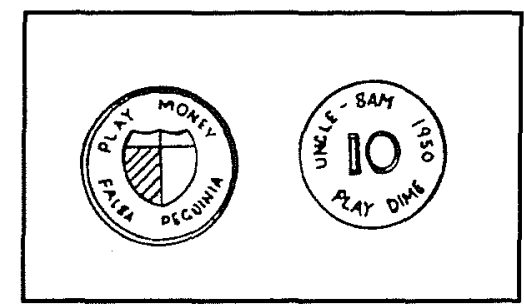

Figure 3-11. Plastic play dime.

Shown actual size.

Surface. Half of a wooden yoyo with a cotton string fragment. It is $5.5 \mathrm{~cm}$ in diameter and is painted red. There are no yoyos represented in available toy catalogs between 1878 and 1930 .

Trench A, S2: A pink rubber ball about six centimeters in diameter (Figure 3-9k). White points out that "two and a half inches in diameter is a convenient size for a ball when held in the hand and most tossing balls, whether of plaited rushes, leather or wood, are about this size" (White 1975:23). In this case the ball is made of rubber. Balls of this size and material have been available since at least 1893 , when they sold wholesale for $\$ .75$ a dozen (Stirn 1990:66).

\section{Demazieres Site (41BX896)}

S79/E107. A large iron wagon wheel for a toy wagon (Figure 3-91). It is seven centimeters in diameter.

S83/E87. A small plastic toy car wheel, one centimeter in diameter.

S104/E69. Small toy wheel. with axle, made of metal and rubber. The wheel is one centimeter in diameter.

S107/E107. A small metal pin in the shape of an airplane propeller with a man's face in the center (Figure 3-12). It is marked "Capt. Hawks/Sky Patrol." This is a cereal box premium from Post. Captain Frank Hawks was a real aviator who endorsed Post cereals until shortly before his death in a plane crash in 1938 (Tumbusch 1991:29).

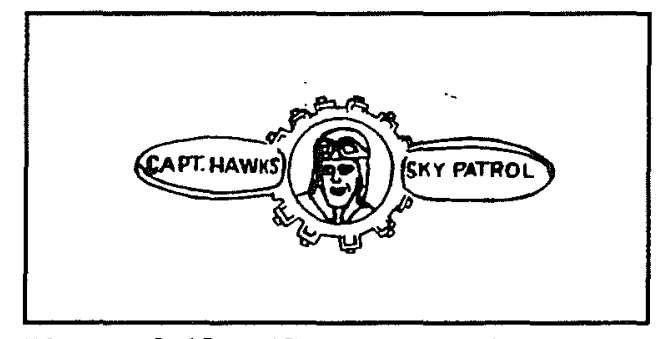

Figure 3-12. "Captain Hawks" cereal premium pre-dating 1938. Shown actual size.

S111/E111. A small (2.5 cm diameter) black plastic wheel.

S111/E119. A fragment of a horseshoe magnet painted red and yellow (Figure 3-9m). The advertisement for a similar magnet in a toy catalog from 1875 states that "every boy and girl, we think, would be pleased to become the owner of this beautiful Magnet" (Schroeder 1971:19), and such magnets were an item in many later catalogs (see Stirn 1990:29 and Schroeder 1971:32, 163). 
S118/E143, Privy Test. A red solid rubber ball about $3.5 \mathrm{~cm}$ in diameter (Figure 3-13a). Balls like this sold for $\$ .25$ a dozen in 1893 (Stirn 1990:66).

S118/E143. A small jingle bell, $1.5 \mathrm{~cm}$ in diameter, with wire loop for attachment.

Trench D. A fragment of a small metal wheel with spokes.

Trench E. A small, blue plastic car, $4.7 \mathrm{~cm}$ long.

Shovel Test \#6. An old plastic jet plane/rocket ship (Figure 3-14a). The plastic was a pinkish color, but was covered with black paint. A hole in the underside suggests that this was intended to attach to something. A very similar, though not identical, vehicle appears in Tumbusch (1991:142) as the removable top of a ring which was a radio premium from 1948. This item may have come from a similar ring, but the style of the plane suggests it may be a "rocket-plane"-type spaceship from the 1930s. By the late 1940s spaceships had lost their wings (see Tumbusch 1991:132).

Shovel Test \#17. A plastic car engine replica, possibly from a scale model kit (Figure 3-14b). It has been handpainted by an amateur hand with silver, red, and yellow enamel. The modeling is not very detailed. It is $5.5 \mathrm{~cm}$ long.

Shovel Test \#25. A black plastic wheel for a toy truck or car. It is $2.7 \mathrm{~cm}$ in diameter and has fairly good detail in the molding.

Surface, Room 2. A set of small green plastic wheels joined by an axle. This toy part is $3.8 \mathrm{~cm}$ long and would have been part of a cheaply made wheeled vehicle.

\section{Webb Site (41BX897)}

Trench H. Black solid rubber wheel fragment about $7.5 \mathrm{~cm}$ in diameter.

Trench H-Ext. A small brass bell (Figure 3-14c). Though this may not be from a toy at all, it is likely to be the sounder for a "chime" or "bell" toy. Most of these toys were meant to be pulled or pushed along the floor. They were designed in one of two basic ways.
In one, the bell or chime was attached between two wheels and had a heavy ball inside. As the wheel and chime rotated, the ball would fall against the inside of the chime, making it ring. The other method was to mount the bell either vertically or horizontally on a platform and attach some sort of striker to a mechanism on the wheel that caused the striker to hit the bell rhythmically as the wheels turned. The shape of this bell suggests the latter method. Toys like this seem to have been quite popular in the late nineteenth and early twentieth century. Stirn's 1893 catalog has at least 25 varieties (see Stirn 1990:45-46, 57-58). Though toys of this type are still sold today, later catalogs do not show so many types (Schroeder 1971).

Well Expansion. A copper-alloy bell (Figure 3-13b). This bell also appears to be from a "chime" pull toy, though it is also possible that this is from a bicycle bell or a "call" bell, as the shape is similar for all these varieties of bells (Stirn 1990:58).

The Webb site provides us with evidence that many toys are not available for study in the archaeological record. There were at least six boys who grew up on the site during its occupation. The 1870 census shows William Webb's son Willis, aged 5, and another small boy, named Seth Jones, aged 3, living with the Nancy Webb family (U.S. Census 1870). In addition, after Charlotte Webb grew up, she married Ben Deman and they continued to live on the Webb lot (City Directory 1881-82). In 1900, the Demans had four sons, John, aged 18, Charles, aged 16, Frank, aged 14, and Harry, aged 11 (U.S. Census 1900). Only two girls can be definitely identified as living on this site, yet there are very few items that can be clearly identified as "boys' toys." It seems likely that these boys played mostly with toys either perishable or not identifiable as toys in the archaeological record. The exception to this is marbles. Twenty-four marbles were found on the Webb site and in the Well Expansion Trench of 41BX883, and an additional 20 marbles found on the King site other than the Expansion Trench, some of which probably belonged to the Deman boys (see Zapata, this volume).

\section{Gordon Site (41BX900)}

Trench E, Feature A. Tiny metal toy soldier, only three centimeters tall (Figure 3-10f). This toy is very 


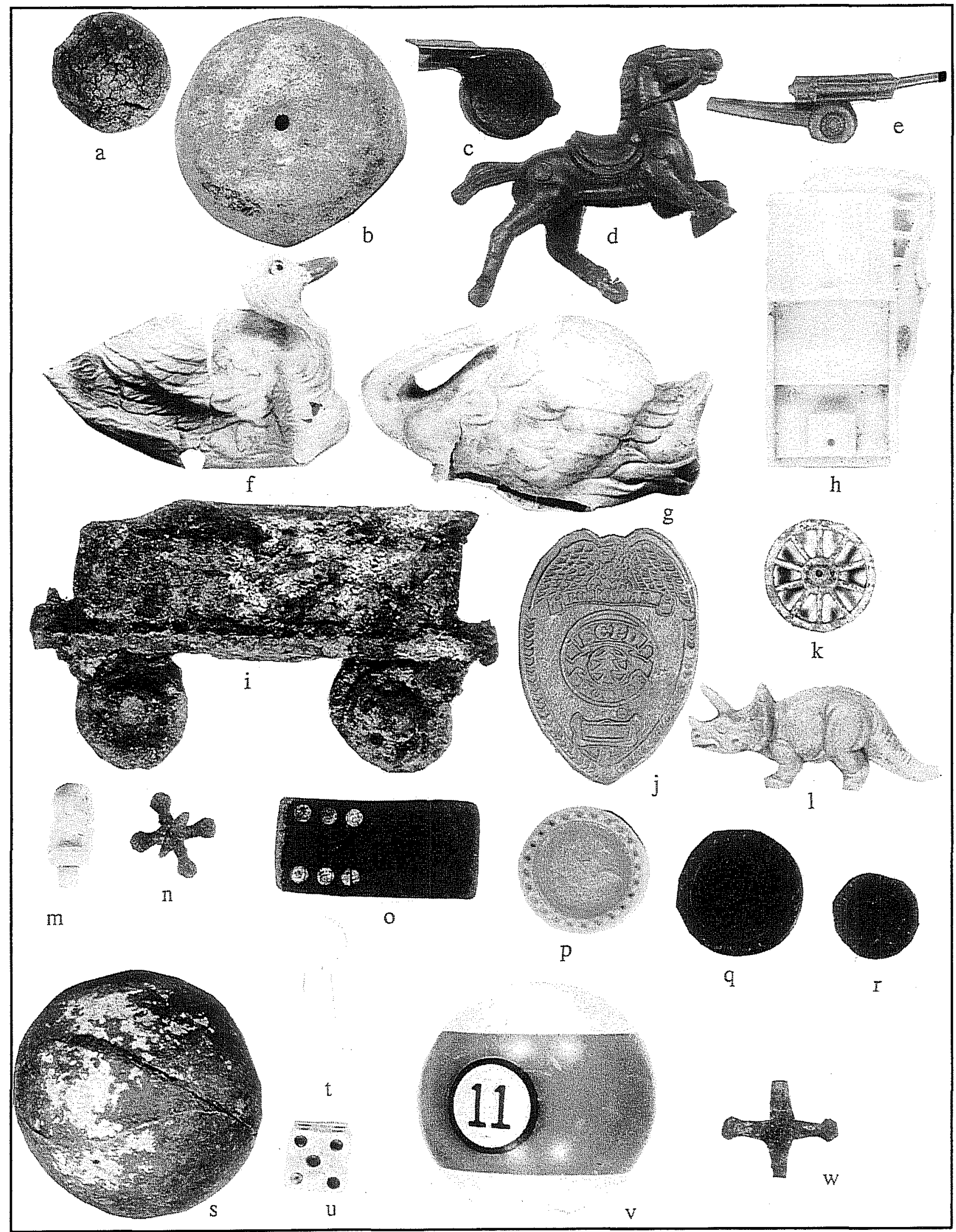

Figure 3-13. Miscellaneous toys and game pieces. a, s: rubber; b, i, k, n, w: metal; d, e, h, j, l, p-r, t: plastic; $\mathrm{f}, \mathrm{g}$ : celluloid; o, v: wood; $\mathrm{u}$ : bone. See detailed descriptions in text. All shown actual size. 


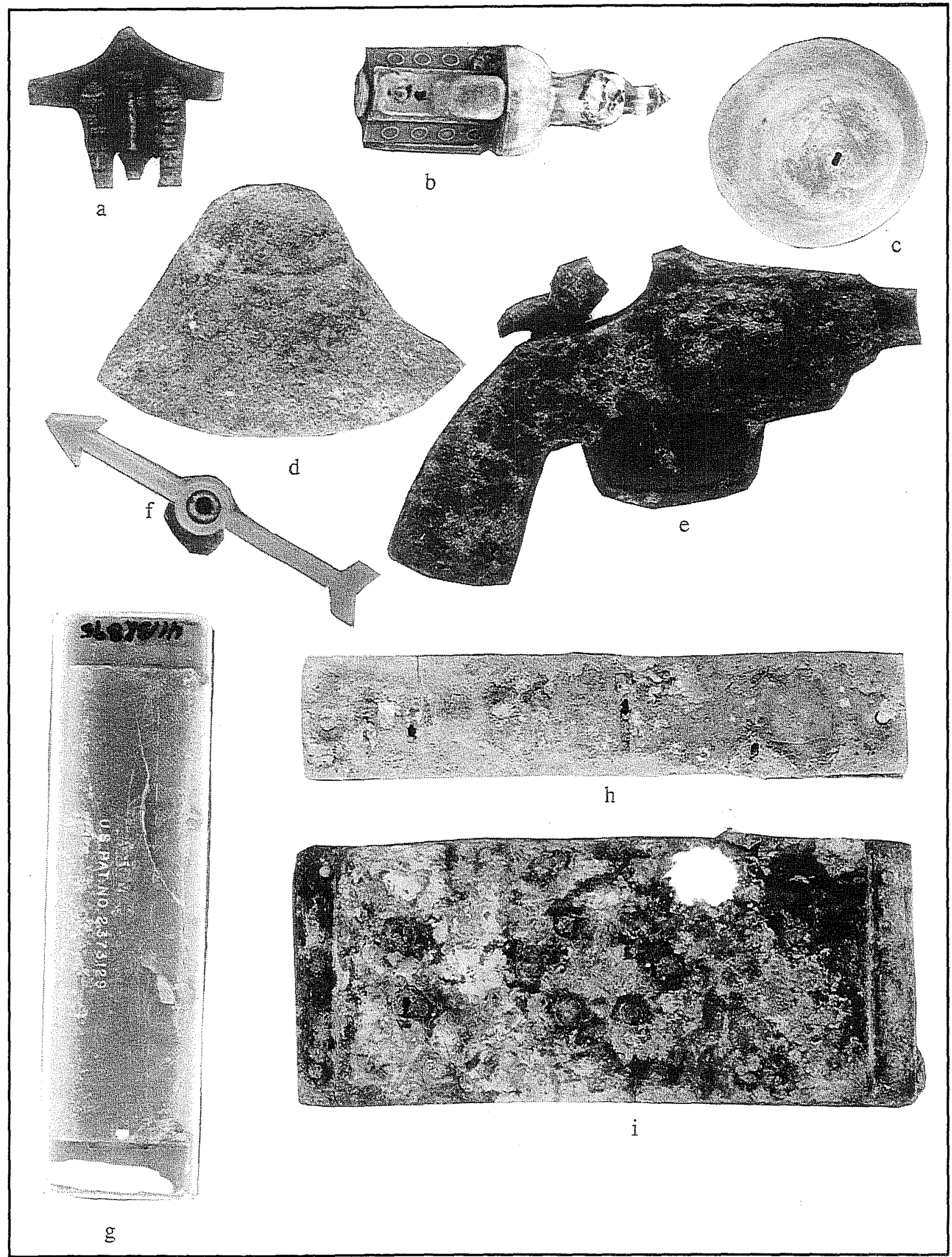

Figure 3-14. Miscellaneous toys. a, b, f: plastic; c-e: metal; g-i: harmonica fragments. All shown actual size. 
flat, almost two dimensional, and represents a man with rifle at shoulder arms. A metal stand allows him to stand alone. This toy looks very much like the sort of thing that could be found in a Cracker Jack box before plastics completely dominated this kind of toy making (Jaramillo 1989).

\section{Burleson Site (41BX936)}

Trench A, S5. Half of a broken black plastic whistle (Figure 3-13c). Embossed on the side is a police badge with the word "Dragnet" superimposed on it. This television show ran from 1951 to 1959 , and returned for another run from 1967 to 1970 (Terrace 1979:274). This toy was probably from a cheap set of plastic handcuffs, gun, whistle, and badge. These sets are sold to this day, with a tie-in to whatever police show is popular at the moment, however this badge was probably manufactured during the first series, as the later show was not popular with young children as the first show had been.

\section{Gilbert Site (41BX937)}

N99/W140. A small, green plastic airplane, probably intended to represent an $\mathrm{F}-4$ jet (Figure 3-10e). The modeling is mediocre. The plane is marked with two incompatible insignia, a "USMC" on one wing and an Air Force star on the other.

Trench B, Level 1. A fragment of a yellow plastic truck. This is very thin and cheap plastic.

\section{Conrad Site (41BX938)}

Trench B, S8. A brown plastic horse about seven centimeters high at the head (Figure 3-13d). The molding has minimal detail of the animal, its saddle and bridle. The feet have been badly chewed by a small animal with sharp teeth, probably a puppy. This item is marked "Made in U.S.A." on the underside.

Trench B, S8. A small black rubber wheel fragment, about $3.5 \mathrm{~cm}$ in diameter.

\section{Houston Site (41BX941)}

Trench D, S9. A small metal gun (Figure 3-10d). There is a rim and the remains of rubber at the place where the grip should be. Holes in the metal there and in the barrel indicate that this was a water pistol, with a rubber bulb in place of the grip. An almost identical toy was sold for $\$ .08$ each by Sears Roebuck \& Co. in 1912. (Schroeder 1971:150). This kind of water pistol worked by squeezing the bulb, not by pumping the trigger. The later method was available by 1914 in the Butler Brothers Catalog at a much higher price, $\$ 1.75$ a dozen for a trigger pump versus $\$ .38$ a dozen for the squeeze bulb (Schroeder 1971:162).

\section{Harris Site (41BX942)}

Trench D, S13 (Figure 3-13e). A grey plastic artillery piece about six centimeters long. This piece is very flat, almost two- dimensional, and is not intended to stand alone. It looks very much like a Cracker Jack prize or gum ball machine toy.

\section{Pauly Site (41BX945)}

Feature A, N1/2, Level 1. Approximately half of a small celluloid duck (Figure 3-13f). The celluloid is dyed to approximate natural coloring. Celluloid was a mid-nineteenth-century invention (White 1971:19) that was, by the turn of the century, used for many of the cheaper toys, and for replacing more breakable materials in toys for small children (see Schroeder 1971). A set of six celluloid toys very much like this were sold as bath toys for small children in the 1919 Sears, Roebuck catalog (Schroeder 1971:228). For $\$ .67$ one received a pair of ducks, a pair of swans, and a pair of fish, all of which would float in bath water (note that the celluloid swan below may have come from the same set). By 1927 Sears was selling the same set for $\$ .39$ (Mirken 1970:589).

Privy, $\mathrm{N}^{1} / 2$, Level 3. A jingle bell, two centimeters in diameter.

Privy, S1/2, Level 3. A jingle bell, two centimeters in diameter. 
Privy, N1/2, Level 4. About one-half of a celluloid swan (Figure 3-13g). The colors are brownish, but this probably happened after deposition. This may have come from the same set of bath toys as the duck above.

Privy, S1/2, Level 4. A large metal toy wagon wheel, about three inches in diameter.

Privy, N1/2, Level 7. A toy colander or sifter made of metal. Kitchen sets which included metal pots, pans, and other cooking utensils were sold as accessories for a toy range, or separately (Schroeder 1971:89, 138). In the 1912 Sears Catalog, kitchen sets ranged in price from $\$ .33$ to $\$ 1.47$ (Schroeder 1971:138). This item would have been from a fairly expensive set, as the cheap sets included only a few pots and pans and did not have colanders or sifters.

Privy, N1/2, Level 10. A hubcap from a spoked wheel, probably from a tricycle or bicycle. Montgomery Ward offered a three-wheeled "velocipede" for between $\$ 3.15$ and $\$ 5.85$, depending on size, in 1878 (Schroeder 1971:21). Clearly, this was not a toy that the average child could expect to have, as three dollars was a good bit of money at that time. By 1930 tricycles costing between $\$ 2.98$ and $\$ 5.48$ were available (Schroeder 1971:255). Given the increase in standard of living during the same period, these little wheeled vehicles had become much more the plaything of the average child.

Privy, S1/2, Level 12. A metal whistle with hole for a chain lanyard and a bit of chain still in the hole (Figure 3-10g). A similar whistle, called a "policeman's call whistle," sold with two other kinds of whistles for $\$ .10$ in 1912 (Schroeder 1971:137).

Privy, S1/2, Level 12. Iron railroad car (Figure 3-13i). This is a large, heavy-duty open-top toy, $6 \mathrm{~cm}$ high and $11 \mathrm{~cm}$ long. It appears to have been a coal tender. A cast iron engine with a tender in about this size sold for \$2.75 in 1912 (Schroeder 1971:145).

Privy, N1/2, Level 13. A hollow rubber ball in 16 fragments: This ball would have been between 4 and 6 inches in diameter; $4 \frac{1}{2}$-inch rubber balls sold for $\$ 2.00$ a dozen in 1893 (Stirn 1990:66), and Sears sold them for \$.39 each in 1912 (Schroeder 1971:146).
Feature D. A plastic gun stock for a small toy molded to look like wood.

Feature E, NE Quad, Level 15. Small plastic fire truck with missing wheels (Figure 3-13h). It was probably originally red, but is badly sun bleached. It is $7.5 \mathrm{~cm}$ long with minimal detail in the molding. This is a very cheap little toy.

Feature F, House Interior. Grey plastic police badge with "SCPD/Police" superimposed over a generic city shield (Figure 3-13j). On the back is the mark "Hong Kong" and a self clip for attaching to a pocket. This is the sort of toy that would have come with a set, including handcuffs, possibly a gun, and other police items.

Feature F, House Interior. Small wheel from a toy. It is made of metal and is about $2.5 \mathrm{~cm}$ in diameter. It could have come from a wagon or car or a number of other toys, but it should be noted that the wheel looks as if it belonged on a fairly old toy. There are only four spokes. An examination of the excellent illustrations in Stirn (1990) suggest that this wheel might have been on the platform of a pull toy. These little toys consisted of a figure, usually an animal, but sometimes a type of doll, set on a wheeled platform to which a string is attached so that it can be pulled around. These toys are very popular with toddlers. Some are designed so that some part of the figure moves when the spring is pulled (see Stirn 1990:34-36, 44-47 for examples).

Feature F, House Interior. A small brass bell of the type that could easily have been part of a chime pull toy (Figure 3-14d). This item and the one above could have come from the same toy.

Trench B, S4. A metal hammer for a cap pistol. The firing pin area is flat, to strike the caps soundly. The hole in the base would have been attached to a spring and a trigger to provide sufficient force on impact to fire the cap. Percussion caps for toy guns were available by 1893 , but were quite expensive ( $\$ 1.88$ for a dozen 26-inch rolls of paper caps [Stirn 1990:27]). The 1895 Montgomery Ward Catalog describes paper caps as dangerous, though it offers at least one cap gun for sale (Montgomery Ward and Company 1969:230). Cap guns do not seem to have been very popular before the $1930 \mathrm{~s}$, as they are seldom seen in toy 
catalogs before that time. By the 1950 s, however, most toy pistols and many toy rifles were cap guns with hammers much like this item.

Trench D, S6. A small metal, spoked wheel (Figure $3-13 k)$. It is three centimeters in diameter, is well made, and is painted pink on one side. This strongly suggests that it was not for a wagon or automobile, as these were always considered boy's toys and pink was not a boy's color. However, doll carriages and various kinds of pull toys might have metal wheels such as this and might be painted pink (see Stirn 1990:34, 44-47; Remise and Fondin 1967:97).

Trench E, Surface. A small yellow plastic building block of the LEGO variety. It has two pegs and is one of the smaller of this kind of block. This is a fairly recent toy.

Trench E, Surface. A light brown plastic fragment molded to resemble an engine or motor of some kind, possibly a railroad engine. It is marked on the underside, "R" and "M-4301-6."

Trench F, S2. A metal toy revolver, with a broken barrel (Figure 3-14e). This is a single-shot cap pistol made of cast iron. It is about $100 \mathrm{~cm}$ long.

\section{$41 B \times 956$}

Surface. A solid orange plastic triceratops, inaccurately molded with only one large horn above the eyes instead of two (Figure 3-131). The other molding is fairly detailed. The inaccuracy is probably an economy measure dictated by molding requirements, i.e., extra molding steps might have been necessary to make the horns correctly.

Surface. A blue plastic dolphin, $13.2 \mathrm{~cm}$ long. There is almost no detail in the molding. There is a hole in the nose and a groove at about where the dorsal fin should be where a fin might once have fit. This is a very cheaply made toy.

Surface. A card, 10.5 by $6.4 \mathrm{~cm}$. Printed in bright colors on the front of the card are Harry, Cookie, and Frazzle Monster, puppet characters from the popular children's show Sesame Street. The reverse shows the same picture in black and white outlining with a large number 3 superimposed on it. This is probably from a flash-card set used to help young children learn their numbers. The copyright date on the card is 1978 .

\section{Games}

A game can be loosely defined as play by a set of formal rules, with a distinct beginning and end. Many games played by children do not require any material object. Games of "Red Rover" require only a group of people (Abernethy 1989:101), and "King of the Mountain" requires only a group of people and a hill or some other height from which to defend one's sovereignty. Other games require objects with which to play. The most common game object in the archaeological record at the Alamodome was the marble. Because of the potential importance of marbles to the archaeologist, they are examined in detail elsewhere in this volume (see Zapata). The other game pieces are described below.

Kleiber and Kelly have noted, "Games are a substantial part of the enculturative process and are passed down from one generation to the next. By structuring social interaction, they serve to bring order to the confusing social relations" (Kleiber and Kelly 1980:100. Games are encountered by children as they mature and are thrust more and more into relationships with people outside their immediate family.

Of course, games are not just for children. In the years before the invention of radio and television, evenings had to be filled with some activity and reading, though it might "maketh a full man," was not a very social activity. Card games were extremely popular as early as the fourteenth century (Ketchum 1981:97). Board games, intended for adults to play, were very popular in nineteenth century America. The 1892 Marshall Field \& Co. catalog had five pages of parlor games (Schroeder 1971:75-80), and the 1893 Stirn wholesale catalog had nine and a half pages of board games alone, not counting such games as "floor croquet," bean bag toss games, bagatelle, and billiards (Stirn 1990). Yet by 1927, the Sears Roebuck catalog had only one page of board games and another of other indoor games (Mirken 1970:576-577). Instead, there are six pages of radios for sale and another page of radio accessories (Mirken 1970:707-713). Card and 
board games are still popular today, but they no longer have the place in society that they once held.

Thirty-three items are included in this category. Each game piece is described, by site, and then a brief history of the kind of games played with each object, if known, is made.

\section{Haas Site (41BX882)}

N35/E05. A light orange stylized knight's head on a peg (Figure 3-13m). This is probably from a "travel" chess set, in which pieces are placed in a peg board.

N49/E40. A metal jack stone (Figure 3-13n).

\section{King Site (41BX883)}

Surface. Two wooden dominoes painted black. One is a six/blank (Figure 3-13o) and the other is a double blank. The dots are painted white.

Surface. A solid rubber ball, three centimeters in diameter. Because it looks like the kind of ball used for playing jacks, it is included in this section instead of Other Toys.

\section{Griesenbeck Site (41BX884)}

Surface. A clear glass game piece, two centimeters in diameter. This piece could have come from any one of a wide range of board games, made at any time during the study period. There are no marks on the piece to aid identification.

Surface. A red plastic checker with a star and eagle design (Figure 3-13p).

Surface. A black plastic checker with a star and eagle design (Figure 3-13q). It could be from the same set as the one above.

Trench A, Feature A. A small, black plastic checker with a crown on one side and the trademark of the TootsieToy Company on the other (Figure 3-13r).

Trench A, Feature A. A metal jack.
Under Garza Store. An ivory-colored plastic game piece, probably from a backgammon game.

Under Garza Store. A rubber tennis ball (Figure $3-13 s)$.

\section{Maffi/Mendit Site (41BX885)}

N43/W72. A needle to attach to a pump to inflate a large ball.

\section{Rilling Site (41BX892)}

Trench A, Feature A. A red plastic checker with an eagle in the "U.S. seal" style on one side and a large five pointed star on the other. This piece is sunbleached on one side.

\section{Czernecki Site (41BX893)}

S29/E5. A cheaply made plastic chess pawn, from the white side (Figure 3-13t).

S29/E5. A turquoise plastic game piece in a squatbarrel shape, $1 \mathrm{~cm}$ high and $1.5 \mathrm{~cm}$ in diameter.

S152/E23. A green plastic game piece from a Parcheesi or similar game.

\section{Czernecki Rental Site (41BX894)}

Surface. A red plastic checker with a star on one side and a crown on the other.

S134/E56. A fragment of a white plastic poker chip.

S144/E56. A metal jack.

\section{Demazieres Site (41BX896)}

S118/E143. A bone die (Figure 3-13u). It appears to have been handmade, as it is not a perfect cube even to casual observation. The dots, which are drilled part way into the bone, are placed off center in several cases. 
Surface, Room 2. A red plastic arrow, still attached to a bit of cardboard (Figure 3-14f). This is from a board game, and would have functioned as a sort of primitive random number generator. To operate, the player would flick one end of the arrow with a fingertip causing the arrow to spin. When it stopped, the arrow would be pointing to one of several possible options, depending on the game. Players would then act according to this option.

Webb Site (41BX897)

Trench I. A metal jack.

\section{Burleson Site (41BX936)}

N99/W140. A metal jack.

\section{Pauly Site (41BX945)}

Privy, $\mathrm{N} 1 / 2$, Level 2. Four metal jacks. Three are medium-sized, the fourth is a larger variety.

Privy, S1/2, Level 3. A metal jack.

$\mathrm{N}^{1} \frac{1}{2}$, Level 10. A large jack.

Feature F, House. A billiard ball (Figure 3-13v). There is a number 11 in a red circle with a red stripe around the white ball.

Trench E. A black plastic checker with a star on one side and a "U.S. seal"- style eagle on the other.

\section{BX956}

Surface. A large metal jack (Figure 3-13w).

\section{Games Summary}

Numerous games are represented by the recovered artifacts. These games are discussed below.

\section{Backgammon}

This game is one of the oldest known, probably thousands of years older than chess (Morehead and Mott-Smith 1959:245). It is probably related to the ancient game of Pachisi (now called Parcheesi). Backgammon became a popular game in the United States in the 1920s (Goren 1961:388). The backgammon pieces are called stones. Players move their stones along a set course on a game board, according to the roll of dice (Goren 1961:338).

\section{Billiards}

This is a fairly old game. The origin of the game is unknown and may well have predated the birth of Christ (The Encyclopedia American 1957 III:705). The current form of the game had developed in England by 1830 (White 1975:30). It has traditionally been played on a cushioned, rectangular table and involves the propulsion of balls made of ivory or composition by the use of wooden cues tipped with leather. Numerous different games can be played with this basic equipment, some involving hitting the balls into pockets set into the perimeter of the table, and others involving hitting the balls against the cushions and each other in a certain manner (The Encyclopedia American 1957 III: 705-706).

\section{Chess}

Chess has always had a very high status, considered by many throughout the ages as the ultimate strategy game, the game of kings (Ketchum 1981:100). Chess is often referred to as one of the oldest games known to man (Goren 1961:388), however the earliest account of a game that is unmistakably chess comes from the eighth century (Morehead and Mott-Smith 1959:228). It seems to have come from India originally, and in its present form the game is about four hundred years old (Morehead and Mott-Smith 1959:228). The rules of the game are quite simple and even young children can learn them, but the "ultimate science of the game is unfathomable" (Goren 1961:341) and can continuously challenge even its masters. 


\section{Checkers}

In every language but English, checkers is known by some variant of the word for woman and is rated scornfully as "chess for women," but though the rules of the game are simpler than those for chess, and it can be played at a very simple level, the game has been shown to be as fully as profound as chess (Goren 1961:363). Checkers can be traced with certainty only to the fourteenth century, but it is probably much older (Morehead and Mott-Smith 1959:235).

\section{Dice}

Dice are the most ancient gambling instrument known to man, and the most universal, known in nearly all parts of the world (Morehead and Mott-Smith 1959:257). Dice come in many shapes and serve as random number generators in many games, ancient and modern. The modern standard, six-sided numbered die is probably from China (Goren 1961:424).

\section{Dominoes}

A domino is a flat tile, with some representation, usually rows of dots, of a number from zero to six on each end. The game is played by placing matching numbers next to each other until all a player's tiles are used. A standard set of dominoes represents all the combinations of numbers that can turn up in the cast of two six-sided dice (including, in Western domino sets, the zero) (Goren 1961:424). In $1120 \mathrm{AD}$, the Chinese standardized the game of dominoes as it is now played, but other evidence suggests the game had been played for many centuries before that time (Goren 1961:424).

\section{Jacks}

The modern jackstone or jack is a metal (or often today, plastic) version of a very old gaming piece, the "knucklebones" (i.e. the tarsals and carpals) of goats or sheep. These bones were used for a wide variety of games, including some that came from China, brought by silk traders (Vinton 1970:151). In one of these games a bone was tossed in the air and the player attempted to catch it on the back of his hand. Two, three and more bones were then tossed, until one bone fell off the hand (Vinton 1970:152). In another game, a bone was thrown in the air, each of several others picked up in turn, and the first bone caught before it could hit the ground. The bones were picked up in twos and then in threes, and so on. Letting the first bone hit the ground ended the turn. It was this game, modified by Latin Americans to include a soft grass or rubber ball in the place of the tossing bone (Vinton 1970:153), that became the modern game of jacks.

\section{Parcheesi}

The name is an Anglicization of the word "Pachisi," perhaps the oldest known sedentary game (Goren 1961:399). Developed in India, it can be considered the mother of most board games where the idea is to move counters on a figured board according to the roll of dice (Morehead and Mott-Smith 1959:245).

\section{Poker}

Though it has its origin in older European and Oriental games, poker in its current form is an American invention (Morehead and Mott-Smith 1959:85). There are hundreds of versions, but all involve betting, and poker chips are often used as a token for cash.

\section{Entertainment}

As in so many other areas of life, the changes in technology that began to accelerate in the last two decades of the nineteenth century (and continues to accelerate today), had a profound effect on leisure activities of the working class. In the first place, there was a growing amount of time available for such activities (Smelser 1976:137). In addition, entertainment changed, as many things did, from "homespun" to mass produced. The artifacts found in the Alamodome area reflect this change. Brass harmonicas in older contexts give way to 78-RPM phonograph records, which in turn give way to $331 / 3-$ RPM records.

Twenty-one artifacts are listed in this category. A brief history of the forms of entertainment they represent follows the descriptions below. 


\section{Griesenbeck Site (41BX884)}

N187/W36. A 35-mm film fragment, about $90 \mathrm{~cm}$ long.

\section{Czernecki Rental (41BX894)}

Feature A. Four fragments of a 78-RPM phonograph record.

Feature A. Two 331/3-RPM record fragments.

\section{Garza Store Site (41BX895)}

Surface. A red, white, and black plastic harmonica (Figure 3-14g). The bottom outer plate is missing. There are ten reed sets. The top is marked "Harmotone/Harmonica/U.S. Pat. No. 2.373.129" and there is a number from 1 to 10 embossed above each reed hole.

\section{Demazieres House (41BX896)}

S77/E134. Three fragments of a metal harmonica reed plate.

S107/E107. A fragment of a 45-RPM record.

S107/E107. A record fragment in reddish vinyl. This is probably from a child's 45-RPM record.

S107/E107. A plastic tuning peg from a guitar or other stringed instrument. This item is small and cheaply made and may be from a child's toy.

\section{Webb Site (41BX897)}

Well, Level 1. A reed plate from a copper alloy harmonica (Figure 3-14h). There are 10 reeds.

Well, Level 3. Possible photographic film, 62-mm wide.

Well Expansion Baulk. A metal harmonica, 4.7 by 113 $\mathrm{cm}$ (Figure 3-14). The inner part appears to be made of iron, with riveted copper reeds. The outer part is a copper alloy, perforated with a pattern of holes. There are 12 reeds.

Well Expansion. A reed plate from a harmonica. There are 12 riveted copper reeds.

\section{BX931}

N67/W131 A 78-RPM record fragment.

\section{BX942}

Trench D, S13. Fragment of a 331/3-RPM phonograph record.

The harmonica, or mouth organ, consists of a metal tongue riveted over an accurately cut aperture in a metal frame, which is caused to vibrate by blowing across it (Baines 1961:318). Originally an Asian invention, the mouth organ began to interest European musicians at the end of the eighteenth century (Baines 1961:319). The advantage of the harmonica on the frontier is obvious. Its portability and durability made it popular at a time when space was at a premium and ruggedness the sine qua non of material culture. After the railroad came to San Antonio, other musical instruments could be shipped but the harmonica remained popular because of the relatively low cost. The 1902 Sears Roebuck catalog lists harmonicas between $\$ .07$ and $\$ 1.30$, while accordions ranged from $\$ 2.25$ to $\$ 12.75$, and the cheapest brass band instruments were at least $\$ 8.00$ (Sears, Roebuck and Company 1969:205, 207, 210). Considering this, the popularity of the harmonica in the Alamodome area is understandable.

The entertainment provided by people in the home, with their own musical instruments, found itself in competition with a new technology by the turn of the century. The phonograph was invented on December 7, 1877 by Thomas Alva Edison (Hitchcock 1980:vii). Like so many of Edison's inventions, it had a profound effect on the daily lives of the industrial world. The very nature of the performance of music, even live unrecorded music, changed once it became possible to store a particular performance. Music was not, of course, the only thing stored. The Sears Roebuck catalog of 1905 lists "humorous stories," and 
recordings of contemporary historic events such as the funeral of President McKinley as well as its musical phonograph offerings (Lewis 1940:31, 34). People apparently found these professional performances, which could be listened to again and again, to be more appealing than homespun musical offerings. The selection of musical instruments in the Sears catalogs plunged from 60 pages in 1905 to 8 pages in 1935 (Lewis 1940:43).

Originally, sounds were mechanically recorded on wax or tin cylinders with the same needle that was used to play them (Gelatt 1955:21-22, 34). The first commercial recordings were made in 1890 (Gelatt 1955:46). It was not until about 1925 that a standard speed of 78 RPMs was established for disks, which were by then made of Bakelite or hard rubber (Gelatt 1955:66). In 1948 the long playing record was introduced, played at 331/3 RPM (Gelatt 1955:292). The next year, 45-RPM. records were introduced (Gelatt 1955:294). By the 1990s, the record disk and its player were essentially obsolete, replaced by cassette tape recording and laser compact disks.

The first forms of photography became available to the public in 1839 (MacDonald 1979:5), but it was not until George Eastman developed the celluloid film camera in 1888 that photography became a cheap, easy form of entertainment for middle class families (MacDonald 1979:55-57).

\section{Other Diversions and Activities}

This is a miscellaneous category, consisting of evidence of fishing, bicycling, the keeping of pet animals in the Alamodome area, and other activities. Thirty-six items constitute this category.

\section{Oeffinger Site (41BX881)}

N27/W57. A plastic inner tube stem cap.

\section{Griesenbeck Site (41BX884)}

N22/W44. A small yellowish, translucent plastic fishing bobber, about three centimeters in diameter.
N22/W44. A red, plastic birthday candle holder (Figure 3-15a).

\section{Rilling Site (41BX892)}

Trench A, Feature A. A slightly flattened round wooden ball, with a hole through the axis and the remains of light blue and yellow paint (Figure 3-15b). This is probably a fishing bobber.

\section{Czernecki Site (41BX893)}

S177/E23. A metal fishing swivel (Figure 3-15a).

\section{Czernecki Rental (41BX894)}

Surface. One piece of blue plastic aquarium gravel.

S18/E74. Ten pieces of blue plastic aquarium gravel.

S18/E76. One piece of blue plastic aquarium gravel.

S40/E77. Four pieces of blue plastic aquarium gravel.

Feature A. Five pieces of blue plastic aquarium gravel.

\section{Garza Store Site (41BX895)}

N35/E35. A metal rabies vaccination tag (Figure $3-16 \mathrm{~b})$. It is $3.6 \mathrm{~cm}$ tall, in a diamond shape, with a hole in the top and a chain link to attach to a collar. It is engraved "Vaccinated/Jen-Sal/Rabies Vaccine/159/ 1943/D."

\section{Demazieres Site (41BX890)}

Surface. A stainless-steel tag, $2.8 \mathrm{~cm}$ in diameter, with a loop in the top to attach to a dog collar. It is intended to be engraved with the owner's name and address and there are the remains of a paper sticker on both sides which give instructions on how to send it in to be engraved. Most of the sticker is illegible, but the trade name "Hartz" is visible. 


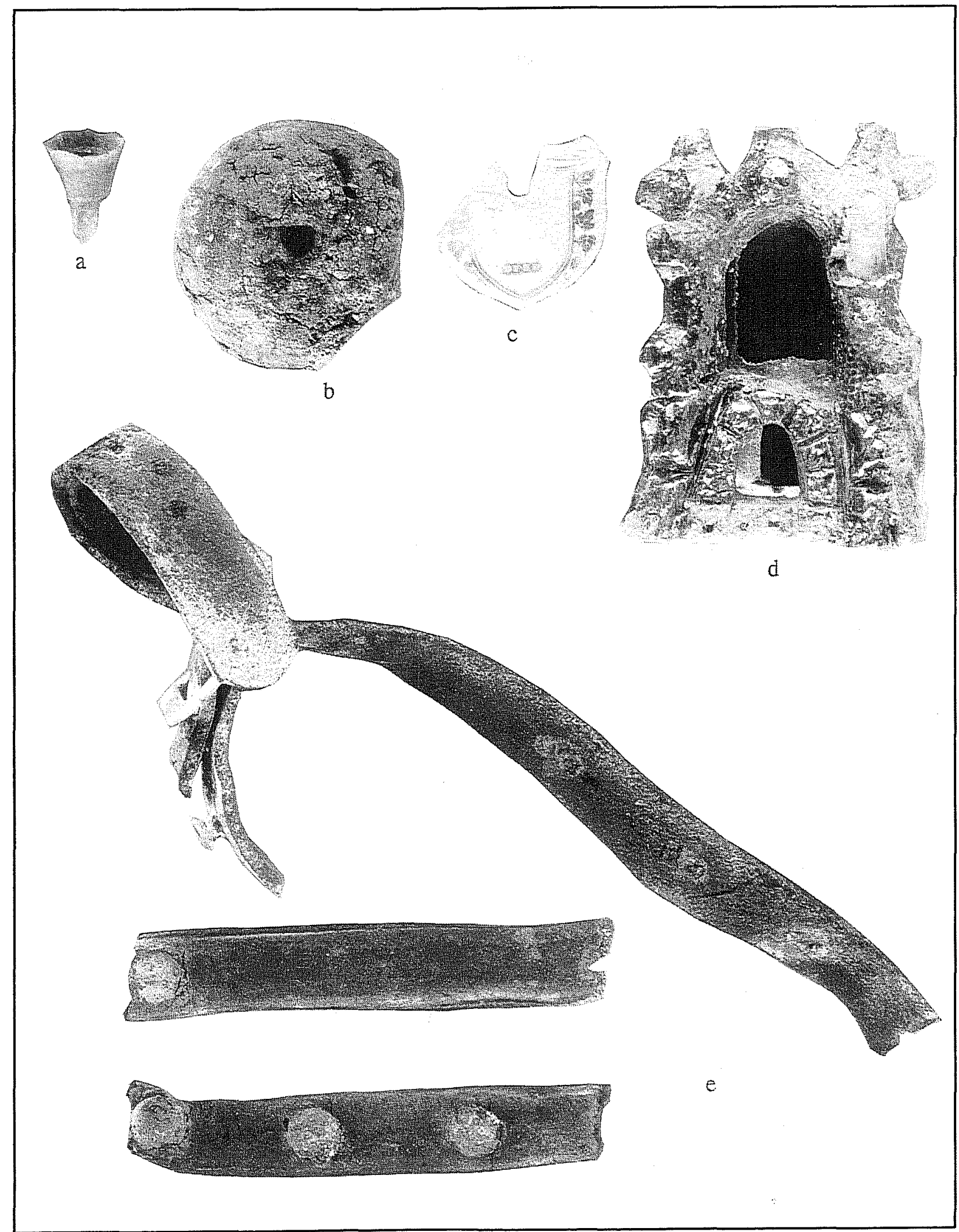

Figure 3-15. Miscellaneous items. a: birthday candle holder; b: cork fishing float; c: plastic beer tag; d: aquarium castle; e: fragments of a leather dog collar. All shown actual size. 


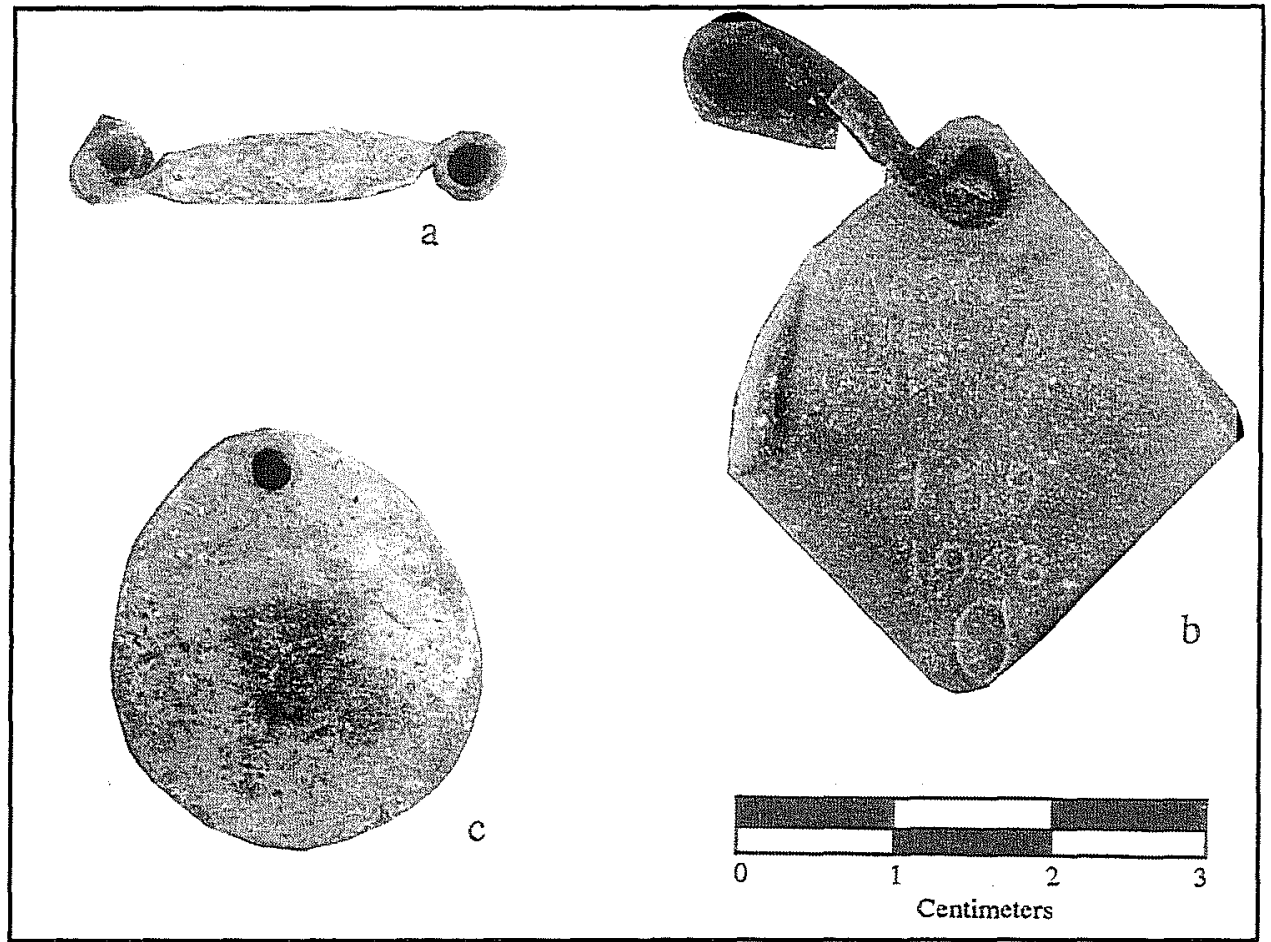

Figure 3-16. Miscellaneous items. a: fishing sinker; b: a rabies vaccination tag; c: fishing lure fragment.

Trench D, S 1. A metal fishing lure, $2.5 \mathrm{~cm}$ tall (Figure 3-16c).

Trench D, S2. A bicycle pedal with orange plastic reflectors.

\section{Conrad Site (41BX938)}

Trench B, S9. A white plastic tag with a Lone Star Beer emblem on the front and "Certified Quality" on the back (Figure 3-15c). Lone Star is a local brewery.

\section{Harris Site (41BX942)}

Trench D, S12. An orange plastic bicycle reflector.

Trench D, S12. A piece of green plastic aquarium gravel.

\section{Pauly Site (41BX945)}

Privy. Two fish hooks.
Privy $\mathrm{N}^{1 / 2}$, Level 7. A glazed ceramic piece representing castle ruins (Figure 3-15d). This was used as decoration in a fish bowl or aquarium. It is seven centimeters tall.

Feature E, NE Quad. A leather dog collar for a medium to large dog (Figure 3-15e). The collar is $1.7 \mathrm{~cm}$ wide, with metal rivets and the remains of a red dye on the outer surface.

An interest in keeping fish as pets has existed for several centuries in Europe (Schneider and Whitney 1957:8), but this was a hobby relegated primarily to the east coast of America by problems associated with transportation of the fish until after World War II (Schneider and Whitney 1957:9). The plastic gravel also suggests a date after the war for these items.

\section{Discussion and Conclusions}

The archaeological record shows a discrepancy in deposition of toys. There were 115 fragments of dolls, only two of which (1.7 percent) are probably of postWorld War II manufacture. There were 98 non-doll toys (excluding doll dishes, which can only be dated to between 1870 and 1990), of which 47 (47.9 percent) were probably made after World War II. There is no readily apparent reason why there should be so much difference in deposition between the two kinds of toys.

Perhaps the answer lies after World War II when the materials used to make dolls changed. Before World War II, most dolls were made of perishable material and/or ceramics (see Schroeder 1971). After the war, ceramics, composition and other perishable materials, were replaced by plastic. Therefore, before the war, doll parts likely to survive deposition in archaeological 
context were also likely to be broken in the assembly line. The main body of the doll might then end up in the "official" trash picked up by the city (see Brown and $\mathrm{DeLaO}$, this volume), but some of the broken fragments would not. After dolls were constructed of plastic, however, they were unlikely to break, but were instead worn out and thrown into the trash can, usually intact. There is some evidence for this explanation. As a rule, only a small portion of each ceramic doll was recovered while most other toys recovered were whole or almost whole, especially those made of plastic. These toys were very small, and therefore likely to be lost rather than deliberately thrown away. Thus, the discrepancy could be a matter of what is likely to be lost, or tossed into more informal trash deposits like privies, rather than what is deliberately thrown into the trash can, collected by the city and therefore not left in the neighborhood for archaeologists to come upon.

Neumeyer and Neumeyer (1936:19) state "the modern industrial machine has delivered two products-goods and leisure." This report has been concerned with categories of material culture from the Alamodome which reflect the truth of this epigram. The residents of the project area left behind the remains of many hours of children's play and adult leisure activities.

Yet these remains reflect only a tiny portion of the physical material of toys and games, which in turn reflect only a portion of the kinds of play which enlivened the days and nights of these residents. As has been shown, most toys and games were constructed on the site, made by the children themselves, or by adults who thereby taught a traditional way of making toys. Most, if not all, of these toys are lost to us. They were either made of perishable materials or were made from "recycled" materials we can no longer identify as toys.

Almost all the toys and game items listed here, however, were bought in a store, and most were made far from San Antonio (Riordan and Adams 1985:5). These two facts are indicative of the change in our society which began to have an impact in San Antonio in 1877 , when the railroad came into town. At that time, there were about 10 residences in the Alamodome area, some of which had been there for 20 years (Cox, Volume I). Though there certainly must have been children living in those houses, we have not found anything identifiably a toy from that period. The oldest doll fragments were probably made no earlier than about 1870, and may have traveled to San Antonio in an ox cart, but we can be fairly sure that the other toys and games arrived here on the railroad, and were part of the increasing industrialization of everyday life in America.

Increasing industrialization brought increasing disposable income (Smelser 1976:136), as well as increasing numbers of manufactured toys to buy with that income. The archaeological record at the Alamodome reflects this social change. 


\section{References Cited}

Abernethy, F. E (editor)

1989 Texas Toys and Games. Southern Methodist University Press, Dallas.

Angione, G.

1973 All Bisque and Half-Bisque Dolls. Thomas Nelson, Nashville.

1975 Goo-Goos and Pixies. In Spinning Wheel's Complete Book of Dolls, edited by A. C. Revi, pp.140-141. Galahad, New York.

Ariès, $\mathbf{P}$.

1965 Centuries of Childhood: A Social History of Family Life. Translated by R. Baldick. Alfred A. Knopf, New York.

Bach, J.

1985 The Main Street Dictionary of Doll Marks. Main Street Press, Pittstown, New Jersey.

Baines, A. (editor)

1961 Musical Instruments Through the Ages. Penguin, Baltimore.

Byfield, $M$.

1986a Dolls' House Dolls. In The Best of the Doll Reader, Volume II, edited by V. A. Heyerdahl, pp. 35-38 Hobby House, Cumberland, Maryland.

1986b Googlies. In The Best of the Doll Reader, Volume II, edited by V. A. Heyerdahl, p. 109. Hobby House, Cumberland, Maryland.

Coleman, D. S.

1975 Philip Goldsmith (1844-1894): An American Dollmaker. In Spinning Wheel's Complete Book of Dolls, edited by A. C. Revi, pp. 3-8. Galahad, New York.

Coleman, E. J.

1986 Later Than You Think. In The Best of the Doll Reader, Volume II, pp. 25-28. Hobby House, Cumberland, Maryland.

Collier, J.

1988 Official Identification and Price Guide to Antique and Modern Dolls. Fourth edition. Ballentine, New York.

Encyclopedia Americana

1957 The 1957 edition, vol. III. Americana Corporation, New York.

Frost, J. L.

1985 Introduction. In When Children Play, edited by J. L. Frost and S. Sunderlin, pp. ix-xi. Association for Childhood Education International, Wheaton, Maryland.

Gelatt, R.

1955 That Fabulous Phonograph, from Tin Foil to High Fidelity. Lippincott, Philadelphia. 
Goren, C. H.

1961 Goren's Hoyle Encyclopedia of Games. Greystone, New York.

Harpur, P. (editor)

1982 The Timetable of Technology: A Record of the Twentieth Century's Amazing Achievements. Hearst, New York.

Hart, L.

1975 The Rag Doll. In Spinning Wheel's Complete Book of Dolls, edited by A. C. Revi, pp. 18-27. Galahad, New York.

Hillson, S.

1986 Teeth. Cambridge University Press, Cambridge.

Hitchcock, H. W. (editor)

1980 The Phonograph and Our Musical Life: Proceedings of a Centennial Conference 7-10 Dec 1977. Institute for Studies in American Music, Brooklyn College, New York.

Hunt, D.

1970 Parents and Children in History: The Psychology of Family Life in Early Modern France. Harper and Row, New York.

Isenberg, J. P., and J. E. Jacobs

1982 Playthings as Learning Tools: A Parent's Guide. Wiley, New York.

Israel, F. L. (editor)

19681897 Sears, Roebuck Catalog. Chelsea House, New York.

Jaramillo, A.

1989 Cracker Jack Prizes. Abbeville, New York.

Ketchum, W. C., Jr.

1981 Toys \& Games. Cooper-Hewitt Museum, New York.

Kleiber, D. A., and J. R. Kelly

1980 Leisure, Socialization, and the Life Cycle. In Social Psychological Perspectives in Leisure and Recreation, edited by S. E. Iso-Ahola. C. C. Thomas, Springfield, Illinois.

Lewis, C. D.

1940 The Good Old Days, A History of American Morals and Manners as Seen Through the Sears, Roebuck Catalogs, 1905 to the Present. Simon and Schuster, New York.

MacDonald, G.

1979 Camera Victorian Eyewitness: A History of Photography 1826-1913. Viking, New York.

MacDowell, R. and K. MacDowell

1986 Simon \& Halbig Portfolio. In The Best of the Doll Reader, Volume II, edited by V. A. Heyerdahl, pp. 110-112. Hobby House, Cumberland, Maryland. 
Merken, B.

1984 Toys and American Culture: Objects as Hypotheses. In American Material Culture: The Shape of Things Around Us, edited by E. Mayo. Bowling Green State University Popular Press, Bowling Green, Kentucky.

Mirken, A. (editor)

19701927 Edition of the Sears, Roebuck Catalogue: The Roaring Twenties. Bounty, New York.

Montgomery Ward and Company

1969 Catalogue and Buyers' Guide, No. 57, Spring and Summer 1895. Reprinted by Dover Publications, New York.

Morehead, A. H. , and G. Mott-Smith (editors)

1959 Hoyle Up-To-Date. Grosset and Dunlap, New York.

Noël Hume, I.

1970 A Guide to the Artifacts of Colonial America. Alfred A. Knopf, New York.

Neumeyer, M. H., and E. S. Neumeyer

1936 Leisure and Recreation: A Study of Leisure and Recreation in Their Sociological Aspects. Barnes, New York.

Prichett, J., and A. Pastron

1983 Ceramic Dolls as Chronological Indicators: Implications from a San Francisco Dump Site. In Forgotten Places and Things: Archaeological Perspectives on American History, edited by E. W. Albert, pp. 321-334. Center for Anthropological Studies, Albuquerque.

Remise, J., and J. Fondin

1967 The Golden Age of Toys. Translated by D. B. Tubbs. Edita Lausanne, Lausanne, Switzerland.

Riordan, T. B., and W. H. Adams

1985 Commodity Flows and National Market Access. Historical Archaeology 19(2):5-18.

Roach, J.

1989 Dolls Generally. In Texas Toys and Games, edited by F. E. Abernethy, pp. 61-65. Southern Methodist University Press, Dallas.

Schneider, E., and L. F. Whitney

1957 The Complete Guide to Tropical Fishes. Thomas Nelson and Sons, New York.

Schroeder, J. J., Jr. (editor)

1971 The Wonderful World of Toys, Games \& Dolls: 1860-1930. DBI, Northfield, Illinois.

Schwartzman, H. B.

1978 Transformations: The Anthropology of Children's Play. Plenum, New York.

Sears, Roebuck and Company

19691902 Edition of the Sears, Roebuck Catalogue. Reprinted by Bounty, New York. 
Smelser, N.

1976 The Sociology of Economic Life. Second edition. Prentice Hall, Englewood Cliffs, New Jersey.

St. George, E.

1948 The Dolls of Yesterday. Bonanza, New York.

Stirn, C. P.

1990 Turn-of-the-Century Dolls, Toys, and Games: The Complete Illustrated Carl P. Stirn Catalog from 1893. Dover, New York.

Sutton-Smith, B.

1986 Toys As Culture. Gardener, New York.

Terrace, V.

1979 The Complete Encyclopedia of Television Programs, 1947-1979, Vol. I. A. S. Barnes, New York.

Tumbusch, $\mathrm{T}$.

1991 Tomart's Price Guide to Radio Premiums and Cereal Box Collectibles. Wallace-Homestead, Radnor, Pennsylvania.

Vinton, I.

1970 The Folkways Omnibus of Children's Games. Stackpole, Harrisburg, Pennsylvania.

White, G.

1971 Antique Toys and Their Background. B. T. Batsford, London.

1975 Toys and Dolls: Marks and Labels. Charles T. Branford, Newton, Massachusetts.

Wolf, W., and L. K. Wolf

1979 Landmark Films: The Cinema in Our Century. Paddington, New York.

Wortham, S. C.

1985 A History of Outdoor Play 1900-1985: Theories of Play and Play Environments. In When Children Play, edited by J. L. Frost and S. Sunderlin, pp. 3-7. Association for Childhood Education International, Wheaton, Maryland. 


\title{
Chapter 4 \\ Alamodome and Abroad: \\ A Composite Inquiry on Toy Marbles
}

\author{
José E. Zapata
}

\section{Preface}

Among the myriad of cultural material excavated from historical sites are toy marbles. Yet site reports are almost devoid of detailed references to marbles, a point which Mark E. Randall noted over 20 years ago (Randall 1971). Excepting the continuing work of Randall, Gartley, Carskadden, and Webb (Carskadden and Gartley 1990a, 1990b; Carskadden et al. 1985; Gartley and Carskadden 1987; Randall 1971, 1986; Randall and Webb 1988), few others in the field of historical archaeology have ventured into this area of research.

Clearly then, the most significant factor which motivated the current research is this noted lack of information and/or unfamiliarity with the topic. It is quite incredible to think that an artifact with as many individual attributes and with such durability as a stone, clay, or glass marble should go virtually unattended. Despite this latter point, it is not my intent to further debate the significance of toy marbles in historical archaeology. Instead, I hope to advance the pioneering work of Randall.

\section{Introduction}

In total, 235 marbles were recovered from the Alamodome Project area. Of these, 3 were of stone, 73 of clay and 159 of glass. Of the total, 77 were extracted from within 2-x-2-ft units; another 155 were located within various features, trenches, and shovel tests; the remaining 43 were surface finds. Twelve of the marbles were not located within designated sites.

This paper is framed around two specific research questions. The first of these presents a composite study on the origins of marbles. The second objective is designed to capsulize the range and variety of marble types. Color illustrations of some of the more unique specimens are also presented.

This paper is presented in four parts. The first part summarizes the origins of toy marbles. The second presents a synopsis of marble typologies. The third presents some of the more unique specimens recovered, and the fourth is a summation of this study. Beyond listing cited references, included is an index of supplementary readings which may aid others in their pursuit of additional research objectives.

\section{Origins}

\section{Prehistoric}

The archaic nature of toy marbles has been reported by Baumann (1970) and Ferretti (1973). Their work suggests that this toy and form of play may have prehistoric origins. Their suggestion is based on the excavation of small spherical objects from burials in both the Old and New worlds; however, the function of these items is not clear. 


\section{Historic}

The most prolific sources of information are recorded accounts of the game. Possibly one of the first of such accounts, as related by Ferretti (1973:13-14), can be found in William Wells Newell's 1883 work, Games and Songs of American Children. Newell traces the game of marbles to ancient Rome by noting that the Roman poet Ovid (ca. 43 B.C.-A.D. 17) mentioned a child's game very similar to marbles in his writings. As described by Ovid, the game was played with small spherical shaped nuts which were rolled down an inclined plane.

Old World accounts of children's play from the Middle Ages are scarce. Philippe Aries (1962) and Shulamith Shahar (1990) have done extensive research on childhood in the Middle Ages. Although seemingly divergent, these scholars provide some interesting hypotheses on Old World attitudes towards childhood and child-nurturing during this epoch.

In the Middle Ages, life for the lower socioeconomic classes was harsh. Access to goods was limited, disease and epidemics persisted, and infant mortality was exceedingly high. Given this backdrop, it is not surprising that childhood themes are scarce in the period literature. The archaeological record reflects a limited sample of trinkets and figurines dating to this period (Grober 1928:10-11).

It is not until the fifteenth century that childhood themes begin to emerge (Aries 1962:47). These themes are particularly obvious in works of art, and appear more prominent at about the end of the sixteenth century (Aries 1962:47). The modified attitudes of this era, coupled with a growth in economic prosperity, signaled a rise in the demand for toys (Grober 1928:15). By 1566, German toys were being sold in Venice (Fraser 1966:74).

This developing enthusiasm for play and toys is evident within the subject of one of the most renowned works of art produced during the sixteenth century: Children's Games (1560) by Pieter Bruegel, The Elder. Of some 80 games discernable in the painting, one scene depicts children playing a form of marbles (Grossman 1973:191).
Many eighteenth and nineteenth centuries works make reference to marbles. In The Voices of Children: 1700-1914-a compilation of previously unpublished children's themes, letters, and diary entries-Irina Stickland contributes two notable excerpts. The first of these makes mention of an incident, The Rebellion of 1793, which transpired at Winchester College. In brief, the students, feeling somewhat oppressed and slighted by the administration, pummeled the school master with marbles upon his arrival on campus (Stickland 1973:87-88). The second clipping provides some insight as to how children aged 11 and under, in ca. 1833 Lancashire cotton mills, were enticed into continuing with their tasks: they were coaxed by allotting them meat, marbles, and tops (Stickland 1973:87-88).

Antonia Fraser (1966) notes that the resurgence in childhood play and toys reached its peak during the eighteenth century, and that many portraits of that period depict children with toys. This trend influenced New World markets. There was an apparent emphasis on amusements, and an increased demand for imported toys (Fraser 1966:90).

This was a pivotal episode for the emerging German cottage industries and trade guilds. It was especially significant to the city of Nuremberg, which arose as the toy capital of the world; a distinction it retained well into the nineteenth century (Grober 1928:14-15). Germany's preeminence was a consequence of the quality and variety of their products, their originality and, most importantly, their adaptability to the varied needs of the international consumer (Kuhnert 1928:371).

Within the context of United States foreign trade were three treaties of amity, commerce, and navigation with Prussia prior to the founding of the German Empire: 1871-1919 (Kuhnert 1928:19). The treaties of 1785, 1799 , and 1828 , served to facilitate and promote the exchange of commodities between the two parties. These amicable trade relations were furthered as a result of a consular agreement between the United States and Germany, dated December 11, 1871 (Kuhnert 1928:19).

Grober (1928:51) notes that for the year 1729 alone, 600 tons of toys were exported by Germany. The fact that Germany was the leading manufacturer and 
exporter of toys is reiterated by Fraser (1966:73-74) and Remise and Fondin (1967:14). For the year 1913, the value of German toy exports exceeded 2.8 million dollars (Kuhnert 1928:372). German-made toy marbles, of stone, clay, and glass, also figured prominently in United States imports (Randall and Webb 1988:12-14).

Germany's lead in the United States toy market was stifled as a result of World War I (1914-1919). Its relatively brief absence from the United States toy industry/market during this period was enough to allow United States entrepreneurs to gain an unceasing dominance. As a consequence, by 1928 only five percent of the United States demand for toys was satisfied by foreign imports (Randall and Webb 1988:12-14).

Given the preceding points and authorities, in terms of longevity, it can be ascertained that Germany was a major player in the United States toy market from 1785 through 1914 (Table 4-1). This rather long period of dominance was seemingly effective in setting toy trends into and across the United States, particularly during its early growth and development. Beginning in the late nineteenth century, United States marble companies became common (Table 4-2)

German emigration between 1820 and 1930 was an estimated 5,989,400; of these, 89 percent settled in the United States (Stolper 1940:39). It is difficult to ascertain the number of German immigrants that settled in Texas. Some came to Texas by way of New Orleans, while others took a more direct route by way of Galveston, and still others came overland. The precise numbers that emigrated to Texas between the years $1840-1860$ (as might be inferred by arrivals to Galveston), cannot be ascertained as a consequence of the 1900 flood which devastated Galveston's Customs House. Therefore, the records for these years were lost (Benjamin 1910:55). In his investigations, Benjamin (1910:55-65) found numerous inconsistencies with the unofficial, as well as official, reports on German immigration during the 1850 s. In mediating the varied reports, Benjamin arrived at a conservative estimate of 30,000 Germans residing in Texas by about 1857 .

Table 4-1. Significant Dates in United States Marble History

\begin{tabular}{|l|l||}
\hline Date & \multicolumn{1}{|c|}{ Highlight } \\
\hline ca. 1700 & $\begin{array}{l}\text { Beginning of commercial production of stone marbles in East Germany (terminal date: ca. 1927); } \\
\text { agate marbles located in a seventeenth-century site, in Williamsburg, Virginia }\end{array}$ \\
\hline ca. 1840 & $\begin{array}{l}\text { Beginning of commercial production of clay, China marbles; Germany (terminal date: ca. 1910); } \\
\text { other clay marbles were produced in Europe and the United States during this same period. }\end{array}$ \\
\hline ca. 1846 & Beginning of commercial production of handmade glass marbles, Germany (terminal date: ca. 1905). \\
\hline ca. $1880-1897$ & The first three marble companies founded in the United States. \\
\hline ca. 1905 & Commercial production of machine-made glass marbles gains momentum. \\
\hline ca. $1914-1918$ & $\begin{array}{l}\text { Germany's involvement in WwI hampers its toy industry, United States manufacturers gain a } \\
\text { foothold. }\end{array}$ \\
\hline ca. $1901-1926$ & $\begin{array}{l}\text { Transitional period for machine-made glass marbles-"early machine-made"-exhibit discrete } \\
\text { attributes. }\end{array}$ \\
\hline ca. 1951 & The "Cateye" glass marble from Japan is introduced into the U.S. market, exhibits discrete attributes. \\
\hline ca. 1955 & $\begin{array}{l}\text { The Vitro Agate und Marble King companies (U.S.) began to produce their own design of the "Cateye" } \\
\text { (see Table 4-2). }\end{array}$ \\
\hline
\end{tabular}


Table 4-2. United States Marble Companies

(Adapted from Randall 1986 and Randall and Webb 1988)

\begin{tabular}{|c|c|c|}
\hline Company & Dates & Notes \\
\hline $\begin{array}{l}\text { Iowa City Flint Glass } \\
\text { Manufacturing Co. }\end{array}$ & $1880-1882$ & $\begin{array}{l}\text { Iowa City, IO-the only documented American company to have } \\
\text { produced handmade glass marbles - marbles production was a minor } \\
\text { sideline and ceased operating after only about a year and a half }\end{array}$ \\
\hline $\begin{array}{l}\text { Navarre Glass Marble } \\
\text { Co. }\end{array}$ & $1897-1905$ & \\
\hline $\begin{array}{l}\text { M.F. Christensen Glass } \\
\text { Co. }\end{array}$ & $1905-1917$ & \\
\hline Akro Agate Co. & 1910-1951 & $\begin{array}{l}\text { Akron, OH (1910-1912) \& Clarksburg, WV (1914-51) -founded } \\
\text { by Horace C. Hill (formerly of the M. F. Christensen Glass Co.), } \\
\text { Dr. George T. Rankin and Gilbert C. Marsh. In 1929, Akro Agate } \\
\text { files suit against Peltier Glass Co.-Akro Agate claimed that W. J. } \\
\text { Miller's marble-making machine (Pat. 1,601,699) infringed on } \\
\text { certain parts of H. C. Hill's machine (Pat. 1,164,718). The Court } \\
\text { found in favor of Akro Agate, but this was later reversed by the } \\
\text { U.S. Circuit Court of Appeals. }\end{array}$ \\
\hline Peltier Glass Co. & ca.1920-present & \\
\hline Nivison-Weiskopf & ca.1921-1924 & \\
\hline Christensen Agate Co. & $1925-1933$ & \\
\hline Master Marble Co. & $1930-1941$ & \\
\hline $\begin{array}{l}\text { Lawrence Glass Novelty } \\
\text { Co. }\end{array}$ & ca.1930s & \\
\hline Alox Manufacturing Co. & ca. $1930 \mathrm{~s}-1950 \mathrm{~s}$ & \\
\hline Alley Agate/Glass Co. & $1931-1949$ & \\
\hline $\begin{array}{l}\text { Ravenswood Novelty } \\
\text { Works }\end{array}$ & $1931-1955$ & \\
\hline Vitro Agate Co. & 1938-Present & \\
\hline Champion Agate Co. & 1938-Present & \\
\hline Heaton Agate Co. & 1939-1971 & \\
\hline Master Glass Co. & $1941-1973$ & \\
\hline Jackson Marble Co. & ca.1945 & \\
\hline Cairo Novelty Co. & $1948-1950$ & \\
\hline Marble King, Inc. & 1949-Present & \\
\hline Bogard Co. & $1971-1987$ & \\
\hline JABO, Inc. & 1987-Present & \\
\hline
\end{tabular}


Locally, beginning around the mid-1840s and on through the 1860s, San Antonio's German population grew considerably. During this period, settlement and development of San Antonio's east side-Wards 3 and 4-were spurred on by a large German contingent (Miller and Sanders 1990:35-36). The Alamodome site is located within Ward 4-an area of early San Antonio located east of the San Antonio River and south of E. Commerce Street. By 1878, San Antonio had 3,101 registered voters, of these 26.7 percent were German $(n=828)$ and 23.3 percent were American $(n=723)$. Of the 828 German voters, 42.3 percent resided within Ward $3(n=350)$ and 29.2 percent within Ward $4(n=242)$ (City Directory [CD], San Antonio Public Library, San Antonio, Texas, 1879:52-54). It should be noted that at this early date, among other criteria, only the adult males were eligible to vote. San Antonio's population in 1878 numbered 21,707, with Germans comprising 35 percent $(n=7,610)$ of the total (CD 1879: 52-54).

As a whole, the German immigrants in Texas contributed considerably to its politics, economics, education, and religion. Many of the periodicals, societies and clubs they instituted were explicitly intended to preserve and promote German language and customs (Biesele 1930:208-227). Given this prolific German influence, we can consequently infer that their traditions also affected popular tastes in games and toys.

For example, several local references to toys and, specifically, marbles during this period are available. An 1851 account of San Antonio notes that its stores were selling German toys and other fancies (Schuchard 1951:11). An early San Antonio periodical reports a "chap who wished to know 'how to plant marbles,' as he had only two, and wished to increase his stock" (The Alamo Star $[A S], 6$ May 1854). Within this same periodical is an advertisement; drafted in such a fashion so as to entice the reader to "run down to Dr. Lyons Drug Store on Main street," which was stocked with a large assortment of "amusing toys" $(A S, 29$ July 1854).

A San Antonio Express advertisement touted "Toys And Fancy Goods, At Rates Lower Than Anywhere Else, To Suit All Parties. Call And See, Hertzberg \& Simon" (19 December 1868:2). The 1877 San Antonio City Directory carried an advertisement for " $H$.
Barbeck-Importer and Dealer in Fancy Goods, Stationery, Glassware, Toys, etc." In his account for the year 1882, Newcomb commented that San Antonio's first high school had been completed. He went on to note that the seniors preferred to remain indoors during recreation periods, because the school yard was crowded with fourth-graders playing marbles and spinning tops (Newcomb 1926:109).

The Meyer Pottery (ca. 1887-1962) of Atascosa, located just a few miles southwest of San Antonio, manufactured a variety of toys, notions, and marbles in small quantities. Most were produced as "end-ofthe-day" items, to be distributed to family and friends. Toward the mid-1900s, these were manufactured in some quantity and distributed for resale as souvenir items (Greer 1981:127, 251). Five-and-ten stores, the Alamo Shop, and the Buckhorn Saloon were regular buyers of these resale items (Greer and Black 1971:90).

\section{Marble Types}

The following discussion, adapted from Randall (1971) and Carskadden et al. (1985), presents some of the more specific features of the toy.

\section{Size and Composition}

Typically, regardless of source material, marbles range in size from 0.5 to 1.5 inches in diameter. Stone, clay, and glass are the principal materials for toy marbles, from earliest to latest, respectively. Randall and Webb (1988) offer this chronological scheme on the basis of what we know of our sequential expertise and exploitation, of available naturally occurring material. Although the focus here is on commercially produced varieties, a brief discussion on marbles of other source materials is also submitted.

\section{Stone (ca.1700-1927) (Figure 4-1a, b)}

Paul Baumann (1970) suggests that several mills which manufactured stone marbles were in existence in parts of East Germany since the early $1700 \mathrm{~s}$. Baumann further notes that the industry peaked in the mid-1700s and then again in the mid-1800s. 


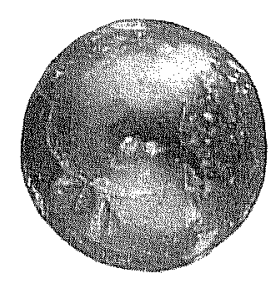

a
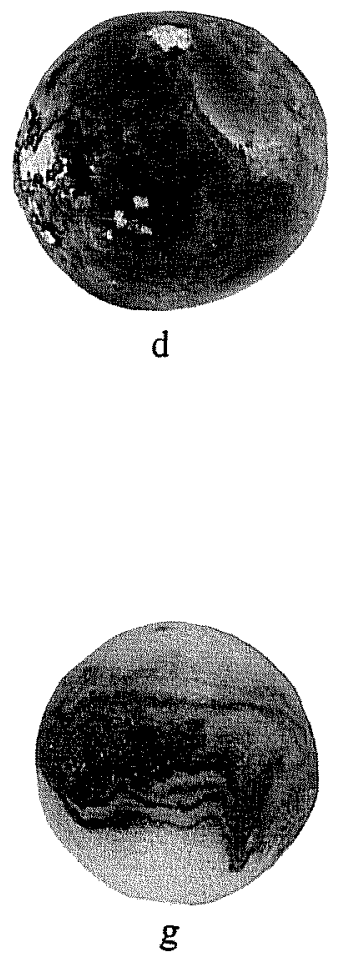

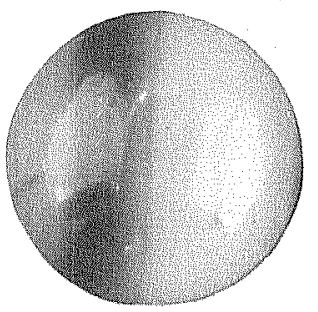

b
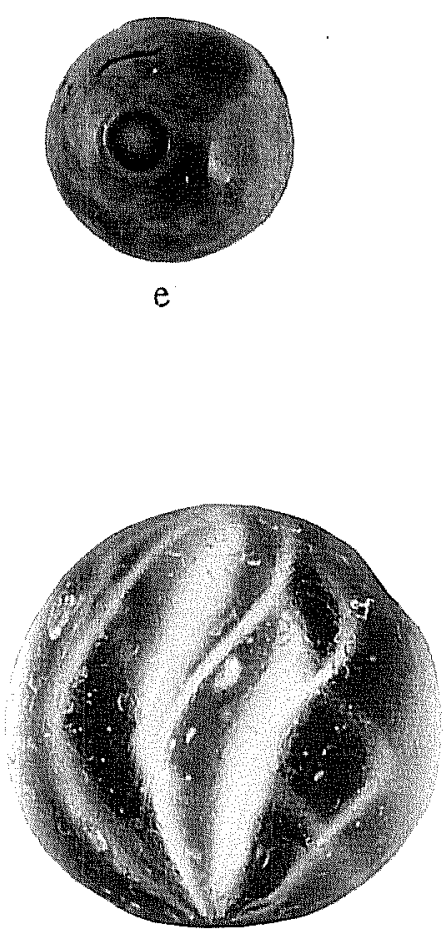

h

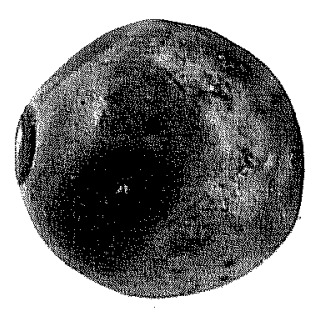

c
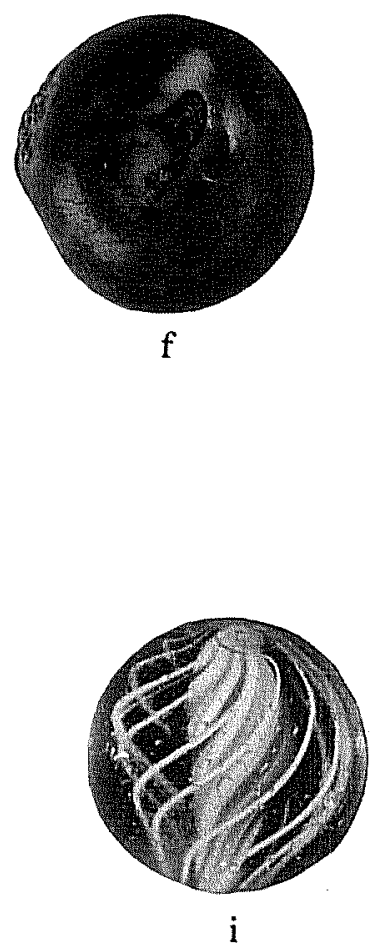

i

Figure 4-1. Marbles from the Alamodome Project. a: handmade, stone, German (Webb site, 41BX897); b: handmade, stone, German, Carnelian agate shooter (Pauly site, 41BX945); c: stoneware, German, Bennington Brown (Haas site, 41BX882); d: stoneware, German, Bennington Brown (Pauly site, 41BX945); e: stoneware, German, Bennington Blue (Pauly site, 41BX945); f: stoneware, German, Bennington Blue (Webb site, 41BX897); g: stoneware, German, Agateware (Webb site, 41BX897); h: handmade glass, German, Transparent Swirl, (Demazieres, 41BX896); i: handmade glass, German, Transparent Swirl, (Demazieres, 41BX896). All shown actual size. 

The earliest archaeological record of stone marbles in the New World is from a seventeenth-century site in Williamsburg, Virginia. Among the cultural material excavated from the site was a collection of agate marbles, which were evidently brought by the immigrants (Randall 1979, cited in Randall and Webb 1988:12).

Stone marbles were quite popular with United States children as "shooters," and remained so well into the nineteenth and early twentieth centuries. This type of marble was relatively expensive and, therefore, constituted a small percentage in any child's marble assemblage. The Carl P. Stirn toy catalog of 1893 lists the cheapest stone marbles at $\$ 2.00 / 100$, while the cheapest glass marbles listed for $\$ 1.50 / 1,000$ (Schroeder 1971).

Stone marbles were made of chalcedony (agate, onyx), limestone (calcite, alabaster), quartz (amethyst, flint), tigereye, jade, opal, and turquoise. The mineral marble, which may have inspired the name for the toy (Randall and Webb 1988:11-12), was also utilized.

Manufacturing of stone marbles varied, and methods appear to relate to the stones' hardness. It appears that the harder chalcedony and quartz varieties were turned by hand; the cube-shaped stones being held up against a grinding wheel and rotated back and forth until spherically shaped. The process results in a less than perfectly round product, but the final polishing served to remove most of the individual grinding facets (Randall and Webb 1988:12). Evidence of this manufacturing process can be detected by holding the specimen so that light reflects from the surface. As the marble is slowly rotated, one will notice that the light bounces off each facet, like small sections of a manysided mirror (Randall and Webb 1988:12).

In contrast, marbles made of limestone, which is less hard and more consistent in composition, were manufactured using a water-power-driven device, or "marble mill." The cube-shaped stones were pressed between the concentric grooves of a beechwood platform and grindstone. Attached to the upper section of the mill, which included the grindstone, is a series of paddles which served to activate (propel) this section as the force of the water pushed up against them (Randall and Webb 1988:12). As illustrated (Randall and Webb 1988:20), the platform and top section of the mill had three concentric grooves, and could have accommodated as many as $\mathbf{3 0}$ stones during each procedure. Randall and Webb (1988:12) suggest that in some rare instances, marbles produced in this manner may display a flat area (a remnant of a face of the cubic stage).

\section{Limestone}

Limestone marbles are usually white, grey, or brown, although many of the limestone marbles were originally dyed various shades of red, blue, yellow, and black. These marbles generally have a smooth finish, but may exhibit small, flat facets on one or more sides, which are remnants of the cubic stage in the manufacturing process.

\section{Agate}

Agate marbles were probably the most well-known, and were popular as "shooters" because they did not chip when they struck other marbles. Agates were made in Germany by at least 1869 , with production reaching a peak in the 1880s (Baumann 1970). These marbles occur in infinite varieties of natural colors, and patterns of banding. The early German agates, and modern hand-held stone marbles, show parallel facets of grinding, which appear very faintly when the marble is held so that the light reflects off the surface.

\section{Alabaster \\ Alabaster marbles were imported from Europe during the mid to late eighteenth and early nineteenth centuries. They are sometimes poorly preserved in archaeological contexts due to the softness of the stone. Alabasters are often whitish or pink, with reddish veins.}

The stone marble industry was jeopardized around the mid-1840s, with the introduction of clay and glass marbles (Carskadden and Gartley 1990b:8). The inevitable demise of stone marbles was marked by the introduction of new and/or improved technologies beginning around 1905, by the up-and-coming United States manufacturers (1986). Adding to this weakened demand was the United States involvement in World War I (1917-1918). Since Germany was the major supplier of toy marbles, United States restrictions on imports served to further impede their availability. Although rapidly on the decline, Baumann (1970) suggests that some German stone marble mills were still active as late as 1927 . 
Clay (ca. 1840-1920)

Germany was the initial and major supplier of porcelain or "China" marbles from the mid-1840s to around 1910 (Carskadden and Gartley 1990a). During this same period, United States production of clay and stoneware marbles was quite popular.

Earthenware or common clay marbles were poorly manufactured as a result of low firing temperatures. These marbles, referred to as "commies," were inexpensive to manufacture, appear frequently in the archaeological record, and were produced up until the 1920s. Stoneware marbles were produced by American potters around the time of the Civil War. These are quite distinguishable due to their grayish coloration, decorations of cobalt blue splashes and an orange peel texture. According to Carskadden and Gartley (1990b) "Chinas" (porcelain marbles) were manufactured using the purest white clays (kaolin/ feldspar clays). These were fired at higher temperatures than the earthenware and stoneware varieties. This allowed for an almost pure white translucent coloration, and resulted in their being impermeable to liquids. This same source tells us that the name China is a spinoff from the name of the porcelain vessels which were originally brought in from Asia.

Literature relating to ceramic marbles, more specifically Chinas, is quite extensive. This is a result of archaeological investigations undertaken in Zanesville, Ohio, and New Orleans, Louisiana (Carskadden and Gartley 1990a).

Earthenware

Earthenware marbles, fired at low temperatures, include several types.

\section{Common clay-"commies"}

Commies were easily manufactured by children, simply by rolling the clay in their hands and baking the round balls in their mother's oven for about 15 minutes. These handmade varieties are usually out-ofround; some show finger or palm prints and/or fingernail impressions. They are usually grey, tan, or reddish-the original colors of the clay and method of firing.
The date of the first commercially produced clay marbles in the United States is thought to be 1884 . Machine or molded-clay marbles were made in the latter half of the nineteenth century; these were often dyed, painted very bright colors, or speckled. Sometimes coloring agents were blended into the clays before firing, but the exact date of the introduction of colored clay marbles is not known. Most machinemade were more perfectly round than their handmade/home-made counterparts. It is not known if European and American varieties can be distinguished from each other. These marbles are generally of a single opaque color, blue, green, purple, pink (or faded red), or white, with mixed colors appearing infrequently. In spite of competition from German handmade glass marbles, and later United States machine made glass marbles, children continued to play with common clays because they were cheap. Common clays were still listed in the 1928 Sears catalogue.

\section{Yellowware}

Yellowware marbles were apparently made by at least one pottery in Zanesville, Ohio, in the $1870 \mathrm{~s}$, and were either unglazed or clear lead glazed.

\section{Pipe clay}

Pipe clay marbles are of low-fired kaolin. Most of these white marbles have a few rather haphazardly applied parallel lines of various colors, applied after firing, encircling the marble. This type was imported from Germany by at least the 1890 s.

\section{Whiteware}

Whiteware marbles are typically out-of-round, porous, partially glazed, and were often decorated with a few concentric lines or spirals.

\section{Crockery Marbles}

Crockery marbles, also known as stoneware marbles, were medium fired. Germany was the center for crockery production in the nineteenth century, and it follows that the Germans developed a crockery marble industry.

\section{Bennington (Figure 4-1c-f)}

Bennington marbles are of a clay base with a blue (cobalt) or brown (manganese) glaze. Collectors call these blue and brown marbles Benningtons because they are of a similar glaze to the Bennington 
kitchenware and dinnerware-apparently no other relationship exists. Benningtons generally have small pock marks on their sides, where they rested against others in the firing process. The peak German Bennington production was probably in the 1880 s and $1890 \mathrm{~s}$, although it is not known at what date Benningtons should start appearing in archaeological contexts (Carskadden et al. 1985). No definite dates of production are available; on the basis of the techniques employed in the production, it might be assumed that it occurred at least in part concurrently with the existence of the Bennington stoneware firm (1842-1858). Judging from the relative abundance and good condition of this type in collections, the production of this type continued long after the terminal date of the firm (Randall 1971).

\section{Agateware (Figure 4-1g)}

Agateware marbles are known from Colonial sites and pre-1850 privies in Cincinnati. These marbles may have been produced by European potteries that made "agate ware" in the mid- to late-eighteenth and early nineteenth centuries. These may have actually been stoneware or porcelain products and included blue-, grey-, or green-swirled clay in a white or grey clay matrix. Some of the agateware marbles resemble the Scroddled ware of the 1850 s from Bennington, Vermont. These marbles are referred to as "lined crockery" marbles by collectors.

\section{Porcelain}

Porcelain marbles were fired at high temperatures, and were of a fine kaolin clay.

\section{Chinas}

Chinas were produced beginning in the last third of the eighteenth century in Germany (Baumann 1970); the closing date is unknown. These are white ceramic marbles, either glazed or unglazed, of kaolin/ feldspar clay. Both glazed and unglazed are often decorated with hand-painted designs; parallel lines, concentric lines or bull's eyes, stars, leaves, and flowers. The designs on the glazed variety appear to consist of a low-fired enamel put on after the glaze had been fired-it is rare to find glazed porcelain marbles on which these designs have been preserved. Advertisements for porcelain marbles have been located in Montgomery Ward and Sears catalogues from 1886 to 1903 . Germany apparently had a thriving porcelain marble industry as early as 1800 , and may have been importing into the United States well before the $1870 \mathrm{~s}$. These marbles exhibit thin colored concentric rings of red, brown, blue, green, or purple, and sometimes include a leaf or flower design or an unpatterned delicate swirly design of various colors.

Hand-painted Chinas appeared in the United States between 1846 and continued through 1910. Archaeological excavations have turned these up in privies and subfloor areas of houses. Although the manufacturing range of these marbles is rather expansive (65 years), Carskadden and Gartley (1990a) propose that they can be dated to within 10 to 20 years by the types of hand-painted decorations (Carskadden and Gartley 1990a).

1. The early period (ca. 1846-1870) is replete with recurring motifs. These motifs include parallel lines of varying widths and colors, the pinwheel, and several bull's-eye. The motifs also included elaborate and realistic flowers.

2. The middle period (ca. 1870-1890) is characterized by a more rapid mode of decorating; more than likely to increase production. The helix and spiral replaced the use of parallel lines and concentric circles while the pinwheel motif ceased to be used.

3. During the late period (ca. 1890-1910), most of the Chinas were being glazed while the motifs were painted onto the glazed surfaces. Due to the high price of these marbles, the market began to dwindle. In order to cut-back costs, manufacturers increased production and the designs suffered considerably. Manufacturers went back to the early period designs and began using only three different colors (green, orange, and black).

\section{Glass (ca. 1846-present)}

Baumann (1970) postulates that glass marbles were first produced in Germany on or about 1846. Small glass factories began to produce glass marbles after a Lauscha glass cottage worker invented the "marbleschere" (marble scissors). This innovation allowed for rapid production of glass marbles of uniform quality. 
As reported, German-manufactured marbles of stone, clay, and glass figured quite prominently with United States retailers. The United States production of marbles did not begin until ca. 1880. By about the latenineteenth and early twentieth centuries, at least three glass marble companies were active in the United States: The Iowa City Flint Glass Mfg. Co. (1880s); the M. B. Mishler Co. of Ravenna, Ohio (1890s); and the Navarre Glass Marble Co. of Navarre, Ohio (1890s).

Today's marbles are made of glass with pigments inserted for color. Most of these originate from companies in five West Virginia towns, due to the close proximity of the resources required for glass production. It is said that the rate of production exceeds a little over 200 a minute, or 350 million per year.

\section{Handmade marbles}

The earliest record of glass marbles is in the fifteenth century (Freeman and Freeman 1962). It is not improbable that some glass marbles were produced by Venetian glass workers, since the techniques employed in producing early Venetian glass trade beads are practically identical (Baumann 1970). Marbles were probably produced sporadically up until 1846 , when Germany began to produce them for export. It can be assumed that none of this type was imported into the United States during its involvement in World War I (1914-1918), when distribution was curtailed if not completely halted. Although still advertised in Sears catalogs until 1923, these handmade marbles may have been stock leftover from before the war. Handmade glass marbles were also produced in the United States, but not until 1880. The German and United States varieties are apparently indistinguishable (Randall and Webb 1988).

Handmade glass marbles are distinguishable from the machine-made type by the presence of two irregular spots at opposite sides. These spots were the points where the marble was twisted and cut from a glass rod, and then ground to a rough finish. One spot is usually more rough, having been cut and ground down, and the other more smooth, having been pushed into a "rounding cup" while hot, and twisted (Baumann 1970).

\section{Transparent and Translucent Swirls}

Transparent and translucent swirls are the most common of the handmade varieties (Figure 4-1h, i).

Transparent. Transparent marbles were made of transparent glass which contained variously colored spiraling threads and ribbons running between the two cut-off marks. The centers, which probably have no chronological significance, include ribbon core; latticino core; solid core; lobed core; coreless; and a minority type of translucent glass, usually amber or blue. The latter had a variety of colored ribbons or threads just under the surface of the glass, with no central core.

Translucent. A common type of translucent swirl is called "onion skin" by collectors. These consist of transparent glass, which is completely covered just under its outer surface by variously colored swirled ribbons, giving the marble an overall translucent appearance. Quite often the colors of the ribbons in the onion skin marble are mottled or spotted.

\section{Opaque Swirls}

These are made of opaque or semi-opaque colored glass, sometimes decorated with multicolored threads or ribbons on or just under the surface of the marble. There are three main categories, all of them fairly rare and possibly having some chronological significance.

Peppermint Swirls. These were fashioned from white opaque glass partially covered with alternating red and blue ribbons. According to folklore these were produced in 1876 in honor of America's centennial celebration.

Clambroth Swirls: These were fashioned from white, or rarely black, opaque glass inlaid with fine, colored glass threads, giving the marble a striped appearance.

Indian Swirls. This type is made of black opaque glass with broad multicolored spiraling ribbons on the marble surface. Sometimes these ribbons appear to have been painted or enameled on the surface.

\section{Miscellaneous Varieties}

Micas or Glimmers. These are made of translucent colored glass containing flecks of mica near the surface, reportedly made in the early 1890 s (CD 1968). 
Lutzs. Lutzs are transparent swirls or onion skins containing ribbons of ground-up copper, resembling gold.

Solid Opaques. This type is defined as white/milk glass or pastel-colored opaque glass marbles.

Sulphides. These are transparent glass marbles with human or animal figures of clay in the center. These were made at least as early as 1878 .

Some early United States producers of handmade marbles:

1. The Iowa City Flint Glass Manufacturing Company may have made swirls between 1880 and 1882 (Baumann 1970).

2. The Sandwich Glass Company of Massachusetts was reportedly producing Lutz-type marbles sometime between 1869 and 1888 (Baumann 1970).

3. The Navarre Glass Marble and Specialty Company of Ohio made marbles between 1897 and about 1902 (Baumann 1970). Purple and white polychrome marbles with cut-off marks have been reported from the old factory site at Navarre, Ohio.

Machine-made marbles

The first marble-making machine was introduced in 1902 in Ohio; by 1905 glass machine-made marbles were being produced in quantities substantial enough to be competitive with the handmade varieties (Baumann 1970; Randall 1971). These were produced in a variety of designs, whose range is so varied that it is beyond the scope of a brief study. In form, they are essentially the same as modern machine-made marbles, with roughened ends being present until only 1926.

The types produced from 1901 to 1926 were transitional, having evidence of cutting and grinding at one end. The distinguishing characteristics of the early machine-made marbles from the handmade types is that they are generally opaque, whereas the handmade varieties were clear. The early machine-made types usually have a thick application of swirling colored glass very near the surface, which can sometimes be felt.

\section{Other Materials}

In considering what may constitute a toy marble, we might also consider a host of other spherical objects. "Things like marbles," as Randall and Webb (1988) refer to them, can be of diverse compositions, such as wood, metal, or plastic. Most can be inferred to have been some sort of game piece and perhaps subsequently, used as a marble.

Although they may have been used as marbles, this class of marbles are not treated in this paper for the following reasons:

1. Familiarity with this form of play strongly suggests that "marbles" of wood and plastic are too light and therefore unsuitable as "shooters"; on the other hand, "steelies" (usually ball bearings) were much too heavy and routinely banned from play due to their potential for damaging the target marbles.

2. We should consider the fact that since one typically played for keeps or "keepsies," the ante (in the form of the target marbles) had to be enticing, of which the aforementioned imitations were not. Consequently, "things like marbles" were unpopular and, in all respects, inappropriate for marble playing.

3. Finally, we cannot ascertain that these types of marbles were specifically manufactured for marble playing, much less attempt to place them in time.

\section{The Game}

One of the first to provide a detailed description of this form of play was Fred Ferretti in The Great American Marble Book (1973). As a result of his investigation, Ferretti concluded that "basically, in all cultures, marbles games fall generally into three categories." These are: (1) chase games in which two or more players alternately shoot at each other along a make- 
shift meandering course; (2) enclosure games in which marbles are shot at other marbles contained within a marked-off circular area; and (3) hole games in which marbles are shot or bowled into holes.

Although these forms of play can be simulated in solitaire, the gist of the game is lost without the benefit of an ante. The main attraction of the game was the fact that we all played for "keeps." As a child (ca. 1965), I lost more marbles to school teachers than I did to other kids.

\section{Summary}

Considering the manufacturing ranges of marbles (Table 4-3) and the occupation span of the Alamodome project area (ca. 1850 through 1950), the use of most varieties for dating sites is limited. However, the comparatively short date range of agate marbles (ca. 1865 to 1890 ), the relatively late date of the first Bennington ceramic marbles (ca.1975), and the beginning dates for manufacture of early and late machine-made glass marbles (ca. 1900 and ca. 1925) could be useful for some purposes. It is also interesting to speculate on the possibility for identifying and dating the presence of young boys in an occupant's family by the approximate date of manufacture of marbles found on a site.

The site inventory of marbles (Table 4-4) shows some interesting differences in marble distribution. First and most obvious is that all but two of the sites investigated contained marbles. These two, the Biesenbach site (41BX890) and the Glaeser site (41BX899) were found to be sufficiently disturbed that the original occupation surface was gone, which suggests a possible explanation for the absence of marbles on these sites. The nearly universal presence of marbles certainly demonstrates the appeal of marble playing throughout the occupation period of the project.

It is also apparent that cheap clay marbles were part of the collection of most youngsters up to the early $1900 \mathrm{~s}$. Houses built after 1910 do not appear to have them.
The only stone marbles were found on the Webb site (41BX897) and the Pauly site (41BX945), both occupied by the $1860 \mathrm{~s}$. The marble from the Pauly site was an agate (Figure 4-1b), which suggests the boy who owned it was not of marble-playing age until after the Civil War. As might be expected, marbles found in the Runge Street area, developed in the 1920s, were nearly all late machine-made glass varieties, still available today.

This chapter is intended to carry forward the research on marbles, on the history of their manufacture and use, particularly on the American scene. We also suggest ways this information could be used to comparatively date and analyze archaeological collections from specific sites. 
Table 4-3. Suggested Manufacturing Ranges

(Adapted from Carskadden and Gartley 1990a)

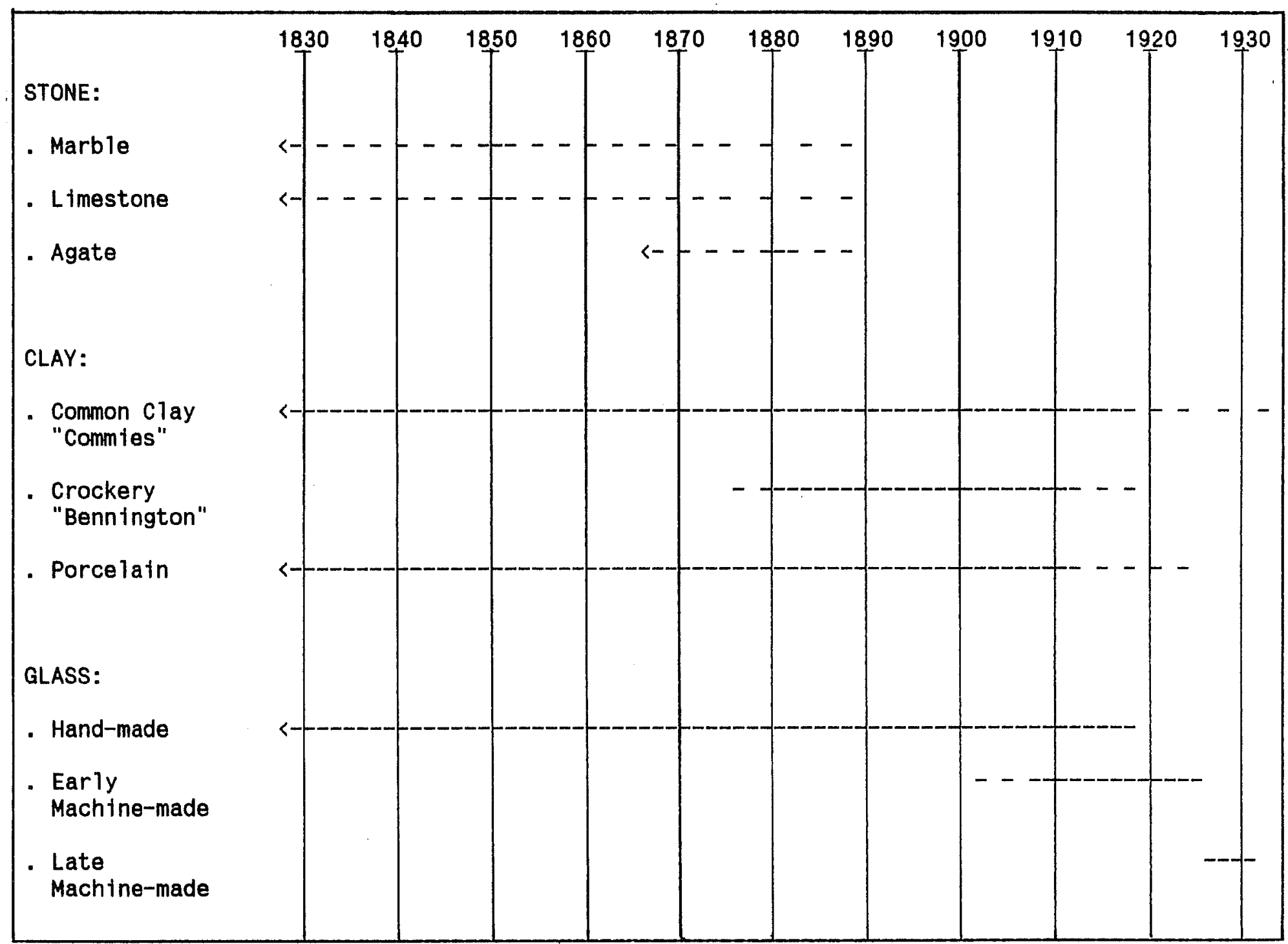


Table 4-4. Marble Inventory, Site Specific

\begin{tabular}{|c|c|c|c|c|c|c|c|}
\hline Site & $\begin{array}{l}\text { Dates of } \\
\text { Occupation }\end{array}$ & $\begin{array}{c}\text { Stone } \\
1700-1927\end{array}$ & $\begin{array}{c}\text { Clay } \\
1840-1920\end{array}$ & $\begin{array}{c}\text { Glass } \\
\text { Handmade } \\
\text { 1846-1904 }\end{array}$ & $\begin{array}{l}\text { Glass-Early } \\
\text { Machine- } \\
\text { made } \\
\text { 1905-1926 }\end{array}$ & $\begin{array}{c}\text { Glass-Late } \\
\text { Machine- } \\
\text { made } \\
\text { 1927-Present }\end{array}$ & Totals \\
\hline 41BX881 & $1893-1922$ & & 3 & & & & 3 \\
\hline 41BX882 & $1900-1970$ & & 7 & 1 & & & 8 \\
\hline 41BX883 & $1884-1987$ & & 11 & & & 8 & 19 \\
\hline 41BX884 & $1883-1990$ & & 2 & & & 22 & 24 \\
\hline 41BX885 & $1892-1990$ & & 2 & & & 6 & 8 \\
\hline 41BX891 & $1857-1925$ & & 1 & & & & 1 \\
\hline 41BX892 & $1855-1926$ & & 1 & & & 1 & 2 \\
\hline 41BX893 & $1899-1990$ & & 1 & & & 14 & 15 \\
\hline 41BX894 & $1910-1990$ & & & & & 9 & 9 \\
\hline 41BX895 & $1882-1990$ & & & & & 10 & 10 \\
\hline 41BX896 & $1856-1990$ & & 2 & & & 20 & 22 \\
\hline 41BX897 & $1866-1989$ & 1 & 11 & 2 & 2 & 6 & 22 \\
\hline 41BX898 & $1850-1904$ & & 1 & & & & 1 \\
\hline 41BX900 & $1858-1926$ & & 4 & 1 & & & 5 \\
\hline 41BX926 & $1882-1904$ & & 1 & & & & 1 \\
\hline 41BX931 & $1920-1990$ & & 1 & & & 3 & 4 \\
\hline 41BX932 & $1880-1990$ & & & & & 2 & 2 \\
\hline 41BX936 & $1920-1990$ & & & & & 1 & 1 \\
\hline 41BX937 & $1880-1990$ & & 1 & 1 & & 3 & 5 \\
\hline 41BX938 & $1890-1920$ & & & & & 3 & 3 \\
\hline 41BX939 & $1920-1990$ & & & & & 7 & 7 \\
\hline $41 B \times 940$ & $1929-1962$ & & & & & 3 & 3 \\
\hline 41BX941 & $1927-1990$ & & & & & 1 & 1 \\
\hline 41BX942 & $1927-1990$ & & & & & 1 & 1 \\
\hline $41 B \times 943$ & $1921-1974$ & & & & & 1 & 1 \\
\hline 41BX944 & $1929-1990$ & & & & & 2 & 2 \\
\hline 41BX945 & $1855-1968$ & 2 & 23 & 2 & 1 & 11 & 39 \\
\hline 41BX955 & $1877-1915$ & & 1 & & & & 1 \\
\hline 41BX956 & $1880-1990$ & & & & & 2 & 2 \\
\hline 41BX957 & $1880-1990$ & & & & & 1 & 1 \\
\hline Totals & & 3 & 73 & 7 & 3 & 137 & 223 \\
\hline
\end{tabular}




\section{References Cited}

Alamo Star, The $(A S)$ [San Antonio, Texas]

1854 [article] 6 May:2.

1854 [advertisement] 29 July:3.

Aries, P.

1962 Centuries of Childhood: A Social History of Family Life. Jonathan Cape, New York.

Baumann, P.

1970 Collecting Antique Marbles. Wallace-Homestead, Des Moines.

Benjamin, G. G.

1910 The Germans in Texas: A Study in Immigration. Reprinted 1974. Jenkins, Austin.

Biesele, R. L.

1930 The History of the German Settlements in Texas. German-Texan Heritage Society, San Marcos, Texas.

Carskadden, J., and R. Gartley

1990a A Preliminary Seriation of 19th-Century Decorated Porcelain Marbles. Historical Archaeology 24(2):55-69.

1990b Chinas: Hand-Painted Marbles of the Late 19th Century. McClain, Parsons, West Virginia.

Carskadden, J., R. Gartley, and E. Reeb

1985 Marble Making and Marble Playing in Eastern Ohio: The Significance of Ceramic, Stone, and Glass Marbles in Historic Archaeology. Proceedings of the Symposium on Ohio Valley Urban and Historic Archaeology 3:86-96.

Ferretti, F.

1973 The Great American Marble Book. Workman, New York.

Fraser, A.

1966 A History of Toys. Delacorte, New York.

Freeman, G. L., and Freeman R. S.

1962 Yesterday's Toys. Century House, Watkins Glen, NY.

Gartley, R., and J. Carskadden

1987 Marbles from an Irish Channel Cistern, New Orleans, Louisiana. Proceedings of the Symposium on Ohio Valley Urban and Historic Archaeology 5:112-125.

Greer, G. H.

1981 American Stonewares, The Art and Craft of Utilitarian Potters. Schiffer, Exton, Pennsylvania.

Greer, G. H., and H. Black

1971 The Meyer Family: Master Potters of Texas. Trinity University Press, San Antonio.

Grober, $\mathbf{K}$.

1928 Children's Toy of Bygone Days. Frederick A. Stokes, New York. 
Grossman, F.

1973 Pieter Bruegel: Complete Edition of the Paintings. Phaidon, London.

Kuhnert, H. (editor)

1928 German Commerce Yearbook: 1928. Westermann, New York.

Miller, C., and H. T. Sanders (editors)

1990 Urban Texas: Politics and Development. Texas A\&M University Press, College Station.

Newcomb, P.

1926 The Alamo City. Standard, San Antonio.

Randall, M. E.

1971 Early Marbles. Historical Archaeology 5:102-105.

1986 The Use of Patent Records in Historical Archaeological Research: Examples from the Glass Marble Industry. Proceedings of the Symposium on Ohio Valley Urban and Historical Archaeology 4:159-164.

Randall, M. E., and D. Webb

1988 Greenberg's Guide to Marbles, edited by M. A. Davis. Greenberg, Sykesville, Maryland.

Remise, J., and J. Fondin

1967 The Golden Age of Toys. English text by D.B. Tubbs. Edita Lausanne, Greenwich, Connecticut.

San Antonio Express (SAE)

1868 [advertisement] December 19.

Schroeder, J. J., Jr. (editor)

1971 The Wonderful World of Toys, Games \& Dolls: 1860-1930. DBI, Northfield, Illinois.

Schuchard, E.

1951 100th Anniversary-Pioneer Flour Mills, San Antonio, Texas: 1851-1951. Naylor, San Antonio.

Shahar, S.

1990 Childhood in the Middle Ages. Routledge, New York.

Stickland, I.

1973 The Voices of Children: 1700-1914. Barnes and Noble, New York.

Stolper, G.

1940 German Economy: 1870-1940. Reynal \& Hitchcock, New York. 


\section{Supplementary Readings}

Dickson, $\mathbf{P}$.

1988 Kids and Collectors are Still Knuckling Down to Business. Smithsonian, April:94-103.

DiNoto, A. (editor)

1979 The Encyclopedia of Collectibles: Lalique to Marbles. Time-Life Books, Alexandria, Virginia.

Galvan, J. L.

1982 Marble Terminology in a Bilingual South Texas Community: A Sociolinguistic Perspective on Language Change. In Spanish in the United States: Sociolinguistic Aspects, edited by J. Amastae and L. Elias-Olivares, pp. 413-430. Cambridge University Press, Cambridge.

Grist, E.

1992 Everett Grist's Machine-Made \& Contemporary Marbles. Collector, Paducah, Kentucky.

1992 Antique \& Collectible Marbles: Identification \& Values. Collector, Paducah, Kentucky.

Highley, L.

1976 Feature 9: A Latrine Pit Littered with Late 19th Century Artifacts. Manuscript on file, Center for Archaeological Research, The University of Texas at San Antonio. Katz, San Antonio.

Ketchum, W. C., Jr.

1981 Toys and Games. Smithsonian Institution, Washington, D.C..

King, C. E.

1978 The Encyclopedia of Toys. Crown, New York.

Krueger, M. A. P.

1976 Second Fatherland: The Life and Fortunes of a German Immigrant. Texas A\&M University Press, College Station.

Maguire, J.

1992 Game of Marbles Has Become Virtual Lost Art. San Antonio Light. September 27:B6.

Miller, R. W.

1975 Wallace-Homestead: Price Guide to Toys. Wallace-Homestead, Des Moines.

Moncure, H. B.

1984 Historical Archeology at the Walling Cabin-41RK104, Rusk County, Texas. Texas Archeological Society Survey, Research Report 88, Austin.

Newson, J., and E. Newson

1979 Toys and Playthings. Pantheon, New York.

Oakley, R.

1989 Games Children Play Around the World: Games with Sticks, Stones and Shells. Marshall Cavendish, New York. 
Roberson, W. R.

1974 The Carrington-Covert House, Archaeological Investigation of a 19th Century Residence in Austin, Texas. In Texas Historical Commission, Office of the State Archaeologist 25:51-52.

Stirn, C. P.

1990 Turn-of-the-Century Dolls, Toys and Games: The Complete Illustrated Carl P. Stirn Catalog from 1893. Dover, New York.

Sutton-Smith, B.

1972 The Folkgames of Children. University of Texas Press, Austin.

Tunnell, C. D., and H. P. Jensen, Jr.

1969 Archeological Excavations in Lyndon B. Johnson State Park (Summer, 1968). State Building Commission Archeology Program 17, Austin.

Weaver, M. P.

1981 The Aztecs, Maya, and Their Predecessors. Academic, New York.

White, G.

1971 Antique Toys and Their Background. B. T. Batsford, London.

Wigginton, E. (editor)

1980 Foxfire 6. Anchor Books, Garden City, New York. 


\title{
Chapter 5
}

\section{Making the Man: Clothing Remains from the Alamodome Project}

\author{
Barbara A. Meissner
}

\section{Introduction}

Clothing is one of the primary ways that people send signals to each other regarding their status (economic or social), and current intentions (play, casual social gathering, formal occasion, work). Clothing can provide a great deal of information about the socioeconomic standing of the wearer. Unfortunately, most clothing items are not very durable, at least by archaeological standards. For the most part, archaeological evidence of clothing consists of the fasteners used to hold it together. Buttons, hook-andeye fasteners, zippers, and snaps are usually all that is recovered from archaeological contexts. These items do provide some clues to dating and socioeconomic status.

This report is concerned with the remains of clothing and clothing-related items from 28 historic sites excavated during the Alamodome Project. These remains are associated with all periods of habitation of the area, i.e., from about 1853 to 1990 . In total 1,069 items related to clothing were recovered during the project; of those, 732 were buttons. The clothing items will be discussed by site, starting with a list of buttons recovered and a discussion of the more interesting buttons. Other clothing items will then be listed and discussed.

\section{Buttons}

Where and when buttons were first used as fasteners is a source of some controversy. The button-like objects found in Egyptian sites were probably decorations rather than fasteners, as the Egyptians did not wear clothing that needed them (Albert and Kent 1949:xv) Some feel that buttons are one of those inventions probably made in prehistory (Epstein 1968:13). Their use became most noticeable in Europe during the Dark Ages. Button makers were among the many craftsmen's guilds in France after the thirteenth century (Albert and Kent 1949:xvi).

Until the middle of the nineteenth century fancy decorative buttons were largely a men's clothing fashion, while women seldom wore buttons at all (Epstein 1968:39). The middle of the nineteenth century brought the mechanization of most kinds of button-making and the sudden popularity of large numbers of buttons as trim for casual dresses. Though evening wear was still buttonless, the ladies of the last decades of the 1800s often wore rows of buttons of all sizes on their "walking dresses," "skating dresses," and "street suits" (Blum 1974). For the rich, many of these were handmade works of art, made of gold and silver, inlaid with mother-of-pearl, jeweled, or decorated with tiny mosaics constructed of seed pearls and bird feathers. Most buttons were, however, utilitarian. The Sears Roebuck catalog for 1897 included two styles of fancy dress buttons in several sizes, but most of its wares were intended for practical uses. Plain shell buttons were sold by the gross, as were plain metal 
buttons for pant flies and bone buttons for underwear (Israel 1968:319-20).

Buttons are a common find in historic archaeological sites, as they are small, easily lost items, usually made of highly durable substances such as ceramics or glass. Though the basic dress/shirt button has remained more or less stable, differing only in composition, throughout the period under consideration in this report, other buttons are more diverse, with changes of style and technology. These changes can provide insight into dating and socioeconomic class.

\section{Button Materials}

Buttons have been made with almost any material both shapeable and hard enough to stand up to the wear. A list of the materials used in buttons found at the Alamodome follows, with a brief discussion of the material.

\section{Bone}

Bone buttons have been very popular since the beginning of buttons, and were probably one of cheapest available until the mechanization of button manufacture. They are sometimes difficult to differentiate from vegetable ivory. Examination under a microscope, however, reveals the tiny Haversian canals found in the lamellar bone used to make buttons (Webster and Webster 1974:49), while vegetable ivory does not have these canals. Since the eighteenth century, bone buttons were most popular for underwear (Albert and Kent 1949:25).

\section{Ceramic}

Before 1840 , ceramic buttons were expensive because the clay was molded by hand. Soon after, a machinemethod was first used for the job and inexpensive ceramic buttons became commonplace (Epstein and Safro 1991:74). A fine powder of kaolin clay, either dry or dampened, was pressed into molds and then fired (Albert and Kent 1949:35). This method usually leaves a few tiny pits or a rough area on the bottom of the button, making the differentiation between ceramic and glass buttons easier. Ceramic buttons have sometimes been mistaken for glass because they are often quite translucent (Pool 1987:281). In fact, milk glass was first devised as an imitation of Chinese porcelain (Albert and Kent 1949:50). However, the plain, white four-hole shirt/ dress buttons so common in historic sites are ceramic (Parsons and Burnett 1984:429). They are referred to as "agate" buttons in nineteenth-century catalogs (Pool 1987:281). Ceramic buttons are occasionally incorrectly called milk glass, even in archaeological literature (Roberson 1974:46). By 1850 a wide variety of sizes were common, and remained so until about 1910 (Albert and Kent 1949:35).

\section{Composition}

Composition is a mixture of cellulose and glue which is pressed into molds and allowed to harden. Other materials were often added to provide unusual textures and colors (Pool 1987:286). These buttons were largely replaced by celluloid, casein, and Bakelite by World War I and by more modern plastics after World War II (Whittemore 1992:11).

\section{Fabric}

Fabric buttons are not often found intact in archaeological context, but the metal backing for such buttons are fairly common. Fabric buttons were used mostly by the aristocracy until the 1850s (Epstein 1968:44).

\section{Glass}

Glass can be shaped into buttons, usually of a fancy design. Milk glass buttons are occasionally seen, but in general, buttons which appear to be milk glass are actually ceramic. The most common glass buttons in this collection are black, intended as imitation jet. There was a fashion for jet buttons after Queen Victoria's husband died, and jet (and imitations) continued to be a popular style until World War I (Whittemore 1992:15). 


\section{Gutta Percha}

Gutta Percha is a natural polymer, the purified sap of the gutta percha tree. Very similar to India rubber, gutta percha was discovered around 1842 (Albert and Kent 1949:66). This material was used for many items which are today made of plastic, including buttons. Buttons made of gutta percha are often found in poor condition in archaeological contexts.

\section{Hard Rubber}

Hard rubber was first used to make buttons shortly after the process of vulcanization was patented by Goodyear in 1844 and improved by his son in 1851 (Hughes and Lester 1991:48). None of the buttons recovered from the Alamodome Project have patent marks. The Goodyear Company was an ardent protector of its patent rights (Berendt 1989:42). Therefore, it is likely that they were all made after 1870 when the patent rights for hard rubber expired (Hughes and Lester 1991:48).

\section{Horn}

Horn was a popular material for buttons on men's clothing, especially for "sporting" (i.e. hunting) wear (Whittemore 1992:10). Horn could be heated and formed almost like plastic. Unfortunately, horn is one of the least durable button materials in archaeological context, and only one horn button was found at the Alamodome.

\section{Metal}

Metal buttons have the advantage of being easily moldable, embossable, and engraveable, and the disadvantage of being susceptible to corrosion. Most metal buttons found at the Alamodome Project were badly corroded, and details of their design and construction were no longer visible. The exception to this is buttons made of copper alloys, especially brass. Though corroded, these buttons were often in good enough condition that many details of construction and even very fine embossing were preserved. Many brass buttons have the remains of gilding on them. Gilding is a thin wash of gold sealed to the brass, a process invented around 1790 in Birmingham, England (Epstein 1968:40).

\section{Mica}

Mica, the layered, transparent mineral, is sometimes used for buttons. These fragile buttons were called isinglass. All the mica buttons in this collection are highly fragmented and in very poor condition.

\section{Plastic}

Plastic, in this case meaning modern man-made polymers, has been used to make buttons of many shapes and colors. Bakelite is one of the earliest manmade plastics. It was first patented in 1909 (Harpur 1982:30), and was soon used for button manufacture. Celluloid is another early manufactured plastic. It was invented in 1869 (Collier 1988:19), but was apparently used for buttons only after World War I. Both early plastics were replaced by modern plastics after World War II.

\section{Shell, Pearl, Mother-of-Pearl}

Shell, pearl, and mother-of-pearl buttons can be made from either marine or freshwater shell, though the marine are generally more richly iridescent (Albert and Kent 1949:58). Most are made from bivalves, such as oysters, but a few are made from marine snails of the Trochus and Turbo genera (Hughes and Lester 1991:230). Buttons made from freshwater mussels have a rather dull, yet attractive surface. Colors vary from pure white, shades of pink and purple, light to dark tan, and light to very dark grey. Machine-cut shell buttons replaced hand-cut starting about 1850 (Albert and Kent 1949:59).

\section{Vegetable Ivory}

Vegetable ivory is the name given to items carved from the South American corozo nut. The first vegetable ivory buttons manufactured in Europe appeared in 1862 (Albert and Kent 1949:72). Vegetable ivory could be dyed many colors, and was a popular and fairly cheap button. Its use for military 
clothing buttons declined sharply during World War I when it was discovered that the rats in the trenches were partial to these buttons (Whittemore 1992:19), but vegetable ivory buttons continued to be a popular variety until after World War II and the coming of modern plastics (Albert and Kent 1949:74). The vegetable ivory buttons recovered at the Alamodome were usually undyed; or they may have been colored with water-soluble pigments which did not withstand burial.

\section{Wood}

Wood buttons are fairly easily broken, and are not as durable as many other materials. They are often stained a dark color.

\section{Summary}

Table 5-1 shows the composition of all the buttons recovered from the Alamodome Project. Clearly, shell and ceramic buttons, both very utilitarian, were the most common. Figure 5-1 shows the variation in button composition percentages across the 28 sites.

\section{Button Types}

By far the most common type of button found during the Alamodome Project was the plain, white (or pearl) dress/shirt button. These buttons generally are one of three sizes: $1.0,1.1$ or $1.6 \mathrm{~cm}$. The ceramic version usually has four holes and a well. The shell version usually has two holes, and either a shallow well or a catseye design. A variation of these buttons is the ceramic "pie crust" design (Pool 1987:282), in which the flat rim around the well is embossed with shallow lines. Shell buttons sometimes have fancier designs cut into them.

Shortly after the invention of the ceramic button machinery, it became the practice for some ceramic buttons to be transfer printed with calico and gingham patterns intended to match particular fabrics (Epstein and Safro 1991:74). Ceramic buttons were also sold with their rims painted in various colors (Montgomery Ward 1969:85).
Collar buttons are another common type. They are generally made of ceramics. The most common type is a ceramic half-ball shape with a metal wire inserted in the flat back. This wire was attached to an identical button on the other end (see illustration). Some collar buttons are of the "stud" type. Like studs for shirt buttons, or cuff links, these collar buttons consisted of a large flat backing attached to a smaller, usually decorated front. Cuff buttons are usually metal and usually identified by the metal wire attached to the back. In a complete button, this wire would have been attached to the second, usually identical button. As with collar buttons, they were pushed through button holes in each side of the cuff, which was held closed by the short wire between them.

Shoe buttons were usually in one of two forms. One was a small dome-shaped button with a self or wire shank. The other is a fat disk shape with a wire all the way through it.

Buttons for work clothing, especially overalls, were usually made of metal. Some had manufacturers' trademarks embossed on them, but for the most part they were plain metal buttons with deep wells and four sewing holes.

"Hand snap" or "Bachelor's" buttons were sold in the Sears catalog. These buttons were sold expressly for men under the assumption that they could not be expected to sew on missing buttons. One piece was placed on each side of the fabric, and then snapped together (Israel 1968:320).

In total, 15 military uniform buttons were recovered during the Alamodome Project. They represent all periods of U.S. military uniform buttons from the Civil War to modern times. Most are "General Service" buttons, which were worn by enlisted men and by officers after 1902 (before 1902, officers had buttons which differed according to corps, i.e., artillery, ordinance, engineering, etc. [see Wyckoff 1984]). Three styles of General Service buttons were recovered at the Alamodome. The oldest design, a spread eagle with narrow high wings and a curved neck, was used between 1854 and about 1872 (Wyckoff 1984:88). In about 1872, at the time when an entire new set of uniforms was issued by the Army (Chappell 1972:15), the spread eagle device was 
Table 5-1. Composition of Buttons from the Alamodome Project

\begin{tabular}{|c|c|c|c|c|c|c|c|c|c|c|c|c|c|c|c|}
\hline & Ceramic & Shell & Metal & Plastic & Bone & Wood & Hrd. Rub. & Gut. Per. & Comp. & Veg. Ivory & Glass & Horn & Mica & Total & $\%$ of Total \\
\hline $41 \mathrm{BX} 881$ & 1 & 8 & 4 & 1 & 0 & 0 & 1 & 0 & 0 & 2 & 0 & 0 & 0 & 17 & $2.32 \%$ \\
\hline $41 \mathrm{BX} 882$ & 2 & 7 & 0 & 1 & 0 & 0 & 1 & 0 & 0 & 0 & 0 & 0 & 0 & 11 & $1.50 \%$ \\
\hline $41 \mathrm{~B} \times 883$ & 15 & 21 & 8 & 8 & 1 & 0 & 1 & 1 & 1 & 1 & 0 & 1 & 0 & 58 & $7.92 \%$ \\
\hline $41 \mathrm{BX884}$ & 4 & 20 & 4 & 10 & 1 & 0 & 1 & 2 & 0 & 1 & 0 & 0 & 2 & 45 & $6.15 \%$ \\
\hline $41 \mathrm{BX} 885$ & 0 & 1 & 2 & 2 & 0 & 0 & 0 & 0 & 0 & 0 & 0 & 0 & 0 & 5 & $0.68 \%$ \\
\hline $41 B \times 890$ & 4 & 0 & 0 & 0 & 1 & 0 & 0 & 0 & 0 & 0 & 0 & 0 & 0 & 5 & $0.68 \%$ \\
\hline $41 \mathrm{BX} 891$ & 0 & 0 & 1 & 0 & 0 & 0 & 0 & 0 & 0 & 0 & 0 & 0 & 0 & 1 & $0.14 \%$ \\
\hline $41 \mathrm{BX} 892$ & 5 & 0 & 0 & 1 & 1 & 0 & 0 & 0 & 0 & 0 & 0 & 0 & 0 & 7 & $0.96 \%$ \\
\hline $41 \mathrm{BX} 893$ & 1 & 2 & 6 & 2 & 1 & 0 & 0 & 1 & 0 & 0 & 2 & 0 & 0 & 15 & $2.05 \%$ \\
\hline $41 B \times 894$ & 0 & 6 & 1 & 13 & 0 & 0 & 0 & 0 & 0 & 0 & 0 & 0 & 0 & 20 & $2.73 \%$ \\
\hline $41 \mathrm{BX} 895$ & 1 & 4 & 4 & 1 & 0 & 0 & 0 & 0 & 0 & 0 & 0 & 0 & 0 & 10 & $1.37 \%$ \\
\hline $41 \mathrm{BX} 896$ & 14 & 78 & 15 & 23 & 1 & 0 & 2 & 2 & 0 & 4 & 5 & 0 & 0 & 144 & $19.67 \%$ \\
\hline $41 \mathrm{BX897}$ & 65 & 22 & 13 & 3 & 2 & 1 & 0 & 2 & 0 & 0 & 1 & 0 & 0 & 109 & $14.89 \%$ \\
\hline $41 \mathrm{BX898}$ & 0 & 1 & 0 & 0 & 0 & 0 & 0 & 0 & 0 & 0 & 0 & 0 & 0 & 1 & $0.14 \%$ \\
\hline $41 B \times 900$ & 11 & 21 & 1 & 0 & 0 & 0 & 0 & 0 & 0 & 0 & 0 & 0 & 0 & 33 & $4.51 \%$ \\
\hline $41 \mathrm{BX} 931$ & 2 & 2 & 1 & 0 & 0 & 0 & 0 & 0 & 0 & 0 & 0 & 0 & 0 & 5 & $0.68 \%$ \\
\hline $41 \mathrm{BX} 932$ & 0 & 13 & 0 & 19 & 0 & 0 & 2 & 2 & 0 & 0 & 0 & 0 & 0 & 36 & $4.92 \%$ \\
\hline $41 \mathrm{BX} 936$ & 0 & 10 & 1 & 5 & 0 & 0 & 0 & 0 & 0 & 0 & 0 & 0 & 0 & 16 & $2.19 \%$ \\
\hline $41 \mathrm{BX} 937$ & 0 & 5 & 1 & 4 & 0 & 0 & 4 & 0 & 0 & 0 & 0 & 0 & 0 & 14 & $1.91 \%$ \\
\hline $41 \mathrm{BX} 938$ & 1 & 3 & 4 & 1 & 0 & 0 & 0 & 0 & 0 & 0 & 0 & 0 & 0 & 9 & $1.23 \%$ \\
\hline 41BX939 & 0 & 7 & 1 & 3 & 0 & 0 & 2 & 0 & 0 & 0 & 0 & 0 & 0 & 13 & $1.78 \%$ \\
\hline $41 \mathrm{BX} 940$ & 0 & 4 & 0 & 8 & 0 & 0 & 0 & 0 & 0 & 1 & 0 & 0 & 0 & 13 & $1.78 \%$ \\
\hline 41BX941 & 0 & 1 & 0 & 1 & 0 & 0 & 0 & 0 & 0 & 0 & 0 & 0 & 0 & 2 & $0.27 \%$ \\
\hline $41 \mathrm{BX} 942$ & 1 & 0 & 1 & 3 & 0 & 0 & 2 & 0 & 0 & 0 & 0 & 0 & 0 & 7 & $0.96 \%$ \\
\hline 41BX943 & 0 & 0 & 0 & 6 & 0 & 0 & 0 & 0 & 0 & 0 & 0 & 0 & 0 & 6 & $0.82 \%$ \\
\hline $41 \mathrm{BX} 945$ & 64 & 12 & 22 & 4 & 5 & 1 & 1 & 0 & 0 & 13 & 1 & 0 & 0 & 123 & $16.80 \%$ \\
\hline $41 \mathrm{BX} 956$ & 0 & 0 & 0 & 5 & 0 & 0 & 0 & 1 & 0 & 0 & 0 & 0 & 0 & 6 & $0.82 \%$ \\
\hline $41 \mathrm{BX} 957$ & 0 & 0 & 0 & 1 & 0 & 0 & 0 & 0 & 0 & 0 & 0 & 0 & 0 & 1 & $0.14 \%$ \\
\hline Totals & 191 & 248 & 90 & 125 & 13 & 2 & 17 & 11 & 1 & 22 & 9 & 1 & 2 & 732 & $100.00 \%$ \\
\hline$\%$ of Total & $26.09 \%$ & $33.88 \%$ & $12.30 \%$ & $17.08 \%$ & $1.78 \%$ & $0.27 \%$ & $2.32 \%$ & $1.50 \%$ & $0.14 \%$ & $3.01 \%$ & $1.23 \%$ & $0.14 \%$ & $0.27 \%$ & $100.00 \%$ & \\
\hline
\end{tabular}




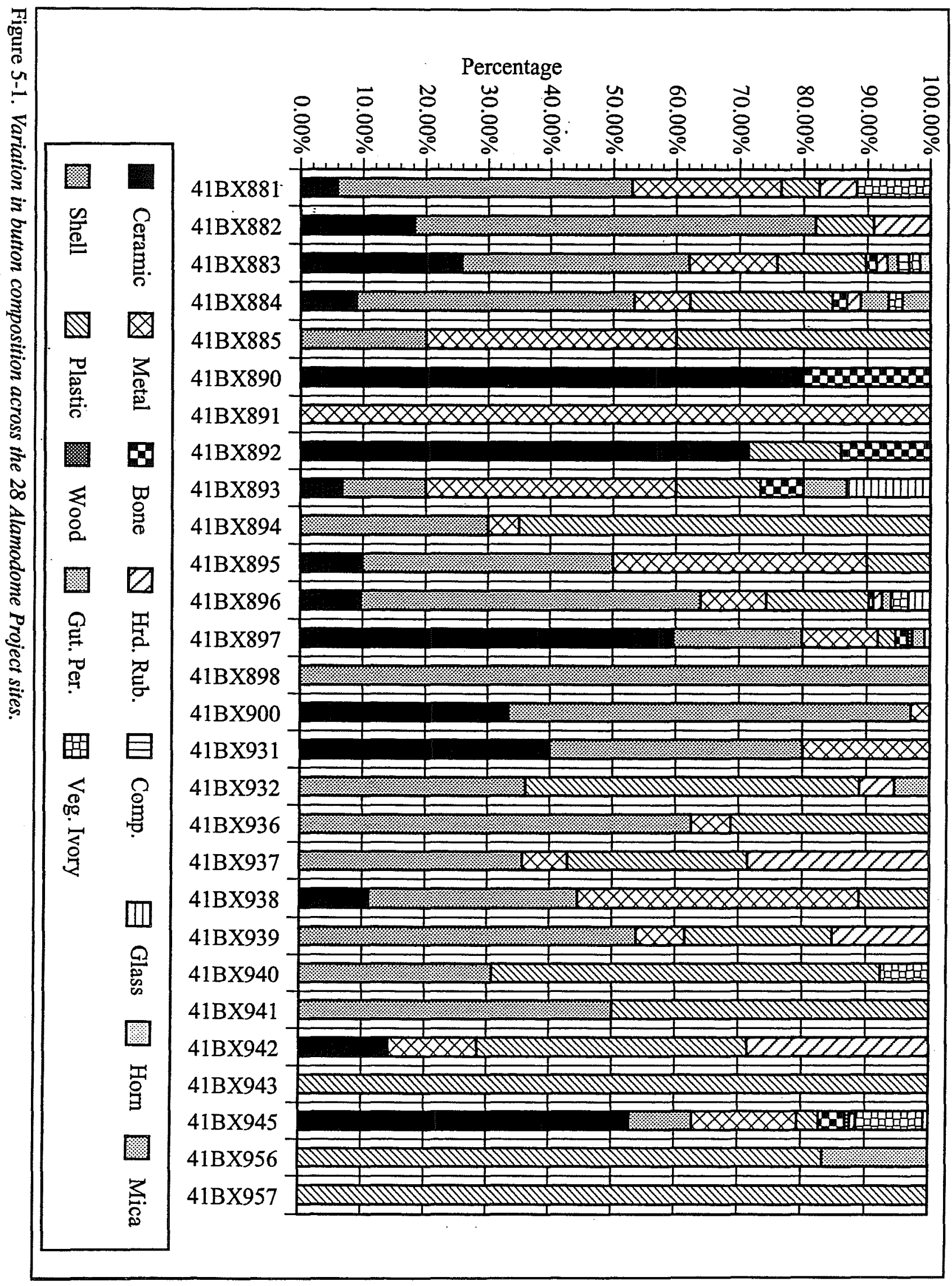


changed somewhat, with the wings shorter and thicker, and the neck held almost straight up. This is often referred to as a "Prussian" eagle (Wyckoff 1984:91). This design was used until 1902, when a design copying the Great Seal of the United States became standard for all, including officers. Backmarks, i.e., the markings placed on the back of military buttons by manufacturers, often provide a tighter date than the front of the button, which may have been in use for several decades (McGuinn and Bazelon 1990).

\section{Button Sizes}

Alhough a few metal buttons were sold without reference to their size, most buttons were sold in sizes defined by "lines," from the French lignes. There were 40 lines to the inch (Herskovitz 1978:37) A conversion chart of lines to centimeters of the most common sizes is given in Table 5-2.

Most shirt and/or dress buttons are 1.0-1.1 or 1.5-1.6 $\mathrm{cm}$ in diameter. Buttons smaller than this are usually either glove buttons, buttons for baby clothes, or shoe buttons. Buttons larger than this are usually coat or cloak buttons.

\section{Other Clothing Remains and Clothing-Related Items}

\section{Fasteners}

Most clothing remains other than buttons are also fasteners. Eyelets, zippers, hook-and-eye fasteners, and snaps were recovered during the Alamodome project.

The zipper, originally called the "clasp locker," was first patented in 1891. The patent was refined about
1913, and "hookless fasteners" began to be used for corsets, gloves, wallets and other small jobs. In 1925, looking for a more attractive name for the hookless fasteners on their new rubber boots, Goodyear Company came up with the word "zipper," and registered it (Berendt 1989:42). Zippered flies, considered vulgar, were not used for anything but workmen's clothes until 1934, when it was noticed that certain members of the British Royal Family were wearing zippered flies on all but the most formal of their outfits. Zippered flies had suddenly lost their vulgarity, and by 1937 , Goodyear failed to maintain legal exclusivity of the word zipper because it had "entered the English language" (Berendt 1989:42).

The metal eyelet, a ring of metal used to support the edges of a hole in fabric or leather in both clothing and shoes, was invented in 1828 , initially devised to allow extremely tight lacing on corsets (Finch 1991:343).

The hook-and-eye fastener is quite old, present in portraits by the seventeenth century (Cunnington and Cunnington 1951:19). Though still in use during the period under study at the Alamodome, they had been largely replaced by snaps, except for brassiere fasteners and occasionally to fasten the necks of dresses.

Snaps are a late nineteenth century invention. The original design was a metal frame with perforated edges which were forced slightly apart by the insertion of the "male" part of the snap. The tension on the metal acted as a kind of spring, which pinched the inserted part hard enough to hold it. About 1900 the "S" spring type, in which the male end is held with a small wire spring, was developed (Cunnington and Cunnington 1951:19-20). These two types are still in use today.

Table 5-2. Lines to Centimeters Conversion

\begin{tabular}{|c|r|r|r|r|r|r|r|r|r|}
\hline lines & 14 & 16 & 18 & 20 & 28 & 30 & 32 & 36 & 38 \\
\hline $\mathbf{c m}$ & .9 & 1.0 & 1.1 & 1.2 & 1.5 & 1.6 & 1.7 & 2.2 & 2.3 \\
\hline
\end{tabular}


The hose supporter was first seen in about 1878. These supporters came in two pieces, with a rubber, or sometimes metal, knob on the back piece, over which the stocking fabric is placed, and the metal loop in which the rubber knob and the fabric are caught. Before that time, hose and stockings were held up with garters (Cunnington and Cunnington 1951:180).

Strap fasteners, often no more than two loops of metal through which the strap is wound, vary greatly in size and complexity. Everything from overalls, to hose supporters, to baby clothes may use strap fasteners.

Buckles are another common find in archaeological sites. Unfortunately, they are often in very poor condition because they are usually made of iron. In some cases differentiating between buckles that are horse tack and those that are for human use is difficult. For this report, buckles which are shaped to allow for a very thick strap are assumed to be horse tack.

\section{Button Hooks}

Fastening long rows of tiny buttons, especially when there is considerable tension on them, is greatly facilitated by the use of a button hook. A button hook is inserted through the button hole, hooks the button, and pulls the button through the button hole. Button hooks are especially useful in buttoning shoe buttons and were sometimes also used for buttoning corsets.

\section{Shoes}

The use of machinery to aid in the construction of shoes began in the United States, around 1811, when a machine was used to make the little wooden pegs used to hold the shoe together. By 1843, the use of wooden pegs for much of the shoe, especially the heel, was standard (Anderson 1969:58). A machine to sew soles to uppers largely replaced the wooden pegs after about 1862 (Anderson 1969:59). Hard rubber inserts for shoe heels were used during the $1850 \mathrm{~s}$, but it was not until 1895 that all rubber heels were used (Anderson 1969:59). With the exception of the practice of gluing the sole to the upper, which became practical in 1926, the various methods of shoe production have not changed since 1912 (Anderson 1969:62). 


\section{Clothing Artifacts from the Alamodome Project}

\section{Oeffinger Site (41BX881)}

Twenty-four clothing items were recovered from this site. Button descriptions are given in Table 5-3, with notes following. Other clothing items are presented in Table 5-4.

Table 5-3. Buttons from the Oeffinger Site

\begin{tabular}{||c|l|c|l||}
\hline \hline Count & \multicolumn{1}{|c|}{ Composition } & Diameter $(\mathbf{c m})$ & \multicolumn{1}{|c|}{ Notes } \\
\hline 1 & Ceramic fragment & $?$ & Fragment \\
\hline 1 & Shell & .9 & See \#1 below \\
\hline 5 & Shell & 1.1 & \\
\hline 2 & Shell & 1.2 & See \#2 below \\
\hline 2 & Metal & 1.4 & Badly corroded \\
\hline 1 & Metal, hexagonal shape & 1.7 & Badly corroded \\
\hline 1 & Metal, military & 2.3 & See \#3 below \\
\hline 1 & Plastic, translucent white & 1.1 & \\
\hline 1 & Hard rubber & 2.1 & See \#4 below \\
\hline 1 & Vegetable Ivory & 1.3 & See \#5 below \\
\hline 1 & Vegetable Ivory & 1.7 & \\
\hline 17 Total & & & \\
\hline
\end{tabular}

\#1: A small grey shell button with a single hole and a wire shank still in place. This was probably a shoe button.

\#2: A standard shell button with two holes and a well.

\#3: A U.S. Army or Air Force blouse (jacket) button, made of plastic. The Great Seal design is a separate piece, glued onto the lined field. The outer rim has been painted with metallic paint, but the face has a non-metallic yellow-gold paint intended to look like brass. This is obviously a very modern button.

\#4: Hard rubber button with no patent number or "Goodyear" printed on it probably dates to after 1870 , when the patent expired.

\#5: A vegetable ivory button with part of the brown dye worn off.

Table 5-4. Other Clothing Items from the Oeffinger Site

\begin{tabular}{||c|l|c|l||}
\hline Count & \multicolumn{1}{|c|}{ Item Name } & Size $(\mathrm{cm})$ & Notes \\
\hline 2 & Snap & 1.1 & \\
\hline 1 & Snap & 2.0 & \\
\hline 1 & Zipper head & 1.2 & Brass \\
\hline 1 & Safety pin & 5.2 & Fragment \\
\hline 1 & Eyelet & 1.1 & \\
\hline 1 & Shoe heel & & Medium child size \\
\hline 7 Total & & \\
\hline
\end{tabular}




\section{Haas Site (41BX882)}

Twenty-one clothing items were recovered from this site. Button descriptions are given in Table 5-5, with notes following. Other clothing items are presented in Table 5-6.

Table 5-5. Buttons from the Haas Site

\begin{tabular}{|c|l|c|l||}
\hline Count & \multicolumn{1}{|c|}{ Composition } & Diameter $(\mathrm{cm})$ & Notes \\
\hline 1 & Ceramic & 1.0 & \\
\hline 1 & Ceramic & 1.1 & \\
\hline 1 & Shell & .7 & See \#1 below \\
\hline 1 & Shell & 1.2 & \\
\hline 1 & Shell & 1.3 & \\
\hline 1 & Shell, grey & 1.3 & \\
\hline 1 & Shell & 1.4 & \\
\hline 1 & Shell & 1.8 & \\
\hline 1 & Shell & 1.9 & See \#2 below \\
\hline 1 & Plastic & 1.1 & \\
\hline 1 & Hard rubber & 1.9 & \\
\hline $\mathbf{1 1}$ Total & & & \\
\hline
\end{tabular}

\#1: A tiny shell button with two holes, probably from an infant's clothing, or from a glove.
\#2: An example of a standard kind of large shell button with a catseye and two holes.

Table 5-6. Other Clothing Items from the Haas Site

\begin{tabular}{|c|l|c|l||}
\hline Count & \multicolumn{1}{|c|}{ Item Name } & Size (cm) & \multicolumn{1}{|c|}{ Notes } \\
\hline 1 & Snap & .6 & \\
\hline 1 & Snap & .7 & Sew-on type \\
\hline 1 & Snap & 1.3 & \\
\hline 2 & Snap & 1.4 & Probably from a child's jacket \\
\hline 1 & Buckle & 2.5 & \\
\hline 1 & Safety pin & 4.5 & Old style \\
\hline 1 & Safety pin & & Fragment \\
\hline 1 & Baby shoe & & Imitation leather, white, soft sole \\
\hline 1 & Heel & & Hard rubber, large adult size \\
\hline $\mathbf{1 0}$ Total & & \\
\hline
\end{tabular}




\section{King Site (41BX883)}

Seventy-five clothing items were recovered from the King site. Button descriptions are given in Table 5-7, with notes following. Other clothing items are presented in Table 5-8.

Table 5-7. Buttons from the King Site

\begin{tabular}{|c|c|c|c|}
\hline Count & Composition & Diameter $(\mathrm{cm})$ & Notes \\
\hline 2 & Ceramic & 1.0 & \\
\hline 1 & Ceramic & 1.1 & \\
\hline 3 & Ceramic & 1.3 & \\
\hline 6 & Ceramic & 1.4 & See \#1 below \\
\hline 2 & Ceramic & 1.5 & \\
\hline 1 & Ceramic & 1.6 & \\
\hline 5 & Shell & .9 & \\
\hline 5 & Shell & 1.0 & \\
\hline 3 & Shell & 1.1 & \\
\hline 1 & Shell, grey & 1.1 & \\
\hline 2 & Shell & 1.2 & \\
\hline 4 & Shell & 1.4 & \\
\hline 1 & Shell & 1.7 & \\
\hline 1 & Shell & 2.2 & See \#2 below \\
\hline 1 & Metal & 1.1 & \\
\hline 1 & Metal, hole and bar & 1.4 & \\
\hline 2 & Metal & 1.4 & \\
\hline 1 & Metal & 1.7 & See \#3 below \\
\hline 1 & Metal, military & 1.9 & See \#4 below \\
\hline 1 & Metal "Pullman" & 2.3 & See \#5 below \\
\hline 1 & Metal, military & 2.8 & See \#6 below \\
\hline 1 & Plastic & 1.1 & \\
\hline 1 & Plastic & 1.2 & \\
\hline 2 & Plastic & 1.5 & \\
\hline 1 & Plastic & 1.9 & See \#7 below \\
\hline 1 & Plastic & 2.2 & \\
\hline 1 & Plastic & 2.3 & \\
\hline 1 & Plastic & 2.8 & See \#8 below \\
\hline 1 & Bone & 1.6 & See \#9 below \\
\hline 1 & Hard nubber & 1.9 & See \#10 below \\
\hline 1 & Gutta percha & 2.0 & Fragment \\
\hline 1 & Composition & 1.4 & See \#11 below \\
\hline 1 & Vegetable Ivory & 1.7 & \\
\hline 1 & Horn & 1.7 & See \#12 below \\
\hline
\end{tabular}


\#1: Standard-size shirt buttons.

\#2: A large, thick shell button with engraved catseyes around edge.

\#3: A metal button with a well, four holes, and a fine line cross-hatching engraved on the face.

\#4: A brass U.S. Army button from the period between 1854 and the early 1870s (Albert 1976: 40-41; Brinckerhoff 1965:74). The backmark reads “*Extra*Quality**”, a Civil War era mark (McGuinn and Bazelon 1990:28). This button came from a part of the site associated with the Webb site (on the lot to the north)(see 41BX897). Separating the artifacts on these sites is difficult (see Volume II), but it is believed that the trash area in which this button was found is actually part of the Webb site not the King site.

\#5: A brass button from a "Pullman" uniform. This is a three-piece button with wire shank, raised rim, fine horizontal lines, and the word "Pullman" embossed on the face. Pullman sleeping railroad cars first came into general use after the Civil War. The last Pullman railroad cars were built in 1930 and the last cars still in use were turned over to the government during World War II (Hughes and Lester 1991:764).
\#6: A brass U.S. Army overcoat button from the post 1902 period, when all Army buttons were changed to a design which was a copy of the Great Seal of the United States. The backmark reads "Horstmann"**Phila***", which indicates that this button is from the World War I period (Samuel Nesmith, personal communication 1992).

\#7: A black plastic button with a design of rectangles and squares cut on the face.

\#8: A large white plastic button, probably from a coat or other outer garment.

\#9: A standard type of bone button.

\#10: A dome-shaped hard rubber button with a whirling design embossed on it.

\#11: A button of black composition material, with tiny specks of mica or some other sparkling material.

\#12: A dark-colored horn button. This is one of the very few items made of horn or antler that was found at the Alamodome site.

Table 5-8. Other Clothing Items from the King Site

\begin{tabular}{||c|l|c|l||}
\hline Count & \multicolumn{1}{|c|}{ Item Name } & Size $(\mathbf{c m})$ & \multicolumn{1}{|c|}{ Notes } \\
\hline 1 & Zipper head & 1.1 & Brass \\
\hline 1 & Zipper pull & & \\
\hline 3 & Buckles & 2.3 & \\
\hline 1 & Buckle & 3.2 & Decorated \\
\hline 2 & Buckles & & Fragments \\
\hline 1 & Strap fastener & 2.0 & \\
\hline 1 & Strap fastener & 4.5 & Probably from overalls \\
\hline 2 & Eyelet & .6 & \\
\hline 1 & Eyelet & .7 & \\
\hline 3 & Leather & & Fragments \\
\hline 16 Total & & \\
\hline
\end{tabular}




\section{Griesenbeck Site (41BX884)}

Sixty-five clothing items were recovered from the Griesenbeck site. Button descriptions are given in Table 5-9, with notes following. Other clothing items are presented in Table 5-10.

Table 5-9. Buttons from the Griesenbeck Site

\begin{tabular}{|c|c|c|c|}
\hline Count & Composition & Diameter (cm) & Notes \\
\hline 4 & Ceramic & 1.1 & \\
\hline 1 & Shell & $? ?$ & Fragment \\
\hline 1 & Shell & .8 & \\
\hline 1 & Shell & .9 & \\
\hline 3 & Shell & 1.0 & \\
\hline 1 & Shell & 1.1 & \\
\hline 3 & Shell & 1.2 & \\
\hline 5 & Shell & 1.3 & \\
\hline 1 & Shell & 1.4 & \\
\hline 2 & Shell & 1.5 & \\
\hline 1 & Shell & 1.8 & \\
\hline 1 & Shell & 2.2 & \\
\hline 2 & Metal & 1.4 & \\
\hline 1 & Metal, stud with glass stone & 1.4 & See \#1 below \\
\hline 1 & Metal & 1.6 & \\
\hline 1 & Plastic & .9 & \\
\hline 1 & Plastic & 1.0 & \\
\hline 1 & Plastic & 1.2 & \\
\hline 1 & Plastic & 1.3 & \\
\hline 2 & Plastic & 1.4 & \\
\hline 4 & Plastic & 1.9 & \\
\hline 1 & Bone & 1.6 & \\
\hline 1 & Hard rubber & 1.8 & \\
\hline 1 & Gutta percha & 1.4 & \\
\hline 1 & Gutta percha & 2.0 & Fragment \\
\hline 1 & Vegetable ivory & 1.7 & \\
\hline 1 & Mica & .9 & Very fragmented \\
\hline 1 & Mica & 1.5 & See \#2 below \\
\hline
\end{tabular}


\#1: A white metal stud with a glass stone. This item is probably from after the 1920 s, since before that time, even mail-order jewelry intended for farmers and remote small towns was made from precious metal and at least semi-precious stone (see Meissner, this volume, Chapter 6).
\#2: A button made of mineral mica, with a single hole. This button is in a very fragmentary condition, as mica tends to break into transparent layers.

Table 5-10. Other Clothing Items from the Griesenbeck Site

\begin{tabular}{||c|l|c|l|}
\hline Count & \multicolumn{1}{|c|}{ Item Name } & Size (cm) & \\
\hline 1 & Snap & .8 & \\
\hline 1 & Snap & 1.0 & Notes \\
\hline 1 & Snap & 1.1 & \\
\hline 1 & Snap & 1.8 & \\
\hline 1 & Hook & & Large, for belt or corset \\
\hline 2 & Safety pin & 3.8 & \\
\hline 2 & Safety pin & 4.0 & \\
\hline 1 & Safety pin & 5.0 & \\
\hline 2 & Safety pin & & \\
\hline 1 & Button hook & 7.7 & Metal \\
\hline 2 & Hose supporter grip & & Large back \\
\hline 1 & Eyelet & .6 & \\
\hline 1 & Eyelet & .7 & \\
\hline 1 & Leather strap & & For sandal, dyed white \\
\hline 1 & Scissors & 6.5 & Fragment \\
\hline 1 & Fiber & 2.1 & Fisal, hemp, or manila \\
\hline 20 Total & & & \\
\hline
\end{tabular}


Mendit/Maffi Site (41BX885)

Nine clothing items were recovered from the Mendit/Maffi site. Button descriptions are given in Table 5-11, with notes following. Other clothing items are presented in Table 5-12.

Table 5-11. Buttons from the Mendit/Maffi Site

\begin{tabular}{||c|l|c|l||}
\hline \hline Count & \multicolumn{1}{|c|}{ Composition } & Diameter $(\mathrm{cm})$ & \multicolumn{1}{|c|}{ Notes } \\
\hline 1 & Shell & 1.9 & \\
\hline 1 & Metal & 1.4 & See \#1 below \\
\hline 1 & Metal & 1.7 & See \#2 below \\
\hline 1 & Plastic & 1.4 & \\
\hline 1 & Plastic & 1.8 & \\
\hline 5 Total & & \\
\hline
\end{tabular}

\#1: A copper alloy button with "White, Howard, \& \#2: A standard metal overall button. Major" embossed around the well. This button is probably from men's underwear.

Table 5-12. Other Clothing Items from the Mendit/Maffi Site

\begin{tabular}{|c|l|c|l||}
\hline Count & \multicolumn{1}{|c|}{ Item Name } & Size (cm) & \multicolumn{1}{|c|}{ Notes } \\
\hline 1 & Safety pin & 4.0 & \\
\hline 3 & Eyelets & .9 & $\begin{array}{l}\text { Remains of leather in eyelet-probably } \\
\text { from shoes. }\end{array}$ \\
\hline 4 Total & \multicolumn{2}{|l}{} \\
\hline
\end{tabular}




\section{Biesenbach Site (41BX890)}

Six clothing items were recovered from the Biesenbach site. Button descriptions are given in Table 5-13, with notes following. Other clothing items are presented in Table 5-14.

Table 5-13. Buttons from the Biesenbach Site

\begin{tabular}{|c|l|c|l||}
\hline Count & \multicolumn{1}{|c|}{ Composition } & Diameter $(\mathrm{cm})$ & Notes \\
\hline 1 & Ceramic & .9 & \\
\hline 1 & Ceramic & 1.0 & \\
\hline 1 & Ceramic & 1.1 & \\
\hline 1 & Ceramic & 1.6 & \\
\hline 1 & Shell & 1.7 & Fragment \\
\hline 1 & Plastic & 1.4 & Fragment \\
\hline 6 Total & & \\
\hline
\end{tabular}

Table 5-14. Other Clothing Items from the Biesenbach Site

\begin{tabular}{||c|c|c|c|}
\hline \hline Count & Item Name & Size (cm) & Notes \\
\hline 1 & Safety pin & 4.2 & Old style \\
\hline 1 Total
\end{tabular}

\section{Horn Site (41BX891)}

Five clothing items were recovered from the Horn site. Button descriptions are given in Table 5-15, with notes following. Other clothing items are presented in Table 5-16.

Table 5-15. Buttons from the Horn Site

\begin{tabular}{|c|c|c|c|}
\hline Count & \multicolumn{1}{|c|}{ Composition } & Diameter (cm) & Notes \\
\hline 1 & Metal & 2.4 & See \#1 below \\
\hline 1 Total
\end{tabular}

\#1: This double convex metal item is the face of a two- or three-piece button. 
Table 5-16. Other Clothing Items from the Horn Site

\begin{tabular}{|c|l|c|l||}
\hline Count & \multicolumn{1}{|c|}{ Item Name } & Size (cm) & \multicolumn{1}{c|}{ Notes } \\
\hline 1 & Buckle & 3.0 & \\
\hline 1 & Leather & $2.0 \times 6.0$ & Fragment \\
\hline 1 & Straight pin & & Fragment \\
\hline 1 & Round-nosed scissors & 11.8 & Probably for a child \\
\hline 4 Total & \multicolumn{2}{|l}{} \\
\hline
\end{tabular}

\section{Rilling Site (41BX892)}

Eleven clothing items were recovered from the Rilling site. Button descriptions are given in Table 5-17, with notes following. Other clothing items are presented in Table 5-18.

Table 5-17. Buttons from the Rilling Site

\begin{tabular}{|c|l|c|l||}
\hline Count & \multicolumn{1}{|c|}{ Composition } & Diameter $(\mathrm{cm})$ & \multicolumn{1}{|c|}{ Notes } \\
\hline 1 & Ceramic, printed & 1.0 & See \#1 below \\
\hline 4 & Ceramic & 1.5 & \\
\hline 1 & Plastic & 1.6 & See \#2 below \\
\hline 1 & Bone, metal fastener? & 1.5 & See \#3 below \\
\hline 7 Total & & \\
\hline
\end{tabular}

\#1: Decal printed with a pattern of short green lines.

\#2: A purple plastic button with a nobby face.
\#3: A bone button with the rusted remains of what appears to be some kind of metal fastener on the underside. The face is slightly convex and smooth.

Table 5-18. Other Clothing Items from the Rilling Site

\begin{tabular}{|c|l|c|l||}
\hline \hline Count & \multicolumn{1}{|c|}{ Item Name } & Size (cm) & \multicolumn{1}{|c|}{ Notes } \\
\hline 1 & Snap & .8 & Brass \\
\hline 1 & Belt link & 2.5 & Thin and cheaply made \\
\hline 1 & Leather shoe upper w/3 eyelets & & \\
\hline 1 & Shoe heel w/ part of upper & & Heel is fastened with wooden pegs. Small child's size. \\
\hline 1 & Metal heel tap & & \\
\hline 5 Total
\end{tabular}




\section{Czernecki Site (41BX893)}

Twenty-eight clothing items were recovered from the Czernecki site. Button descriptions are given in Table 5-19, with notes following. Other clothing items are presented in Table 5-20.

Table 5-19. Buttons from the Czernecki Site

\begin{tabular}{|c|l|c|l||}
\hline \hline Count & \multicolumn{1}{|c|}{ Composition } & Diameter $(\mathrm{cm})$ & \multicolumn{1}{|c|}{ Notes } \\
\hline 1 & Ceramic & 1.9 & Fragment \\
\hline 2 & Shell & 1.3 & \\
\hline 2 & Metal & 1.4 & See \#1 below \\
\hline 2 & Metal & 1.5 & See \#2 below \\
\hline 1 & Metal & 2.6 & See \#3 below \\
\hline 1 & Metal, military & 2.8 & See \#4 below \\
\hline 1 & Plastic & 1.3 & See \#5 below \\
\hline 1 & Plastic & 1.4 & \\
\hline 1 & Bone & 1.7 & Fragment \\
\hline 1 & Gutta percha & 1.1 & \\
\hline 2 & Glass & 1.5 & See \#6 below \\
\hline 15 Total & & \\
\hline
\end{tabular}

\#1: One has a cloth gripper type fastener.

\#2: A convex, gilded face.

\#3: A heart-shaped copper alloy button with a railroad car and the word "Carhartt" in script embossed on the front. The Carhartt company makes overalls and other work clothes.

\#4: A Marine overcoat button from about the World War II period (Samuel Nesmith, personal communication 1992). This button is listed in Albert (1976:111) as type MC 13.
\#5: A domed, translucent white plastic button with a rose embossed on the front, which has been pierced for sewing.

\#6: These buttons are in well- and four-hole styles usually seen in ceramic buttons. Except for being unusually translucent, they appear almost identical to ceramic buttons on the surface, but since they are both broken, it is possible to see that the interior surfaces are completely smooth and glassy. In addition, there are no small pits on the underside as are seen in most ceramic buttons. 
Table 5-20. Other Clothing Items from the Czernecki Site

\begin{tabular}{||c|l|c|l||}
\hline \hline Count & \multicolumn{1}{|c|}{ Item Name } & Size (cm) & Notes \\
\hline 2 & Snap & .8 & \\
\hline 1 & Snap & .9 & \\
\hline 1 & Buckle & 3.0 & \\
\hline 1 & Safety pin & 3.5 & \\
\hline 1 & Safety pin & 4.0 & \\
\hline 2 & Safety pin & 4.8 & \\
\hline 1 & Strap fastener & 1.6 & Brass \\
\hline 1 & Strap fastener & 2.5 & Fragment \\
\hline 1 & Hose supporter grip & 1.5 & \\
\hline 1 & Eyelet & .7 & \\
\hline 1 & Eyelet & 1.2 & \\
\hline 13 Total & & & \\
\hline
\end{tabular}

\section{Czernecki Rental Site (41BX894)}

Twenty-six clothing items were recovered from the Czernecki Rental site. Button descriptions are given in Table 5-21, with notes following. Other clothing items are presented in Table 5-22.

Table 5-21. Buttons from the Czernecki Rental Site

\begin{tabular}{|c|l|c|l||}
\hline Count & \multicolumn{1}{|c|}{ Composition } & Diameter $(\mathbf{c m})$ & \multicolumn{1}{|c|}{ Notes } \\
\hline 1 & Shell & .9 & \\
\hline 2 & Shell & 1.1 & \\
\hline 3 & Shell & 1.3 & \\
\hline 1 & Metal, 3 piece & 2.0 & See \#1 below \\
\hline 1 & Plastic & 1.0 & See \#2 below \\
\hline 4 & Plastic & 1.1 & See \#3 below \\
\hline 1 & Plastic & 1.3 & \\
\hline 5 & Plastic & 1.4 & \\
\hline 1 & Plastic & 1.5 & See \#4 below \\
\hline 2 & Plastic & 1.9 & See \#5 below \\
\hline 21 Total & & \\
\hline
\end{tabular}

\#1: A three-piece copper alloy button in very poor condition. The face is in a fragmented condition, with the cork spacer in the interior visible. There is lettering stamped on the face, but only the letters "STA" are legible.
\#2: A translucent blue plastic button with a design embossed on the face.

\#3: One of the $1.1 \mathrm{~cm}$ buttons has a light purple and blue plaid design on the face and a self shank. 
Buttons like this are designed to match a particular fabric.

\#4: A yellowish plastic intended to simulate mother of pearl.
\#5: One of these is blue with a swirling pattern embossed on it.

Table 5-22. Other Clothing Items from the Czernecki Rental Site

\begin{tabular}{|c|l|c|l||}
\hline Count & \multicolumn{1}{|c|}{ Item Name } & Size $\mathbf{( c m )}$ & Notes \\
\hline 1 & Snap & & Fragment \\
\hline 2 & Snap & 1.1 & \\
\hline 1 & Eyelet & 1.0 & \\
\hline 1 & Eyelet & 1.1 & \\
\hline 5 Total & & \\
\hline
\end{tabular}

\section{Garza Store Site (41BX895)}

Twenty clothing items were recovered from the Garza Store site. Button descriptions are given in Table 5-23, with notes following. Other clothing items are presented in Table 5-24.

Table 5-23. Buttons from the Garza Store Site

\begin{tabular}{|c|l|c|l||}
\hline Count & Composition & Diameter $(\mathbf{c m})$ & Notes \\
\hline 1 & Ceramic & 1.5 & \\
\hline 1 & Shell & 1.0 & \\
\hline 1 & Shell & 1.2 & \\
\hline 1 & Shell & 1.3 & \\
\hline 1 & Shell & 1.6 & \\
\hline 1 & Metal & $? ?$ & Fragment \\
\hline 1 & Metal & 1.2 & See \#1 below \\
\hline 1 & Metal & 1.9 & \\
\hline 1 & Metal, cloth gripper & 2.0 & See \#2 below \\
\hline 1 & Plastic, white & 1.0 & \\
\hline $\mathbf{1 0}$ Total & & & \\
\hline
\end{tabular}

\#1: The wire shank base of a two-piece button.

\#2: Probably part of a two-piece "hand-snap" or "bachelor's" button. 
Table 5-24. Other Clothing Items from the Garza Store Site

\begin{tabular}{|c|l|c|l|}
\hline Count & \multicolumn{1}{|c|}{ Item Name } & Size (cm) & \multicolumn{1}{|c|}{ Notes } \\
\hline 1 & Buckle & 4.7 & \\
\hline 2 & Buckle & & Fragments \\
\hline 7 & Leather shoe pieces & & Fragments, medium child sized \\
\hline 10 Total & \multicolumn{2}{|l}{} \\
\hline
\end{tabular}

\section{Demazieres Site (41BX896)}

A total of 261 clothing items was recovered from the Demazieres site. Button descriptions are given in Table 5-25, with notes following. Other clothing items are presented in Table 5-26.

Table 5-25. Buttons from the Demazieres Site

\begin{tabular}{|c|c|c|c|}
\hline Count & Composition & Diameter (cm) & Notes \\
\hline 4 & Ceramic & 1.0 & \\
\hline 1 & Ceramic & 1.1 & \\
\hline 1 & Ceramic & 1.2 & See \#1 below \\
\hline 4 & Ceramic & 1.4 & \\
\hline 2 & Ceramic & 1.5 & \\
\hline 2 & Ceramic & 1.6 & \\
\hline 3 & Shell & $? ?$ & Fragments \\
\hline 3 & Shell, grey & .9 & \\
\hline 8 & Shell & 1.0 & 1 fragment \\
\hline 3 & Shell, grey & 1.0 & 1 fragment \\
\hline 7 & Shell & 1.1 & 1 fragment \\
\hline 3 & Shell, grey & 1.1 & \\
\hline 8 & Shell & 1.2 & 1 fragment \\
\hline 1 & Shell, grey & 1.2 & \\
\hline 7 & Shell & 1.3 & See \#2 \& \#3 below \\
\hline 1 & Shell, grey & 1.3 & \\
\hline 4 & Shell & 1.4 & 1 fragment \\
\hline 16 & Shell & 1.5 & 4 fragments, See \#4 below \\
\hline 4 & Shell & 1.7 & 4 fragments \\
\hline 2 & Shell & 1.8 & See \#5 below \\
\hline 4 & Shell & 1.9 & \\
\hline 2 & Shell & 2.2 & \\
\hline 1 & Shell & 2.4 & \\
\hline
\end{tabular}


Table 5-25. continued

\begin{tabular}{|c|c|c|c|}
\hline Count & Composition & Diameter (cm) & Notes \\
\hline 1 & Shell & 2.5 & See \#6 below \\
\hline 1 & Metal & 1.1 & \\
\hline 1 & Metal & 1.4 & Badly corroded \\
\hline 4 & Metal & 1.5 & 1 badly corroded, See $\# 7, \# 8, \& \# 9$ below \\
\hline 1 & Metal, military & 1.5 & See \#10 below \\
\hline 2 & Metal & 2.3 & See \#14 \& \#15 below \\
\hline 2 & Metal, military & 2.3 & See \#16 below \\
\hline 4 & Plastic & 1.0 & Pearl, tan, grey; see \#17 below \\
\hline 1 & Plastic & 1.1 & Pearl \\
\hline 2 & Plastic & 1.2 & Yellow, gold; see \#18 below \\
\hline 4 & Plastic & 1.4 & Tan, black; see \#19 below \\
\hline 4 & Plastic & 1.5 & Tan, black; see \#20 below \\
\hline 1 & Plastic & 1.7 & White \\
\hline 4 & Plastic & 1.8 & $\begin{array}{l}\text { Red, white, black, grey-brown; see \#21 \& \#22 } \\
\text { below }\end{array}$ \\
\hline 1 & Plastic & 1.9 & Transparent; see \#23 below \\
\hline 1 & Plastic & 2.2 & Ivory color \\
\hline 1 & Plastic & 2.3 & Pearl \\
\hline 1 & Plastic & 4.0 & Brown, fragment \\
\hline 1 & Bone & 1.3 & \\
\hline 1 & Hard rubber & 1.1 & \\
\hline 1 & Hard nubber & 1.5 & See \#24 below \\
\hline 1 & Gutta percha & 1.3 & \\
\hline 1 & Gutta percha & 1.4 & Unusually good condition \\
\hline 1 & Vegetable Ivory & 1.2 & \\
\hline 3 & Vegetable Ivory & 1.5 & 1 fragment \\
\hline 2 & Glass & $? ?$ & Fragments \\
\hline 1 & Glass & 1.0 & \\
\hline 2 & Glass & 1.3 & \\
\hline
\end{tabular}

\#1: A "pie crust" design with a well and an incised rim.

\#2: This button has a wire loop through a single hole in the middle of the button. It is probably a shoe button, most likely for a woman.

\#3: This button may in fact be more of a decoration than a functional button. It has two holes offset near the edge of its flat surface.
\#4: This button is curved upward along the line of the buttonholes. This may be a taphonomic change rather than a deliberate design.

\#5: This button is cut on the bias so that the natural layers of shell appear to be stripes running across the surface. 
\#6: This large button has a flat face with the remains of a metal loop glued to the back.

\#7: This is a two-piece button with a series of holes set near the joint of the two pieces.

\#8: This button is probably for a pair of overalls or other work clothes. It is embossed "Big Smith" (Figure 5-2a).

\#9: This button has an embossed star design (Figure 5-2b). A very similar button is sold in the 1902 Sears Roebuck catalog for $\$ .04$ a dozen (Sears Roebuck 1969:940).

\#10: This is a dull finish brass Army cuff button in the Great Seal design. The backmark reads "R. L. MFG Co. New Haven." It is probably of World War I origin (Samuel Nesmith, personal communication 1992).

\#11: A gilded U.S. Army collar button. The style is the "Prussian" spread eagle, which dates it between 1870 and 1902 . The backmark reads "Horstmann Philadelphia," which gives us a date after 1893 (McGuinn and Bazelon 1990:55).

\#12: This is plain metal button, possibly the backing for a cloth covered button.

\#13: This is a button from "Lee Riders" jeans (Figure 5-2c).

\#14 This is a fancy embossed button made of a copper alloy, in the form of a stylized flower (Figure 5-2d).
\#15: This is a three-piece Post Office Department button. The design is a walking figure, facing right, carrying a bag over his left shoulder and reaching out with his right hand-presumably with a letter. Beneath this figure are the letters "POD" (Figure 5-2e).

\#16: This is a Great Seal style, dull-finish, brass Army button. The backmark reads "City Button Works New York." This company was making buttons from 1877 to 1955 (McGuinn and Bazelon 1990:29)

\#17: This is a hemispheric white button with a self loop.

\#18: This is a slightly melted translucent yellow button.

\#19: One of these is a Bakelite button.

\#20: This is a Bakelite button.

\#21: This is a black button with gilding.

\#22: This is a red plastic button with pink paint, a swirl pattern on the edges and a backmark reading "22."

\#23: This is a clear button with self loop and nobby pattern on the front.

\#24: A hard rubber button with four holes and an anchor embossed on the front (Figure 5-2f).

Table 5-26. Other Clothing Items from the Demazieres Site

\begin{tabular}{|c|l|c|l||}
\hline Count & \multicolumn{1}{|c|}{ Composition } & Diameter $(\mathbf{c m})$ & \multicolumn{1}{||}{ Notes } \\
\hline 1 & Snap & .7 & \\
\hline 1 & Snap & .9 & \\
\hline 1 & Snap & 1.0 & \\
\hline 20 & Snap & 1.1 & $\begin{array}{l}\text { One has a decorated back, a square with a nobby } \\
\text { pattern }\end{array}$ \\
\hline 8 & Snap & 1.2 & \\
\hline 4 & Snap & 1.5 & \\
\hline 3 & Snap & 1.6 & \\
\hline 1 & Snap & & Fragment \\
\hline 1 & Hook & & Medium size \\
\hline 2 & Eyes & 1.1 & \\
\hline 1 & Zipper head & .7 & \\
\hline 1 & Zipper head & .9 & \\
\hline 2 & Zipper head & 1.0 & One is brass \\
\hline
\end{tabular}


Table 5-26. continued

\begin{tabular}{|c|c|c|c|}
\hline Count & Composition & Diameter (cm) & Notes \\
\hline 7 & Zipper head & 1.1 & \\
\hline 3 & Zipper head & 1.5 & Two have chain pulls \\
\hline 1 & Zipper pull & & \\
\hline 1 & Buckle & 1.4 & \\
\hline 2 & Buckle & 1.7 & \\
\hline 1 & Buckle & 1.8 & \\
\hline 2 & Buckle & 1.9 & \\
\hline 1 & Buckle & 2.0 & \\
\hline 2 & Buckle & 2.1 & One is brass \\
\hline 1 & Safety pin & 2.2 & \\
\hline 1 & Safety pin & 2.6 & \\
\hline 1 & Safety pin & 3.0 & \\
\hline 2 & Safety pin & 3.8 & \\
\hline 2 & Safety pin & 4.0 & \\
\hline 2 & Safety pin & 5.0 & \\
\hline 4 & Strap fasteners & .7 & \\
\hline 2 & Strap fasteners & 1.3 & One is brass \\
\hline 2 & Strap fasteners & 2.3 & \\
\hline 2 & Strap fasteners & 3.2 & \\
\hline 2 & Strap fasteners & 3.5 & \\
\hline 1 & Hose supporter base & & \\
\hline 2 & Hose supporter grip & & \\
\hline 2 & Eyelet & .6 & \\
\hline 10 & Eyelet & .7 & \\
\hline 1 & Eyelet & .8 & \\
\hline 4 & Eyelet & .9 & \\
\hline 2 & Eyelet & 1.1 & \\
\hline 1 & Eyelet & 1.2 & Incised ring \\
\hline 1 & Hard rubber shoe sole & & Fragment \\
\hline 1 & Shoestring & ca. 3.0 & Fragment \\
\hline 1 & Sock & ca. 10.0 & Fragment \\
\hline 1 & Straight pin & 3.1 & \\
\hline 1 & Thimble & & Brass \\
\hline 1 & Burlap & & Fragment \\
\hline
\end{tabular}




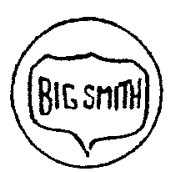

a

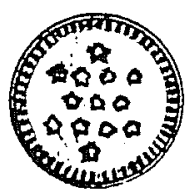

b

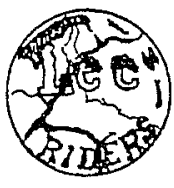

c

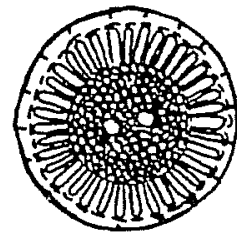

d

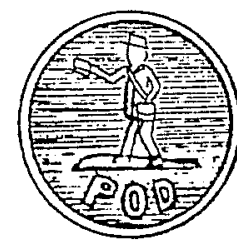

e

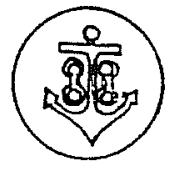

f

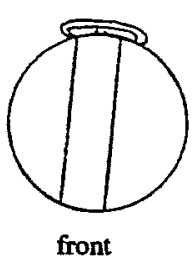

g

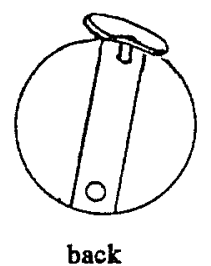

政
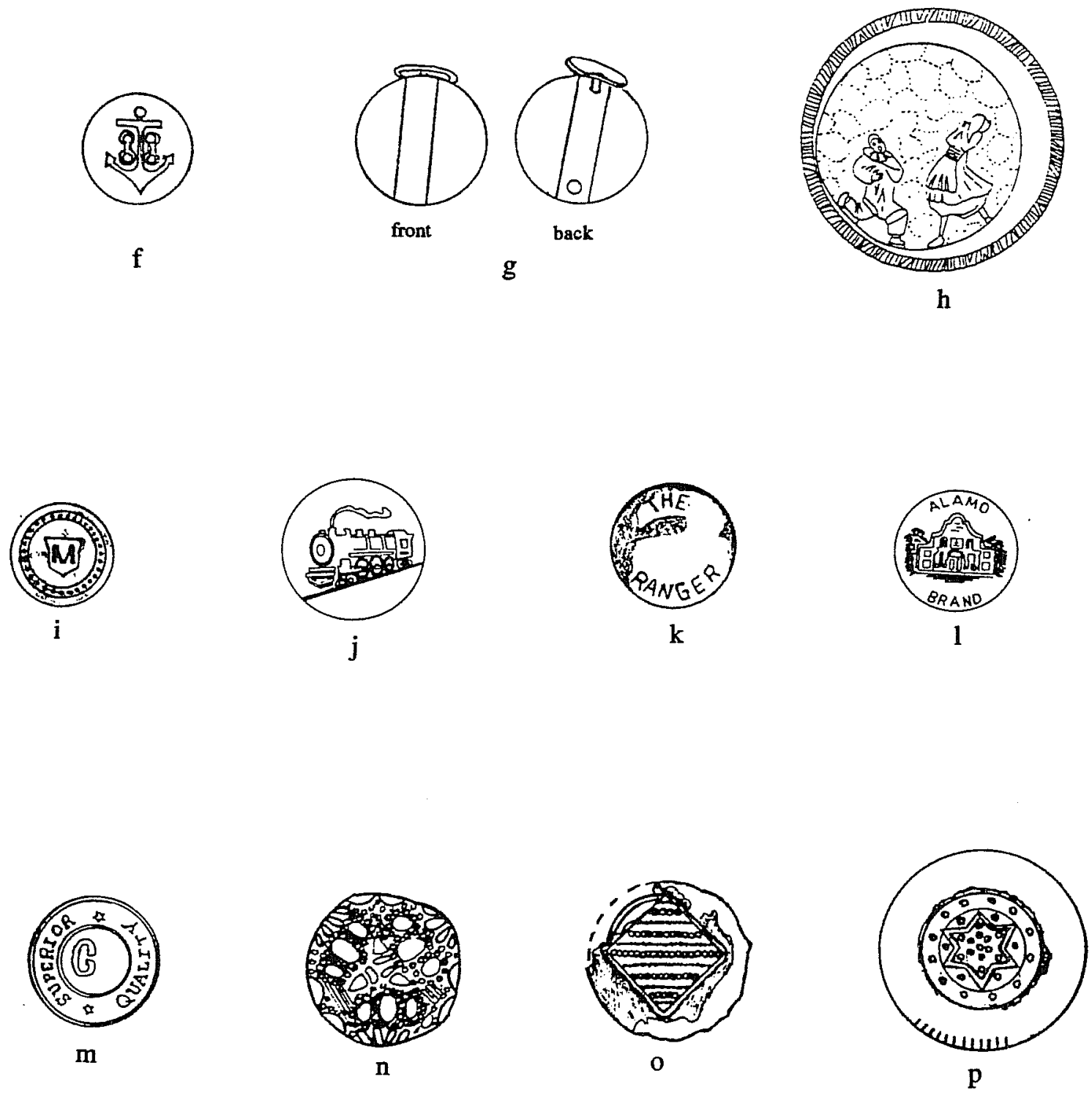

Figure 5-2. Buttons from the Alamodome Project. All shown actual size. 


\section{Webb Site (41BX897)}

A total of 122 clothing items was recovered from the Webb site. Button descriptions are given in Table 5-27, with notes following. Other clothing items are presented in Table 5-28.

Table 5-27. Buttons from the Webb Site

\begin{tabular}{|c|c|c|c|}
\hline Count & Composition & Diameter (cm) & Notes \\
\hline 5 & Ceramic & $? ?$ & Fragments \\
\hline 1 & Ceramic & .8 & \\
\hline 11 & Ceramic & 1.0 & See \#1 below \\
\hline 26 & Ceramic & 1.1 & 8 are "pie crust" design; see $\# 2, \# 3, \# 4, \# 5$, and $\# 6$ below \\
\hline 1 & Ceramic & 1.2 & \\
\hline 3 & Ceramic & 1.3 & \\
\hline 1 & Ceramic & 1.4 & \\
\hline 1 & Ceramic & 1.5 & "Pie crust" design \\
\hline 10 & Ceramic & 1.6 & 1 is "pie crust" design \\
\hline 7 & Ceramic & 1.7 & 1 is "pie crust" design \\
\hline 1 & Ceramic & 1.8 & \\
\hline 1 & Shell & $? ?$ & Fragment \\
\hline 1 & Shell & .8 & \\
\hline 2 & Shell & .9 & \\
\hline 1 & Shell & 1.0 & \\
\hline 3 & Shell & 1.1 & \\
\hline 3 & Shell & 1.2 & 1 fragment \\
\hline 4 & Shell & 1.3 & \\
\hline 2 & Shell & 1.4 & \\
\hline 3 & Shell & 1.5 & \\
\hline 1 & Shell & 1.8 & \\
\hline 1 & Shell & 1.9 & \\
\hline 1 & Metal & 1.1 & Badly corroded \\
\hline 1 & Metal & 1.3 & \\
\hline 4 & Metal & 1.6 & 1 badly corroded; see \#7 below \\
\hline 1 & Metal, military & 1.6 & See \#8 below \\
\hline 1 & Metal & 1.7 & See \#9 below \\
\hline 2 & Metal & 1.8 & 1 badly corroded; See \#10 below \\
\hline 1 & Metal & 1.9 & See \#11 below \\
\hline 1 & Metal, military & 2.3 & See \#12 below \\
\hline 1 & Metal & 3.8 & See \#13 below \\
\hline 1 & Plastic & 1.0 & Brown \\
\hline 2 & Plastic & 1.1 & Pearl, blue \\
\hline
\end{tabular}


Table 5-27. continued

\begin{tabular}{|c|l|c|l||}
\hline Count & Composition & Diameter $(\mathrm{cm})$ & Notes \\
\hline 2 & Bone & 1.7 & 1 fragment \\
\hline 1 & Wood & $? ?$ & fragment \\
\hline 2 & Gutta percha & 1.8 & \\
\hline 1 & Glass & 1.4 & See \#14 below \\
\hline 1 & Glass & 1.5 & See \#15 below \\
\hline 109 Total
\end{tabular}

\#1: Seven of these buttons are hemispheric collar buttons.

\#2: Three of these are hemispheric collar buttons.

\#3: This button has a deep well, with the wide rim painted blue.

\#4: This button appears to be a collar button. It is less dome-shaped than the others, and there is blue paint in the center and in a ring around the edge. Note that the color of blue is different than the button mentioned above.

\#5: This button has a deep well and a rim painted reddish-brown.

\#6: This is a "calico" button printed in two sizes of brown circles.

\#7: This is probably the backing for a cloth button.

\#8: This is a U.S. Army brass cuff button from the period between 1854 and 1870 . Both the style and the backmark, which reads "Scovill MFG Co. Waterbury" (see McGuinn and Bazelon 1990:87) confirm this date.

\#9: This is also probably a cloth button backing.

\#10: This is a fancy button with a convex face, embossed with a design and gilded. There are three tiny bits of turquoise set into the design, and there appears to have been at least one more piece at one time.

\#11: This is a Confederate Corps of Engineers officers button. This button has no backmark, making precise dating difficult, however, the good quality of the button strongly suggests that it was of British manufacture. The supply of British buttons, along with everything else, was gradually cut off by the Union blockade. Later, locally made buttons were not of as high quality. It seems likely that this button was manufactured in England, in the early part of the war (Albert 1976:372). This is an especially interesting find, as the Webbs were African-American.
\#12: This is a cheaply made collar button of the stud type (Figure $5-2 \mathrm{~g}$ ). It is a very thin copper alloy, gilded, with a small oval front and a large $(1.9 \mathrm{~cm})$ backing.

\#13: This is a "picture button," a form of decoration popular in the Victorian period (Figure 5-2h). They were worn in single or double rows down the front of coats and dresses. Large matching buttons were sometimes sewn on as additional decoration (Epstein 1968:69-70). Themes for these buttons ranged from animals to fables to the Bible. Very popular were the buttons based on opera and mythology. This button represents "Pierro and Pierrette" with the former on bended knee and both surrounded by a crescent, representing the moon, that was once a steel mirror, unfortunately now rusted. It is a large button and was probably decoration rather than a practical fastener. This button was fairly common, and was retailed under the title "True Love" in the 1880s (Hughes and Lester 1991:391).

\#14: This is a broken glass button with a nobby domed face and a hollow interior, colored blue. This type of button is called a "whistle," because it has one hole in the upper surface, but two holes in the lower surface (Hughes and Lester 1991:33).

\#15: This is a hollow glass button, broken in half. It is milk glass, with a flat base and a nobby dome shape. It is also a "whistle," very much like \#14, however there is no blue coloration and the nobby pattern is different. 
Table 5-28. Other Clothing Items from the Webb Site

\begin{tabular}{|c|l|c|l||}
\hline \hline Count & \multicolumn{1}{|c|}{ Composition } & Size (cm) & \multicolumn{1}{c|}{ Notes } \\
\hline 1 & Hook w/ strap fastener & & $\begin{array}{l}\text { Large, with decorated metal, probably from a } \\
\text { corset }\end{array}$ \\
\hline 1 & Buckle & 1.4 & Remains of a plastic sandal strap \\
\hline 2 & Buckle & & Fragments \\
\hline 1 & Hose support back & & Remains of a rubber nob \\
\hline 1 & Hose support catch & & Does not match hose support back above \\
\hline 1 & Eyelet & .7 & \\
\hline 1 & Button hook & 8.0 & Metal, with loop on end \\
\hline 1 & Thimble & & Fragment, brass \\
\hline 1 & Thimble & & Fragment, iron \\
\hline 2 & Straight pin & 3.0 & \\
\hline 1 & Scissors & 11.3 & Fragment \\
\hline 1 & Cotton knit cloth & & Probably from baby clothing \\
\hline 13 Total & \multicolumn{2}{l}{} \\
\hline
\end{tabular}

\section{E. Glaeser Site (41BX898)}

A single button was recovered from the E. Glaeser site (Table 5-29).

Table 5-29. Button from the E. Glaeser Site

\begin{tabular}{|c|l|c|c|}
\hline Count & \multicolumn{1}{|c|}{ Composition } & Diameter (cm) & Notes \\
\hline 1 & Shell & 1.0 & \\
\hline 1 Total & & \\
\hline
\end{tabular}




\section{Gordon Site (41BX900)}

Fifty-four clothing items were recovered from the Gordon site. Button descriptions are given in Table 5-30, with notes following. Other clothing items are presented in Table 5-31.

Table 5-30. Buttons from the Gordon Site

\begin{tabular}{|c|c|c|c|}
\hline Count & Composition & Diameter (cm) & Notes \\
\hline 1 & Ceramic & .9 & See \#1 below \\
\hline 6 & Ceramic & 1.1 & \\
\hline 1 & Ceramic & 1.2 & fragment \\
\hline 1 & Ceramic & 1.5 & \\
\hline 2 & Ceramic & 1.6 & 1 fragment \\
\hline 1 & Shell, grey & $? ?$ & badly fragmented \\
\hline 1 & Shell & .8 & \\
\hline 4 & Shell & .9 & 2 are fragmented \\
\hline 1 & Shell & 1.0 & fragment \\
\hline 3 & Shell & 1.1 & \\
\hline 3 & Shell & 1.2 & \\
\hline 2 & Shell & 1.3 & 1 is a fragment \\
\hline 2 & Shell & 1.4 & See \#2 below \\
\hline 2 & Shell & 1.5 & \\
\hline 1 & Shell & 1.8 & See \#2 below \\
\hline 1 & Shell & ca. 4.0 & fragment of very large button \\
\hline 1 & Metal & $? ?$ & Badly corroded fragment \\
\hline 1 & Metal & 1.5 & \\
\hline 2 & Metal & 1.6 & 1 is badly corroded \\
\hline 1 & Metal & 1.9 & \\
\hline 1 & Metal & 2.0 & See \#3 below \\
\hline 1 & Metal & 2.3 & badly corroded \\
\hline 1 & Metal/Plastic & 1.1 & See \#4 below \\
\hline 1 & Bone & 1.5 & \\
\hline \multicolumn{4}{|l|}{41 Total } \\
\hline
\end{tabular}

\#1: This is a tiny ceramic button with a metal wire through a single hole. It is probably a shoe button.

\#2: These shell buttons have an unusual pattern of a raised area where there is usually a well. Both sizes, $1.4 \mathrm{~cm}$ and $1.8 \mathrm{~cm}$ are probably from the same dress/shirt.
\#3: This badly corroded button could be a hand snap "bachelor's button."

\#4: This is a turquoise-colored plastic button with metal backing and wire shank. 
Table 5-31. Other Clothing Items from the Gordon Site

\begin{tabular}{||c|l|c|l||}
\hline \hline Count & \multicolumn{1}{|c|}{ Composition } & Size (cm) & \\
\hline 1 & Snap & 1.1 & \\
\hline 1 & Buckle & 2.6 & \\
\hline 2 & Buckle & 3.0 & \\
\hline 1 & Buckle & & Fragment \\
\hline 1 & Safety pin & 3.8 & \\
\hline 2 & Hose supporter catch & & \\
\hline 2 & Hard rubber shoe heel & & One is a fragment \\
\hline 1 & Eyelet & 1.1 & \\
\hline 2 & Scissors & 7.0 & Fragment \\
\hline 13 Total & & \\
\hline
\end{tabular}

\section{Schulze Site (41BX927)}

Three clothing items were recovered from the Schulze site (Table 5-32).

Table 5-32. Clothing Items from the Schulze Site

\begin{tabular}{||c|l|c|l|}
\hline Count & \multicolumn{1}{|c|}{ Composition } & Size (cm) & \multicolumn{1}{|c|}{ Notes } \\
\hline 1 & Snap & .6 & \\
\hline 1 & Buckle & 3.0 & \\
\hline 1 & Shoe & & $\begin{array}{l}\text { Fragment with heel fastened with wooden pegs, a } \\
\text { small child's size }\end{array}$ \\
\hline 3 Total
\end{tabular}

\section{Ries Well Site (41BX930)}

A single eyelet, $1.1 \mathrm{~cm}$ in diameter, was recovered from the Ries well. 


\section{Petit Site (41BX931)}

Six clothing items were recovered from the Petit site: 5 buttons (Table 5-33) and a single safety pin.

Table 5-33. Buttons from the Petit Site

\begin{tabular}{||c|l|c|l||}
\hline \hline Count & \multicolumn{1}{|c|}{ Composition } & Diameter $(\mathrm{cm})$ & \multicolumn{1}{|c|}{ Notes } \\
\hline 1 & Ceramic & 1.1 & \\
\hline 1 & Ceramic & 1.6 & \\
\hline 1 & Shell & 1.4 & See \#1 below \\
\hline 1 & Shell & 2.3 & See \#2 below \\
\hline 1 & Metal, military & 2.1 & See \#3 below \\
\hline 5 Total
\end{tabular}

\#1: This shell button has the remains of an orangeish dye. Dyed shell buttons are a fairly recent phenomena (Whittemore 1992:20).

\#2: This shell button is probably hand carved. The pattern is a catseye in the center with a ring of catseyes between the center and the edge.
\#3: A brass U. S. Army blouse button, of the "Prussian" style spread eagle design used after 1870. The backmark reads "Thos. G. Hood*Phil." which dates the button to around 1890 (McGuinn and Bazelon 1990:54). 


\section{Thomas Site (41BX932)}

Forty clothing items were recovered from the Thomas site. Button descriptions are given in Table 5-34, with notes following. Other clothing items are presented in Table 5-35.

Table 5-34. Buttons from the Thomas Site

\begin{tabular}{|c|l|c|l||}
\hline Count & \multicolumn{1}{|c|}{ Composition } & Diameter $(\mathbf{c m})$ & \multicolumn{1}{|c|}{ Notes } \\
\hline 3 & Shell & $? ?$ & 2 fragments are grey \\
\hline 1 & Shell & .8 & \\
\hline 3 & Shell & 1.1 & See \#1 below \\
\hline 1 & Shell & 1.2 & \\
\hline 1 & Shell & 1.3 & \\
\hline 3 & Shell & 1.5 & \\
\hline 1 & Shell & 1.8 & \\
\hline 2 & Plastic & .9 & Off-white \\
\hline 3 & Plastic & 1.1 & White \\
\hline 3 & Plastic & 1.2 & Off-white, pale transparent yellow \\
\hline 1 & Plastic & 1.3 & Pearl \\
\hline 1 & Plastic & 1.5 & White \\
\hline 2 & Plastic & 1.8 & Green, clear \\
\hline 1 & Plastic & 1.9 & Pale transparent yellow \\
\hline 3 & Plastic & 2.1 & Off-white, white \\
\hline 1 & Plastic & 2.7 & See \#2 below \\
\hline 2 & Plastic & 2.8 & See \#3 below \\
\hline 1 & Hard rubber & 1.2 & Light brown \\
\hline 1 & Hard rubber & 1.4 & See \#4 below \\
\hline 1 & Gutta percha & 1.8 & \\
\hline 1 & Gutta percha & 2.6 & See \#5 below \\
\hline 36 Total & & & \\
\hline
\end{tabular}

\#1: This fine quality shell button has a self shank, and a smooth face with an iridescent line across it placed off center. Buttons virtually identical to this appear in the Sears Roebuck Catalog for 1902 (Sears Roebuck 1969:940), though only in sizes smaller than this particular button. It is made from the "pink snail" (Trochus sp.), and the iridescent line is referred to as a "blaze" or a "chatoyance" (Hughes and Lester 1991:247).
\#2: This is a large dome-shaped red plastic button with about 20 rhinestones set into it (several are missing).

\#3: These buttons are imitation tortoise shell, and are probably coat buttons.

\#4: This hard rubber button has a flat face and a self shank. White dyes for hard rubber were not invented until 1908 (Harpur 1982:28).

\#5: This gutta percha button was painted with silver paint. 
Table 5-35. Other Clothing Items from the Thomas Site

\begin{tabular}{|c|l|c|l||}
\hline Count & \multicolumn{1}{|c|}{ Composition } & Size $(\mathbf{c m})$ & Notes \\
\hline 1 & "Eye" from hook-and-eye & 1.1 & Large and heavy, probably from a corset \\
\hline 1 & Zipper head & .7 & \\
\hline 1 & Strap fastener & .9 & \\
\hline 1 & Eyelet & 1.3 & \\
\hline 4 Total & & \\
\hline
\end{tabular}

\section{Burleson Site (41BX930)}

Eighteen clothing items were recovered from the Burleson site. Button descriptions are given in Table 5-36, with notes following. Other clothing items are presented in Table 5-37.

Table 5-36. Buttons from the Burleson Site

\begin{tabular}{|c|l|c|l||}
\hline Count & \multicolumn{1}{|c|}{ Composition } & Diameter $(\mathbf{c m})$ & Notes \\
\hline 2 & Shell & .9 & See \#1 below \\
\hline 1 & Shell & 1.1 & \\
\hline 2 & Shell & 1.2 & \\
\hline 1 & Shell & 1.3 & \\
\hline 3 & Shell & 1.5 & \\
\hline 1 & Shell & 1.6 & \\
\hline 1 & Metal & 1.4 & See \#2 below \\
\hline 2 & Plastic & 1.1 & See \#3 below \\
\hline 1 & Plastic & 1.5 & White \\
\hline 1 & Plastic & 1.8 & White \\
\hline 1 & Plastic & 2.2 & Pearl \\
\hline 16 Total & & \\
\hline
\end{tabular}

\#1: This button was made from the shell of the Trochus snail, and has a "blaze." It sold in the 1902 Sears Catalog for $\$ .13$ per dozen (Sears Roebuck 1969:940). These are very expensive even for shell buttons.
\#2: This metal button has a cloth gripper back and a monogram " $M$ " in a shield embossed on the front (Figure 5-2i). This is probably from work clothes. \#3: One of these buttons is plain white plastic. The other, a fragment, is iridescent, made to imitate opal. It is part of a two-piece button. 
Table 5-37. Other Clothing Items from the Burleson Site

\begin{tabular}{|c|l|c|c|}
\hline \hline Count & \multicolumn{1}{|c|}{ Composition } & Size $(\mathbf{c m})$ & Notes \\
\hline 1 & Zipper head & 1.1 & \\
\hline 1 & Rubber heel & & Probably from a child's shoe \\
\hline 2 Total & & \\
\hline
\end{tabular}

Gilbert Site (41BX937)

Twenty-one clothing items were recovered from the Gilbert site. Button descriptions are given in Table 5-38, with notes following. Other clothing items are presented in Table 5-39.

Table 5-38. Buttons from the Gilbert Site

\begin{tabular}{|c|l|c|l||}
\hline Count & \multicolumn{1}{|c|}{ Composition } & Diameter $(\mathbf{c m})$ & \multicolumn{1}{c|}{ Notes } \\
\hline 1 & Shell, grey & $? ?$ & fragment of a large button \\
\hline 1 & Shell & 1.0 & \\
\hline 1 & Shell & 1.1 & \\
\hline 1 & Shell & 1.5 & See \#1 below \\
\hline 1 & Shell & 1.9 & See \#2 below \\
\hline 1 & Metal & 1.6 & \\
\hline 1 & Plastic & 1.0 & Pearl \\
\hline 2 & Plastic & 1.1 & Pearl \\
\hline 1 & Plastic & 1.5 & \\
\hline 1 & Hard rubber & .9 & See \#3 below \\
\hline 1 & Hard rubber & 1.4 & Reddish brown \\
\hline 2 & Hard rubber & 1.7 & Black \\
\hline 12 Total & & \\
\hline
\end{tabular}

\#1: This button has a wire shank set into the back of the shell.

\#2: This button has a wire shank set into a single hole in the face. It is probably a shoe button.
\#3: This tiny little button was probably from a glove rather than children's clothing, as it is black. 
Table 5-39. Other Clothing Items from the Gilbert Site

\begin{tabular}{||c|l|c|l||}
\hline Count & \multicolumn{1}{|c|}{ Composition } & Size (cm) & Notes \\
\hline 1 & Snap & .8 & \\
\hline 1 & Snap & 1.2 & \\
\hline 2 & Zipper heads & 1.1 & One has a chain pull \\
\hline 2 & Zipper pull & & \\
\hline 1 & Buckle & 2.3 & \\
\hline 1 & Safety pin & 2.8 & \\
\hline 1 & Eyelet & .9 & \\
\hline 9 Total & & \\
\hline
\end{tabular}

\section{Conrad Site (41BX938)}

Eighteen clothing items were recovered from the Conrad site. Button descriptions are given in Table 5-40, with notes following. Other clothing items are presented in Table 5-41.

Table 5-40. Buttons from the Conrad Site

\begin{tabular}{|c|l|c|l||}
\hline Count & \multicolumn{1}{|c|}{ Composition } & Diameter $(\mathbf{c m})$ & \multicolumn{1}{|c|}{ Notes } \\
\hline 1 & Ceramic & 1.7 & See \#1 below \\
\hline 1 & Shell & 1.1 & \\
\hline 1 & Shell & 1.2 & \\
\hline 1 & Shell & 1.8 & Fragment \\
\hline 1 & Metal & 1.6 & \\
\hline 1 & Metal & 1.9 & \\
\hline 1 & Metal & 2.0 & See \#2 below \\
\hline 1 & Metal & 2.2 & See \#3 below \\
\hline 1 & Plastic & 1.2 & Grey \\
\hline 9 Total & & \\
\hline
\end{tabular}

\#1: This is not the standard ceramic button with a simple well. This button is fancier, with a raised center and a groove around the rim.
\#2: The is a dome-shaped metal button.

\#3: This button is brass, with the remains of gilding on it. It has a peaked-dome shape. 
Table 5-41. Other Clothing Items from the Conrad Site

\begin{tabular}{|c|l|c|l||}
\hline Count & \multicolumn{1}{|c|}{ Composition } & Size (cm) & Notes \\
\hline 2 & Snap & 1.1 & \\
\hline 1 & Zipper head & & \\
\hline 1 & Buckle & 3.7 & \\
\hline 1 & Safety pin & 4.3 & \\
\hline 1 & Eyelet & 1.1 & \\
\hline 1 & Leather sole & & Fragment, medium adult size \\
\hline 1 & Leather heel & & Medium adult size \\
\hline 1 & Plastic heel & & Marked "Made in USA", large adult size \\
\hline 9 Total & & \\
\hline
\end{tabular}

\section{Jones Site (41BX939)}

Sixteen clothing items were recovered from the Jones site. Button descriptions are given in Table 5-42, with notes following. Other clothing items are presented in Table 5-43.

Table 5-42. Buttons from the Jones Site

\begin{tabular}{|c|l|c|l||}
\hline Count & \multicolumn{1}{|c|}{ Composition } & Diameter $(\mathrm{cm})$ & \\
\hline 3 & Shell & 1.0 & \\
\hline 1 & Shell & 1.1 & \\
\hline 2 & Shell & 1.3 & \\
\hline 1 & Shell & 1.8 & \\
\hline 1 & Metal & 1.1 & \\
\hline 1 & Plastic & 1.1 & Pearl \\
\hline 1 & Plastic & 1.2 & Grey \\
\hline 1 & Plastic & 1.5 & Grey-green \\
\hline 2 & Hard rubber & 1.9 & See \#1 below \\
\hline 13 Total
\end{tabular}

\#1: Though the same size and material, these are two very different buttons. One is flat, with an embossed design, colored a rusty brown. The other is a slightly dome-shaped button with the backmark "Canotex." Both are probably from work clothes. 
Table 5-43. Other Clothing Items from the Jones Site

\begin{tabular}{|c|l|c|l||}
\hline Count & \multicolumn{1}{|c|}{ Composition } & Size (cm) & \multicolumn{1}{|c|}{ Notes } \\
\hline 1 & Buckle & 2.2 & \\
\hline 1 & Hose supporter base & & Fragment \\
\hline 1 & Hose supporter catch & & Fragment \\
\hline 3 Total & \\
\hline
\end{tabular}

\section{Meeks Site (41BX940)}

Thirteen clothing items, all buttons, were recovered from the Meeks site (Table 5-44).

Table 5-44. Buttons from the Meeks Site

\begin{tabular}{|c|l|c|l||}
\hline Count & \multicolumn{1}{|c|}{ Composition } & Diameter $(\mathrm{cm})$ & \multicolumn{1}{c|}{ Notes } \\
\hline 2 & Shell & 1.2 & \\
\hline 1 & Shell & 1.3 & \\
\hline 1 & Shell & 1.4 & \\
\hline 4 & Plastic & 1.2 & White \\
\hline 2 & Plastic & 1.3 & See military section \\
\hline 1 & Plastic & 1.4 & See military section \\
\hline 1 & Plastic & 1.9 & See military section \\
\hline 1 & Vegetable ivory & 1.4 & \\
\hline 13 Total & & \\
\hline
\end{tabular}

\section{Houston Site (41BX941)}

Four clothing items were recovered from the Houston site. Button descriptions are given in Table 5-45, other clothing items are presented in Table 5-46.

Table 5-45. Buttons from the Houston Site

\begin{tabular}{|c|l|c|c||}
\hline \hline Count & \multicolumn{1}{|c|}{ Composition } & Diameter $(\mathbf{c m})$ & Notes \\
\hline 1 & Shell & 2.7 & \\
\hline 1 & Plastic & 1.8 & Dark grey \\
\hline 2 Total & & \\
\hline
\end{tabular}


Table 5-46. Other Clothing Items from the Houston Site

\begin{tabular}{||c|l|c|l||}
\hline Count & \multicolumn{1}{|c|}{ Composition } & Size (cm) & \multicolumn{1}{|c|}{ Notes } \\
\hline 1 & $\begin{array}{l}\text { Belt buckle, probably of "German } \\
\text { silver", a nickel-silver alloy }\end{array}$ & & $\begin{array}{l}\text { Large, broken, embossed with a replica of a } \\
\text { "Southern Comfort" whiskey label }\end{array}$ \\
\hline 1 & Buckle w/ strap & & Probably from a sandal \\
\hline 2 Total & \multicolumn{2}{|l}{} \\
\hline
\end{tabular}

\section{Harris Site (41BX942)}

Thirteen clothing items were recovered from the Harris site (Table 5-47). A single shoe buckle with the remains of gilding on it, was the only clothing item other than buttons found at the site.

Table 5-47. Buttons from the Harris Site

\begin{tabular}{|c|l|c|l|}
\hline Count & \multicolumn{1}{|c|}{ Composition } & Diameter $(\mathrm{cm})$ & \multicolumn{1}{c|}{ Notes } \\
\hline 1 & Ceramic & 1.0 & \\
\hline 1 & Shell, grey & $? ?$ & Fragmented \\
\hline 1 & Shell & .9 & \\
\hline 2 & Shell & 1.0 & \\
\hline 1 & Shell & 1.1 & \\
\hline 1 & Shell & 1.5 & \\
\hline 1 & Metal & 1.7 & See \#1 below \\
\hline 1 & Plastic & 1.3 & White \\
\hline 1 & Plastic & 1.4 & White \\
\hline 1 & Plastic & 2.1 & Blue \\
\hline 1 & Hard rubber & 1.3 & Brown \\
\hline 12 Total & & \\
\hline
\end{tabular}

\#1: This button has a railroad car embossed on it. It is probably from a pair of overalls. An identical button is listed among those dated 1900-1935 in Hughes and Lester (1991:684).

\section{Grant Site (41BX943)}

Six clothing items, all buttons, were recovered from the Grant site (Table 5-48). 
Table 5-48. Buttons from the Grant Site

\begin{tabular}{||c|l|c|l||}
\hline \hline Count & \multicolumn{1}{|c|}{ Composition } & Diameter $(\mathrm{cm})$ & \multicolumn{1}{|c|}{ Notes } \\
\hline 2 & Plastic & 1.1 & See \#1 below \\
\hline 1 & Plastic & 1.2 & See \#1 below \\
\hline 1 & Plastic & 1.4 & Blue \\
\hline 1 & Plastic & 1.5 & See \#1 below \\
\hline 1 & Plastic & 1.9 & See \#1 below \\
\hline 6 Total & \multicolumn{2}{|l}{} \\
\hline
\end{tabular}

\#1: These buttons are probably from a "sewing kit" designed for modern military persons to keep with them when they travel. Such kits contain a button of each size and color found on a military uniform. Since only coat buttons on "Class A" uniforms are still made of metal, these are all plastic, each a different size and color. The colors indicate they were intended to match Army uniforms currently in use.

\section{Pauly Site (41BX945)}

A total of 174 clothing items was recovered from the Pauly site. Button descriptions are given in Table 5-49, with notes following. Other clothing items are presented in Table 5-50.

Table 5-49. Buttons from the Pauly Site

\begin{tabular}{||c|l|c|l||}
\hline Count & \multicolumn{1}{|c|}{ Composition } & Diameter $(\mathbf{c m})$ & \multicolumn{1}{|c|}{ Notes } \\
\hline 2 & Ceramic & .7 & See \#1 below \\
\hline 18 & Ceramic & .9 & See \#1 below; 8 are "pie crust" design \\
\hline 2 & Ceramic & 1.0 & \\
\hline 28 & Ceramic & 1.1 & See \#1 below; 6 are "pie crust" design \\
\hline 2 & Ceramic & 1.2 & \\
\hline 1 & Ceramic & 1.3 & \\
\hline 3 & Ceramic & 1.4 & \\
\hline 1 & Ceramic & 1.5 & \\
\hline 3 & Ceramic & 1.6 & \\
\hline 3 & Ceramic & 1.7 & \\
\hline 1 & Ceramic & 1.8 & See \#2 below \\
\hline 2 & Shell & .9 & \\
\hline 2 & Shell & 1.1 & \\
\hline 2 & Shell & 1.2 & \\
\hline 3 & Shell & 1.4 & \\
\hline 1 & Shell & 1.5 & \\
\hline
\end{tabular}


Table 5-49. continued

\begin{tabular}{|c|c|c|c|}
\hline Count & Composition & Diameter (cm) & Notes \\
\hline 1 & Shell & 1.6 & \\
\hline 1 & Shell & 1.7 & \\
\hline 1 & Shell & 1.9 & \\
\hline 1 & Metal & $? ?$ & Badly corroded \\
\hline 1 & Metal & 1.1 & \\
\hline 2 & Metal & 1.2 & See \#3 below \\
\hline 3 & Metal & 1.4 & See \#4 below \\
\hline 2 & Metal & 1.6 & Badly corroded \\
\hline 3 & Metal & 1.7 & See \#5 \& \#6 below \\
\hline 1 & Metal & 1.8 & See \#7 below \\
\hline 1 & Metal & 1.9 & Badly corroded \\
\hline 2 & Metal, military & 1.9 & See \#8 below \\
\hline 1 & Metal & 2.1 & See \#9 below \\
\hline 1 & Metal, military & 2.2 & See \#10 below \\
\hline 2 & Metal & 2.3 & See \#11 \& \#12 below \\
\hline 1 & Metal, military & 2.3 & See \#13 below \\
\hline 1 & Metal & 2.8 & See \#14 below \\
\hline 1 & Plastic & 2.3 & Blue \\
\hline 1 & Plastic & 1.9 & Off white \\
\hline 1 & Plastic (celluloid?) & 1.4 & Blue \\
\hline 1 & Plastic, Bakelite & 1.4 & Dark brown \\
\hline 2 & Bone & 1.4 & \\
\hline 1 & Bone & 1.6 & \\
\hline 2 & Bone & 1.8 & \\
\hline 1 & Wood & 1.4 & Burned \\
\hline 1 & Hard rubber & 1.2 & Brown \\
\hline 3 & Vegetable Ivory & 1.2 & 1 burned \\
\hline 6 & Vegetable Ivory & 1.4 & 1 fragment; see \#1 below \\
\hline 4 & Vegetable Ivory & 1.7 & See \#1 below \\
\hline 1 & Glass & 1.1 & See \#15 below \\
\hline
\end{tabular}

\#1: The Pauly Privy (Privy \#13), unlike areas of most sites, contained some levels where there were large numbers of buttons, many of which were identical. Button composition in this group includes ceramic, shell and vegetable ivory. The possible explanations for this are that there had been a tailor or seamstress living there at the time, or that several whole items of clothing were thrown into the privy at about the same time. The latter seems to be the most likely, as most of the buttons are in groups that would correspond to the buttoning needs of individual pieces of clothing (with the exception of the 
most common sizes of ceramic buttons, which could have come from several garments).

\#2: This is a large, dome-shaped ceramic button, broken about in half.

\#3: This is a composite button consisting of a bluegreen plastic dome on a metal base.

\#4: This is probably a button from work clothing. The words "Head Light" are embossed on the rim.

\#5: An overall-type button with a wire shank and the words "The Ranger" embossed on the flat face (Figure 5-2k).

\#6: Another overall or work-clothes type button with "Alamo Brand" and a line drawing of the Alamo chapel embossed on it (Figure 5-2.1).

\#7: This is the backing piece for a two piece button. It is marked "Superior*Quality" (Figure 5-2m). This is a common backmark on military buttons, but is also seen on other types of uniform buttons, including police, fire, etc.

\#8: These U.S. Army button were both found in the south half of the Pauly Privy (Privy \#13), close enough that they may have come from the same shirt. The style is the kind used between 1854 and 1870. Both are gilded and both have backmarks which are illegible.

\#9: This is a composite button consisting of a white plastic dome shape on a metal backing.

\#10: This is an U.S. Army Great seal button, with a backmark reading "Scovill MF'G Co Waterbury."
It dates to between 1902, when the design became standard, to 1920, the most recent date for this particular backmark (McGuinn and Bazelon 1990:88).

\#11: This slightly dome-shaped copper alloy button has a fancy floral design embossed on it (Figure 5-2n).

\#12: This button is made from two metals. The center is a copper alloy in a diamond shape with diagonal beaded lines (Figure 5-20). The outer rim is an iron alloy too corroded now to be sure, but it seems likely that the iron part was once a polished steel mirror, a common Victorian element in fancy buttons.

\#13: This is a U.S. Army Ordinance Corps officer's button, with most of the gilding still intact, of a design in use between 1851 and 1902 (Wyckoff 1984:76). The backmark, however, allows us to narrow down the dates to 1860-1870 (McGuinn and Bazelon 1990:53).

\#14: This button is composed of a copper alloy rim around an embossed design which is covered by a flattened glass dome (Figure 5-2p). The practice of covering buttons with glass was seen in the eighteenth century and had another vogue in the mid-nineteenth century. (Albert and Kent 1949:94).

\#15: This is a small, faceted, iridescent black button with a self shank.

Table 5-50. Other Clothing Items from the Pauly Site

\begin{tabular}{||c|l|c|l||}
\hline \hline Count & \multicolumn{1}{|c|}{ Composition } & Size (cm) & Notes \\
\hline 1 & Snap & 1.0 & \\
\hline 1 & Buckle & 2.0 & \\
\hline 1 & Buckle & 2.5 & \\
\hline 2 & Buckle & 3.0 & \\
\hline 1 & Safety pin & 4.8 & Fragment \\
\hline 1 & Strap fastener & 1.2 & For very thin, light-weight strap \\
\hline 1 & Strap fastener & 1.3 & \\
\hline 1 & Strap fastener & 1.6 & \\
\hline 2 & Strap fastener & 2.5 & One is marked "Hickory" \\
\hline 1 & Strap fastener & & $\begin{array}{l}\text { Large, heavy-duty, but decorated, back is marked "Crown } \\
\text { Mala Pat. May 29, 94" (1894?) }\end{array}$ \\
\hline
\end{tabular}


Table 5-50. continued

\begin{tabular}{|c|l|c|l||}
\hline Count & \multicolumn{1}{|c|}{ Composition } & Size (cm) & \multicolumn{1}{c|}{ Notes } \\
\hline 1 & Strap fastener & 3.5 & Made to attach 3 small straps to 1 large strap \\
\hline 2 & Clip-type hose supporter & & Made like a blunted alligator clip \\
\hline 6 & Eyelet & .6 & \\
\hline 2 & Eyelet & .7 & \\
\hline 1 & Eyelet & .8 & \\
\hline 4 & Eyelet & .9 & Three are painted white \\
\hline 1 & Eyelet & 1.1 & \\
\hline 1 & Leather strap w/ metal studs & 8.2 & \\
\hline 12 & Leather fragments & & Five are definitely shoe uppers, the rest are pieces of strap \\
\hline 1 & Thread spool, plastic & 3.5 & Modern item \\
\hline 1 & Straight pin & 3.0 & \\
\hline 1 & Scissors & 11.0 & Fragment \\
\hline 2 & Metal collar stays & 2.5 & \\
\hline 1 & Cloth fragment & & Floral print \\
\hline 48 & Total & \\
\hline
\end{tabular}

\section{W. Hoefgen/S. Nevada Site (41BX956)}

Seven clothing items, all buttons, were recovered from this site (Table 5-51).

Table 5-51. Buttons from 41BX956

\begin{tabular}{|c|l|c|l||}
\hline Count & \multicolumn{1}{|c|}{ Composition } & Diameter (cm) & \multicolumn{1}{|c|}{ Notes } \\
\hline 1 & Ceramic & 1.1 & \\
\hline 2 & Plastic & 1.4 & Dark brown, white \\
\hline 1 & Plastic & 1.8 & Translucent yellow \\
\hline 2 & Plastic & 2.4 & "Horn" \\
\hline 1 & Gutta Percha & 1.1 & See \#1 below \\
\hline 7 Total & & \\
\hline
\end{tabular}

\#1: This is a small button with a concave face incised with deep radiating lines. 


\section{E. Hoefgen/S. Nevada Site (41BX957)}

A single button was recovered from this site (Table 5-52).

Table 5-52. Button from 41BX957

\begin{tabular}{||c|l|r|r|}
\hline \hline Count & Composition & Diameter $(\mathrm{cm})$ & Notes \\
\hline 1 & Plastic & 1.5 & Transparent pink \\
\hline 1 Total & \\
\hline
\end{tabular}

\section{Discussion}

Most (66.2 percent) of the buttons recovered from the Alamodome project were shell, ceramic, bone, gutta percha, or vegetable ivory, types of buttons most common between 1850 and about 1920. Many of the metal and glass buttons were probably also from this period, though after 1945 , most buttons are plastic or with a few made of metal. When one considers that the period between 1850 and 1940 is 90 years while the period between 1940 and 1990 is only 50 years, it is clear that button loss has been more or less constant throughout the period under discussion.

\section{Buttons as Indicators of Economic Rank}

In an attempt to use buttons as a guide to the economic ranking of the 36 sites of the Alamodome "prices" were chosen by reference to the 1902 Sears Roebuck catalog (Sears Roebuck 1969:940). The 1902 catalog was printed in about the middle of the period in which most of the buttons recovered from the Alamodome were made, i.e. between 1870 , when the population in the area became significant (Cox, Volume I), and 1930 (see Pool 1987:289). These "prices" are not intended to reflect the actual cost of the buttons, but rather a cost relative to each other, which reflects the realities of button purchasing during those years. The button prices were assigned as shown in Table 5-53.

If the total number of each type of button is multiplied by the "price," all these "prices" added together and then divided by the total number of buttons for the site, a single "average button price" is available, suitable for ranking sites. Figure 5-3 is a graph of the "average button price" for selected sites with more than ten buttons which were probably made before World War II. The Pauly site has the highest average, while the Czernecki site has the lowest.

Numerous factors can influence a "price" index like this one, some of which have nothing to do with the economic ranking of the sites. As an example, the Pauly site would probably have had an even higher average if someone had not thrown lots of clothing with cheap ceramic buttons on it into the privy (see Table 49 and note \#1). This act was unlikely to have had anything to do with economic standing at all. Because it is difficult, if not impossible, to detect many such factors, a single item like buttons cannot alone give an accurate economic ranking of historic sites. However, combined with other data which indicate the economic ranking of the site, button "average price" can aid in making such rankings more reliable.

\section{Acknowledgments}

The author wishes to thank Gary Embrey, of the National Button Society, for his assistance in learning about military buttons. Thanks are also due to Guillermo Mendez for the illustrations. 
Table 5-53. Assigned Button Prices

\begin{tabular}{||l|c|c|c||}
\hline \multicolumn{1}{|c|}{ Button type } & Size & Catalog cost & Price \\
\hline Plain ceramic & $>1.4 \mathrm{~cm}$ & .04 gross & .00027 \\
\hline Plain ceramic & $\leq 1.3 \mathrm{~cm}$ & .10 gross & .00069 \\
\hline "Pie crust" ceramic & $>1.4 \mathrm{~cm}$ & .05 gross & .00035 \\
\hline "Pie crust" ceramic & $\leq 1.3 \mathrm{~cm}$ & .11 gross & .00079 \\
\hline Plain shell & $>1.4 \mathrm{~cm}$ & .025 dozen & .0021 \\
\hline Plain shell & $\leq 1.3 \mathrm{~cm}$ & .04 dozen & .003 \\
\hline Bone & & .25 gross & .0017 \\
\hline Vegetable Ivory & & .05 dozen & .0042 \\
\hline Plain metal & $\leq 1.3 \mathrm{~cm}$ & .05 gross & .00035 \\
\hline Fancy metal & $\leq 1.3 \mathrm{~cm}$ & .07 dozen & .0058 \\
\hline Large fancy metal & $>2.3 \mathrm{~cm}$ & .47 dozen $^{2}$ & .039 \\
\hline
\end{tabular}

\footnotetext{
' This price came from the 1908 Sears Roebuck (Schroeder 1989) catalog because there were no bone buttons of the plain fly variety sold in the 1902 catalog.

${ }^{2}$ This price came from the 1897 Sears Roebuck catalog (Israel 1968:320) because the large fancy metal buttons had gone out of style by the time of the 1902 catalog.
}

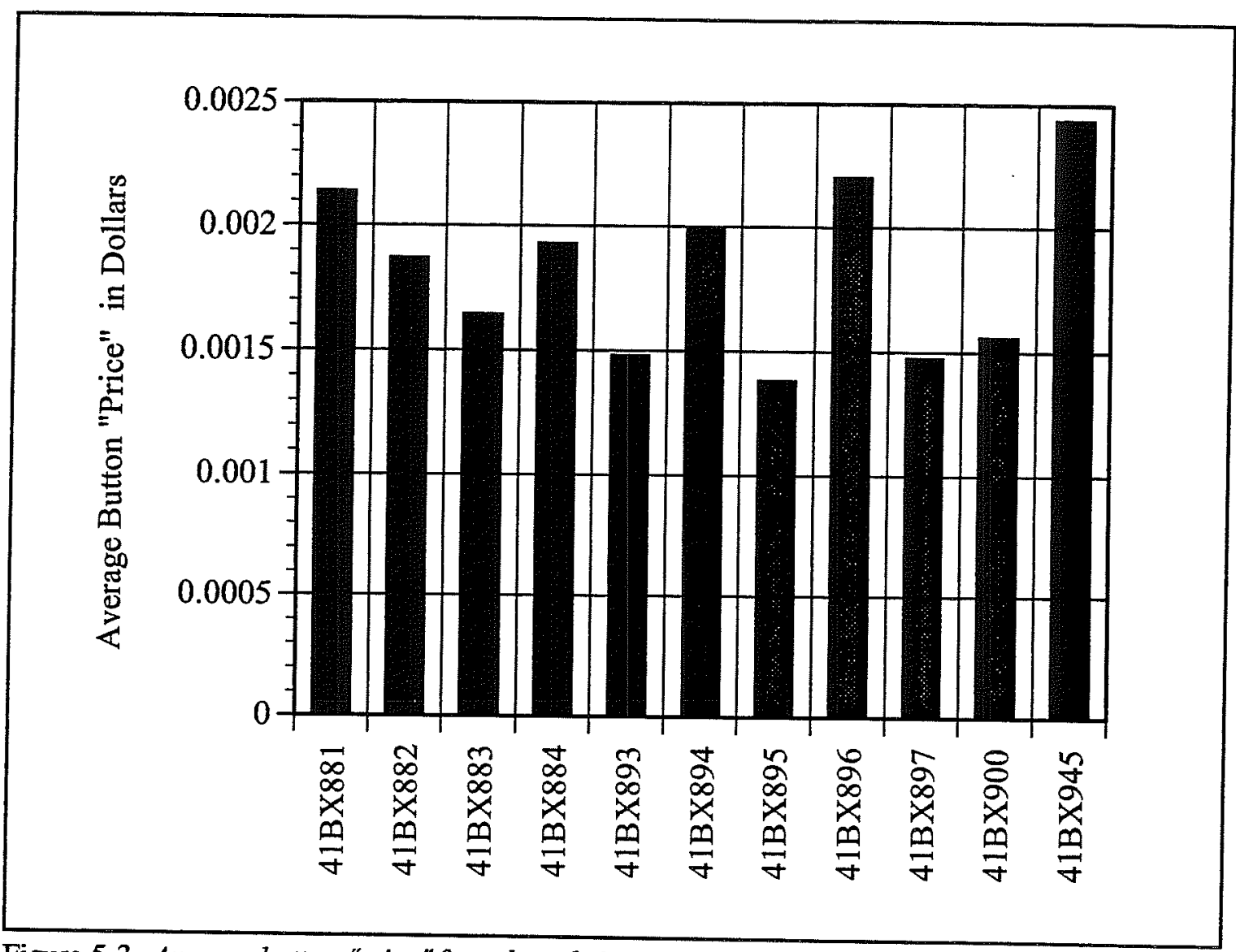

Figure 5-3. Average button "price" for selected sites. 


\section{References Cited}

Albert, L. S., and K. Kent

1949 The Complete Button Book. Appledore, Stratford, Connecticut.

Anderson, A.

1969 The Archaeology of Mass-Produced Footwear. Historical Archaeology 3:56-65.

Berendt, J.

1989 The Zipper. Esquire. viii(5):42.

Blum, S. (editor)

1974 Victorian Fashions \& Costumes from Harper's Bazaar: 1867-1898. Dover, New York.

Brinckerhoff, S. B.

1965 Metal Uniform Insignia of the U.S. Army in the Southwest, 1846-1902. The Journal of Arizona History, summer.

Chappell, G.

1972 The Search for the Well-Dressed Soldier 1865-1890. Arizona Historical Society Museum Monograph No. 5. Tucson, Arizona.

Collier, J.

1988 Official Identification and Price Guide to Antique and Modern Dolls, 4th edition. Ballentine, New York.

Cunnington, C. W., and P. Cunnington

1951 The History of Underclothes. Michael Joseph, London.

Epstein, D.

1968 Buttons. Walker, New York.

Epstein, D., and M. Safro

1991 Buttons. Abrams, New York.

Finch, C.

1991 Hooked and Buttoned Together: Victorian Underwear and Representation of the Female Body. Victorian Studies 34(3):337-363.

Harpur, P. (editor)

1982 The Timetable of Technology: A Record of the 20th Century's Amazing Achievements. Hearst, Washington, D.C.

Herskovitz, R. M.

1978 Fort Bowie Material Culture. University of Arizona Press, Tucson. 
Hughes, E., and M. Lester

1991 The Big Book of Buttons. New Leaf, Sedgewick, Maine.

Israel, F. L. (editor)

19681897 Sears, Roebuck Catalog. Chelsea House, New York.

Johnson, D. F.

1948 Uniform Buttons 1784-1948. Volume 1. Century House, Watkin's Glenn, New York.

McGuinn, W. F. and B. S. Bazelon

1990 American Military Button Makers and Dealers: Their Backmarks and Dates. Bookcrafter's, Chelsea, Michigan.

Montgomery Ward

1969 Catalogue No. 57 Montgomery Ward \& Co.: Catalogue and Buyers' Guide, Spring \& Summer 1895. Dover Publications, New York.

Parsons, M., and R. E. Burnett

1984 Landmark Inn State Historic Site: Archeological Investigations Medina County, Texas 1975-1980. Texas Parks and Wildlife Department Historic Sites and Restoration Branch, Austin.

Pool, J. C.

1987 Appendix V: Fanthorp Inn: A Study of Nineteenth and Twentieth Century Buttons. In Archeological Excavations at Fanthorp Inn State Historic Site (41GM79), Grimes County, Texas, Spring and Fall 1982, pp. 277-290. Texas Parks and Wildlife Department, Historic Sites and Restoration Branch, Austin.

Roberson, W. R.

1974 The Carrington-Covert House: Archeological Investigation of a 19th-Century Residence in Austin, Texas. Office of the State Archeologist Reports Number 25. Texas Historical Commission, Austin.

Sears Roebuck

19691902 Edition of The Sears, Roebuck Catalogue. Bounty, New York.

Schroeder, J. J. (editor)

1969 Sears, Roebuck \& Co. 1908 Catalogue No. 117: The Great Price Maker. DBI, Northbrook, Illinois.

Webster, D., and M. Webster

1974 Comparative Vertebrate Morphology. Academic Press, New York.

Whittemore, J.

1992 The Book of Buttons. Dorling Kinsersley, New York.

Wyckoff, M. A.

1984 United States Military Buttons of the Land Services 1787-1902: A Guide and Classificatory System. McLean County Historical Society, Bloomington, Illinois. 


\title{
Chapter 6
}

\section{Matters Public and Private: Items of Personal Use from the Alamodome Project}

\author{
Barbara A. Meissner
}

The moment just past is extinguished forever, save for the things made during it.

- George Kubler (1962)

By your eyebrow pencils, your encyclopedias, and your alarm clocks shall ye be known.

- Sinclair Lewis (1940)

\section{Introduction}

Archaeologists recovered 572 artifacts classified as "Personal Items" from the 36 historic sites within the Alamodome Project area. Anything, except clothing, which could be considered an item of personal use was included in this category (clothing is addressed in Meissner, this volume, Chapter 5). Personal items ranged from mirror glass to figurines and from jewelry to condom cases. The enormous variety of personal items presents a problem in the reporting of these artifacts and in the attempt to place information about them into a context that provides better understanding of the lives of the people who lived in the project area. In a sense, each item tells its own little story, and each story is a minute part of the jigsaw puzzle that presents a picture of the personal lives of people living in the past in this part of San Antonio. Of course, while we know that many pieces of that puzzle are missing, we have no idea how many and how important they are. This is the perennial problem of the archaeologist, made more frustrating because these personal items often provide such brilliantly colored pieces to that puzzle.
The period under study in the Alamodome Project is from the mid-1850s, when the first houses were constructed in the outskirts of a frontier town still under threat of attack by Indians, to 1990, when the last residents and small businesses were moved out of a somewhat dilapidated mid-town neighborhood of a modern American city. Throughout this period America in general, and San Antonio in particular, underwent an enormous change in the nature of its material culture. Before this time most material items used by people were either hand made in the home or made in small local shops. This was especially true in San Antonio, where there was no railroad until 1877.

By the turn of the century, even the most remote American family had access to a wide range of consumer goods through mail-order catalogs, resulting in an "urbanization" of American material culture (Kavanaugh 1978:71). By the end of World War I, industrialization had its profound effects on even outof-the-way San Antonio. To those living in the 1930s, horse-and-buggy days which were only two decades in the past seemed like ancient history (Cohn 1940:vii). People were much more likely to buy an item made in a factory far away than to make the item at home or have it made in a local shop. By the end of World War 
II, with the advent of modern plastics, the transformation to the material culture with which we are familiar was complete.

When possible, artifacts are discussed as they, or similar items, appear in reprints of various mail-order and wholesale catalogs dating from 1893 to 1925 . Included in this survey are the Carl P. Stirn wholesale catalog of 1893 (Stirn 1990); the 1895 Montgomery Ward catalog (Blum 1969); and the Sears Roebuck catalogs from 1897 (Israel 1968), 1902 (Sears Roebuck 1969), and 1927 (Mirken 1970) . Together these catalogs cover most of the period of particular concern to this report, in which many changes in the material culture of San Antonio took place. Cohn (1940:xxx) notes that the primary customer of the Sears Roebuck Company, especially in its early years, was the farm family, and those living in what were once the frontier areas of the United States. They were, in general, religious, conservative, and frugal. Thus the Sears catalogs of those periods do not show us the forefront of fashion, or the material desires of the sophisticate of the city, but the needs of cautious, hard-working and often isolated people who counted every penny. As Cohn points out, the Sears catalogs were not in the business of leading social behavior, but in following it (Cohn 1940:xxix). Because of this, Sears and other catalogs provide a glimpse of what life in rural and small- town America was like.

Both individual items and general categories of items recovered from the Alamodome Project are discussed in relation to changes in material culture. It is not possible, or even useful, to include photographs of every personal item; instead unique items and a sampling of common items are illustrated. Specific proveniences are provided for most items. Information regarding these proveniences, including site, and excavation maps is given in Volume II.

In some cases, the simple listing of what has been found is sufficient. In the author's opinion, little useful information can be gleaned from, say, a statistical analysis of the inter and intrasite counts of mirror glass sherds. On the other hand, an analysis of jewelry or cosmetics recovered from the project area may have a great deal to say about everything from the impact of the Industrial Revolution on consumerism in San Antonio to socioeconomic class and ethnicity in the archaeological record.

\section{A Short Course on Plastics}

We have a tendency to think that anything made of plastic is of little or no archaeological value. In fact, plastics themselves offer insights into the ways that technology creates changes in the material record.

The noun plastic means "any of various nonmetallic compounds, synthetically produced (usually from organic compounds by polymerization)" (Webster's Dictionary, 1983). The process of polymerization creates chemicals of unusually high molecular weight, containing up to millions of linked units by chaining simpler compounds, called monomers.

The practical result of this process is to create a material that is plastic (adjective), that is, pliable and able to be formed or shaped, at a certain temperature, and yet is harder and not pliant at cooler temperatures. The actual temperature at which these chemicals become plastic varies a great deal among the various kinds. Some are still plastic at room temperature, others only at very high temperatures.

Long-chain polymers are naturally occurring as well as manufactured. The most commonly used natural plastic is the sap of several tropical trees. Soft, natural rubber was too pliable to be of use for very many things other than balls. In 1851, Goodyear patented a process by which sulfur could be added to natural rubber, heated and formed, then cooled into a much harder substance (Albert and Kent 1949:66). It was used to make buttons, to replace wood or bone in handles and pipe stems, and of course, to make tires. Although hard rubber could be dyed, most colors were dark. Not until 1908 was a pure white dye available for rubber products (Harpur 1982:28).

The first commonly available manufactured plastic was celluloid. Invented in 1869 (Collier 1988:19), this highly flammable plastic was used for combs, brushes, spectacle frames, and other household items. Celluloid could be dyed, although the colors tended to be pale. Additionally, three visual effects could be produced: tortoise shell, ivory, and pearl (Harpur 1982:66).

Celluloid and hard rubber were the only commercially available plastic products until after the turn of the century. However, other plastic-like substances were available in the late-nineteenth century. The most 
common was a material similar to paper mache, often called "composition," in which fine wood pulp was mixed with a glue, pressed into molds, and then dried into a hard form. Composition was generally very dark in color.

After the turn of the century, more plastics became available. Bakelite was patented in 1909, and was soon used for a wide variety of things, from telephones to billiard balls, and as a substitute for rubber, amber, and celluloid (Harpur 1982:30). Plastics began to have a wider range of colors, but it was not until the 1930s that polyvinyl chloride, polystyrene, melamine, nylon, and acrylic plastics were invented (Harpur 1982:67). These plastics could be made in many different hardness, and many different, often brilliant, colors. World War II interfered with the commercial exploitation of these new materials, but their use exploded after the war. Because plastics were so moldable, so colorful and, most importantly, so cheap, they completely took over many markets in household and personal items (Harpur 1982:67).

It is not easy, with the facilities available to most archaeological laboratories, to identify specific kinds of plastic, and even celluloid, if used for bulkier items, is not always easy to differentiate from more modern plastics. However, in general, older plastics, including celluloid, rubber and composition, are generally dark colored and opaque or translucent, with a less "fused" looking interior than modern plastics. In the descriptions below plastics will be identified as celluloid or composition only when that identification is fairly certain. Otherwise, plastics should be considered to be modern type unless they are specifically described as "old." Old plastics are dark, opaque or translucent, with fairly hard surfaces, and generally pre-date World War II. Most composition is likely to date sometime before World War I. Celluloid was in general use until after World War II, and is still occasionally seen. "Modern" plastics will be defined as brightly colored, opaque, translucent or transparent materials with wide variation in surface hardness.

\section{Items of Personal Adornment}

This category includes 189 artifacts, consisting of jewelry and other ornaments, metal pin "buttons," and mirror glass.
An examination of some social behaviors, as reflected in the Sears catalogs available to us, makes it clear that the whole idea of "costume jewelry," that is, jewelry made from synthetics intended to simulate gold and precious stones, had a comeback beginning after World War I. In the early days of the modern market economy, the growing middle class had copied the jewelry fashions of the court and aristocracy in less precious metals and stone, and the wearing of such jewelry was very common (Evans 1970:181). After the Civil War in America, however, the influence of Queen Victoria's widowhood was felt and large amounts of jewelry were no longer worn (Evans 1970:181), especially by the middle class.

The Industrial Revolution provided an increase in disposable income, and the opening of the South African diamond mines caused a fall in prices that allowed even lower-middle-class people to purchase a few jewels (Evans 1970:181). This is reflected in the Sears Roebuck and Montgomery Ward catalogs of the last decades of the nineteenth century. In the 1897 Sears catalog (Israel 1968), jewelry is offered on 21 pages; 46.43 percent of the pages show items made of solid gold and genuine gemstones, the rest were goldfilled, gold plated, or solid silver, and had synthetic gems. Though not of the best quality, they could hardly be called "costume," as precious metals were used in their construction. In 1902, jewelry was offered on only 11 pages; 43.18 percent of the pages show items of solid gold with genuine stones. All pieces still had at least some precious metals involved in the design. But rapid social change was underway, spurred on by the increased influence of industrialization and the trauma of World War I. In the 1927 Sears catalog, jewelry was offered on 17 pages. Jewelry made of solid gold and genuine stones were shown on 44.12 percent, as were the gold-filled and other "lesser" kinds of jewelry. But for the first time we see 11.76 percent of the jewelry pages dedicated to long strings of imitation pearls, and jewelry made of "white metal" (made to simulate gold) and silver plating (Mirken 1970). By the 1950s their wedding rings were sometimes all the "real" jewelry that middle- and lower-class women owned, although they often had quite a bit of costume jewelry (Candy, personal communication 1992). The days of the great jewelers (along with the royalty they adorned) were over. Jewelry making had become an industry, not an art (Evans 1970:183), and "American manufacturers 
are producing costume jewels that are intended to have no longer a life than that of the dress they adorn" (Evans 1970:184).

In the nineteenth century the set of behavior associated with death and mourning reached a formality, an intricacy, and an importance that has seldom been seen in Western societies (Pike 1984:48). During this period a wide range of customary behaviors related to the memorialization of the dead developed. Included in these practices was the wearing of "mourning," i.e., clothing made specifically to be worn after the death of a loved one (Blum 1974:291). Women were particularly expected to wear mourning, in some cases, for years after a death. To go with the clothing traditionally worn was jewelry, usually of onyx or jet. The practice of wearing mourning continued, though somewhat modified, until "the shattering cataclysm of World War I" (Pike 1984:64). As might be expected, mourning jewelry was sold in both the 1897 (Israel 1968:424,430) and 1902 (Sears Roebuck 1969:90) Sears catalogs, but not in the 1927 (Mirken 1970). Mourning jewelry was the only category of jewelry seen in the mail order catalogs in which imitations were common before World War I.

The women living in the Alamodome area certainly took advantage of the acceptance of costume jewelry. Only two amber beads found on the Czernecki Rental site (41BX894) were genuine semi-precious gems. All the other ornamentation found during the project were made of glass, plastic, and cheap metals. They are listed below, by site.

\section{Oeffinger Site (41BX881)}

N25/W55. A black glass bead shaped like two slightly faceted domes with their bases together and the hole through the apex of the dome (Figure 6-1a). It is 1.4 $\mathrm{cm}$ in diameter.

N32/W48. A silver-gilded copper-alloy horseshoeshaped pin, measuring 2.2 by $2.0 \mathrm{~cm}$ (Figure 6-1b). Thirteen rhinestones are set evenly around the pin, each about $.2 \mathrm{~cm}$ in diameter. Some kind of backing was on the pin at one time, but is now gone. The horseshoe motif is evident in all catalogs examined for this study, but all were of precious or semi-precious materials. This item is probably from after the 1920 s.
N40/W25. A glass bead in whirled shades of tan and light brown (Figure 6-1c). It is $1.0 \mathrm{~cm}$ in diameter, with a broken metal pin extending $1.4 \mathrm{~cm}$ from the bead. This was probably a hat pin.

N45/W55. A copper-alloy cuff link back. It is oval, 1.4 by $.9 \mathrm{~cm}$.

N119/W80. A clear glass, faceted bead, $.9 \mathrm{~cm}$ in diameter.

Trench D. An elongated plastic orange-red bead with the hole through the narrow axis of the bead instead of the long axis. The bead is $.8 \mathrm{by} .4 \mathrm{~cm}$.

Trench D. A transparent aqua bead, $.7 \mathrm{~cm}$ in diameter.

Most of the jewelry found on this site is probably postWorld War II in origin. The exceptions are the glass hat pin bead and the black glass bead. The latter is one of several found during the project that is probably intended as imitation jet. This bead may have been mourning apparel, and, if so, probably dates to before World War I.

\section{Haas Site (41BX882)}

Surface. Two yellowish celluloid "tortoise shell" fragments, consisting of two curving pieces with flat backs and slightly domed surfaces (Figure 6-1d). They are $.6 \mathrm{~cm}$ wide. One piece is $1.9 \mathrm{~cm}$ long, the other is $2.5 \mathrm{~cm}$. They are probably from a decorative comb. Both real and imitation (celluloid) tortoiseshell side and back combs were sold in the 1895 Montgomery Ward catalog (Blum 1969:183). The combs in the catalog have cut-out loops and swirls which resemble the pieces found on the Haas site. By the time the bobbing of women's hair became popular, these kinds of combs were seldom made. Although a resurgence of side combs has occurred in more recent decades, they are usually made of modern plastics. It seems likely, therefore, that these pieces came from an older variety.

N19/E58. A clear, faceted glass bead, $1.4 \mathrm{~cm}$ in diameter (Figure 6-1e). 


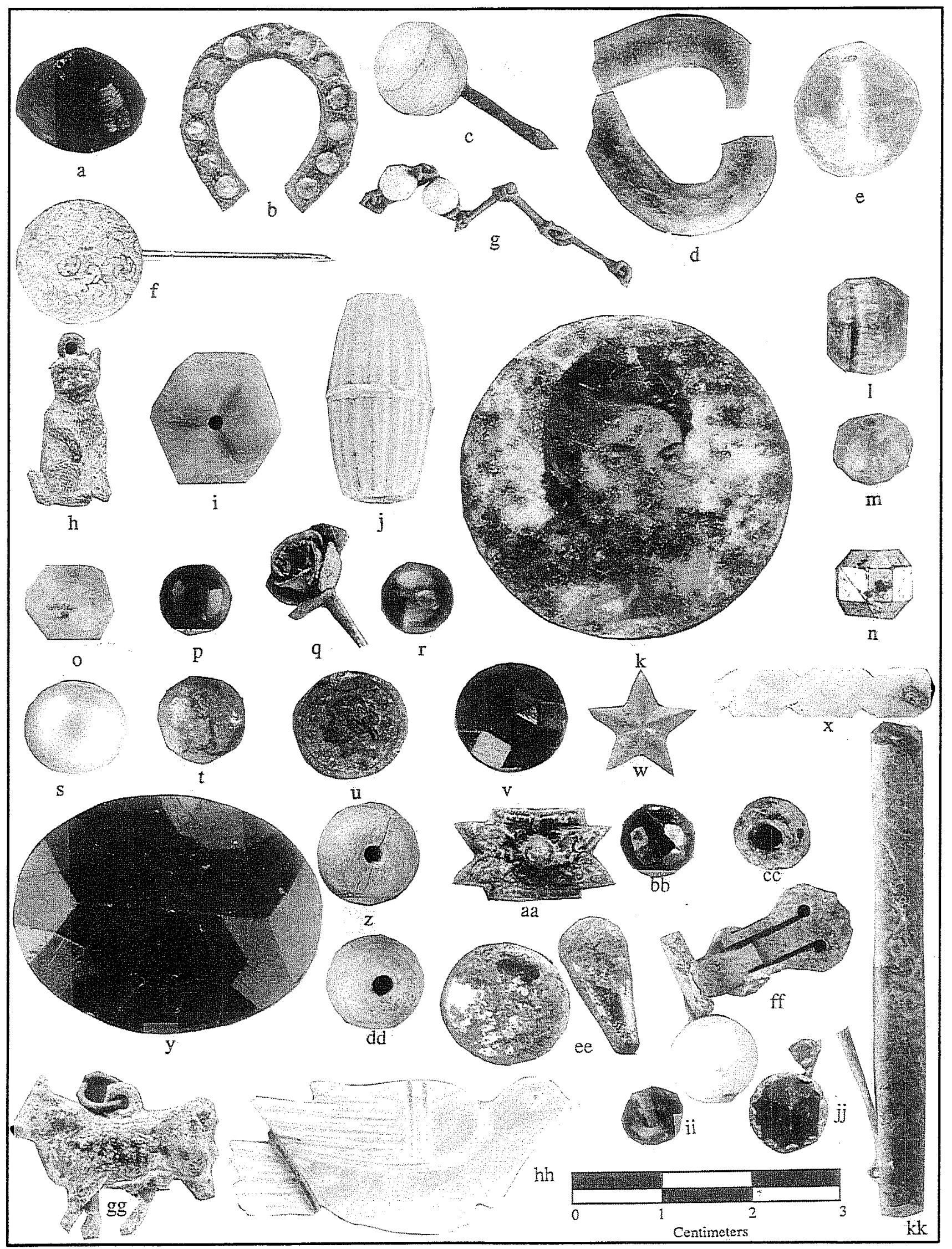

Figure 6-1. Miscellaneous personal items from the Alamodome Project. 
N25/E4. A blue-green, hollow glass bead with a translucent gold glaze. It measures $.6 \mathrm{~cm}$ in diameter.

N40/E88. Two identical silver-gilded stick pins. One is complete and the pin of the other is broken off. Both have a "curly" brocade pattern on slightly domed faces $1.4 \mathrm{~cm}$ in diameter. The total pin length is $3.2 \mathrm{~cm}$. There is another small pin in the back of each about .4 $\mathrm{cm}$ long, pointing in the direction opposite that of the long pin (Figure 6-1f shows the complete pin).

Trench C. A purple glass bead, $1.1 \mathrm{~cm}$ in diameter.

Trench C. A turquoise glass bead, $1.1 \mathrm{~cm}$ in diameter.

Much of the jewelry found at this site is likely to date between the World Wars. The large number of beads suggests post World War I dating, while the use of glass instead of plastic for all the beads suggests a preWorld War II dating. The celluloid comb fragments may be older, as hair bobbing became popular after World War I and fewer women needed decorative hair combs. By the time of the resurgence of long hair at various times after World War II, the combs would probably have been made of modern plastic, not celluloid.

\section{King Site (41BX883)}

N58/E91. Half of a large blue plastic bead, measuring $1.5 \mathrm{~cm}$ in diameter.

Trench B. A red plastic bead, measuring $1.0 \mathrm{~cm}$ in diameter.

Trench C, Feature A. A small mirror in a badly corroded metal frame. The frame is about $4.7 \mathrm{~cm}$ in diameter. It could be a part of a compact case, but is too corroded to tell (Figure 6-2a).

Test D, Structure B. Two white glass bead fragments about $.6 \mathrm{~cm}$ in diameter.

Three mirror glass fragments were found on the King site.

The artifacts from the King site must be considered in relation to the Webb site (41BX897), next door to the north. These two sites have been shown to be inextricably jumbled together (see Volume II). In most categories of artifacts, this mixture is obvious but here we see a distinct difference in artifacts. The jewelry from the King site is all quite modern, while much of the jewelry from the Webb site is quite old, some possibly from the late nineteenth century (see below).

\section{Griesenbeck Site (41BX884)}

N22/W44. A chain fragment with five links and two celluloid beads (Figure 6-1g). Each bead is strung separately on a wire and the ends of the wire are looped around each other to form the chain. The total length is $4.3 \mathrm{~cm}$, each link is approximately $.8 \mathrm{~cm}$ long, and the beads are $.4 \mathrm{~cm}$ in diameter. The chain appears hand made, and is probably part of a rosary.

N42/W47. A metal cat charm, with a flat back and detailed molding, including little lines representing fur (Figure 6-1h). The metal, probably lead, has some damage.

N65/W27. A translucent plastic bead with blue paint, measuring $1.1 \mathrm{~cm}$.

N65/W27. A faceted, black plastic bead, measuring $1.1 \mathrm{~cm}$ in diameter.

N65/W27. A faceted, aqua glass bead, measuring 1.0 in diameter.

N80/W32. A barrel-shaped bead in dark pink plastic. It is $.1 \mathrm{~cm}$ in diameter.

N107/W36. Half of a transparent pink plastic bead, measuring $1.0 \mathrm{~cm}$ in diameter.

Trench A, Feature A. A red plastic bead in a threedimensional Z-shape (Figure 6-1i). It is $1.4 \mathrm{~cm}$ across.

Trench A, Feature A. A very large blue barrel-shaped plastic bead, measuring 1.2 by $2.3 \mathrm{~cm}$ (Figure 6-1j).

Trench A, Feature A. A gilded loop earring for pierced ears. The wire, which is broken off near its base, is meant to go through the earlobe and then attach to a catch on the other end of the loop. The 


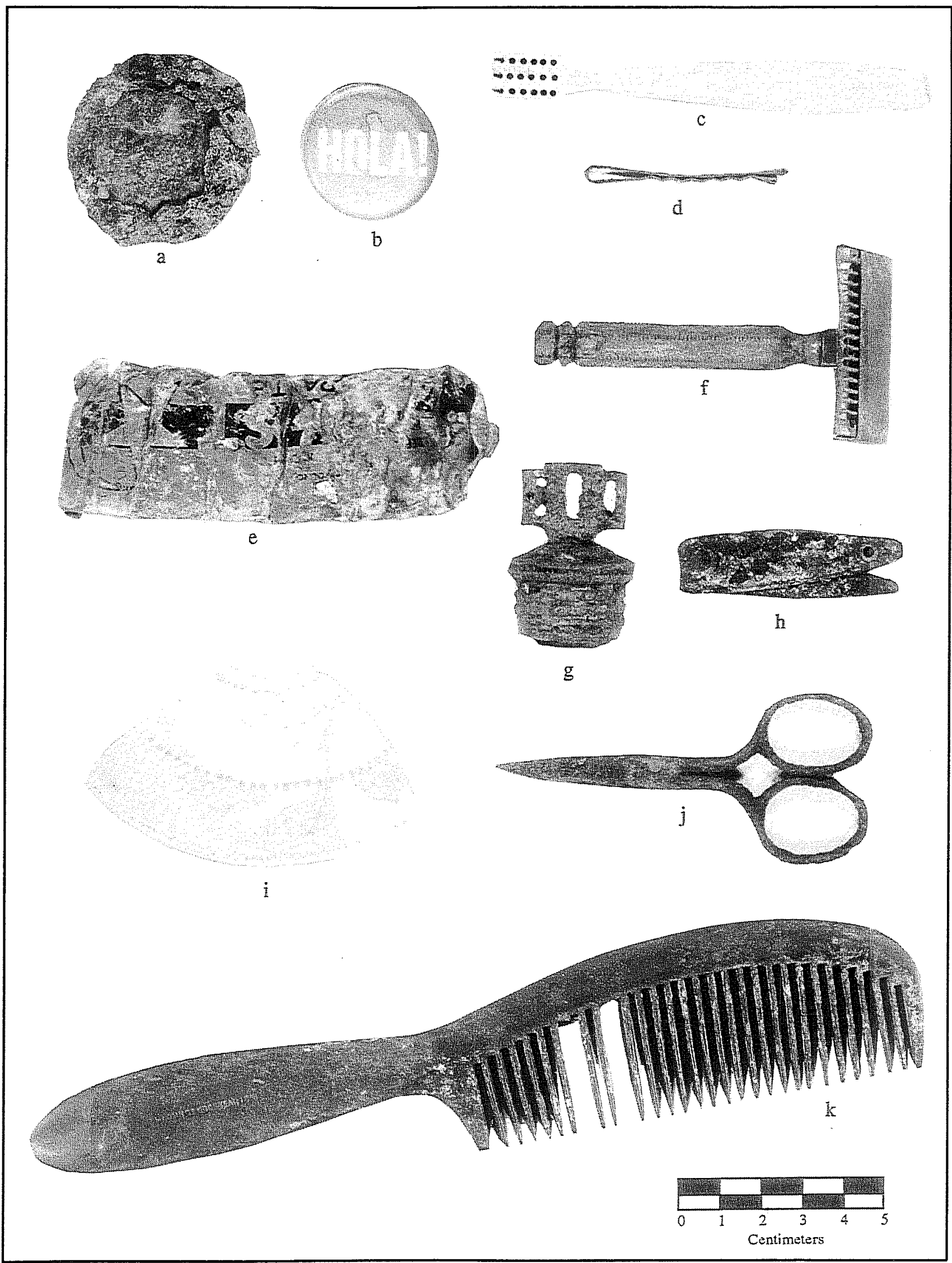

Figure 6-2. Miscellaneous personal items from the Alamodome Project. 
loop is bent, but the original diameter was about 2.3 $\mathrm{cm}$. This is a very cheaply made version of a style popular from at least the late nineteenth century (Blum 1969:179), and still popular today.

Trench A, Feature A. A small decorative pin with a plain gilded face. The pin is $2.4 \mathrm{~cm}$ long and $.4 \mathrm{~cm}$ wide.

Trench A, Feature A. The back of a metal cuff link.

Trench A, Feature A. A gilded clip-type earring. The front has space for a jewel to be glued. There is a small ring attached to the lower loop from which another ornament could be hung. This is a very cheap piece of jewelry.

Trench B. A composition bead with some kind of shell around it, possibly celluloid or other early plastic. The outer surface of this shell is damaged, but was apparently intended to look like a pearl. The bead is .7 $\mathrm{cm}$ in diameter.

Eight mirror glass fragments were found on the Griesenbeck site.

Numerous jewelry-related artifacts were recovered form this site, most having a post-World War II origin. The exceptions are the rosary chain, the cat charm, and the composition bead listed above. All three are likely to have been made before World War I.

The earring intended for unpierced ears has undergone a complete cycle of fashion in the last 100 years. Screw-type earrings were a novelty in 1899 (Cunnington and Cunnington 1970:568), but these, along with clip-type earrings, were not available to Sears customers until 1927 (Mirken 1970). By the 1950s, most women did not get their ears pierced, and clip or screw-type earrings were standard (Candy, personal communication 1992). In fact, pierced ears were often considered a sign of less-than-wholehearted virtue (Anne A. Fox, personal communication 1992). Beginning in the 1960 s, however, ear piercing became popular again, and this popularity grew until, at the time of this report, most women (and many men) have pierced ears and it is not always easy to find earrings of the unpierced variety.

\section{Mendit/Maffi Site (41BX885)}

Surface lithographed metal "button" pin with a picture of pop singer Michael Jackson on it. The fastener is pin-and-hook. Because of his penchant for plastic surgery, it is possible to date the manufacture of this pin to the period of Thriller (ca. 1983), when the modification of Jackson's original facial features was still minimal (Figure 6-1k)

\section{Rilling Site (41BX892)}

Trench A (ext.), Feature A. A copper piece stamped with an attractive flower design (Figure 6-3a). Although not enough of the piece is left for identification, it is presumed to be decorative in intent.

Trench A (ext.), Feature A. A celluloid cameo brooch (Figure 6-3b). The color is a mottled, almost iridescent blue-purple. The molding is fairly detailed. Remains of a pin are found on the back.

Trench C, Feature A. An opaque blue glass bead, .6 $\mathrm{cm}$ in diameter.

\section{Czernecki Site (41BX893)}

S83/E55. A swirled tan and grey plastic bead, possibly intended as imitation horn (Figure 6-11). It is a good quality bead, measuring $1.1 \mathrm{~cm}$ in diameter.

S83/E55. A transparent, faceted, green plastic bead, $.8 \mathrm{~cm}$ in diameter (Figure 6-1m).

S83/E55. A hollow, faceted plastic bead with gold metallic coating, $.8 \mathrm{~cm}$ in diameter (Figure 6-1n).

S83/E55. A red-orange, faceted plastic bead, $.9 \mathrm{~cm}$ in diameter (Figure 6-10).

S126/E31. A broken, hollow glass bead about $.6 \mathrm{~cm}$ in diameter. It has a gold color with fragment of what appears to be a handpainted leaf pattern in green. 


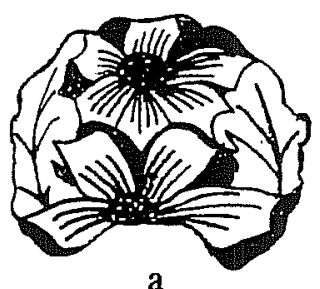

a

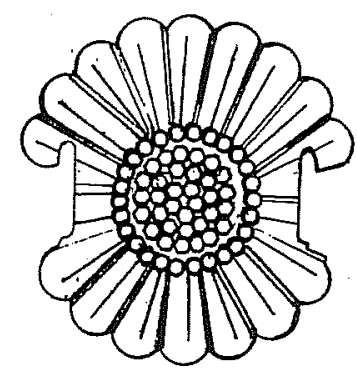

d

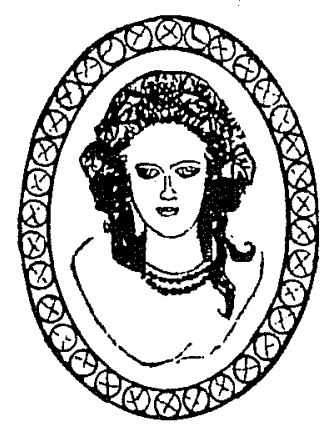

b
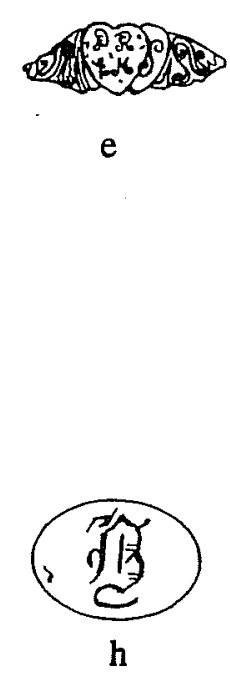

(2)

j
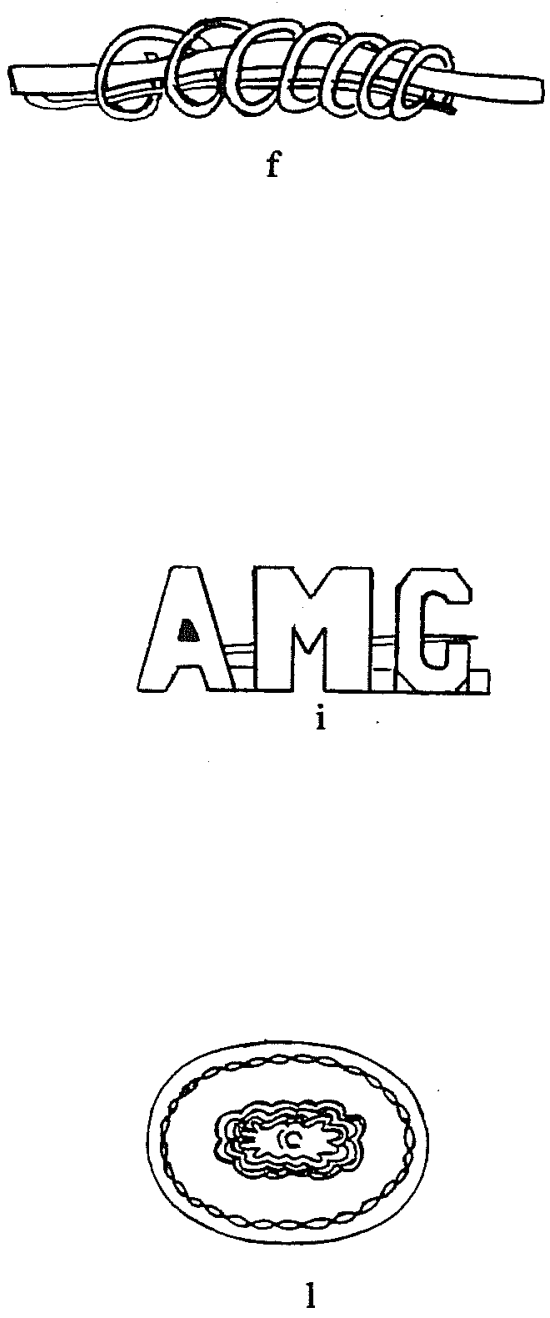

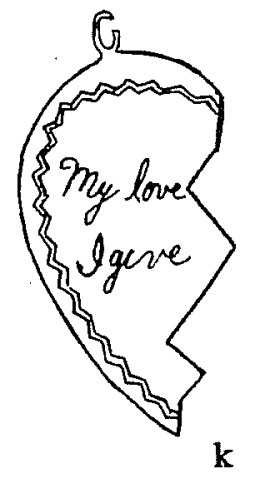

Figure 6-3. Miscellaneous personal items from the Alamodome Project. All shown actual size. 
S130/E10. A red opaque plastic bead which looks sun bleached. It measures $.6 \mathrm{~cm}$ in diameter and is of very poor quality.

One piece of mirror glass was found on the Czernecki site.

All the jewelry listed for this site was probably made after World War II.

\section{Czernecki Rental (41BX894)}

Surface. A genuine amber bead, $.8 \mathrm{~cm}$ in diameter (Figure 6-1p).

S16/E74. A metal earring. The piece is the shape of a flower with gold-colored metal stamped out and layered together to form the petals (Figure 6-1q). In the center is the setting for a stone, with the stone missing. The earring is a post type. This is a wellmade piece of costume jewelry.

S18/E72. A genuine amber bead, $.8 \mathrm{~cm}$ in diameter (Figure 6-1r).

S18/E72. A white plastic bead with a yellowish "pearl" coating. It measures $1.1 \mathrm{~cm}$ in diameter (Figure 6-1s).

S18/E72. A hollow copper bead. It measures $1.0 \mathrm{~cm}$ in diameter and is faceted (Figure 6-1t).

S18/E76. A dark blue plastic bead, $.6 \mathrm{~cm}$ in diameter . This is high-quality hard plastic and is probably very modern.

S134/E56. A metal token, stamped to imitate a Roman coin. It is $1.3 \mathrm{~cm}$ in diameter. The design consists of a woman's profile surrounded by 12 stars and a raised circle near the rim. The back is a negative of the front. A small hole is punched in the top to allow hanging from a chain. The wearing of coin jewelry first became popular in the mid-nineteenth century (Tait 1987:183) and continued to be in fashion off and on to the present. The fact that this coin is made of base metal suggests that it originated after World War I (Figure 6-1u).

S144/E56. Two blue plastic beads, each $.6 \mathrm{~cm}$ in diameter. Remains of metallic gilt is seen on the edges; this may have rubbed off the beads next to them on a string.

One mirror glass fragment was found on this site.

The most interesting jewelry at this site were the two genuine amber beads. These beads are the only "real" jewelry found at the Alamodome site. All the jewelry on this site probably dates to post-World War I.

\section{Garza Store (41BX895)}

Under Garza Store. A blue-green plastic bead. The bead measures $1.4 \mathrm{~cm}$ in diameter and is scored with numerous abrasions.

Under Garza Store. A green faceted plastic jewel, 1.3 $\mathrm{cm}$ in diameter, with traces of glue along the edges. The jewel is fairly flat with a low peak in the center (Figure 6-1v).

\section{Demazieres House (41BX896)}

Trench A. A small $(.5 \mathrm{~cm})$, red, faceted plastic bead.

Trench A. A copper piece with a high-quality glass "diamond" set in the center. This item would have been part of a piece of jewelry, probably an earring (Figure 6-3c).

Trench A. Backing of a screw-type earring.

Trench C, S3. A small $(.3 \mathrm{~cm})$, dark pink plastic bead.

Trench C, S4. A very cheap gold-colored flowershaped earring or pin (Figure 6-4a). There is space in the center for a gem.

Trench C, S4. A copper alloy concho from a belt (Figure 6-3d). It has a sunflower pattern and measures $3.4 \mathrm{~cm}$ wide. There are the remains of wide holes where the piece was once linked to others on each side.

Trench D, S1. A metal ring, about size $6 \frac{1}{2}$. The ring is gilded and embossed with a pattern of two hearts, one partially covering the other, surrounded by a 


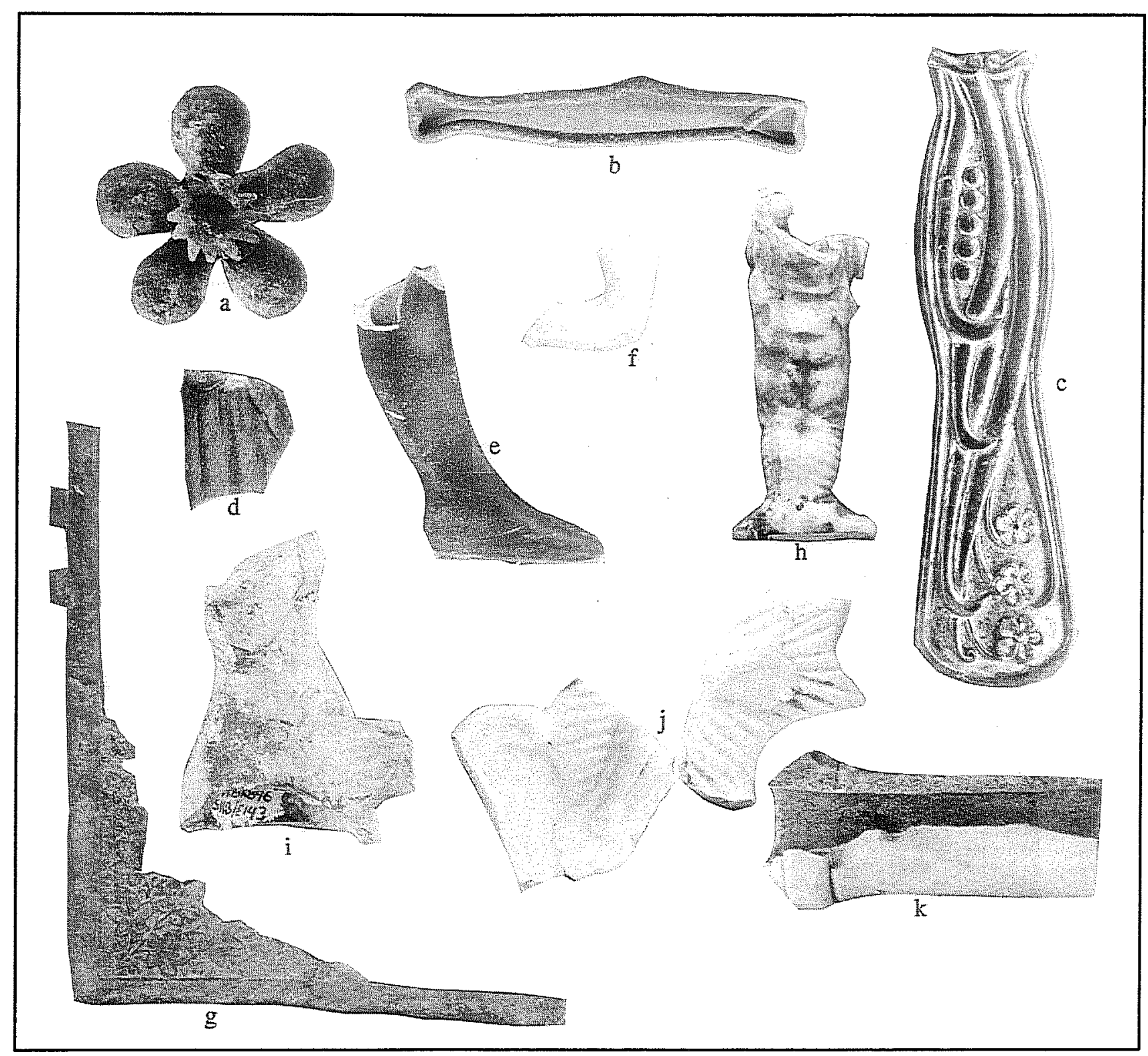

Figure 6-4. Miscellaneous personal items from the Alamodome Project. All shown actual size.

swirly pattern. Engraved on the upper heart are the initials "D. R. \& E. M." (Figure 6-3e).

Trench D, S1. A pin made from copper alloy wire (Figure 6-3f). It may once have been gilded. The pin is constructed of wide loops of wire with a thin curved bar about $5.4 \mathrm{~cm}$ long resting in the loops. A pin was made from a wire bent almost in half, with a point on one end and a loop to serve as a catch on the other, also passing through the loops. It appears to be handmade.
Trench D, S3. A ruby-colored glass gem. This gem is has a high faceted dome on one side and is flat on the other. It measures $1.2 \mathrm{~cm}$ in diameter.

Trench D, S3. A very thin, hollow glass bead with a powdery white covering, measuring $.6 \mathrm{~cm}$ in diameter.

Trench E, S1. A dark green, transparent plastic cross, 6.4 by $4.4 \mathrm{~cm}$. The plastic is acrylic, but does not appear very scratched, indicating this is a very modern piece. 
Trench G. A small, five-pointed star made of white metal about $1.2 \mathrm{~cm}$ in width (Figure 6-1w). This item could be either part of a cheap earring or intended to decorate clothing. The quality, which is poor, suggests the latter.

Shovel Test \#12. A piece of copper alloy in an oval shape with one long side flatted by a break (Figure $6-3 \mathrm{~g}$ ). It is 3.8 by $3.1 \mathrm{~cm}$, and is handpainted with a black background and a plant with green leaves and silver colored flowers. It was probably part of a pendant.

Shovel Test \#16. A transparent red glass bead, $.7 \mathrm{~cm}$ in diameter.

Shovel Test \#16. A clear plastic piece with an embossed four-point design and evidence of "frosted" paint left in the grooves. The back is flat and appears to have once been mounted as a piece of jewelry .

S39/E76. A gilded metal piece, intended as part of a piece of jewelry. It is engraved with an Old English letter B (Figure 6-3h).

S64/E109, Level 2. An orange glass bead in a flattened oval shape. It is faceted and $.6 \mathrm{~cm}$ in diameter.

S64/E109, Level 2. Pink plastic bead, .4 cm in diameter.

S76/E146. A translucent white glass bead, $.8 \mathrm{~cm}$ in diameter.

S87/E109. A copper alloy pin, formed in the letters "A.M.C." (Figure 6-3i).

S87/E109. Three links of copper wire, with two shell pieces attached. The shell appears hand cut. This was probably just a small part of a piece of jewelry (Figure $6-3 \mathbf{j})$.

S107/E107. Red, faceted plastic bead, $.6 \mathrm{~cm}$ in diameter.

S118/E143, Privy \#5 Test. A flat, rectangular piece of mother-of-pearl jewelry, measuring 2.5 by $.6 \mathrm{~cm}$. It has little indentations cut into each edge (Figure 6-1x). A hole at one end has a copper wire loop through it, the other end is broken. This piece was probably part of a necklace or bracelet.

S118/W143, Privy \#5, Level 8. A large faceted oval glass gem. This item is amethyst-colored and faceted on both sides. It measures 3.5 by $2.7 \mathrm{~cm}$. This is a good quality synthetic amethyst (Figure 6-1y)

S199/E130, Level 1. A metal earring for an unpierced ear, with a screw-type closure. The earring has a gilded dome-shaped piece as well a small loop on which some other part of the earring once hung. This is very cheap costume jewelry.

Room 2. blue plastic bead, $.8 \mathrm{~cm}$ in diameter

\section{Webb/Deman Site (41BX897)}

Trench H. A copper pendant, measuring 3.8 by 2.2 $\mathrm{cm}$ (Figure 6-3k). This would have been part of a twopiece set, with one piece given to the object of affection and the other retained by the purchaser. Each piece is in the shape of a broken heart, and the two pieces would fit together. The words "My love ..." and "I give . . . " are engraved on the front in script. The rest of the saying would have been on the other piece of the set. A zig-zag decoration goes around the rim of the piece. There is a self loop at the top, set to hang this half-heart as a single piece of jewelry.

Trench $\mathrm{H}$. A bone bead, $1.3 \mathrm{~cm}$ in diameter (Figure 6-1z). A blind hole is found in one side and a flatbottomed well in the other. The remains of red paint are evident in the bottom of the hole. This bead could have been part of the head of a hat pin.

Trench H-Ext. A large, copper jewelry clasp, decorated with a zig-zag pattern (Figure 6-1aa). The clasp is 1.8 by $1.1 \mathrm{~cm}$ and would have been for a large necklace.

Trench K. A shell bead, measuring $1.0 \mathrm{~cm}$ in diameter. The bead is in poor condition, with the shell beginning to separate into layers.

Area A. A faceted black glass bead with dark blue iridescent highlights (Figure 6-1bb). It measures $.8 \mathrm{~cm}$ in diameter. 
Well Expansion 1 East. A composition bead (Figure 6-1cc). This bead looks handmade, as it is irregular in shape. It is $.8 \mathrm{~cm}$ in diameter and is a dark brown color. A very thin coating of crumbly white material covers part of the bead, but it is difficult to tell if this is the remains of paint or the early stage of a caliche accretion.

One mirror glass fragment was found on the Webb site.

All the jewelry listed above is probably quite old; that is, from the 1890 s or earlier, as are the other artifacts found in association with them (see Meissner; Tennis; Zapata, this volume).

\section{G. Glaeser Site (41BX899)}

Trench C, West Wall. An opaque blue glass bead, 1.0 $\mathrm{cm}$ in diameter.

\section{Gordon Site (41BX900)}

Interior Wall. A decorated, oval metal disk, from a brooch or a cuff link face, probably the former (Figure 6-31). It is a very thin copper alloy which has an engraved design and was gilded. It measures 2.8 by $2.0 \mathrm{~cm}$ and has a mark in the center for a metal attachment

NW Foundation. Two thin metal disks, $1.7 \mathrm{~cm}$ in diameter, intended to imitate Roman-style coins, but with the profiles of George Washington and William T. Sherman (Figure 6-5a). The opposite side is a negative of the front. In each disk, four holes are punched, two on each side. Each hole has a fragment of the double chain that once held the coins together into a necklace or bracelet. The presence of Sherman's profile on this piece strongly suggests that it arrived here among the personal effects of a Northerner visiting or relocating to this town.

Trench C, S8. A circular metal disk, $3.6 \mathrm{~cm}$ in diameter. This artifact was probably part of a locket. It is badly corroded and little can be said about its original appearance, but it does have an applied rim made of wires twisted around each other. One side has a flat face, the other is recessed, and would have been the interior of the locket (Figure 6-5b).

Trench E. Half of an aqua plastic bead, $.9 \mathrm{~cm}$ in diameter. It appears sun-bleached.

\section{Petit Site (41BX931)}

N67/W131. A black, faceted, barrel-shaped, glass bead, 1.0 by $1.2 \mathrm{~cm}$. It may have been intended as imitation jet.

\section{Thomas Site (41BX932)}

S74/W108, Level 2. A fragment of a green glass barrel-shaped bead, about $.7 \mathrm{~cm}$ in diameter.

N74/W106. Translucent green glass bead, $1.1 \mathrm{~cm}$ in diameter (Figure 6-1dd). This bead has slight parallel grooves encircling it. It appears to be handmade glass.

\section{Burleson Site (41BX936)}

Trench D, S7. A red plastic bead, in a squared-off elliptical shape. It is $1.0 \mathrm{~cm}$ by $2.0 \mathrm{~cm}$.

\section{Gilbert Site (41BX937)}

N99/W140. A hollow, silver-colored glass bead, $.6 \mathrm{~cm}$ in diameter.

N99/W140. A white plastic bead, $.3 \mathrm{~cm}$ in diameter, covered with a thin shell of blue plastic.

Trench C, S7. A rectangular opaque green plastic bead, measuring .6 by $1.3 \mathrm{~cm}$.

\section{Conrad Site (41BX938)}

Trench B, S8. A bright yellow plastic bead, $1.0 \mathrm{~cm}$ in diameter.

Trench C, S2. A gilded cuff link in two pieces. One side is a slightly domed circle $1.4 \mathrm{~cm}$ in diameter with 
no decoration. The other side is a $1.6 \mathrm{~cm}$ long teardrop shape, also with no decoration. The hinged connector is broken (Figure 6-1ee).

One piece of mirror glass was found on the Conrad site.

\section{Jones Site (41BX939)}

Three pieces of mirror glass were found on this site.

\section{Meeks Site (41BX940)}

Trench D, S6. A blue plastic bead, $.9 \mathrm{~cm}$ in diameter.

\section{Houston Site (41BX941)}

Trench D, S7. A teardrop-shaped faceted clear glass bead. The hole is near the tip of the drop. The bead is $.7 \mathrm{~cm}$ wide.

Trench D, S10. A fragment of an earring. The upper part of the earring is gone. The lower part consists of a pink glass "pearl" bead, $1.0 \mathrm{~cm}$ in diameter, and the bottom of the spring-hinged type clip (Figure 6-1ff).

Seven pieces of mirror glass were found on the Houston site.

\section{Harris Site (41BX942)}

Trench D, S11. A lead charm portraying a Brahma bull (Figure 6-1gg). A self shank with a copper wire loop in it is seen on the back of the bull. The surface is badly pitted and scarred, but the molding was originally quite good. A similar charm made of aluminum with gold plating was sold in the 1895 Montgomery Ward catalog (Blum 1969:167). This charm is probably pre-World War II in origin. Animal-shaped charms, representing everything "from the elephant to the shrimp" (Cunnington and Cunnington 1970:537), were very popular beginning in the 1880 s and continuing to the end of the century (Cunnington and Cunnington 1970:537).
Fifteen pieces of mirror glass were found on the Harris site.

\section{Grant Site (41BX943)}

Trench E, S1. A mother-of-pearl dove (Figure 6-1hh). The figure is carved out of a flat piece, with stylized engraved features on the wing and tail. A copper wire is twisted around the tail, and there is a cut out in the shell at the base of the tail as a seat for the wire. A similar cut out is found on the breast, suggesting that another piece of wire once held the bird around the neck as well.

\section{Pauly Site (41BX945)}

Trench $\mathrm{H}, \mathrm{S1}$. A purple plastic bead, $1.0 \mathrm{~cm}$ in diameter. There are straight lines of white layered in the plastic, parallel to the axis, creating a swirl near the poles and a streaky appearance near the "equator." This is a high-quality bead.

Pauly Privy, S1/2, Level 2. A .4-cm, pink plastic bead. The color matches the next beads described.

Pauly Privy, S1/2, Level 2 . Two $.3 \mathrm{~cm}$ pink plastic beads.

Pauly Privy, S1/2, Level 2. A .4 cm red plastic bead.

Pauly Privy, N1/2, Level 5. A copper-alloy cuff link. The face is 1.9 by $.8 \mathrm{~cm}$ and it is decorated with an elongated sun pattern cut into a layer of gilding (Figure $6-5 c)$.

Pauly Privy, N1/2, Level 7. A copper bar or belt pin. It is a thin rectangle, 5.6 by $.6 \mathrm{~cm}$, with an embossed design consisting of a floral pattern with a beaded line on each side. The design is set at an angle across the center of the pin. The area of the design was gilded, but the rest appears to have been ungilded. On the back is the mark "Pat. 6.21..10". The closure is a wire-and-hook type. Bar or belt pins like this are common in the older catalogs, with the design set on the diagonal on nearly all of them (Blum 1969:99). This would have been one of the cheaper varieties (Figure 6-1kk). 


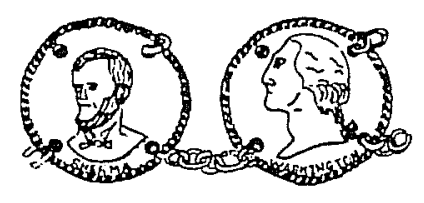

a

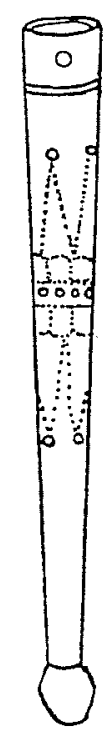

d

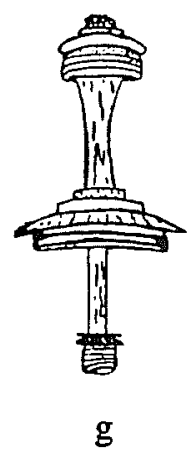

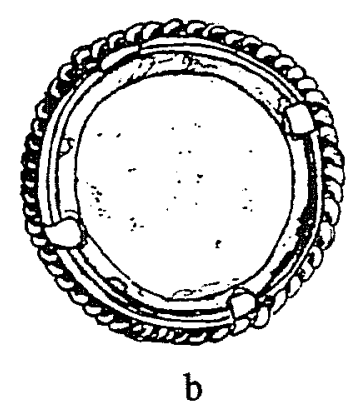
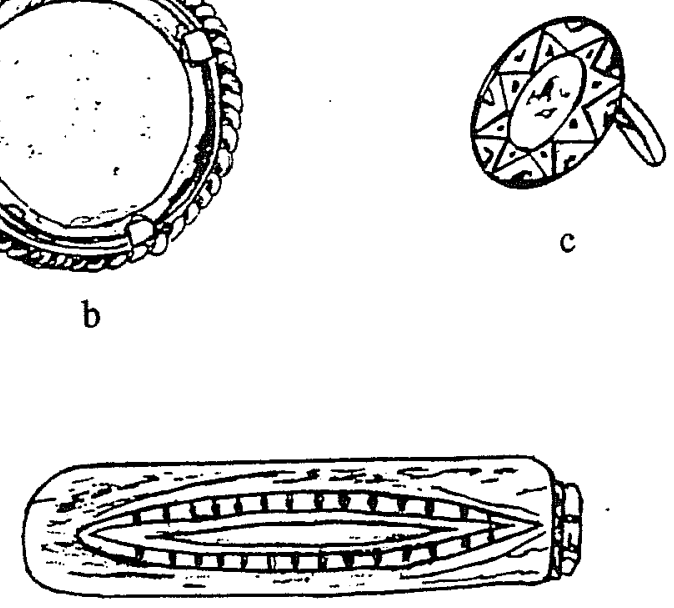

e
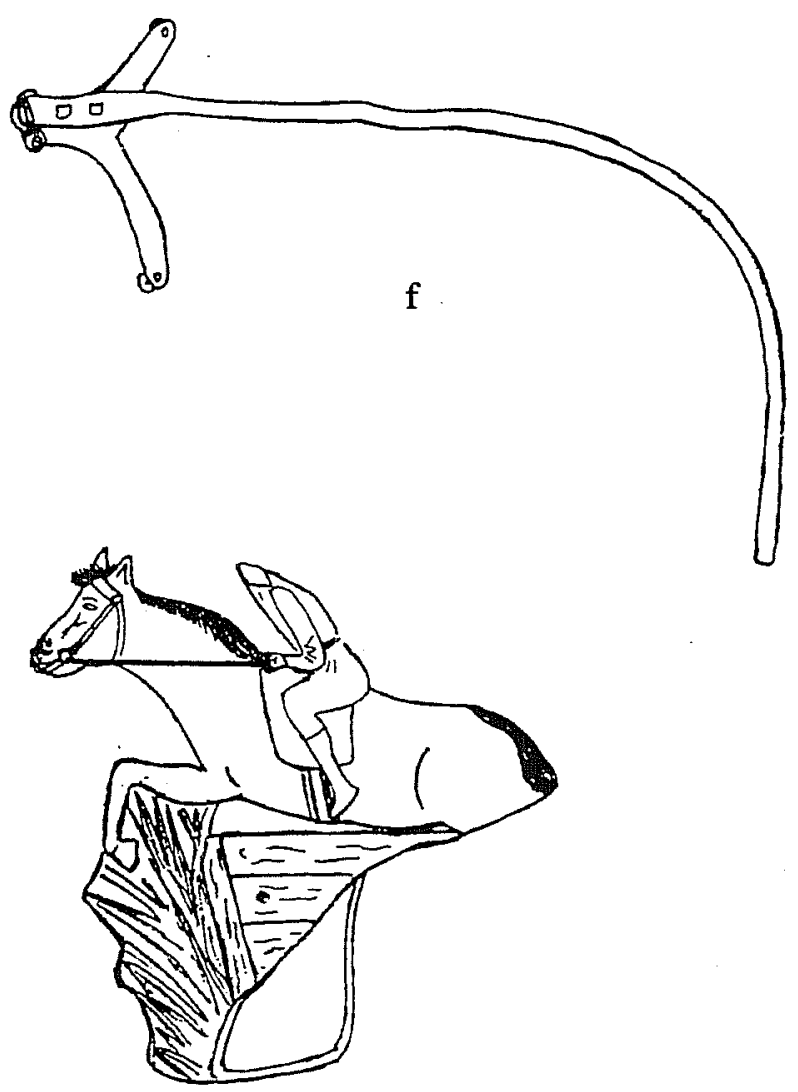

h

Figure 6-5. Miscellaneous personal items from the Alamodome Project. All shown actual size. 
Pauly Privy, N1/2, Level 7. A blue glass bead. The bead is faceted and measures $.6 \mathrm{~cm}$ in diameter (Figure 6-1ii).

Pauly Privy, S1/2, Level 7. A fragment of plastic and metal jewelry of unknown type. There is a blue plastic faceted "gem" set in metal, about $.8 \mathrm{~cm}$ in diameter. From the back, a straight piece of wire extends $.6 \mathrm{~cm}$. On this wire is a small broken loop. This could be from an earring or pin or other cheap jewelry piece (Figure 6-1ij).

Pauly Privy, N1/2, Level 13 . An opaque blue glass bead, measuring $.4 \mathrm{~cm}$ in diameter.

Feature F, house interior. The metal tip from a bolotype tie. It is made from a rolled sheet of copper alloy metal, has a tapering shaft and a small ball on the end. The shaft is $7.1 \mathrm{~cm}$ long and is decorated with a zigzag and dot pattern. The top is $.9 \mathrm{~cm}$ in diameter (Figure 6-5d). Bolo ties appear to have been confined to the Southwest at least as late as 1927 . Nothing like a bolo tie is available in any of the mail order catalogs studied for this report.

Nineteen pieces of mirror glass were found on the Pauly site.

\section{BX957}

Surface. A large, rectangular, silver-plated earring with embossed design. The style is very modern. The earring measures 3.3 by $4.5 \mathrm{~cm}$.

\section{No Site Number}

NCB 636, Lot 6 . A button pin consisting of a plastic cover over red paper with the Spanish word "Hola" ("Hello") in white lettering attached to a metal backing. The closure is a pin-and-hook type. This artifact is probably no older than the early 1970s (Figure 6-2b).

Several possible explanations exist for the quality, or rather, the lack of quality, of jewelry found at the Alamodome site, all of which are probably true to some extent. One explanation is that the people who lived in this neighborhood, were, almost without exception, working class, and hence unlikely to own any precious jewelry. Another suggestion is that people tend to take very good care of genuinely precious gems. Thus, it is not surprising that two amber beads in 41BX893 were the only fine jewelry found. A third reason has to do with the dating of most of the jewelry to after World War II. As was mentioned at the beginning of the jewelry section, costume jewelry did not become commonly available until the 1920 s, when a combination of better transportation, industrialization, and a change in fashion made such jewelry available to almost anyone. The amount of jewelry of all kinds owned by average women increased dramatically after this period, with most of this jewelry being fairly cheap and disposable (Evans 1970:184), thus making it more likely to turn up in the archaeological record.

Seventy-two beads were found during the Alamodome project, representing 40.2 percent of the jewelry. This figure is of particular interest because, with the occasional exception seen on hat pins and earrings, no beads were sold in the Montgomery Ward 1895 (Blum 1969), the 1897 Sears (Israel 1968), or the 1902 Sears (Sears Roebuck 1969) catalogs. An examination of drawings from fashion history texts indicates that beaded necklaces more or less disappeared, except in formal evening wear for the rich and fashionable (Blum 1974; Cunnington and Cunnington 1970; Mansfield and Cunnington 1973). Although formal evening ensembles in the Victorian era sometimes included strings of pearl and/or other beads (though a bare neck, or a velvet ribbon decorated with a cameo was more popular) (see Blum 1974), these would have been precious jewels. Women living away from large cities, except perhaps the most wealthy, did not go out to such formal occasions until after World War I; this is reflected in the fact that no evening gowns were sold in Sears catalogs until after 1925 (Cohn 1940:302). In the 1927 Sears (Mirken 1970) catalog, strings of beads were at last being sold.

Though six beads were found in contexts which have been dated to older periods-in particular, the trenches on the Webb site (41BX897), including the Well Expansion Trench, the Rilling site (41BX892), and the lower part of the Pauly Privy (41BX945)-they are all of a type which could easily have come from earrings or hatpins. The bone bead found on the Webb site, for instance, was almost certainly from a hat pin. 
The implications of this for urban archaeologists working in this period, that is, from the 1850 s to the 1990s, are fairly obvious: if you are finding lots of beads, you are probably in a context dating either before the 1870 s or after World War I.

\section{Items of Personal Hygiene}

This category-which includes hair care items; personal grooming items such as toothbrushes, razors and cosmetics; and items that can perhaps be referred to as "personal medical" items, such as pill boxes, hypodermic syringes, enema syringes, and condom containers-is represented by 94 items. Glass medicine bottles and jars are considered in the report on glass in this volume (Munoz, Chapter 2). In examining the catalogs, we see once again, a major social change underway after the turn of the century, this time reflected in the use of cosmetics.

Like many other forms of fashion, the use of various "paints" and other cosmetics has fluctuated a great deal over the centuries. Upper-class women of the mideighteenth century whitened their complexions with a lead-based compound that could and did poison them (Williams 1957:59). Rouges of many kinds and shades were considered absolutely necessary in "an age when women blush so little" (from a "beauty book" quoted in Williams 1957:79).

At the time of Queen Victoria's accession in 1837, the use of heavy paints was no longer acceptable, though great attention was still paid to the use of other cosmetics (Williams 1957:93). More and more "beauty" advisors recommended soap and exercise as being the most important contributors to a good complexion (Williams 1957:94). The somber tone of Victoria's widowed years took its toll on the gaiety of rouge and powder. By the middle of the century, and more so in America than in Europe, the wearing of obvious makeup became unacceptable, the mark of women of easy virtue (Cohn 1940:268; Cunnington and Cunnington 1970:568). Married women could get away with a little rouge on their cheeks, provided it was not too obvious, but lip color was not to be enhanced, on pain of being accused of looking like an actress or courtesan (Williams 1957:108). Unmarried women were confined to a little face powder and a light perfume (Williams 1957:111). Still, no puritanism could completely banish makeup. In $1890 \mathrm{~s}$ lipstick made its debut (Williams 1957:115) and, by 1905 , rouge was in use even by the rural women served by the Sears catalog (Cohn 1940:274).

However, the subtle pressure for social change, especially for women, had been building all through the nineteenth century (Cohn 1940:296-301). The long fight to make skirts which did not drag on the ground socially acceptable was just the surface of a desire on the part of many women to change their place in society. World War I acted as a violent catalyst, playing havoc with the structure of society, and allowing more change of fashion and of behavior in a few years than had been possible in a century of the past.

For many women, the cutting of their hair was the most significant symbol of that change. The "bobbing" of hair began in earnest during World War I by women working in ordinance factories in England, but the practice quickly spread over all of Europe and America (Williams 1957:122). In the years immediately after the war skirts went to the knees and above. Chemical hair curling under various names became popular (Williams 1957:129). Lipstick was no longer confined to high society. Rouge, paints of various kinds, and strong perfumes could now be used, and not just by the sophisticated women of the cities. The mail order catalogs responded to the change. The 1857 Montgomery Ward Catalog (Blum 1969) offers only two kinds of face powder, with advertising which emphasizes their invisibility, and no rouge or lipstick is available. The 1927 Sears, Roebuck and Company catalog, however, offers 43 varieties of face powder, as well as many kinds of "vanity cases" containing cake or loose face powder, rouge, and a lipstick holder (Mirken 1970).

\section{Haas Site (41BX882)}

\section{N24/E71. A metal bobby pin, $4.9 \mathrm{~cm}$ long.}

N35/E05. A white plastic pick about $7.3 \mathrm{~cm}$ long. These picks were used to secure brush rollers. A thin strand of wet hair was rolled around a plastic mesh tube with a brush interior. The ends of the brush helped hold hair in place, but the plastic pick was pushed through the holes in the mesh to hold the roller 
in position until the hair was dry. The hair was then unrolled and was left with a curl.

N50/E88. A thermometer fragment.

\section{King Site (41BX883)}

N13/E85. A black plastic comb tooth.

N37/E65. A thermometer fragment.

N50/E86. A piece of waxed dental floss $3.0 \mathrm{~cm}$ long.

Trench C, Feature A. An old plastic comb tooth with a dark green-brown coloration.

\section{Trench C, Feature A. A comb fragment of composition material.}

Well Expansion, 3 East. A decorated metal lid for a small container about $5.5 \mathrm{~cm}$ in diameter (Figure 6-6a). A complex design is engraved on the outer surface, and the piece has a broken area where there was probably a hinge. It appears to be a container for makeup.
Well Expansion, 3 East. A small metal container, possibly of crumpled aluminum (Figure 6-6b). The container is marked "Epris" on the bottom.

Well Expansion, 3 East. A bone toothbrush handle, broken at the end about half-way along the head. It is $11 \mathrm{~cm}$ long. The head is not tapered. The handle is marked "Warrant [a stylized British lion, rampant] London". There is also a "3" near the head (Figure 6-2c).

Well Expansion, 3 West. A bone handle, $9.4 \mathrm{~cm}$ long. The shape strongly suggests it is from a toothbrush, broken where the handle narrows before it widens for the bristle head. It is marked ". . . I N LO . ..."

Well Expansion, 3 West. A bone handle measuring 6.0 by $1.5 \mathrm{~cm}$ (Figure 6-5e). It is probably from a toothbrush. A design is carved in relief on both sides of the handle.

Well Expansion, 3 West. A white plastic make-up pencil sharpener, with a metal blade. It measures 3.9 by $3.2 \mathrm{~cm}$. It is marked "AVON/ POWDERSTICK" and "KUN [in a circle] W. Germany."

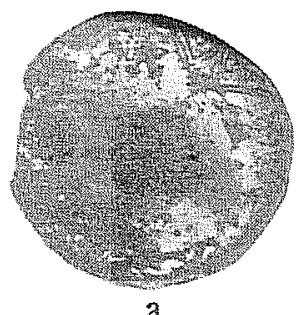

a
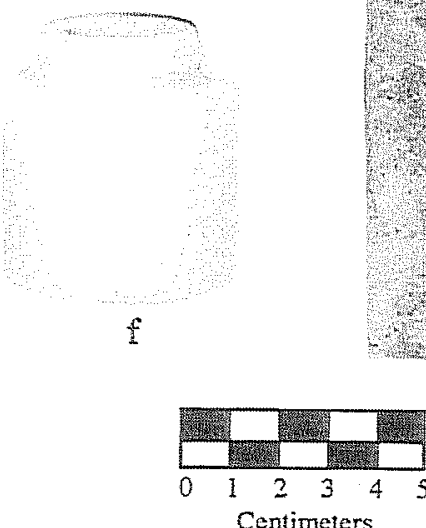
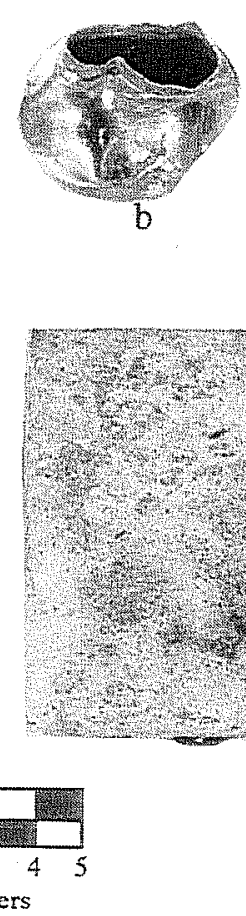
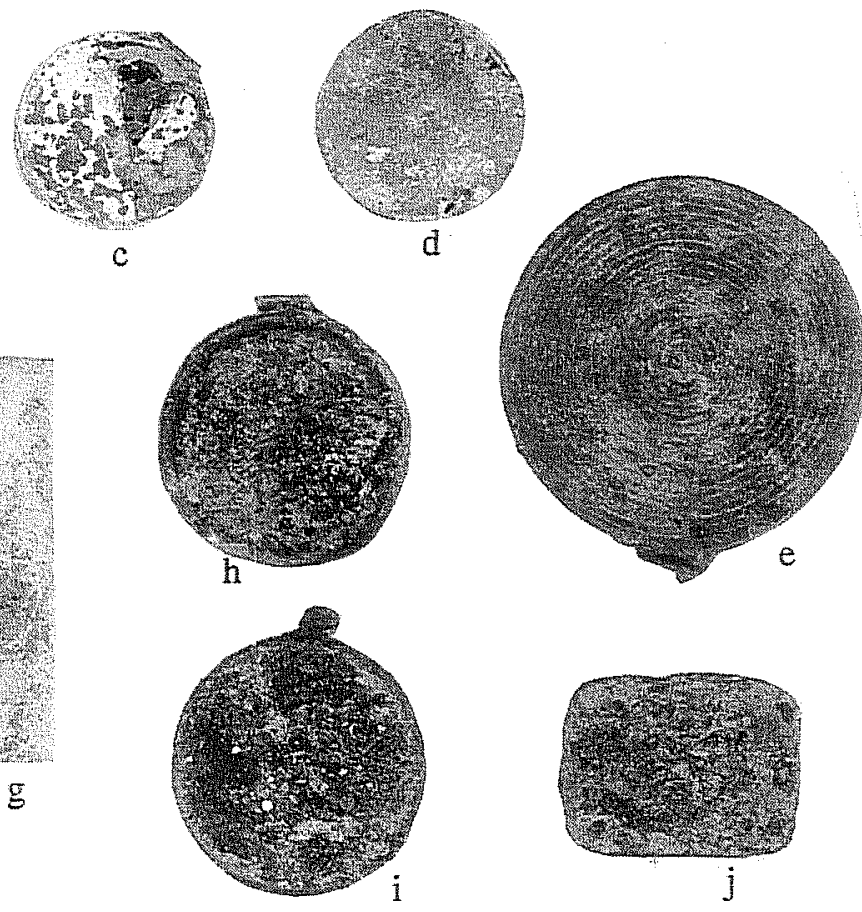

Figure 6-6. Miscellaneous personal items from the Alamodome Project. 
Monitor Slurry Trench. A red plastic mascara tube, colored red and black, grooved for a screw cap. It is marked "Maybelline Magic Mascara/Blue."

\section{Griesenbeck Site (41BX884)}

N42/W47. A metal bobby pin with plastic tips (Figure $6-2 \mathrm{~d})$. It is $5.0 \mathrm{~cm}$ long.

N65/W45. A transparent clear plastic tooth from a comb.

N65/W45. A broken blade from a safety razor. It could be from either a single or double-edged style.

N80/W32. A white plastic curler, $6.4 \mathrm{~cm}$ long. There are indents on each end for a clip to catch, holding a strand of hair around the curler. This style of curler was used primarily for permanents, in which chemicals are used to impart a permanent curl in the hair.

N187/W36. A red transparent plastic comb tooth.

Trench A, Feature A. A metal squeeze-tube dispenser. It appears to be "Starkist" brand, but much of the printing has worn off. This printing is dark blue on a lighter blue background. There is no cap (Figure 6-2e).

Trench A, Feature A. A white plastic curler, $6.4 \mathrm{~cm}$ long exactly like the one listed above.

Trench A, Feature A. A transparent red plastic comb fragment $1.2 \mathrm{~cm}$ long.

Trench A, Feature A. Two single-edged razor blade fragments.

\section{Mendit/Maffi Site (41BX885)}

Surface. A metal "safety razor" intended for a singleedged razor blade. Razors like this were first patented by Gillette and Nickerson in 1901 (Harpur 1982:17). It is marked "Ever Ready/ BKLYN, N.Y., U.S.A.I Pat. App'd For" (Figure 6-2f).

N47/W55. An opaque red plastic comb fragment.

\section{Horn Site (41BX891)}

S89/W118. A thermometer fragment.

\section{Rilling Site (41BX892)}

Monitored South End of Lot. A metal lipstick tube, 3.2 $\mathrm{cm}$ long. The metal is gilded and the base is marked "Tayton Company / Distributors / Kansas City Hollywood."

\section{Czernecki Site (41BX893)}

S150/E23. A fragment of a bobby pin, $3.2 \mathrm{~cm}$ long.

S152/E23. A comb fragment with no teeth made of an old style plastic.

Trench A. A metal screw-in stopper for a hot-water bottle. The opening would have been $2.5 \mathrm{~cm}$ in diameter (Figure 6-2g).

\section{Czernecki Rental (41BX894)}

S18/E74. A comb tooth made of translucent pink plastic.

S18/E74. A comb tooth made of blue plastic.

Feature A. A small metal squeeze tube dispenser fragment, squeezed out and rolled up. It is white, but no legible writing is evident.

\section{Garza Store (41BX895)}

N26/E19. Metal nail clippers of the standard variety, with a curved clipper, one blade that also serves as a lever for operating the clippers, and a second blade with serrations for filing nails (Figure 6-2h).

Under Garza Store. A small circular metal container which appears to be a cosmetics case (Figure 6-6c). It is $4.0 \mathrm{~cm}$ in diameter, and blotches of light green paint and bits of gilding are left on the surface. No marks or other decoration remain. 
An amber-colored plastic and metal barrette with a pinch-wire closure. The barrette is in the shape of a flat loop, and the plastic has a swirl pattern. It measures 4.2 by $1.5 \mathrm{~cm}$. This kind of hair clip, called "Ladies hair lock retainers" and "New hair barretts" are first seen in the 1902 Sears catalog (Sears Roebuck 1969:935).

\section{Demazieres House (41BX896)}

S59/E146. A copper alloy cap from a lipstick tube. It is marked "Elizabeth Post." The high-quality metal cap suggests a date from before World War II.

S106/E131. A possible hairpin made from a single piece of copper wire, folded in half, with heart-shaped designs bent into each end (Figure 6-4b).

S107/E107. A gilded metal barrette, $7.7 \mathrm{~cm}$ long. It once had a pinch-wire closure.

S119/E130. A child-sized plastic hair clip with a pinch-wire closure. It is off-white and is $3.5 \mathrm{~cm}$ long.

Trench A. A rouge compact, $4.0 \mathrm{~cm}$ in diameter and $1.0 \mathrm{~cm}$ thick. It is silvered metal decorated with concentric circles engraved on the top and marked "Armand/Compact Rouge/Made in/U.S.A." on the bottom.

Trench A. A lipstick tube, made of metal, $4.0 \mathrm{~cm}$ long.

Trench A. A lipstick tube, $3.6 \mathrm{~cm}$ long with, a copperalloy base marked "Made for/COLGATE/Jersey City N.J./Made in U.S.A."

Trench D, S1. A fragment of the lid of a porcelain bowl (Figure 6-2i). The lid is hand painted in a leaf and dot motif. The bowl would have had an opening of about $11 \mathrm{~cm}$. In the top of the lid is a $3 \mathrm{~cm}$ hole. This was probably a "hair catcher," a part of the dressing table accouterments in the 1920s (see Mirken 1970). Hair was removed from combs and brushes and pushed through the hole in the top of the bowl. Hair collected this way could be either used as stuffing for something or thrown away.
Trench D, S1. Small pair of manicure scissors with curved blades (Figure 6-3j). They are $8.9 \mathrm{~cm}$ long and one blade is broken off. Manicure scissors have always been quite expensive, because of the skilled craftsmanship that goes into the grinding of the curved blades (Encyclopedia Americana 1957:342).

Trench F, S3. A modern plastic comb fragment in pinkish "tortoiseshell" color. A geometric design is embossed on one side.

Shovel Test \#18. A large hair pin, $7.2 \mathrm{~cm}$ long.

S118/E143, Privy \#5, Test. A vulcanized rubber comb, $22.3 \mathrm{~cm}$ long, with a handle (Figure 6-3k). Two teeth are missing. It has a dark brown color and is marked "Imperial" on one side of the handle and "I. P. Comb Co. Goodyear 1851" on the other. This date is probably not the date the comb was made, but is the date of the patent of the vulcanization process.

S118/E143, Level 11. A rubber enema syringe (Figure 6-7). The syringe is complete, with a hard rubber tip. A length of rubber tubing leads from the tip to the bulb, which is about $4.0 \mathrm{~cm}$ in diameter. Another rubber tube leads from the bulb to a stoppered end. The entire length is about $60 \mathrm{~cm}$. Mail-order catalogs of the late-nineteenth and early twentieth centuries devote a great deal of space to syringes intended for douching and enemas. Most came with both vaginal and rectal tips. In 1902 Sears sold syringes of this kind for from $\$ .50$ to $\$ 1.75$ (Sears Roebuck 1969:455-456). The tip on this syringe is intended for rectal use.

S118/E143, Level 11. A double-sided, fine-toothed comb, made of hard rubber. The comb is $8.5 \mathrm{~cm}$ by $5.5 \mathrm{~cm}$ and is marked "Lorelei" with a small floral design on each side of the lettering (Figure 6-8a).

S118/E143, Level 11. A large (20-cm) comb made of composition material (Figure 6-8b).

\section{Webb/Deman Site (41BX897)}

Area A. A comb made from an early plastic, possibly celluloid. It is $8.4 \mathrm{~cm}$ long. The teeth are gone and there is a fancy design at the base of the handle, which is broken off. 
Area A. An old plastic comb fragment with an olive green-brown color. The fragment is $4.2 \mathrm{~cm}$ long and the teeth are gone.

Area A, west half. An old plastic comb tooth, colored a dark olive green-brown.

Trench H-Extension A comb tooth made of composition material.

Trench J. A fragment of a comb with a wavy design on one side, $3.6 \mathrm{~cm}$ long. It has three teeth remaining. It looks as if it could have been the kind of comb which is used to hold hair up on the head.

Well Expansion 1 West. A small bone handle, probably from a toothbrush.

\section{Gordon Site (41BX900)}

Trench D, S6. The spine of a single-edged razor blade with the blade broken off.

\section{Schulze Site (41BX927)}

Monitored Privy. a copper-alloy safety razor head, made for a single-edged razor blade. The bottom is marked ". . . M . . . Chromatic." The inside is marked "Made in USA. Pat. Nos. 1789 . . 80-17786 . . ." (Figure 6-8c).

\section{Burleson Site (41BX936)}

Trench A, S6. A green plastic toothbrush head, $6.0 \mathrm{~cm}$ long. The bristle rows are arranged in $3 \times 11$ rows, and the head is tapered.

Trench A, S6. A small plastic barrette in the shape of a blue bird.

Trench A, S6. A small (4.2 in diameter) round metal container, probably for makeup (Figure 6-6d).

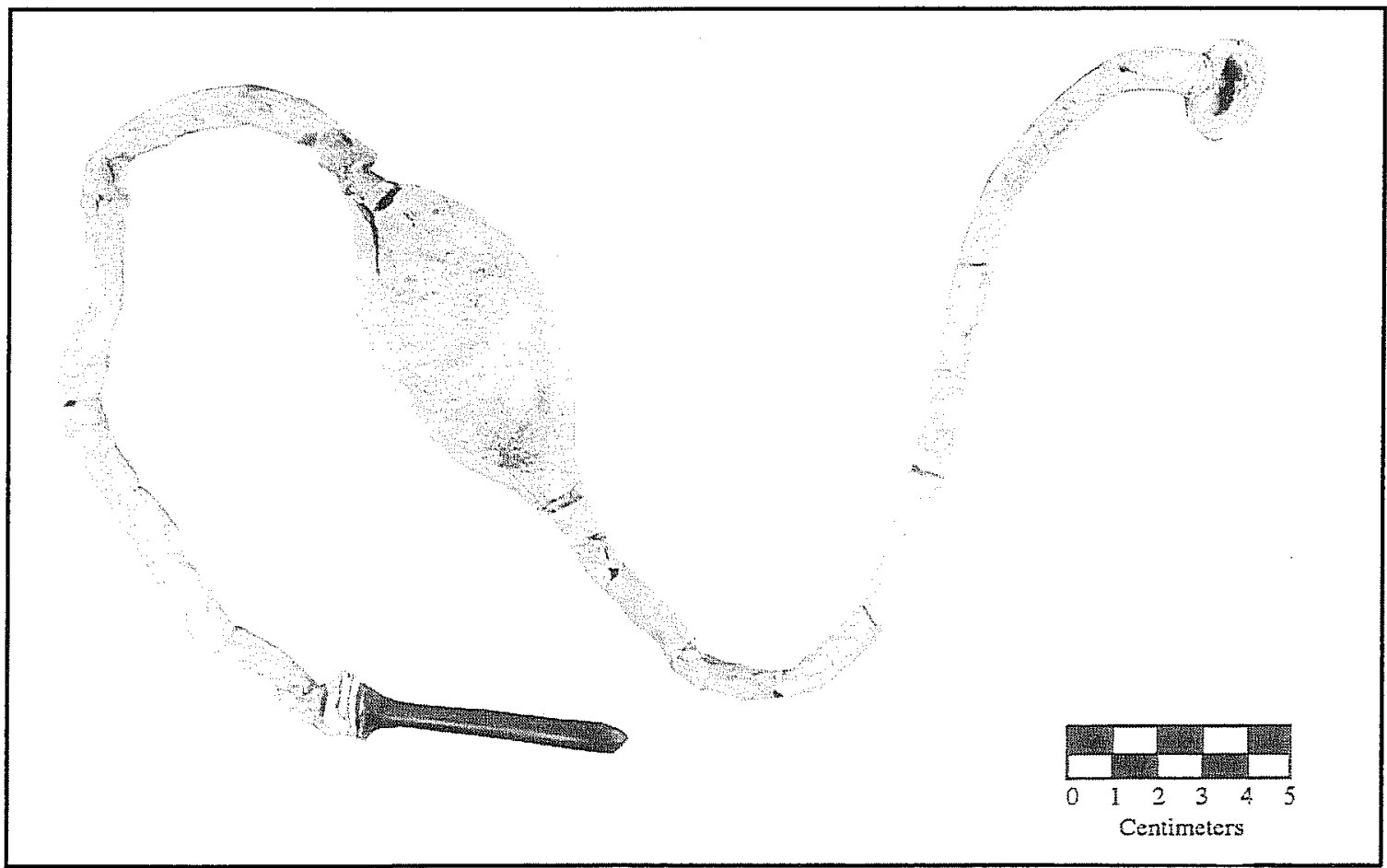

Figure 6-7. A rubber enema syringe from the Demazieres House (41BX896). 


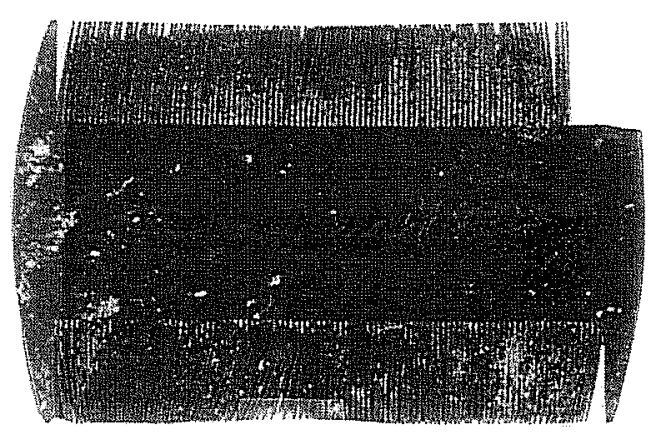

a
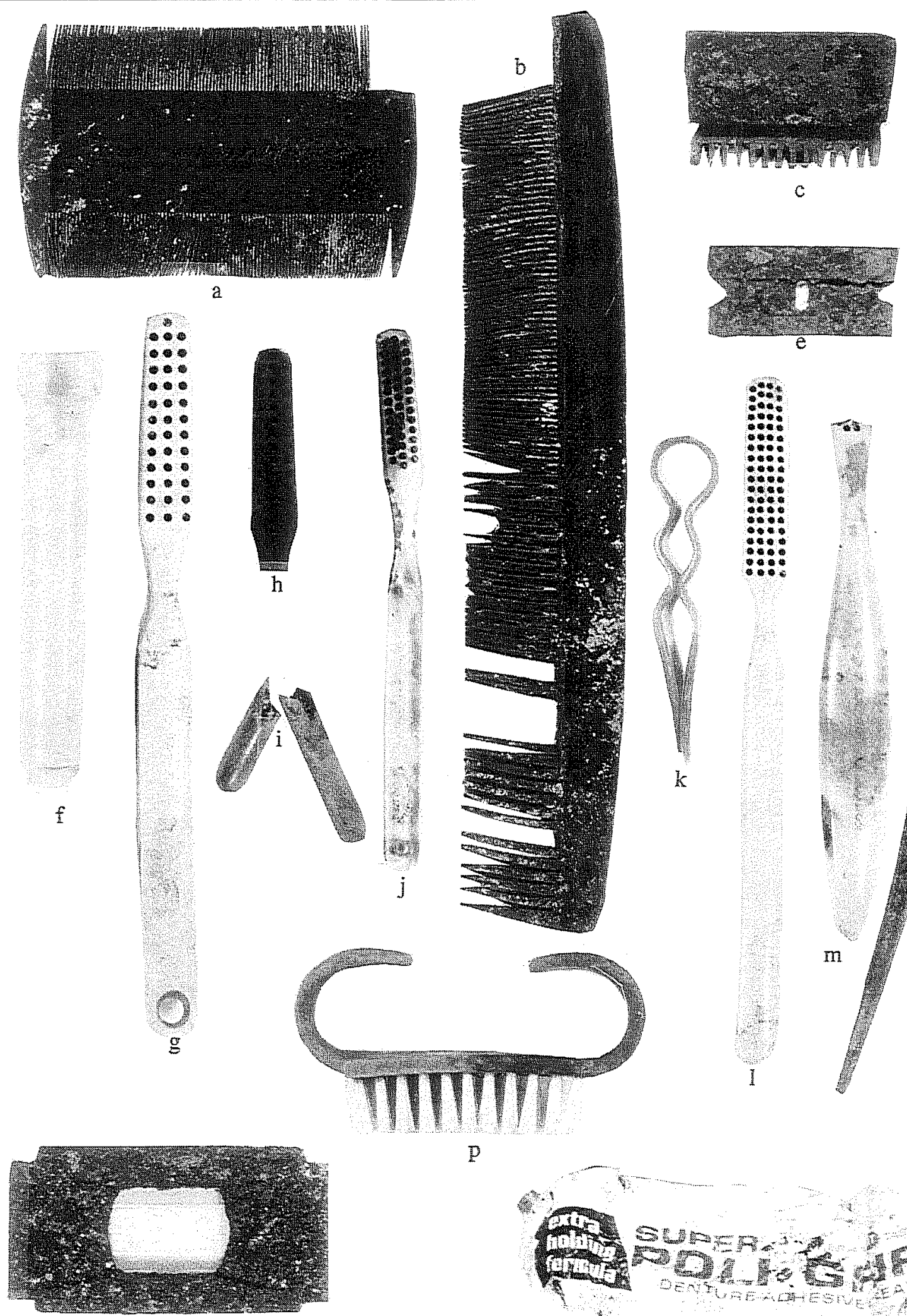

p

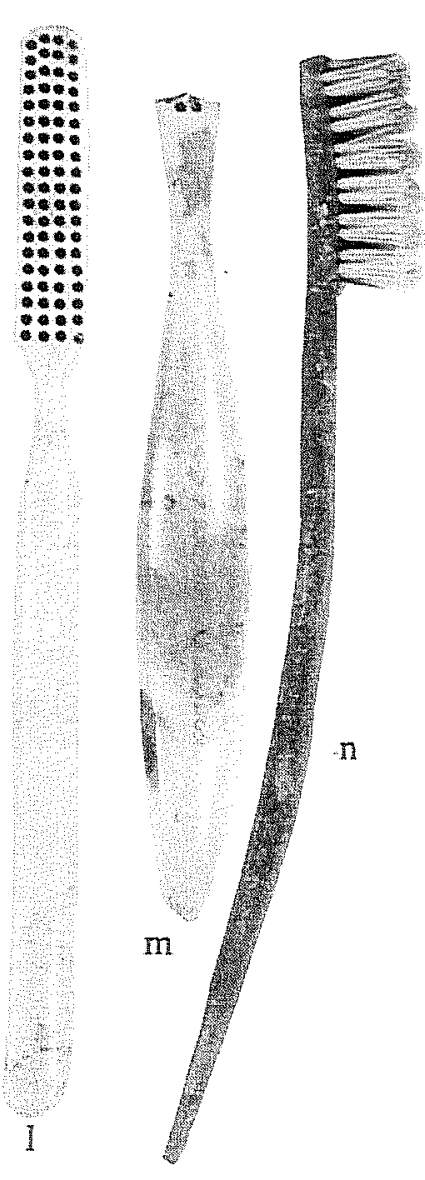

o
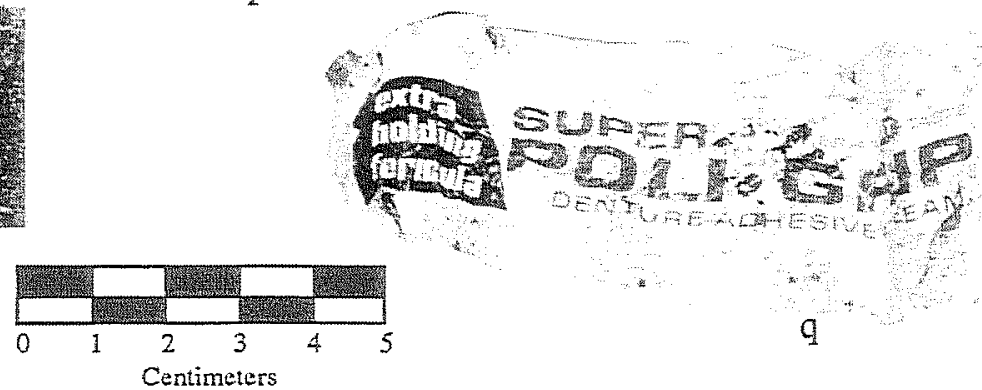

q

Figure 6-8. Miscellaneous personal items from the Alamodome Project. 


\section{Gilbert Site (41BX937)}

Trench B, S3. A metal squeeze tube dispenser, 12.7 $\mathrm{cm}$ long. This once probably contained toothpaste, as the only legible word is "Dental." The label is black and the lettering was originally white, but most letters have flaked off.

Trench B, S3. A black plastic comb fragment.

\section{Conrad Site (41BX938)}

Trench B, S8. A glass dropper (Figure 6-8d). There is a ridge at the base for a rubber bulb to attach, to make a liquid medication dispenser. The dropper is large, $6.9 \mathrm{~cm}$ long.

Trench B, S8. A transparent blue plastic toothbrush handle, broken at the first row of bristles. The handle is $12.5 \mathrm{~cm}$ long. There is a hole in the handle for hanging. It is marked "[Dupont trademark] Park Avenue Dupont 'Tynex'/Nylon Bristles.”

Trench C, S4. A metal squeeze tube dispenser. The printing reads "Gleem Tooth Paste." The tube is rolled up from the bottom making the rest of the writing illegible except "contains mir ...."

Trench C, S8. An empty metal squeeze tube dispenser. The printing on this item is no longer legible.

Trench C, S9. A fragment of a clear red plastic toothbrush handle, broken on the distal end and melted on the proximal end. The fragment is about $5.8 \mathrm{~cm}$ long.

\section{Jones Site (41BX939)}

Trench D, S3. A metal lid for a container, probably for face powder (Figure 6-6e). The lid is $7.4 \mathrm{~cm}$ in diameter and has many engraved concentric circles. There is the remains of a hinge on one side and metal catch for a fastener on the other.

Trench D, S4. A single edged razor blade marked "Gem" (Figure 6-8e).

\section{Harris Site (41BX942)}

S70/W55. Two milk glass container bottoms. and a fragment of a matching milk glass lid. The containers are 5.1 by $8.4 \mathrm{~cm}$ rectangles and have a recessed rim for the lid to sit on. The containers are about $1.0 \mathrm{~cm}$ deep. The bottom is embossed "Nadinola Cream/a Complexion Beautifier/National Toilet Co./Paris, Tenn., U.S.A." On one of the containers the lettering was embossed twice, once in an incorrect angle, the other in the correct position.

S70 $/ W 55$. A heavy milk glass jar, $5.0 \mathrm{~cm}$ tall, with an oval shape. The bottom is marked " $8 /$ Woodbury $/ 1 \mathrm{c}$ " (Figure 6-6f).

Trench D, S12. A plastic container for a small hypodermic syringe (Figure 6-8f). The container is 8.9 $\mathrm{cm}$ long and would have held a $10 \mathrm{cc}$ syringe. This is the most popular size for both diabetics and illegal drug users .

Trench D, S12. A makeup compact measuring 7.2 by $8.2 \mathrm{~cm}$ (Figure 6-6g). The compartment is about 1.0 $\mathrm{cm}$ deep and is divided in two by a metal divider.

Trench D, S12. A round compact lid, $5.2 \mathrm{~cm}$ in diameter, with one edge broken where there was once a hinge (Figure 6-6h).

\section{Runge Rental Site (41BX944)}

Surface. A handle, probably for a hair brush, made of celluloid, with an embossed floral design. There are remains of silver-colored paint on the celluloid (Figure $6-4 c)$.

\section{Pauly Site (41BX945)}

Trench A. A single-edged razor blade. This is a standard size, 2.0 by $4.0 \mathrm{~cm}$.

Trench C, S1. A fragment of a perforated metal hair roller.

Trench C, S3. A metal squeeze tube dispenser with the top section missing. The color is white with yellow and orange lettering is largely illegible but the words 
"Super Glue/Warning: Eye and skin irritant." The tube has a "chewed" look, but this probably results from being stepped on repeatedly on a rough surface.

Pauly Privy, N1/2, Level 2. A bone toothbrush, $16 \mathrm{~cm}$ long (Figure 6-8g). The head tapered from 1.2 to 1.0 $\mathrm{cm}$ wide. The bristles, which are gone, were arranged in rows 12 by 3 with one extra at the end. The handle is marked "Extra Fine" and has a hole in the end for hanging.

Pauly Privy, N1/2, Level 2. A fragment of a toothbrush made from composition material or some other early plastic (Figure 6-8h). The material is dark brown and has a shiny surface. The head is small, 4.0 by $1.1 \mathrm{~cm}$, tapering to $.8 \mathrm{~cm}$ at the tip. The bristles are arranged in rows 12 by 3 with one extra at the tip. The toothbrush is marked "Japan" near the base of the bristles.

Pauly Privy, N1/2, Level 2. Two parts of a broken glass container, closed at both ends (Figure 6-8i). This was intended to dispense a highly volatile liquid such as smelling salts (ammonia) or the drug amyl nitrate. Containers like this would be sewn into a thick pad of cotton gauze. To use, one broke the glass vial inside the gauze. The fluid would spread through the gauze and evaporate quickly. One could then hold the gauze under the nose and inhale the fumes.

Pauly Privy, N1/2, Level 2. A composition handle, probably for a toothbrush, $3.4 \mathrm{~cm}$ long. It narrows sharply at one end. The color is a mottled dark brown. It is marked "Trade [crown] Mark."

Pauly Privy, N1/2, Level 3. A composition plastic handle, probably for a toothbrush. It is dark brown in color, is $5.0 \mathrm{~cm}$ long and is marked "Pyro . . . $/ \mathrm{Jr}$. Scient ... " on the handle.

Pauly Privy, N1/2, Level 3. A clear yellow plastic toothbrush. This brush is small, only $12.2 \mathrm{~cm}$ long, and is probably intended for a child. The head is a rounded rectangle with no taper, and is curved back at an unusually sharp angle. There is a hole at the end. The handle is marked "Japan/Superfine Pure Bristle/ Sterilized" (Figure 6-8j).

Pauly Privy, N1/2, Level 3. A large celluloid hairpin, $7.2 \mathrm{~cm}$ long. Hairpins like this were sold in the 1927
Sears catalog with a price of $\$ .17$ for six (Mirken 1970:123). Before this time, these large hairpins were made of rubber (see Israel 1968:322) (Figure 6-6-8k).

Pauly Privy, N1/2, Level 3. A dark brown composition comb tooth.

Pauly Privy, S1/2, Level 7. A circular metal container, $5.1 \mathrm{~cm}$ in diameter and $2.1 \mathrm{~cm}$ thick, with the lid (Figure 6-6i). A metal bar-which would have swung on a pivot to release the lid-is attached to one side. It appears to be some kind of pill box, though it is very corroded and this use cannot be confirmed.

Pauly Privy, S1/2, Level 9. A metal container top, 3.6 by $4.8 \mathrm{~cm}$ (Figure 6-6j). The size and shape suggest this may be the top of an aspirin container, but it is too badly corroded to be sure.

Pauly Privy, N1/2, Level 1. A metal condom container lid, $4.2 \mathrm{~cm}$ in diameter. It is marked "3/Merry Widows/Agnes-. . . abel-Beckie."

Pauly Privy, N1/2, Level 1 . A long nail file, $17.2 \mathrm{~cm}$ long, with a broken tip, made of thin metal.

Pauly Privy, N1/2, Level 14. A bone toothbrush with no bristles remaining (Figure 6-81). The toothbrush is $15.3 \mathrm{~cm}$ long with 4 by 19 bristle rows in a tapered head. The handle is bent backwards.

Pauly Privy, N1/2, Level 14 . An antler toothbrush handle broken after the first two sets of bristles. Marked "T[arrow] F Extra-Fine London" (Figure 6-8m).

Feature E, NE Quad, Level 4. A translucent green plastic toothbrush with white bristles (Figure 6-8n). Handle is back-curved (away from bristle side). The plastic is very soft and the surface is badly scored. The bristle head is a rounded rectangle $3.0 \times 1.0 \mathrm{~cm}$. The bundles of bristles are arranged in rows of 12 by 4 , with only 3 bundles in the last row.

Feature E, SE Quad, Level 4. An opaque blue plastic toothbrush, $16 \mathrm{~cm}$ long. The bristle head is $3.5 \mathrm{~cm}$ long and tapers from 1.3 to $1.2 \mathrm{~cm}$ in width. The bristles are arranged in a 12 by 4 pattern with three in the last row. The outer bristles are white and the inner are somewhat short and blue in color. There is a hole 
at the end of the handle for hanging. The handle is marked "Colgate."

Feature E, SE Quad, Level 4. An opaque pink plastic toothbrush, $16 \mathrm{~cm}$ long. It is identical to the described toothbrush above except for the color. Bits of brown shoe polish are seen on the bristles and partially down the handle.

Feature E, SE Quad, Level 4. A plastic and metal razor blade box for double-edged blades, measuring 3.6 by $6.5 \mathrm{~cm}$ (Figure 6-80).

Feature E, NE Quad, Level 6. An opaque pink plastic toothbrush, identical to the one above, except this brush does not have any shoe polish.

Feature E, NE Quad, Level 11. A fingernail brush with three rows of nylon bristles and a blue plastic handle which curves around fingers where the brush is used (Figure 6-8p).

Feature E, NE Quad, Level 12. A metal squeeze tube labeled, "Super Poli- Grip Denture Adhesive" (Figure $6-8 q)$. The net weight is listed as 1.40 ounces, and the U.S. patent number is 29768812 . This produce was made by "Dentco, Inc., Jersey City, NJ."

Trench C, S1. A piece of plastic "bubble" packaging for medication. It could be from either over-thecounter or prescription drugs. There are two cells and a small remaining fragment of the aluminum foil that covered the bottom of the cells.

Trench D, S3. A single-edged "safety" razor blade, 4.0 by $1.9 \mathrm{~m}$, which is the standard size.

\section{No Site Number}

A metal squeeze tube dispenser for toothpaste. It is labeled "Colgate/ Ribbon Dental Cream" in red letters on white. Advertising on the back claims that the product gets rid of "decaying food" and "reveals the natural sparkle of your teeth." The net weight is 1.75 $o z$. There is a brown plastic cap. Tooth marks in the tube appear to be those of a small dog.

\section{Items Carried on the Person}

This category, numbering 70 items, includes such things as eyeglasses, watches, purses and wallets, pocket knives, and items related to personal habits such as tobacco use.

Material remains of tobacco use can provide us with some general dating of artifacts. Most tobacco was consumed in pipes or cigars until the turn of the century, and it was not until the 1920s that cigarette smoking became the norm (Herment 1957:153). Cigarettes were mostly handmade until this time. Cigarette cases and lighters, therefore, can generally be dated to post-World War I. Clay pipes, on the other hand, are primarily artifacts of the nineteenth century and earlier (Herment 1957:13). After that time, most pipes were made of less fragile (and less durable) materials. By the 1950s, however, even pipes made of perishable substances such as wood or briar root usually had mouthpieces made of vulcanized rubber (Herment 1957:44-45).

\section{Oeffinger Site (41BX881)}

Surface. A metal eye glass case with remains of felt lining. The case measures about 7.0 by $15.5 \mathrm{~cm}$.

Trench D. A possible watch case, $4.9 \mathrm{~cm}$ in diameter. The rounded metal disk is a copper alloy with a very complicated design engraved on the top (Figure 6-9a).

\section{Haas Site (41BX882)}

N44/E71. A pipe stem fragment made of unglazed clay, $2.6 \mathrm{~cm}$ long (Figure 6-9b).

Trench C. A metal cigarette lighter. This lighter is gasoline-fired, a type which first appeared on the markets in 1909 (Harpur 1982:31) (Figure 6-9c).

\section{King Site (41BX883)}

$\mathrm{N} 13 / \mathrm{W} 71$. The interior of a watch about $3.4 \mathrm{~cm}$ in diameter. From the weight and thickness, it appears to be from a pocket watch (Figure 6-9d). 


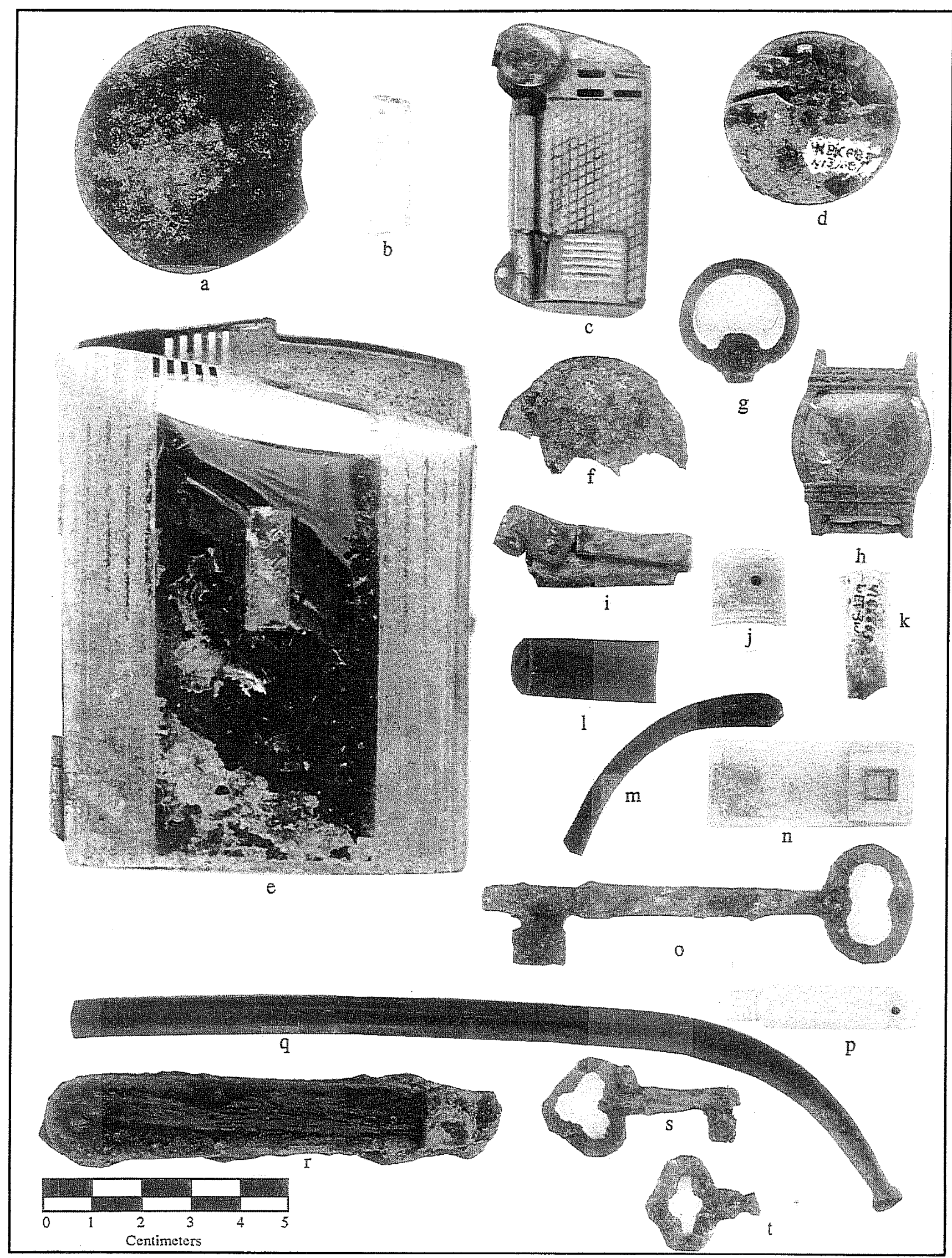

Figure 6-9. Miscellaneous personal items from the Alamodome Project. 
Feature A. A chrome-plated cigarette case engraved with the initials "J H W" (Figure 6-9e). The shape of the top suggests that a lighter which could be lit with the case closed was included.

Trench C, Feature A. A fragment of metal which appears to be a watch part (Figure 6-9f).

Trench C, Feature A. A stem of a pocket watch with a loop to hold a watch chain (Figure 6-9g).

Test D, Structure B. A metal watch, gilded on the face, with a chrome-alloy back (Figure 6-9h). The numerals are engraved in the face. The hands stopped at 9:10. The glass cover is broken and the watch band is gone. This watch is small enough that it might have been a woman's watch, but it is a casual style.

Test D, Structure B. The top of a metal cigarette lighter of the gasoline type (Figure 6-9i).

Well Expansion, 3 West. A small brass metal piece from a pocket knife handle (Figure 6-9j).

Well Expansion, 3 West. A small fragment of a ceramic tobacco pipe stem.(Figure 6-9k) The ceramic is unglazed.

\section{Griesenbeck Site (41BX884)}

N65/W27. A type "a" battery, which is a small watch or camera type battery, only about $1.0 \mathrm{~cm}$ across. This item dates no earlier than the 1970 s.

N65/W29. A mouth piece from a tobacco pipe, $3.0 \mathrm{~cm}$ long (Figure 6-91). The mouthpiece is made of composition material .

N65/W29. A fragment of the earpiece of a pair of eye glasses (Figure 6-9m). The piece is made of composition material, suggesting that it pre-dates World War I.

N65/W45. A clear plastic and metal identification tag for a key chain or luggage (Figure 6-9n). This item, measuring 4.0 by $1.7 \mathrm{~cm}$, is designed so the owner can write the desired identification on a piece of paper and slip the paper into the transparent plastic. The kind of plastic strongly suggests manufacture after World War II.

N187/W36. An old-style door key of the old-fashioned "three tumbler" type (Figure 6-90). The key is $8.5 \mathrm{~cm}$ long, probably for a mortise knob lock.

Trench A, Feature A. A bone tobacco pipe mouth piece (Figure 6-9p). The end which fits into the stem is grooved to screw in. There is a small hole in the bite groove of the tip. The use of bone for a mouthpiece suggests a date prior to World War I.

\section{Biesenbach Site (41BX890)}

Trench B, Feature A. A long, hard rubber pipe stem) (Figure 6-9q). This item is $16.0 \mathrm{~cm}$ long and is marked “. . . y Rubber co. Goodye. . .. " Long-stemmed pipes are called "churchwardens" (Herment 1957:36.

\section{Horn Site (41BX891)}

S89/W118, Feature A. A badly corroded folding pocket knife (Figure 6-9r). This knife is a single-blade jackknife. There is a fragment of the wood inset of the handle still remaining, but the rest of the knife is made entirely of iron, strongly suggesting a very early date, probably no more recent than the mid-1800s (Hood, personal communication 1993).

S89/W120, Feature A. A copper top for a cloth clasp purse (Figure 6-10a). The frame is $14.5 \mathrm{~cm}$ across the top.

\section{Rilling Site (41BX892)}

Trench A, Feature A. Three fragments of a metal clasp purse frame (Figure 6-10b). The top of the frame measures about $9.0 \mathrm{~cm}$.

\section{Czernecki Site (41BX893)}

S150/E23. A small old style key, probably for a lock box or small padlock (Figure 6-9s). The key is $4.0 \mathrm{~cm}$ long. 


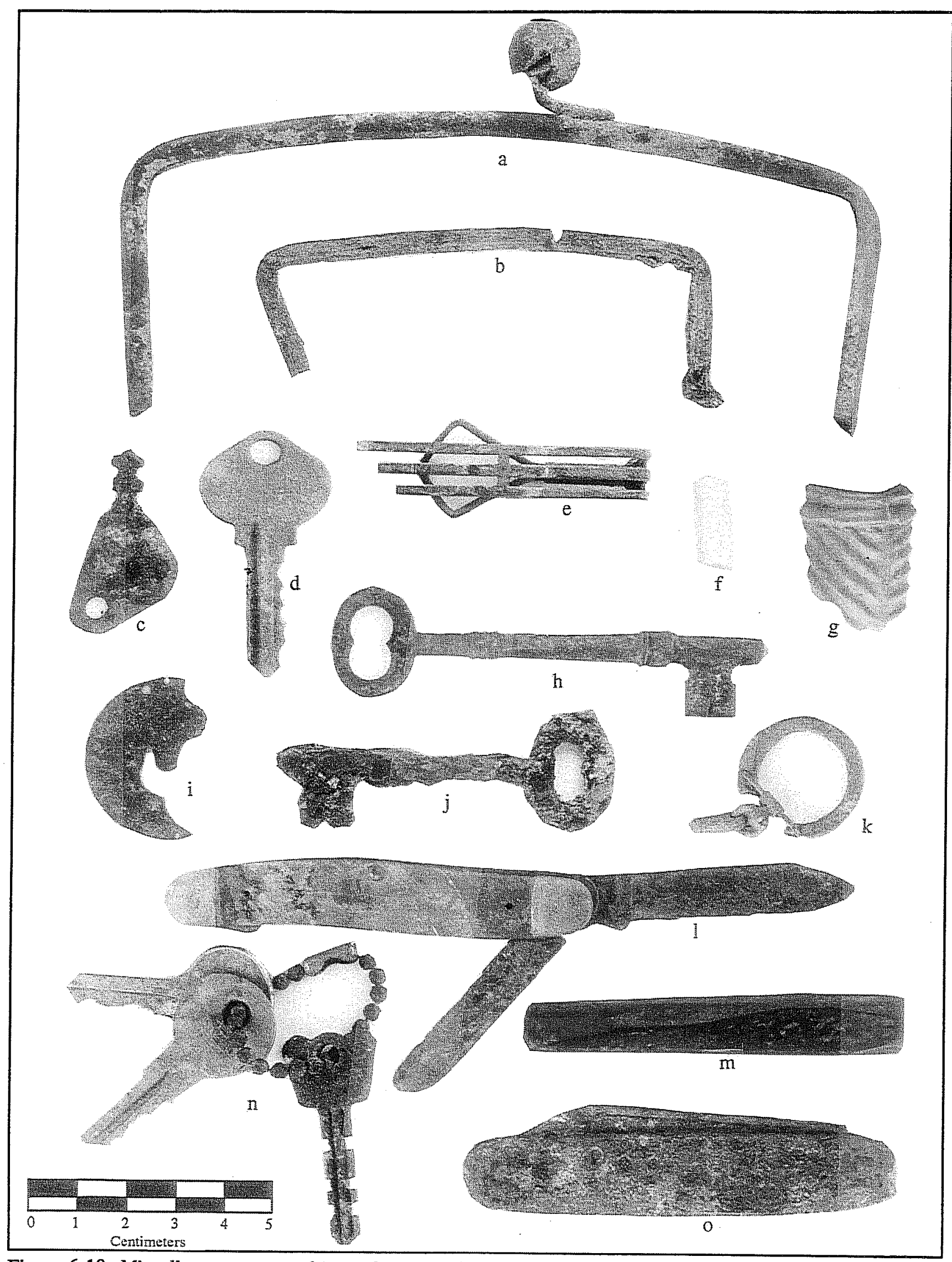

Figure 6-10. Miscellaneous personal items from the Alamodome Project. 
S177/E37. A fragment of a small key, $2.3 \mathrm{~cm}$ long. This key was probably for a diary or other very small lock (Figure 6-9t).

\section{Czernecki Rental (41BX894)}

Feature A. A leather photo compartment from a wallet. The leather folds into a rectangle about 5.5 by $7.5 \mathrm{~cm}$. There is a snap closure, but the plastic or cellophane photo holders that would have been inside are gone.

Feature A. A key with a large top and a small stem (Figure 6-10c). This is the kind of key used for diaries or other very small and not very sturdy locks. The key is $3.9 \mathrm{~cm}$ long.

Feature A. A modern style padlock key, $5.0 \mathrm{~cm}$ long (Figure 6-10d). The key is marked "Sargent" on one side and "U6" is stamped into the metal on the other side.

\section{Demazieres House (41BX896)}

S87/E107. A small, old-fashioned key, $4.3 \mathrm{~cm}$ long.

S87/E109. The left earpiece and frame of a pair of "rimless" eyeglasses made of copper alloy (Figure 6$5 \mathrm{f})$. The earpiece is very short (ca. $8 \mathrm{~cm}$ ) and is almost certainly intended for a child. The lens would have been held in place with small brass screws. The earpieces are curved to fit around the ear, a style called variously "riding," "hook-bow" (Blum 1969:203), or "riding bow" (Israel 1968), intended for constant use or for rough conditions. Children were not ordinarily given glasses, except in the most extreme cases of poor vision. The use of metal instead of rubber or celluloid suggests that these glasses are quite old, probably nineteenth century, but exact dating is not possible.

S107/E107. A fragment of a sunglass lens of yellowbrown glass.

S188/E148. A folding pocket knife, too corroded to tell how many blades it once had, but the thickness suggests there were at least three. There was once an insert on the handle, probably of bone or wood or other organic material, but this is now gone. The handle is $8.5 \mathrm{~cm}$ long.

Trench C. A plastic coin purse, colored black, with a logo showing a setting sun, palm trees and a sailboat. Beneath this is printed "Padre Island/Texas."

Trench D, S1. A gilded metal money clip (Figure 610e). The front of the clip is designed as three metal bars of increasing length, the longest being $5.9 \mathrm{~cm}$ long. These bars are folded back on themselves, then combined into a single spring-like backing to hold the money.

Shovel Test \#1. A three-tumble style key, $7.4 \mathrm{~cm}$ long.

\section{Webb Site (41BX897)}

Surface. A tobacco pipe stem fragment of unglazed ceramic (Figure 6-10f). The pipe stem is $1.8 \mathrm{~cm}$ long.

Trench K, West. A stoneware pipe bowl fragment with a molded diagonal ribbed pattern and a reddish overslip (Figure 6-10g). The pattern and the shape of the rim appears to be identical to a pipe produced in Ohio by a pottery shop which operated under various owners between the 1840s and 1890 (Sudbury 1979:plate 10, \#7, and page 182).

Well Expansion, 1 East. A small brass plate from a pocket knife handle.

Well Expansion, 1 East. A bone-handled folding knife of the "Barlow pattern" (Hood, personal communication 1993). There were originally two blades, but both are now broken. The handle is $9.5 \mathrm{~cm}$ long. An apparently identical knife sold in the 1895 Montgomery Ward catalog for $\$ .60$ (Blum 1969:442). This is a fairly well-made and rather expensive knife.

Well, Level 1 . The end of a small three-tumbler type key.

\section{Gordon Site (41BX900)}

Trench C, S9. A three-tumbler style key fragment, 4.9 cm long. 
Trench D, S2. Fragment of a possible porcelain pipe.

Trench E, S6. A three-tumbler style key, $5.9 \mathrm{~cm}$ long.

Trench E, Feature A. A three-tumbler style brass key in excellent condition, $8.7 \mathrm{~cm}$ long (Figure 6-10h).

\section{Petit Site (41BX931)}

N73/W145. A metal plate from the interior of a watch (Figure 6-10i). The size is too big for a wrist watch, so it is probably from a pocket watch.

\section{Burleson Site (41BX930)}

Trench A, S7. A pocket knife with two blades (Figure 6-101). It probably once had three blades, in what is called a "Stockman's pattern," consisting of a master blade, a pen knife, and a "sheep's foot" knife" (Hood, personal communication 1993). The handle is $7.9 \mathrm{~cm}$ long and once had inserts on each side, probably of bone or ivory, but this material is now gone.

\section{Meeks Site (41BX940)}

Trench D, S1. An old-style, three-tumbler door key, $8.5 \mathrm{~cm}$ long (Figure 6-10j).

Trench D, S1. A metal key ring which is opened with a loop-and-lever type catch (Figure 6-10k). One loop of the chain and a small piece of metal are still attached. The ring is $2.5 \mathrm{~cm}$ in diameter.

\section{Houston Site (41BX941)}

Trench D, S9. A ball chain with three modern keys (Figure 6-10n): 1) a key $4.7 \mathrm{~cm}$ long marked "Briggs and Stratton" on one side and "GAS/A1005" on the other; 2) a key $4.2 \mathrm{~cm}$ long marked "L. L." in script on one side and "Laminated Padlock/Hong Kong" on the other; and, 3) a key $4.2 \mathrm{~cm}$ long that appears to be a lock box key, rather than a door or padlock key, marked ". . . WAL/WIS ..." on one side and "Master Lock Co." on the other.

\section{Harris Site (41BX942)}

S70/W55. A tobacco pipe mouthpiece, measuring 7.5 $\mathrm{cm}$ long (Figure $6-10 \mathrm{~m}$ ). This item is made of a reddish brown composition material.

\section{Pauly Site (41BX945)}

Trench C, S3. A folding pocket knife with a single blade (Figure 6-100). The handle is $8.8 \mathrm{~cm}$ long and once had an inset of some material, probably bone or wood, though this is now missing. This is an extremely cheaply made knife (Hood, personal communication 1993).

Trench E, S3. A fragment of a metal chain watch band, $1.2 \mathrm{~cm}$ wide (Figure 6-11a). This band is quite narrow, so it may have been for a woman's watch.

Pauly Privy, N1/2, Level 3. Two thin copper alloy pieces $3.6 \mathrm{~cm}$ long stamped with a shell design in the center (Figure 6-11b). These were possibly cigar "rings," that is, part of the packaging of fancy cigars.

Privy, S1/2, Level 4. A metal frame for a clasp purse (Figure 6-11c). The frame is $6.7 \mathrm{~cm}$ wide at the top.

Privy, N1/2, Level 4. Three pieces of a heavy cotton belt material. These thick cotton webbed belts are each about $2 \mathrm{ft} 3$ inches long and have eyeleted holes spaced along their length. They appear to be military type equipment belts. The appearance of a hand grenade in this level also speaks to a military presence.

Privy, N1/2, Level 7. A metal case, 5.3 by $7.5 \mathrm{~cm}$, with a hinged bottom and a hole in the top with grooves for something to be screwed in (Figure 611d). On one side is a button and a slide mechanism to hold button down. It appears to be a pocket flashlight, in which case the bulb would have been screwed into the hole at the top. While the 1902 Sears catalog does not mention flashlights, the 1927 catalog lists both single and double cell varieties and also sells batteries for them (Sears Roebuck 1969:666). 


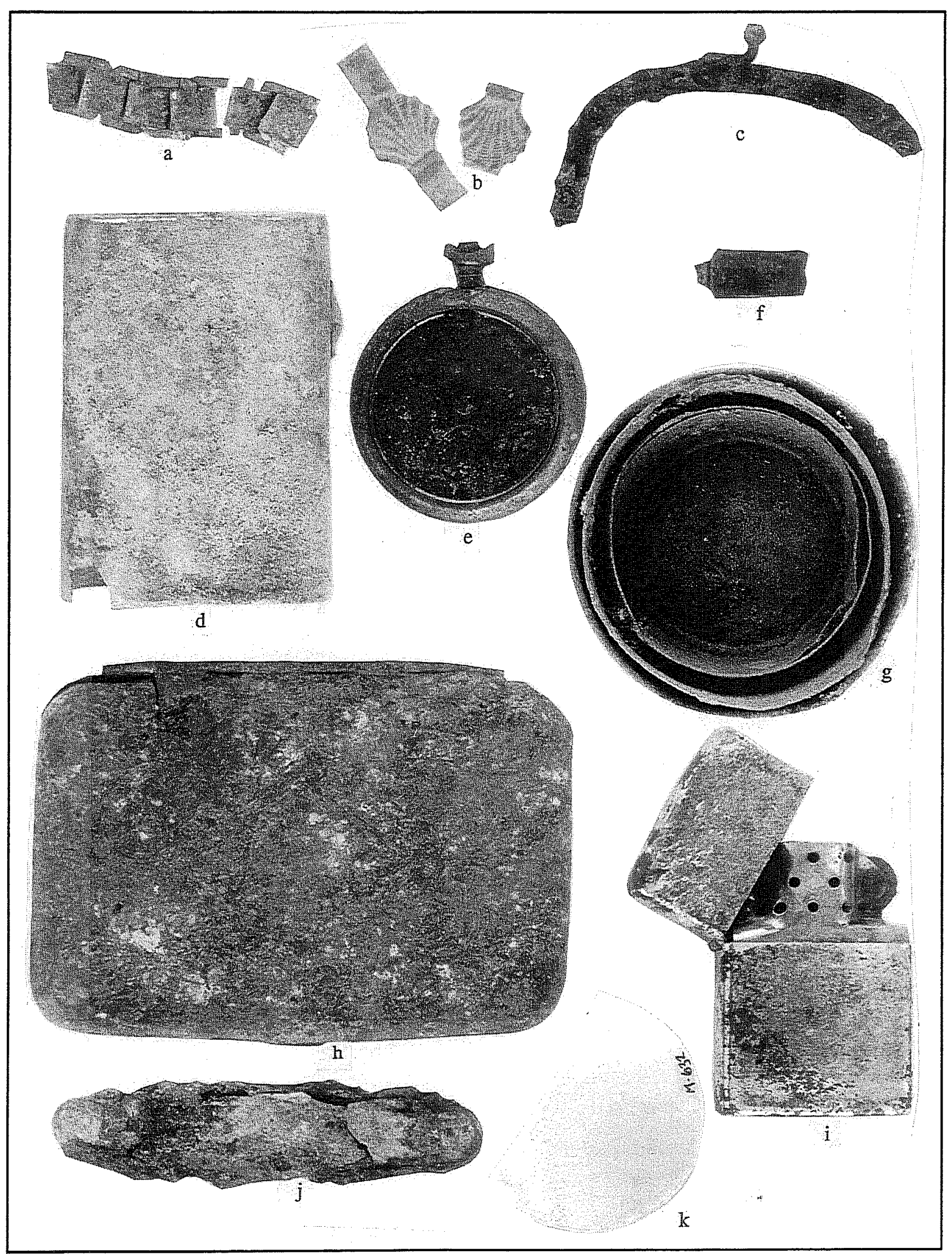

Figure 6-11. Miscellaneous personal items from the Alamodome Project. All shown actual size. 
Privy, N1/2, Level 7. A pocket watch with the back missing and two loose pieces. The hands, glass top and face markings are missing. It was a stem wound watch, marked on the back (inside the case) “. . . 0575." This watch had a small second hand in separate circle below the hour and minute hands (Figure 6-11e shows the watch alone).

Privy, N1/2, Level 7. A wooden tobacco pipe stem fragment with a grooved end for screwing into the rest of the pipe (Figure 6-11f). The fragment measures 2.1 $\mathrm{cm}$.

Privy, S1/2, Level 9. A badly corroded pocket knife broken into several fragments. The handle is about 8.4 $\mathrm{cm}$ long.

Privy, N1/2, Level 11. A collapsible metal "traveling cup" made of a series of metal rings designed to function as a small cup when expanded and able to collapse into a much smaller size when not in use (Figure 6-11g). The widest ring (the top of the cup) is $6.6 \mathrm{~cm}$ in diameter. The narrowest ring (the bottom) is $4.8 \mathrm{~cm}$.

Privy, N1/2, Level 11. A copper-alloy cigarette case with fancy engraving on both sides (Figure 6-11h). It measures 7.3 by $10.5 \mathrm{~cm}$.

Feature E, NE Quad, Level 1. A chrome-plated cigarette lighter, designed to burn gasoline (Figure 6-11i). It has a thumb operated flint and steel wheel type ignition. It is marked on the bottom ". . . /Bradford, PA." The lighter measures 5.6 by $3.9 \mathrm{~cm}$. The perforated metal screen around the wick makes this a "windproof" type lighter (Herment 1957:105).

\section{No Site Number}

Monitoring NCB 636. A pocket knife with three blades (Figure 6-11j). The handle once had an inset, probably of wood or bone, but that is now gone. The handle measures $8.4 \mathrm{~cm}$ in length.

Monitoring NCB 636. A fragment of glass from a pair of prescription eye glasses. The shape is circular and the glass is $4.7 \mathrm{~cm}$ in diameter (Figure 6-11k).

\section{Writing Materials}

This category, numbering 174 items, consists of the remains of pens, pencils, blackboard slate, and other writing materials and office supplies. There is little variation in the types of artifacts in this category, that is, one metal eraser end from a wood and graphite pencil looks very much like any other. However a few observations of intrasite variations are made at the end of the artifact list.

A few notes can be made about dating writing artifacts. In the first place, it is obvious that the metal dip pen was first used before the fountain pen, which was not invented until 1904 (Harpur 1982:18), which was in use before the ball point pen, invented in the 1930s (Harpur 1982:131). However, the dip pen is still in use by artists and occasionally by others (including archaeologists) to this day, and the fountain pen and the ball point pen are also still made and used. We, therefore, can come to only the most general conclusions about dates by looking at these items.

Slate is another item which can provided only ambiguous dating. Though few blackboards are made of slate these days, there is no good information available as to just when this became the case. In addition, there is always a possibility of mistaking roofing slate for blackboard slate. All the slate listed here is thin and has at least one side that has been carefully smoothed, suggesting that it is slate intended for blackboards, but the possibility still exists that some of this slate was construction material.

By the early 1890 s, wholesalers were selling plain wood pencils with rubber erasers for about $\$ 1.00$ a gross (Stirn 1990:100). Mechanical pencils had already been invented, and dip pens cost between $\$ .30$ and $\$ 4.00$ a gross, depending on the fanciness of material and construction(Stirn 1990:100).

\section{Oeffinger Site (41BX881)}

N6/W90. Three slate fragments.

N19/W80. Three slate fragments.

N32/W48. Four slate fragments. 
N32/W48. A metal eraser end.

N32/W48. A paper clip.

N52/W48. A paper clip.

Trench D. A metal eraser end with a fragment of graphite.

\section{Haas Site (41BX882)}

N35/E05. A slate fragment.

Trench B. A slate fragment.

Trench C. A fragment of composition material covered with plastic which is probably part of a pen or mechanical pencil. It is marked ". . IN USA QFLEXIBLE L . ..."

\section{King Site (41BX883)}

N30/W29. A slate fragment.

N58/W91. Three tiny fragments of a blue wax crayon.
Trench C, Feature A. Two metal eraser ends.

Trench C, Feature A. Two graphite fragments.

Trench C, Feature A. Five pencil fragments.

Test D, Structure B. A fragment of a wooden pencil.

Well Expansion, 3 East. A slate fragment.

Well Expansion, 3 East. A slate pencil fragment.

Well Expansion, 3 West. Three slate fragments.

Well Expansion, 3 West. Three slate pencil fragments.

\section{Griesenbeck Site (41BX884)}

N8/W90. Two metal dip pen tips (Figure 6-12a). The ends are very broad, suggesting that these may be intended for art work rather than writing.

N65/W27. A metal eraser head.

N65/W29. A metal eraser end with a fragment of wood.
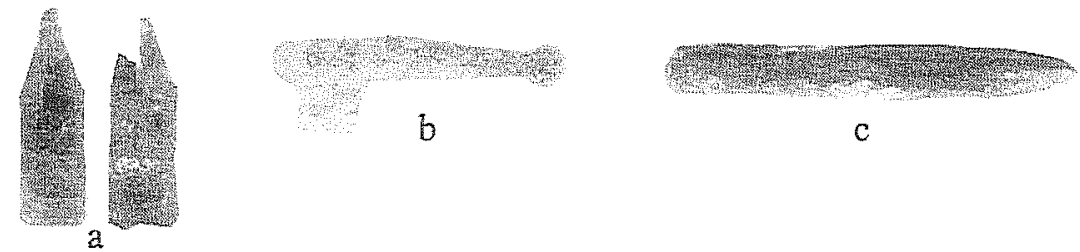

\section{c}

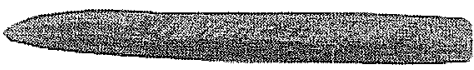

h
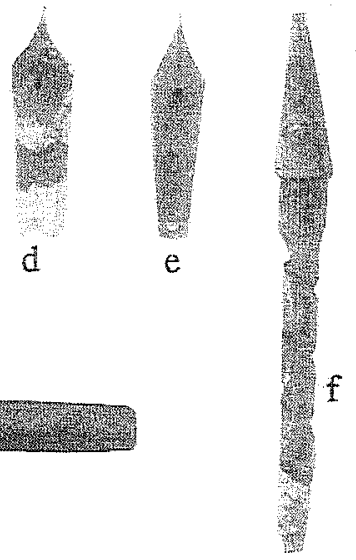

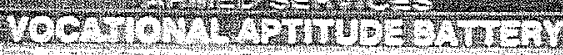

i

Figure 6-12. Miscellaneous writing tools from the Alamodome Project. All shown actual size. 
N107/W27. A wooden pencil fragment.

Trench A, Feature A. A metal pocket clip from a pen or mechanical pencil (Figure 6-12b).

\section{Mendit/Maffi Site (41BX885)}

9/W71. A paper clip.

N56/W76. A slate fragment.

Biesenbach Site (41BX890)

Trench A, Feature A. A slate fragment.

\section{Rilling Site (41BX892)}

S75/W48. Two slate fragments.

Trench A, Feature C. Two slate fragments.

Monitored Trash Pit. A slate pencil fragment (Figure 6-12c).

\section{Czernecki Site (41BX893)}

S15/E11. Nine slate fragments.

S83/E55. A paper clip.

S95/E58. An eraser end.

S100/E55. A slate fragment.

S152/E23. An eraser end.

S177/E37. Two eraser ends.

\section{Czernecki Rental (41BX894)}

S13/E74. A brown artist's pencil fragment marked "PEDIG . .. " in gold letters.

S18/E74. A pencil fragment with wood and graphite and an eraser end.
S40/E77. A metal pen cap.

S144/E56. A gilded dip pen tip with a very fine point (Figure 6-12d).

S174/E71. A paper clip.

\section{Garza Store (41BX895)}

Under the store. An eraser end.

\section{Demazieres House (41BX890)}

S39/E76. A fragment of wooden pencil.

S50/E7. A graphite fragment.

S76/E146. An eraser end.

S87/E109. A ink shaft and point from a retractable ballpoint pen.

S87/E109. A pencil fragment with eraser end and graphite.

S87/E111. A fragment of graphite.

S115/E115. A pencil fragment with the eraser end and graphite.

S107/E107. A plastic pen cap.

S107/E107. An eraser from a pencil end.

S107/E115. A paper clip.

S115/E130. A pen cap with a metal pocket clip.

S118/W148, Test. A slate fragment.

Trench A. A metal end cap for a pen or pencil.

Trench A. A blue plastic covered ballpoint pen.

Trench D. A fragment of graphite.

Trench D. Two pencil fragments. 
Trench E. A piece of graphite.

Trench E. A metal pen cap decorated with red, white, and blue stripes.

Trench E. An eraser end.

Trench E. A green rubber eraser, measuring 5.0 by $2.4 \mathrm{~cm}$.

Room 3. An eraser end.

\section{Webb/Deman Site (41BX897)}

N37/E96. Five slate fragments.

Trench $\mathrm{H}$, extension. Two slate fragments.

Trench K, west. Three slate pencil fragments.

Area A. A fragment of graphite pencil lead.

Area A. Two eraser ends.

Area A, west half. Two slate fragments.

Feature B. Two slate fragments.

Webb Well, Level 1. A gilded dip pen tip with a broken tip (Figure 6-12e). On the top it is marked "A.A. WATERMAN/\& CO./NEW YORK." Beneath is a number " 4 " inside a shield outline. The underside is marked " $K$."

Webb Well, Level 7. Two slate fragments.

Well Expansion, 1 East. Three slate fragments.

Well Expansion, 2 East. Five slate fragments.

Well Expansion, 2 West. Three slate fragments.

\section{Gordon Site (41BX900)}

NW Foundation. A slate fragment.

Trench D, S6. A slate fragment.
Trench E, S6. Two slate fragments.

Trench E, Feature A. Two graphite fragments.

Petit Site (41BX931)

N56/W145, Level 2. An eraser end with a graphite fragment.

N67/W131. Twenty-four slate fragments.

\section{Gilbert Site (41BX937)}

N99/W140. Two fragments of graphite.

N99/W140. A mechanical pencil tip made of brass (Figure 6-12f).

Trench B, S1. An eraser end.

\section{Conrad Site (41BX938)}

Trench B. A fragment of a gilded lever-fill fountain pen (Figure 6-12g).

\section{Pauly Site (41BX945)}

Trench B, S1. Two slate fragments.

Trench C, S1. Two eraser ends.

Trench C, S3. A black plastic pen cap.

Pauly Privy, N1/2, Level 2. An eraser end.

Pauly Privy, S1/2, Level 4. An eraser end.

Pauly Privy, N1/2, Level 11. A slate fragment.

Pauly Privy, S1/2, Level 14. A slate pencil fragment (Figure 6-12h).

Feature E, Surface. A brown plastic ballpoint pen with an eraser end (Figure 6-12i). It is marked "Armed Services/ Vocational Aptitude Battery/ See Your Counselor Today" in gold lettering. 
Shovel Test \#8. An eraser end with wood fragment.

Any attempt to find useful information from the writing material listed above is limited by the wide range in dating and in pricing of items such as pencils and dip pens. In addition, slate is like any other highly brittle item. The existence of a great deal of slate at one site could be the result of a single blackboard shattered to many pieces or it could be the result of many blackboards in use on the site over a period of many years. If we assume, however, that the more scattered the deposit of slate, the more likely that the slate from each provenience represents a separate blackboard, we can see that the slate in the Webb and King sites is not only abundant but also widely scattered, suggesting that slate blackboards were used more often here than anywhere else in the project area. The reasons for this are not known. However, it is known that both William Webb and Ben Deman were express drivers. It is possible that the large number amount of slate found on these sites is related to that profession.

\section{Miscellaneous Personal Items}

The items in this category are here because they do not readily fit elsewhere. They include clock fragments, figurines, and other miscellany. Also included are unidentified items which seem likely to have been personal items of some kind. Forty-five items are included in this category.

\section{Oeffinger Site (41BX881)}

N15/W15. A small bird's claw figure made of metal (Figure 6-13a). The modeling is fairly simple, and there is a wire extending from the molded part. This would have fit up inside the leg of a bird figure.

N25/W55. A small petrified shark's tooth (Figure 6-13b). This would probably have been some kind of keepsake.

N32/W48. A gear from a clock.
Haas Site (41BX882)

N24/E71. An unglazed porcelain figurine fragment representing the waist and part of the skirt of a dress. The fragment is hand-painted green (Figure 6-4d).

N44/E71. A gear from a clock.

\section{King Site (41BX883)}

N9/E91. A barefoot bisque (unglazed porcelain) leg, colored to resemble an African-American skin tone, and broken at the knee (Figure 6-4e). This item is listed here and not in the doll report because there were signs on the bottom of the foot that it had once been joined with a thin coat of slip to a base. The bottom of the foot has no complexion coat, but is stained with green paint around the edge. There was always a considerable market for black dolls during our study period, not among black children, who could seldom have had the money for store-bought toys, but among white children (Collier 1988:348). In addition, bisque "Negro" figurines, as well as figurines representing Eskimos, Amerindians, and European nationalities, dressed in "native" costumes, were also very popular with white children well into the 1960 s and 1970s, long after dolls intended for play were no longer made of ceramic material. The possible date on this figure is thus too broad to be of any value to the archaeologist. There is also a fragment of the same figurine.

Trench C, Feature A (Privy \#1, Level 3). Twenty-eight fragments of a clay figurine (Figure 6-14a shows a front view, $14 \mathrm{~b}$ shows the left side). This little man was made by pressing wet clay by hand into a mold, and then finishing by hand and firing. There is no glaze. The face and hands are carefully, although simply, detailed, while the feet are mere blobs of clay stuck onto the ends of the legs. The figure is wearing an open vest with buttons made of clay pellets added after the molding, and a molded belt across the back. The figure is in a squatting position, with arms extended outward, and with the trousers dropped in the rear, revealing bare buttocks. The right hand has broken fingers, but appears to have been empty. The left hand, also with fingers missing, is holding 


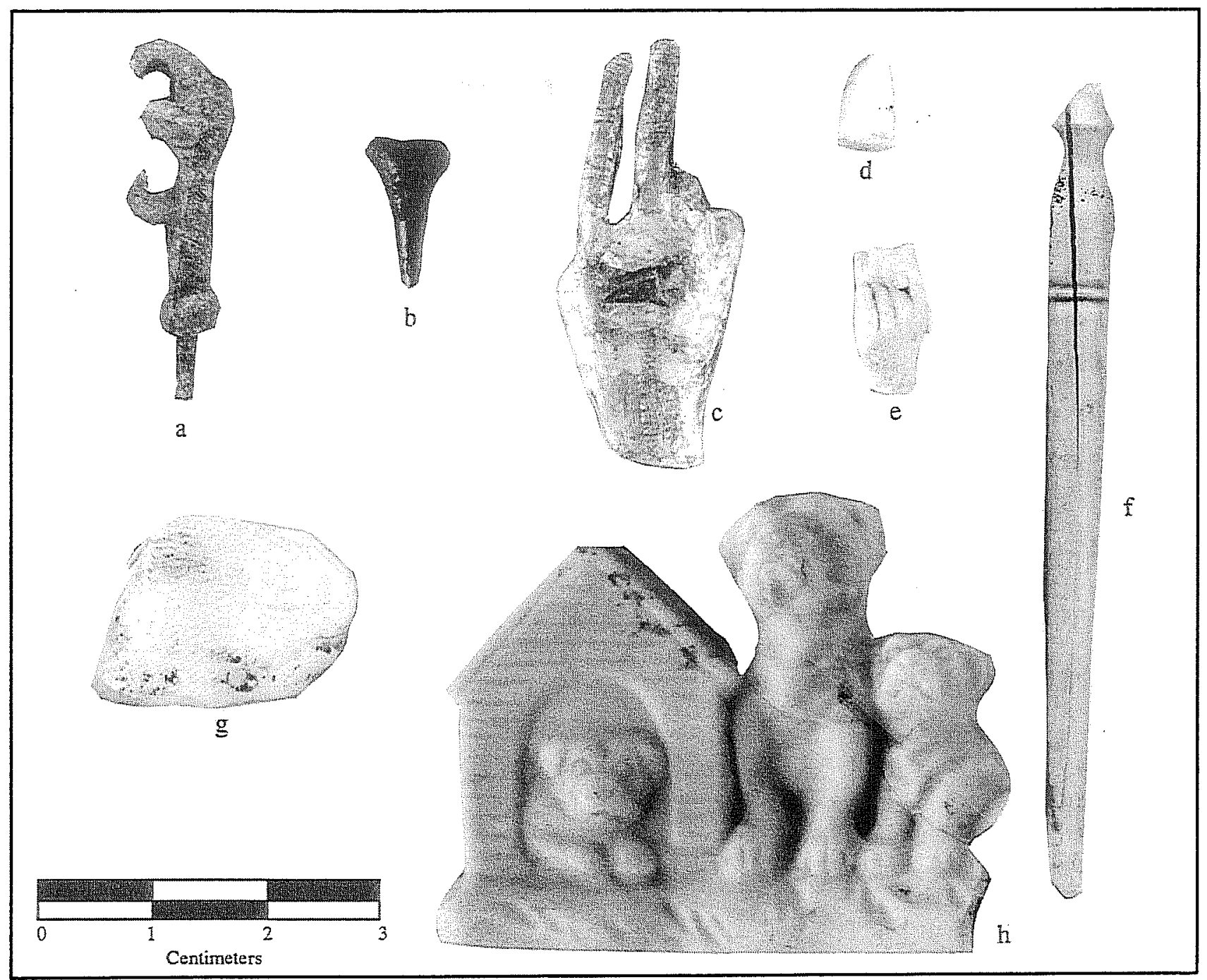

Figure 6-13. Miscellaneous personal items from the Alamodome Project.

something, but all identifying portions have been broken off. The expression on the round, fat face is one of nasty good humor. Most of the right side is missing.

Trench B. A copper plate, 2.2 by $4.5 \mathrm{~cm}$. The shape is a rounded rectangle, with holes at the four corners so that the plate can be riveted to something. This is the type of plate used for engraving, but it was never engraved.

Trench B. A ceramic fragment that appears to be from a figurine. The poor quality ceramic is hand painted yellow.

Well Expansion 3 West. An unidentified object made from bone. It appears to be machine turned and has been cut for screwing into something. It is $4.0 \mathrm{~cm}$ long (Figure 6-5g).

\section{Griesenbeck Site (41BX884)}

N42/W47. A figurine hand made of metal. The first two fingers are extended, with the other fingers and thumb folded. Two small blobs of metal have been added to the back of the hand with a space between them, forming a groove in which a bit of red thread and some glue remain. Also on the back of the hand is the embossed mark "Hong Kong." This item is reminiscent of a "milagro," a Mexican-Catholic charm often hung in churches when a believer is asking for a special favor from God. This is a custom modified from the sixteenth-century Spanish habit of wearing many little amulets on the clothing as a protection against evil (Tait 1987:212-213) (Figure 6-13c). 


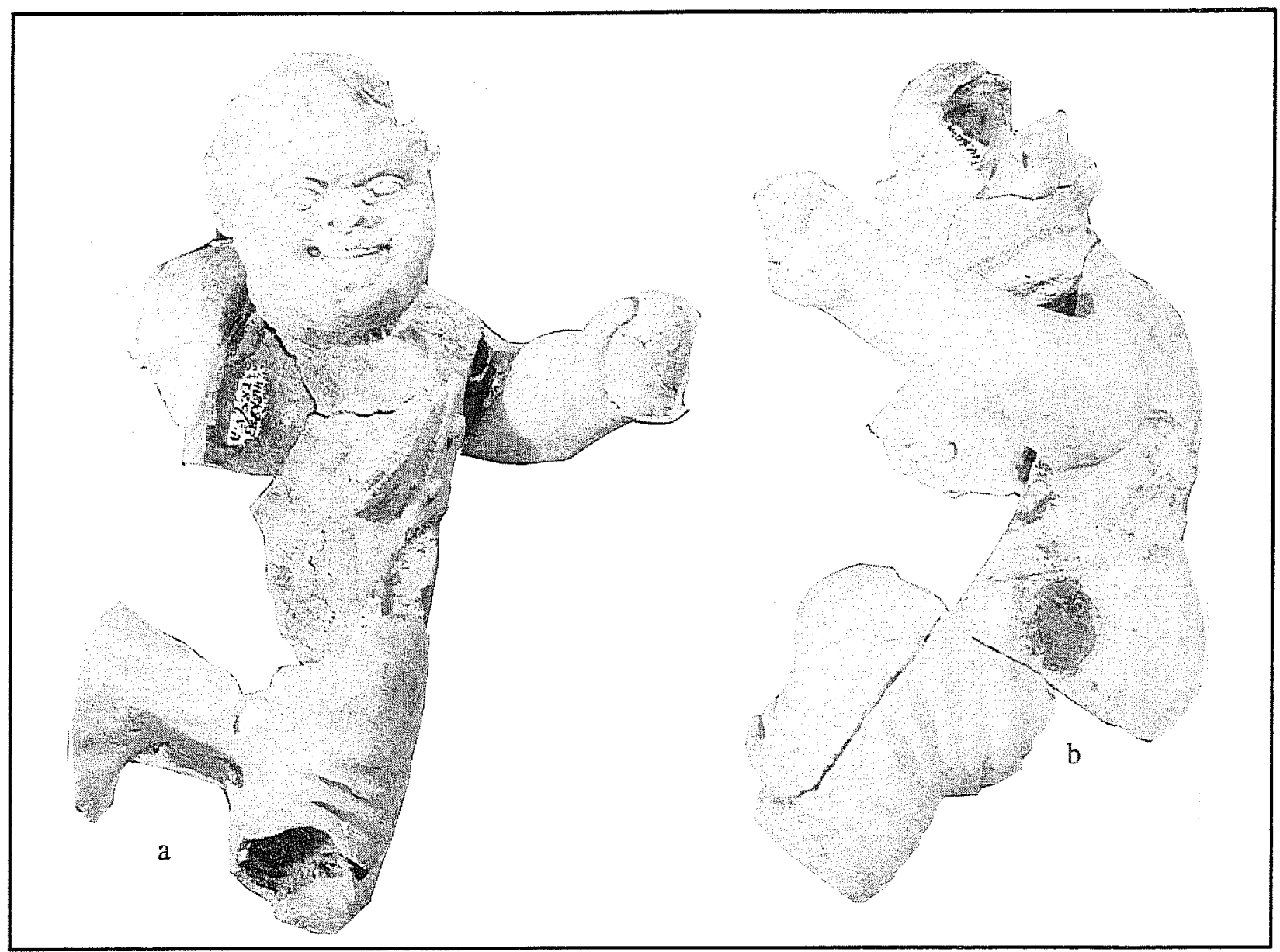

Figure 6-14. Clay figurine from the King site. Shown one-half actual size.

$\mathrm{N} 187 / \mathrm{W} 36$. A fragment of porcelain in a pointed shape. The fragment is $.8 \mathrm{~cm}$ long and has a tooth-like shape. There is a dull, mottled glaze on the rounded side and a bright white enamel glaze on the flat side. The exact nature of this fragment is unknown, but it looks suggestively like part of a denture (Figure 6-13d).

Trench A, Feature A. A clock gear.

Trench A, Feature A. A brass plaque, representing a young girl, a dog (setter), and a rose hedge. The girl is definitely Victorian in her face and clothing. The plaque measures 14.8 by about $12.5 \mathrm{~cm}$, and was intended to stand on its bottom, with its back flat against a surface.

\section{Biesenbach Site (41BX890)}

Trench A, Feature A. An untinted porcelain figurine fragment representing an arm bent at the elbow. The arm is broken at the shoulder and waist (Figure 6-4f).

\section{Horn Site (41BX891)}

S89/W120. A fancy metal frame fragment, probably from a picture frame. There is a stamped floral design in the corner and the remains of a hinge. This suggests it was part of a two-or-more-piece folding picture frame (Figure 6-4g).

\section{Rilling Site (41BX892)}

Trench A-Extension, Feature A. A tiny hand from a figurine, only $.5 \mathrm{~cm}$ across the hand. It is made of unglazed porcelain, painted a pink flesh tone. The hand is pointing the forefinger. The other fingers and thumb are folded (Figure 6-13e).

Trench C, Feature A. A cog from a clock. 


\section{Czernecki Site (41BX893)}

Surface. A plaster wall plaque of an angel with folded hands in relief, surrounded by a frame. A hanging wire is found on the back. This piece is badly burned and broken in two pieces.

S152/E23. Hand-painted whiteware flowers. This is possibly part of a figurine.

\section{Demazieres House (41BX896)}

Trench A. A small bisque hand-painted figurine of a male figure lying on his stomach (Figure 6-4h). The figure is broken across the back near the shoulders. He is wearing a jacket, reddish-brown knee-pants with ribbed white stockings, and black shoes. The figure is marked "Made in Japan," which suggests that it dates to post 1920 s, as the Japanese changed from "Nippon" to "Japan" on its export mark at that time (Angione 1973:328).

Trench A. A small (4.5 cm tall) unglazed ceramic figurine representing a jumping horse with rider (Figure 6-5h). Most of the base, and the rider's head are broken off. The detailing is shown on both sides. On one side near the base are the letters ". .. any" and the numeral 9. This probably means the figurine was made in Germany.

S118/E143, Privy \#5 Level 2. A very crude gray clay figurine fragment representing the front half of an unidentified animal (Figure 6-4i). The nose, ears, and forefeet are broken off. The interior is hollow but the figurine appears completely hand made. There is also another fragment of the same clay, possibly from a different part of the animal.

S118/E143, Privy \#5 Level 4. A possible metal picture frame fragment.

\section{Webb Site (41BX897)}

Well Expansion 1 East. An unglazed figurine fragment, painted a dull orange and white. It appears to have been handmade, but what it represents is not identifiable.
Well Expansion 1 East. A fragment of a lathe-turned bone implement, broken at both ends (Figure 6-13f). The shape, small diameter $(.3$ to $.5 \mathrm{~cm})$, and length suggest this was the handle of a small crochet hook or tatting (lace-making) hook.

Well Expansion 2 West. Two fragments of a ceramic crucifix (Figure 6-3j). The left arm and the feet of the Christ figure are surrounded by gilded rays streaming from the cross. The back is unglazed.

Well Expansion Baulk. An unidentified bone item. The outside was turned on a lathe and highly polished, while the inside appears to be hollowed out by hand (Figure 6-3k). The purpose of this item is unknown, but it was probably some sort of handle or case for a hand tool or other instrument.

\section{Gordon Site (41BX900)}

Trench E, S4. A large, untinted porcelain boot from a figurine. The boot is solid porcelain but as it goes up into the leg, it becomes hollow. The heel and toe are broken. The fragment is $5.0 \mathrm{~cm}$ high and does not reach the top of the boot.

Trench E, Feature A. The head from a molded milk glass turtle figurine (Figure 6-13g).

\section{Schulze Site (41BX927)}

Privy \#7. A thin-walled glass tube. The end has been heated and drawn out to a small point (which is broken off). Inside the tube is a tiny ceramic doll about $2.5 \mathrm{~cm}$ tall, with mold clothing and hair. The figure has handpainted features and brown hair. This item appears to be part of a barometer (Figure 6-15).

\section{Thomas Site (41BX932)}

Surface. A small porcelain deer figurine. Glazed in tan and brown with pink near the ears, this little animal stands only $4.2 \mathrm{~cm}$ high. The molding is crude, with few details. The ears are broken off (Figure 6-16a).

S74/E91. A clock gear. 


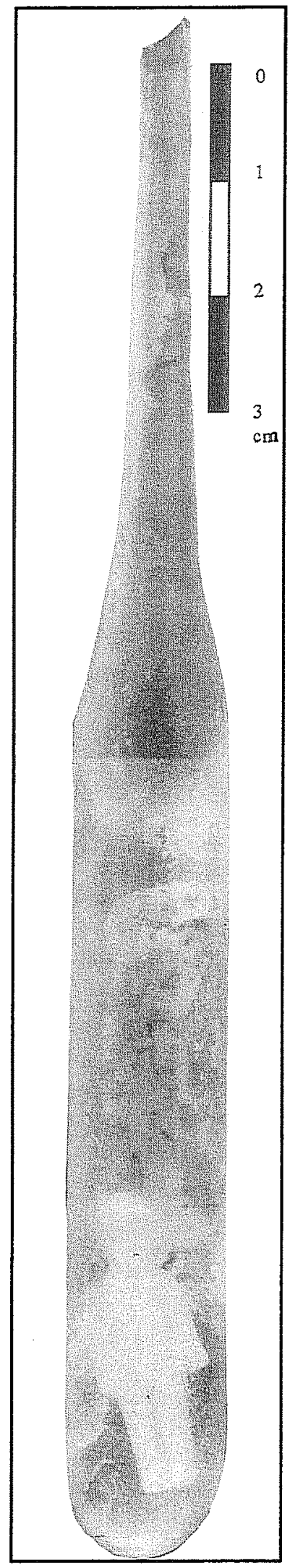

Figure 6-15. Possible barometer from the Schulze site.
Gilbert Site (41BX937)

N99/W140. Two small porcelain figurine fragments.

\section{Conrad Site (41BX938)}

Trench B, S4. A small square clear glass box measuring $3.3 \mathrm{~cm}$ across. There is an inset near the top for a lid. The use is not readily identifiable, but may have been a ring box.

Trench B, S8. A thin metal tag, possibly a luggage tag, 3.2 by 6.0 $\mathrm{cm}$.

Trench B, S9. A fragment of the face of a whiteware "piggy" showing the snoot, a "cheek," and part of one eye. It is painted pink on cheek, nose and lips. The tongue is red and the pupil black (Figure 6-16b).

Trench C, S5. A porcelain fragment representing the shoulder of a woman wearing a blue dress with yellow polka dots and a white collar with orange flowers on it. The colors are hand painted over the glaze. The base of the figurine is just below the shoulder, so the entire figure would have consisted of the head and shoulders (Figure 6-16c).

Trench C, S5. A clock gear.

\section{Jones Site (41BX939)}

Trench D, S3. A clock gear.

Trench D, S5. An unglazed porcelain figurine fragment representing a dog house and three dogs. The figure is three dimensional but somewhat flattened and is $3.9 \mathrm{~cm}$ tall (Figure 6-13h).

\section{Houston Site (41BX941)}

Trench D, S10. A circular glass lens with one flat side and one convex side. This is probably part of a telescope rather than a hand-held magnifying glass. It is $5.2 \mathrm{~cm}$ in diameter.

\section{Runge Rental Site (41BX944)}

Fence Cut. A figurine fragment in the shape of an anthropomorphized pig face. The eyebrow, eyelashes on the closed eyes, snout, and cheeks are handpainted. This is probably from a "piggy" bank (Figure 6-16d).

\section{Pauly Site (41BX945)}

Pauly Privy, N1/2, Level 6. A fragment of a ceramic figurine with a green glaze.

Monitoring. A base of a figurine made from undecorated whiteware.

\section{Conclusions}

Cultures are systems. Each aspect of a culture interacts with all other aspects, forming a constantly changing, yet dynamically stable framework within which each human lives his/her life. Changes in a single aspect of the system bring changes in all aspects. A project of the scope of the Alamodome, both in physical size, and in duration of habitation, offers insights into the ways in which the changing technology of the late nineteenth and the twentieth century have affected the lives and the culture of ordinary Americans. The archaeological record makes clear that, during the period under examination in the Alamodome project, the working- 


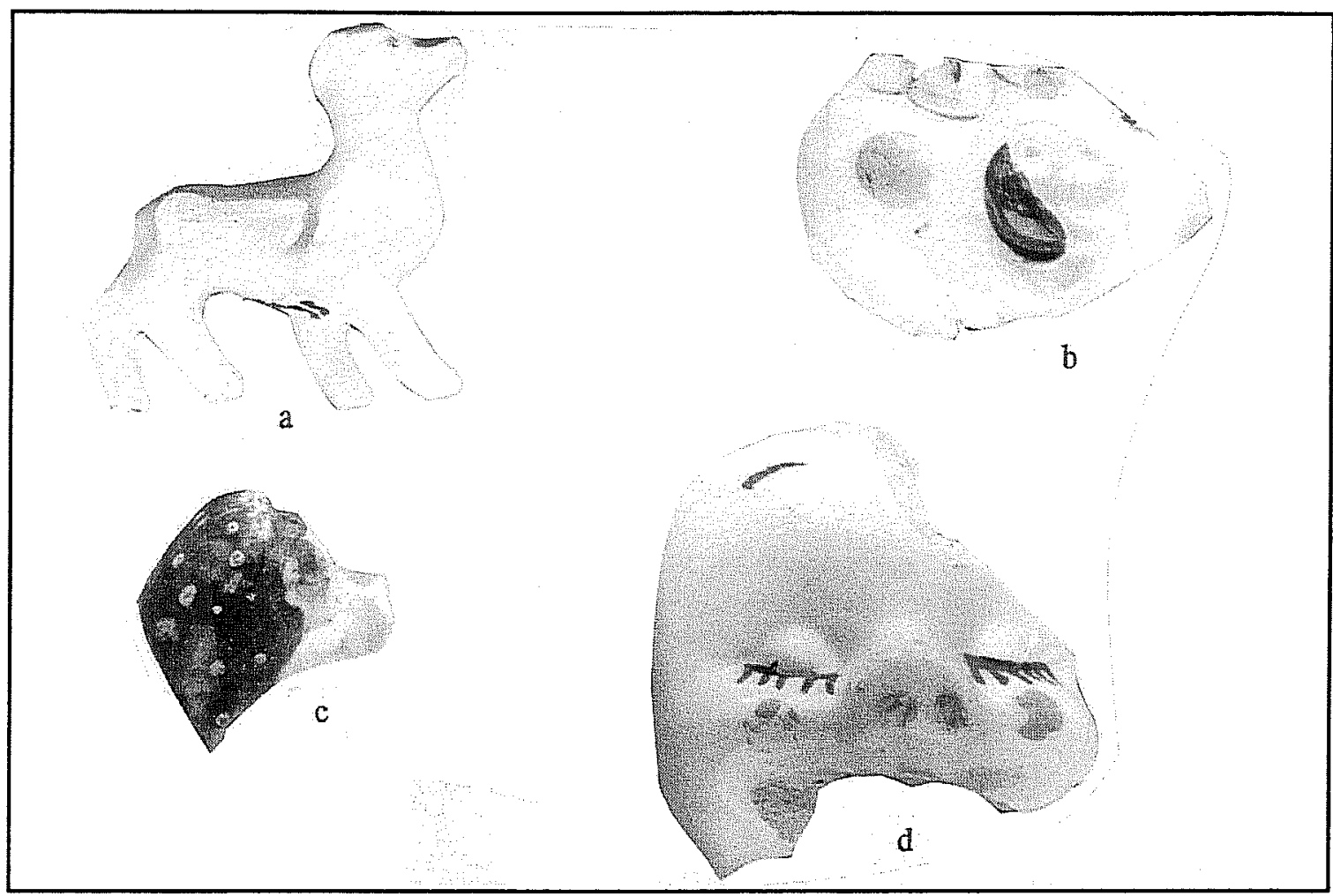

Figure 6-16. Miscellaneous personal items from the Alamodome Project. All shown actual size.

class people of San Antonio underwent remarkable changes in material culture. Thes changes occur not just in the materials available, such as plastics, but also in what was manufactured and who had access to it. These transformations are evident in the archaeological record of personal items found at the Alamodome sites. Hand- or locally made items in the older proveniences gave way to manufactured items in the later areas.

The social changes which reflect these changes in technology are also very evident at the Alamodome. Changes in fashion, especially in jewelry and cosmetics can be seen. Jewelry, which was, in effect, not available to the women living in the Alamodome area until after World War I, became easily available, at least in the form of costume jewelry, after World War II. Cosmetics, evidence for which is slight to nonexistent in the oldest contexts, became commonplace in contexts dating after World War I.

Perhaps most notably there is a distinctive increase in the number of different kinds of personal items in use in the area. A comb, a few hat pins, a toothbrush, a small trinket, a slate and slate pencil, or a small bone implement are the extent of early personal items found in the archaeological record. Later, many kindsof items are found, including cheaply made cufflinks and false pearls, denture adhesive and dental floss, safety razors, automatic pencils, and figurines made in Japan. The push to sell a greater variety of itmes to more and more people is reflected in the Sears catalogs. Cohn (1940:275-276) notes that dentifrices sold in the 1905 Sears catalog were advertised as mere aids to clean teeth. By 1934 toothpaste was advertised as a necessity to provide the user with success in social and business life. By this time, success in social and business life became hostage, if one believed advertisers, to a large number of other new necessities as well. The workingclass people of San Antonio were no longer the isolated inhabitants of a frontier town. The people who inhabited the "quiet, agrarian, easygoing America of 1905" (Cohn 1940:1) had become full-fledged members of the consumer culture, bolstered by the technology of the twentieth century, participating in an increasingly international market.

It has been said that "the modern industrial machine has delivered two products-goods and leisure" (Neumeyer and Neumeyer 1936:19). The general 
trend toward increases in per capita income (Smelser 1976:136), paralleling the improvement in transportation, allowed the purchase of these goods by San Antonians. In the Alamodome area, we see this influx of consumer goods and (by implication) the surplus income available to buy them, even among the working poor. It is in the area of personal items that this surplus is most notable, because so many of the items in this category are not necessities-except perhaps in the minds of the people who bought them.

Cohn, in his analysis of America between 1905 and 1935 , as seen through the Sears catalogs, wrote, "all the chapters in this book are bound together by a single thread running through them-the thread of change" (Cohn 1940:1). This thread of change can also be seen in archaeological record at the Alamodome. 


\section{References Cited}

Albert, L. S., and K. Kent

1949 The Complete Button Book. Appledore, Stratford, Connecticut.

Angione, G.

1973 All Bisque and Half-Bisque Dolls. Thomas Nelson, Nashville.

Blum, S. (editor)

1974 Victorian Fashions \& Costumes from Harper's Bazaar: 1867-1898. Dover, New York.

1969 Catalogue No. 57 Montgomery Ward \& Co.: Catalogue and Buyers' Guide, Spring \& Summer 1895. Dover, New York.

Cohn, D. L.

1940 The Good Old Days: A History of American Moral and Manners as seen through the Sears, Roebuck Catalogs, 1905 to the Present. Simon and Schuster, New York.

Collier, J.

1988 The Official Identification and Price Guide to Antique and Modern Dolls. 4th edition. Ballentine, New York.

Cunnington, C. W., and P. Cunnington

1970 Handbook of English Costume in the Nineteenth Century. Plays, Boston.

Encyclopedia Americana

1957 The 1957 edition, vol. III. Americana, New York.

Evans, J.

1970 A History of Jewelry 1100-1870. Faber and Faber, London.

Harpur, P. (editor)

1982 The Timetable of Technology: A Record of the 20th Century's Amazing Achievements. Hearst, New York.

Herment, G.

1957 The Pipe: A Serious Yet Diverting Treatise On The History Of The Pipe And All Its Appurtenances, As Well As a Factual Withal Philosophical Discussion Of The Pleasurable Att Of Selecting Pipes, Smoking, And Caring For Them, translated by A. L. Hayward. Simon and Schuster, New York.

Israel, F. L. (editor)

19681897 Sears, Roebuck Catalog. Chelsea House, New York.

Kavanaugh, J. V.

1978 The Artifact in American Culture: The Development of an Undergraduate Program in American Studies. In Material Culture and the Study of American Life, edited by I. M. G. Quimby. Norton, New York.

Kubler, G.

1962 The Shape of Time: Remarks on the History of Things. Yale University Press, New Haven. 
Lewis, $\mathrm{S}$.

1940 Introduction. In The Good Old Days: a History of American Moral and Manners as seen through the Sears, Roebuck Catalogs, 1905 to the Present, by D. L. Cohn. Simon and Schuster, New York.

Mansfield, A., and P. Cunnington

1973 Handbook of English Costume in the Twentieth Century, 1900-1950. Plays, Boston.

Mirken, A. (editor)

19701927 Edition of the Sears, Roebuck Catalogue: The Roaring Twenties. Bounty, New York.

Neumeyer, M. H., and E. S. Neumeyer

1936 Leisure and Recreation: a Study of Leisure and Recreation in Their Sociological Aspects. Barnes, New York.

Pike, M.

1984 In Memory Of: Artifacts Relating to Mourning in Nineteenth Century America. In American Material Culture: The Shape of Things Around Us, edited by E. Mayo. Bowling Green State University Popular Press, Bowling Green, Ohio.

Sears Roebuck

19691902 Edition of The Sears, Roebuck Catalogue. Bounty, New York.

Smelser, N.

1976 The Sociology of Economic Life. Second edition. Prentice Hall, Englewood Cliffs, New Jersey.

Stirn, C. P.

1990 Tum-of-the-Century Dolls, Toys, and Games: The Complete Illustrated Carl P. Stim Catalog from 1893. Dover, New York.

Sudbury, B.

1979 Historic Clay Pipemakers in the United States of America. In The Archaeology of the Clay Tobacco Pipe, Vol. 2: The United States of America, edited by P. Davey. BAR International Series \#60, Oxford.

Tait, H. (editor)

1987 Jewelry 7000 Years: An International History and Illustrated Survey from the Collections of the British Museum. Harry N. Abrams, New York.

Webster's Dictionary

1983 Webster's New Universal Anabridged Dictionary. Deluxe second edition. Simon and Schuster, New York.

Williams, $\mathrm{N}$.

1957 Powder and Paint: A History of the English-Woman's Toilet, Elizabeth I-Elizabeth II. Longmans, London. 


\title{
Chapter 7 Kitchen Utensils and Tablewares
}

\author{
Mary Vaughan
}

\section{Introduction}

This chapter deals with selected metal objects used in the kitchen and dining room. Some of them are only a part of the whole object, which also included perishable parts not preserved in the archaeological sites such as wooden knife handles. These types of objects are particularly common on twentieth-century sites, since it was really in the early twentieth-century that metal began to dominate kitchen and household utensils. These changes were part of a larger picture taking place around that time, as summarized by Miller (1987:47).

Between 1830 and 1920 a technological revolution occurred in the American kitchen which completely restructured its physical character and the type and number of utensils it contained. Within this period, women working in the home witnessed the introduction of new materials such as aluminum, new methods of storage such as refrigeration, new sources of power such as gas and electricity, and new forms of food preservation and distribution such as canning and home delivery of milk in glass containers.

The change from cast or hand-forged utensils to lighter-weight, mass-produced ones-brought about by the invention of rapidly moving machine parts-resulted in the invention of the factory. This and the replacement of water power by steam engines brought about a change in attitude and a cultural orientation toward technology among the American public.
Many of these changes are reflected in the following descriptions of the evolution of familiar household objects. Careful observation of something so common as a bottle cap or the broken handle of a spoon or fork can often reveal the date that object was in use and, therefore, the date of a particular archaeological deposit. Much of the detailed dating information for these objects has not been commonly known. For this reason, we decided to pursue it for this project. Numerous telephone calls, letters, and personal interviews have produced an accumulation of facts about the invention, evolution, and methods of production of common household objects found in nineteenth and twentieth century archaeological sites.

\section{The History of Food Preservation}

Long ago people discovered that certain spices helped keep food from spoiling. This is one reason why spices were highly valued during the Middle Ages. The longterm preserving power of spices was not, however, very great.

It was then discovered that very sweet substances would not spoil easily. Ultimately, this was responsible for the early success in the preservation of jams, jellies, marmalades, fruit conserves, and even sweetened condensed milk. Whole fruits were sometimes boiled in sugar syrup, which prevented their decay (The Book of Knowledge 1957:2174). Pickling was another way of preserving. People learned to make grape wines and apple ciders, knowing that both can turn sour and become vinegar. It is not known when they learned that this vinegar 
would preserve food (The Book of Knowledge 1957:2173).

Spoiled foods caused Napoleon Bonaparte great distress due to the number of troops he was losing due to food poisoning. Wanting a swift solution, he offered 1,200 francs as a reward and challenged the scientific community to come up with a method for preserving food (Pet, Inc. 1985:6).

Coincidentally, Nicolas Appert, a French scientist, was experimenting with food preservation techniques about this same time. He was a native of the champagne country and had been intrigued by the fact that corked bottles could preserve expensive wines indefinitely (Pet, Inc. 1985:7). He tried putting vegetables and meats in glass bottles (cans were at this time unknown), sealing them with corks and wires, and boiling them in water (Busch 1981:95-96), and, eventually, he was able to perfect the timing. In 1809 , Appert was awarded the prize of 1,200 francs for his discoveries. Regardless of the success in preserving foods by heating them in sealed glass jars, he incorrectly assumed that the food was preserved because of the absence of air (The Illustrated Encyclopedia of Science and Technology 1977(4): 1034). It was not until Pasteur's experiments with fermentation about 50 years later that scientists understood that the reason that Appert's method was not entirely successful was because of the continued presence of microorganisms in the containers (The Encyclopedia Americana 1957[5]:508).

Time periods in which various types of cans were being made are described as follows by Maxwell (1993:97-110):

Pre-World War II Era: punch-top cans and containers opened with a can punch, and cone-top cans with crown caps.

The World War II Era: production ceased in 1942, resumed in 1947, no change in basic design.

The 1950s: demise of cone tops and containers, aluminum began to be used.

The 1960s: pop-top or tab-top self-opening device was invented and became almost universal.
The 1970s: pull-rings introduced, anti-littering pressure forced abandonment of these and tab tops, resulting in the invention of stay-tab devices that stayed with the can, in a number of different designs.

\section{Beverage Containers}

The soda water industry began in the early 1800 s with the discovery of carbonated water and the subsequent bottling of this on a large scale in the 1830 s. About 10 years later, a Philadelphia perfume dealer began to add flavors to the soda water and the idea quickly caught on (Munsey 1970:103).

The first containers used for soda water were glass bottles closed with corks wired to the bottle neck to contain the internal pressure of the contents. Various types of stoppers were developed during the last 20 years of the nineteenth century to replace corks. The most popular type, the Hutchinson stopper, consisted of a rubber gasket between two metal plates attached to a spring wire stem which was held in place by the pressure of the carbonation (Munsey 1970:104).

In 1891, William Painter of Baltimore patented the crown cork, which required uniformity in the forming of the bottle lip, something seldom possible in the bottles then available. It was not until the invention of the Owens automatic bottle-making machine in 1903 that crown caps became the most popular bottle closure. Corks were then rapidly replaced by crown cap closures on many bottled products and all internal closures were declared unsanitary (Munsey 1970:105). The crown cap continues to the present day as the most inexpensive and efficient solution to the storage of carbonated beverages and beer.

\section{Tin Can Canning}

It was in 1825 that New York seafood canner Thomas Kensett was granted a U.S. patent for preserving foods in tin vessels. However, the first recorded use was in 1839 , when he switched to tin due to the rising price of glass. Tinned canneries began spreading as one opened in Baltimore during 1840 and sardine canning began in Eastport, Maine in 1841 (Busch 1981:96). The Underwood Company continued to bottle most of its 
products until 1846, when lobster canning began at branch plants in Maine (Switzer 1974:78).

These first cans could be cylindrical, flat and rectangular, or oval in shape (Franklin 1976:32), with straight or tapered sides (The Illustrated Encyclopedia of Science and Technology 1977[4]:445). In the beginning, the output for cans was five to six an hour because each one was handmade. The style known as hole-in-top (Figure 7-1a) remained the same whether handmade or mechanically produced. Small pieces of food were pushed through a hole in the top of the can before a cap with a little vent hole was soldered over this opening. After the filled can was heated, the vent hole was closed with a drop of solder (Busch 1981:96). This method of closure was in use until the $1900 \mathrm{~s}$ (Fontana and Greenleaf 1962:69).

Like Appert, Gail Borden also suffered a failure in preserving milk in 1853 . His patent for "producing concentrated sweet milk by evaporation in vacuo, the same having no sugar or foreign matter mixed with it" (Busch 1981:96) was rejected. Finally, a patent was granted in 1856, but this was for vacuum-processed canned sweetened condensed milk (Busch 1981:96). The milk would not keep unless large amounts of sugar were added, similar to the way jams and jellies are preserved (Pet, Inc. 1985:7).

Borden opened his first permanent factory at Wassaic, New York, in 1861, two months after the outbreak of the Civil War. "The United States Government immediately commandeered its output for the army" (Clark 1949:33) and the navy. During the war, canned foods-including milk-were used extensively for soldier rations (Busch 1981:97). The soldiers confined at times to a makeshift diet in the field, plus the soldiers recovering in hospitals, created the perfect market for condensed milk (Clark 1949:33). Borden's milk was credited with saving Union lives and for convincing the public that canned foods were safe (Busch 1981:97).

The war also stimulated the canning of fruits and vegetables (Clark 1949:33). The greater demand for canned goods served as an impetus for improved can mechanization. By the 1870 s, factories could make 60 cans per hour. In 1883, all the processes of can making could be done by machine and the peak can production was 2,500 cans per hour.
Housewives soon learned that cans emptied of their original contents could be used for other purposes. Cans with replaceable lids (Figure 7-1b) made to contain lard and other cooking ingredients were adapted as lunch pails for schoolchildren or containers for workshop items such as nails and screws.

The soldered hole-in-top can changed little through most of the nineteenth century. Developments in the late 1890 s and early 1900 s resulted in the open-top or sanitary can (Figure 7-1c) (Busch 1981:97). This type was considered sanitary because it was soldered on the outside only. Since the end was not attached until after the can was filled, larger pieces of food could be canned. Therefore, by the early 1920 s, the sanitary can was generally accepted and virtually replaced other food can types (Busch 1981:98).

With World War I, the American government again placed huge orders of canned milk and foodstuffs for the troops overseas. The war also made demands on the materials the canning companies needed in order to operate. Tin became scarce and what was available was of poor quality. During the World War II, shortages of labor, materials, overseas shipments, and war-time food rationing affected the canning business. Only essential food items could be packed and many companies were limited to single products only. After the war, the government immediately lifted the canning restrictions.

\section{The Marketing of Beer and Soda Water}

Meanwhile, brewers had been experimenting to overcome weaknesses in can design and problems with the reaction of beer to metal. In 1935 the first 12-ounce cans of beer had been put on the market and by the end of the year, 18 breweries were canning beer (Maxwell $1993: 95,96)$. In an analysis of the history of the manufacturing of beer cans, Maxwell (1993:95-113) describes the evolution of the beer can from this time forward. For the purposes of this report, we deal primarily with the problems of closures design, their evolution, and, therefore, the implications for dating archaeological deposits. 


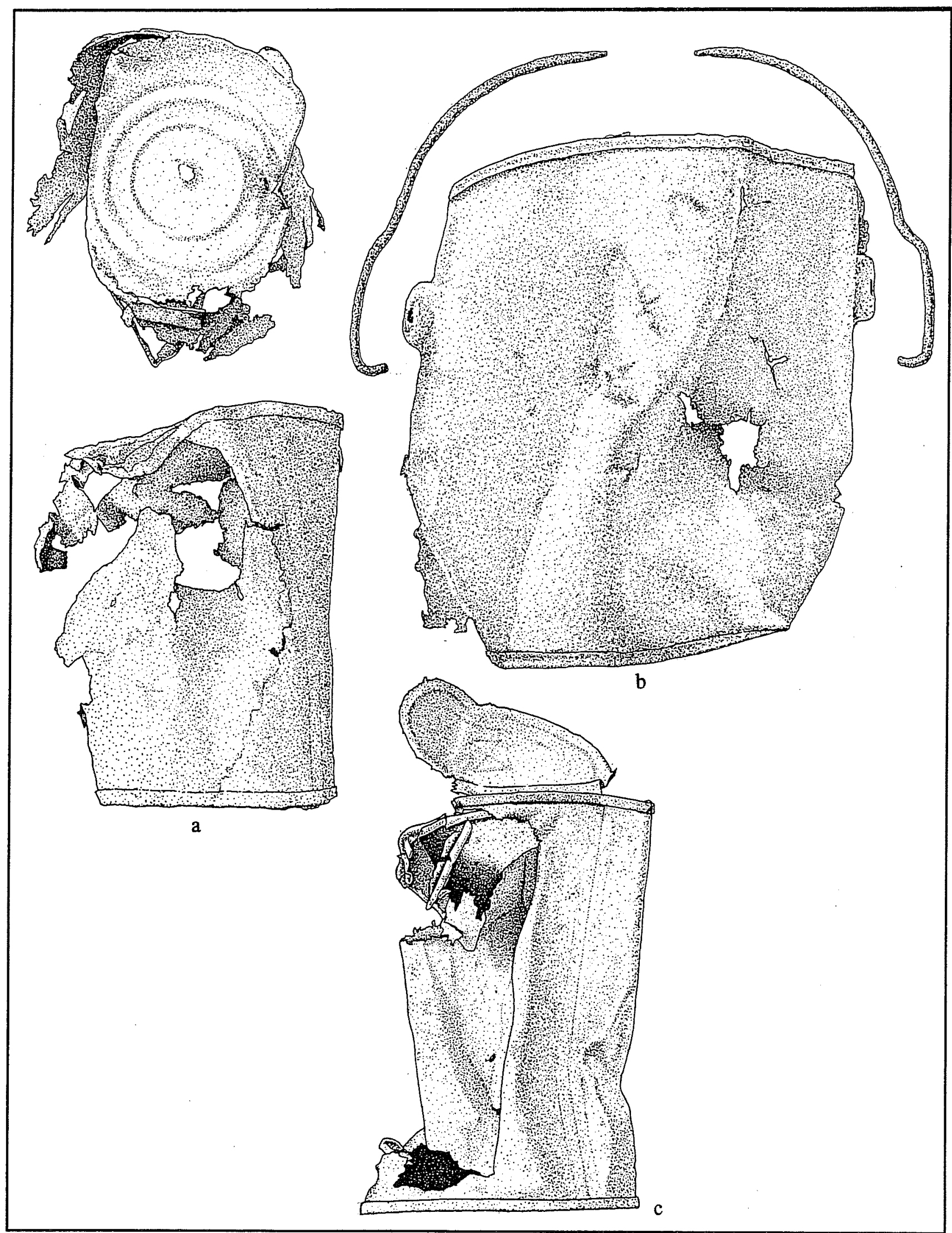

Figure 7-1. Metal can types. a: hole-in-top can; b: lard or paint can; c: open-top or sanitary can. Shown approximately half size. 


\section{Methods of Opening Containers}

The only site where metal cans were preserved sufficiently to be identifiable was beneath the Garza store, where they were kept dry and protected. Fortunately for this report, one can of each type may be illustrated from this location (Figure 7-1). Much more likely to survive in urban sites are the remains of closures and the instruments used to open cans and bottles. The following discussion describes the methods used for opening different types of containers, the tools used for this purpose, and the remains of bottle and can closures, many of which can be used to approximate the dates of a deposit within a site.

\section{Can Keys}

Some types of cans lend themselves to opening with a can key-a key-shaped instrument designed to remove a strip of the can metal in such a way as to access the contents of the can. These come attached to the can and are immediately available rather than requiring a separate gadget such as a can opener to open the can. Can keys were at first a selling point for merchants. In 1897, the Sears, Roebuck Catalogue specified which sardine cans had keys and charged two cents more per can for the convenience (Israel 1968:14).

Can keys have traditionally been made of "pot-metal" (Gene Goodrich of Crown Cork and Seal Company, personal communication 1993). The term pot-metal means that the metals used could be copper and lead or perhaps iron (Webster's New Universal Unabridged Dictionary 1983:1410). Keys were either galvanized or tin-coated. The small keys were used only on one- to three-pound shortening cans and similar-sized coffee cans. The larger keys were used exclusively on cans containing meats such as corned beef, ham, Spam, etc. (Gene Goodrich, personal communication 1993). Cans of meats must be heated to $121^{\circ}$ centigrade $\left(250^{\circ}\right.$ Fahrenheit) for three minutes, in order to kill the bacteria causing botulism in such low-acid foods (The Illustrated Encyclopedia of Science and Technology 1977: 1034). These cans must be of very heavy, rigid metal because of the internal pressure from such intense heating. Therefore, cans of meat require a longer can key for that extra leverage necessary in opening the extra-rigid metal can.
Can Keys Recovered from the Alamodome Project

Fifteen can keys were recovered from six sites. Two other sites had only the rolled-up strip of metal which remained from the opening process. All of these examples have rusted and a few are distorted from corrosion (Figures 7-2 and 7-3). The most common key is the longest type. It is about $3^{5} / 8$ inches long. There are six of these keys, and they come from only two sites, 41BX893 and 41BX884 (Figure 7-2a-c). These long keys are the same strip-type can opener that was recovered at Fort Bowie in Arizona (Herskovitz 1978:74). The Fort Bowie material collection represents the years 1862 through 1894 .

Three shorter keys are similar only because they all have small, flattened oval heads (Figure 7-3a-I). The shortest one comes from 41BX893 and is $13 / 16$ inches long. The next key, from 41BX938, measures $1 \% 16$ inches in length. A third key comes from 41BX939 and measures about $1 \frac{5}{8}$ inches in length, which is somewhat longer than the actual key due to the metal strip still attached to the key.

\section{Corkscrews}

The earliest type of stopper or plug for bottles was the cork (Ferraro and Ferraro 1966:32). It is not known when cork was first used as a closure on bottles and other containers (Munsey 1970:60); however, the ancient Greeks and Romans used corks and other similar substances in their earthenware jugs and glass containers. By the sixteenth century, the cork was firmly established as a closure. Structurally, cork is an elastic mass of lifeless cells from tree bark containing a substance which makes it practically impervious to water. Its light weight and flexibility are due to its composition being mostly thin-walled cells filled with air (Munsey 1970:60).

The main disadvantage of using cork was the time and trouble it took to remove it from the bottle, which resulted in the invention of the corkscrew (Ferraro and Ferraro 1966:34). The first United States patent for a corkscrew was granted in 1860 (Franklin 1976:59). Basically, a corkscrew consists of a cast steel spiral- or convex-twist screw with a sharp point and some sort of handle. The handle is usually $T$-shaped and transverse, 


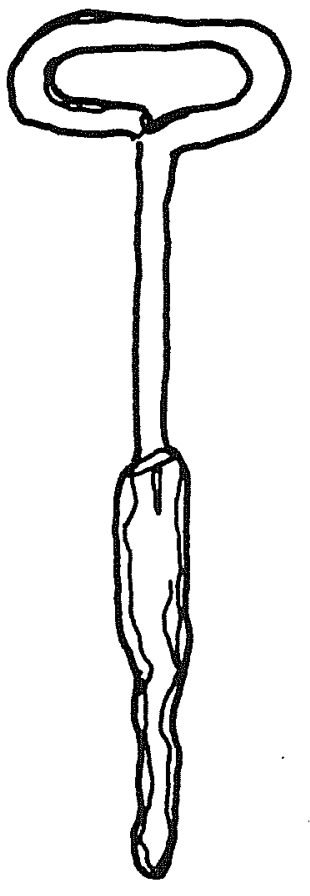

a
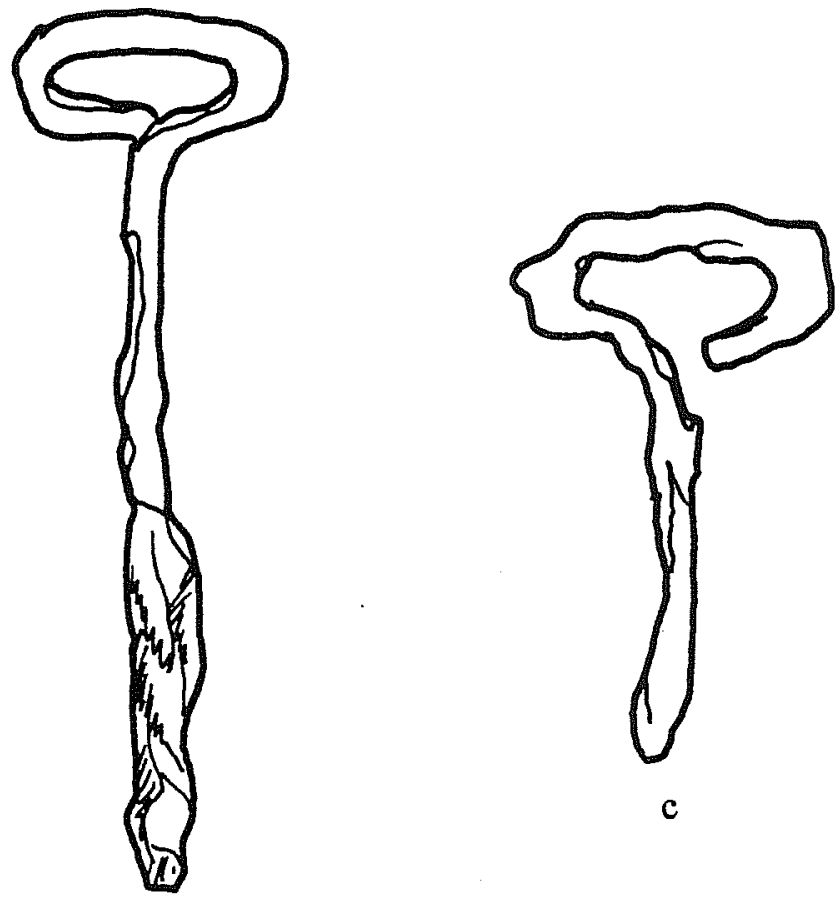

c

Figure 7-2. Large can keys. a: 41BX884; b, c: 41BX893. All shown actual size.

although handles of other types such as a ring or hoop are also common (Franklin 1976:59).

\section{Corkscrews Recovered from the Alamodome Project}

Portions of eight cast steel corkscrews were recovered from two Alamodome sites. Seven of these come from 41BX891 (Figure 7-4a, b), the Horn Site. All seven have a spiral coil screw (Illustrated Catalogue of the Russell and Erwin Manufacturing Company 1980:377). An 1880 catalogue from Whitall, Tatum and Company (1971 [1880]:69) sold these, calling them wire cork rings. The Horn Site collection consists of six small rings, of which only two are complete, measuring $15 \%$ inches long. They are too small for an average index finger to insert easily, requiring the index finger and thumb to grasp the outer edge of the ring. The larger one, $25 \%$ inches long, has a heavier gauge of wire cast in a double loop or ring for a handle.
The other corkscrew (Figure 7-4c) was recovered from 41BX897, the Webb site. The handle on this one is T-shaped and its overall length is $31 / 2$ inches. This is a convex-twist corkscrew with a solid metal handle. In 1865 , a cast steel corkscrew with a convex twist was available from the Illustrated Catalogue of the Russell and Erwin Manufacturing Company (1980:377) (Figure 7-4d).

\section{The Punch-top Can Opener}

The punch-top can opener became necessary with the introduction of canned beer in 1935 (Martels 1977:43). This first type of beer can was called "punch-top" or "flat-top" and was so named because its flat top required a punch opener (Maxwell 1993:97). Cans made in the 1930s and early 1940s were very substantial and heavy (Martels 1977:33). During these early years the concept of canned beer was still unfamiliar to a great many customers. Therefore, the 


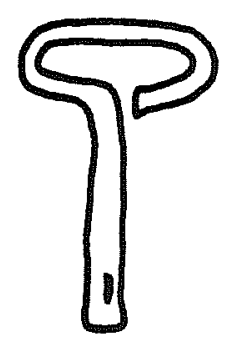

a
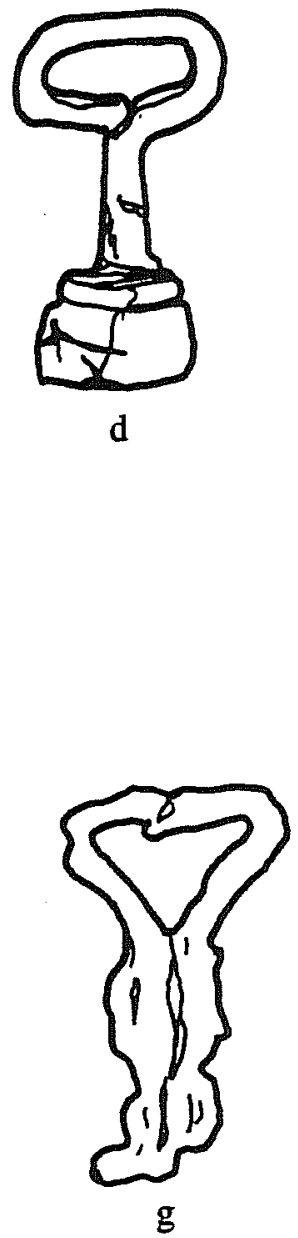

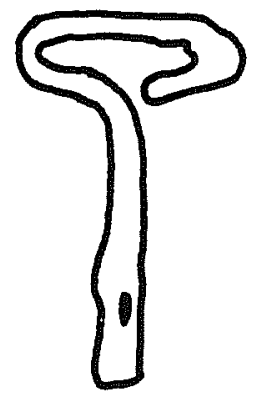

b
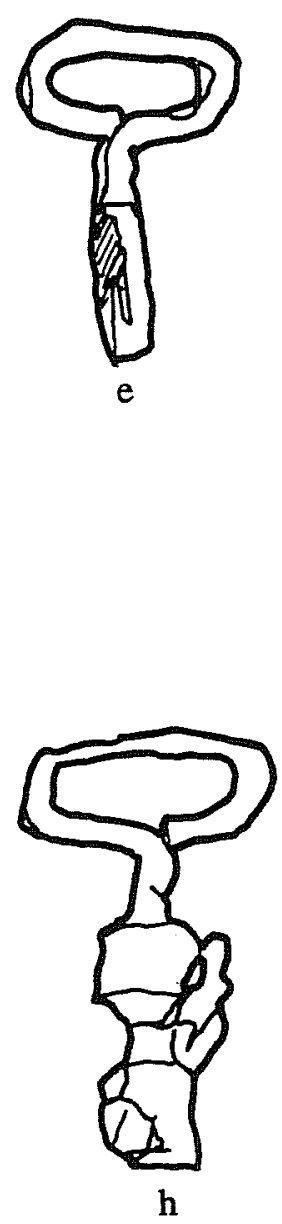

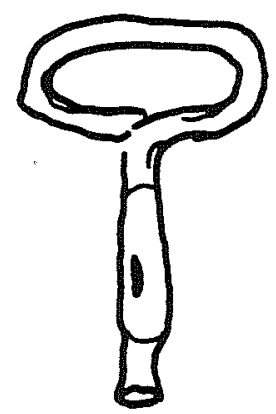

c
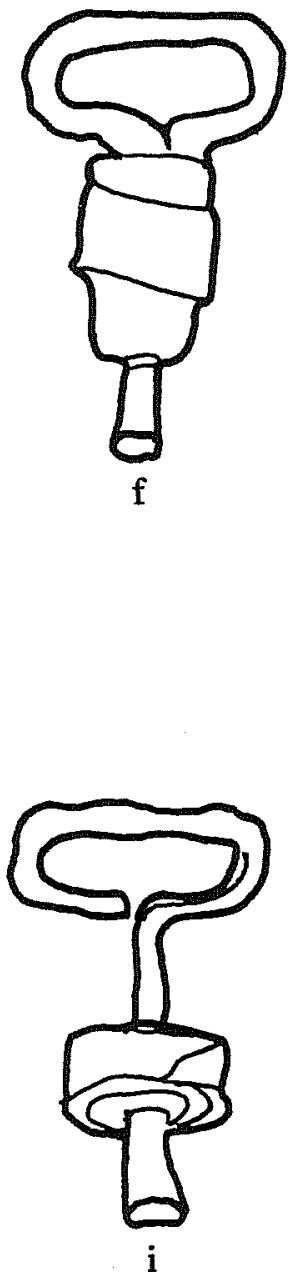

Figure 7-3. Small can keys from the Alamodome Project. a: 41BX893; b: 41BX938; c: 41BX896; d, e: 41BX884; f: 41BX896; g: 41BX931; h, i: 41BX896. All shown actual size. 


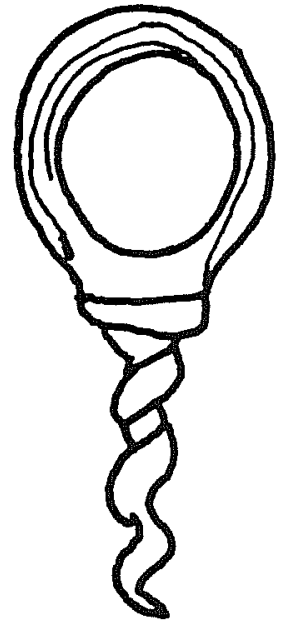

a

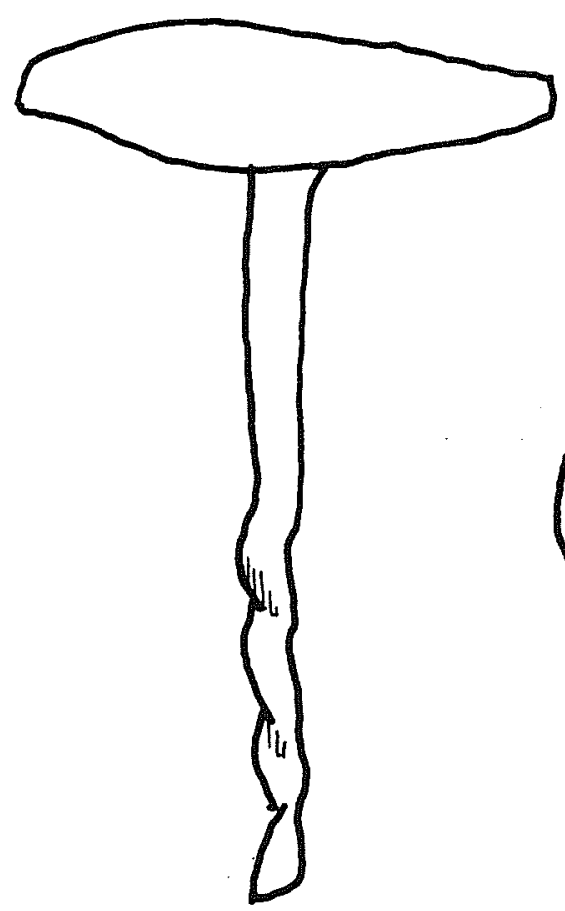

b

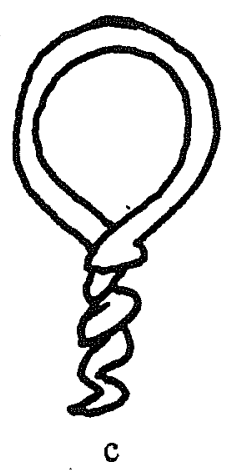

$\mathrm{c}$

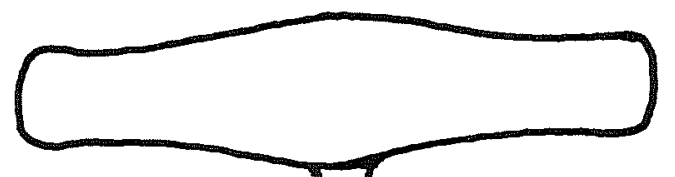

Figure 7-4. Corkscrews from the Alamodome Project. All shown actual size.

early punch-top cans usually had opening instructions and diagrams along the seam of each can (Maxwell 1993:100).

As time passed and pasteurizing pressures were reduced through improved methods of brewing, the need for heavier steel cans was eliminated. The body and lid-tops became progressively thinner and lighter until finally, in the late 1950 s and early 1960 s, beer can engineers put an aluminum top on a steel can body. This soon led to the pull-tab and by 1965, 70 percent of all canned beer featured pull-tab tops (Maxwell 1993:105) eliminating the need for an opener.

The first openers carried imprinted advertisements of brand names. As liquor stores sold beer, they would pass out an opener (Martels 1977:43). The first opener was $5 \frac{1}{2}$ inches long by $3 / 4$ of an inch wide and almost
$1 / 8$ of an inch thick. It was imprinted "QUICK AND EASY OPENER" and "PAT. PENDING" (Martels 1977:43). The second version of this opener had a puncturing blade about 18 inches shorter than the first models. Punch-top openers continued to shrink in size with each modification of the can design.

The punch-top opener was designed with a hole-punching blade on one end and a lifter on the other for removing crown caps (Martels 1977:45). This versatile tool continues to be popular today in lighter-weight versions. Once the need for punching a hole in the can had disappeared, a lighter version appeared for opening bottles only. However, both designs are still presently in use. Various businesses besides beer manufacturers have taken advantage of the opportunity to print advertising on either face of these objects. 
Punch-tops Recovered From the Alamodome Project

The openers illustrated in Figures 7-5 and 7-6 demonstrate the variety in design of these objects and the fact that they can be found almost anywhere in urban areas. As more work is done on twentieth century sites, it appears that openers may play a role in dating deposits, using the gradual changes in size in reaction to the changes in can weight and closure design.

\section{Crown Caps}

Although there were 150 patents for the various types of stoppers available to the soft drink industry in 1885 , none were totally satisfactory. Some allowed carbonation to escape, others allowed the beverage to contact the cap altering the flavor. Still others were made of rubber which deteriorated on contact with the product (Crown Cork and Seal 1991:11).

In that same year, William Painter of Baltimore invented the bottle seal, a flat rubber disk with an impermeable canvas facing which was pushed down inside the bottle neck into a retaining groove. In the groove it expanded to form a tight seal (Crown Cork and Seal 1991:11). Painter continued to improve upon his patent for six years and, in 1892, patented the Crown Cork (Table 7-1). This was a metal cap with a corrugated flange lined with a cork disk and specially prepared paper to prevent the contents of the bottle from contacting the metal (Crown Cork and Seal 1991:11).
In 1913 an economical substitute for imported cork was invented by Charles McManus. The seal made from this material was lacquered, resulting in what was called the "Nepro" process (Crown Cork and Seal 1991:16).

Prohibition in 1819 struck a devastating blow to the bottling business. Up to that time, the greatest volume of business for the crown cap industry had been derived from beer. The only breweries to survive did so because they switched to soft drink bottling (Crown Cork and Seal 1991:14).

During Prohibition, the bottlers were also suffering because people did not return the bottles for refilling, but kept them to make home-made beer (Busch 1981:71), thus causing a shortage of bottles. However, by 1927 the public could order home bottling supplies from Sears, Roebuck and Company, which offered the bottles, bottle caps, and several varieties of bottle capping machines (Mirkin 1970:978). The homemaker was then able to fill these bottles with ketchup, sauces, corn beer, root beer, and fruit wines (Busch 1981:71).

In 1930 McManus introduced the "spot crown," an improved crown cap lined with tin foil for beverages incompatible with cork. Beer in particular reacted with the cork in such a way that it became discolored and undrinkable (Maxwell 1993:95). Spot crowns were used on near-beers in the United States until the end of Prohibition in 1933 and the revival of the beer industry, then continued in use until, in 1937, McManus's Baltimore plant was producing $103,680,000$ crown caps a day (Crown Cork and Seal 1991:17).

Table 7-1. The Evolution of the Crown Cap

$\begin{array}{ll}1892 & \text { Crown cork patented } \\ 1912 & \text { Hutchinson stoppers going out of use } \\ 1913 & \text { "Nepro" process invented, lacquered cork seal } \\ 1920 & \text { Prohibition effectively started } \\ 1921 & \text { breweries switched to soft drinks } \\ 1922 & \text { severe bottle shortages } \\ 1927 & \text { shortages eased } \\ 1930 & \text { "Spot crown" lined with tin foil invented } \\ 1933 & \text { end of Prohibition } \\ 1941-1946 & \text { World War II, crown cap shortages, recycling } \\ 1958-1962 & \text { plastic inner seal replaced cork and tin-foil seals } \\ 1969 & \text { "Sure-twist" and "Sure-seal" crowns invented }\end{array}$



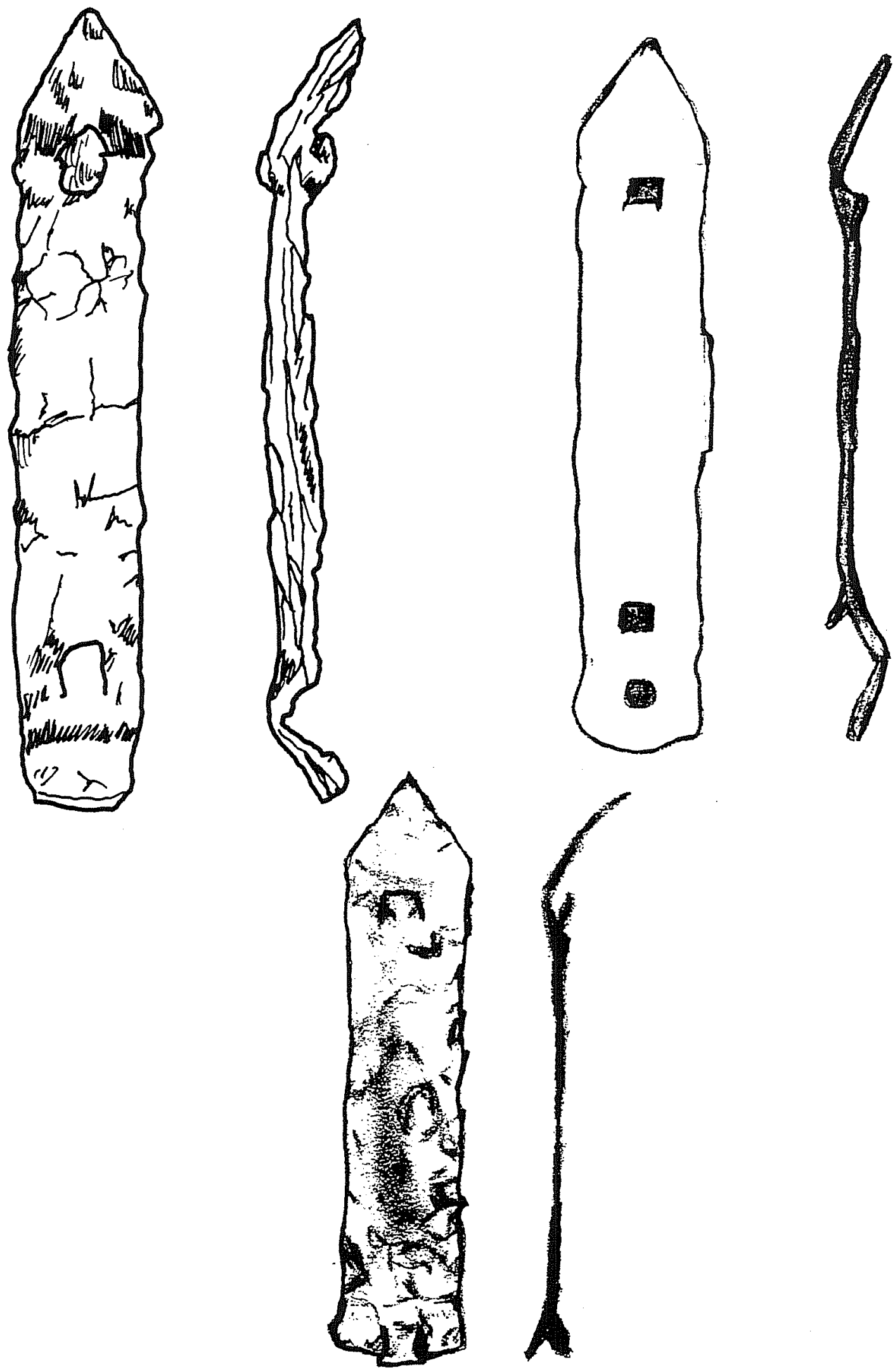

Figure 7-5. Punch-top openers from the Alamodome Project. All shown actual size. 

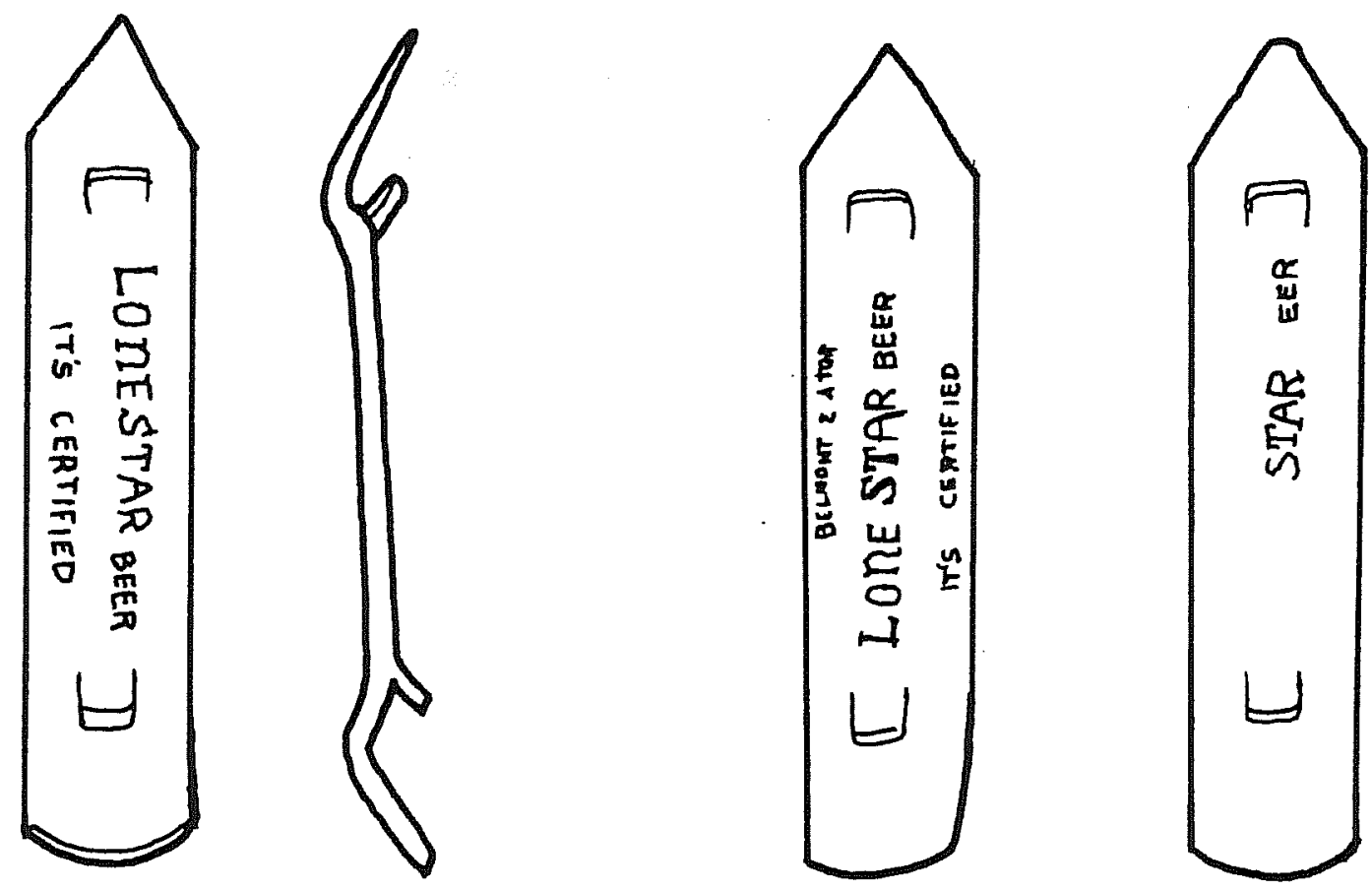

Figure 7-6. Late punch-type openers from the Alamodome Project. All shown actual size.

The entry of the United States into the World War II altered crown cap production. Tin and steel normally used for crown caps went for manufacture of war material (Crown Cork and Seal 1991:18). Crown caps were still being produced, but at a greatly reduced rate (Gene Goodrich, personal communication 1993).

The growth of local San Antonio bottlers halted during the war. One company, the Lone Star Brewery, had a program encouraging customers to save their crown caps, which were then picked up at several locations by delivery trucks for recycling (History of Lone Star Brewing Company 1993). Crown corks were recycled up to three times during those years. The original cork was retained and fluffed as the caps passed through a process of straightening and cleaning. The crown cap at this point had lost its paint. Some bottlers repainted them, others did not (Harold Jansing, former owner of Barq's Root Beer and Big Red Bottling Plant, San Antonio, personal communication 1993).

In 1958, plastic seals replaced both the cork and tin-foil seals in crown corks and spot crowns. This allowed the same crown to be used both for beer and for soft drinks. By the 1960s, all San Antonio bottlers had exhausted their old inventories and made the change. On the national level, Coca Cola had completed the switch by 1962 (Coca Cola Consumer Information Center, Atlanta, personal communication 1993).

The next crown cap innovation happened about 1968. The twist-off crown was developed so that beer drinkers could open a bottle without using a bottle opener. Crown Cork and Seal retailed two versions of this cap in 1969. The first sold was the "Sure-Twist" crown which had all the regular skirt dimensions of the former crowns. Immediately after this came the "Sure-Seal" crown, which had a skirt about ${ }^{1} / 16$ inch shorter. Both of these caps were made from a lighterweight and lighter-temper steel. The softer steel would contour itself onto the bottle when the cap was twisted onto and around the bottle's threaded lip. Since an opener was not necessary, the cap could be removed without bending the metal. However, an opener could also be used, meaning that some of these caps could show evidence of forcible removal (Gene Goodrich, personal communication 1993). 
Crown Caps Recovered From the Alamodome Project

Eight hundred fifty-four crown caps were recovered and analyzed from 24 of the Alamodome Project sites. Whether fragmented or whole, every crown cap was rusted. Some were barely distinguishable, but 14 caps were identifiable by cap color or by product name. Of the total, 320 of the whole and fragmented crowns exhibited cork seal remnants, 31 of which had a whole seal in place. A variety of inner seals gave additional information regarding product type and consumption habits.

Three sites had inner seals but no crown caps. Seven sites had individual inner seals separated from but located adjacent to crown caps. However, two of these seven sites had crowns with attached inner seals and additional orphaned inner seals nearby. Of the 39 orphaned inner seals, the following offer further information:

\section{One Whole Composite Cork Seal}

This seal was in a swollen or very thick condition $(1 / 8$ inch thick). Although composite crown corks became available after World War I, it is doubtful that this cork comes from this earlier period. Perhaps it is a recycled crown cork from the time of World War II when caps were being recycled and the corks "fluffed." Recycling of caps lasted through 1946 in San Antonio and nationally. No new cork was ever applied during reconditioning and many recycled crown caps were applied to beverages with partial cork seals or without any seal at all (Harold Jansing, personal communication 1993).

Thirty-five tin foil spots (inner seals for spot crowns).

Metallic spots are dated from 1930 to 1957. All orphaned spot seals were most definitely capping bottles of beer. However, it has not been established whether spot crowns were available during Prohibition in home-brew kits and/or used by bottlers of nearbeer. A similar lag period of two to five years for breweries to exhaust their spot crown inventories must be considered when dating these seals. It was more than likely 1960 before any brewery started using the plastic inner sealed crown caps that replaced the tin spot.
Three Plastic Seals With Advertising

Three seals can be identified as capping soft drinks because of the product advertising printed on them, "Sprite,", "7-UP-the Un-cola," and "Coke." Sprite was first marketed by Coca Cola in 1961. 7-UP has continuously used their slogan, the Un-Cola, since 1974. The word Coke was first copyrighted in 1940 but was not nationally printed onto plastic seals until their bottlers had exhausted their crown cork supplies in the early $1960 \mathrm{~s}$.

\section{Tablewares}

Knives, in one form or another, have been used for cutting up food resources since prehistoric times. The idea of using forks for eating utensils can be traced back at least as far as seventeenth-century England, where forks were used for carving meat. Spoons of wood, stone, and ivory were used by the early Egyptians. In Greece and Rome, wealthy people used bronze and silver eating utensils (The Book of Knowledge 1957:1305).

The silver fork did not become popular in England until the end of the seventeenth century (Noël Hume 1970:180). Simple designs in silverware, copied from English designs, were made by colonial American silversmiths. Central Texas silversmiths were making handsome silver spoons and forks in the midnineteenth century (Steinfeldt 1973:178-183). However, silver was expensive and until the midnineteenth century, the average American had eating utensils of steel. Steel implements discolored quickly and required energetic scouring to keep them bright (The Book of Knowledge 1957:1306).

\section{Silver Plate}

The technique of welding a layer of silver to a copper base was discovered in Sheffield, England, in the mid-eighteenth century, and from this time Sheffield plate became popular. This was particularly important because it accustomed the general public to using plated silver. Before long, the process of electrolysis was being used for plating white metal with silver, a process still in use today (The Book of Knowledge 1957:1309). 


\section{Sterling Silver}

Absolutely pure silver is too soft to use for tableware. Therefore, a standard alloy of 75 parts copper to 925 parts silver is presently used. This metal alloy is known as sterling. Any piece so marked in Great Britain or the United States must by law contain 925 parts of pure silver to every 1,000 parts of metal (The Book of Knowledge 1957:1306).

\section{Nickel Silver}

Various silver substitutes were invented during the late-nineteenth and early twentieth centuries. The 1927 Sears, Roebuck Catalogue advertised tableware of "nickel silver." This was described as resembling silver but not containing any silver. The advertisement admonished that this tableware "should not be left standing in fatty or acid foods. With proper care it will retain its bright polish indefinitely" (Mirkin 1970:760).

\section{Stainless Steel}

A stainless steel was accidentally invented by Harry Brearley in Sheffield, England, in 1913. Although he was not the first to discover the stainless quality of the alloy (12.7 percent chromium and 0.25 percent carbon), he was the first to make knives from this metal (The Timetable of Technology 1982:41). Content of the stainless steel made in the United States in the past 50 years has been controlled by the Trade Mark Act of 1946. Chromium must be present in percentages ranging from 9 to 16 percent and carbon in percentages not exceeding 7 percent.

\section{Tablewares in San Antonio}

Very few objects that could be called tablewares were used by the earliest San Antonio residents. Simple knives were used for cutting meat, probably primarily in food preparation. Larger knives and tablespoonsized spoons of pewter or other metal alloys have been found in mission areas inhabited by the Franciscan missionaries, but these are few, either because there never were many or because they were valued and treated with care. The Indian and Spanish inhabitants of the town and the missions apparently ate with the traditional tortilla and/or with their fingers. Since meals at this time consisted primarily of soups and stews (Fox 1986), much of their food could have been consumed by drinking from hand-held bowls. Any wooden utensils, which may well have existed, have not survived in the archaeological record.

The first European immigrants in the early nineteenth century brought their traditional steel knives, forks, and spoons and introduced the idea of serving meat and vegetables on a plate. By the time of the settlement of the Alamodome area in the mid-nineteenth century, the San Antonian of the lower or middle class was accustomed to eating with steel utensils, probably purchased individually rather than in sets. Wealthier citizens bought silver spoons made by local silver smiths (Steinfeldt 1973:Plates 196-203). However, it was not until the late-nineteenth century that the average San Antonio family could afford matched sets of silver-plated tablewares such as were advertised in the Sears Roebuck and Montgomery Ward catalogues of the time (Israel 1968; Montgomery Ward and Company 1969). Copies of early silver and silver plate patterns in stainless steel appearing in the mid-twentieth century have since cornered the middle-class market.

The more valuable sterling silver articles that a family might own were carefully guarded and handed down within the family. Therefore, the fact that we seldom find these in archaeological sites does not mean that some were not present among the household's belongings.

Tablewares recovered during the Alamodome excavations are listed in Table 7-2. A representative sample of these artifacts is illustrated in Figures 7-7 through 7-10. The illustrations are keyed to Table 7-2. 
Table 7-2. Identifiable Tablewares Recovered During the Alamodome Project

\begin{tabular}{|c|c|c|c|}
\hline Site & Description & Figure \# & Notes \\
\hline $41 B X 881$ & knife & & rat-tail tang, steel \\
\hline $41 B \times 882$ & tablespoon & $7-7 \mathrm{a}$ & $\begin{array}{l}\text { "Simeon L \& George H. Rogers Stainless knives were used for } \\
\text { cutting meat, probably table- }\end{array}$ \\
\hline 41BX884 & fork & & full-flat tang, wooden handle, 3 tines ${ }^{1}$ \\
\hline 41BX891 & teaspoon & & steel (possibly plated?) \\
\hline \multirow[t]{2}{*}{ 41BX892 } & table knife & & steel \\
\hline & table knife & & plated \\
\hline $41 \mathrm{BX} 893$ & teaspoon & & "R. C. Co"; plated \\
\hline \multirow[t]{9}{*}{ 41BX896 } & teaspoon & $7-7 b$ & "Supreme Cutlery 18-8 Japan" \\
\hline & fork & $7-7 \mathrm{c}$ & "Niagara Silver Plate"; 4 tines \\
\hline & table knife & $7-7 d$ & "Stainless Steel Japan" \\
\hline & table knife & $7-7 e$ & "Stainless U.S.A."; hollow handle \\
\hline & table knife & & "Customcraft Stainless Taiwan" \\
\hline & cream soup spoon & $7-8 \mathrm{a}$ & "Plated" \\
\hline & dessert spoon & $7-8 b$ & "Japan-Carlton Stainless" \\
\hline & teaspoon & $7-8 \mathrm{c}$ & "1881 Rogers Stainless Oneida Ltd." \\
\hline & teaspoon & & "Nickel Silver" \\
\hline \multirow[t]{4}{*}{$41 B X 897$} & fork & $7-8 d$ & full, flat tang and wooden handle, 3 tines \\
\hline & fork & $7-9 a$ & push tang, 3 tines \\
\hline & berry spoon & $7-9 b$ & silver-plated, bowl only \\
\hline & teaspoon & & steel \\
\hline \multirow[t]{5}{*}{$41 \mathrm{BX} 900$} & table knife & & solid steel handle and blade fragment \\
\hline & teaspoon & & plated \\
\hline & table knife & & steel \\
\hline & carving fork & $7-9 c$ & steel, 2 tines \\
\hline & coffee spoon & & plated \\
\hline 41BX932 & teaspoon & & unknown alloy \\
\hline \multirow[t]{2}{*}{$41 \mathrm{BX937}$} & table knife & $7-9 \mathrm{~d}$ & unmarked \\
\hline & fork & & "3877 N.F.Cs V"; plated \\
\hline \multirow[t]{6}{*}{ 41BX938 } & fork handle & $7-9 \mathrm{e}$ & "Monroe Silver Co."; plated \\
\hline & fork & & stainless steel, 4 tines \\
\hline & meat can knife ${ }^{2}$ & $7-10 \mathrm{a}$ & " $1917^{\prime \prime}$ \\
\hline & teaspoon & $7-10 b$ & "Silco Stainless S.P." \\
\hline & table knife & & steel \\
\hline & fork & & "Silverbrite Stainless"; 4 tines \\
\hline 41BX941 & tablespoon & $7-10 c$ & "Joske Bros Co Solid" \\
\hline \multirow[t]{2}{*}{$41 \mathrm{BX} 945$} & tablespoon & $7-10 \mathrm{~d}$ & plated \\
\hline & tablespoon & & plated \\
\hline \multirow[t]{2}{*}{$41 \mathrm{BX} 945$} & steak knife & & "Regent Sheffield Stainless England" \\
\hline & table knife & & steel \\
\hline
\end{tabular}

${ }^{1}$ Two-tined forks generally date to the seventeenth century in Europe; three-tined forks became popular at the end of the seventeenth century, and four-tined by the mid-eighteenth century (Noël Hume 1970:180). However, three-tined forks with bone or wood handles are found on many early nineteenth-century sites in Texas.

${ }^{2}$ Meat can is the term used for a mess knit by the U.S. Army in the early 1900s (Ordinance Department, U.S.A. 1908:Plate $\mathrm{XV})$. 


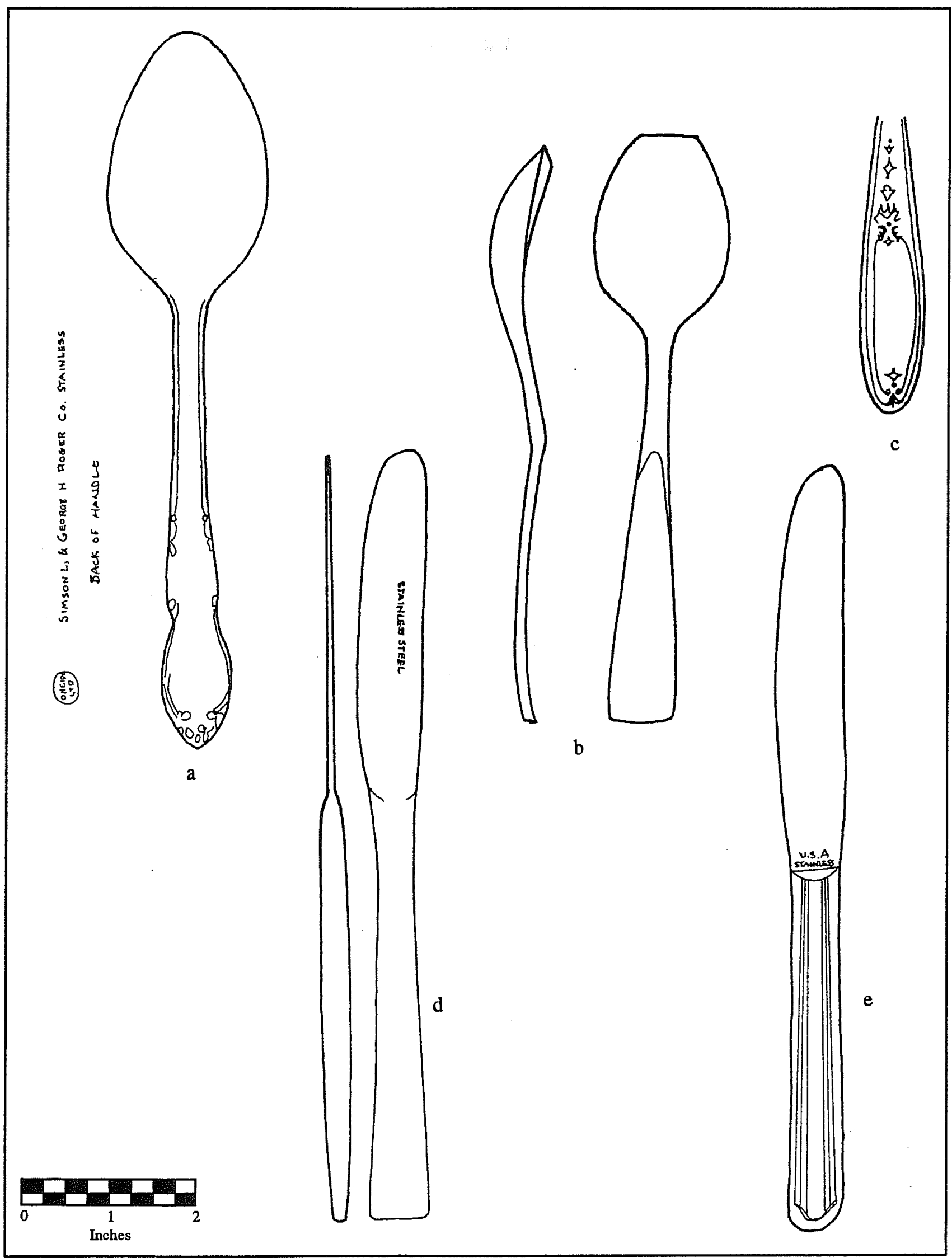

Figure 7-7. Miscellaneous tablewares from the Alamodome Project. a: 41BX882; b-e: 41BX896. 


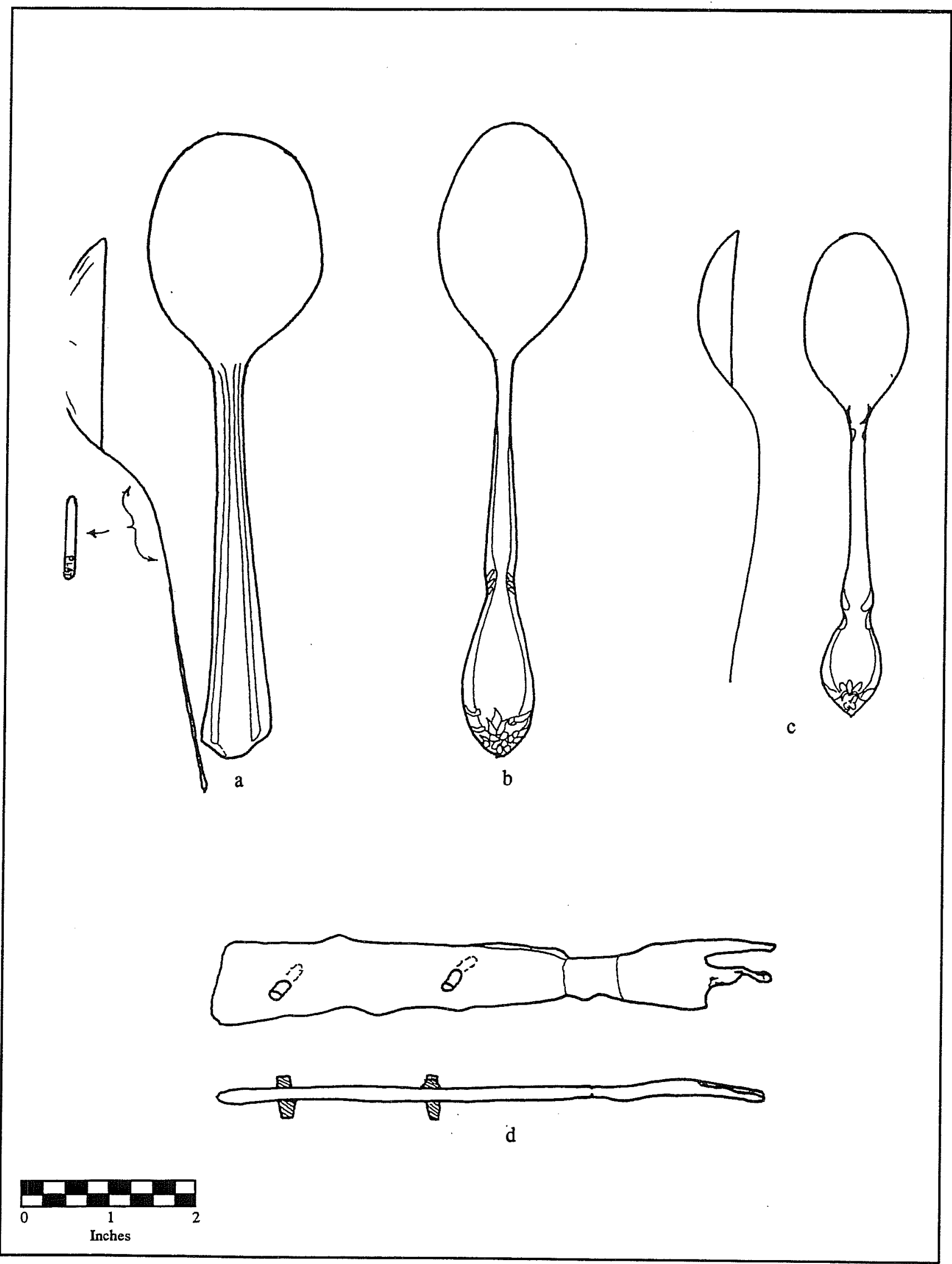

Figure 7-8. Miscellaneous tablewares from the Alamodome Project. a-c: 41BX896; d: 41BX897. 


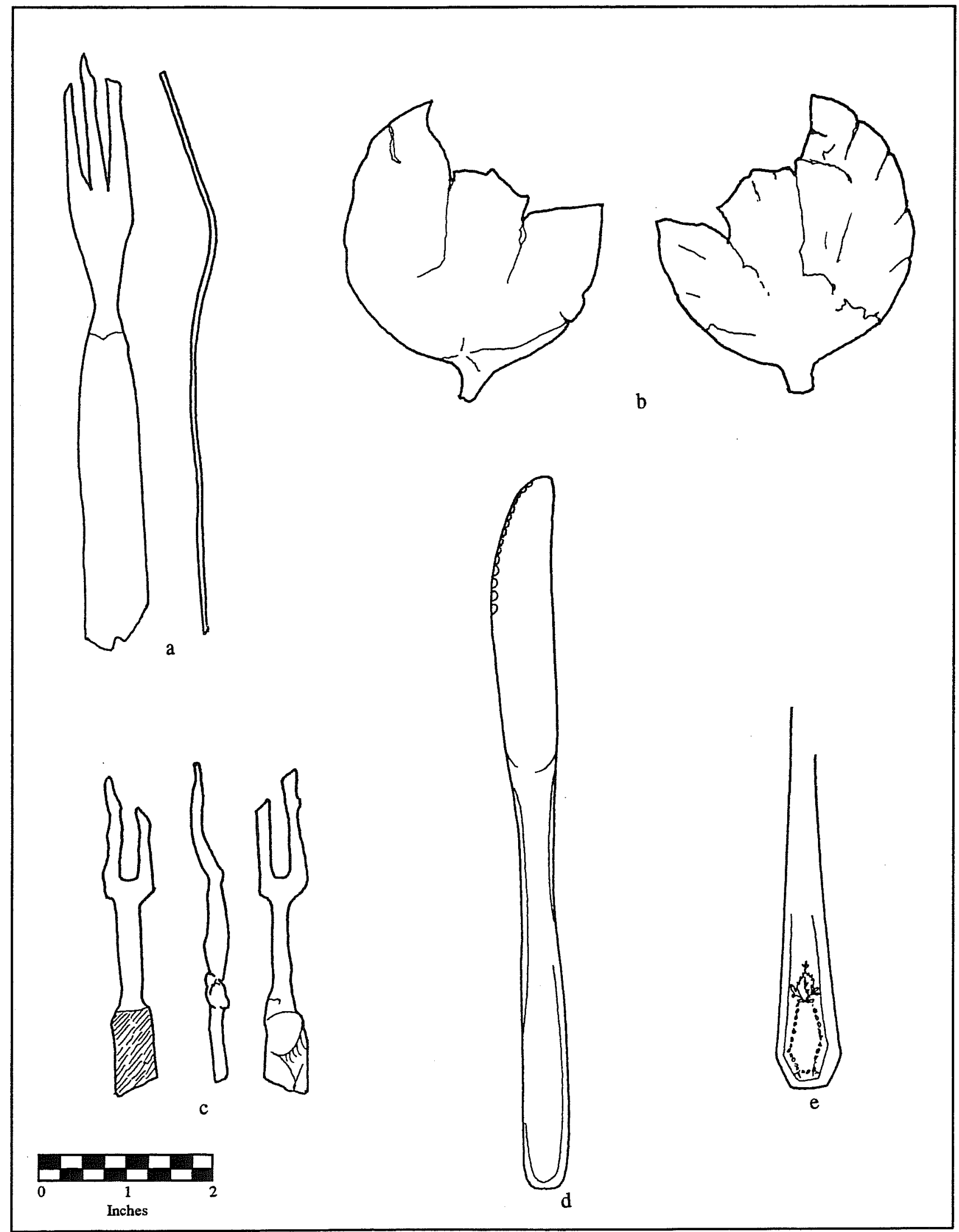

Figure 7-9. Miscellaneous tablewares from the Alamodome Project. a, b: 41BX897; c: 41BX900; d: 41BX937; e: 41BX938. 


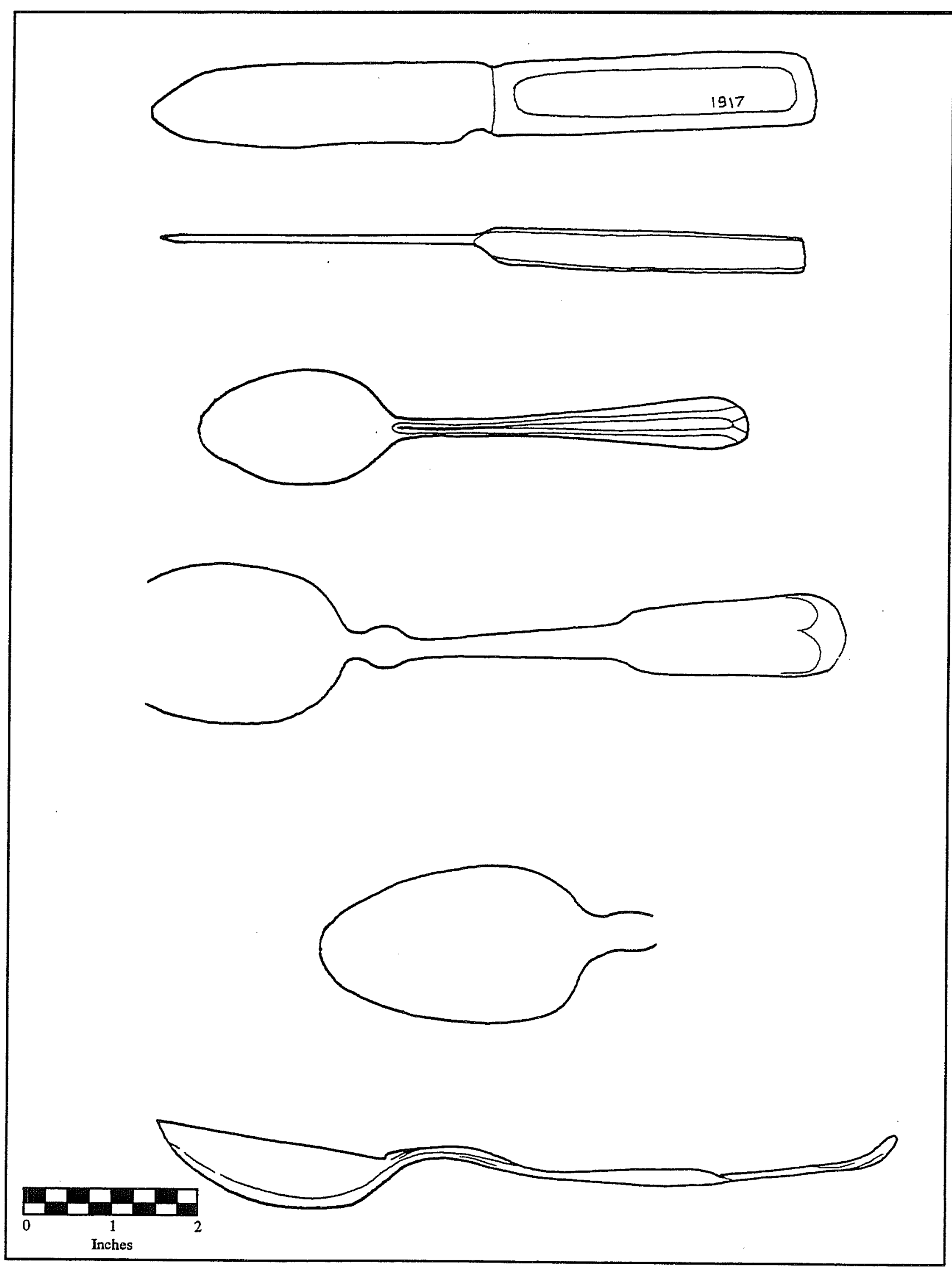

Figure 7-10. Miscellaneous tablewares from the Alamodome Project. a, b: 41BX938; c: 41BX941; d: 41BX945. 


\section{References Cited}

The Book of Knowledge

1957 The Grolier Society, New York.

Busch, J.

1981 An Introduction to the Tin Can. Historical Archaeology 15(1):95-104.

Clark, V. S.

1949 History of Manufactures in the United States, Vol. 2 of 3, 1860-1893. Carnegie Institution of Washington, Peter Smith, New York.

Crown Cork and Seal

1991 One Hundred Years (1892-1992). Crown Cork and Seal, Philadelphia.

The Encyclopedia Americana

1957 Volumes 4 and 5. Americana Corporation, New York.

Ferraro, P., and B. Ferraro

1966 The Past in Glass. Western, Sparks, Nevada.

Fontana, B. L., and J. C. Greenleaf

1962 Johnny Ward's Ranch: A Study in Historic Archaeology. The Kiva 28:1-2.

Fox, A. A.

1986 What Did They Eat at the Missions? Paper presented at the Annual Meeting of the Texas State Historical Association, Austin.

Franklin, L. C.

1976 From Hearth to Cookstove. House of Collectibles, Florence, Alabama.

.

Herskovitz, R. M.

1978 Fort Bowie, Material Culture. The University of Arizona Press, Tucson.

History of Lone Star Brewing Company

1993 Unpublished manuscript used by tour guide at Buckhorn Hall of Fame Museum, Lone Star Brewery, San Antonio.

Illustrated Catalogue of American Hardware of the Russell and Erwin Manufacturing Company

1980 Volume 8. The Association for Preservation Technology, Baltimore.

The Illustrated Encyclopedia of Science and Technology

1977 Volume 4. Marshall Cavendish, New York.

Israel, F. L., editor

19681897 Sears Roebuck Catalogue. Chelsea House, New York.

Martels, J.

1977 The Beer Can Collector's Bible. Ballantine Books, New York. 
Maxwell, D. B. S.

1993 Beer Cans: A Guide for the Archaeologist. Historical Archaeology 27(1):95-113.

Miller, D. W.

1987 Technology and Ideal, Production Quality and Kitchen Reform in Nineteenth-Century America. In Dining in America, 1850-1900, edited by K. Grover, pp 47-84. The University of Massachusetts Press and the Margaret Woodbury Strong Museum, Rochester, New York.

Mirkin, A., editor

19701927 Edition of The Sears, Roebuck Catalogue. Crown, New York.

Montgomery Ward and Company

1969 Catalogue and Buyers' Guide, No 57, Spring and Summer, 1895. Reprint by Dover, New York.

Munsey, C.

1970 The Illustrated Guide to Collecting Bottles. Hawthorn, New York.

Noël Hume, I.

1970 A Guide to Artifacts of Colonial America. Alfred A. Knopf, New York.

Ordnance Department, U.S.A.

1908 Horse Equipments and Equipments for Officers and Enlisted Men, \#1719. Government Printing Office, Washington, D.C.

Pet, Inc.

1985 Creating a Masterpiece, the First 100 Years of Pet Incorporated. St. Louis.

Steinfeldt, C.

1973 Early Texas Furniture and Decorative Arts. Trinity University Press, San Antonio.

Switzer, R. R.

1974 The Bertrand Bottles. A Study of 19th Century Glass and Ceramic Containers. Publications in Archeology 12. National Park Service, United States Department of the Interior. Washington, D.C.

The Timetable of Technology

1982 Hearst Books, New York.

Webster's New Universal Unabridged Dictionary

1983 Dorset and Baber, New York

Whitall, Tatum and Company

1971[1880] American Catalogue Collection, Pyne, Princeton. 


\title{
Chapter 8
}

\section{Architectural Materials}

\author{
Kevin J. Gross and Frank Meissner
}

\section{Artifact Groups}

Approximately 40,000 architectural artifacts were collected during the Alamodome archaeological research project (Table 8-1). The architectural group is composed of 16 separate artifact types. The totals given are incomplete and therefore no proportional data should be interpreted from them. Often only representative samples were collected to document the presence of a certain artifact type. It would have been impractical and inefficient, for instance, to have collected all the wire or cut nails that were encountered. The largest groups-wire nails, cut nails, and window glass fragments-may represent only a five percent collection. Less frequently occurring samples, such as staples, may represent as much as a 95 percent collected sample. Only two artifact types from the construction assemblage allowed for detailed analysis: window glass and bricks. There was no systematic attempt during this analysis to differentiate between those artifacts associated with the original construction episode and subsequent building or remodeling events.

\section{Window Glass}

Window glass includes 5,472 fragments of window and other flat plate glass, representing 13.83 percent of total construction artifacts. A later section discussion describes the relationship between window glass mean thickness and the original date of occupation.

\begin{abstract}
Nails
Nails were by far the most frequently occurring artifact at the Alamodome sites. They were present at all investigated sites. Both whole and fragmentary wire and cut nails are included in the totals. Eight thousand five hundred sixty-four cut nails (21.65 percent of construction artifacts) were recovered while 21,285 wire nails ( 53.81 percent) were recovered. General chronological distinctions can be made between the two: in San Antonio, cut nails represent a pre-1880 manufacture date and were almost entirely replaced by wire nails after about the turn of the century. The collection strategies, however, made relative dating of horizontal or vertical distributions impossible. The totals also suggest an inflated proportional frequency of cut nails: greater attention was given to their recovery, as it was assumed that these could serve as general chronological indicators. It is estimated that only 10 percent of the nails encountered were actually collected. Nails were routinely overlooked during the monitoring phases of the project.
\end{abstract}

\section{Hinges}

Two hundred seventy-four hinges ( 0.6 percent of construction artifacts) were located at 20 of the 36 sites investigated. The largest concentrations were recovered in three 2-x-2-ft hand excavated units at 41BX884, the Griesenbeck site. No explanation can be suggested for this high incidence. A majority of the hinges are small and typical of cupboard construction. Similar quantities and sizes were also recovered at 41BX896, the Demazieres site. 
Table 8-1. Architectural Artifacts from the Alamodome Project

\begin{tabular}{|c|c|c|c|c|c|c|c|c|c|c|c|c|c|c|c|c|c|}
\hline Sites & 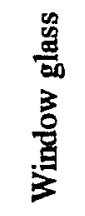 & 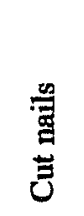 & 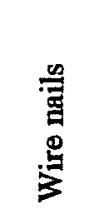 & 品 & 总 & 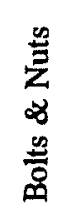 & $\frac{\sqrt[n]{5}}{\frac{g}{5}}$ & $\frac{\stackrel{a}{a}}{\stackrel{\tilde{s}}{\sigma}}$ & 兽 & $\stackrel{\mathscr{E}}{=}$ & 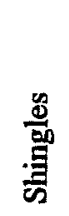 & $\underset{\Sigma}{5}$ & $\begin{array}{l}\frac{5}{\mathfrak{s}} \\
\frac{\mathfrak{Z}}{\mathfrak{a}}\end{array}$ & 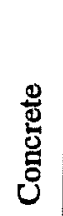 & 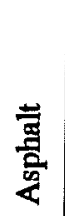 & $\frac{\underline{g}}{\delta}$ & 푤 \\
\hline 41BX881 & 142 & 178 & 926 & 2 & 15 & 11 & 3 & 13 & 32 & 28 & 1 & 1 & 0 & 0 & 1 & 6 & 1359 \\
\hline 41BX882 & 178 & 117 & 594 & 13 & 11 & 4 & 6 & 25 & 42 & 34 & 67 & 0 & 0 & 1 & 1 & 42 & 1135 \\
\hline $41 \mathrm{BX} 883$ & 387 & 2343 & 1702 & 4 & 27 & 13 & 2 & 10 & 68 & 11 & 0 & 3 & 23 & 8 & 0 & 53 & 3494 \\
\hline 41BX884 & 317 & 249 & 507 & 100 & 50 & 37 & 20 & 21 & 21 & 3 & 14 & 6 & 2 & 0 & 7 & 45 & 1399 \\
\hline 41BX885 & 51 & 51 & 225 & 0 & 7 & 3 & 3 & 2 & 11 & 0 & 0 & 0 & 7 & 0 & 0 & 3 & 363 \\
\hline $41 B \times 890$ & 29 & 90 & 11 & 0 & 1 & 0 & 0 & 0 & 8 & 0 & 0 & 0 & 1 & 0 & 0 & 0 & 140 \\
\hline $41 B \times 891$ & 15 & 12 & 9 & 1 & 0 & 1 & 1 & 0 & 3 & 0 & 0 & 0 & 0 & 0 & 0 & 0 & 42 \\
\hline 41BX892 & 60 & 74 & 451 & 4 & 1 & 5 & 0 & 1 & 5 & 1 & 1 & 1 & 2 & 0 & 0 & 3 & 609 \\
\hline $41 \mathrm{BX} 893$ & 110 & 206 & 1090 & 5 & 28 & 22 & 3 & 25 & 9 & 31 & 13 & 2 & 14 & 3 & 0 & 10 & 1571 \\
\hline $41 \mathrm{BX894}$ & 221 & 12 & 287 & 0 & 8 & 20 & 10 & 6 & 14 & 4 & 1 & 0 & 7 & 2 & 0 & 43 & 635 \\
\hline 41BX895 & 866 & 111 & 174 & 5 & 4 & 3 & 1 & 2 & 2 & 1 & 13 & 0 & 7 & 11 & 1 & 9 & 1209 \\
\hline 41BX896 & 663 & 1270 & 4426 & 83 & 123 & 58 & 50 & 156 & 55 & 94 & 33 & 29 & 61 & 1 & 2 & 132 & 7235 \\
\hline $41 \mathrm{BX} 897$ & 104 & 1712 & 1021 & 11 & 10 & 22 & 8 & 2 & 60 & 2 & 5 & 4 & 13 & 10 & 0 & 21 & 3007 \\
\hline 41BX898 & 1 & 0 & 2 & 1 & 0 & 0 & 0 & 0 & 1 & 0 & 0 & 0 & 0 & 0 & 2 & 0 & 5 \\
\hline 41BX899 & 0 & 2 & 0 & 0 & 0 & 0 & 0 & 0 & 2 & 0 & 0 & 0 & 0 & 0 & 10 & 0 & 6 \\
\hline $41 \mathrm{BX} 900$ & 285 & 547 & 1158 & 2 & 13 & 21 & 8 & 4 & 12 & 13 & 1 & 0 & 19 & 1 & 0 & 23 & 2117 \\
\hline $41 \mathrm{BX} 926$ & 5 & 3 & 13 & 0 & 1 & 0 & 0 & 0 & 0 & 1 & 0 & 0 & 0 & 0 & 0 & 0 & 23 \\
\hline $41 \mathrm{BX} 927$ & 12 & 1 & 3 & 0 & 1 & 5 & 2 & 0 & 0 & 0 & 0 & 0 & 0 & 0 & 0 & 0 & 24 \\
\hline $41 \mathrm{~B} \times 928$ & 11 & 5 & 0 & 0 & 0 & 0 & 0 & 0 & 1 & 0 & 0 & 0 & 0 & 0 & 0 & 1 & 18 \\
\hline $41 \mathrm{BX} 929$ & 0 & 0 & 0 & 0 & 0 & 0 & 0 & 0 & 2 & 0 & 0 & 0 & 0 & 0 & 0 & 0 & 2 \\
\hline 41BX930 & 0 & 7 & 10 & 0 & 2 & 0 & 0 & 0 & 0 & 0 & 0 & 0 & 1 & 2 & 0 & 37 & 59 \\
\hline 41BX931 & 97 & 110 & 250 & 0 & 6 & 2 & 0 & 2 & 5 & 5 & 81 & 5 & 9 & 1 & 10 & 21 & 604 \\
\hline 41BX932 & 11 & 152 & 289 & 2 & 4 & 1 & 2 & 5 & 0 & 0 & 0 & 0 & 0 & 1 & 0 & 3 & 470 \\
\hline 41BX936 & 101 & 89 & 343 & 0 & 1 & 9 & 1 & 0 & 7 & 5 & 23 & 3 & 11 & 0 & 0 & 19 & 612 \\
\hline 41BX937 & 65 & 49 & 423 & 3 & 6 & 2 & 0 & 0 & 8 & 191 & 20 & 11 & 4 & 0 & 31 & 65 & 878 \\
\hline 41BX938 & 42 & 48 & 740 & 4 & 10 & 14 & 10 & 5 & 1 & 32 & 3 & 0 & 1 & 4 & 0 & 3 & 917 \\
\hline 41BX939 & 35 & 157 & 603 & 1 & 3 & 9 & 2 & 3 & 1 & 11 & 0 & 0 & 0 & 1 & 0 & 0 & 826 \\
\hline $41 \mathrm{BX} 940$ & 49 & 12 & 160 & 0 & 3 & 8 & 0 & 0 & 5 & 0 & 7 & 0 & 0 & 0 & 0 & 0 & 244 \\
\hline $41 \mathrm{BX} 941$ & 63 & 206 & 299 & 2 & 2 & 6 & 2 & 0 & 2 & 1 & 9 & 1 & 1 & 0 & 3 & 11 & 608 \\
\hline 41BX942 & 183 & 188 & 763 & 2 & 6 & 10 & 3 & 2 & 3 & 4 & 4 & 1 & 0 & 0 & 2 & 18 & 1189 \\
\hline 41BX943 & 0 & 0 & 23 & 1 & 0 & 1 & 1 & 0 & 0 & 0 & 0 & 0 & 0 & 0 & 0 & 1 & 27 \\
\hline 41BX944 & 0 & 0 & 0 & 0 & 0 & 0 & 0 & 0 & 0 & 0 & 0 & 0 & 0 & 0 & 0 & 0 & 0 \\
\hline $41 \mathrm{BX} 945$ & 1365 & 1721 & 4783 & 28 & 112 & 170 & 73 & 32 & 43 & 66 & 36 & 49 & 96 & 15 & 2 & 108 & 8699 \\
\hline $41 \mathrm{BX} 955$ & 4 & 2 & 0 & 0 & 0 & 0 & 0 & 0 & 0 & 2 & 0 & 0 & 0 & 0 & 0 & 0 & 8 \\
\hline 41BX956 & 0 & 0 & 0 & 0 & 0 & 0 & 0 & 0 & 0 & 0 & 0 & 0 & 1 & 0 & 0 & 2 & 3 \\
\hline $41 \mathrm{BX} 957$ & 0 & 0 & 0 & 0 & 0 & 0 & 0 & 0 & 0 & 3 & 0 & 0 & 0 & 0 & 0 & 10 & 13 \\
\hline Totals & 5472 & 8564 & 21285 & 274 & 455 & 457 & 211 & 316 & 423 & 543 & 332 & 116 & 280 & 61 & 72 & 689 & 39550 \\
\hline
\end{tabular}




\section{Screws}

Four hundred fifty-five screws (1.15 percent of construction artifacts) were recovered at 26 of the 36 sites. Screws ranged in occurrence from 1 (five sites) to 123 from excavations at the Demazieres site. Too wide a variety of sizes and types exists for any useful generalization about their usage or distribution.

\section{Nuts and Bolts}

Nuts and bolts were originally calculated as separate categories, but were merged as a single class because so many had corroded into single units. Four hundred and fifty-seven bolts and nuts (1.15 percent of architectural artifacts) were excavated at 25 of the 36 sites. The largest quantity (170) was recovered from 41BX945, the Pauly site.

\section{Washers}

Two hundred eleven washers ( 0.53 percent) were recovered at 21 of the Alamodome sites. The highest concentration (73) is from 41BX945, the Garza store, and may reflect the intensive excavations conducted in and adjacent to the primary structure.

\section{Staples}

Three hundred sixteen staples (about 0.80 percent of construction artifacts) were recovered at 18 of the 36 sites examined. The largest sample, from 41BX896, the Demazieres site, represents about half the entire staple collection. Most of the sites that contained staples have a more recent (post-1920) date of construction; this suggests that staples were not a component of earlier structures.

\section{Bricks}

A total of 423 bricks or brick fragments was collected. Sample size is poorly represented by count, however, because of the enormous variability in size. It appears that bricks were used minimally in the Alamodome project area for small features in the late-nineteenth century. They gradually became a popular alternative to wood for some purposes in the early $1900 \mathrm{~s}$. (See the later, more detailed discussion for distributions by weight, identification, and chronological significance of bricks.)

\section{Tile}

Five hundred forty-three tiles or tile fragments were recovered at 22 of the 36 sites. The largest concentrations (191 total) were excavated at 41BX937, 124 Martin Luther King. The tile collection includes a number of non-diagnostic handpainted kitchen and counter tiles and monochromatic bathroom floor and wall tiles.

\section{Shingles}

Three hundred thirty-two whole composition shingles and shingle fragments were collected at 18 of the sites. Shingles and other roofing materials were most often collected a distance away from primary structures during attempts to locate non-standing outbuildings.

\section{Mortar}

One hundred sixteen mortar samples were collected from 13 of the 36 sites. Mortar was collected to identify sites, or intrasite areas, that may have contained structures or features comprised of brick. That almost half of the sample (43) was collected at 41BX945, the Pauly site, certainly reflects the numerous horizontal brick alignments (walkways and outbuilding floors) that were uncovered at the site.

\section{Plaster}

Two hundred eighty wall plaster samples $(0.70$ percent of the architectural assemblage) were collected at 19 of the Alamodome sites. The largest sample (96) was recovered from the cistern at the Pauly site. The cistern's interior walls, including the collapsed ceiling, had all been plastered. 


\section{Concrete}

Sixty-one concrete fragments $(0.15$ percent of architectural artifacts) were excavated at 14 sites. Concrete is believed to have been developed and first utilized in quantity in San Antonio in the late nineteenth century. Therefore, it was often collected as a gross chronological reference when there was an absence of other dateable artifacts.

\section{Asphalt}

Seventy-two fragments of asphalt ( 0.18 percent of architectural artifacts) were excavated at 12 of the 36 sites. The largest concentration of asphalt (31 fragments) was excavated at 41BX937, 124 Martin Luther King. A 94-ft mechanical trench bisected the site north to south. An asphalt surface underlying a gravel layer was encountered in the upper levels for most of the trench, explaining the high occurrence of asphalt collected at this site.

\section{Other}

The architectural "other" category includes 50 types of material composed of 689 individual artifacts (1.74 percent of the architectural assemblage). The most frequently occurring types are linoleum, wood fragments, tacks, and pieces of asbestos.

\section{Brick Making in San Antonio and Texas}

The earliest European and American immigrants to Texas brought with them their brick-making skills. Brick production was not a primary concern for them, however. It has been suggested that it was common practice for families to farm during favorable weather and lay up clay and firewood for brick making during the winter months (Steinbomer 1983:33). Because of the abundance of wood and stone throughout the state, many families only needed to produce a small quantity of brick for chimneys, foundations, and other small features. There is also evidence that the making and selling of brick may have provided a good second income for some families during the early and middlenineteenth century (Steinbomer 1983:38).
The state's population quadrupled between 1850 and 1870 (U.S. Census 1850, 1870), which seems to have had a corresponding impact on brick production. In the decade from 1860 to 1870 , brick making assumed the twelfth place among the top 15 industries in the state (Steinbomer 1983:48). But many people, including a majority of those living in San Antonio, maintained the earlier, self-sufficient production techniques (Steinbomer 1983:39).

The construction of military forts during the 1870s, and the protection they provided, allowed Texas to build at an even more rapid rate. It was the military, in fact, that first made extensive use of brick. Unfortunately for Texas brick manufacturers, in order to meet the specification requirements established in Washington, most of the construction materials utilized in Texas forts originated in the Northeast (Steinbomer 1983:45).

The contemporaneous introduction of the railroad also contributed to larger population growth for the state. Consequently, brick making ranked fifth in the top 10 industries by 1880 . The Texas portion of the Census of Industry for that year reported 113 brick and tile plants with 1,185 employees (Steinbomer 1983:43).

Shipping costs were the greatest hindrance to centralization of brick production. Transportation was disproportionately more expensive than labor, production, and material. Bricks, rather obviously, are heavy and given to breakage in handling. Only a small number of bricks could be moved, in the early years, with horse and wagon (Steinbomer 1983:43). Consequently, prior to the railroad, brick plants were limited to product distribution in a small, regional area. Until the process for bundling and binding brick was mechanized, each brick was handled as a single piece.

The arrival of railroads immediately allowed the regional brick plants to expand their distribution area. Rail cars could move an unlimited amount of bricks at a reasonable rate. As people moved to new areas, fairly remote brick plants could supply them until a local plant opened. Even then, it has been suggested, the local product had to be less expensive and of similar quality to compete with the more distant plant (Steinbomer 1983:44). 
The railroads introduced brick from the Mississippi Valley, especially Missouri, as well as a limited amount of brick from East Texas, to frontier Texas. The railroad entered San Antonio in 1877. Two bricks recovered during excavations at the Alamodome were imprinted with marks from Missouri brick factories. Bricks from 41BX893, the Czernecki site, and 41BX897, the Webb site, can be dated to 1927 and 1921 respectively (Gurcke 1987:266-7, 272-3).

There is record that brick began arriving in San Antonio immediately after the introduction of the railroad. In what quantity is not certain. In 1879, for example, about one car load a month arrived (City Directory [CD] 1879:51). Five years later, however, the annual total was estimated at 194 car loads (or about 16 cars a month). A small amount of brick from the eastern states also entered Texas by ship. It is unclear how much of this brick, if any, arrived in San Antonio.

Brick manufacturing in San Antonio was ephemeral. In fact, after the first local attempt in 1860 by Gustave Toudouze, it was 18 years before another individual in the city had brick making as his sole occupation. Beginning in about 1878, a number of small companies began brick production, but a majority lasted only one brick making season. In 1880, for example, Fries Brothers employed between six and 14 workers for nine months of the year and produced about 350,000 bricks. Another manufacturer, Toudouze, also employed six workers, but produced about 400,000 bricks in eight months of operation (Agricultural and Manufacturing Census Records 1880).

At least 10 different brick making companies continued the trend of stopping operations shortly after opening in the decade before the turn of the century. The Bexar Brick Company (later renamed the San Antonio Pressed Brick Company) had the most longevity: it lasted about five years, from 1890 to about 1895 (CD $1889,1892,1895$ ). The lack of success in San Antonio seems inconsistent with the rest of the state. By 1890 , Texas ranked twenty-second in common brick production and eleventh in pressed brick in the nation (Steinbomer 1983:43).

Most of the common building brick used in Texas was produced within the state boundaries, but firebrick and fine china clays were imported until about the turn of the century because equipment and deposits had not yet been developed (Steinbomer 1983:45). Advertisements suggest that red bricks had to be imported into the city until the late 1890s (CD 1897). The Bem Brick Company began making red fire and common bricks in San Antonio from 1897.

Table 8-2 includes all known brick manufacturers in San Antonio between 1860 and 1935. It is unknown if any of these manufacturers included diagnostic marks on their bricks. The list is included, nonetheless, as a reference tool for future archaeologists.

In 1909, Texas's brick and tile establishments employed 1,935 persons. Statewide, there had been a 95 percent increase in production from 1904 to 1909 and a 27 percent increase from 1899 . But brick production declined nationally during the World War I years (Steinbomer 1983:53). After the war, technological improvement and innovation allowed for a gradual recovery for a few years. Post-war increases in population also encouraged the establishment of brick yards in many Texas cities. In San Antonio, the population almost quadrupled during this time from 53,321 in 1900 to 231,542 in 1930 , but there is no evidence for new local brickyards to supply the increasing building market (U.S. Census 1900, 1930).

Most cities heavily restricted the use of lumber in urban areas to prevent fires. There are records that indicate that San Antonio prohibited lumber structures in the central portion of the city very early. In subsequent years, most noticeably from the early 1870 s until the turn of the century, the fire limit rapidly included more areas of the city (CD 1877, $1883,1892)$. In the early part of the twentieth century, however, brick was challenged by improvements in the lumber industry. Lumber could be fireproofed by covering wood used on interior spaces with gypsum board or with stone or brick on the exterior wood (Steinbomer 1983:60).

At the same time, brick veneer frame houses became popular throughout the state. The most typical of these, the bungalow style, used wood siding and stucco, but later also incorporated brick (Steinbomer 1983:61). A number of the Alamodome houses were identified as bungalows, but a majority used shingles or milled siding (Andrew Perez and Associates, Volume I). 
Table 8-2. San Antonio Brick Manufacturers, ca. 1860-1935

\begin{tabular}{|l|l|}
\hline \multicolumn{1}{|c|}{ Name } & Years in Operation \\
\hline Toudouze, Gustave & 1860 \\
\hline San Antonio Brick and Tile Mfr. and Coal Mining & $1878-1898$ \\
\hline Bergstrom Brothers Brick Manufacturers & 1879 \\
\hline Mariano, Paul & 1879 \\
\hline Fries Brothers and Fire Brick & 1880 \\
\hline Alamo Brick Company & 1880 -present \\
\hline J. S. Magnus, began Bem Brick, became Alamo Brick & 1920 \\
\hline Alamo Clay Products & 1944 to present \\
\hline Toudouze Brothers & 1880 \\
\hline Walter Scott & 1883 \\
\hline Harrison and Harrison & 1883 \\
\hline Allen, L. W., Fire Brick & 1887 \\
\hline Bexar Brick and Tile Company & 1889 \\
\hline Taylor, P. C. & $1889-1890$ \\
\hline Alvord, H. H. Brick Manufacturer & $1889-1890$ \\
\hline Mackey Brick and Tile & $1890-1897$ \\
\hline Fenstermaker and Younger & 1891 \\
\hline Laredo Brick Company & 1891 \\
\hline Sunset Brick and Tile Company & 1891 \\
\hline San Antonio Brickyard & 1892 \\
\hline Phelan and Son & 1892 \\
\hline Dunfee, C. W. & $1894-1895$ \\
\hline Oppenheimer Brick and Tile Company & $1895-1896$ \\
\hline Schuwirth, W. G. & $1895-1896$ \\
\hline San Antonio Pressed Brick Company & $1895-1910$ \\
\hline Elmendorf Brick and Tile Company & 1905 \\
\hline Phoenix Clay Corporation & $1908-1920$ \\
\hline Star Clay Product Company & $1908-1926$ \\
\hline Williams Brick Company & $1909-1918$ \\
\hline Star Brick and Tile Company & 1929 \\
\hline Martin, J. R. Tile and Brick Company & 1944 \\
\hline San Antonio Brick Company & 1929 \\
\hline
\end{tabular}

\section{Brick Construction in the Alamodome Area}

Home builders in the Alamodome Project area showed an overwhelming preference for wood construction. Only three of the structures standing when site clearing began for the Alamodome had at least one masonry wall. These were the Oeffinger house (41BX881), the Demazieres house (41BX896), and the Griesenbeck house (41BX884). Bricks were used minimally at many of the sites for foundations, chimneys, walkways, and secondary structures. 
A total of 22,997.0 grams (50.59 lbs.) of bricks and brick rubble was collected during the testing and mitigation phases of the Alamodome project. Bricks were recorded at 27 of the 36 sites. Their distribution by weight is presented in Table 8-3.

Whole bricks, brick fragments, and rubble were weighed. The varied collection strategies for the different phases of the project resulted in the uneven distribution reflected in Table 8-3. It is not suggested that these reflect proportional differences. There was also no attempt to calculate differences in type, since most fragments were too small to be identified. A visual inspection, however, would suggest a fairly even distribution between common yellow bricks and red firebricks.

One complete red, dry-pressed brick imprinted with "SECO" was recovered from 41BX941 on Runge Street. The dwelling was constructed in 1927 and used continuously as a rental property until demolition. The brick also had two insignia (Figure 8-1) that identified it with the Common Brick Manufacturers Association, a national trade organization. The Seco Brick Company operated in Medina County from 1910 to 1939 (Steinbomer 1983). The CBMA logo suggests the brick was probably produced sometime after 1920 (Steinbomer 1983). The brick measures $81 \frac{1}{2} \times 4 \times 2 \frac{114}{4}$ inches.

Four fragments with diagnostic markings were collected. A yellow soft mud, sandstruck brick was collected at 41BX896, the Demazieres house. It was imprinted with ". . .c LANE/LAREDO" (Figure 8-2). This is most likely the McLane that has been identified (Clark 1989:70-71) as a Webb County (Laredo) brick manufacturer. No exact date of manufacture can be established, but it is likely that McLane was in operation from about 1900 to 1925.

Table 8-3. Site Distribution of Bricks and Brick Rubble

\begin{tabular}{|c|c|c|c|}
\hline Site & $\begin{array}{l}\text { Total Weight } \\
\text { (in grams) }\end{array}$ & Site & $\begin{array}{l}\text { Total Weight } \\
\text { (in grams) }\end{array}$ \\
\hline 41BX881 & 201.9 & 41BX928 & 2039.2 \\
\hline $41 \mathrm{BX} 882$ & 996.0 & 41BX929 & 1900.5 \\
\hline 41BX883 & 2984.3 & 41BX930 & - \\
\hline $41 B X 884$ & 165.6 & 41BX931 & 212.3 \\
\hline $41 B \times 885$ & 74.2 & 41BX932 & - \\
\hline $41 \mathrm{BX} 890$ & 61.9 & $41 B \times 936$ & 838.6 \\
\hline $41 B \times 891$ & 489.3 & $41 \mathrm{BX} 937$ & 424.8 \\
\hline 41BX892 & 298.6 & 41BX938 & 15.1 \\
\hline $41 B X 893$ & 700.4 & 41BX939 & 21.5 \\
\hline 41BX894 & 86.1 & 41BX940 & 2069.7 \\
\hline 41BX895 & 297.0 & 41BX941 & 1900.5 \\
\hline $41 B \times 896$ & 2430.2 & $41 \mathrm{BX} 942$ & 212.3 \\
\hline 41BX897 & 3877.3 & $41 B \times 943$ & - \\
\hline 41BX898 & 118.5 & 41BX944 & - \\
\hline 41BX899 & 33.8 & 41BX945 & 786.3 \\
\hline 41BX900 & 627.3 & 41BX955 & - \\
\hline 41BX926 & - & $41 B \times 956$ & - \\
\hline 41BX927 & - & $41 \mathrm{BX} 956$ & - \\
\hline
\end{tabular}




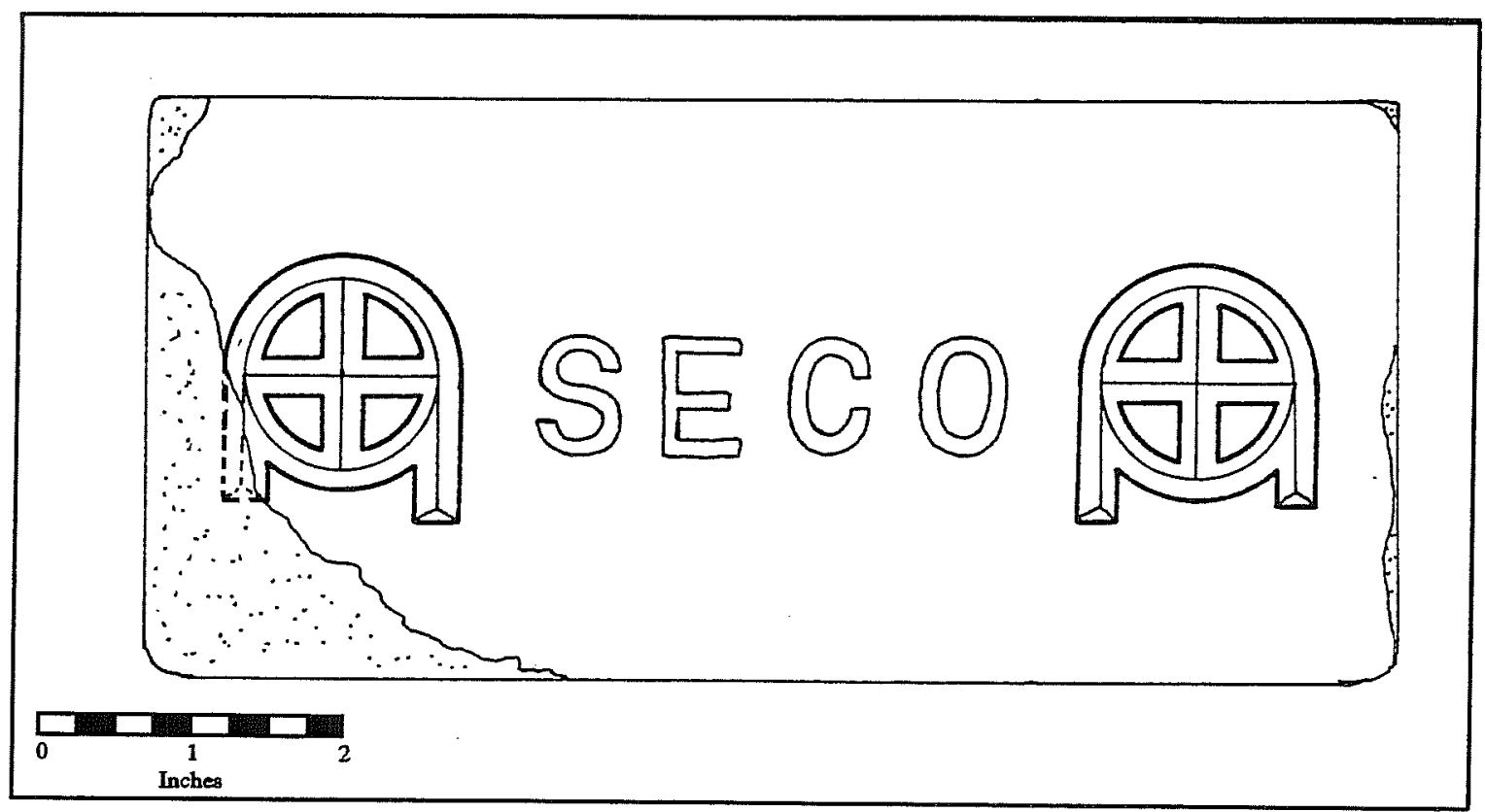

Figure 8-1. Seco brick from Medina County, ca. 1910-1939.

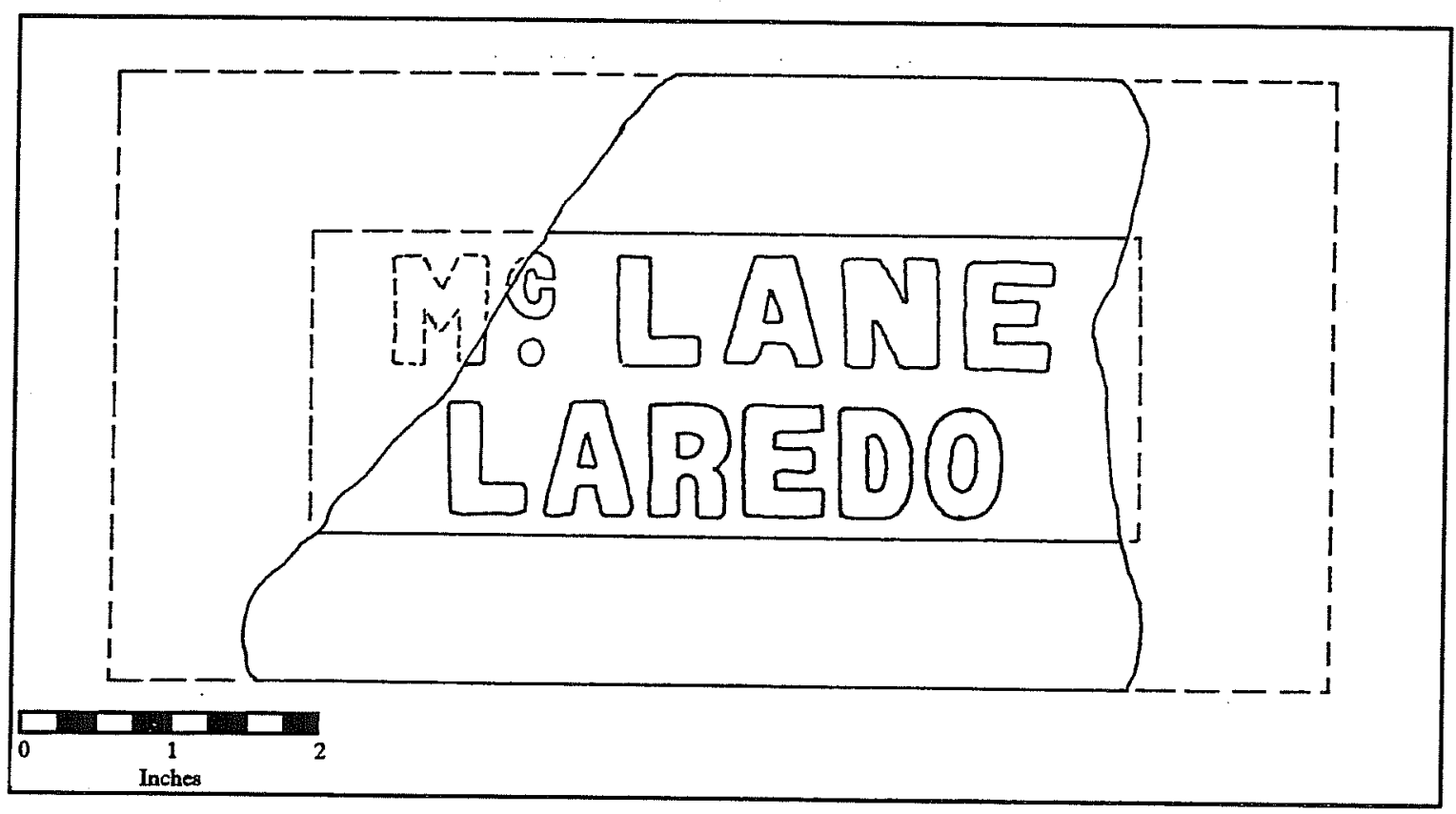

Figure 8-2. McLane brick made in Laredo ca. 1900-1925.

A gray, dry-pressed fragment impressed with "LAC . . ./EX. . . " was collected at 41BX897, the Webb site (Figure 8-3). The measurable sections suggest that the brick was extremely large, $91 / 4 \times 41 / 2 \times 23 / 8$. The maker and date of manufacture are unknown.
A reddish yellow, machine-made, blade-trimmed fragment with a "MISSOUR . . .IXXX/ST LOUIS" imprint was collected at 41BX883, the King house (Figure 8-4). The brick has been identified (Gurcke 1987:266) as a brand produced from about 1927 to 1930 by the Missouri Fire Brick Company. 


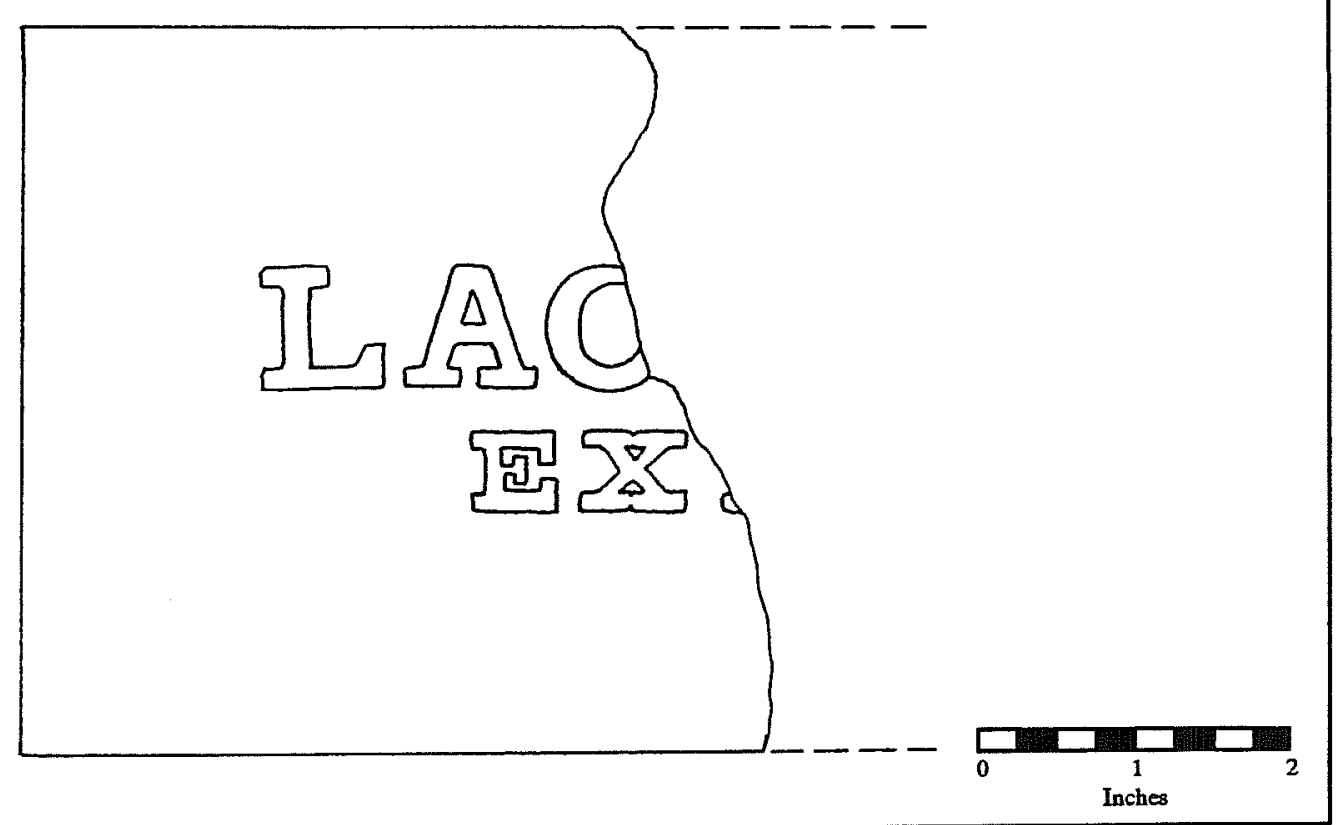

Figure 8-3. Brick of unknown date and manufacture.

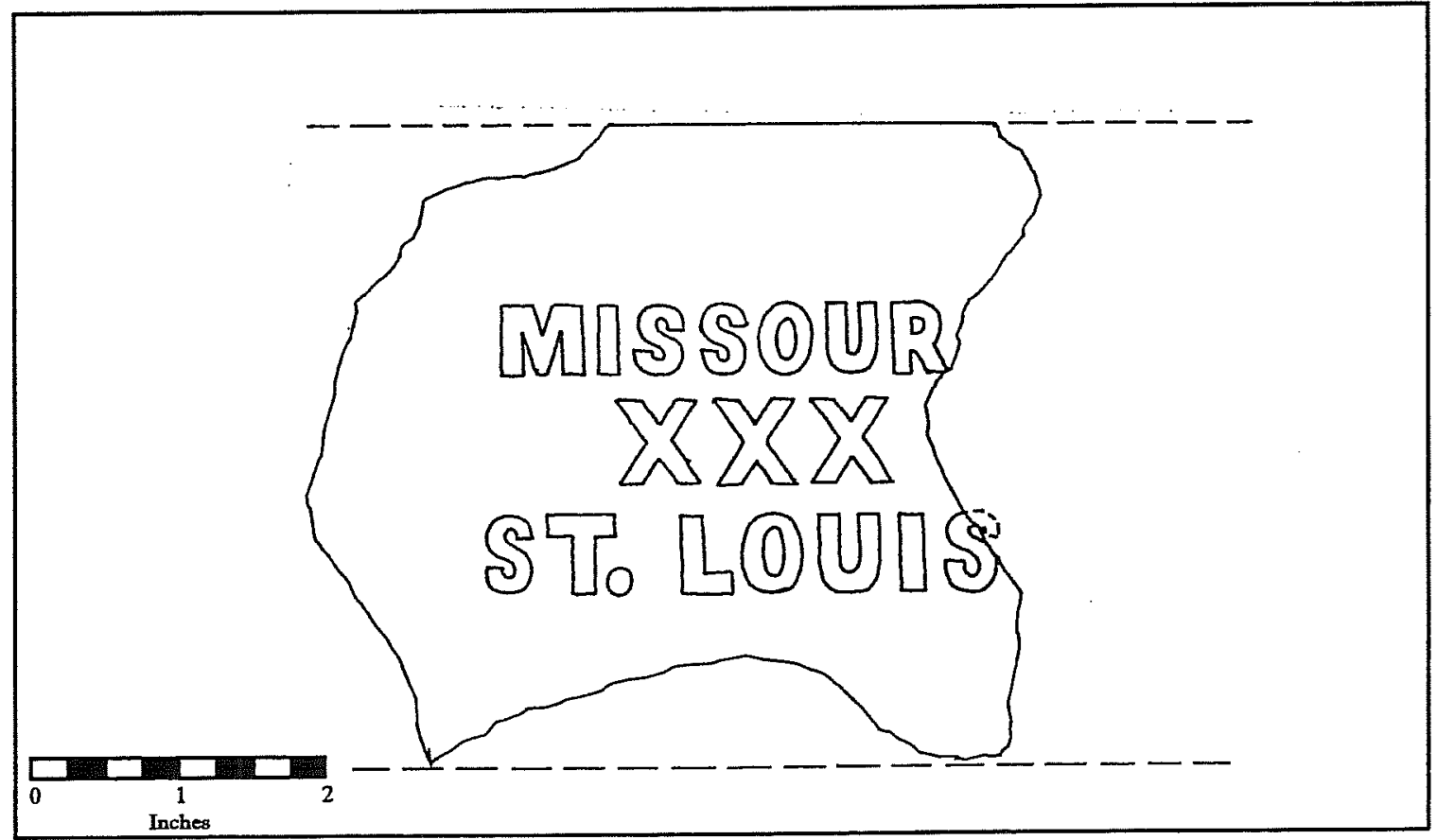

Figure 8-4. Missouri Fire Brick Company, ca. 1927-1930.

A red, machine-made fragment bearing ". . .ER RU/ MANF/. . .T LOU. . .No.1" was recovered at 41BX897, the Webb Site (Figure 8-5). It has been identified as brand No 1 from the Parker and Russell
Mining and Manufacturing Company of St. Louis, Missouri. It is believed that it was produced sometime after 1921 (Gurcke 1987:272-273). 


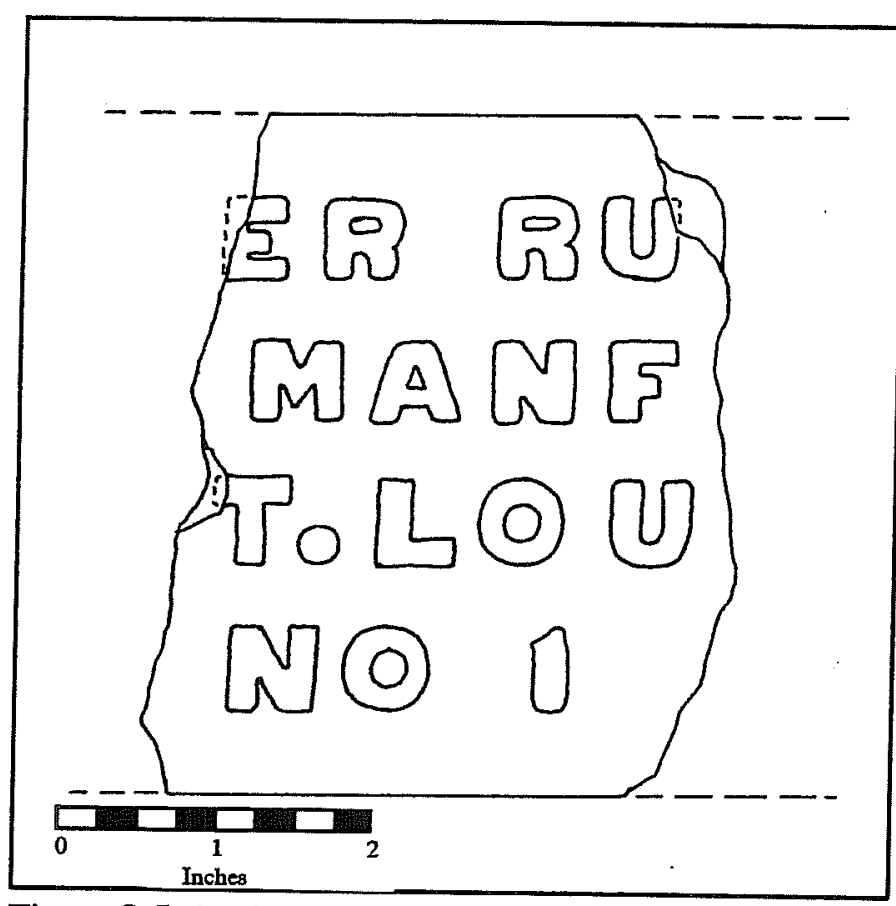

Figure 8-5. Parker and Russell Mining and

Manufacturing Company of St. Louis, after 1921.
Two complete bricks with no markings were collected. A salmon colored, water-struck common brick, $71 / 2 \times 31 / 2 \times 21 / 2$ inches, was collected at 41BX928, 319 Hoefgen. An $8 \frac{1}{4} \times 41 / 4 \times 21 / 4$ inch, yellow machine-made, blade trimmed paving brick was recovered at 41BX940, 112 Runge Street. The makers and dates of manufacture are unknown.

Six brick rubble pieces had too little of their brand marks left to be identified. They are illustrated in Figure 8-6.

No attempt to measure or quantify non-isolated bricks was made. Bricks that were included in house structures or features (walkways, privies, wells) were photo documented and, in some cases, drawn. Color and diagnostics (impressed marks), where applicable, were also recorded in the field notes. For instance, we encountered "D'HANIS" bricks at many of the sites. None, however, was collected. The D'Hanis Brick and Tile Company has operated

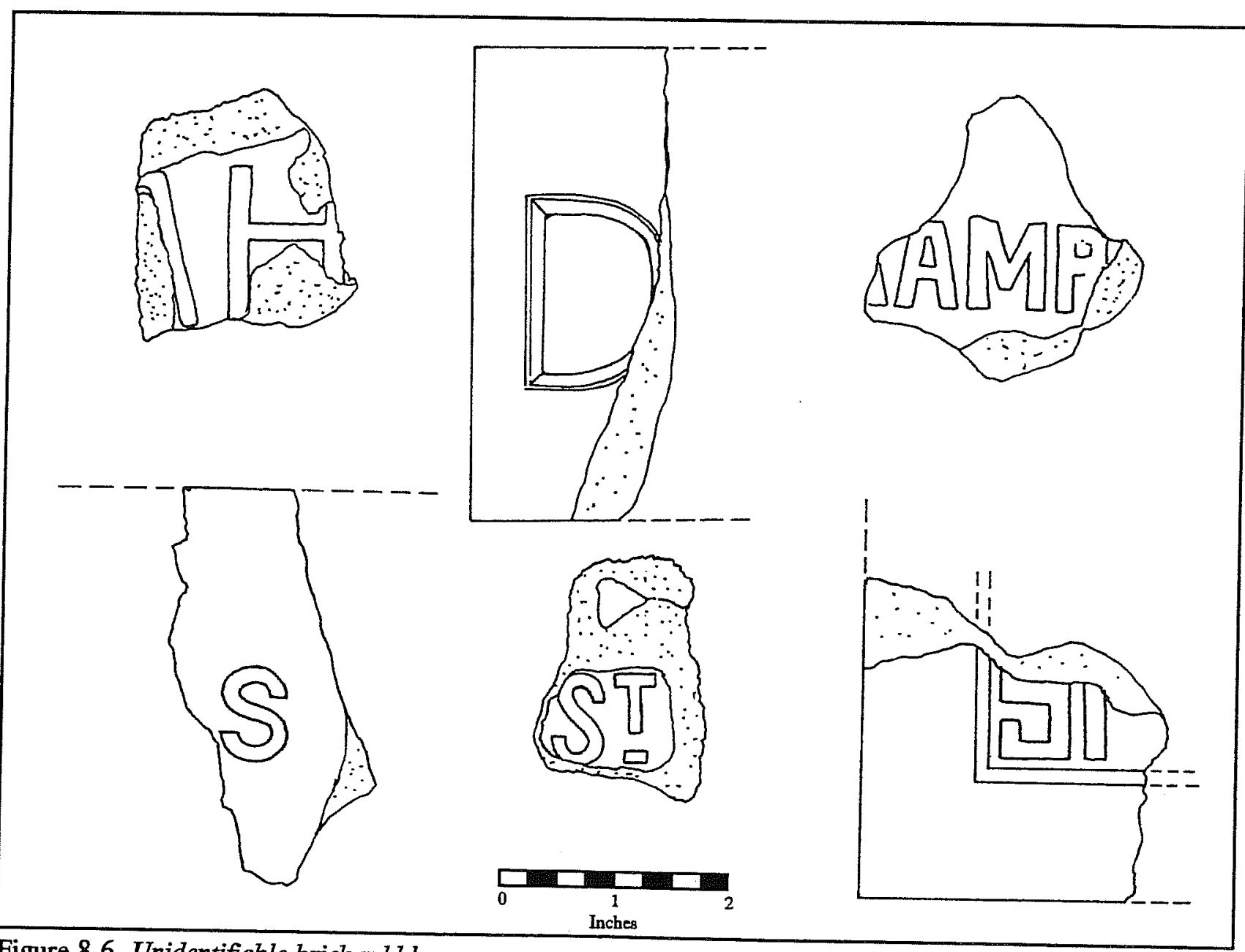

Figure 8-6. Unidentifiable brick rubble. 
in Medina County from 1905 to the present (Steinbomer 1983). Many of the D'Hanis bricks were without the CBMA logo, indicating pre-1920 manufacture.

Bricks were used infrequently in the Alamodome project area probably because it was less expensive to construct a wooden frame house. There was no archaeological evidence for bricks of local manufacture in the area, although the technology was present for brick production for even the earliest residents. Builders also had continuous access to locally produced bricks beginning in 1878 . Even then, of the limited number of bricks recorded, a fair percentage seem to have been imported from other parts of the state. Relatively large quantities of bricks from other regions of the country, especially the Mississippi valley and the Midwest, also entered the city beginning in the $1890 \mathrm{~s}$. An explanation may be that "foreign" bricks were simply less expensive.

\section{Window Glass}

Archaeologists first recognized the potential of window glass as a dateable artifact in the early 1970s. In the next 10 years, archaeological research provided strong observational evidence that window glass increased in thickness during the nineteenth century. Consequently, numerous methods for dating glass assemblages were developed. Randall W. Moir (1987:77, 1988:271) was the first to use window glass thickness as a dating tool for rural sites in Texas.

Using the method of least squares linear regression, Moir proposed a regression equation $\mathrm{I}=84.22(\mathrm{~T})+1712.7$ (where $\mathrm{T}=$ mean thickness and $\mathrm{I}=$ initial date of construction) for explaining the relationship between window glass thickness and initial date of construction for dwelling occupied between 1810 and 1915 in North Central Texas. Moir's regression coefficient was .93 (95 percent confidence \pm 7 years) for 35 structures with known dates that he analyzed (Moir 1987:80, 1988:272).

To properly use this dating technique, window glass sherds must be measured to the $0.1 \mathrm{~mm}$ and their mean computed to the $0.01 \mathrm{~mm}$. Certain preconditions must be met to use the regression equation. The site must have been constructed between 1810 and 1915 , but have a total occupation of less than 70 years. Glass thicker than $3.2 \mathrm{~mm}$ must be excluded to filter out special varieties of pane glass (i.e., security or safety glass) and flat glass for non-window pane functions (i.e., mirror or aquarium). The glass must be collected from within four meters $(13.12 \mathrm{ft}$ ) of the structure being tested. Finally, structural additions must be recognized and sampled separately.

Window glass thickness has also been used successfully as a predictor of initial date of construction in urban Central Texas. Terry Jones (personal communication 1995) reports a high percent accuracy rate for middle- to late-nineteenth-century sites tested in Austin. The three sites chosen from the Alamodome project are the first sites to be tested with this technique from urban South Texas.

We know precise construction dates for the three Alamodome sites chosen for this study. This allowed us to validate the applicability of window glass as a chronological indicator for urban sites in San Antonio. The window glass dating technique, however, can only be used for sites from an urban context if the residents were of lower to lower middle socioeconomic status (Randall Moir, personal communication 1992). The occupants of the Alamodome sites met this requirement.

\section{BX881 (Oeffinger Site)}

Archival research revealed that John and Anna Oeffinger constructed their home at 123 Grape Street in ca. 1895. A second dwelling at 127 Grape Street was constructed in 1911 behind the primary structure and was used as a rental house. Both houses were demolished sometime around 1938. Nine 2-x-2-ft hand-excavated units and one small trench were within the four-meter limit. Excavation produced 130 flat glass sherds with a mean thickness of $2.22 \mathrm{~mm}$. Using the regression equation, the initial date of construction was estimated as being $1899.6 \pm 7$ years.

\section{BX882 (Haas Site)}

Brothers Julius and Louis Haas constructed their home at 217 Nevada in 1892. They built a rental home (41BX882) at 326 Plum Street on the western portion of the lot sometime between 1900 and 1904. A 1904 map produced by the Sanborn Map and Publishing Company, Ltd., reveals that there was also a two-story outbuilding (undated) in the northeast corner of the lot. The map identifies the structure as 3261/2 Plum Street, 
but does not list it as a dwelling. It would have been unusual for the Sanborn Company to have assigned a numerical address to a non-dwelling. Even more unusual, however, was a 1911 Sanborn map that shows the structure still as not being a dwelling, but this time without an address.

Window glass from 41BX882 was tested from the rental house and the outbuilding. Thirty-one flat glass sherds with a mean thickness of $2.33 \mathrm{~mm}$ were found in association with the rental. One hundred seventeen window glass sherds with a mean thickness of $2.29 \mathrm{~mm}$ were recovered in excavations around the outbuilding. Using the regression equation, the predicted initial dates of construction are $1909 \pm 7$ for the rental house and $1900 \pm 7$ for the outbuilding. Thus, one might suggest that the 3261/2 Plum Street structure was constructed contemporaneously with the Haas home at 211 Nevada, as a guest house or similar temporary dwelling. It may have later (1904-1911) been converted to a shed or storage building, possibly with the completion of 326 Plum Street.

\section{BX900 (Gordon Site)}

Charles Gordon constructed his small "adobe" house at 305 Nevada Street in 1859. The house was sold in 1870 and there is record that the house was expanded upon at about this time (Mechanic and Builders' Liens [MBL], 1872, Bexar County Deed Records, Bexar County Courthouse, San Antonio, Texas). The house was razed in ca. 1925 and covered by a parking lot.

Eighty-three glass sherds were collected from the fourmeter limit around the house. A majority of the sample was recovered while exposing the foundations. The sherds had a mean thickness of $1.97 \mathrm{~mm}$, which would produce a predicted date of construction of $1879 \pm 7$. This is consistent with the glass sample representing the 1870 expansion.

Moir, however, explicitly cautions against using his dating technique on houses that have had additions. The Gordon site graphically illustrates that point: the foundations indicated that the house was originally of the settlement saltbox variety. Photographic evidence of other settlement saltboxes in San Antonio, as well as descriptions found in Mechanics and Builders Liens, suggest that these types of homes had few windows
(Brieg and Associates 1979; MBL 1873). And although the glass sample was collected primarily from around the original foundations, the frame additions in the 1870 s would inevitably have included more windows, and hence the sample reflects this later date.

\section{Conclusion}

We have validated the use of Moir's regression equation for urban lower-middle class dwellings in which independent archival research precisely pinpointed the year of construction. The only case in which the window glass dating technique yielded a result inconsistent with initial construction date proved to be the exception which proves the rule, in that window glass dating yielded a date consistent with that known for the secondary construction added to the primary structure.

We conclude that Moir's regression equation is a valid independent dating method for urban lower-middle class sites ca. 1810-1915 in which the prerequisite sampling assumptions are met. 


\section{References Cited}

Agricultural and Manufacturing Census Records

1880 Manuscript on file at the Center for Archaeological Research, The University of Texas at San Antonio.

Brieg \& Associates

1979 Survey of Historic Structures: Vista Verde South. Submitted to the San Antonio Conservation Society. Copy on file at Center for Archaeological Research, The University of Texas at San Antonio.

Clark, J., Jr.

1989 Urban Archeology: A Culture History of a Mexican-American Barrio in Laredo, Webb County, Texas, Volume 2. Publications in Archeology, Report No. 32. Texas State Department of Highways and Public Transportation, Austin.

Gurcke, K.

1987 Bricks and Brickmaking: A Handbook for Historical Archaeology. The University of Idaho Press, Moscow, Idaho.

Moir, R. W.

1987 Socioeconomic and Chronometric patterning of Window Glass In Historic Buildings, Material Culture, and People of the Prairie Margin: Architecture Artifacts, and Synthesis of Historic Archaeology, Volume V, edited by D. H. Jurney and R. W. Moir, pp. 73-81. Archaeology Research Program, Institute for the Study of Earth and Man, Southern Methodist University, Dallas.

1988 Windows and Window Glass. In Historic Farming on the Hogwallow Prairies: Ethnoarchaeological Investigations of the Mountain Creek Area, North Central Texas, Volume II, compiled by D. H. Jurney, S. A. Lebo, and M. M. Green, pp. 263-272. Archaeology Research Program, Institute for the Study of Earth and Man, Southern Methodist University, Dallas.

Steinbomer, R. A.

1983 Brickmaking in Texas (working draft). Texas Historical Commission, Austin. Copy on file at the San Antonio Conservation Society Library, San Antonio. 


\title{
Chapter 9
}

\section{An Examination of Acequias, Wells, and Cisterns in San Antonio, Texas, Ca. 1850-1930}

\author{
Kevin J. Gross and Guillermo Mendez
}

\section{Introduction}

The Alamodome Project presented an opportunity to learn about mid-nineteenth- and early twentiethcentury water system technology. Evidence recovered from the Alamodome Project suggests that our original assumptions had overemphasized the importance of water acquisition in San Antonio's early urban development. We mistakenly believed that individuals would have actively sought and utilized improved methods for water supply. Instead, we learned that most San Antonians relied on a combination of lessadvanced sources even after the technology for piped water became available.

\section{Valley Ditch}

Spanish missionaries began their first acequia in San Antonio around 1720 . In total, six irrigation ditches were completed by 1745 and remained functional until the late-nineteenth century. In the later years, not only was acequia water being used for irrigation, but also for cooking, bathing, and waste disposal. Because the acequias were constructed within the narrow confines of the San Antonio River's flood plain, they provided little water to the more remote areas of the city. Residents from the east side of the river had plans for the construction of a ditch as early as 1867 . The newly created East Alamo Ditch Co. petitioned the city council on January 19 of that year to construct a branch ditch, known as the East San Antonio and Concepcion Ditch, and to make any consequent repairs to the Alamo Ditch and its dam (City Ordinance [CO] 1867a). It appears that the acequia was to be privately financed. A secretary, a treasurer, and five individualsDevine, Dauchy, Schwartz, Pauly (a project-area resident), and Dewey-were elected to represent the company. The city council appointed Aldermen Smith, McAllister, and Giraud to act on the city's behalf concerning the project. It is also assumed that the ditch commissioner, T. D. Wurzbach, oversaw the venture.

On January 24, all parties concerned met on the west bank of the San Antonio River at the tannery (near the present day Witte Museum) to survey the dam and the Alamo Madre Acequia (City Council Minutes [CCM] 1867:580, Bexar County Courthouse, San Antonio, Texas). They reconvened on the next day to survey the proposed course for the ditch:

That Said Ditch Shall commence at, or near a point on the East bank of the Alamo ditch, where the upper line of North 8th Street strikes said Ditch. Thence in an eastern direction to the East line of Walnut Street, 90 varas [249 ft]. Thence with the East line of Walnut Street, crossing the Seguin Road [Nacogdoches or Nolan St.], at a point 520 varas [1440 ft] from the Alamo ditch, South about 1600 varas to the lower line of Alameda Street [Commerce St.], 575 varas [1592.75 ft] East of the Madre ditch. Thence with Said lower line of Alameda Street, S 753/4 [and] E 175 varas [ $484.75 \mathrm{ft}$ ] to the East line of Cherry Street. Thence with the East line of Cherry Street, South, crossing the Old Goliad Road at a point about 1300 varas [3601 ft] from the Alamo 
ditch, 2050 varas $[5,678.5 \mathrm{ft}]$ to the lower line of the City Tract. Thence with Said lower line of the City Tract $\left(S 73^{\circ} \mathrm{W}\right.$ about 860 varas $[2,382 \mathrm{ft}]$ to the West line of Mission San Juan Road) to the [Mission Concepcion] lands [CO 1867b].

The city council's committee concluded that the East San Antonio and Concepcion Ditch would be of an "incalculable advantage" to the city (CCM 1867:580). Their enthusiasm certainly was related to their belief that the ditch would help drain the elevated eastern portion of the city during heavy rains. The alternative would have been to widen the Alamo Madre, a more costly undertaking that would have been at municipal expense (CCM 1867:580). The project, renamed at an unknown time the San Antonio Valley Ditch, was never begun, however. On May 7, 1868, the San Antonio Herald reported that "when the lamented Mr. Dauchy died, all prospects and hopes of ever having this ditch completed also died" (San Antonio Herald [SAH], 7 May 1868). The article continued, "money was subscribed ... [ [and] the city and county have both given their consent" all that was needed was an enterprising person to take responsibility for the project (SAH, 7 May 1868). The Valley Ditch would remain unexcavated for almost another seven years. Possibly, people believed that since the city would greatly benefit from the ditch's completion, that it should contribute for the construction.

By the early $1870 \mathrm{~s}$, the city council could no longer avoid the issue of constructing new ditches. A steadily increasing population-from 8,235 in 1860 , to 12,256 in 1870 , to 20,550 in 1880 -demanded more irrigated land (U.S. Department of the Interior, Office of the Census [USDI-CO]: 1860,1870,1880). An ordinance for the establishment of two irrigating ditches, one west and one east of the San Antonio River, was considered by city council on February 9, 1874 (CCM 1874a:99). It gave its approval for the construction of the Alazan and Valley ditches (west and east, respectively) later that spring.

The Alazan served residents west of San Pedro Creek, beginning at San Pedro Springs and joining the river south of the city. It was operational by 1875 and completed in 1876 (Noonan-Guerra 1978:18). Bids for the excavation of the Valley Ditch were opened on May 5, 1874. The city council awarded the project to Patrick Campbell on May 15 (CCM 1874a:109). The project was supervised by the city engineer, G. Freisleben. Sources are ambiguous as to how the project was financed. City council records reveal that land owners on the intended line of the Valley Ditch had raised "sufficient [funds] to secure the construction."

The city council had also approved a $\$ 5,000$ construction subsidy, but this portion of the record had been marked out at an unknown time (CCM 1874b:107). Regardless, excavation was completed in about seven months, in December 1874 (CCM 1874b:134). The Valley Ditch has been located on two historic maps, both suggesting different courses. A portion of the ditch appears on an 1877 map created by the City Engineer's Office. This map shows the Valley Ditch flowing on the east side of Cherry Street adjacent to the Alamodome project area (Figure 9-1). The ditch originates at an unknown point north of the project area and continues south beyond Goliad Street (Durango Street) (map in San Antonio City Engineer's Office 1877). It is assumed that Campbell would have utilized the survey records from 1867 for the northern course. An 1889 street map created by J. J. Olsen, however, depicts the ditch following the same course down Walnut Street, but turning east at Centre Street and then turning south on Cherry Street where it flows away from the project area in a southeasterly direction (Figure 9-1). Adding to the confusion, the 1889 map was replicated in 1986 by the San Antonio Historic Preservation Office.

A simple explanation for the inconsistencies is that the 1877 map depicts the original, main channel of the Valley Ditch while the 1889 and 1986 maps depict a second phase of construction, the addition of the Young Valley Ditch, without recognizing the main ditch.

Construction of the Young Valley Ditch apparently began immediately after the Valley Ditch had been completed. It was a fourth-class ditch that began " 190 feet south of Alameda Street [Commerce Street] and [extended] in a southeast direction . . . for three or more miles" (Bexar County Deed Records [BCDR] 1876, Bexar County Courthouse, San Antonio, Texas). The description corroborates the location as depicted on the 1889/1986 maps: it branches off from the Valley Ditch at (approximately) Idaho and Cherry streets. 


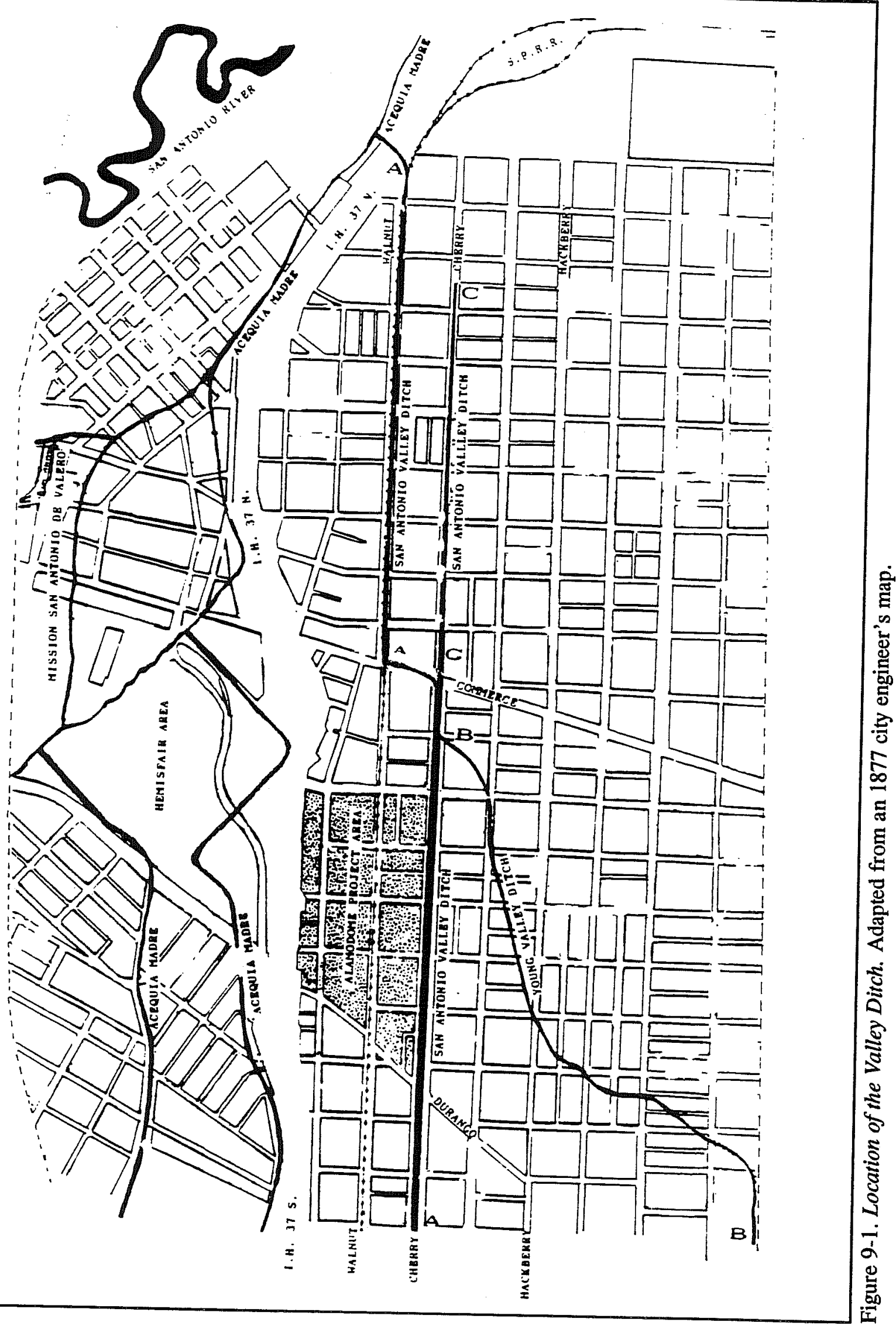


The Young Valley Ditch was constructed by William H. Young, a realtor and attorney, at his own expense. At the time, the state was encouraging "the construction of Canals and Ditches for navigation and irrigation purposes" and had compensated Young with $\$ 1,500$ worth of land adjacent to this ditch. Young completed the project on March 10, 1975, but it was apparently an unsuccessful venture and he sold the Young Valley Ditch (and the adjoining land) to Edward Steves for $\$ 475$ in December of 1876 (BCDR 1876).

Ample information substantiates the location of the main branch of the Valley Ditch as indicated on the 1877 engineer's office map. In a photo taken March 14,1881 , of Steves Lumber Yard at the corner of East Commerce and Cherry streets, a ditch is present. The photograph was presumably taken facing south. Assuming that the ditch in the photograph is the Valley Ditch, it would have run north-south parallel to Cherry Street (Steinfeldt 1979:91). There is also evidence that Carl Runge, whose property was just outside the project area's southeastern-most point, at the corner of Cherry Street and Goliad Road (Durango Street), was using the ditch (San Antonio Express [SAE], 22 June 1881:1a). Northern and southern locations of the main channel relative to the project area can thus be established from this information. The ditch flowed between these two points at the eastern boundary of the project area.

Excavations at the Pauly House (41BX945), revealed a French drain system that supported a Cherry Street location for the main channel of the Valley Ditch. The house, at a point between the Steves and Runge properties, was constructed in 1855 and was located at the corner of Dakota and Cherry streets. A branch of the drain was located 19 inches beneath the surface. It began about $15 \mathrm{ft}$ from the front of the house and extended $40 \mathrm{ft}$ south toward Dakota Street. A second branch, $16 \mathrm{ft}$ south of the northern end of the first, extended east $45 \mathrm{ft}$ until the trench came close to the Alamodome construction area boundary fence, where excavations were terminated. The system was intended to channel water away from the house's limestone foundation toward Dakota Street and the Valley Ditch. It seems highly probable that the Valley Ditch flowed along the entire eastern boundary of the Alamodome Project area.
Little information is available describing how individuals transported water from the acequias to their gardens. Apparently, secondary ditches connecting with the main channel were constructed. The secondary ditches would have been equipped with sluice or control gates to regulate consumption. Users paid a subscription fee which entitled them to use the water at a specified time. The newspapers list numerous accounts of (small) fines being levied against persons for having their gates open at an incorrect time.

A second addition to the Valley Ditch was completed in 1879. It extended south on Cherry Street from North 5th Street to the northeast corner of South Centre Street, where it then connected with the main channel (Figure 9-1). This ditch was intended to relieve the Valley Ditch during heavy rains and floods. The beneficial effect of the extension was marginal, however. Ed Steves complained to the city council about damages to his lumber and shingles by the overflow waters of the Valley Ditch at Cherry Street (CCM G:665). Many homeowners made similar complaints about property damage.

The Valley Ditch also frequently suffered from lack of water. In the late 1870 s, the San Antonio Water Works Company began drawing large amounts of water from the river. As a result, decreased amounts of water made it into the acequia system. The erratic flow caused the Valley Ditch to dry up and become stagnant in places. Carl Runge organized a group of residents to protest the lack of water in the Valley Ditch and complained bitterly because he could not get water from it (see Waterworks). Droughts, obviously, also influenced the amount of water in the acequias.

In the next few years, the city council approved numerous expenditures to keep the ditch operational. In $1881 \$ 380$ was appropriated for repairing and cleaning the ditch and mending six bridges spanning it ( $S A E, 2$ March 1881, 16 March 1881). A year later the city council allocated another $\$ 7,000$ for repairing and cleaning the Valley and Young ditches (SAE, 6 September 1882).

Apparently these attempts were unsuccessful. In 1883 citizens began petitioning for the filling of the main channel from North 8th Street to Center Street. Aldermen Pauly and Bolton thought that the action would be premature. Other members of the 
committee, however, felt the city had already lost a great deal by keeping the ditch open and it was of no benefit to anyone to continue to maintain it ( $S A E$, 4 July 1883). Demands to have the ditch filled continued. The city had to refund subscription fees to an increasing number of people because the ditch was not functioning.

Local health officials also discouraged the use of ditch water. Dr. Menger, the city physician, had been a vocal opponent of the ditches since the early 1880 s. In one letter to the editor, he wrote,

the ditches are the receptacles of all manner of filth and refuse matter [but are] used by the lower class for all purposes . . . the water is shut off once a year, during the month of February, for the purpose of cleaning them out, and this process consists of a gang of men dragging the years accumulation of mud, filth and rubbish upon the banks and leaving it to fester in the sun and to be washed back by the first rains [SAE, 12 October 1880].

Very limited accounts of the Valley Ditch appear after 1884. In the last two years of the decade, parts of the acequia were filled while others had to be constantly drained.

The declining media interest in the Valley Ditch may reflect the change of the area from frontier neighborhood to metropolitan suburb. Increasing industrialization allowed wage earners to purchase more of their food items and the decreased emphasis on gardening would have minimized the importance of the ditches. The gradual acceptance of piped water and increasing knowledge of water-borne diseases would also have influenced the changing perceptions of the function of the ditches. During the mid-1880s and early 1890 s, ditches made a slow transition from being a subsistence necessity to serving as storm drainage and waste disposal areas. If effect, they became just another part of the urban infrastructure.

In all probability the ditches were used by few individuals living in the project area, even when they were working well. Other than at the Pauly site, no archaeological evidence was found of secondary connections.
The Valley and Young ditches were entirely abandoned in early 1890 (SAE, 29 July 1893). One historian concluded that "from the time of its completion, about 1875 , to when it became abandoned in 1890 , the Valley ditch proved to be an utter failure, and but a sorry venture to the city" (Corner 1890:45).

\section{Wells and Cisterns}

Water was difficult to acquire for the residents in the project area. The nearest natural water source, the San Antonio River, was more than a mile away. The Valley Ditch performed poorly and served only a few persons in the area. Archaeological investigations at the Alamodome suggest that most people chose not to go through the time and expense of digging wells and cisterns. Instead, they used a variety of more economical sources, primarily rain barrels, aboveground cisterns constructed of wood, stone, or concrete, and, to a limited degree, aguadores. The latter are water haulers who traveled the city on horseor mule-driven carts, selling river water from a barrel (Figure 9-2). Hand pumps may also have been used after 1870 when auger technology became available in the city (Waynne Cox, personal communication 1993). Such pumps would have been difficult to recognize during excavations.

Only three of the 36 sites had permanent water-holding structures. Two wells and one subterranean cistern were located and subsequently excavated. It is possible that during the monitoring phase, other wells and cisterns were inadvertently demolished or were never exposed.

We anticipated that controlled excavation of wells and cisterns would reveal variable ethnic preference for construction technique and materials utilized; this goal was not realized, however. The two wells that were located had been severely disturbed. Their curbing (superstructure) and portions of their top courses had been destroyed during recent construction. Because of this we are unable to determine if the wells had protective aprons or covers; therefore, only general statements about their construction techniques can be made. 


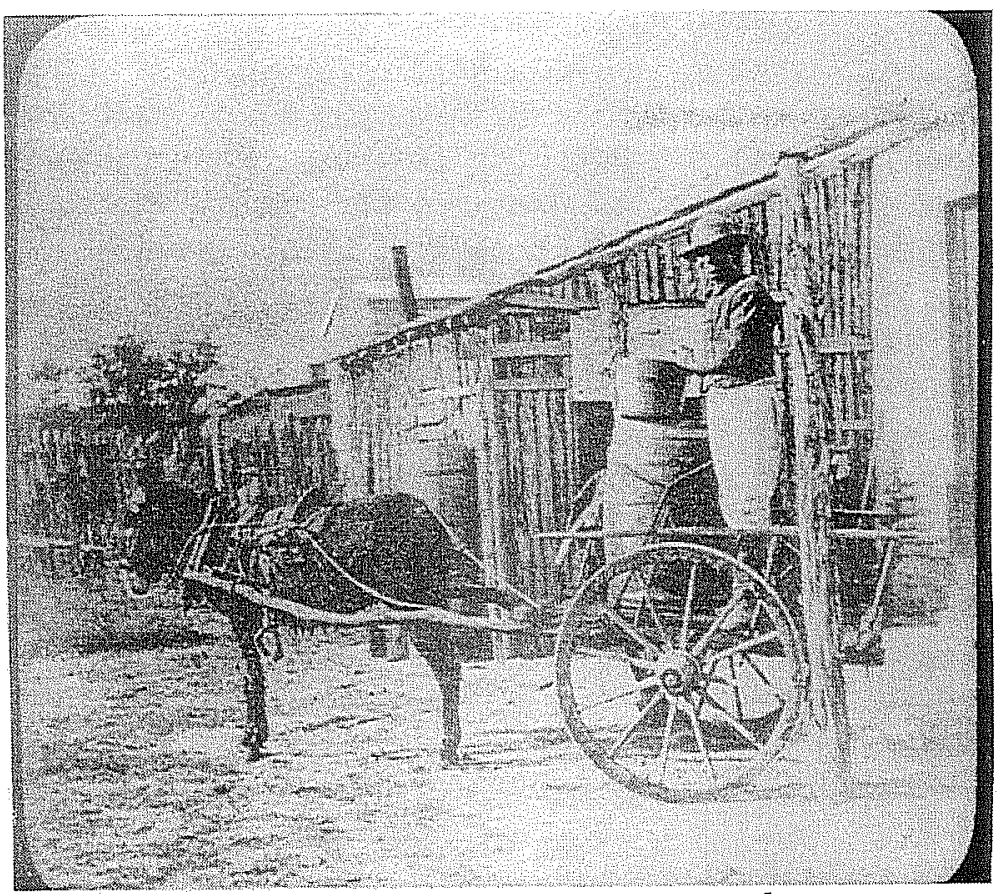

Figure 9-2. Aguador in San Antonio, late-nineteenth century. Photograph from the collection of the Institute of Texan Cultures.

\section{The Webb Well}

The Webb (41BX897) well was found in a backhoe trench during the testing phase. The lot (316 Plum Street/516 Hoefgen Street) had been occupied since ca. 1866 by William Webb, a freed African-American slave. A second dwelling was constructed on the lot around 1889 by Benjamin and Charlotte Deman (Webb's daughter).

A backhoe was used to remove the south portion of the feature with the intention of providing a cross-section for better analysis of the construction techniques utilized (Figure 9-3). Eleven levels (soil changes) were excavated starting at 16 inches beneath the surface and continuing for 144 more inches until the water table was located. Artifacts were recovered at all levels, but nothing of chronological significance was recovered. Artifact density declined at about 76 inches beneath the surface (see Volume II).

The interior of the well was 36 inches in diameter. The average thickness of the wall was 18 inches. Thus, the well was six feet in diameter from wall exterior to wall exterior. The well lining was constructed bottom to top. A variety of limestone debris, rubble, and chunks were densely stacked on top of one another. This method apparently continued until about 36 inches beneath the surface. From this point, two to four courses of poorly cut limestone blocks were laid side by side. Apparently this was an attempt to protect the sensitive zone, extending down about $10 \mathrm{ft}$ below the surface, which is prone to contamination from ground seepage. The exact depth at which this transition occurred, however, is unknown because the top 16 inches had been removed before excavation. We assume the cutblock construction would have continued up into the curbing.

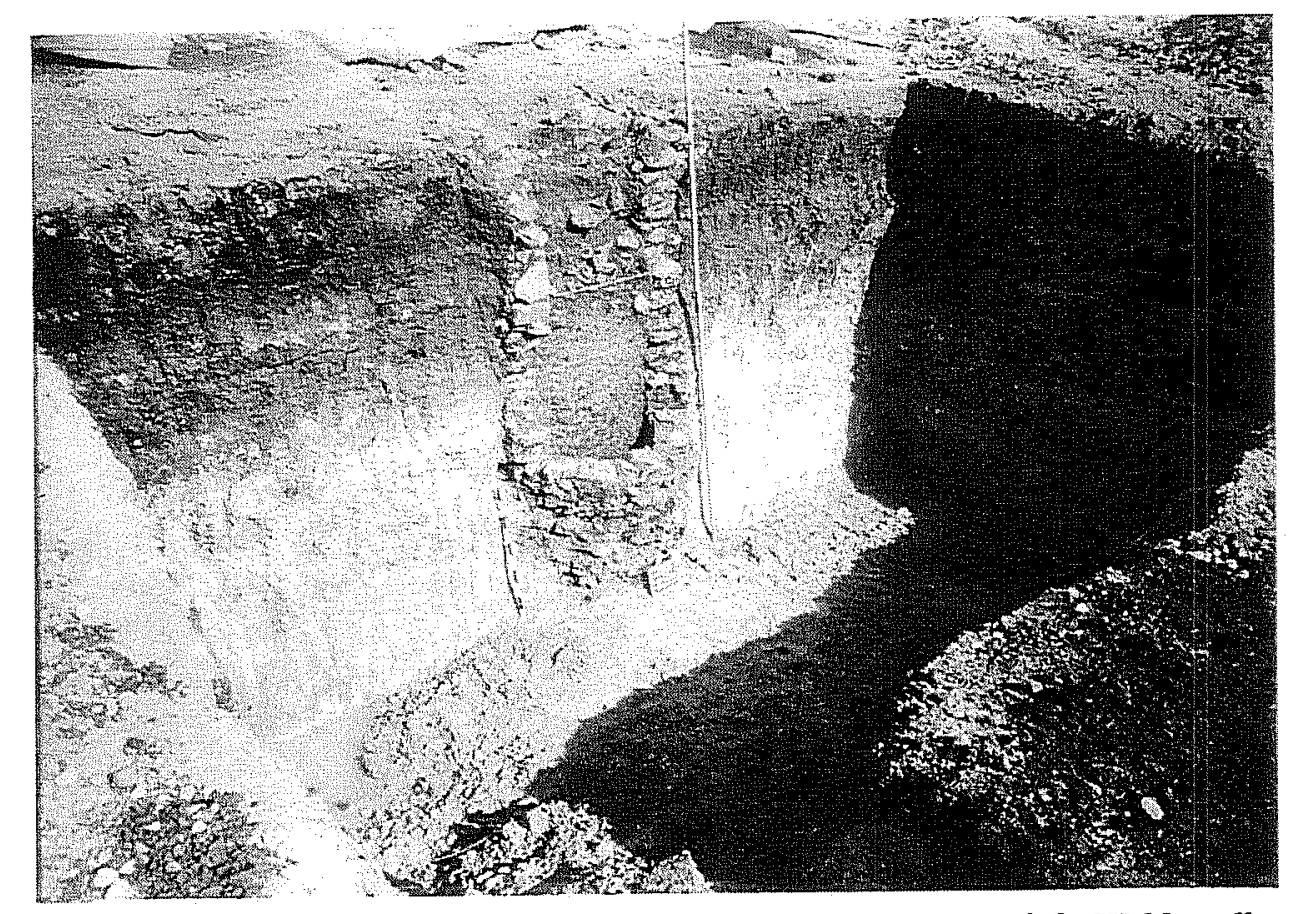

Figure 9-3. Webb well. 


\section{The Ries Well}

The Ries well (41BX930) was found while monitoring demolition within the Alamodome footprint. August Ries had purchased the lot (302 Plum Street/502 Hoefgen Street) in 1888. In 1892 Ries moved to the site with his brother, Adolph. August resided on the property until after 1916. The 1904 Sanborn map suggests that a wellhouse had been constructed around the feature. The entire site, including the well, was covered by asphalt paving in the $1960 \mathrm{~s}$.

Cedar posts had been placed across the well horizontally, serving as a makeshift cap. A track machine had exposed the posts and the unfilled well shaft. The top seven feet of the well were removed in preparation for excavation. The well contained almost no cultural material and the small amount of fill dirt appeared to be related to the recent demolition. The interior measured four feet in diameter and the walls were approximately 12-18 inches thick. Large lime-stone chunks and other limestone debris were used as lining. The water table was encountered at $13 \mathrm{ft}$ 7 inches.

The late construction date (after 1892) of the well is interesting. Waterworks were already in operation in parts of the city. The intensive labor required to construct such a well suggests that the Rieses were not intending to use piped water in the foreseeable future.

It is also intriguing that the two wells were found on the same block (NCB 621). Perhaps this indicates that the water table is at variable depths through the project area, and that it is closer to the surface at the Webb and Ries sites.

\section{The Pauly Cistern}

The only subterranean cistern was located during excavations at the Pauly house at 325 Dakota Street. Peter Pauly was an architect and stonemason of German descent. He purchased the lot in 1855 and lived there until 1895. The cistern system was excavated as three discrete features: channel, filter, and storage area (Figure 9-4).

Rainwater from the roof was carried by eave troughs and directed toward the southeast corner (front) of the primary structure. From there it was carried by downspout to a subsurface channel about 14 inches beneath the surface. The channel was 4-6 inches wide and 5-6 inches top to bottom. The bases of the channels were plastered and flat limestone pavers were used for the sides and top. The channel was $5 \mathrm{ft}$ east of the house and ran south to north for $35 \mathrm{ft}$ until emptying into a subterranean filter.

The filter measured $3.75 \times 2.9 \times 4.58 \mathrm{ft}$ and was east of the northeast corner of the primary structure. It contained four layers which, from top to bottom, included: sand and gravel, pea-sized gravel, charcoal, and large chert cobbles at the floor. Such materials improved the taste and smell of the water and aided in removing unwanted organic materials (leaves, for instance). The water then entered the main storage chamber through two small apertures in the northeast and northwest corners of the filter. The apertures also contained chert cobbles.

The cistern was appended to the northeast corner of the house. The interior measured $9.1 \mathrm{ft}$ east-west and $8 \mathrm{ft}$ north-south and was $12 \mathrm{ft}$ deep. The cistern was constructed of cut limestone blocks, the interior was plaster-lined, and the bottom showed evidence of being heavily plastered. The angled top two courses suggest a vaulted limestone roof had existed. Wright (Volume II) estimates that the cistern could have held up to 6,535 gallons of water. A channel that transported excess water back into the filter during overflows was also located.

Pauly may have chosen to construct a subterranean cistern because it may have been less expensive than an above-ground system. Knowing he was a stonemason, this certainly seems plausible. A reason as innocuous as cooler water temperatures may have also influenced his decision.

The health risks associated with water drawn from a well or a cistern were well known by the general public. It was known that wells and cisterns near privies tended to become contaminated. Recent literature suggests that water sources such as wells and cisterns should be separated from privies by at least $150 \mathrm{ft}$. But San Antonio's relatively arid climate may retard seepage and, hence, reduce this distance. 


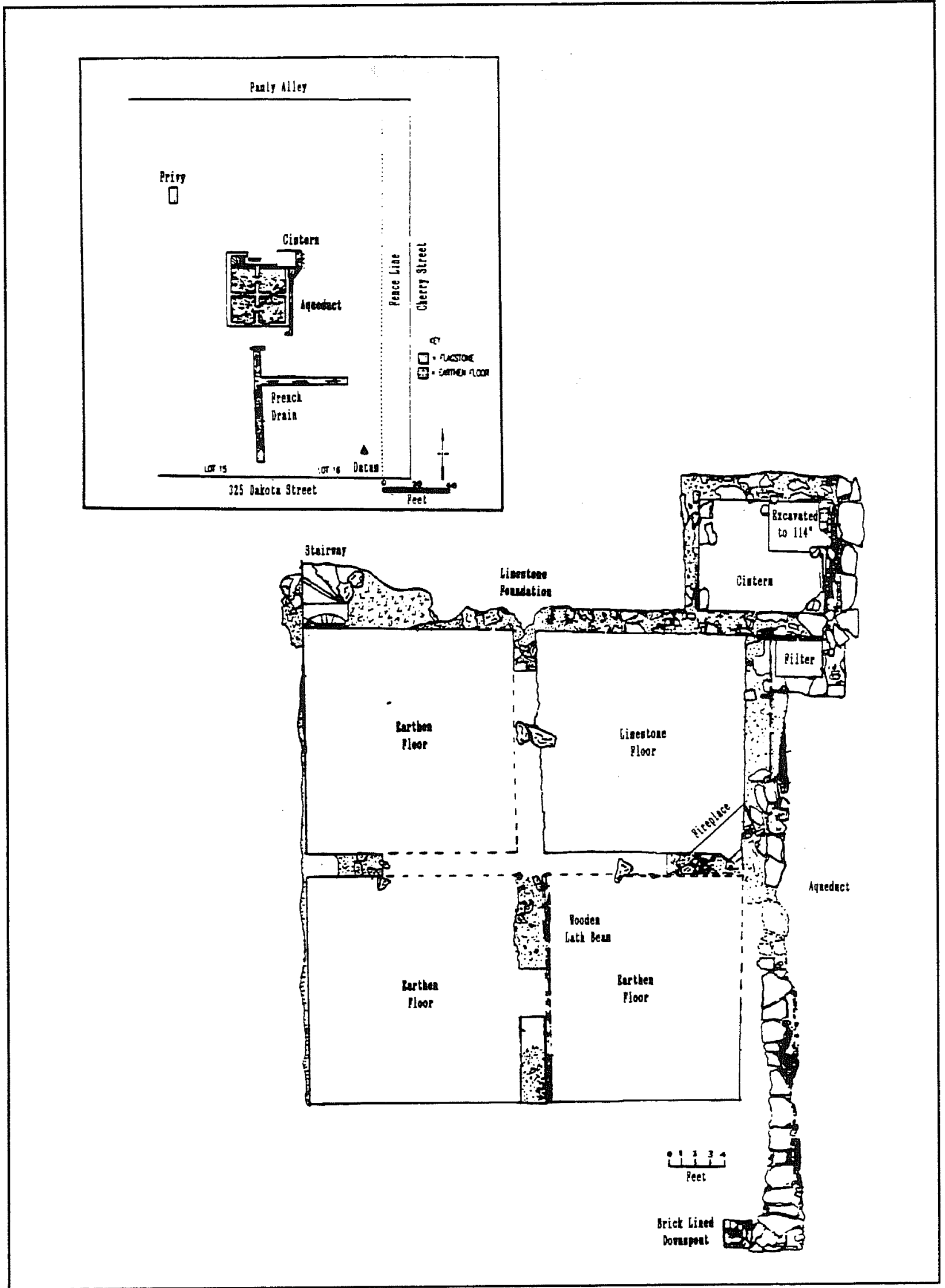

Figure 9-4. Plan map of the Pauly site. 
Newspaper articles also frequently warned against careless contamination. The decomposition of animal and vegetable matter and disposal of soap suds were known to have contributed to pollution ( $S A E, 4$ August 1878). Well owners were specifically reminded of some basic precautions: "have the top of the well at least two feet above the level of the yard, and be certain that there is no contaminating substances at the bottom. No slops or dirty water should be thrown near the well, and the farther away that ... sinks are located the better" ( $S A E, 9$ August 1878). These articles, however, do not mention that the rope and bucket method of drawing water could also be a source of bacteria that could contaminate the water.

In 1883 a chemical and microscopic analysis of city's water was undertaken by Drs. Christian and Menger. Their report suggests that the city's water quality was extremely poor. Well water taken from the fourth ward (at a location just north of the project area) was described as being "very bad." The water had relatively higher amounts of nitrates, albuminoid (water soluble proteins), ammonia, chlorides, and miscellaneous organic material when compared with water drawn from other sources in the city. They also measured 25 grams per quart of (unidentified) solid material. Their report concluded that the best water in the city was from the hydrants of the city water system ( $S A E, 16$ November 1883).

It would not be for another 12 years that the fourth ward would be supplied with piped water. Even then, it took the residents another 10 years to fully utilize the convenience of piped water.

Simple, above-ground water structures appear to have been popular alternatives to wells and subterranean cisterns in San Antonio. City directories and newspapers contain numerous advertisements for cisterns and rain barrels. Lumber and cement companies probably dealt in such items. Individuals may also have constructed such devices for their own needs. Photographs in the collection of the Institute of Texan Cultures indicate that rain barrels may have served as informal, above-ground cisterns. Barrels were inexpensive, reusable, transportable, and easily cleaned.

George Mandry appears to have been one of the more successful coopers and cistern builders in the city. His advertisements in the city directories from 1873 to 1904 reveal changes that were occurring across the city. In the earlier advertisements, Mandry sold cisterns ranging in size from 300 to 2,500 gallons and barrels of various sizes (City Directory [CD] 1877). Beginning in the mid-1880s, Mandry and other coopers and cistern builders began de-emphasizing barrels for collecting rain, but simultaneously began diversifying their product line to include plumbing goods (CD 1881,1883 , 1885). Mandry specifically began targeting the rural market in the late 1880s (CD 1887). In 1890 he increased the maximum capacity of his cisterns to 100,000 gallons, probably for stock tanks or commercial use (CD 1892, 1895, 1897). The market for rain barrels may not have entirely died out in the city, though, for the city directory indicates that Frank Steffen began his cooperage firm at the late date of 1895.

\section{Waterworks}

Piped water was a relatively late development in San Antonio. Numerous cities had operating water systems decades before: Cincinnati had a functioning woodenpipe network by the mid-1820s, Pittsburgh had completed its water system by 1830 , and Boston and St. Louis had piped water by the late-1840s.

The San Antonio city council first considered a waterworks system in 1858. There were failed attempts to organize such a company in 1873 and again in 1875 , but it was not until 1877 that the waterworks were established. On April of that year, the city council gave a 25-year contract to J. B. LaCoste and his associates, W. R. Freeman and S. A. Oliver, for supplying the city with piped water.

The San Antonio Water Works Company generated only a moderate amount of public support. Two weeks after LaCoste's announcement, an informal poll conducted by the San Antonio Express showed that the city was divided between approval and disapproval (SAE, 20 April 1877). In a letter to the editor, an anonymous writer was annoyed because the matter had not been decided by a vote. This seems to have been the most common concern as the $S A E$ published numerous articles and letters condemning Mayor French and the city council as "dictators" (SAE, 20 April 1877). Other letters to the editor expressed fears 
about piped water being an invitation to mass disease (SAE, 14 April 1877).

Previous researchers (Baker 1978a; McLean 1924) suggest that memories of the cholera epidemic of 1866 provided the impetus for the construction of the waterworks system. LaCoste's motivation may not have been so altruistic. This was a for-profit venture and there was a large potential market. It was common practice for the city to rely on private financing for public improvements. Unprofitable public services, in fact, remained undeveloped (Mayer 1976).

A pump station and reservoir were constructed within a year. Water was drawn from near the head of the San Antonio River. An enormous mechanical plunger would force water through a mile-long raceway to the $5,000,000$ gallon capacity reservoir. Water was then distributed by gravity through the main pipes of the waterworks (McLean 1924:6). The average decline in elevation from the reservoir to the central part of the city was between 100 and $150 \mathrm{ft}$. Excess water from the reservoir was put back into the river at a point just below the Alamo Ditch.

The waterworks completion on July 9, 1878, was announced by the San Antonio Express with little fanfare ( $S A E, 10$ July 1878). Contractually, it appears that the supply of potable water was the tertiary interest of the Water Works Company. The company's more immediate interests were to supply the city's fire protection and sanitation needs.

The Water Works Company's initial success at selling subscriptions to private homes was limited. After one year of operation, only 350 persons or places were paying to receive piped water. This number seems astonishingly low when one considers that the summer of 1879 was described by local media as being a "terrible drought" (SAE, 26 July 1879). In fact, San Antonians reportedly for the first time had to rely on aguadores.

The earliest private customers of the waterworks were those families who could afford the hidden expenses of being connected to the system. In a peculiar policy, the company tapped the main, but after that the homeowner was responsible for installing pipes. There was also the considerable expense of purchasing kitchen and bathroom fixtures. This may explain in part why many of the early customers simply installed a spigot in the yard and carried water in buckets.

The waterworks had its first, indirect impact on residents in the project area as early as April 1880. Eastside residents complained that the Valley Ditch had far less water than the other ditches ( $S A E, 7$ April 1880). By July so little water was flowing from the San Antonio River's springs that almost no water was to be found in the Valley Ditch. The Alamo Ditch, which was the source of supply for all ditches east of the river, originated below the out-take channel for the waterworks. The channel was taking water out of the river above the Alamo Ditch's origin and returning it to the river below the ditch. After receiving several complaints, the city council ordered the Water Works Company to decrease their pumping by 50 percent (SAE, 9 July 1880$)$.

More than 500 people were paying for ditch water on the Eastside ( $S A E, 9$ July 1880). They believed that their claims to water had precedence over those of the waterworks, even if it meant that the company would have to stop operations entirely. On July 13, 1880, a meeting of concerned residents from the fourth ward was called. They demanded that the city council act on their behalf, "citizens had the right to the privilege of irrigation. It came to them from the King of Spain, and the city council, as the guardian of the people, should be appealed to for protection" ( $S A E, 14$ July 1880 ).

The eastsiders met frequently during the next month and soon decided that they should be known as the San Antonio Irrigation Association (SAIA). The previously mentioned Carl Runge, whose property was adjacent to the southern project area boundary, was elected chairman. The SAIA's only stated objective was to prevent the Water Works Company from interfering with their irrigation privileges ( $S A E$, 20 July 1880, 24 July 1880).

The dispute between the SAIA and the Water Works Company was settled by a flood on August 13, 1880. Reportedly, all the ditches in the city flooded their banks when a storm dropped 7.5 inches of rain on the city ( $S A E, 14$ July 1880). The SAIA met just one more time. They expressed their dissatisfaction with the indefinite manner in which the city council had disposed of such an important matter ( $S A E, 10$ September 1880). Furthermore, they promised to 
make the ditch question a leading issue in the next city election. They were, however, never heard from again.

The number of waterworks customers continued to be small for several more years. This slow transition could be due to the water rates, the company's excessively restrictive usage policy, and/or the expense of making the necessary additions to the house. There were far fewer subscriptions than anticipated and LaCoste was forced to sell the Water Works Company to George W. Brackenridge in 1883. The latter was a banker who had accumulated his wealth from selling cotton during the Civil War (Webb 1952:202). The company grew rapidly in the first years of his control.

Brackenridge's success is reflected in the increasing number of men who listed their sole occupation as plumbers in the city directories. There were never more than three plumbers in San Antonio while LaCoste owned the Water Works Company (CDs 1877,1881 ).Throughout the 1890 s, however, as many as eight individuals supported themselves by connecting customers to the waterworks (CDs 1892, $1895,1897)$. An increase in the number of advertisements for pipes, plumbing equipment, and kitchen and bathroom fixtures occurred during this time.

In the next five years, growth of the city and a consequent extension of the company's mains forced the construction of a second pumping plant and the installation of a steam turbine pump. The original water turbine and pumphouse were still used as an auxiliary.

The extent of the waterworks through time was approximated by following the city's fire limits. In the first five years of operations (1878-1883), for instance, the mixed residential-commercial central portion of the city had access to piped water (CD 1881). By 1893 the waterworks expanded to include a large area concentrated in the northern parts of the city (CD 1892). Segments of the project area were first included in the fire limits sometime before 1898, probably by 1895 (CDs 1897,1899 ).

In 1888 Brackenridge became convinced that there was danger of the complete failure of the river as a source of supply following any long period of drought; consequently, he drilled a well near the reservoir as a reserve. This well did not flow and its capacity was small. The well was eventually abandoned because of the difficulties associated with pumping it (Baker 1978a:8).

Sill intent upon getting a new source of water supply, Brackenridge purchased property on Market Street in the belief that he could strike the artesian basin at a lower level. In addition to the economic reasons for seeking an artesian supply of water, Brackenridge also considered the importance of health to the city. Dr. Ferdinand Herff, an epidemiologist-and close friend of Brackenridge-recognized the potential danger of the reservoir system. Herff urged Brackenridge to secure an absolutely pure protection against certain germ diseases or at least against any epidemic from any such diseases (McLean 1924:10).

An eight-inch well was sunk at the Market Street site in 1891 to a depth of $890 \mathrm{ft}$. This well flowed at $3,000,000$ gallons per day. It was quickly followed by other wells, 12 inches in diameter. In 1895 steam pumps were installed for the direct distribution of water through mains radiating from the plant and serving the district south of Houston Street, including the project area, where the pressure had been inadequate from the reservoir supply (McLean 1924:10).

Examination of the Sanborn insurance maps (SM) reveal that by 1904 no house in the project area was more than one block from a water main. A 16-inch secondary pipe ran north-south along Cherry Street, terminating at an unknown location. Smaller five- and six-inch pipes were laid down on Dakota and Hoefgen streets, respectively. Pipes were installed on Nebraska Street, Victoria Street, and short sections of Walnut Street sometime between 1904 and 1911 (SM 1904, 1911). No documentation reveals when individual houses were connected, but we assume the presence of pipes indicates that families began connecting to the waterworks between 1895 and 1911.

Brackenridge had endured public criticism for a quarter of a century. He worried about new sources of water and the possibility of epidemics, all the while fighting a running battle with the city government over the water system (Sibley 1973:159). In 1906 Brackenridge opened negotiations with investors from 
St. Louis. The waterworks company was purchased in that same year with George Kobusch as the majority stockholder (Baker 1978b:15). In 1909 the Mississippi Valley Trust (MVT) Company, acting as a representative for Kobusch, negotiated the sale of 90 percent of the stock to a Belgian capitalist group. Operations continued under the name Compaigne des Eaux de San Antonio with the MVT acting as the principle representative (Baker 1978b:15).

The company continued to increase their output to keep up with the demand. In 1914 the waterworks company drilled three additional wells at the Brackenridge Park pumpstation, increasing its output to 20,000,000 gallons per day (McLean 1924:13). A third pumping plant was constructed in the southern portion of the city in 1922 . The electrical pumps there had a daily capacity of $6,000,000$ gallons per day (McLean 1924:14).

The Belgians were forced to sell the company to 12 local investors in 1920 to aid in the post-World War rebuilding efforts. Five years later the city purchased the company, which today operates under the name San Antonio Water System.

\section{Conclusion}

Techniques for the acquisition and disbursement of water have changed widely over time. Health concerns, economics, and technological innovation have influenced consumer preference. In the period from ca. 1850-1930, families in San Antonio had many options for securing water.

Archival research substantiates that the residents in the Alamodome Project area had access to the Valley Ditch. Through time it went from being regarded as a subsistence necessity to serving as a storm drainage channel. Growing knowledge of waterborne diseases and the area's increasing industrialization may have influenced the disuse of the Valley Ditch for irrigation purposes in the late 1800 s.

Wells and cisterns provided drinking and cooking water for a limited number of these families. Early chemical and microscopic analysis, however, suggest that the quality of the water in the area was poor. Also, water drawn from these structures was easily contaminated. As a consequence, less expensive and more sanitary above-ground water structures became a popular alternative.

As the city passed into the twentieth century, families in the Alamodome Project area finally had access to piped water. The transition to being sole supplier of water was a gradual process across the city. The cost of installing the system may have been too expensive for some families; they had to hire a plumber, purchase fixtures, and consider the substantial expense of building onto their house. Other families may have puzzled over the concept of paying for water when they could draw it for free. These families may not have regarded the waterworks system as an improvement, but as a convenience.

After 1911 most of the project area residents were turning on their faucets. Eventually the acceptance of the waterworks system allowed the area to develop from a frontier neighborhood into a metropolitan suburb. 


\section{References Cited}

Baker, T. L.

1978a A Brief History of the San Antonio Waterworks. Perspective, March:7-8.

1978b An Interesting History . . . How San Antonio Water Planners can Guarantee Adequate Supply for Fast Growing City. Southwest and Texas Water Works Journal 4:12-15.

Corner, W.

1890 San Antonio de Bexar: A Guide and History. Bainbridge and Corner, San Antonio.

Mayer, J. A.

1976 San Antonio, Frontier Entrepot. Ph.D. dissertation, The University of Texas at Austin. University Microfilms International, Ann Arbor.

McLean, B. J.

1924 The Romance of San Antonio's Water Supply and Distribution. San Antonio Printing, San Antonio.

Noonan-Guerra, M. A.

1978 The Story of the San Antonio River. San Antonio River Authority, San Antonio.

San Antonio Express [SAE]

1877 The Waterworks Question. How Our People Received the Action of the Council. 20 April.

1877 The Waterworks Question. A Citizen's Views on the Subject. 14 April.

1878 A Timely Appeal-The Physicians of San Antonio to the City Council. 4 August.

1878 Clean Your Wells. 4 August.

1878 Doings of the City Dads. 10 July.

1879 Local News and Gossip. 26 July.

1880 [article about drought]. 7 April.

1880 The Waterworks Forced to Reduce the Pressure. 9 July.

1880 Irrigation vs. Waterworks. 14 July.

1880 A Watery Affair. 20 July.

1880 The Irrigators Organizing. $24 \mathrm{July}$.

1880 Heavy Rains. 14 August.

1880 [article about city council meeting]. 10 September.

1880 Our City's Health. 12 October.

1881 City Council Proceedings. 22 June.

1881 Committee Report. 2 March.

1881 The City Fathers. 16 March.

1882 City Council. 6 September.

1883 City Fathers. 4 July.

1883 Water. 16 November.

1893 Ditches of San Antonio. 29 July.

San Antonio Herald [SAH]

1868 [article] 7 May.

Sibley, $\mathbf{M}$.

1973 George W. Brackenridge, Maverick Philanthropist. University of Texas Press, Austin. 


\section{Steinfeldt, C.}

1978 San Antonio Was. San Antonio Museum Association, San Antonio.

Texas State Department of Health [Texas Water Commission]

1970 Untitled pamphlet. Texas State Department of Health, Austin. On file at the Center for Archaeological Research, The University of Texas at San Antonio.

\section{Webb, W. P.}

1952 The Handbook of Texas. Volume 1. The Texas Historical Association, Austin. 


\title{
Chapter 10
}

\section{Beneath a Crescent Moon: A Contextual and Architectural Analysis of Privies from the Alamodome Project Area}

\author{
Maureen Brown and Nora DeLaO
}

\section{Introduction}

The word "privy" comes from a Latin word meaning "private place." For this study, the definition of a privy pit is a pit lined with wooden posts, cut stone, brick, or containers such as wooden crates or trunks, interred or dug below an outhouse for the primary purpose of the disposal of human waste materials. To historical archaeologists, the privy pit or vault can provide a wealth of economic and social information about the system's users (Geismar 1993:1). Privies were not only used for depositing human excreta, but also served as convenient trash receptacles for both organic and inorganic materials. Once the vaults no longer functioned as repositories for human waste, they were filled with trash immediately or in gradual stages. Many objects discarded in the pits in the Alamodome Project area were items used daily by the early urban San Antonio residents. Today, these discarded items are the artifacts that tell a story about their previous owners.

In this chapter we compare the archaeological and historical data from 12 privy pit features excavated during the Alamodome Project. Several objectives are addressed in this paper. First, to review the information available from previous excavations of privy pits in the San Antonio area. Second, to compare this with the San Antonio city ordinances that regulated matters regarding privies and the disposal of human waste within the city limits. Correlations of the individual privy pit features are made and include a comparison of privy pit placement on city lots, construction materials used to build the pits, and size. This information has a dual purpose: to see how well the privy pit features conform to the ordinances, and to determine whether there are patterned stylistic variations in the construction materials utilized and in the size of the pit features. These comparisons and differences in the construction material and size for the Alamodome privy pit features are also compared to the same approach used to compare the New Orleans privy pit features reported by Douglas Bryant (1988:66-76). Bryant suggests that the study of the privy pits can provide information related to chronology, ethnicity, and status (Bryant 1988:76). The main premise in his study was that

groups separated by temporal, ethnic or social distance will mark their creations, whether pottery or house foundations, with mutually distinguishable stylistic loads that go beyond strictly functional considerations. In this manner, style marks group affiliation and distinguishes one group from another. Style defines boundaries which serve to mark and even preserve ethnic and social divisions [Wobst 1977 in Bryant 1988:66].

It is hoped that the analysis of the data from these 12 privy pit features can not only add to this hypothesis of patterned variations, but go further in suggesting that standard construction materials and dimensions, or patterned similarities, are a reflection of urban development. The third objective is to analyze the 
artifacts within the privy pit features to determine whether artifact group percentages for each feature can provide information and patterned variation on chronology, socioeconomic status, and ethnic background of the individuals responsible for the deposition of the contents.

\section{Methodology}

Due to the pressures of the Alamodome construction schedule, particularly within the dome footprint and laydown areas, not all of the sites desirable for investigation could be excavated, and the removal of certain sites was monitored rather than tested or mitigated. When significant features were uncovered during the monitoring phase, construction machinery was halted briefly and the feature was examined and recorded. The sites chosen for mitigation were those that were accessible for sufficient time to do a careful excavation and which promised significant structural and historical information.

The 17 city blocks investigated during the project yielded 12 features determined to be privy vaults. The privies were numbered 1 through 12 in the order in which they were found. Five of the privy pits were monitored, four were tested, and three were totally excavated. Site excavation techniques included excavations by hand, combined when appropriate with use of a backhoe to expose the top of the pit. Vertical control on hand excavations was maintained using arbitrary 5-inch and 10-inch levels. All feature matrix was screened through $1 / 4$-inch mesh for maximum recovery of artifacts. Artifact group frequencies are given in Appendix 10-A, Table 10-A1, and count comparisons for three privies are listed in Appendix 10-A, Table 10-A2. In addition, soil and flotation samples were taken for studies on soil composition and light and heavy fraction analysis (see analysis of finescreened privy samples in Dering, this volume).

Level notes and feature forms were completed during the field excavations. Scaled black-and-white photographs and color slides were taken, and plan maps and profiles were drawn for the pit features.

Archival documents aided in the study of the pit features during the field investigations and during the analyses of the features. The archival documents include the following.

1) Sanborn Insurance Maps (SM) from 1904 and after, available at John Peace Library, The University of Texas at San Antonio

2) City directories (CD), available at the San Antonio Public Library, San Antonio, Texas.

3) Waste water management records (WWMR), archived San Antonio Water Systems, San Antonio, Texas.

4) U.S. census records (CR), available at CAR, San Antonio, Texas.

5) City ordinance (CO) books, available at San Antonio City Hall.

6) County abstracts (CA) available from Bexar County Court House, San Antonio, Texas for 1850-1930.

Laboratory procedures for the privy pit artifacts included washing, sorting, labeling, and cataloging. Once the artifacts were cataloged, further detailed analysis of the ceramics and bottles was done to facilitate dating the contents of each privy pit.

\section{Previous Privy Excavations in San Antonio}

Before the Alamodome project, CAR had carried out three other urban archaeological projects that included the excavation of privy pit features. Of the three projects, one identified a "latrine pit." This pit, conforming in appearance to others discovered in rural Texas areas, was an unlined earthen vault. Highley (1978:1-45) analyzed the contents of this pit which was found within a test trench during excavations on Arciniega Street in downtown San Antonio (Katz 1978). The analysis of the pit's contents suggested that the materials were trash deposited from a residential household and dated from ca. 1880-1890. The bulk of the material was bottle glass fragments, but other typical trash pit items included broken dishes, tin cans, food scraps (animal bone, egg shell, etc.), and other broken or expended items that reflected the household's daily activities (Highley 1978:42). It was 
noted that only a small amount of construction material was recovered, probably due to the limited construction on the site during the 1880-1890 period. This house was constructed in 1850 , but the discarded items probably represent materials worn out and discarded during a limited, later period of occupation (Highley 1978:34). Highley did not discuss the occupants of the house at the time of the privy pit fill episode.

Two other projects included excavations of lined privy pit features that were similar in construction to some of the Alamodome features. One feature was excavated by Labadie during additional excavations at the Fairmount Hotel Project in 1986 (Labadie 1986). A brick-lined, one-meter-square feature located within a backhoe test trench was completely excavated by hand to sterile caliche at a depth of 2.4 meters (Labadie 1986:17). The upper $50 \mathrm{~cm}$ was a coal/cinder matrix containing only a few artifacts. Below this was a deposit of animal bone, bottles, ceramics, metal objects, toys, and construction debris. These dated from the late-nineteenth to early twentieth centuries. This feature was suggested by Labadie at the time to be an incinerator where trash had been burned, although he noted that out of the 140 animal bones recovered, only 14 were thermally altered (Labadie 1986:17).

The other downtown archaeological project by CAR that included excavation of privy pits was the Las Tiendas project, later renamed Rivercenter Mall. Of seven features recorded, four stone-lined pits and one brick-lined pit could be confidently recognized as privy pits by their general size and shape. Two smaller, brick-lined pits were not immediately identified. It was not until the city ordinances were compared with the dates of construction during the analysis for the Alamodome project that all of these small-capacity, brick-lined pits were confirmed to be privy vaults. The Las Tiendas Project report is currently in preparation. Table $10-1$ provides information about the privy pit features from this project (Anne Fox and Kevin Gross, personal communication 1993).

\section{Privy Pits in General, City Ordinances, and the Alamodome Features}

Many complex societies such as the Greeks, the Romans, and civilizations in the Indus Valley had water and sewage disposal systems, but these systems were developed and then lost or abandoned at different periods and by different cultures over time (Geismar 1993:58). During the Middle Ages, the urban privy pit apparently functioned throughout Europe, but other means such as dumping sewage into streets or rivers were also used. However, where there was no flowing water, there was usually the need for the privy pit and, of course, the privy cleaner (Geismar 1993:58-59). In San Antonio well before the turn of the century, many ordinances were already in place regulating the construction and upkeep of privies within the city limits. Everything was regulated, from where to place

Table 10-1. Construction Information for the Las Tiendas Privy Pit Features

\begin{tabular}{||c|l|c|l|l|c||}
\hline Site & Construction & $\begin{array}{c}\text { Interior } \\
\text { Dimensions (ft) }\end{array}$ & Occupation & Ethnicity & Date \\
\hline 41BX632 & Limestone & $5.0 \times 7.0$ & Brewer & German & $1860 \mathrm{~s}$ \\
\hline 41BX633 & Brick & $4.5 \times 4.5$ & Bookseller & German & $1870 \mathrm{~s}$ \\
\hline 41BX634 & Limestone & $4.0 \times 4.0$ & Carpenter/Mason & Belgian & $1860 \mathrm{~s}$ \\
\hline 41BX635 & Limestone & $3.0 \times 5.0$ & Storekeeper & German & 1865 \\
\hline 41BX637 & Limestone & $3.6 \times 7.0$ & Builder & German & $1860 \mathrm{~s}$ \\
\hline 41BX642 & Brick & $2.6 \times 2.6$ & & German & $1880 \mathrm{~s}$ \\
\hline 41BX643 & Brick & $3.0 \times 3.0$ & & Anglo & $1880 \mathrm{~s}$ \\
\hline
\end{tabular}


the privy on one's property, to the proper maintenance of the privy. However, the San Antonio city ordinances were in place relatively late compared to earlier established cities in New England and the Southeast. This was primarily due to the late establishment of San Antonio as a modern city, which did not take place until the 1870 s. This was not unusual in that many cities in Texas and the western region of the United States did not experience urban growth until the late-nineteenth and early twentieth centuries. Like most modern cities, the population of San Antonio began to increase during the 1870 s and 1880 s with an influx of immigrants. As cities grow in population, a need arises to develop laws to regulate certain everyday behavior of all who live and work within the set boundaries of the city. For the purpose of this paper, we look at some of the San Antonio city ordinances that regulated privies, privy pits, and related topics (i.e. garbage, sewage, odor, health and hygiene, etc.). It is argued that there became a need for privy pits to become standardized and lined with brick as San Antonio became more heavily populated. Previous pits were lined with whatever material the individual selected. We see this in the earlier constructed privy pits in the San Antonio area. Even today where privy pits and latrines remain in rural areas and on old farmsteads, we see the pits are often randomly dug as an earthen pit. When this pit fills, another is dug in its place (Anne Fox, personal communication 1993). When living space is not as much a factor, there are more choices in style and innovation; however, with less living space as in the city, everyday needs such as garbage and sewage disposal become more standardized and controlled. In this case, especially during the 1880s in the city of San Antonio, it became necessary to clean the pits on a regular basis.

\section{Health Hazards and the Regulation of Privies}

Many health-related city ordinances came into being because of cholera epidemics and concerns about other transmittable diseases. The city created ordinances for disease prevention and for the upkeep of privies and other refuse that might contribute to the spread of disease. A primary purpose of the health-related ordinances was to encourage upkeep of the city so that trash and offensive odors, associated with rotting waste, would not contaminate the neighborhoods. A Board of Health was created and special sanitary inspectors were assigned to individual wards to control city sanitation and to make sure that the ordinances were upheld (CO, 1883:56; $\mathrm{CO}, 1883: 61)$.

Other cities also instituted laws and practices to improve sanitary conditions. For example, by 1799 New York City was prompted to do so by annual onslaughts of yellow fever during the mid- to late1790s (Geismar 1993:59). In New Orleans the first sanitary code was established by the city council in 1817. It was founded to administer the Quarantine Act, but the board also shouldered increasing responsibility for the cleanliness of the city (Gillson 1967:132 in Bryant 1988:69).

Concerns about San Antonio's cleanliness had been expressed as early as 1867 , when an ordinance was passed requiring inhabitants to deposit garbage on Mondays, Wednesdays, and Fridays in barrels to be carried outside the city limits because of an epidemic of fever. The ordinance also dealt with "regulating the cleaning of yards, streets, kitchens and dwellings because of epidemic" (CO, 1867:330).

An ordinance of April 18, 1882 (CO, 1882:64), revised several of the health issues. A city physician was named to direct "the mode and designate the proper materials or disinfectants to be used by individuals in cleaning their premises and in cleaning and disinfecting their sinks and privies and any person who shall violate, refuse, or fail to comply ... shall be fined."

An ordinance passed in 1883 dealt with the assignment of public officers to deal with the inspections of "diseased" homes and businesses and the strict enforcement of all of the sanitary ordinances that the city had passed (CO, 1883:81). Section 13 of this ordinance specifically mentioned the sanitary inspector's responsibility to report

all privies, stagnant water or stagnant pools, to cause the removal of all dead animals, garbage and filth, to report any locality that may be infected with low fevers or any kind of epidemic, report all persons who are using the streets as sewers emptying slops and refuse therein and to see that they are brought up before the recorder and make to understand through penalties imposed that they cannot persist in such acts. 
Section 5 of this same ordinance states that

fecal matter not thoroughly deodorized and disinfected every 2 weeks, in any privy in this city ... the Board of Health shall upon receipt of complaint, cause any privy to be inspected, and if necessary cleaned and disinfected and it shall be the duty of any person or persons occupying premises on which any such privy is situated to permit the same to be inspected cleaned or disinfected at the time designated by the Health Officer of the Board of Health [ CO, 1883:81].

In many of the Alamodome privy pit features, remains of lime and ash deposits were discovered. Geismar (1993:65) mentions that within many if not all of New York City's excavated mid- to late-nineteenth-century privies, identifiable night soil was missing. She suggests that the use of lime and other disinfecting agents was a factor. Both lime and ashes are deodorizers, but chloride of lime is a disinfectant that when introduced into a privy would inhibit the creation of gases and permit the formation of an enriched soil rather than an organic deposit (Geismar 1993:65).

Section 6 of the San Antonio ordinance forbids "the cleaning or emptying of any privy in this city without disinfecting the same in this manner prescribed by the health board" and "the deposit of contents of any privy in any place other than such as may be approved by the board of health" (CO, 1883:81). Section 7 forbids

the removal of night soil, cleaning privies, privy boxes or barrels, vaults, sinks and cesspools within this city by buckets or other processes agitating or exposing the contents thereof in open air, transporting said contents in carts and other vehicles not air tight through the streets, alleys and other public places within said city [CO, 1883:81].

In $1886(\mathrm{CO}, 1886: 114)$ the city licensed the occupation of emptying privies. In 1888 (CO, 1888:119) they regulated the process in which the privies were to be emptied, recommending a system patented by W. Carrico of San Antonio and known as Carrico's Patent Dry Out House System as authorized for use.

\section{The Placement of Privies on Lots Within the City Limits}

In 1882 all owners of premises situated within the "inner fire limits" were instructed not to "build or repair any privy within five feet from any street or alley, or within 10 feet from the San Antonio River, San Pedro Creek, or any of the irrigating ditches" (CO, 1882:69). The location of such features depended upon the climate, soil conditions, proximity to the property's water supply, and exposure to public view. All of these required serious consideration when deciding where to build the structure.

The distance from the dwelling had to be navigable by small children and the elderly. The location in regard to the water source was vital so that the drinking water not be contaminated by waste. The location of the privy for privacy was very important especially for the prim and proper women of the late- nineteenth century. Barlow (1989) mentions that certain Victorian ladies would "hold their urges" because they were too embarrassed to be seen walking to the privy. They would have wood piles or other items strategically placed between the house and privy so that they could use the excuse of "fetching wood" to go to the outhouse.

Within the Alamodome Project area, all 12 privy pit features investigated followed the San Antonio City Ordinance placement specifications. None was located within five feet of a street or alley or was even close to any drainage system. In New York City, Greenwich Mews privies also conformed to their ordinances of 1833 stipulating that privies were to be located two feet within the property line (Geismar 1993:63). It also appears that each lot owner within the project area had his privy constructed in a convenient and relatively secluded place, in the back yard area near other outbuildings, and far enough from the neighbors' house so as not to be a nuisance. However, the location of one monitored privy, when pinpointed on the 1904 Sanborn Insurance Map, appears to have been placed in a location disadvantageous to their neighbors. The neighbors had a secondary smaller dwelling in the back lot that was unfortunately adjacent to the privy at 119 Plum Street. However, due to the lot size and house orientation at the Plum Street location, it appears that the owners were left with no other choice. 
Moir (1987:237) in his analysis of the use of yard space on Texas farmsteads, states that two featureswater wells and privies-often served as intrasite boundary markers for the division points of different yard zones. Privies were usually placed on the outside edge of the outer active yard and averaged ca. 10-24 $\mathrm{m}$ (32.5-78 $\mathrm{ft}$ ) from the house. For the urban areas such as those at the Alamodome site, residents were limited as to where they could place their privies. Comparing the location of the privies at the Alamodome site to Moir's statements about yard space usage, those at the Alamodome site closely conform to the distances Moir mentions, even when yard space at the rural setting was larger than the typical city lot (Table 10-2).

\section{Construction Materials and the Size of Privy Pits}

In 1882 the city regulated the construction of privies in certain areas. Section 2 of the ordinance made it unlawful for any owner or occupant within the inner fire limits to use anything other than a well-constructed vault, water tight, not more than six feet deep, built of brick or stone, laid in cement and extending one foot above the ground (CO, 1882:69). City ordinances for both New Orleans (Bryant 1988:69) and New York City (Geismar 1993:63) also stipulated that privy pits were to be built of brick or stone and must be between three and four feet deep.

Section 3 stated that all privies between the inner and the outer fire limits not built as described in Section 2 must consist of an air-tight barrel about two feet in diameter and three feet deep set on the surface of the ground and connected to the building, and so constructed that the barrel and its contents could be removed and another substituted (CO, 1882:69). This arrangement might not leave any archaeologically recoverable traces; no such construction has yet been found nor have any drawings or photographs been located that would show exactly how this was built.

Section 4 decrees that all owners or occupants who have vaults as described shall, whenever the contents of such vaults become even with the surface of the ground or when directed by the health officer, have the vaults cleaned and disinfected (CO, 1882:69). Section 5 states it is illegal to use anything other than an

Table 10-2. Location of Alamodome Privy Pit Features

\begin{tabular}{|c|c|c|c|c|}
\hline Privy \# & Site \# & Back Outer Yard Location & $\begin{array}{l}\text { Shortest Distance } \\
\text { from Main Dwelling }\end{array}$ & $\begin{array}{l}\text { Shortest Distance } \\
\text { from Property Line }\end{array}$ \\
\hline 1 & $41 B \times 883$ & Midway - South Wall & $40 \mathrm{ft}$ & $5 \mathrm{ft}$ \\
\hline 2 & $41 B X 890$ & Midway - Southeast Corner & $58-60 \mathrm{ft}$ & $10 \mathrm{ft}$ \\
\hline 3 & $41 B \times 892$ & Southwest Corner & $40-44 \mathrm{ft}$ & $5 \mathrm{ft}$ \\
\hline 4 & $41 B \times 892$ & West Corner & $50 \mathrm{ft}$ & $5 \mathrm{ft}$ \\
\hline 5 & 41BX896 & East Corner & $50-55 \mathrm{ft}$ & $5 \mathrm{ft}$ \\
\hline 6 & $41 B \times 926$ & $\begin{array}{c}\text { Southwest Area Between Main \& } \\
\text { Secondary Dwelling }\end{array}$ & $65-70 \mathrm{ft}$ & $5 \mathrm{ft}$ \\
\hline 7 & 41BX927 & Midway - West Area & $45-50 \mathrm{ft}$ & $5 \mathrm{ft}$ \\
\hline 8 & 41BX928 & $\begin{array}{l}\text { Midway - Southwest Area (Near } \\
\text { Neighbor's Secondary Dwelling) }\end{array}$ & $60 \mathrm{ft}$ & $5 \mathrm{ft}$ \\
\hline 9 & $41 B \times 930$ & Southwest Corner & $40-45 \mathrm{ft}$ & $5 \mathrm{ft}$ \\
\hline 10 & $41 B \times 929$ & $\begin{array}{l}\text { Midway - Southwest Corner } \\
\text { of Dwelling }\end{array}$ & $75-80 \mathrm{ft}$ & ca. $15 \mathrm{ft}$ \\
\hline 11 & $41 B \times 900$ & Northeast Corner & $65-70 \mathrm{ft}$ & $5 \mathrm{ft}$ \\
\hline 12 & $41 B \times 945$ & Midway - Northwest Corner & $40 \mathrm{ft}$ & $5 \mathrm{ft}$ \\
\hline
\end{tabular}


odorless process in the emptying of privies, vaults, or sinks (CO, 1882:69). It would be interesting to know how one could do this in an odorless manner.

The 12 privy pit features located during the Alamodome project investigations were found to be constructed from several types of materials (Table 10-3). Seven were constructed of soft, yellow-colored bricks. This type of brick is believed to be Laredo brick, brought into the area after the rail system was connected as far as Laredo ca. 1878 (Waynne Cox, personal communication 1993). These brick privy pit features were all fairly similar in style and size. When excavated, most of the brick pits were found to be bowing in on the side walls due to soil pressure through time (Figure 10-1). The only variations in the brick patterns were found on the top few courses of brick, some with the bricks in a header pattern and others with both header and stretcher patterns. All lower, interior bricks were laid in a stretcher, common bond pattern. Only one, Privy 10 , had mixed yellowand orange-colored irregular-shaped bricks.

Another pit was made of large limestone rock that would have been quarried locally (Figure 10-2). One feature was lined with vertically placed cedar posts. Cedar (Juniperus ashii) grew in abundance in the San Antonio area, particularly north of town and was used for many types of construction. Other construction included one unlined earthen vault, and two odd woodlined vaults. One of these consisted of several stacked crates, each measuring approximately $2 \times 2 \mathrm{ft}$, with the tops and bottoms removed. The other appeared to be an inverted wooden trunk, judging by the dimensions and the metal corner reinforcements.

Of the 12 privy pit features, eight were constructed of brick or stone as specified in the above ordinance of October 1882. Of the other four that were not brick or stone, only one appears to predate the 1882 ordinance. This was the cedar post-lined privy (Privy \#2) from site $41 \mathrm{BX} 890$, believed to have been constructed during the late $1850 \mathrm{~s}$. The other three privy pits include the two wood-lined pits and one earthen pit. Each of these features was constructed of materials that would make it difficult for the pits to be easily cleaned. The material contents within the features postdate the 1882 ordinance; therefore, it appears that even though these laws were passed specifying the type of materials with which the vaults were to be constructed, not everyone was quick to follow. What are the explanations for persons not building their privies with materials specified by the law? One obvious reason might be the cost factor. Building a privy of bricks and stone would be more expensive than using an old crate or trunk as a lining. The next question might be, what was the occupation of the individuals who constructed their privy vaults with cheaper items in comparison with the occupation of those who used stone or brick? (Table 10-3).

Only contemporaneous privy pits features were compared to each other. In this case, only two privy pits were constructed during the 1850 s: the cedar post vault (Privy \#2 at 41BX890) and the cut limestone vault (Privy \#12 at 41BX945). Both residents were of German heritage and had houses constructed with limestone foundations. However, Mr. Pauly at 41BX945 owned a considerable amount of property, was a stonemason and architect by trade, and constructed an elaborate drainage system on his

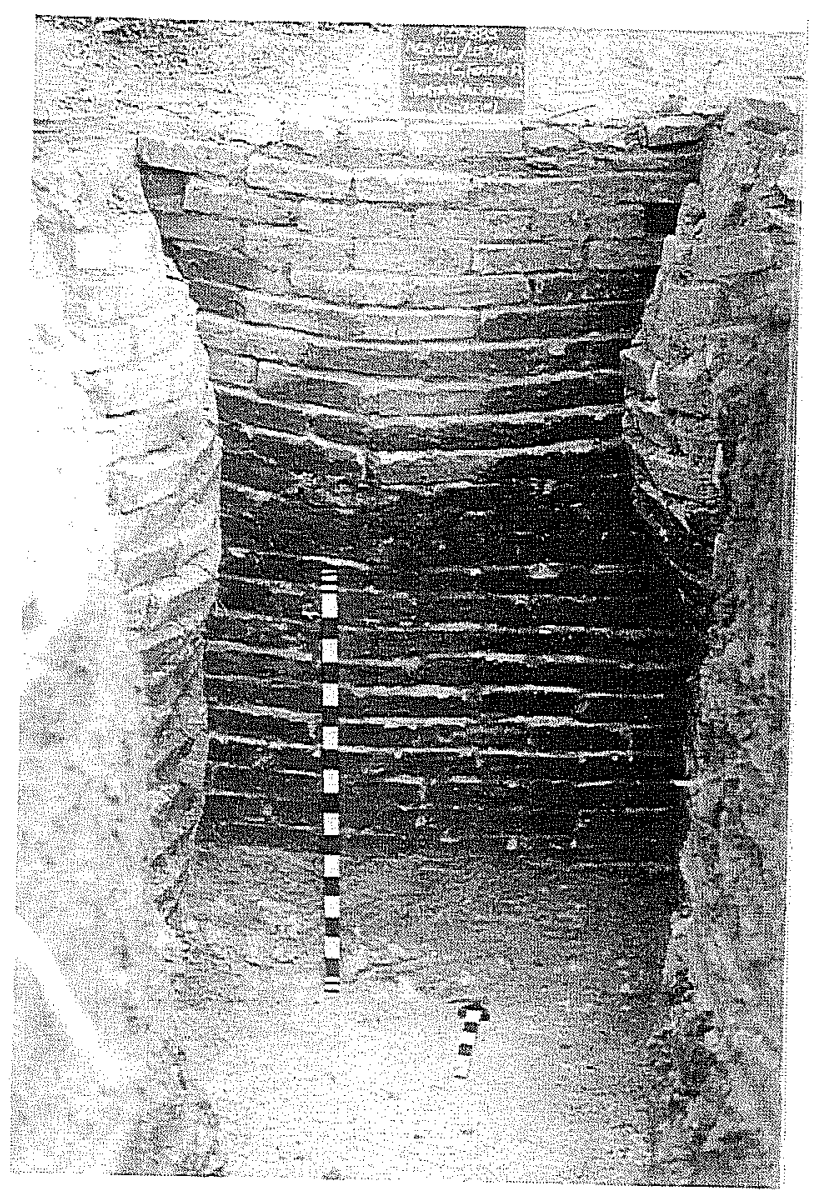

Figure 10-1. 41BX883, Feature A, brick-lined privy vault illustrating bowing of side walls. 


\begin{tabular}{|c|c|c|c|c|c|c|c|c|c|c|c|c|}
\hline 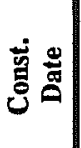 & 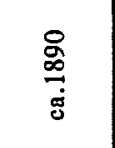 & 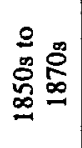 & $\begin{array}{l}\text { 怘 } \\
\text { ¿ }\end{array}$ & $\begin{array}{l}\frac{8}{0} \\
\frac{1}{2} \\
\frac{1}{\infty}\end{array}$ & 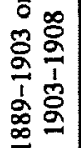 & 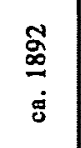 & $\begin{array}{l}\underset{\infty}{E} \\
\stackrel{5}{0}\end{array}$ & 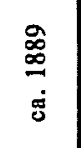 & 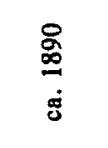 & 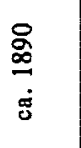 & 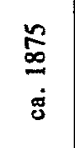 & $\begin{array}{l}\vec{\infty} \\
\stackrel{\vec{\delta}}{\delta}\end{array}$ \\
\hline $\begin{array}{l}\text { 总 } \\
\text { 兽 }\end{array}$ & 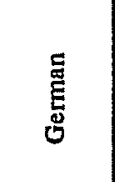 & 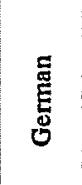 & $\begin{array}{l}\text { 宧 } \\
\text { S. }\end{array}$ & 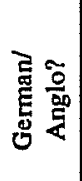 & 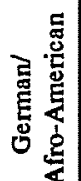 & 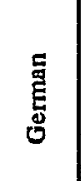 & 焉 & 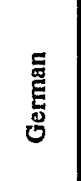 & 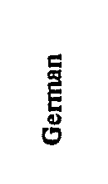 & 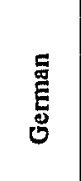 & 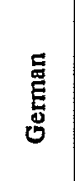 & 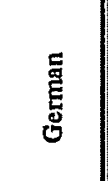 \\
\hline 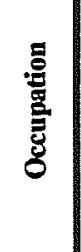 & $\begin{array}{l}\text { 岕 } \\
\frac{\mathrm{g}}{\mathrm{E}} \\
\text { 产 }\end{array}$ & $\begin{array}{l}\text { 䔍 } \\
\text { 惫 } \\
\text { 葛 } \\
\text { 点 }\end{array}$ & 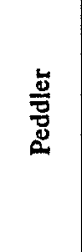 & 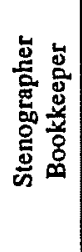 & 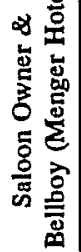 & 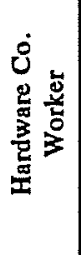 & 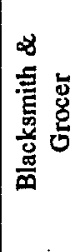 & 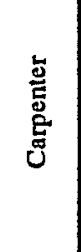 & 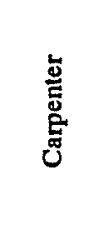 & 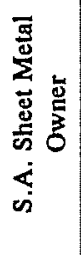 & 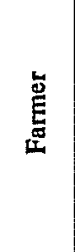 & 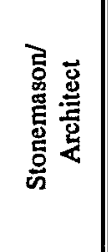 \\
\hline 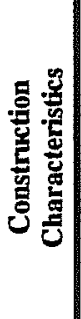 & 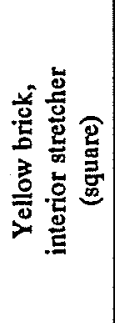 & 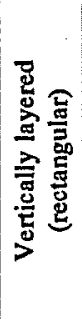 & 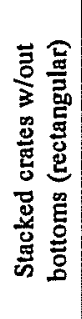 & 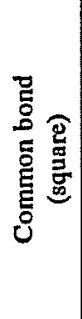 & 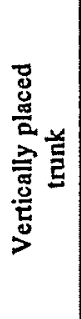 & 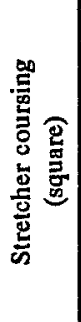 & 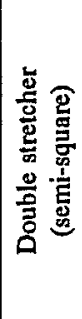 & 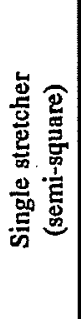 & 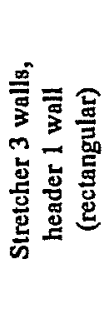 & 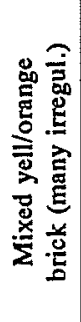 & 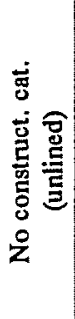 & 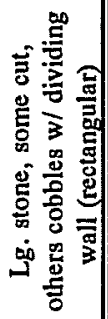 \\
\hline 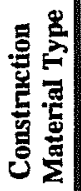 & 弟 & 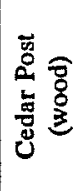 & 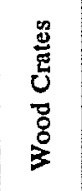 & 苑 & 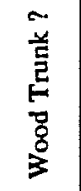 & 总 & 总 & 弟 & 弟 & 苛 & 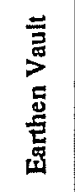 & 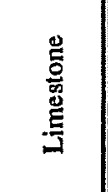 \\
\hline$\dot{\rho}$ & $\begin{array}{l}\stackrel{n}{\Xi} \\
\mathcal{N} \\
\stackrel{m}{*}\end{array}$ & 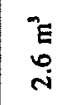 & 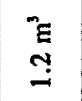 & $\sigma$ & 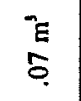 & $\sim$ & 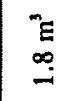 & $\sim$ & $\sim$ & $\sim$ & $\sim$ & $\frac{{ }^{\prime}}{\infty}$ \\
\hline 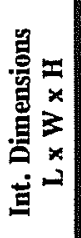 & 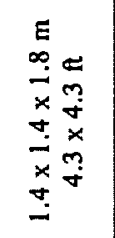 & 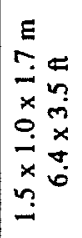 & 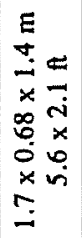 & 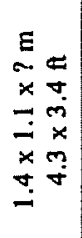 & 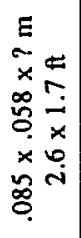 & 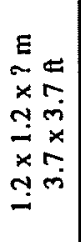 & 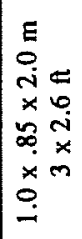 & 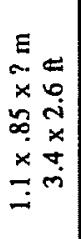 & 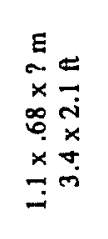 & 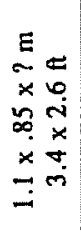 & $\begin{array}{l}E \\
\ddot{x} \\
\dot{x} \\
\infty \\
\dot{x} \\
x \\
\sim\end{array}$ & 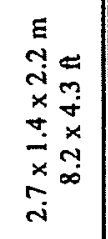 \\
\hline 苛 & 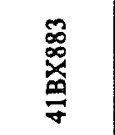 & 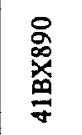 & 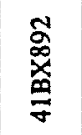 & 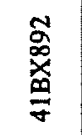 & 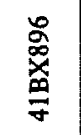 & 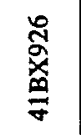 & 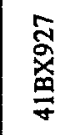 & 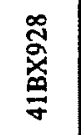 & 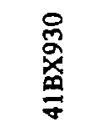 & 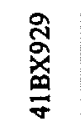 & $\begin{array}{l}\text { 总 } \\
\text { 畺 }\end{array}$ & 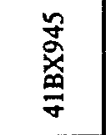 \\
\hline 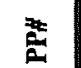 & - & $\mathrm{N}$ & m & + & $n$ & 0 & $r$ & $\infty$ & $a$ & 은 & $=$ & $\simeq$ \\
\hline
\end{tabular}




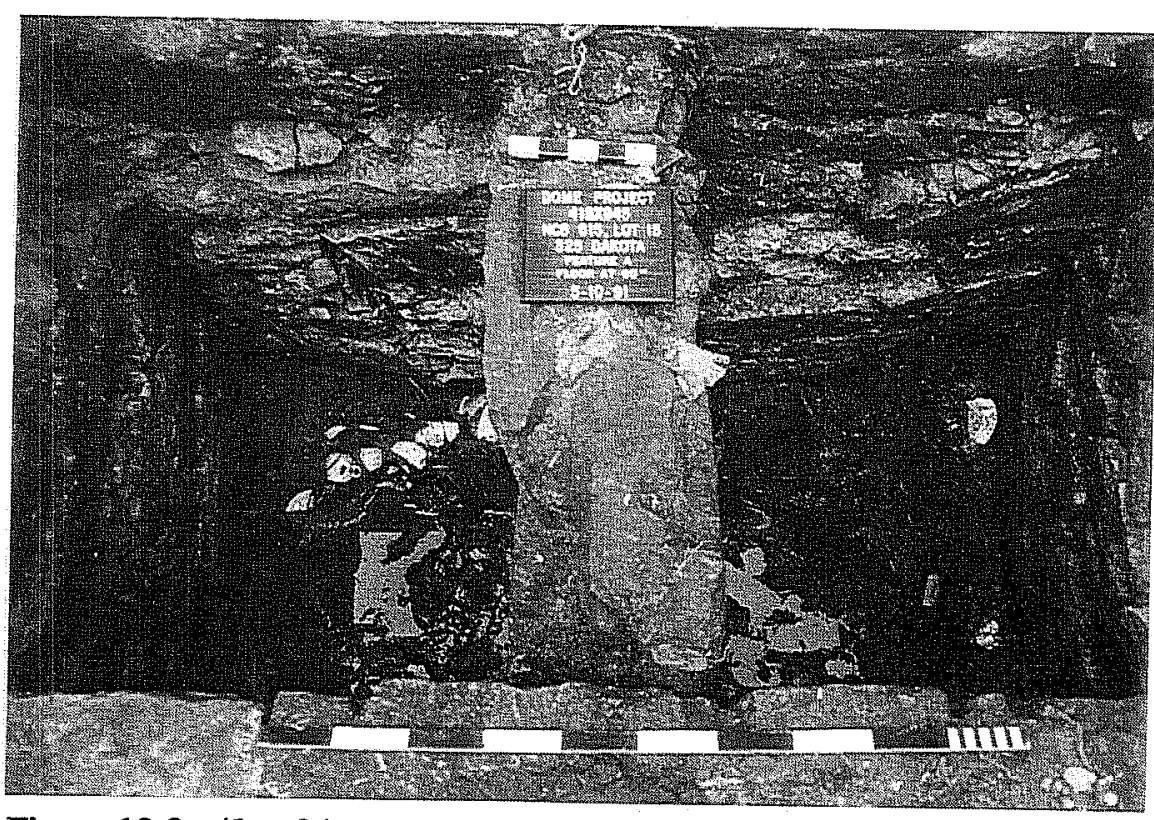

Figure 10-2. 41BX945, Feature A, limestone-lined privy vault.

These can now be compared to the Las Tiendas project privy pits (Table 10-1). Four out of seven of the latter were made of limestone and dated prior to the 1882 ordinance. All but one of the builders or original homeowners of the sites were German, the exception was Belgian. Of these, all the German limestone privies were rectangular in shape, while the Belgian one was square and slightly smaller.

Bryant (1988:72) using privy length, width, depth, volume, and associated ratios based on inside measurements of the brick- or wood-lined privy pits he found in New Orleans,

property complete with a large cistern attached to his basement. The modest two-room "adobe" structure associated with the cedar post-lined privy was owned by Mr. Houzeau, a shoemaker.

The remaining 10 privy pits were probably constructed post-1880 when the first rail system came to San Antonio. The post-1880 date is supported by the fact that most of the houses in the area were constructed during that time period. Most of the individuals who owned brick privy pits appear to be of middle- to upper-middle-class status and included a salesman, a black-smith shop owner, carpenters, a San Antonio sheet metal company owner, and a hardware worker (CDS 1901-1930; CRs 1880-1910). Of the two households that had the wood-lined privy pits, one was a peddler and one a bellboy for the Menger Hotel, probably from a lower income bracket (CDS 1901-1908; CRs 1900, 1910). The earthen vault appears to have belonged to a Mr. Hildebrandt who was a farmer. It cannot be determined whether the farmer had an unlined pit because that was what he was accustomed to or because of his financial status. It seems from the other two individuals, however, that preference of style of privy construction may be determined by social status. Further studies of a larger sample of excavated privy vaults from throughout the city might help verify this theory. defined four chronological periods based on mean pit dimensions. He suggests that volume was found to be the best measure for ranking pits according to size, and that shape was generally rectangular, but variation in the ratio of length to width provides a quantifiable measure for comparisons (Bryant 1993:72). In the San Antonio privy pit samples, most of the rectangular limestone privies were constructed by Germans. Ratios of length to width variations are interesting if we compare known occupations for the Las Tiendas Project and the Alamodome Project. Within Las Tiendas, the brewer has the much larger privy $(7.0 \times 5 \mathrm{ft})$ compared to the storekeeper's privy $(5.0 \times 3.0 \mathrm{ft})$. Within the Alamodome, the architect/stonemason has the largest $1850 \mathrm{~s}$ pit $(8.2 \times 4.3 \mathrm{ft})$ compared to the smaller cedar-lined pit of the shoemaker $(4.6 \times 3.0 \mathrm{ft})$. Therefore, the length-to-width ratio definitely seems to be a factor in measuring the socioeconomic status of the privy pit builders or owners. Likewise, the use of stone instead of wood or earthen pits also appears to reflect status.

The depth of the privy pits was determined in only five cases. Many of the monitored pits were examined only for construction type, top dimensions, and material content, or they were found when it was too late in the demolition phase for the depth to be determined. However, of the available depths taken, most, with the exception of wood-lined Privy \#5, followed the six-foot 
depth specifications set in the San Antonio City Ordinance of 1882. It is interesting that the six-foot depth was chosen because at this depth the soil matrix changes to a hard caliche/clay layer. Caliche tends to provide a solid base that holds water. This could explain why none of the privy pits found was lined on the bottom.

Only one privy (\#12) was divided into two sections, perhaps representing male and female sections. This was by far the largest of those tested. Others vary in size, some rectangular in shape and others square (Table 10-2). The two wood-lined pits are drastically smaller in length and width than the brick- and stonelined privies. The smaller, square-shaped brick privy pits were owned by a vegetable huckster, a hardware worker, and a carpenter. From these data it is believed that not only can the construction materials used be an indicator of social status of the owners, but the size of the pit appears to indicate status as well. This makes for much the same reason; the larger size of the construction, the greater the cost.

\section{Sewer Lines Introduced into the Area}

Once sewers were laid in the city (at the Alamodome site ca. 1895-1900), ordinances regulating the new construction of privies were created. These ordinances were intended to make city dwellers tap into the newly laid sewers and to dissuade them from constructing new privies. The time of connection with the newly laid sewer lines by particular households may have depended on the cost of plumbing (Angie Montgomery, City of San Antonio Wastewater Management Office, personal communi-cation 1991). During this time, strict ordinances were enforced on the continued upkeep of existing privies. An ordinance passed in 1905 stated,

it shall be unlawful for any person or persons to hereafter construct any privy vault or cesspool within the limits of the city without first applying in writing to the Mayor or city council for a permit to do so, and obtaining such permit before commencing erection of same . . . no such permit shall be granted to construct a privy vault or cesspool on premises that abut any street or alley on which there is a city sewer main [CO 1905: 106].

The San Antonio City Waste Water Management Office was very helpful in providing information regarding when the project area tapped into the sewage lines. From the Waste Water Management records (WWMR, City Waste Water Management Office, San Antonio, Texas), the earliest lines were put in from 1904-1906 (Table 10-4). The records also list three

Table 10-4. Summary of Estimated Fill Dates

\begin{tabular}{|c|c|c|c|c|}
\hline Privy \# & Site \# & Construction Date & Tapped In & Estimated Fill Date \\
\hline 1 & 41BX883 (brick) & ca. 1890 & & ca. 1920 \\
\hline 2 & 41BX890 (cedar post) & $1850 s-1870 s$ & & ca. 1905 \\
\hline 3 & 41BX892 (wood crates) & ca. 1900 & 1906 & 1925 \\
\hline 4 & 41BX892 (brick) & ca. $1870-1900$ & & 1905 \\
\hline 5 & 41BX896 (trunk) & $1889-1908$ & & 1910 \\
\hline 6 & 41BX926 (brick) & 1892 & & ca. 1910 \\
\hline 7 & 41BX927 (brick) & ca. 1877 & & 1915 \\
\hline 8 & 41BX928 (brick) & ca. 1889 & & ca. 1910 \\
\hline 9 & 41BX930 (brick) & ca. 1890 & & insufficient evidence \\
\hline 10 & 41 BX929 (brick) & ca. 1895 & 1905 & insufficient evidence \\
\hline 11 & 41BX900 (earth) & ca. 1875 & & 1910 \\
\hline 12 & 41BX945 (cut limestone) & ca. 1851 & 1906 & post-1910 \\
\hline
\end{tabular}


individuals' names and the exact date when they tapped into the sewer line. This information was important because it confirmed the other records that these men and their families were the last owners of the privy pits and, therefore, were the last users of the artifacts found in the pit fill. These include: Charles Spau, 132 Wyoming Street (Privy \#3) who tapped into the line on October 22, 1906; John Umscheid, 115 Plum Street (Privy \#10), who tapped into the sewer line on March 28, 1905; and William Mueller, 325 Dakota Street (Privy \#12), who tapped into the line on June 4, 1906 (WWMR, 1905-1906). Not enough data are available to determine whether one's economic status affected when he connected his indoor plumbing to the sewer lines, but it is known that the property owner was responsible for the expense of tapping of lines and the plumbing costs (for more information on this subject, see Gross and Mendez, this volume). The information provided does, however, provide a general date when privies were beginning to go out of use and when indoor plumbing began to be used in the urban San Antonio neighborhood. Although sewer lines were in place at an earlier date elsewhere in the city, the evidence from the material culture found in the privy pits shows that these privies were still in use until much later.

\section{The Privy Pit Contents: an Analysis of the Cultural Material}

Once the main sewer lines were laid, many privies went out of use for human waste disposal. But rather than fill the vaults with soil, the depressions were used for the disposal and, at times, burning of trash (Labadie 1986; Uecker et al.1991).

Because so many ordinances were based on the upkeep and continual cleaning of privies within the city limits, the material culture obtained from within these privies can probably be attributed to the residents of the associated household at the time the house was connected to the newly laid sewer mains.

As Highley (1978) noted from her finds at the Arciniega privy excavations, the artifacts that were found within appear to have been deposited within a short period of time. This may be because of the amount of everyday trash that can rapidly fill a receptacle that no longer needs to be continuously maintained and emptied. Within the fill are cultural artifacts from a short and very specific period in the life of the inhabitants.

Mean dates for the ceramics and bottles from the privy fill were determined using South's mean ceramic dating formula (South 1977:220). Also, other diagnostic artifacts discovered were used to determine the date of the fill. Again, only three of the privy pit features were completely excavated in 5- to 10-inch arbitrary levels and therefore provide an unbiased sample. These include the brick-lined privy vault (privy \#1) on site 41BX883, the wood-lined, possible trunk-privy pit (privy \#5) on site $41 \mathrm{BX} 896$, and the divided cut-limestone vault on site 41BX945. Below is a brief summary of the privy pit contents, the mean ceramic and bottle dates, and the estimated date for the privy pit fill for each of the 12 privy features investigated at the Alamodome project. This method of studying privies appears to have some utility, at least in a general way. Looking at the summary in Table $10-4$, and considering that the sewer lines were laid in the area ca. 1895-1900, it would appear from the estimated fill dates that most home owners waited about 10 years to tap into the lines. In reality, however, the three known dates of hook-up suggest that the estimates are probably about five to 10 years late. Considering the probable reluctance of some homeowners (and perhaps even their inability) to go to the expense of tapping into the sewer lines, the spread of estimated fill dates may be realistic, even if based on generalities such as mean dates and estimated dates of specific artifacts. 
Privy \#1: 41BX883, Brick-lined Privy

$\begin{array}{ll}\text { Mean Ceramic Date } & 1893 \\ \text { Latest Type } & \text { Homer Laughlin (1900-1960) } \\ \text { Ceramic Marks } & \text { Post 1855; post 1881; 1900-1960 } \\ \text { Mean Glass Date } & 1906 \\ \text { Latest Attribute } & 1920 \\ \text { Glass Marks } & 1902 \\ \text { Other Material } & \text { Pullman button "Scovil Mfg. Co.," 1805-present } \\ \text { Last Episode of fill } & \text { ca. 1890-1920 } \\ \text { Estimated fill date } & \text { ca. } 1920\end{array}$

Privy \#2: 41BX890, Cedar Post-lined Privy Pit

Mean Ceramic Date

Latest type

Ceramic Marks

Mean Glass Date

Latest Attribute

Glass Marks

Other Material

Last Episode of Fill

Estimated Fill Date
1883.7

1908

1900-1908; 1888-1893; Post-1880

1889.3

1920

1832-1886; 1887-1891; 1868-1914

Cartridge shells, post- 1890

1880-1910

ca. 1905

Privy \#3: 41BX892, Feature A, Stacked Wooden Crates

$\begin{array}{ll}\text { Mean Ceramic Date } & 1907.5 \\ \text { Latest Type } & \text { Homer Laughlin, 1900-1960 } \\ \text { Ceramic Marks } & 1900-1960 ; \text { post-1902 } \\ \text { Mean Glass Date } & 1917 \\ \text { Latest Attribute } & 1930 \\ \text { Glass Marks } & 1920-1930 \\ \text { Other Material } & \text { German newsprint, "San Antonio Zietung"? } \\ \text { Last Episode of Fill } & 1900-1925 \\ \text { Estimated Fill Date } & 1925\end{array}$

Privy \#4: 41BX892, Feature B, Brick-Lined Privy

Mean Ceramic Date

Latest Type

Ceramic Marks

Mean Glass Date

Latest attribute

Glass marks

Other material

Last Episode of Fill

Estimated Fill Date 1905
1885

Decal, post-1900

1883-1890

1899

Post-1903

None

Ceramic doll leg, 1880-1930 type

1890-1905 


\section{Privy \#5: 41BX896, Wood (Trunk) Lined Privy}

$\begin{array}{ll}\text { Mean Ceramic Date } & 1910 \\ \text { Latest Type } & \text { Bristol glaze, post-1910, stoneware, 1900 } \\ \text { Ceramic Marks } & \text { Post-1896, 1874-1891, post-1897 } \\ \text { Mean Glass Date } & 1905 \\ \text { Latest Attribute } & 1908+ \\ \text { Glass Marks } & 1897-1920,1900-1935 \\ \text { Other Material } & \text { Military button, 1902+; doll's leg, 1890-1910 } \\ \text { Last Episode of Fill } & 1890-1910 \\ \text { Estimated Fill Date } & 1910\end{array}$

Privy \#6: 41BX926, Brick-Lined Privy

$\begin{array}{ll}\text { Mean Ceramic Date } & \text { ca. } 1880 \\ \text { Latest Type } & \text { Stoneware } \\ \text { Ceramic Marks } & \text { None } \\ \text { Mean Glass Date } & 1904 \\ \text { Latest Attribute } & 1903 \\ \text { Glass Marks } & \text { Post-August, 1901 } \\ \text { Other Material } & \text { Ceramic Doll Leg, Post-1860 } \\ \text { Last Episode of Fill } & \text { ca. 1890-19?? (Sample too small) } \\ \text { Estimated Fill Date } & \text { ca. 1910 }\end{array}$

\section{Privy \#7: 41BX927, Brick-Lined Privy}

Mean Ceramic Date

Latest Type

Ceramic Marks

Mean Glass Date

Latest Attribute

Glass Marks

Other Material

Last Episode of Fill

Estimated Fill Date ca. 1894 (sample too small)

Stoneware

1897-1900; 1890-1908

1905

$1907-1909 ; 1920$

$1889-1920 ; 1892-1915 ; 1865-1915 ; 1902-1920$;

$1907-1909 ; 1905-1917 ; 1889-1920$; July 1895

None

1895-1915

1915

Privy \#8: 41BX928, Brick-Lined Privy Pit

Mean Ceramic Date

Latest Type

Ceramic Marks

Mean Glass Date

Latest Attribute

Glass Marks

Other Material

Last Episode of Fill

Estimated Fill Date ca. 1910

Gilded Whiteware

None

ca. 1901

Screw Top Bottles

August 13, 1901

None

ca. $1895-1910$ (sample too small)

ca. 1910 
Privy \#9: 41BX930, Brick-Lined Privy Pit

Mean Ceramic Date None

Latest Type None

Ceramic Marks None

Mean Glass Date None

Latest Attribute Blueing bottle

Glass Marks None

Other Material None

Last Episode of Fill Sample too small for determination

Estimated Fill Date Sample too small for determination

Privy \#10: 41BX929, Brick-Lined Privy Pit

Mean Ceramic Date

Latest Type

Ceramic Marks

Mean Glass Date

Latest Attribute

Glass Marks

Other Material

Last Episode of Fill

Estimated Fill Date ca. 1890 (sample too small)

Yellowware and stoneware ( 2 sherds)

None

None

None

None

None

Sample too small for determination

Sample too small for determination

Privy 11: 41BX900, Earthen Vault Privy

Mean Ceramic Date

Latest Type

Ceramic Marks

Mean Glass Date

Latest Attribute

Glass Marks

Other Material

Last Episode of Fill

Estimated Fill Date
1895

Gilded whiteware

Post-1888; post-1907

1901

Post-1903

1900-1920; post-1903; 1880-1915

Ceramic doll leg, ca. 1905 mean date 1890-1910

1910

Privy 12: 41BX945, Cut Limestone-lined Privy Pit

Mean Ceramic Date

Latest Type

Ceramic Marks

Mean Glass Date

Latest Attribute

Glass Marks

Other Material

Last Episode of Fill

Estimated Fill Date
1910

Decal

1909-1915, post-1920

1905.5

1910-1930

1909-1929, 1910-1930, 1900-1920

Ceramic doll frag., 1880-1930

ca. 1920

post-1910 


\section{References Cited}

Barlow, R. S.

1989 The Vanishing American Outhouse. Windmill, El Cajon, California.

Bryant, D. D.

1988 A Stylistic Approach to the Study of Privies. American Archaeology 7(1):66-76.

Geismar, J. H.

1993 Where is the Night Soil? Thoughts on an Urban Privy. Historical Archaeology 27(2):57-10.

Gillson, G. E.

1966 Louisiana Board of Health, The Formative Years. Ph.D. dissertation. Louisiana State Board of Health, New Orleans.

Highley, L.

1978 Feature 9: A Latrine Pit Littered with Late 19th Century Artifacts. Manuscript on file at the Center for Archaeological Research, The University of Texas at San Antonio.

Katz, P.

1978 Archaeological and Historical Investigations in the Arciniega Street Area, Downtown San Antonio, Texas. Archaeological Survey Report, No. 61. Center for Archaeological Research, The University of Texas at San Antonio.

Labadie, J. H.

1986 Additional Archaeological and Historical Studies for the Fairmount Hotel Project in San Antonio, Texas. Archaeological Survey Report, No. 160. Center for Archaeological Research, The University of Texas at San Antonio.

Moir, R. W., and D. H. Jurney

1987 Pioneer Settlers, Tenant Farmers, and Communities: Objectives, Historical Background, and Excavations. Richland Creek Technical Series, Vol. IV. Institute for the Study of Earth and Man, Southern Methodist University, Dallas.

South, $\mathbf{S}$.

1977 Method and Theory in Historical Archaeology. Academic, New York.

Wobst, H. M.

1977 Stylistic Behavior and Information Exchange. In Research Essays in Honor of J. B. Griffen, edited by C. E. Cleland. Michigan Anthropological Papers 61.

Uecker, H. G., F. K. Meskill, and I. W. Cox

1991 Archaeological Investigations at the Ruiz Family Property (41BX795), San Antonio, Texas. Archaeological Survey Report, No. 198. Center for Archaeological Research, The University of Texas at San Antonio. 


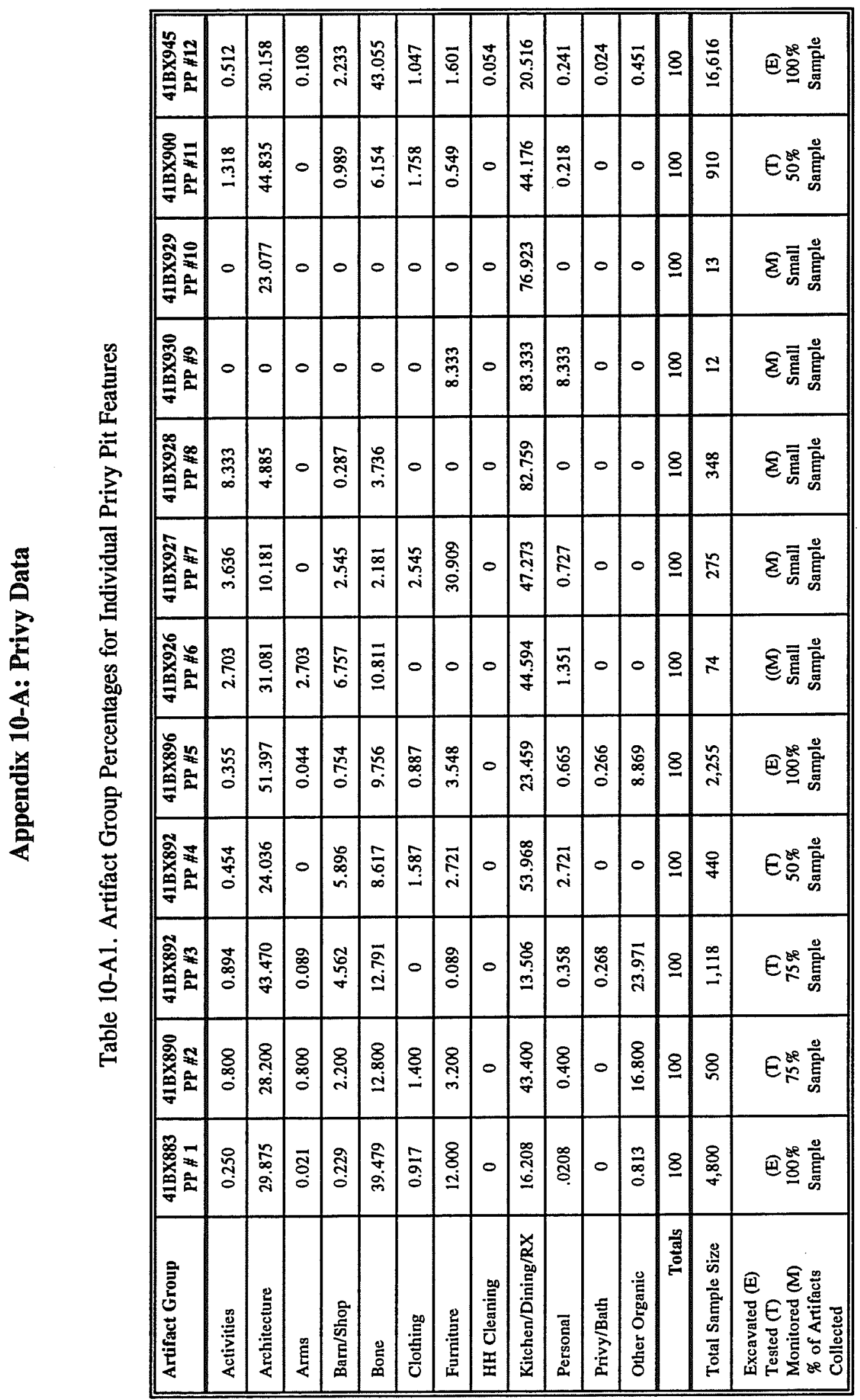




\begin{tabular}{|c|c|c|c|c|c|c|c|c|c|c|c|c|c|c|c|c|c|c|}
\hline & 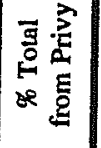 & $\begin{array}{l}\mathscr{R}_{0} \\
\infty \\
\text { ले }\end{array}$ & 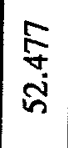 & 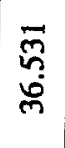 & $\begin{array}{l}\text { \&े } \\
\text { ஜ }\end{array}$ & $\frac{\infty}{\square}$ & : & $\begin{array}{c}\hat{\theta} \\
\dot{\infty}\end{array}$ & $\frac{8}{1}$ & $\underset{\infty}{\infty}$ & $\frac{n}{\infty}$ & $\begin{array}{l}\frac{8}{8} \\
E\end{array}$ & $\frac{8}{8}$ & $\begin{array}{l}8 \\
8 \\
8\end{array}$ & $\frac{8}{8}$ & $\frac{\pi}{5}$ & $\begin{array}{l}\mathscr{N} \\
\infty \\
\infty \\
\infty\end{array}$ & $\frac{\infty}{\stackrel{\infty}{n}}$ \\
\hline $\begin{array}{l}\frac{n}{3} \\
\frac{8}{7}\end{array}$ & 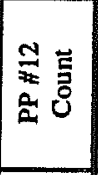 & $\infty$ & $\overline{\bar{n}}$ & 8 & 尽 & $\frac{\bar{\infty}}{m}$ & $\stackrel{\infty}{\sim}$ & $\stackrel{\forall}{\stackrel{Z}{二}}$ & \pm & $\stackrel{n}{=}$ & 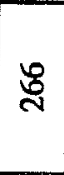 & $\stackrel{8}{0}$ & 宮 & 茂 & $\underset{\sim}{\infty}$ & 令 & 암 & $\frac{\forall}{\frac{8}{0}}$ \\
\hline & 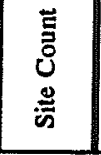 & $\stackrel{\infty}{\stackrel{\infty}{*}}$ & 亭 & ऽิ & $\underline{\mathbf{S}}$ & $\stackrel{\infty}{\stackrel{\infty}{\sigma}}$ & $\vec{d}$ & ถู & $\bar{J}$ & 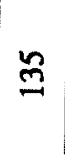 & శ్లె & $\tilde{\Omega}$ & $\overline{8}$ & $\frac{9}{6}$ & $\frac{g}{8}$ & \& & 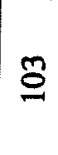 & 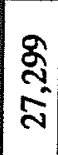 \\
\hline & 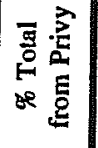 & ஜ & 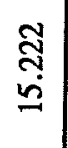 & $\begin{array}{l}\infty \\
\infty \\
\tilde{m} \\
\end{array}$ & $\begin{array}{l}\text { S. } \\
\infty \\
\dot{J}\end{array}$ & $\begin{array}{l}\vec{n} \\
\bar{m}\end{array}$ & $\begin{array}{l}\text { N } \\
\infty \\
\text { ம் }\end{array}$ & $\begin{array}{l}\mathscr{0} \\
\infty \\
\infty \\
0 \\
0\end{array}$ & 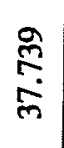 & $\begin{array}{l}\overrightarrow{8} \\
0\end{array}$ & $\frac{\infty}{\tilde{n}^{-}}$ & $\begin{array}{l}\stackrel{8}{8} \\
\text { i் }\end{array}$ & ๙ֶ & 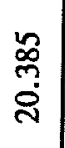 & 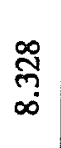 & $\frac{P}{g}$ & 范 & 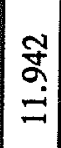 \\
\hline $\begin{array}{l}8 \\
8 \\
0 \\
8\end{array}$ & 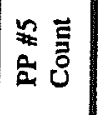 & $\infty$ & $\stackrel{2}{=}$ & $\stackrel{ \pm}{N}$ & $\frac{n}{m}$ & $\stackrel{\infty}{\stackrel{2}{\curvearrowright}}$ & - & స్తి & ్ & 으 & $\varnothing$ & $\mathbb{J}$ & స్ & 电 & $\frac{N}{\forall}$ & $\Rightarrow$ & 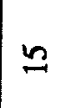 & న్ క్ర \\
\hline & 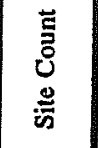 & ஜั & $\frac{\pi}{6}$ & $\frac{n}{a}$ & $\stackrel{?}{\stackrel{ }{(}}$ & 胥 & $\simeq$ & ఫ్లి & $\tilde{n}$ & $\check{\varrho}$ & 욤 & 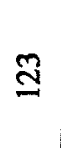 & $\underset{\sim}{\stackrel{N}{n}}$ & స్స & 守 & $\stackrel{\Delta}{\Delta}$ & $\sqrt{n}$ & $\stackrel{0}{\circ}$ \\
\hline & 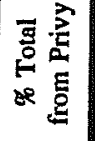 & $\begin{array}{c}8 \\
6 \\
i\end{array}$ & ڤ్ & * & $\frac{2}{2}$ & 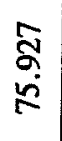 & \& & $\begin{array}{l}\text { q } \\
\text { f }\end{array}$ & $\begin{array}{l}\text { ద్ } \\
\text { तु }\end{array}$ & $\begin{array}{l}\bar{n} \\
\bar{t}\end{array}$ & $\begin{array}{l}\text { Vั } \\
\text { g் }\end{array}$ & 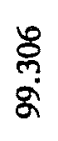 & $\begin{array}{l}\hat{\infty} \\
\tilde{f} \\
\tilde{f}\end{array}$ & $\underset{*}{*}$ & 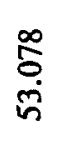 & * & $\begin{array}{l}\stackrel{5}{\infty} \\
\dot{\Omega}\end{array}$ & $\frac{\sigma}{\sigma}$ \\
\hline \begin{tabular}{l}
$\infty$ \\
0 \\
\hdashline
\end{tabular} & 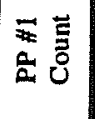 & $\cong$ & 志 & $\stackrel{\infty}{=}$ & $\vec{n}$ & $\stackrel{\infty}{\stackrel{\Xi}{త}}$ & - & $\stackrel{2}{2}$ & $\forall$ & $\vec{m}$ & $\frac{0}{n}$ & $\frac{N}{n}$ & $F$ & $\hat{a}$ & 范 & 으 & 으 & $\frac{8}{8}$ \\
\hline & 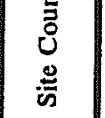 & $\stackrel{ \pm}{\Delta}$ & हె & 荹 & $\bar{q}$ & $\overline{\check{a}}$ & - & g̊ & $R$ & $\tilde{n}$ & $\underset{\infty}{\infty}$ & $\frac{0}{n}$ & $\stackrel{?}{8}$ & $\stackrel{*}{*}$ & $\bar{\Xi}$ & 娄 & 8 & 号 \\
\hline & 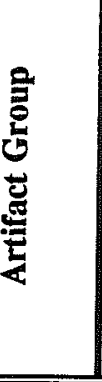 & : & 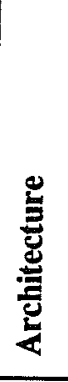 & 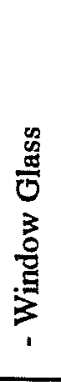 & $\begin{array}{l}\frac{\infty}{\pi} \\
z \\
\bar{\Xi} \\
\bar{\Xi}\end{array}$ & 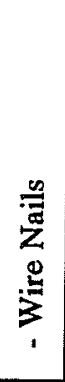 & $\frac{y}{E}$ & 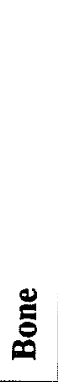 & 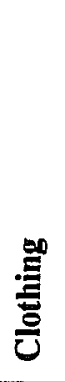 & 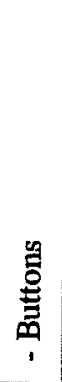 & 岂 & 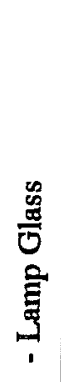 & 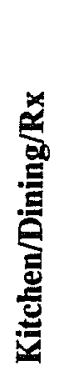 & 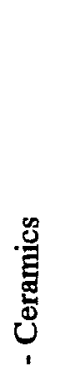 & 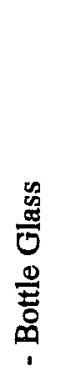 & 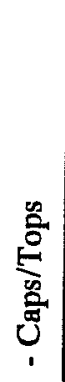 & $\begin{array}{l}\bar{E} \\
\bar{E} \\
\bar{D} \\
\text { D. }\end{array}$ & 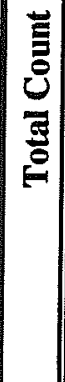 \\
\hline
\end{tabular}




\title{
Chapter 11
}

\section{Plant Remains from Historical Sites at the Alamodome Project}

\author{
J. Philip Dering
}

\section{Introduction}

\section{Data Base}

This report presents results of the macrobotanical analysis of 20 flotation samples. The flotation samples were collected from 11 privies and 4 features from 13 different designated sites. All of the features, including the privies, are associated with late-nineteenth to early twentiethcentury homes occupied primarily by descendants of German immigrants.

The samples and their proveniences appear below in Table 11-1. The feature types include privies, bottle caches, and trash pits.

\section{Interpretive Problems and Research Questions}

Botanical analyses of sediments from historical sites have contributed to reconstructions of land use practices, site formation processes and diet (Beaudry and Mrowsowski 1987:118, 1989:231; Miller 1988). Privies, with their dual use as repositories for both fecal matter and household trash, have the potential of yielding information on land use practices, diet, structural materials and other aspects of the occupants' material culture.

Site formation processes, however, must be considered before any interpretations can be made. For example, at most open prehistoric sites in North America only carbonized plant remains can be safely considered to be of prehistoric origin. The situation is quite different at historic sites because the degradation processes have had a much shorter time to work, and because the botanical materials are often protected from the elements by a structure (Lutzow 1989; Miller 1988). Miller (1988:50), for example, has noted that certain uncarbonized botanical materials that are more resistant than others may survive in a protected setting at an historical site. On the other hand, Gasser and Adams (1981) have demonstrated experimentally that seeds and fruits of most plants seldom last more than a few years because of intense predation from rodents, insects, fungi and microscopic organisms. Because of the short life of most seeds/fruits in any but the most ideal depositional settings, I have chosen to include carbonized seeds only in the analysis. Wood, on the other hand, can last for several decades to a few centuries in many depositional settings. For the purposes of this study I have included both carbonized and uncarbonized wood for the analysis.

I have outlined four general research goals for the macrobotanical study:

1) What plant taxa and plant parts are present in the samples?

2) What is the origin of each plant taxon in the samples. Are they native or introduced plants?

3) What are the sources of the plant remains in the samples? For example, were the plant remains introduced as human fecal material, as trash, or accidentally by independent site formation processes? 
Table 11-1. Flotation Samples from the Alamodome Project

\begin{tabular}{||c|c|l|c|c|c|c||}
\hline $\begin{array}{c}\text { Sample } \\
\text { Number }\end{array}$ & $\begin{array}{c}\text { Site } \\
\text { Number }\end{array}$ & $\begin{array}{c}\text { Feature } \\
\text { Type }\end{array}$ & $\begin{array}{c}\text { Feature } \\
\text { Number }\end{array}$ & Level & $\begin{array}{c}\text { Lot } \\
\text { Number }\end{array}$ & $\begin{array}{c}\text { Identifiable } \\
\text { Plant Remains } \\
\text { Present }\end{array}$ \\
\hline 2 & $41 \mathrm{BX883}$ & Privy & 1 & 3 & 9 & Yes \\
\hline 5 & $41 \mathrm{BX883}$ & Privy & 1 & 7 & 9 & Yes \\
\hline 6 & $41 \mathrm{BX} 891$ & Trash Pit & $\mathrm{A}$ & & 5 & Yes \\
\hline 7 & $41 \mathrm{BX} 892$ & Privy & 4 & & 6 & Yes \\
\hline 8 & $41 \mathrm{BX} 890$ & Privy & 2 & & 4 & Yes \\
\hline 9 & $41 \mathrm{BX} 892$ & Trash Pit & $\mathrm{C}$ & & 6 & Yes \\
\hline 10 & $41 \mathrm{BX} 892$ & Privy & 3 & 4 & 6 & Yes \\
\hline 11 & $41 \mathrm{BX892}$ & Privy & 3 & & 6 & Yes \\
\hline 12 & $41 \mathrm{BX897}$ & & & & 7 & Yes \\
\hline 13 & $41 \mathrm{BX926}$ & Privy & 6 & & 6 & Yes \\
\hline 17 & $41 \mathrm{BX928}$ & Privy & 8 & & 1 & Yes \\
\hline 18 & $41 \mathrm{BX929}$ & Privy & 10 & & 6 & No \\
\hline 19 & $41 \mathrm{BX928}$ & Privy & 8 & & 1 & Yes \\
\hline 21 & $41 \mathrm{BX} 955$ & Privy & 11 & & 11 & No \\
\hline 23 & $41 \mathrm{BX895}$ & Bottles & & & 1 & Yes \\
\hline 24 & $41 \mathrm{BX896}$ & Privy & 5 & 8 & & Yes \\
\hline 27 & $41 \mathrm{BX} 896$ & Privy & 5 & 12 & & Yes \\
\hline 29 & $41 \mathrm{BX} 945$ & Privy & 12 & 3 & 15 & Yes \\
\hline 45 & $41 \mathrm{BX927}$ & Privy & 7 & & 10 & Yes \\
\hline 47 & $41 \mathrm{BX945}$ & Privy & 12 & 15 & 15 & No \\
\hline
\end{tabular}

4) What is the potential function of each of the plant taxa recovered from the samples? For example, were they used as food plants (crop, garden or gathered), building materials or landscape plants?

\section{Methods}

\section{Sample Processing and Sorting}

Sediment samples collected during excavations at the Alamodome sites were processed at the Center for Archaeological Research (CAR) of The University of Texas at San Antonio. The light fractions were submitted to Texas A\&M University for botanical analysis. Each sample was sorted through a series of four brass nested geological screens with mesh sizes ranging from 4 to $0.5 \mathrm{~mm}$. Each size grade was scanned and sorted under a binocular dissecting microscope at 8 magnifications.

All disseminules were separated and counted. In cases where a large amount of wood was encountered, a grab sample of 20 pieces from the 4-mm and 2-mm mesh sieves was identified, counted and weighed.

All identifications were made using reference collections at Texas A\&M University. Appendix 12-A presents the plant remains, counts, and weights (for wood only) from all of the flotation samples. Wood identifications were made to the most precise level possible at 35-75X magnification. Often, however, identifications to the species level are not possible in many cases. Therefore most of the identifications of wood were made to the genus level. It is also quite 
common for the wood of several tree species to be quite similar. I refer to certain groups of tree species or genera as "wood types." The wood types used in this report are

1) southern hard pine wood type, which includes the commercial trees loblolly pine and longleaf pine,

2) white oak wood type, which includes species from the subgenus leucobalanus (most notably post oak, Quercus stellata),

3) leguminous wood type, which includes wood of the genera Acacia and Prosopis (mesquite), and

4) willow wood type, which includes willows and cottonwoods.

The southern hard pine wood type is useful in distinguishing the pinyon pine of western Texas from the pines of East Texas. The oak wood types allow us to separate the red oaks (erythrobalanus) from the live oaks and the white oaks. Root fragments, because they are not identifiable and because they originated from currently growing plants, were not included in the analysis.

\section{Quantification}

\section{Flotation samples}

In this study we used presence (ubiquity) values to quantify the edible plant parts recovered from the flotation samples. Presence or ubiquity value is defined as the percentage of all analyzed samples in which a particular taxon is present. This value should include both productive and unproductive samples. The wood remains are evaluated on the basis of taxonomic frequency. After 20 wood fragments were identified in each sample, the abundance of each taxon or wood type was compared on a percentage basis.

\section{Results and Discussion}

The Context: A Brief Overview of Texas

Agriculture and Forestry as it Applies to Bexar County

Many of the plant remains recovered from the samples are nonlocal in origin or are agricultural products. Many probably originated from landscape plantings in the immediate area. Finally, a few may have been gathered from "wild" contexts either within the city or beyond the limits of the city. In order to begin to understand the context of many of the plant materials recovered from this urban setting, it will be necessary to present a brief overview of the salient characteristics of agriculture, especially horticulture in Texas around the turn of the twentieth century.

Texas has always been primarily an agricultural state. For example, the total acreage devoted to fruit production in Texas actually was greater at the turn of the century than it is today. The tradition of planting orchards was introduced by the Spanish, taken up by some of the Native Americans, and introduced again separately during Anglo settlement by the members of the Austin Colony (Geiser 1945:4; Swanton 1941:224). By 1860 Bexar County was the fifth most productive county in the state in terms of acreage devoted to orchards (Texas Almanac 1945-1946).

By far the most abundant of the introduced fruit crops in Texas were peaches. Pomegranates, oranges and figs were also grown by the Anglo settlers (Geiser 1945:5), although they were all well established by the Spaniards and grown by the Native Americans during the previous century. Other fruit crops included figs, plums and quince. The orchard production of both peaches and plums reached a peak in Texas between 1900-1910. The 1910 census listed 15,381 plum and prune trees and 37,312 peach trees in Bexar County. The 1920 census listed Bexar County as the second largest acreage devoted to the production of peaches and plums (Texas Almanac 1945-1946). By 1930 the number of producing peach trees had increased to 43,522 and plum trees had increased to 48,229 , perhaps as an attempt to diversify after the boll weevil had devastated the cotton industry (Evans 1960:156). After 1930 orchard production began to wane, and the local production of these fruits never recovered to previous levels. 
Apples, pears and apricots at first were not grown in great numbers, because they grow better in cooler climates. By 1900 , however, several varieties of apple trees that produced well in the local climate were introduced, and soon apples were the second-most important fruit crop in Texas (Geiser 1945:12). The surge in apple production did not last, and by 1930 it was evident that long-term apple production was not sustainable in Texas. Bexar County never became a significant center of apple production; these regions were located in the northeast portion of the state.

Pecans are the preeminent native nut crop of Texas, which is blessed with more native pecan trees than any other state. Improved varieties of pecan were first planted near Brownwood in 1880, and pecan orchards soon spread across the state. In the second decade of this century, over 125,000 pecan trees of improved varieties were planted in Texas. Although it was not the greatest center of pecan cultivation in Texas, pecans were harvested from about 20,000 trees in 1900 in Bexar County (Evans 1960:170). This figure grew to nearly 40,000 trees by 1910 (U.S. Census 1913:170).

The great pine forests of east Texas were not exploited commercially until after the Civil War. By this time, wood supplies in the eastern half of the United States were diminishing rapidly. Vast regions of the northeast were literally deforested by the time the southern forests were lumbered commercially. In addition, the forests of the Lake States were logged and burned in a series of great catastrophes in less than 50 years (Walker 1991:97). The great southern pine forests of east Texas were lumbered extensively from 1880 until their near extinction in 1940. By that time the pine forests of east Texas were "all but destroyed" (Maxwell and Martin 1970:13). The time period of the Alamodome houses coincides with a peak in east Texas pine lumber production, suggesting strongly that this building material was shipped from east Texas.

\section{Botanical Assemblage}

With this brief agricultural background in mind, the botanical assemblage from the Alamodome sites can be reviewed. Seventeen of the 20 samples ( 85 percent) contained identifiable plant remains. The botanical assemblage from the flotation samples consists of 445 seeds and 23.9 grams of wood. A total of 233 pieces of wood were identified and counted in grab samples; the rest of the wood was weighed and listed as "unsorted." Thirty-four plant taxa were identified from the samples. Twenty-five disseminule taxa and 10 wood taxa or types are represented in the plant assemblage (Table 11-2).

\section{Wood}

The ten wood types recovered from the samples included native taxa grown locally, introduced taxa grown locally, and native wood utilized as building material that was shipped into the city from the eastern Texas (pines) and the northeastern United States (hardwoods). The seven most frequent taxa are graphically presented in Figure 11-1. The wood taxa

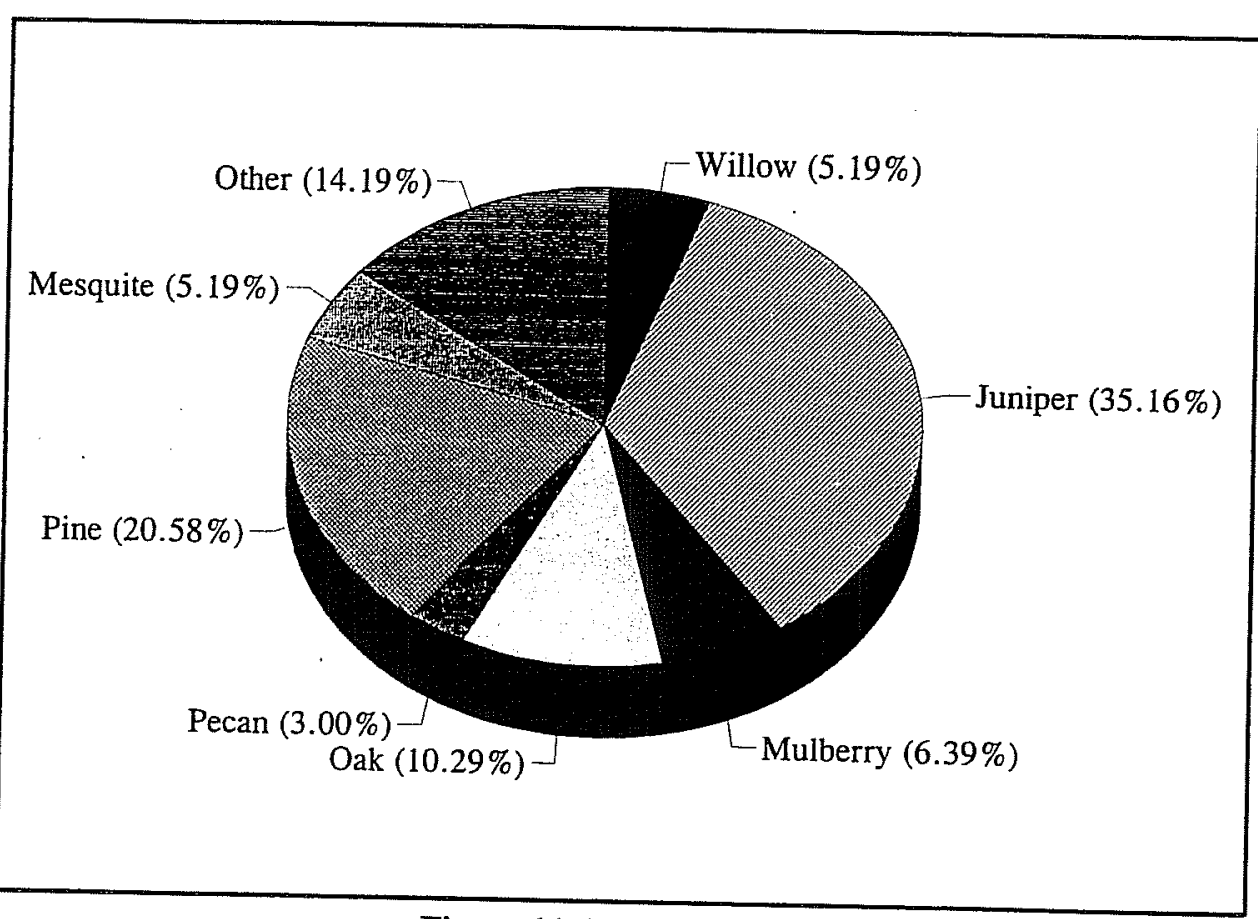

Figure 11-1. Wood frequencies from Alamodome sites. 
Table 11-2. Plant Taxa Recovered from the Alamodome Samples

\begin{tabular}{|c|c|c|c|}
\hline Name & Common & Part Present & $\begin{array}{l}\text { Native (N) or } \\
\text { Introduced (I) }\end{array}$ \\
\hline Brassica nigra & Mustard & Seed & $I$ \\
\hline Carya illinoiensis & Pecan & Wood & $\mathbf{N}$ \\
\hline Celtis sp. & Hackberry & Nutlet & $\mathbf{N}$ \\
\hline Citrullus vulgaris & Watermelon & Seed & I \\
\hline Cratategus sp. & Hawthorn & Fruit fragment & $\mathbf{N}$ \\
\hline Cucumis melo & Melons & Seed & $\mathbf{I}$ \\
\hline Fabaceae & Leguminous wood type & Wood & $\mathbf{N}$ \\
\hline Fraxinus americana & White ash & Wood & $\mathbf{N}$ \\
\hline Juglans nigra & Black walnut & Nut fragment & $\mathbf{N}$ \\
\hline Juniperus sp. & Juniper & Wood and seed & $\mathbf{N}$ \\
\hline Lagerstroemia indica & Crepe myrtle & Seed & I \\
\hline Leptaloma cognatum & Fall witchgrass & Seed & $\mathbf{N}$ \\
\hline Malus pumila & Apple & Seed & I \\
\hline Malvastrum sp. & Falsemallow & Seed & $N$ \\
\hline Morus microphylla & Texas mulberry & Wood & $\mathrm{N}$ \\
\hline Opuntia sp. & Prickly pear & Seed & $\mathrm{N}$ \\
\hline Panicum sp. & Panic grass & Seed & $\mathbf{N}$ \\
\hline Paspalum sp. & Paspalum grass & Seed & $\mathbf{N}$ \\
\hline Pinus sp. & Southern hard pine wood type & Wood & $\mathrm{N}$ (East Texas) \\
\hline Platanus occidentalis & American Sycamore & Wood & $\mathbf{N}$ \\
\hline Polygonum sp. & Knotweed & Seed & $\mathrm{N}$ \\
\hline Prunus persica & Peach & Fruit (Endocarp) & $\mathrm{I}$ \\
\hline Prunus serotina & Black Cherry & Fruit (Endocarp) & $\mathbf{N}$ \\
\hline Pyracantha coccinea & Firethorn & Seed & $\mathrm{I}$ \\
\hline Quercus fusiformis & Plateau Live Oak & Wood & $\mathrm{N}$ \\
\hline Quercus sp. & White Oak Wood Type & Wood & $\mathbf{N}$ \\
\hline Rhus sp. & Sumac & Seed & $\mathbf{N}$ \\
\hline Rubus sp. & Blackberry, Dewberry & Seed & $\mathbf{N}$ \\
\hline Rumex sp. & Dock & Seed & $\mathrm{N}$ \\
\hline Salicaceae & Willow Family Wood Type & Wood & $\mathbf{N}$ \\
\hline Sophora secundiflora & Texas Mountain Laurel & Seed & $\mathbf{N}$ \\
\hline Trifolium sp. & Clover & Seed & $\mathrm{I}$ \\
\hline Ulmus americana & American Elm & Wood & $\mathrm{N}$ \\
\hline Vitis sp. & Grape & Seed & $\mathbf{N}$ \\
\hline
\end{tabular}


are discussed below in categories according to their potential function.

\section{Building Materials}

The three most common woods, juniper, pine and white oak, are all potential building materials. Juniper accounted for over one-third, southern hard pine for one-fifth, and white oak for one-tenth of all the wood fragments. Juniper and some white oak was available locally, while all of the pine planks were shipped from extensive stands in east Texas.

I have identified the southern hard pine wood type in the samples. This wood type was probably obtained from Pinus taeda (loblolly), or Pinus palustris (longleaf) pine stands in east Texas. Pine was a primary building material that was used in the construction of frame houses in the early twentieth century.

The white oak is problematic. The post oak (Quercus stellata) is the most prominent white oak in Texas, but the post oak belt has never been considered a commercial stand of wood. If the white oak wood was originally used as fuel, it was probably logged locally. If it was originally building material, it was probably shipped to San Antonio from the hardwood logging concerns in the Midwest or Northeast of the country. White oak is a wood type comprised of many species that grow locally, including the widespread post oak (Quercus stellata) of the post oak woodlands that lie just to the east and north of San Antonio. The tall, straight post oaks were utilized by Anglo settlers in the construction of log cabins, but were never logged commercially on a grand scale. The post oak woodlands of Texas, however, have never been viewed as a commercial stand of wood (Walker 1991:224). Around the turn of the century hardwoods in Texas were utilized only in furniture and other smaller scale applications (Maxwell and Martin 1979:47). Therefore, most oak hardwood construction timbers in San Antonio may have been shipped by railroad from the lumber mills in the eastern United States.

Juniper was a locally available building material used for a number of purposes, including fence posts, gates and shingles. Juniper was also used in the construction of log structures, a practice whose geographic area stretched through and west of San Antonio (see, for example, Jordan 1975:247). According to the archaeological field reports at the Alamodome excavations, it was also used to line or cover many of the privies or pits.

\section{Fuel Wood}

The fuel woods most heavily utilized in the region were probably juniper, live oak or white oak wood types, and mesquite (leguminous wood type). These are the best potential fuel woods in the assemblage. Juniper produced an excellent charcoal, which provided a fuel that was easier to transport into urban areas. The production of juniper charcoal was effected by "charcoal burners" who, together with the production of juniper fence posts, wiped out huge stands of cedar in central Texas around the turn of the century (Jones ca. 1900:43). Therefore the juniper charcoal present in some of the features may have come from debris that originated in cleaning stoves and fireplaces.

\section{Wood from Landscape Plants}

Much of the charred wood may have resulted from trash being burned and discarded into old privies or pits. The great majority of this refuse would have resulted from regular landscape maintenance practices such as pruning and clearing. Mulberry, pecan, the leguminous wood type which was probably mesquite, ash, sycamore, and oak. All of these plants are indigenous to the region. Also, the diffuse porous wood types (noted in the appendix) include other plants positively identified by the presence of fruits or seeds, including peach and cherry, crepe myrtle, hawthorn and pyracantha. Pyracantha, peach and crepe myrtle were introduced from the Old World.

\section{Seeds, Fruits, and Nuts}

Edible Plants

Apple, peach, wild cherry, dewberry, grape, hawthorn, and watermelon seeds or fruits were recovered from the features. Most of these fruits 
were probably grown near San Antonio, because Bexar County was a major fruit producing county.

Dewberry/blackberry (Rubus sp.) and grape seeds appeared in relatively large quantities in some of the features. These may have been either wild or cultivated, as Texas abounded in wild types as well as some cultivated types. In the 1920 s, northeast Texas was a major dewberry production region (Talbert and Murneek 1939:269). Acreage devoted to grape vines exceeded $1,000,000$ by 1900 , and decreased thereafter (Texas Almanac 1945-1946).

Wild fruits from the assemblage that abound in Texas include hawthorn, grape, dewberry, wild cherry, hackberry, walnut and prickly pear. Each one of these native plants could have been growing in the gardens or yards of the houses in San Antonio. Early accounts emphasize the richness and variety of the local grapes, dewberries, black and red haw and pawpaw (Geiser 1945:18).

Walnut was the only nut fragment recovered in the samples. Both walnuts and pecans were listed as prolific by the early Anglo Texas settlers. The walnut fragment probably came from a tree grown in the yard of the house, because walnuts were never commercialized. On the other hand, pecans were the most important nut crop in Texas, and continue to be so today. During the early days of the Republic of Texas, wild pecans were collected and carried by wagon to Galveston, where they were shipped east (Geiser 1945:13). Improved horticultural varieties of pecans were introduced to Texas around 1870, and in 1880 the first commercial pecan orchard was planted (Rosengarten 1984:175). By 1900 Bexar County was listed as a major producer of pecans in Texas. For this reason, the lack of pecans in the assemblage is a disappointment, but not a total surprise considering the problems encountered in obtaining an adequate botanical sample at archaeological sites.

Both melon (Cucumis melo) and watermelon (Citrullus vulgaris) seeds occur in the botanical assemblage. Watermelon was introduced into the Americas by the Spanish explorers and adopted early as a cultigen by the Native Americans in Texas (e.g. Swanton 1942:124).
Ruderals

Ruderals are plants that colonize areas of disturbed soils, in this case growing around human habitations, especially those that are not well maintained. The presence of ruderals would indicate that the privies were open and probably received accidental inclusions of surface material, or yard trash may have been discarded into the pits. Ruderals recovered from the Alamodome sites include: knotweed, falsemallow, dock, mustard, and grasses.

\section{Feature Analysis}

The botanical analysis of features at historical sites in the Alamodome project was conducted to determine: a) feature function and b) formation processes affecting the features. Obviously the nomenclature utilized to label features assumes much regarding their function. The label privy implies that the feature was utilized as an outhouse. But privies were often cleaned out, and the function of features often changes throughout the occupation history of any site, whether it be of historic or prehistoric origin (Dickens 1985).

\section{Privies}

Pits or other features utilized for a variety of specific functions usually end their life as a repository for trash (Dickens 1985). This seems to be what happened to the privies of the Alamodome project. It is difficult to be certain if any of the plant remains I identified came from human fecal material, especially the large amounts of wood charcoal. Therefore, most of the material recovered from these privies is probably household and yard waste deposited after the privies ended their use as functioning outhouses.

Figure 11-2 presents the amounts of plant fruits, seeds and nut fragments recovered from each privy. The first line includes both cultivated and wild types, some of which may have been edible but were not considered "table" foods. I have included hackberry nutlets and walnuts in this category. The second figure includes only cultivated or potentially cultivated plants fruits or seeds that are "table" foods. 


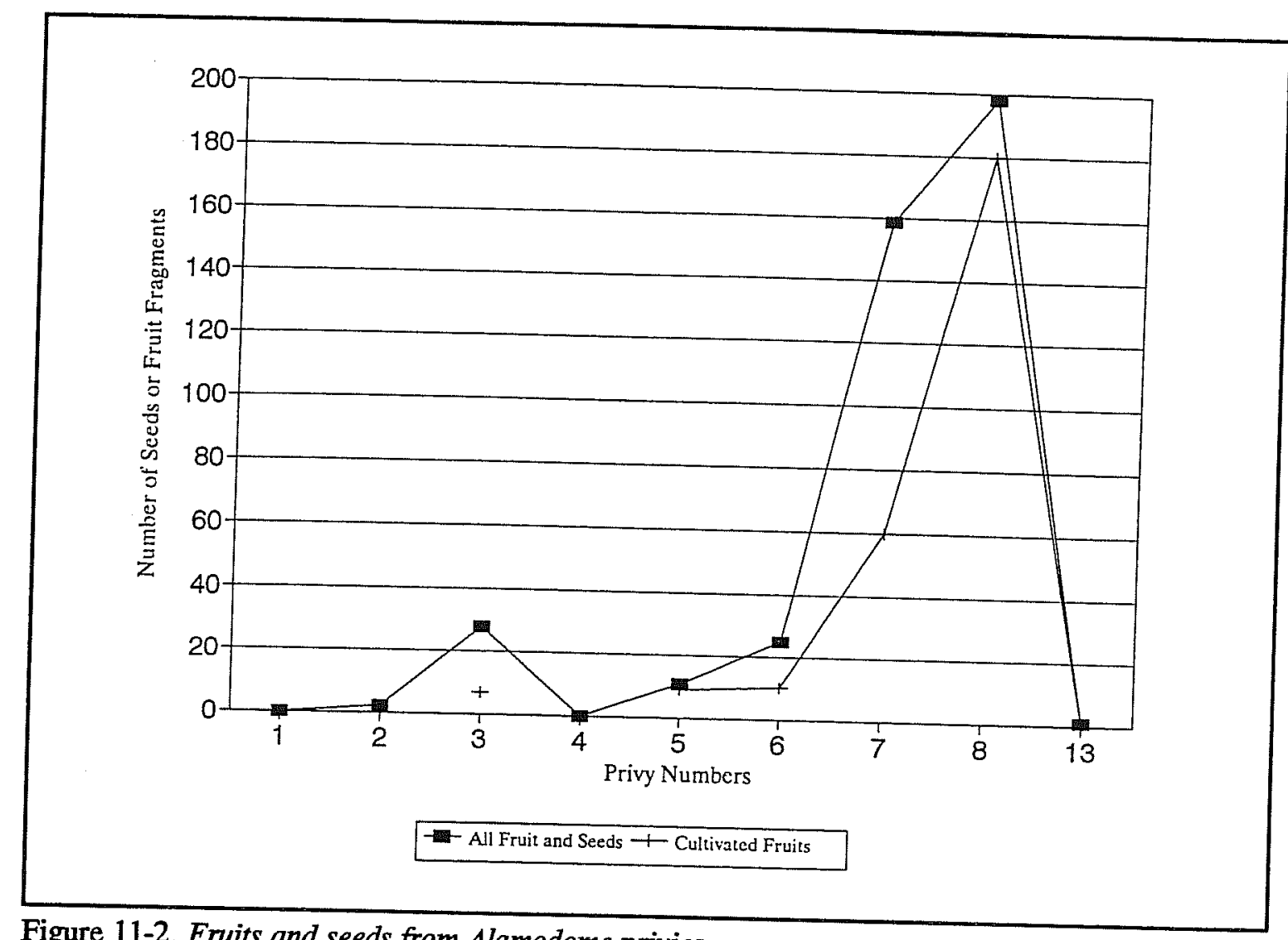

Figure 11-2. Fruits and seeds from Alamodome privies.

Table foods are those which would be stored, prepared in the kitchen and served with meals.

Privies 7 and 8 contain by far the most abundant plant fruit and seed remains. This is an indication that they probably contain the highest amount of household garbage, and may have contained some human feces. Privies 3 and 6 yielded some interesting contents, such as peaches (Privy 6) and watermelon (Privy 3). Privy 3 also contained 20 hackberry nutlets, suggesting that much of the material may have resulted from discarding yard waste. Another possible indication that privies or pits are filled with yard waste or were exposed to the outside is the presence of ruderal seeds. Ruderals occurred in Privy 2, 6, 7, and 8. Privies 6, 7, and 8 also had an excellent representation of edible seeds and fruits.

The equivocal results of the feature analysis make the identification of privy function difficult. Apparently the privies were not utilized for a single purpose, but for multiple purpose. As Dickens (1985) points out, most features have histories of multiple use. The common practice of periodically removing fecal material from privies may have obliterated the direct dietary record they once may have contained.

Pits and Bottle Caches

In contrast to the privies, features identified as pits and bottle caches contained very few seeds. Only Sample 12, the bottle cache from 41BX895, contained seeds of cultivated or potentially cultivated plants, watermelon and dewberry. All of the pits and bottle caches contained wood fragments, suggesting that they were used as trash pits or that they were left open and accumulated various types of garbage accidentally. 


\section{Summary and Conclusions}

This report presents results of the macrobotanical analysis of 20 flotation samples. The flotation samples were collected from 11 privies and 4 features from 13 different designated sites associated with late-nineteenth- to early twentieth-century homes occupied primarily by descendants of German immigrants. Seventeen of the 20 samples $(85$ percent) contained identifiable plant remains. The botanical assemblage from the flotation samples consists of 445 seeds and 23.9 grams of wood. A total of 233 pieces of wood were identified in grab samples; the rest of the wood was weighed and listed as "unsorted." Thirty-four plant taxa were identified from the samples. Twenty-five disseminule taxa and 10 wood taxa or types are represented in the plant assemblage. The most common wood types from the samples were juniper, pine and oak. The juniper was locally abundant on the southern Balcones escarpment in Bexar County. The pine, of the southern hard pine variety, was shipped into the area, probably from the booming east Texas lumber industry. The white oak construction wood probably was shipped from points east.

Fruits and seeds included several cultivars, both native and introduced. Evidence of the production of local orchards was indicated by the presence of peaches and apples. Local gardens produced melon and watermelon. Wild fruits included hackberry, prickly pear and wild plum. Dewberry and grape may have been gathered wild, or cultivated in the garden.

The analysis of feature function suggests that all of the features probably were used as trash receptacles. Even the features designated "privy" were probably cleaned out and used for trash pits. No direct evidence of human fecal material was present in the samples. 


\section{References Cited}

Beaudry, M. C., and S. A. Mrowsowski

1987 Interdisciplinary Investigations at the Boott Mills, Lowell, Massachusetts. Volume II: The Kirk Street Agents' House. Cultural Resources Management Study 19. Center for Archaeological Studies, Boston University, Boston.

1989 Interdisciplinary Investigations at the Boott Mills, Lowell, Massachusetts. Volume III: The Boarding House System as a Way of Life. Cultural Resources Management Study 21. Center for Archaeological Studies, Boston University, Boston.

Dickens, R. S.

1985 Form, Function and Formation of Garbage-Filled Pits. In Structure and Process in Southeastern Archaeology, edited by R. S. Dickens and H. T. Ward, pp. 34-59. University of Alabama Press. University, Alabama.

Evans, S. L.

1960 Texas Agriculture: 1880-1930. Ph.D. Dissertation. Department of Modern History, The University of Texas at Austin.

Gasser, R. E., and E. C. Adams

1981 Aspects of Deterioration of Plant Remains in Archaeological Sites: The Walpi Archaeological Project. Journal of Ethnobiology 1(1):182-192.

Geiser, S. W.

1945 Horticulture and Early Horticulturalists in Texas. University Press, Southern Methodist University, Dallas.

Jones, G.

ca. 1900 Texas Timber Resources. In A Short History of Forest Conservation in Texas: 1880-1940, edited by R. S. Maxwell and J. W. Martin. Bulletin 20, School of Forestry, Stephen F. Austin State University, Nacogdoches, Texas.

Jordan, T. G.

1975 Vegetational Perception and Choice of Settlement Site in Frontier Texas. In Research in Historical

Geography, edited by R. E. Ehrenberg. Howard University Press, Washington, D.C.

Lutzow, C. J.

1989 The Davis Site (21D3-246H): A Case Study for the Development of a Rural Subsistence Model Dependant Upon Indigenous Plant Materials. In Historic Archaeology in Illinois, pp. 117-152. Research Report 8, Midwestern Archaeological Research Center.

Maxwell, R. S., and J. W. Martin

1970 A Short History of Forest Conservation in Texas: 1880-1940. Bulletin 20, School of Forestry, Stephen F. Austin State University, Nacogdoches, Texas.

Miller, N. F.

1988 What Mean These Seeds? A Comparative Approach to Archaeological Seed Analysis. Historical Archaeology 23(2):50-59. 
Rosengarten, F., Jr.

1984 The Book of Edible Nuts. Walker and Company, New York.

Swanton, J. R.

1942 Source Material on the History and Ethnology of the Caddo Indians. Bulletin 132, Smithsonian Institution Bureau of American Ethnology, Washington, D.C.

Talbert, T. J., and A. E. Murneek

1939 Fruit Crops: Principles and Practices of Orchard and Small Fruit Culture. Lea and Febiger, Philadelphia.

Texas Almanac

1945-1946 Published by the Dallas Morning News.

Walker, L C.

1991 The Southern Forest: A Chronicle. The University of Texas Press, Austin. 


\section{Appendix 11-A. Plant Remains from Alamodome Sites}

Table 11-A1. Count Totals from Alamodome Sites

\begin{tabular}{|c|c|c|c|c|c|c|c|}
\hline Sample \# & Site \# & Feature Type & Feature \# & Taxon & Part & Count & Weight (g) \\
\hline 2 & $41 \mathrm{BX} 883$ & Privy & 1 & Juniperus sp. & wood & 20 & 6.8 \\
\hline 6 & $41 \mathrm{BX} 891$ & Trash Pit & $\mathbf{A}$ & Quercus sp. & wood & 2 & 0.1 \\
\hline 6 & $41 \mathrm{BX} 891$ & Trash Pit & $\mathbf{A}$ & Salicaceae & wood & 8 & 0.9 \\
\hline 6 & $41 \mathrm{BX} 891$ & Trash Pit & A & Ulmus americana & wood & 4 & 0.3 \\
\hline 6 & 41BX891 & Trash Pit & A & Juniperus sp. & wood & 4 & 3.0 \\
\hline 6 & 41BX891 & Trash Pit & $\mathbf{A}$ & Pinus sp. & wood & 2 & 0.2 \\
\hline 6 & $41 \mathrm{BX} 891$ & Trash Pit & $\mathbf{A}$ & Lagerstroemia indica & seed & 4 & \\
\hline 7 & $41 \mathrm{BX} 892$ & Privy & 4 & Platanus occidentalis & wood & 2 & 0.1 \\
\hline 7 & $41 \mathrm{BX} 892$ & Privy & 4 & Indeterminable & wood & 4 & 0.2 \\
\hline 7 & $41 \mathrm{BX} 892$ & Privy & 4 & Juniperus sp. & wood & 2 & 0.1 \\
\hline 8 & $41 B \times 890$ & Privy & 2 & Juniperus sp. & wood & 1 & 0.1 \\
\hline 8 & $41 \mathrm{BX} 890$ & Privy & 2 & Pinus sp. & wood & 10 & 0.3 \\
\hline 8 & $41 B \times 890$ & Privy & 2 & Brassica nigra & seed & 2 & 0 \\
\hline 9 & $41 B \times 892$ & Trash Pit & $\mathrm{C}$ & Fraxinus americana & wood & 2 & 0.2 \\
\hline 9 & 41BX892 & Trash Pit & $\mathrm{C}$ & Unsorted & wood & & 0.4 \\
\hline 9 & $41 \mathrm{BX} 892$ & Trash Pit & $\mathrm{C}$ & Indeterminable & wood & 2 & 0.1 \\
\hline 9 & $41 \mathrm{BX} 892$ & Trash Pit & $\mathrm{C}$ & Fabaceae & wood & 12 & 0.5 \\
\hline 9 & 41BX892 & Trash Pit & $\mathrm{C}$ & Juniperus sp. & wood & 2 & 0.1 \\
\hline 9 & 41BX892 & Trash Pit & C & Celtis sp. & wood & 2 & 0.1 \\
\hline 10 & $41 \mathrm{BX} 892$ & Privy & 3 & Quercus sp. & wood & 4 & 0.4 \\
\hline 10 & $41 \mathrm{BX} 892$ & Privy & 3 & Salicaceae & wood & 2 & 0.1 \\
\hline 10 & $41 \mathrm{BX} 892$ & Privy & 3 & Indeterminable & wood & 6 & 0.4 \\
\hline 10 & 41BX892 & Privy & 3 & Juniperus sp. & wood & 5 & 0.2 \\
\hline 10 & 41BX892 & Privy & 3 & Celtis sp. & seed & 1 & \\
\hline 10 & 41BX892 & Privy & 3 & Pinus sp. & wood & 3 & 0.2 \\
\hline 10 & $41 \mathrm{BX} 892$ & Privy & 3 & Citrullus vulgaris & seed & 7 & \\
\hline 11 & $41 \mathrm{BX} 892$ & Privy & 3 & Juniperus sp. & wood & 10 & 0.4 \\
\hline 11 & $41 \mathrm{~B} \times 892$ & Privy & 3 & Celtis sp. & seed & 20 & \\
\hline 12 & $41 \mathrm{BX} 897$ & & & Carya illinoiensis & wood & 4 & 0.3 \\
\hline 12 & $41 \mathrm{BX} 897$ & & & Quercus sp. & wood & 2 & 0.1 \\
\hline 12 & 41BX897 & & & Salicaceae & wood & 2 & 0.1 \\
\hline 12 & 41BX897 & & & Indeterminable & wood & 3 & 0.1 \\
\hline 12 & 41BX897 & & & Juniperus sp. & wood & 4 & 0.2 \\
\hline 12 & 41BX897 & & & Celtis sp. & wood & 2 & 0.1 \\
\hline 12 & $41 \mathrm{BX} 897$ & & & Pinus sp. & wood & 4 & 0.2 \\
\hline 12 & $41 B \times 897$ & & & Rubus sp. & seed & 1 & \\
\hline 12 & $41 \mathrm{BX} 897$ & & & Citrullus vulgaris & seed & 4 & \\
\hline 12 & $41 \mathrm{BX} 897$ & & & Lagerstroemia indica & seed & 6 & \\
\hline 13 & $41 \mathrm{BX} 926$ & Privy & 6 & Carya illinoiensis & wood & 3 & 0.1 \\
\hline 13 & $41 \mathrm{BX} 926$ & Privy & 6 & Salicaceae & seed & & 0.4 \\
\hline 13 & $41 \mathrm{BX} 926$ & Privy & 6 & Sophora secundiflora & seed & 3 & \\
\hline 13 & $41 \mathrm{BX} 926$ & Privy & 6 & Opuntia sp. & seed & 3 & \\
\hline 13 & $41 \mathrm{BX} 926$ & Privy & 6 & Juniperus sp. & wood & 9 & 0.5 \\
\hline 13 & 41BX926 & Privy & 6 & Celtis sp. & seed & 7 & \\
\hline
\end{tabular}


Table 11-A1. continued

\begin{tabular}{|c|c|c|c|c|c|c|c|}
\hline Sample \# & Site \# & Feature Type & Feature \# & Taxon & Part & Count & Weight (g) \\
\hline 13 & 41BX926 & Privy & 6 & Rumex sp. & seed & 4 & \\
\hline 13 & $41 \mathrm{BX} 926$ & Privy & 6 & Vitis sp. & seed & 6 & \\
\hline 13 & 41BX926 & Privy & 6 & Prunus persica & seed & 4 & \\
\hline 13 & 41BX926 & Privy & 6 & Paspalum sp. & seed & 2 & \\
\hline 17 & 41BX928 & Privy & 8 & Crataegus sp. & seed & 3 & \\
\hline 17 & $41 B \times 928$ & Privy & 8 & Leptaloma cognatum & seed & 4 & \\
\hline 17 & $41 \mathrm{BX} 928$ & Privy & 8 & Quercus sp. & wood & 8 & 0.2 \\
\hline 17 & $41 \mathrm{BX} 928$ & Privy & 8 & Juniperus sp. & wood & 12 & 0.9 \\
\hline 17 & 41BX928 & Privy & 8 & Rubus sp. & seed & 13 & \\
\hline 19 & 41BX928 & Privy & 8 & Panicum sp. & seed & 7 & \\
\hline 19 & 41BX928 & Privy & 8 & Opuntia sp. & seed & 1 & \\
\hline 19 & 41BX928 & Privy & 8 & Rubus spp. & seed & 164 & \\
\hline 19 & $41 \mathrm{BX} 928$ & Privy & 8 & Vitis sp. & seed & 2 & \\
\hline 19 & $41 \mathrm{BX} 928$ & Privy & 8 & Brassica nigra & seed & 2 & \\
\hline 19 & 41BX928 & Privy & 8 & Malvastrum sp. & seed & 2 & \\
\hline 23 & 41BX895 & Bottles & & Juglans nigra & nut & 6 & \\
\hline 23 & 41BX895 & Bottles & & Prunus serotina & seed & 3 & \\
\hline 23 & 41BX895 & Bottles & & Rhus sp. & seed & 4 & \\
\hline 23 & 41BX895 & Bottles & & Juniperus sp. & wood & 1 & 0.1 \\
\hline 23 & 41BX895 & Bottles & & Celtis sp. & seed & 4 & \\
\hline 23 & $41 \mathrm{BX} 895$ & Bottles & & Pinus sp. & wood & 19 & 2.0 \\
\hline 24 & $41 \mathrm{BX} 896$ & Privy & 5 & Platanus occidentalis & wood & 6 & 1.0 \\
\hline 24 & 41BX896 & Privy & 5 & Quercus sp. & wood & 6 & 1.1 \\
\hline 24 & 41BX896 & Privy & 5 & Pinus sp. & wood & & 0.4 \\
\hline 24 & 41BX896 & Privy & 5 & Malus pumila & seed & 6 & \\
\hline 27 & 41BX896 & Privy & 5 & Morus microphylla & wood & 7 & 0.3 \\
\hline 27 & 41BX896 & Privy & 5 & Rubus sp. & seed & 3 & \\
\hline 27 & 41BX896 & Privy & 5 & Pyracantha coccinea & seed & 2 & \\
\hline 29 & 41BX945 & Privy & 13 & Morus microphylla & wood & 8 & 0.4 \\
\hline 29 & $41 B \times 945$ & Privy & 13 & Juniperus sp. & wood & 12 & 0.3 \\
\hline 29 & 41BX945 & Privy & 13 & Prunus persica & seed & 1 & \\
\hline 45 & $41 \mathrm{BX} 927$ & Privy & 7 & Quercus fusiformis & wood & 2 & 0.1 \\
\hline 45 & $41 \mathrm{BX} 927$ & Privy & 7 & Polygonum sp. & seed & 6 & \\
\hline 45 & $41 \mathrm{BX} 927$ & Privy & 7 & Pinus sp. & wood & 5 & 0.2 \\
\hline 45 & $41 \mathrm{BX} 927$ & Privy & 7 & Rubus spp. & seed & 17 & \\
\hline 45 & $41 \mathrm{BX} 927$ & Privy & 7 & Cucumis melo & seed & 15 & \\
\hline 45 & $41 \mathrm{BX} 927$ & Privy & 7 & Vitis sp. & seed & 26 & \\
\hline 45 & $41 \mathrm{~B} \times 927$ & Privy & 7 & Trifolium sp. & seed & 80 & \\
\hline 45 & $41 \mathrm{BX} 927$ & Privy & 7 & Prunus persica & seed & 2 & \\
\hline 45 & $41 \mathrm{~B} \times 927$ & Privy & 7 & Brassica nigra & seed & 4 & 0 \\
\hline
\end{tabular}




\title{
Chapter 12
}

\section{Analysis of the Vertebrate Faunal Remains from the Alamodome Project}

\author{
Barbara A. Meissner and Johanna M. Hunziker
}

\section{Introduction}

Of the 36 sites investigated during the Alamodome Project, 32 yielded 24,194 vertebrate faunal remains, weighing a total of $95.85 \mathrm{~kg}$. The first section of this report lists species identified in each site, and general observations and comparisons between sites.

Three areas are given more specific attention. These consist of two privies (Privy \#1 on site 41BX883 and Privy \#12 on site 41BX945), and one trash dump (the trash associated with the Webb complex on site 41BX897, which extended into the lot to the south, site 41BX883). In these three areas, 50.93 percent $(n=12,323)$ of the total bone was recovered.

\section{Methodology}

All bone collected during the project was examined. Identifications were made to the lowest possible taxonomic level, using The Center for Archaeological Research's comparative collection and standard texts on vertebrate anatomy (Gilbert 1990; Hillson 1986; Olsen 1964, 1968; Wheeler and Jones 1989). Identifications were conservative, i.e., cow-sized bone was not assumed to be Bos taurus, even if it showed butcher marks, unless it could be positively identified as such. The presence on one site of butchered horse/donkey bone proved this precaution was prudent.

For most of the sites, data collection was limited to identification of taxon, count, and weight, butcher marks on identified domestic stock, and evidence of burning. Numbers used in this analysis represent final counts and percentages and may thus vary somewhat from those presented in Volume II.

Unidentified (UID) bone was placed in categories Mammalia, Aves, Reptilia, and Osteichthyes when possible. All bone which could not be so placed was called UID Vertebrata. For bone from the three special study areas, not from domestic stock animals (cow, pig, goat, and sheep), the following data were collected, when possible: taxon, count, weight, anatomical element, portion of element, side, type of butcher marks, existence and extent of signs of burning, presence of indications that the animal was juvenile, and any signs of chewing by rodents or carnivores. For bone from the special study areas which was determined to be domestic stock, the following data was collected, when possible: taxon, count, weight, anatomical element, portion of element, meat cut represented, type of butcher marks seen on bone, existence and extent of signs of burning, presence of indications that the animal was juvenile, and any signs of chewing by rodents or carnivores. In addition, notes were made of observations of particular interest. All data was input into a computer database in order to allow quick access.

Species identified during analysis are listed in Table $12-1$, with brief notes concerning the species and taxonomic methodology used in the data collection. Species listed as game animals are non-domesticated animals known to be hunted for food now or in the past. 
Table 12-1. Identified Taxa

\begin{tabular}{|c|c|c|}
\hline Scientific Name & Common Name & Notes \\
\hline Mammalia & \multicolumn{2}{|l|}{ Mammals } \\
\hline Bos Taurus & Cattle & Domestic food animal. \\
\hline Canis familiarize & Dog & Domestic animal. \\
\hline Canis sp. & Dog, wolf, coyote & $\begin{array}{l}\text { In this context most canid bone is probably } C \text {. familiarize; however, } \\
\text { unless it could be definitely identified as dog it was put in this } \\
\text { category, since coyote ( } C \text {. latrans) was and is not uncommon in } \\
\text { undeveloped areas near the city, and wolf ( } C \text {. lupus) has been present } \\
\text { in the area in the past. }\end{array}$ \\
\hline Copra harks & Domestic goat & Domestic food animal. \\
\hline CopralOvis & Goat/sheep & $\begin{array}{l}\text { Domestic animal. Differentiation of these two genera is notoriously } \\
\text { difficult. This category was used when such differentiation could not } \\
\text { be made. }\end{array}$ \\
\hline $\begin{array}{l}\text { Dasypus } \\
\text { novemcinctus }\end{array}$ & $\begin{array}{l}\text { Nine-banded } \\
\text { armadillo }\end{array}$ & $\begin{array}{l}\text { Game animal. Very common in the area today, though uncommon or } \\
\text { absent before the mid-1850s (Davis and Schmidly 1994:85). They are } \\
\text { omnivorous, but prefer insects and other invertebrates. They are still } \\
\text { occasionally hunted for food (Davis and Schmidly 1994:82-84). }\end{array}$ \\
\hline Didelphis virginiana & opossum & $\begin{array}{l}\text { Game animal. The opossum occurs across Texas. It inhabits deciduous } \\
\text { woodlands, prairies, marshes, and farmlands. It was frequently hunted } \\
\text { in the past for meat and pelt, and today is still the second most } \\
\text { commonly harvested fur-bearing animal in Texas (Davis and Schmidly } \\
1994: 17 \text { ). }\end{array}$ \\
\hline Erethizon dorsatum & Porcupine & $\begin{array}{l}\text { This large rodent inhabits a variety of environments that include rocky } \\
\text { areas, slopes and ridges, but prefers forested areas. }\end{array}$ \\
\hline Equip & $\begin{array}{l}\text { Horse, donkey, } \\
\text { burro }\end{array}$ & $\begin{array}{l}\text { Domestic animal. The only equip bone which was identified could } \\
\text { have been Equus caballos, donkey, burro. }\end{array}$ \\
\hline Felis domesticus & Domestic cat & Domestic animal. \\
\hline Felid & Cats & $\begin{array}{l}\text { All wild cats in Texas are rare and extremely shy. The chance that } \\
\text { some of the felid bones from this project are from wild cats is not } \\
\text { overlooked, however, and unless positive identification of } F \text {. } \\
\text { domesticus is made, this category was used. }\end{array}$ \\
\hline Geomys sp. & Pocket gophers & $\begin{array}{l}\text { According to Davis and Schmidly (1994:124), only G. attwateri is } \\
\text { found in Bexar County; however, the presence nearby of two other } \\
\text { species of very similar pocket gophers and the fact that they are known } \\
\text { to interbreed, makes differentiation difficult, and it was not attempted } \\
\text { for this report. They live almost exclusively in their burrow, eating } \\
\text { roots and sometimes whole plants pulled down from the surface (Davis } \\
\text { and Schmidly 1994: 122). }\end{array}$ \\
\hline Lepus californicus & $\begin{array}{l}\text { Black-tailed } \\
\text { jackrabbit }\end{array}$ & $\begin{array}{l}\text { Game animal. The jack is a large rabbit which prefers dry climates, } \\
\text { but is found over most of the state. It was more common in this area } \\
\text { in the past than today. Jacks eat plant materials, especially grasses } \\
\text { (Davis and Schmidly 1994:92-94). }\end{array}$ \\
\hline Neotoma sp. & Woodrats & $\begin{array}{l}\text { Three species of woodrat commonly occur in this part of Texas; the } \\
\text { white-thrated woodrat }(N . \text { albigula), Eastern woodrat (N. floridana), } \\
\text { and the Southern Plains woodrat }(N . \text { micropus). Their habitats range } \\
\text { from marshlands to semi-arid regions. They construct above ground } \\
\text { houses of sticks and other debris, underground burrow systems, or a } \\
\text { combination of both. }\end{array}$ \\
\hline $\begin{array}{l}\text { Odocoileus } \\
\text { virginianus }\end{array}$ & White-tailed deer & $\begin{array}{l}\text { Game animal. Sub species of } O \text {. virginianus in this area are small deer } \\
\text { who prefer brushy, wooded country. They eat grasses, forbes, and } \\
\text { nuts (Davis and Schmidly 1994:281-282). }\end{array}$ \\
\hline
\end{tabular}


Table 12-1. continued

\begin{tabular}{|c|c|c|}
\hline Scientific Name & Common Name & Notes \\
\hline Obis sp. & Domestic sheep & Domestic food animal. \\
\hline Rattus rattus & Black rat, roof rat & $\begin{array}{l}\text { A medium-sized rat, immigrated from Europe. Black rats prefer close } \\
\text { association with humans. They will eat almost anything (Davis and } \\
\text { Schmidly 1994:198). }\end{array}$ \\
\hline Rodentia & Rodent-sized & $\begin{array}{l}\text { Very small mammals which could not be identified to genus were } \\
\text { included in this category. }\end{array}$ \\
\hline Sigmadon hispidus & Cotton rat & $\begin{array}{l}\text { A large, very common, native rat, which generally prefers undisturbed } \\
\text { areas; but is not infrequently found close to human habitations. Cotton } \\
\text { rats eat mostly plant materials (Davis and Schmidly 1994:187-188). }\end{array}$ \\
\hline Sciurus niger & Easter fox squirrel & $\begin{array}{l}\text { Game animal. They are the most common squirrel in San Antonio } \\
\text { area. Fox squirrels adapt well to city living where there are stands of } \\
\text { trees. They eat largely seeds and nuts (Davis and Schmidly } \\
1994: 117-118 \text { ). }\end{array}$ \\
\hline Sus scrofa & Domestic pig & Domestic food animal. \\
\hline Sylvilagus sp. & Cottontail rabbits & $\begin{array}{l}\text { Game animal. The ranges of three very similar species of Sylvilagus } \\
\text { overlap in the San Antonio area: } S \text {. aquaticus (the swamp rabbit), } S \text {. } \\
\text { audubonii (the desert cottontail), and } S \text {. floridanus (the eastern } \\
\text { cottontail). No attempt was made to differentiate them (Davis and } \\
\text { Schmidly 1994:88-92). }\end{array}$ \\
\hline Tayassu tajacu & $\begin{array}{l}\text { Collared peccary } \\
\text { (Javelina) }\end{array}$ & $\begin{array}{l}\text { This pig-like animal inhabits dense brushy area, rocky canons, and } \\
\text { barren wastelands. The peccary was hunted commercially for its hide } \\
\text { in Texas up until } 1939 \text { (Davis and Schmidly 1994). }\end{array}$ \\
\hline Aves & Birds & \\
\hline Anas platyrhynches & Mallard duck & $\begin{array}{l}\text { Game animal/domestic food animal. The mallard duck is common on } \\
\text { ponds, marshes, and streams throughout the fall and winter. Mallards } \\
\text { may also be kept in captivity as a domestic food animal. }\end{array}$ \\
\hline Anas sp. & Ducks & $\begin{array}{l}\text { Several species of duck are commonly found in the area during the fall } \\
\text { and winter months. Differentiation between species is difficult, thus the } \\
\text { genus (Anas) is the lowest taxonomic level possible to identify in many } \\
\text { cases. }\end{array}$ \\
\hline Anser/Anas sp. & Goose/Duck & Many small geese are difficult to distinguish from ducks. \\
\hline Branta canadensis & Canada goose & $\begin{array}{l}\text { Game animal. This is the most common goose and is found across } \\
\text { North America at different times of the year. This area is included in } \\
\text { its winter range. There are at least } 10 \text { subspecies that differ greatly in } \\
\text { size and color (Robbins et al. 1983). }\end{array}$ \\
\hline Columbidae & Pigeons and doves & $\begin{array}{l}\text { Game animal. Several species of doves and pigeons are common in the } \\
\text { area. The domestic pigeon, Columbia livia, and the mourning dove, } \\
\text { Zenaida asiatica, are year round residents. The Inca (sometimes called } \\
\text { Mexican) dove, Columbia inc, is also common. Differentiation } \\
\text { between species is difficult, so the lowest taxonomic level possible is } \\
\text { family. }\end{array}$ \\
\hline Gallus domesticus & Domestic chicken & Domestic food animal. \\
\hline Meleagris gallopavo & $\begin{array}{l}\text { Wild/domestic } \\
\text { turkey }\end{array}$ & $\begin{array}{l}\text { Game animal/Domestic food animal. It is almost impossible to } \\
\text { differentiate domestic from wild turkeys by osteology, especially in } \\
19 \text { th century proveniences. Most of the turkey identified is probably } \\
\text { domestic, but wild turkeys are not uncommon in this area, frequenting } \\
\text { open woodland or forest clearings, and were and are frequently } \\
\text { hunted. }\end{array}$ \\
\hline
\end{tabular}


Table 12-1. continued

\begin{tabular}{|c|c|c|}
\hline Scientific Name & Common Name & Notes \\
\hline Phasianidae & Gallinaceous birds & $\begin{array}{l}\text { Game animals. Wild gallinaceous birds (fowl) that may be found } \\
\text { locally are wild turkey, scaled quail (Callipepla squamata), and } \\
\text { Northern bobwhite (Colinus virginianus). The quail and bobwhite } \\
\text { prefer brushy areas or open clearings. }\end{array}$ \\
\hline Turdus migratorius & American robin & $\begin{array}{l}\text { This robin is a year-round resident of this area, and is commonly } \\
\text { found in suburban settings. }\end{array}$ \\
\hline Reptilia & Reptiles & \\
\hline Testudinata & Turtles & $\begin{array}{l}\text { A minimum of } 11 \text { species of turtle, representing } 5 \text { families, indigenous } \\
\text { to this area. Order is the lowest taxonomic level that was possible. } \\
\text { (Note: The turtle remains recovered could only be excluded from one } \\
\text { family, Trionychidae, the softshell turtles.) }\end{array}$ \\
\hline Osteichthyes & Boney Fish & \\
\hline $\begin{array}{l}\text { Aplodinotus } \\
\text { grunniens }\end{array}$ & $\begin{array}{l}\text { Freshwater drum } \\
\text { fish }\end{array}$ & $\begin{array}{l}\text { This is the only freshwater drum fish locally indigenous. It inhabits } \\
\text { bottoms of medium to large rivers and lakes and can grow to } 39 \text { inches } \\
\text { in length (Page \& Burr 1991). }\end{array}$ \\
\hline Ictalurus sp. & Catfish & $\begin{array}{l}\text { Habitat ranges from pools and backwaters to creeks, small to large } \\
\text { rivers, and lakes. Local species include channel catfish (I. punctatus), } \\
\text { headwater catfish (I. lupus), blue catfish (I. furcatus), black bullhead } \\
\text { (I. melas), and the yellow bullhead (I. natalis) }\end{array}$ \\
\hline Micropterus sp. & $\begin{array}{l}\text { Black bass, } \\
\text { Largemouth bass }\end{array}$ & $\begin{array}{l}\text { Local species are the largemouth bass (M. salmoides), spotted bass ( } M \text {. } \\
\text { punctulatus), and Guadalupe bass ( } M \text {. treculi). These species range in } \\
\text { maximmm size from } 16 \text { inches for the Guadalupe bass to } 38 \text { inches for } \\
\text { the largemouth. All prefer clear lakes and ponds or flowing pools of } \\
\text { creeks and small to medium rivers (Page and Burr 1991). }\end{array}$ \\
\hline Perca flavencens & Yellow perch & $\begin{array}{l}\text { Inhabits ponds, lakes, creeks, and small to large rivers and can grow } \\
\text { to } 16 \text { inches in length. This species of perch is not indigenous, but has } \\
\text { been widely introduced across North America (Page and Burr 1991). }\end{array}$ \\
\hline
\end{tabular}

\section{Vertebrate Remains Recovered From Alamodome Sites}

Each of the Alamodome sites from which vertebrate faunal remains were collected is listed below, with bone identified to the lowest taxonomic level possible.

\section{BX881 (Oeffinger Site)}

The Oeffinger Site dates to the late 1880 s and was named after the first recorded resident of this site, John Oeffinger, a carpenter. Oeffinger is listed as residing on the property from 1893 to 1904 .

A total of 595 pieces of bone was recovered from this site (Table 12-2). Of these only 31 (5.21 percent) specimens were identified. Of the identified mammal remains 87.10 percent were of domesticated food animals. The identified bone consisted of $17 \mathrm{cow}$ (Bos Taurus), 1 canid (Canis sp.), 5 goat/sheep (Copra/ Ovis), 3 blackmail jackrabbit (Lepus californicus), and 5 pig (Sus scrofa) bones. Of the unidentified bone, 94.33 percent was mammal, 5.49 percent was bird, and the remaining 0.18 percent was unknown vertebrate. A total of 48.07 percent $(n=286)$ of the bone was burned.

\section{BX882 (Haas Site)}

The Haas Site dates to ca. 1900 . The property was purchased in 1892 by Julius Haas. The first recorded structure on the site was constructed in 1900 and served as a rental house from 1900 until it was removed after 1970 . 
Table 12-2. Faunal Remains from Site 41BX881

\begin{tabular}{|c|c|c|c|c|}
\hline & $\#$ & $\begin{array}{c}\% \text { of } \\
\text { Identified }\end{array}$ & $\begin{array}{c}\text { Weight } \\
\text { (g) }\end{array}$ & $\begin{array}{c}\% \text { of } \\
\text { Identified }\end{array}$ \\
\hline \multicolumn{5}{|l|}{ Mammalia } \\
\hline Bos Taurus & 17 & 54.84 & 152.27 & 68.46 \\
\hline Canis sp. & 1 & 3.23 & 0.22 & 0.10 \\
\hline Copra/Obis & 5 & 16.13 & 9.93 & 4.46 \\
\hline Lepus californicus & 3 & 9.68 & 10.74 & 4.83 \\
\hline Sus scrofa & 5 & 16.13 & 49.27 & 22.15 \\
\hline Total Identified Mammalia & 31 & $100.00 \%$ & 222.43 & $100.00 \%$ \\
\hline UID Mammalia & 532 & & 514.76 & \\
\hline Total Mammalia & 563 & & 737.19 & \\
\hline \multicolumn{5}{|l|}{ Aves } \\
\hline UID Aves & 31 & & 13.57 & \\
\hline Total Aves & 31 & & 13.57 & \\
\hline Total Identified & 31 & & 222.43 & \\
\hline UID Vertebrata & 1 & & 0.26 & \\
\hline Total Vertebrata & 595 & & 751.02 & \\
\hline
\end{tabular}

A total of 290 pieces of bone was recovered from this site, of these 36 (12.41 percent) were identifiable (Table 12-3). The identified bone included $16 \mathrm{cow}, 4$ goat/sheep, 6 whitetail deer (Odocoileus virginianus), and 4 pig. Identified birds included 2 mallard duck (Anas platyrhynches), 1 dove or pigeon (Columbidae), 2 turkey (Meleagris gallopavo). A single catfish bone (Ictalurus sp.) was also identified. Domesticated food animals constitute 80.00 percent of the identified mammal remains. The unidentified specimens consisted of 94.88 percent mammal, 4.73 percent bird, and 0.39 percent fish bone. A total of 7.59 percent of the bone $(n=22)$ was burned.

\section{BX883 (King Site)}

The structures on the King site date to the 1880 s. In 1884 a structure was constructed on the site for Cornelius King, a vegetable dealer, who later sold the property to Adolph Klar, a butcher. The Klar family sold the property in 1916. A brick-lined privy vault (Privy \#1, see Brown and DeLaO, this volume, for detailed discussion of the privies), associated with the King/Klar occupation of the site was completely excavated and large amounts of bone were recovered.
The analysis of bone from this privy included butchering marks and meat cut identification. This information will be discussed at length in the following section, but the bone counts from the privy are included in Table 12-4.

During excavation of a well in site 41BX897, on the lot immediately to the north of this site, a large trash dump was uncovered, containing thousands of bones. This trash dump extended into site 41BX883. The bone from this trash dump which was inside the boundary of this site is also included in Table 12-4.

A total of 4,469 bones was recovered from $41 \mathrm{BX} 883$ (Table 12-4). Of these, 1,416 (31.68 percent) were identified. The identified specimens of mammals include 841 cow, 1 canid, 7 goat (Copra sp.), 69 goat/sheep, 1 opossum (Didelphis marsupialis), 1 porcupine (Erethizon dorsatum), 1 horse/donkey (Equus sp.), 1 pocket gopher (Geomys sp.), 51 blackmail jackrabbit, 2 white-tailed deer, 12 sheep (Obis sp.), 1 javelina (Tayassu tajacu), 1 fox squirrel (Sciurus niger), 2 cotton rat (Sigmodon hispidus), 271 pig, and 31 rabbit (Sylvilagus sp.). The identified bird bones consist of 18 duck (Alas sp.), 20 goose (Anser sp.), 48 chicken (Gallus domesticus), and 23 turkey. 
Table 12-3. Faunal Remains from Site 41BX882

\begin{tabular}{|c|c|c|c|c|}
\hline & $\#$ & $\begin{array}{c}\% \text { of } \\
\text { Identified }\end{array}$ & $\begin{array}{c}\text { Weight } \\
\text { (g) }\end{array}$ & $\begin{array}{c}\% \text { of } \\
\text { Identified }\end{array}$ \\
\hline \multicolumn{5}{|l|}{ Mammalia } \\
\hline Bos Taurus & 16 & 44.44 & 378.71 & 67.38 \\
\hline Copra/Obis & 4 & 11.11 & 17.39 & 3.09 \\
\hline Odocoileus virginianus & 6 & 16.67 & 14.83 & 2.64 \\
\hline Sus scrofa & 4 & 11.11 & 127.61 & 22.71 \\
\hline Total Identified Mammalia & 30 & $83.33 \%$ & 538.54 & 95.82\% \\
\hline UID Mammalia & 241 & & 369.01 & \\
\hline Total Mammalia & 271 & & 907.55 & \\
\hline \multicolumn{5}{|l|}{ Aves } \\
\hline Alas sp. & 2 & 5.56 & 1.25 & 0.22 \\
\hline Colombidae & 1 & 2.78 & 0.20 & 0.04 \\
\hline Meleagris gallopavo & 2 & 5.56 & 21.70 & 3.86 \\
\hline Total Identified Aves & 5 & $13.89 \%$ & 23.15 & $4.12 \%$ \\
\hline UID Aves & 12 & & 5.68 & \\
\hline Total Aves & 17 & & 28.83 & \\
\hline \multicolumn{5}{|l|}{ Osteichthyes } \\
\hline Ictalurus sp. & 1 & 2.78 & 0.33 & 0.06 \\
\hline Total Identified Osteichthyes & 1 & $2.78 \%$ & 0.33 & $0.06 \%$ \\
\hline UID Osteichthyes & 1 & & 6.50 & \\
\hline Total Osteichthyes & 2 & & 6.83 & \\
\hline Total Identified & 36 & & 562.02 & \\
\hline Total Vertebrata & 290 & & 943.21 & \\
\hline
\end{tabular}

Identified fish remains were made up of 3 catfish, 1 black bass (Micropterus sp.), and 10 perch (Perca flavencens) bones. The unidentified bone was 93.55 percent mammal, 4.36 percent bird, 1.99 percent fish, and 0.10 percent was unknown vertebrate. A total of 19.31 percent of the bone was burned $(n=836)$.

Domestic food animals make up 92.81 percent of the identified mammal remains. With bird remains it is more difficult to determine which are from domesticated individuals and which are from wild individuals since it is not possible to tell the difference from the osteological remains of the ducks, geese, and turkeys. In addition to this problem much of the duck and goose could only be identified to genus. The most common identified bird taxon was chicken, which makes up 44.04 percent of the bird assemblage.

\section{BX884 (Griesenbeck Site)}

The first recorded structure on this site was constructed around 1883 for August and Marie Roatzsch who resided on the site until 1901, at which time the property was sold to Arthur Griesenbeck. Griesenbeck resided on the property until 1929.

A total of 1,042 bones was recovered from this site (Table 12-5), of these only 140 (13.44 percent) were identifiable. The identified bones break down as follows: 68 cow, 1 goat, 6 goat/sheep, 2 blackmail jackrabbit, 1 black rat (Rattus rattus), 1 unknown rodent (Rodentia), 26 pig, 10 rabbit, 1 mallard duck, 4 unknown duck, 6 chicken, 10 turkey, and 4 catfish. 
Table 12-4. Faunal Remains from Site 41BX883

\begin{tabular}{|c|c|c|c|c|}
\hline & $\#$ & $\begin{array}{c}\% \text { of } \\
\text { Identified }\end{array}$ & $\begin{array}{c}\text { Weight } \\
\text { (g) }\end{array}$ & $\begin{array}{c}\% \text { of } \\
\text { Identified } \\
\end{array}$ \\
\hline \multicolumn{5}{|l|}{ Mammalia } \\
\hline Bos Taurus & 841 & 59.39 & $21,447.6$ & 88.29 \\
\hline Canis sp. & 1 & 0.07 & 0.92 & 0.00 \\
\hline Copra sp. & 7 & 0.49 & 27.90 & 0.11 \\
\hline Copra/Obis & 69 & 4.87 & 608.98 & 2.51 \\
\hline Didelphis marsupialis & 1 & 0.07 & 0.85 & 0.00 \\
\hline Erethizon dorsatum & 1 & 0.07 & 0.22 & 0.00 \\
\hline Equus sp. & 1 & 0.07 & 15.44 & 0.06 \\
\hline Geomys sp. & 1 & 0.07 & 0.08 & 0.00 \\
\hline Lepus californicus & 51 & 3.60 & 75.78 & 0.31 \\
\hline Odocoileus virginianus & 2 & 0.14 & 20.97 & 0.09 \\
\hline Obis sp. & 12 & 0.85 & 182.16 & 0.75 \\
\hline Peccari angulatus & 1 & 0.07 & 10.70 & 0.04 \\
\hline Sciurus niger & 1 & 0.07 & 0.17 & 0.00 \\
\hline Sigmodon hispidus & 2 & 0.14 & 0.55 & 0.00 \\
\hline Sus scrofa & 271 & 19.14 & $1,721.01$ & 7.08 \\
\hline Sylvilagus sp. & 31 & 2.19 & 16.04 & 0.07 \\
\hline Total Identified Mammalia & 1,293 & $91.31 \%$ & $24,129.37$ & $99.33 \%$ \\
\hline UID Mammalia & 2856 & & $4,583.83$ & \\
\hline Total Mammalia & 4149 & & $28,713.2$ & \\
\hline \multicolumn{5}{|l|}{ Aves } \\
\hline Alas sp. & 18 & 1.27 & 26.68 & 0.11 \\
\hline Anser sp. & 20 & 1.41 & 51.04 & 0.21 \\
\hline Gallus domesticus & 48 & 3.39 & 32.24 & 0.13 \\
\hline Meleagris gallopavo & 23 & 1.62 & 38.53 & 0.16 \\
\hline Total Identified Aves & 109 & $\mathbf{7 . 7 0 \%}$ & 148.49 & $0.61 \%$ \\
\hline UID Aves & 133 & & 107.55 & \\
\hline Total Aves & 242 & & 256.04 & \\
\hline \multicolumn{5}{|l|}{ Osteichthyes } \\
\hline Ictalurus sp. & 3 & 0.21 & 2.98 & 0.01 \\
\hline Micropterus sp. & 1 & 0.07 & 1.27 & 0.01 \\
\hline Perca flavencens & 10 & 0.71 & 9.64 & 0.04 \\
\hline Total Identified Osteichthyes & 14 & $0.99 \%$ & 13.89 & $0.06 \%$ \\
\hline UID Osteichthyes & 61 & & 46.37 & \\
\hline $\begin{array}{r}\text { Total Osteichthyes } \\
\end{array}$ & 75 & & 60.26 & \\
\hline Total Identified & 1,416 & & $24,291.75$ & \\
\hline UID Vertebrata & 3 & & 18.78 & \\
\hline Total Vertebrata & 4,469 & & $29,048.28$ & \\
\hline
\end{tabular}


Table 12-5. Faunal Remains from Site 41BX884

\begin{tabular}{|c|c|c|c|c|}
\hline & $\#$ & $\begin{array}{c}\% \text { of } \\
\text { Identified }\end{array}$ & $\begin{array}{l}\text { Weight } \\
\text { (g) }\end{array}$ & $\begin{array}{c}\% \text { of } \\
\text { Identified }\end{array}$ \\
\hline \multicolumn{5}{|l|}{ Mammalia } \\
\hline Bos Taurus & 68 & 48.57 & 683.37 & 82.84 \\
\hline Copra sp. & 1 & 0.71 & 6.27 & 0.76 \\
\hline Copra/Obis & 6 & 4.29 & 22.33 & 2.71 \\
\hline Lepus californicus & 2 & 1.43 & 0.95 & 0.12 \\
\hline Rodentia & 1 & 0.71 & 0.36 & 0.04 \\
\hline Rattus rattus & 1 & 0.71 & 0.35 & 0.04 \\
\hline Sus scrofa & 26 & 18.57 & 89.07 & 10.80 \\
\hline Sylvilagus sp. & 10 & 7.14 & 5.79 & 0.70 \\
\hline Total Identified Mammalia & 115 & $82.14 \%$ & 808.49 & $98.01 \%$ \\
\hline UID Mammalia & 825 & & 993.05 & \\
\hline Total Mammalia & 940 & & $1,801.54$ & \\
\hline \multicolumn{5}{|l|}{ Aves } \\
\hline Alas sp. & 5 & 3.57 & 11.09 & 1.34 \\
\hline Gallus domesticus & 6 & 4.29 & 2.59 & 0.31 \\
\hline Meleagris gallopavo & 10 & 7.14 & 1.13 & 0.14 \\
\hline Total Identified Aves & 21 & $15.00 \%$ & 14.81 & $1.80 \%$ \\
\hline UID Aves & 67 & & 35.02 & \\
\hline Total Aves & 88 & & 49.83 & \\
\hline \multicolumn{5}{|l|}{ Osteichthyes } \\
\hline Ictalurus sp. & 4 & 2.86 & 1.59 & 0.19 \\
\hline Total Identified Osteichthyes & 4 & $2.86 \%$ & 1.59 & $0.19 \%$ \\
\hline UID Osteichthyes & 10 & & 3.01 & \\
\hline Total Osteichthyes & 14 & & 4.60 & \\
\hline Total Identified & 140 & & 824.89 & \\
\hline Total Vertebrata & 1,042 & & $1,855.97$ & \\
\hline
\end{tabular}

Domesticated food animals make up 87.83 percent of the identified mammal remains. The unidentified remains consist of 91.46 percent mammal, 7.43 percent bird, and 1.11 percent fish bones. A total of 2.21 percent $(n=23)$ of the bone was burned.

\section{BX885 (Mendit Shop)}

The first recorded resident of this site was Harold Bull, listed as a bartender. The first structure recorded on the property was built in 1891. In 1899 Bull sold the property to the Maffi family and the house served as rental property until about 1925.

A total of 155 pieces of bone was recovered from the site (Table $12-6)$, of which only 8 (5.16 percent) could be identified. These 8 bones consisted of 5 cow, 2 pig and 1 duck. The unidentified bones were 95.92 percent mammal, and 4.08 percent bird. A single bone was burned ( 0.65 percent of the total). 
Table 12-6. Faunal Remains from Site 41BX885

\begin{tabular}{|r|r|r|r|r||}
\hline & \multicolumn{1}{|c|}{$\begin{array}{r}\text { \# } \\
\text { Mos of } \\
\text { Idantified }\end{array}$} & Weight (g) & $\begin{array}{c}\text { \% of } \\
\text { Identified }\end{array}$ \\
\hline Sus scrofa & 2 & 25.00 & 3.34 & 2.27 \\
\hline Total Identified Mammalia & 7 & $87.50 \%$ & 146.92 & $99.65 \%$ \\
\hline UID Mammalia & 141 & & 143.05 & \\
\hline Total Mammalia & 148 & & 289.97 & \\
\hline Anas sp. & 1 & 12.50 & 0.51 & 0.35 \\
\hline Aves Total Identified Aves & 1 & $12.50 \%$ & 0.51 & $0.35 \%$ \\
\hline UD Aves & 6 & & 35.53 & \\
\hline Total Aves & 7 & & 36.04 & \\
\hline Total Identified & 8 & & 147.43 & \\
\hline Total Vertebrata & 155 & & 326.01 & \\
\hline
\end{tabular}

\section{BX890 (Biesenbach Site)}

The earliest recorded structure on this site was built in 1859 by John Houzeau, who sold the property to Peter Biesenbach in 1862 . By 1925 all residencies on this property were abandoned. A cedar post-lined privy vault (Privy \#2) was discovered on this site, but it was only partially excavated and few artifacts were recovered from it.

Seventy-seven bones were recovered from the site (Table 12-7), of these only 7 (9.09 percent) were

Table 12-7. Faunal Remains from Site 41BX890

\begin{tabular}{|r|r|r|r|r||}
\hline & \multicolumn{1}{|c|}{$\begin{array}{r}\text { \# } \\
\text { Identified }\end{array}$} & Weight (g) & $\begin{array}{c}\text { \% of } \\
\text { Identified }\end{array}$ \\
\hline Bos taurus & 5 & 71.43 & 106.66 & 80.47 \\
\hline Sus scrofa & 1 & 14.29 & 24.00 & 18.11 \\
\hline Sylvilagus sp. & 1 & 14.29 & 1.89 & 1.43 \\
\hline Total Identified Mammalia & 7 & $\mathbf{1 0 0 . 0 0 \%}$ & 132.55 & $\mathbf{1 0 0 . 0 0 \%}$ \\
\hline UID Mammalia & 69 & & 171.15 & \\
\hline Total Mammalia & 76 & & 303.70 & \\
\hline Osteichthyes & & & & \\
\hline UID Osteichthyes & 1 & & 1.12 & \\
\hline Total Osteichthyes & 1 & & 1.12 & \\
\hline Total Identified & 7 & & 132.55 & \\
\hline Total Vertebrata & 77 & & 304.82 & \\
\hline
\end{tabular}


identifiable. The identified bones were 5 cow, 1 pig, and 1 rabbit. Domestic food animals make up 85.71 percent of the identified mammal remains. Of the unidentified bone, 98.57 percent was mammal and the remaining 1.43 percent was fish. None of the recovered bone was burned.

\section{BX891 (Horn Site)}

This site was initially owned by Jacob Renz who later sold the property to Joseph Biesenbach in 1858. In 1887 Biesenbach sold the property to John Horn. The first recorded structure on the property was built around 1857 by Jacob Renz.

Sixty-seven bone pieces were recovered (Table 12-8). Fourteen (20.19 percent) of these were identified as follows: 8 cow, 2 goat/sheep, 2 sheep, 1 pig, and 1 chicken. Of the unidentified bone, 96.22 percent was mammal, 1.89 percent was bird, and 1.89 percent was fish. Two of the recovered bones ( 2.99 percent of the total) were burned.

\section{BX892 (Rilling Site)}

The first recorded structure on this property was an adobe house constructed in 1855 by Jacob Rilling. In 1890 the southern portion of the property was sold to Charles D. Hogan and a second house was constructed. By 1911, in addition to the original dwelling on the north half of the property, three shops were present. By 1952 all original structures with the exception of one of the shops were gone, and the Lewis Equipment Company covered the entire lot.

In total, 272 pieces of bone were recovered from the site (Table 12-9). Of these 68 (25.19 percent) were identified, including 43 cow, 7 canid, 4 goat, 1 black

Table 12-8. Faunal Remains from Site 41BX891

\begin{tabular}{|c|c|c|c|c|}
\hline & $\#$ & $\begin{array}{c}\% \text { of } \\
\text { Identified }\end{array}$ & $\begin{array}{c}\text { Weight } \\
\text { (g) }\end{array}$ & $\begin{array}{c}\text { \% of } \\
\text { Identified }\end{array}$ \\
\hline \multicolumn{5}{|l|}{ Mammalia } \\
\hline Bos taurus & 8 & 57.14 & 228.17 & 72.05 \\
\hline Capra/Ovis & 2 & 14.29 & 41.59 & 13.13 \\
\hline Ovis sp. & 2 & 14.29 & 33.87 & 10.70 \\
\hline Sus scrofa & 1 & 7.14 & 9.79 & 3.09 \\
\hline Total Identified Mammalia & 13 & $92.86 \%$ & 313.42 & 98.97\% \\
\hline UID Mammalia & 51 & & 409.60 & \\
\hline Total Mammalia & 64 & & 723.02 & \\
\hline \multicolumn{5}{|l|}{ Aves } \\
\hline Gallus domesticus & 1 & 7.14 & 3.24 & 1.02 \\
\hline Total Identified Aves & 1 & $7.14 \%$ & 3.24 & $1.02 \%$ \\
\hline UID Aves & 1 & & 1.33 & \\
\hline Total Aves & 2 & & 4.57 & \\
\hline \multicolumn{5}{|l|}{ Osteichthyes } \\
\hline UID Osteichthyes & 1 & & 1.26 & \\
\hline Total Osteichthyes & 1 & & 1.26 & \\
\hline Total Identified & 14 & & 316.66 & \\
\hline Total Vertebrata & 67 & & 728.85 & \\
\hline
\end{tabular}


Table 12-9. Faunal Remains from Site 41BX892

\begin{tabular}{|c|c|c|c|c|}
\hline & $\#$ & $\begin{array}{c}\% \text { of } \\
\text { Identified }\end{array}$ & $\begin{array}{c}\text { Weight } \\
\text { (g) }\end{array}$ & $\begin{array}{c}\% \text { of } \\
\text { Identified }\end{array}$ \\
\hline \multicolumn{5}{|l|}{ Mammalia } \\
\hline Bos taurus & 43 & 63.24 & $2,318.80$ & 91.77 \\
\hline Canis sp. & 7 & 10.29 & 50.12 & 1.98 \\
\hline Capra sp. & 4 & 5.88 & 95.25 & 3.77 \\
\hline Rattus rattus & 1 & 1.47 & 0.20 & 0.01 \\
\hline Sus scrofa & 8 & 11.76 & 42.95 & 1.70 \\
\hline Sylvilagus sp. & 1 & 1.47 & 0.81 & 0.03 \\
\hline Total Identified Mammalia & 64 & $94.12 \%$ & $2,508.13$ & $99.27 \%$ \\
\hline UID Mammalia & 155 & & 677.62 & \\
\hline Total Mammalia & 219 & & $3,185.75$ & \\
\hline \multicolumn{5}{|l|}{ Aves } \\
\hline Anas/Anser & 1 & 1.47 & 1.22 & 0.05 \\
\hline Gallus domesticus & 1 & 1.47 & 2.32 & 0.09 \\
\hline Meleagris gallopavo & 2 & 2.94 & 14.95 & 0.59 \\
\hline Total Identified Aves & 4 & $5.88 \%$ & 18.49 & $0.73 \%$ \\
\hline UID Aves & 44 & & 24.05 & \\
\hline Total Aves & 48 & & 42.54 & \\
\hline \multicolumn{5}{|l|}{ Osteichthyes } \\
\hline UID Osteichthyes & 3 & & 2.81 & \\
\hline Total Osteichthyes & 3 & & 2.81 & \\
\hline Total Identified & 68 & & $2,526.62$ & \\
\hline UID Vertebrata & 2 & & 0.20 & \\
\hline Total Vertebrata & 272 & & $3,231.30$ & \\
\hline
\end{tabular}

rat, 8 pig, 1 rabbit, 1 goose/duck, 1 chicken, and 2 turkey. Domesticated food animals make up 85.94 percent of the identified mammals. The unidentified bone consists of 76.73 percent mammal, 21.78 percent bird, and 1.49 percent fish remains. A total of 13.33 percent of the bone was burned $(n=36)$.

\section{BX893 (Czernecki Site)}

This property and the adjacent lot, site 41BX894, were purchased in 1890 by Julian Czernecki, a Polish immigrant. A residence was constructed around this time and shows up on a 1904 Sanborn Insurance map.
Eight hundred bone pieces were recovered from site 41BX893 (Table 12-10). Of these, only 60 (7.50 percent) were identifiable. Identified taxa include 18 cow, 1 goat, 5 armadillo (Dasypus novemcinctus), 1 felid (Felis sp.), 3 pig, 3 rabbit, 2 chicken, 26 turkey, and 1 turtle (Testudinae). Domesticated food animals constitute 70.97 percent of the identified mammal bones. The unidentified remains are composed of 90.11 percent mammal, 9.75 percent bird, are 0.14 percent fish bone. A total of 7.50 percent $(n=60)$ of the bone was burned. 
Table 12-10. Faunal Remains from Site 41BX893

\begin{tabular}{|c|c|c|c|c|}
\hline & $\#$ & $\begin{array}{c}\% \text { of } \\
\text { Identified }\end{array}$ & $\begin{array}{l}\text { Weight } \\
\text { (g) }\end{array}$ & $\begin{array}{c}\% \text { of } \\
\text { Identified }\end{array}$ \\
\hline \multicolumn{5}{|l|}{ Mammalia } \\
\hline Bas taurus & 18 & 30.00 & 153.05 & 66.98 \\
\hline Capra sp. & 1 & 1.67 & 24.50 & 10.72 \\
\hline Dasypus novemcinctus & 5 & 8.33 & 2.25 & 0.98 \\
\hline Felis sp. & 1 & 1.67 & 0.75 & 0.33 \\
\hline Sus scrofa & 3 & 5.00 & 31.48 & 13.78 \\
\hline Sylvilagus sp. & 3 & 5.00 & 2.11 & 0.92 \\
\hline Total Identified Mammalia & 31 & $51.67 \%$ & 214.14 & 93.71\% \\
\hline UID Mammalia & 665 & & 900.29 & \\
\hline Total Mammalia & 696 & & $1,114.43$ & \\
\hline \multicolumn{5}{|l|}{ Aves } \\
\hline Gallus domesticus & 2 & 3.33 & 1.14 & 0.50 \\
\hline Meleagris gallopavo & 26 & 43.33 & 12.77 & 5.59 \\
\hline Total Identified Aves & 28 & $46.67 \%$ & 13.91 & $6.09 \%$ \\
\hline UID Aves & 72 & & 27.35 & \\
\hline Total Aves & 100 & & 41.26 & \\
\hline \multicolumn{5}{|l|}{ Reptilia } \\
\hline Testudinata & 1 & 1.66 & 0.46 & 0.20 \\
\hline Total Reptilia & 1 & 1.66 & 0.46 & 0.20 \\
\hline \multicolumn{5}{|l|}{ Osteichthyes } \\
\hline UID Osteichthyes & 1 & & 0.21 & \\
\hline Total Osteichthyes & 1 & & 0.21 & \\
\hline Total Identified & 60 & & 228.51 & \\
\hline UID Vertebrata & 2 & & 1.65 & \\
\hline Total Vertebrata & 800 & & $1,158.01$ & \\
\hline
\end{tabular}

\section{BX894 (Czernecki Rentals)}

This site is the property adjacent to $41 \mathrm{BX} 893$, and was also purchased in 1890 by Julian Czernecki. Three structures were built on this property by 1911 and served as rental units.

The total bone recovered amounted to 140 specimens (Table 12-11), of which 2 (1.43 percent) were identified. The two identified pieces were cow. The unidentified bone consisted mostly of mammal, 84.78 percent, with 10.15 percent bird and 5.07 percent unidentifiable vertebrate. Four of the bones $(2.86$ percent) were burned.

\section{BX895 (Garza Store Site)}

This property was owned by Albert Weiss who constructed a residence and bluing manufacturing plant on the property in 1888 . In 1891 the plant was converted to a grocery store/residence. The property 
Table 12-11. Faunal Remains from Site 41BX894

\begin{tabular}{|c|c|c|c|c|}
\hline & $\#$ & $\begin{array}{c}\% \text { of } \\
\text { Identified } \\
\end{array}$ & $\begin{array}{c}\text { Weight } \\
\text { (g) }\end{array}$ & $\begin{array}{c}\% \text { of } \\
\text { Identified }\end{array}$ \\
\hline \multicolumn{5}{|l|}{ Mammalia } \\
\hline Bos taurus & 2 & $100.00 \%$ & 53.65 & $100.00 \%$ \\
\hline Total Identified Mammalia & 2 & $100.00 \%$ & 53.65 & $100.00 \%$ \\
\hline UID Mammalia & 117 & & 174.95 & \\
\hline Total Mammalia & 119 & & 228.60 & \\
\hline \multicolumn{5}{|l|}{ Aves } \\
\hline UID Aves & 14 & & 10.81 & \\
\hline Total Aves & 14 & & 10.81 & \\
\hline Total Identified & 2 & & 53.65 & \\
\hline UID Vertebrata & 7 & & 4.78 & \\
\hline Total Vertebrata & 140 & & 244.19 & \\
\hline
\end{tabular}

was eventually sold to Alphonso and Mary Garza in 1946.

In total, 449 bones were recovered from both the store and the residence (Table 12-12). Only 45 (10.02 percent) were identified. The identified bone consists of 24 cow, 8 black rat, 5 pig, 1 rabbit, 5 chicken, and 2 turkey. Domesticated food species comprised 76.32 percent of the identified mammal remains. The unidentified bone was made up of 91.83 percent mammal, 5.69 percent bird, and 2.48 percent unidentifiable vertebrate remains. Ten of the bones (2.23 percent) were burned.

\section{BX896 (Demazieres Site)}

This site covers lots 4 and 5 which were purchased in 1856 by Francis Louis Demazieres. Shortly after these lots were purchased a residence was constructed. In 1874 the property was sold to Bernard Mauermann who then sold the individual lots. In 1885 a frame structure was erected on lot 4 by Adolph Preuss. E. F. Rotzler acquired Lot 5 in 1886 and constructed a residence in 1906 or 1907 that served as rental property. An earthen vault privy, possibly lined with an old truck (Privy \#5), was uncovered and thought to be associated with the Lot 4 property. The excavation of the privy produced a considerable amount of bone, including what appears to be an entire large black bass (Micropterus sp.) which was recovered near the bottom of the privy, resting on a dinner plate. The reason the fish was discarded intact could easily have been because it had spoiled, but the reason for dropping it, plate and all, into the privy, which at that time was still being used for its original purpose, is not known. The fish had not been de-scaled; in fact, more than two-thirds of the Micropterus remains listed in Table 12-13 are scales from this fish.

Also uncovered at the site were two intentional dog burials which account for the large number of canid bones listed below. The first burial was a small adult dog, of approximately small terrier size. The hind legs were uncovered during shovel testing, and the entire skeleton, which was resting on its left side, was exposed and recorded (Figure 12-1). The animal was probably less than two years old at the time of death, as the incisors still showed some of the three-lobed crown form, which is worn off before the age of two years (Hillson 1986:216). There was no obvious sign of the cause of death. Though there was a spent shell casing near the feet, there was no sign of bullet damage to the head or to any of the other bone. However, when the skeleton was removed, it was discovered that the bones of the entire left foreleg, the left scapula, and some of the upper ribs of the left side were not present. Further excavation around the burial did not recover the missing elements. While surgical removal of a foreleg is not unheard of in dogs, this did not appear to be a surgical amputation, as the scapula is not removed in such cases. The burial was otherwise 
Table 12-12. Faunal Remains from Site 41BX895

\begin{tabular}{|c|c|c|c|c|}
\hline & $\#$ & $\begin{array}{c}\% \text { of } \\
\text { Identified }\end{array}$ & $\begin{array}{c}\text { Weight } \\
\text { (g) }\end{array}$ & $\begin{array}{c}\% \text { of } \\
\text { Identified }\end{array}$ \\
\hline \multicolumn{5}{|l|}{ Mammalia } \\
\hline Bos taurus & 24 & 53.33 & 605.13 & 85.57 \\
\hline Rattus rattus & 8 & 17.78 & 1.10 & 0.16 \\
\hline Sus scrofa & 5 & 11.11 & 73.98 & 10.46 \\
\hline Sylvilagus sp. & 1 & 2.22 & 0.87 & 0.12 \\
\hline Total Identified Mammalia & 38 & $84.44 \%$ & 681.08 & $96.31 \%$ \\
\hline UID Mammalia & 371 & & 758.25 & \\
\hline Total Mammalia & 409 & & $1,439.33$ & \\
\hline \multicolumn{5}{|l|}{ Aves } \\
\hline Gallus domesticus & 5 & 11.11 & 13.47 & 1.90 \\
\hline Meleagris gallopavo & 2 & 4.44 & 12.62 & 1.78 \\
\hline Total Identified Aves & 7 & $15.56 \%$ & 26.09 & $3.69 \%$ \\
\hline UID Aves & 23 & & 9.06 & \\
\hline Total Aves & 30 & & 35.15 & \\
\hline Total Identified & 45 & & 707.17 & \\
\hline UID Vertebrata & 10 & & 2.86 & \\
\hline Total Vertebrata & 449 & & $1,477.34$ & \\
\hline
\end{tabular}

completely intact and articulated, ruling out disturbance as an explanation for the missing bones. The foreleg is probably missing because of an accident, possibly involving a train, as tracks are located less than $70 \mathrm{~m}$ from the burial site. If so, this traumatic amputation would almost certainly be the cause of death. In any case, the remains of a black plastic bag above the dog is an indication that the burial was not very old.

The second dog was also found in a shovel test. This animal was very young, less than three months old, as all its teeth were still deciduous (Hillson 1986:217). Most of the epiphyseal joints were unsealed, which explains the large number of bone $(n=410)$ counted in this burial. The

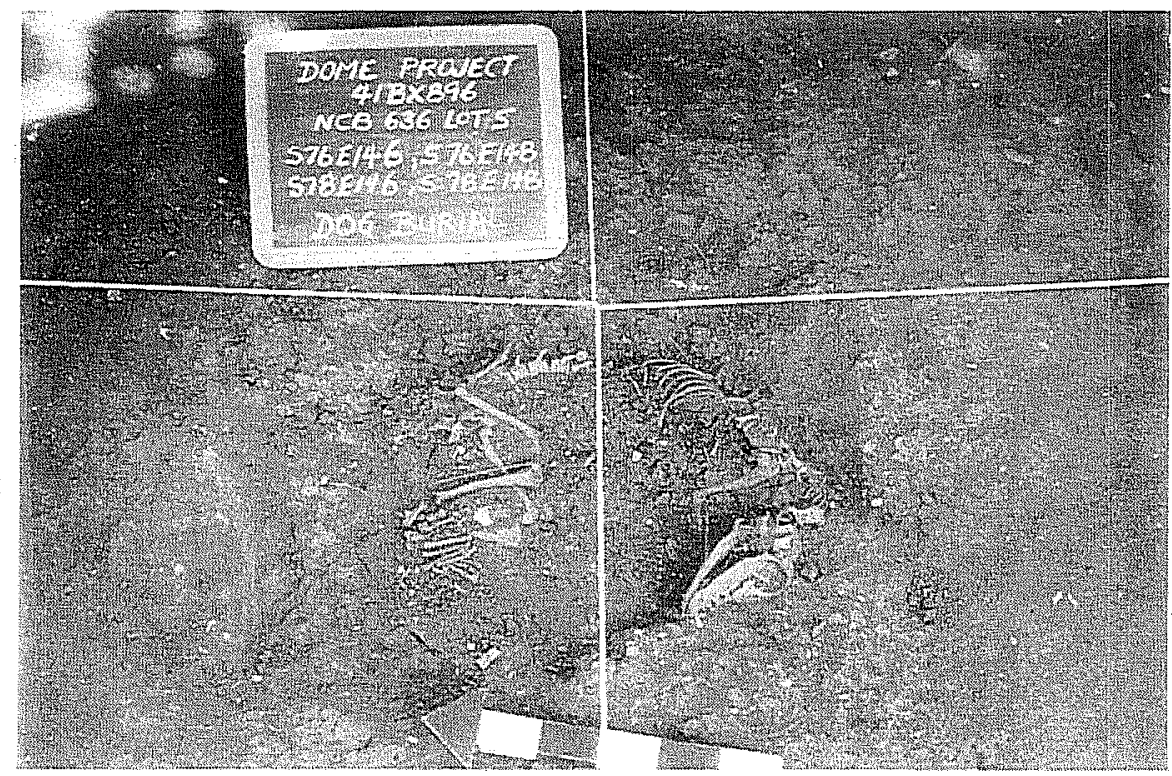

Figure 12-1. Dog burial from site 41BX896. 
Table 12-13. Faunal Remains from Site 41BX896

\begin{tabular}{|c|c|c|c|c|}
\hline & $\#$ & $\begin{array}{c}\% \text { of } \\
\text { Identified } \\
\end{array}$ & $\begin{array}{c}\text { Weight } \\
\text { (g) }\end{array}$ & $\begin{array}{c}\% \text { of } \\
\text { Identified } \\
\end{array}$ \\
\hline \multicolumn{5}{|l|}{ Mammalia } \\
\hline Bos taurus & 148 & 9.83 & 1291.37 & 54.81 \\
\hline Canis familiaris & 588 & 39.07 & 475.60 & 20.18 \\
\hline Canis sp. & 5 & 0.33 & 9.76 & 0.41 \\
\hline Capra/Ovis & 5 & 0.33 & 35.07 & 1.49 \\
\hline Lepus californicus & 1 & 0.07 & 0.94 & 0.04 \\
\hline Ovis sp. & 4 & 0.27 & 108.96 & 4.62 \\
\hline Sigmodon hispidus & 2 & 0.13 & 0.54 & 0.02 \\
\hline Sus scrofa & 46 & 3.06 & 232.54 & 9.87 \\
\hline Sylvilagus sp. & 129 & 8.57 & 20.60 & 0.87 \\
\hline Total Identified Mammalia & 928 & $61.66 \%$ & $2,175.38$ & $92.32 \%$ \\
\hline UID Mammalia & 832 & & 880.39 & \\
\hline Total Mammalia & 1,760 & & $3,055.77$ & \\
\hline \multicolumn{5}{|l|}{ Aves } \\
\hline Anas sp. & 1 & 0.07 & 1.12 & 0.05 \\
\hline Anser sp. & 2 & 0.13 & 5.15 & 0.22 \\
\hline Gallus domesticus & 98 & 6.51 & 78.65 & 3.34 \\
\hline Meleagris gallopavo & 17 & 1.13 & 30.16 & 1.28 \\
\hline Turdus migratorius & 1 & 0.07 & 0.10 & 0.00 \\
\hline Total Identified Aves & 119 & $7.91 \%$ & 115.18 & $4.89 \%$ \\
\hline UID Aves & 162 & & 33.84 & \\
\hline Total Aves & 281 & & 149.02 & \\
\hline \multicolumn{5}{|l|}{ Reptilia } \\
\hline Testudinata & 4 & 0.27 & 1.32 & 0.06 \\
\hline Total Reptilia & 4 & & 1.32 & \\
\hline \multicolumn{5}{|l|}{ Osteichthyes } \\
\hline Ictalurus sp. & 2 & 0.13 & 0.61 & 0.03 \\
\hline Micropterus sp. & 452 & 30.03 & 63.79 & 2.71 \\
\hline Total Identified Osteichthyes & 454 & $30.16 \%$ & 64.40 & $2.73 \%$ \\
\hline UID Osteichthyes & 3 & & 2.09 & \\
\hline Total Osteichthyes & 457 & & 66.49 & \\
\hline Total Identified & 1,505 & & $2,356.28$ & \\
\hline UID Vertebrata & 17 & & 1.11 & \\
\hline Total Vertebrata & 2,519 & & $3,273.71$ & \\
\hline
\end{tabular}


In addition to the two burials, another canid bone was found in the upper levels of Privy \#5. This was the right femur of a small dog. The femur had been broken but never set; the fracture healed badly, with extreme shortening of the bone and large amounts of excess bone growth.

The total bone count from this site was 2,519 (Table 12-13). Of these, 1,505 (59.75 percent) were identified. The following are the identified mammal remains: 148 cow, 588 dog, 5 unknown canid, 5 goat/sheep, 1 blacktail jackrabbit, 4 sheep, 2 cotton rat, 46 pig, and 129 rabbit. Domesticated food animals make up only 21.88 percent of the mammal remains. The bird remains consist of 1 duck, 2 goose, 98 chicken, 17 turkey, and 1 robin (Turdus migratorius). The remaining identified bone include 4 turtle, 2 catfish, and 452 black bass-all but 4 of which were bones and scales from a single individual, as described above. The unidentified bone was comprised of 82.05 percent mammal, 15.98 percent bird, 0.29 percent fish, and 1.68 percent unidentifiable vertebrate. A total of 3.45 percent of the bone $(n=87)$ was burned.

\section{BX897 (Webb Site)}

This property was originally purchased by John Binns in 1860. It had several other owners until it was acquired by Jonathan Hildebrandt in 1866. In turn, soon after acquiring the property, Hildebrandt sold it to William and Francis Webb who constructed a residence on the lot. William Webb was an AfricanAmerican express driver, born in Virginia in 1830 (U.S. Department of the Interior, Office of the Census, 1870). Though we do not know for certain when he arrived in Texas, he had accumulated enough money by 1865 to purchase the lot in the Alamodome area. Almost immediately he sold the southern half of the lot to Charles Webb (presumably a relative). Three houses, one of which was built over the site of the original southern house, were built on the site. They remained in the same family, though serving as rental houses from the 1930s until the mid-1960s, when a parking lot was constructed on the site.

A well was uncovered during testing, and was later excavated. During these excavations, a large trench was excavated by backhoe in order to expose the well from the south side. In this trench a large trash dump was uncovered, containing thousands of artifacts and 3,274 pieces of animal bone. At the time of this discovery it was not possible to excavate both the well and the trash dump. Archaeologists decided to continue with the well, as it appeared at the time to have the most promise of data recovery. Neither the richness of the trash dump nor the lack of artifacts in the lower part of the well could have been anticipated at the time. The well expansion trench was continued with the backhoe. As each full bucket was excavated, it was spread out on the surface and carefully examined. Many thousands of artifacts, including bone, were recovered. The care with which this backdirt was examined can be estimated by the fact that more than 75 buttons were recovered in this trash dump. As mentioned above, the trash dump continued into the lot to the south, the King site (41BX883). Ceramics and other artifacts dating to well before the first occupation of the King site confirmed that the trash dump belonged to the Webb compound. Crossmending of some ceramics found in the dump in both 41BX883 and 41BX897 confirm the field impression that the trash dump continued into the lot next door (see Tennis, this volume). It was apparent that until King moved onto the lot of $41 B X 883$ about 1880 , the Webbs were using it, as well as their own property, at least for dumping trash. The extent to which the trash dump had been disturbed by bulldozing when the houses were removed and the parking lot built is not known. Only bone recovered within the boundaries of 41BX897 is included in Table 12-14. The trash dump bone from both sites will be considered together in the following section.

A large amount of bone was recovered from this site: 3,080 pieces in all (Table 12-14). Of these, 750 (24.35 percent) were identified. The identified mammal bone included 513 cow, 1 canid, 1 goat, 51 goat/sheep, 2 blacktail jackrabbit, 1 wood rat (Neotoma sp.) 1 whitetailed deer, 3 sheep, 4 unidentified rodent, 1 cotton rat, 114 pig, and 13 rabbit. Domesticated food animals make up 96.74 percent of the identified mammal bone. The identified bird remains consist of 1 duck, 1 goose, 2 duck/goose, 1 Canada goose (Branta canadensis.), 1 dove/pigeon, 17 chicken, 9 turkey, and 1 robin. The other identified remains consist of 5 catfish, 4 perch, and 3 turtle bones. The unidentified bones were 92.63 percent mammal, 6.25 percent bird, 1.03 percent fish, and 0.09 percent unidentified vertebrate. A total of 3.80 percent $(n=117)$ of the bone was burned. 
Table 12-14. Faunal Remains from Site 41BX897

\begin{tabular}{|c|c|c|c|c|}
\hline & $\#$ & $\begin{array}{c}\% \text { of } \\
\text { Identified }\end{array}$ & $\begin{array}{c}\text { Weight } \\
\text { (g) }\end{array}$ & $\begin{array}{c}\% \text { of } \\
\text { Identified }\end{array}$ \\
\hline \multicolumn{5}{|l|}{ Mammalia } \\
\hline Bos taurus & 513 & 68.40 & $10,153.36$ & 82.13 \\
\hline Canis sp. & 1 & 0.13 & 0.31 & 0 \\
\hline Capra sp. & 1 & 0.13 & 15.52 & 0.13 \\
\hline Capra/Ovis & 51 & 6.80 & 367.27 & 2.97 \\
\hline Lepus californicus & 2 & 0.27 & 3.57 & 0.03 \\
\hline Neotoma sp. & 1 & 0.13 & 0.23 & 0 \\
\hline Odocoileus virginianus & 1 & 0.13 & 18.52 & 0.15 \\
\hline Ovis sp. & 3 & 0.40 & 59.89 & 0.48 \\
\hline Rodentia & 4 & 0.53 & 0.93 & 0.01 \\
\hline Sigmodon hispidus & 1 & 0.13 & 0.39 & 0 \\
\hline Sus scrofa & 114 & 15.20 & $1,680.75$ & 13.60 \\
\hline Sylvilagus sp. & 13 & 1.73 & 6.46 & 0.05 \\
\hline Total Identified Mammalia & 705 & $94.00 \%$ & $12,307.20$ & $99.55 \%$ \\
\hline UID Mammalia & 2,150 & & 3598.41 & \\
\hline Total Mammalia & 2,855 & & $15,905.61$ & \\
\hline \multicolumn{5}{|l|}{ Aves } \\
\hline Anas sp. & 1 & 0.13 & 0.96 & 0.13 \\
\hline Anser sp. & 1 & 0.13 & 2.09 & 0.28 \\
\hline Anas/Anser & 2 & 0.27 & 3.40 & 0.45 \\
\hline Branto sp. & 1 & 0.13 & 0.93 & 0.12 \\
\hline Colombidae & 1 & 0.13 & 0.31 & 0.04 \\
\hline Gallus domesticus & 17 & 2.27 & 18.34 & 0.15 \\
\hline Meleagris gallopavo & 9 & 1.20 & 20.82 & 0 \\
\hline Turdus migratorius & 1 & 0.13 & 0.09 & 0.00 \\
\hline Total Identified Aves & 33 & $4.40 \%$ & 46.94 & $6.26 \%$ \\
\hline UID Aves & 145 & & 97.96 & \\
\hline Total Aves & 178 & & 144.90 & \\
\hline \multicolumn{5}{|l|}{ Reptilia } \\
\hline Testudinata & 3 & 0.40 & 1.57 & 0.21 \\
\hline Total Reptilia & 3 & $0.40 \%$ & 1.57 & $0.21 \%$ \\
\hline \multicolumn{5}{|l|}{ Osteichthyes } \\
\hline Ictalurus sp. & 5 & 0.67 & 3.98 & 0.03 \\
\hline Perca sp. & 4 & 0.53 & 3.25 & 0.03 \\
\hline Total Identified Osteichthyes & 9 & $1.20 \%$ & 7.23 & $0.06 \%$ \\
\hline UID Osteichthyes & 24 & & 5.65 & \\
\hline $\begin{array}{c}\text { Total Osteichthyes } \\
\end{array}$ & 33 & & 12.88 & \\
\hline Total Identified & 750 & & $12,362.94$ & \\
\hline UID Vertebrata & 11 & & 6.61 & \\
\hline Total Vertebrata & 3,080 & & $16,071.57$ & \\
\hline
\end{tabular}




\section{BX898 (E. Glaeser Site)}

The little information available about this property indicates that it changed hands frequently. Several different owners are listed from the 1850 s through 1900. Twenty-two pieces of bone were recovered from this site, of which 6 (27.27 percent) were identified as being cow (Table 12-15). The remaining 16 bones were unidentified mammal remains. None of the recovered bone was burned.

\section{BX900 (Gordon Site)}

This property was purchased by Charles H. Gordon in 1859. Gordon sold the property in 1870 to Gottlieb Glaeser who gave the property to his daughter. A residence had been constructed on the site during the time it was owned by Gordon. The property was acquired by Southwestern Bell in 1925.

In all, 454 bones were recovered from the site, 70 (15.42 percent) of which were identified (Table 12-16). The identified bones were $43 \mathrm{cow}, 5$ goat/ sheep, 2 blacktail jackrabbit, 1 sheep, 13 pig, 2 rabbit, 2 chicken, 1 turkey, and 1 catfish. Of the mammal remains, 95.38 percent are from domesticated food animals. The unidentified remains are made up of 89.84 percent mammal, 8.60 percent bird, and 1.56 percent unidentified vertebrate bones. A total of 5.29 $(n=24)$ percent of the bone was burned.

\section{BX926 (Doering Site)}

The city block on which this property is located was first purchased in 1851 by Frank LaFitte Paschal who then sold it to a Robert Eager in 1852. In 1858 the block was subdivided into 16 individual lots and sold.

Eight bone pieces were recovered from this site, 7 (87.50 percent) of which were identified (Table 12-17). The identified specimens were $1 \mathrm{cow}, 1 \mathrm{pig}$, and $5 \mathrm{duck} /$ goose. The unidentified piece was bird. None of the bone was burned.

\section{BX927 (Schulze Site)}

Seven bones were recovered, 4 (57.14 percent) of which 3 cow and 1 duck were identified (Table 12-18). The unidentified remains consist of 3 mammal bones. None of the bone was burned.

\section{BX928 (Eckenroth Site)}

Little information about this property is known. In 1854 lots $10-13$ of this block were acquired by a Hermann Schulze, this site is on lot 10. This property was purchased in 1881 by Mrs. Elise Starndebach. Shortly after acquiring the lot, the Starndebach's house was constructed. In 1891, soon after the death of Mr. Starndebach, the southern half of the lot was sold to Adolph Klar. In 1889 the remaining northern half was transferred to a William F. Eckenroth. By 1952 the H. W. Lewis Equipment Co. had extended to cover nearly the entire block.

Table 12-15. Faunal Remains from Site 41BX898

\begin{tabular}{|r|r|r|r|r||}
\hline & \multicolumn{1}{|c|}{$\begin{array}{r}\text { \% of } \\
\text { Identified }\end{array}$} & \multicolumn{1}{|c|}{$\begin{array}{c}\text { Weight } \\
(\mathrm{g})\end{array}$} & $\begin{array}{c}\text { \% of } \\
\text { Identified }\end{array}$ \\
\hline Mammalia Bos taurus & 6 & 100.00 & 57.14 & 100.00 \\
\hline Total Identified Mammalia & 6 & $100.00 \%$ & 57.14 & $100.00 \%$ \\
\hline UID Mammalia & 16 & & 18.31 & \\
\hline Total Mammalia & 22 & & 75.45 & \\
\hline Total Identified & 6 & & 57.14 & \\
\hline Total Vertebrata & 22 & & 75.45 & \\
\hline
\end{tabular}


Table 12-16. Faunal Remains from Site 41BX900

\begin{tabular}{|c|c|c|c|c|}
\hline & $\#$ & $\begin{array}{c}\% \text { of } \\
\text { Identified } \\
\end{array}$ & $\begin{array}{c}\text { Weight } \\
\text { (g) }\end{array}$ & $\begin{array}{c}\% \text { of } \\
\text { Identified } \\
\end{array}$ \\
\hline \multicolumn{5}{|l|}{ Mammalia } \\
\hline Bos taurus & 43 & 61.43 & 893.40 & 82.81 \\
\hline Capra/Ovis & 5 & 7.14 & 23.98 & 2.22 \\
\hline Lepus californicus & 2 & 2.86 & 7.19 & 0.67 \\
\hline Ovis sp. & 1 & 1.43 & 10.07 & 0.93 \\
\hline Sus scrofa & 13 & 18.57 & 134.33 & 12.45 \\
\hline Sylvilagus sp. & 2 & 2.86 & 1.54 & 0.14 \\
\hline Total Identified Mammalia & 66 & $94.29 \%$ & $1,070.51$ & $99.22 \%$ \\
\hline UID Mammalia & 345 & & 966.85 & \\
\hline Total Mammalia & 411 & & $2,037.36$ & \\
\hline \multicolumn{5}{|l|}{ Aves } \\
\hline Gallus domesticus & 2 & 2.86 & 4.15 & 0.38 \\
\hline Meleagris gallopavo & 1 & 1.43 & 3.72 & 0.34 \\
\hline Total Identified Aves & 3 & $4.29 \%$ & 7.87 & $0.73 \%$ \\
\hline UID Aves & 33 & & 31.45 & \\
\hline Total Aves & 36 & & 39.32 & \\
\hline \multicolumn{5}{|l|}{ Osteichthyes } \\
\hline Ictalurus sp. & 1 & 1.43 & 0.52 & 0.05 \\
\hline Total Identified Osteichthyes & 1 & & 0.52 & \\
\hline Total Identified & 70 & & $1,078.9$ & \\
\hline UID Vertebrata & 6 & & 3.64 & \\
\hline Total Vertebrata & 454 & & $2,080.84$ & \\
\hline
\end{tabular}

Table 12-17. Faunal Remains from Site 41BX926

\begin{tabular}{|c|c|c|c|c|}
\hline & $\#$ & $\begin{array}{c}\% \text { of } \\
\text { Identified }\end{array}$ & $\begin{array}{c}\text { Weight } \\
\text { (g) }\end{array}$ & $\begin{array}{c}\% \text { of } \\
\text { Identified }\end{array}$ \\
\hline \multicolumn{5}{|l|}{ Mammalia } \\
\hline Bos taurus & 1 & 14.29 & 145.94 & 67.14 \\
\hline Sus scrofa & 1 & 14.29 & 61.11 & 28.11 \\
\hline Total Identified Mammalia & 2 & $28.58 \%$ & 207.05 & $95.25 \%$ \\
\hline \multicolumn{5}{|l|}{ Aves } \\
\hline Anas/Anser & 5 & & 10.31 & \\
\hline Total Identified Aves & 5 & $\mathbf{7 1 . 4 2 \%}$ & 10.31 & $4.74 \%$ \\
\hline UID Aves & 1 & & 2.05 & \\
\hline Total Aves & 6 & & 12.36 & \\
\hline Total Identified & 7 & & 217.36 & \\
\hline Total Vertebrata & 8 & & 219.41 & \\
\hline
\end{tabular}


Table 12-18. Faunal Remains from Site 41BX927

\begin{tabular}{|c|c|c|c|c|}
\hline & $\#$ & $\begin{array}{c}\% \text { of } \\
\text { Identified }\end{array}$ & $\begin{array}{c}\text { Weight } \\
\text { (g) }\end{array}$ & $\begin{array}{c}\% \text { of } \\
\text { Identified }\end{array}$ \\
\hline \multicolumn{5}{|l|}{ Mammalia } \\
\hline Bos taurus & 3 & 75.00 & 108.32 & 97.65 \\
\hline Total Identified Mammalia & 3 & $75.00 \%$ & 108.32 & $97.65 \%$ \\
\hline UID Mammalia & 3 & & 10.03 & \\
\hline Total Mammalia & 6 & & 118.35 & \\
\hline \multicolumn{5}{|l|}{ Aves } \\
\hline Gallus domesticus & 1 & 25.00 & 2.61 & 2.35 \\
\hline Total Identified Aves & 1 & $25.00 \%$ & 2.61 & $2.35 \%$ \\
\hline Total Identified & 4 & & 110.93 & \\
\hline Total Vertebrata & 7 & & 120.96 & \\
\hline
\end{tabular}

Eleven bones were recovered from the site, $6(54.55$ percent) were identified (Table 12-19). Three cow, 2 pig, 1 duck, 4 unidentified mammal, and 1 unidentified bird bone made up the assemblage. None of the bone was burned.

\section{BX930 (Ries Well Site)}

Little is known about the two lots included in this site, other than the fact that houses were constructed on the lots between 1888 and 1892. During the excavation of

Table 12-19. Faunal Remains from Site 41BX928

\begin{tabular}{|c|c|c|c|c|}
\hline & $\#$ & $\begin{array}{c}\% \text { of } \\
\text { Identified }\end{array}$ & $\begin{array}{l}\text { Weight } \\
\text { (g) }\end{array}$ & $\begin{array}{c}\% \text { of } \\
\text { Identified }\end{array}$ \\
\hline \multicolumn{5}{|l|}{ Mammalia } \\
\hline Bos taurus & 3 & 50.00 & 170.64 & 93.75 \\
\hline Sus scrofa & 2 & 33.33 & 10.30 & 5.66 \\
\hline Total Identified & 5 & $83.33 \%$ & 180.94 & $99.41 \%$ \\
\hline UID Mammalia & 4 & & 7.90 & \\
\hline Total Mammalia & 9 & & 188.84 & \\
\hline \multicolumn{5}{|l|}{ Aves } \\
\hline Anas sp. & 1 & 16.67 & 1.08 & 0.59 \\
\hline Total Identified Aves & 1 & $16.67 \%$ & 1.08 & $0.59 \%$ \\
\hline UID Aves & 1 & & 0.29 & \\
\hline Total Aves & 2 & & 1.37 & \\
\hline Total Identified & 6 & & 182.02 & \\
\hline Total Vertebrata & 11 & & 190.21 & \\
\hline
\end{tabular}


the Alamodome footprint, which was monitored by CAR personnel, a well was discovered and designated site 41BX930. The well had been hand-dug and lined with limestone, and had at some point been capped with lumber and buried. The well was excavated and found to be almost completely empty.

Seventeen bones were recovered from this site, 2 (11.76 percent) of which were identified as cow (Table 12-20). The unidentified remains consisted of 12 ( 80.00 percent) mammal, 1 (6.67 percent) bird, and 2 (13.33 percent) unknown vertebrate bones. None of the bone was burned.

\section{The Runge Street Sites}

The southeastern corner of the project area, including 41BX931-41BX932 and 41BX936- 41BX944, was designated the Runge Street area. The houses in this area had all been built as rental properties by Gus Mauermann in the early to mid-1920s, and were largely occupied by African-Americans, many of whom later purchased their homes. Archival research indicates that only the area encompassing sites 41BX936-41BX944 was developed before this time. The area was part of the wagon yard for Carl Runge's retail and wholesale grocery, which was situated in an area to the south of the project area.

\section{BX931 (Petit Site)}

A total of 131 bones was recovered from 41BX931, 8 (6.11 percent) of which were identified (Table 12-21). The identified bones consist of 1 cow, 1 pig, 5 rabbit, and 1 turkey. Domesticated food species make up 28.57 percent of the identified mammal remains. The unidentified remains are 114 (92.68 percent) mammal, 7 (5.69 percent) bird, and 2 (1.63 percent) unknown vertebrate. Twenty-eight bones ( 21.37 percent) were burned.

\section{BX932 (Thomas House)}

A total of 119 bones was recovered, of which 7 (5.88 percent) were identified (Table 12-22). One cow, 5 pig, and 1 felid comprised the identified bones. Of the unidentified bones, 78 (69.64 percent) were mammal, 25 (22.32 percent) were bird, 2 ( 1.79 percent) were fish, and 7 (6.25 percent) were unknown vertebrate. A total of $7.56(n=9)$ percent of the bone was burned.

\section{BX936 (Burleson Site)}

Sixty-seven pieces of bone were recovered, 13 (19.40 percent) were identified (Table 12-23). The identified specimens include 2 cow, 1 goat/sheep, 6 felid, 1 blacktail jackrabbit, and 3 turkey. Domesticated food animals comprise 30.00 percent of the identified mammal bones. The unidentified bone was made up of 46 (85.19 percent) mammal, 7 (12.96 percent) bird, and 1 ( 1.85 percent) unknown vertebrate bone. Three of the bones ( 4.48 percent) were burned.

Table 12-20. Faunal Remains from Site 41BX930

\begin{tabular}{|c|c|c|c|c|}
\hline & $\#$ & $\begin{array}{c}\% \text { of } \\
\text { Identified }\end{array}$ & $\begin{array}{l}\text { Weight } \\
\text { (g) }\end{array}$ & $\begin{array}{c}\% \text { of } \\
\text { Identified }\end{array}$ \\
\hline \multicolumn{5}{|l|}{ Mammalia } \\
\hline Bos taurus & 2 & 100.00 & 212.51 & 100.00 \\
\hline Total Identified Mammalia & 2 & $100.00 \%$ & 212.51 & $100.00 \%$ \\
\hline UID Mammalia & 12 & & 11.69 & \\
\hline Total Mammalia & 14 & & 224.20 & \\
\hline \multicolumn{5}{|l|}{ Aves } \\
\hline UID Aves & 1 & & 0.10 & \\
\hline Total Aves & 1 & & 0.10 & \\
\hline Total Identified & 2 & & 212.51 & \\
\hline UID Vertebrata & 2 & & 0.84 & \\
\hline Total Vertebrata & 17 & & 225.14 & \\
\hline
\end{tabular}


Table 12-21. Faunal Remains from Site 41BX931

\begin{tabular}{|c|c|c|c|c|}
\hline & $\#$ & $\begin{array}{c}\% \text { of } \\
\text { Identified }\end{array}$ & $\begin{array}{l}\text { Weight } \\
\text { (g) }\end{array}$ & $\begin{array}{c}\% \text { of } \\
\text { Identified }\end{array}$ \\
\hline \multicolumn{5}{|l|}{ Mammalia } \\
\hline Bos taurus & 1 & 12.50 & 20.54 & 53.90 \\
\hline Sus scrofa & 1 & 12.50 & 7.21 & 18.92 \\
\hline Sylvilagus sp. & 5 & 62.50 & 3.60 & 9.45 \\
\hline Total Identified Mammalia & 7 & $87.50 \%$ & 31.35 & $82.26 \%$ \\
\hline UID Mammalia & 114 & & 226.01 & \\
\hline Total Mammalia & 121 & & 257.36 & \\
\hline \multicolumn{5}{|l|}{ Aves } \\
\hline Meleagris gallopavo & 1 & 12.50 & 6.76 & 17.74 \\
\hline Total Identified Aves & 1 & $12.50 \%$ & 6.76 & $17.74 \%$ \\
\hline UID Aves & 7 & & 3.45 & \\
\hline Total Aves & 8 & & 10.21 & \\
\hline Total Identified & 8 & & 38.11 & \\
\hline UID Vertebrata & 2 & & 0.37 & \\
\hline Total Vertebrata & 131 & & 267.94 & \\
\hline
\end{tabular}

Table 12-22. Faunal Remains from Site 41BX932

\begin{tabular}{|c|c|c|c|c|}
\hline & $\#$ & $\begin{array}{c}\% \text { of } \\
\text { Identified }\end{array}$ & $\begin{array}{l}\text { Weight } \\
\text { (g) }\end{array}$ & $\begin{array}{c}\text { \%o of } \\
\text { Identified }\end{array}$ \\
\hline \multicolumn{5}{|l|}{ Mammalia } \\
\hline Bos taurus & 1 & 14.29 & 15.95 & 26.32 \\
\hline Felis sp. & 1 & 14.29 & 4.76 & 7.85 \\
\hline Sus scrofa & 5 & 71.43 & 39.90 & 65.83 \\
\hline Total Identified Mammalia & 7 & $100.00 \%$ & 60.61 & $100.00 \%$ \\
\hline UID Mammalia & 78 & & 93.39 & \\
\hline Total Mammalia & 85 & & 154.00 & \\
\hline \multicolumn{5}{|l|}{ Aves } \\
\hline UID Aves & 25 & & 15.34 & \\
\hline Total Aves & 25 & & 15.34 & \\
\hline \multicolumn{5}{|l|}{ Osteichthyes } \\
\hline UID Osteichthyes & 2 & & 1.43 & \\
\hline Total Osteichthyes & 2 & & 1.43 & \\
\hline Total Identified & 7 & & 60.61 & \\
\hline UID Vertebrata & 7 & & 1.95 & \\
\hline Total Vertebrata & 119 & & 172.72 & \\
\hline
\end{tabular}


Table 12-23. Faunal Remains from Site $41 \mathrm{BX} 936$

\begin{tabular}{|c|c|c|c|c|}
\hline & $\#$ & $\begin{array}{c}\% \text { of } \\
\text { Identified }\end{array}$ & $\begin{array}{l}\text { Weight } \\
\text { (g) }\end{array}$ & $\begin{array}{c}\% \text { of } \\
\text { Identified }\end{array}$ \\
\hline \multicolumn{5}{|l|}{ Mammalia } \\
\hline Bos taurus & 2 & 15.38 & 81.85 & 70.52 \\
\hline Capra sp. & 1 & 7.69 & 4.13 & 3.56 \\
\hline Felis sp. & 6 & 46.15 & 7.44 & 6.41 \\
\hline Lepus californicus & 1 & 7.69 & 2.57 & 2.21 \\
\hline Total Identified Mammalia & 10 & $76.92 \%$ & 95.99 & $82.70 \%$ \\
\hline UID Mammalia & 46 & & 155.61 & \\
\hline Total Mammalia & 56 & & 251.60 & \\
\hline \multicolumn{5}{|l|}{ Aves } \\
\hline Meleagris gallopavo & 3 & 23.08 & 20.08 & 17.30 \\
\hline Total Identified Aves & 3 & $23.08 \%$ & 20.08 & $17.30 \%$ \\
\hline UID Aves & 7 & & 6.64 & \\
\hline Total Aves & 10 & & 26.72 & \\
\hline Total Identified & 13 & & 116.07 & \\
\hline UID Vertebrata & 1 & & 0.18 & \\
\hline Total Vertebrata & 67 & & 278.50 & \\
\hline
\end{tabular}

\section{BX937 (Gilbert Site)}

A total of 128 bones was recovered from this site. The identified bone consists of only 8 ( 6.25 percent $)$ pieces which are 3 cow, 1 goat/sheep, 1 felid, 1 chicken, and 2 turkey (Table 12-24). The unidentified bone consists of 84 ( 70.00 percent) mammal, 30 ( 25.00 percent) bird, and 6 (5.00 percent) unknown vertebrate. Seven of the bone ( 5.47 percent) were burned.

\section{$41 B X 938$ (Conrad Site)}

A total of 149 pieces of bone was recovered of which 46 (30.87 percent) were identified (Table 12-25). The identified pieces are as follows; 24 cow, 2 goat/ sheep, 1 sheep, 12 pig, 4 duck, 2 chicken, and 1 turkey. The unidentified bone is made up of 98 ( 95.15 percent) mammal and 5 ( 4.84 percent) bird. None of the bone was burned.

\section{BX939 (Jones House)}

A total of 258 bones was recovered from 41BX939, 80 (31.01 percent) which were identified (Table 12-26). The identified bone consists of 34 cow, 7 goat/sheep, 6 horse/donkey, 1 blacktail jackrabbit, 27 pig, 2 chicken, 1 turkey, 1 catfish, and 1 perch. The horse/donkey remains consisted of butchered rib segments. The animal may have been consumed by the residents of the house, or used as dog food. Domesticated food animals make up 87.18 percent of the mammal remains. This does not include the horse/donkey remains because they were not normally used as food animals. The unidentified remains consist of 91.57 percent mammal and 8.43 percent bird bone. Ten of the bones ( 3.88 percent) were burned.

\section{BX940 (Meeks House)}

The bone remains recovered from the site total 41 pieces, of which 19 (46.34 percent) were identified (Table 12-27). The identified pieces were 9 cow, 6 pig, and 4 chicken. Unidentified remains consist of 19 ( 86.36 percent) mammal and 3 (13.64 percent) bird bones. One of the bones ( 2.44 percent) was burned. 
Table 12-24. Faunal Remains from Site 41BX937

\begin{tabular}{|r|r|r|r|r||}
\hline & \multicolumn{1}{|c|}{$\begin{array}{r}\text { \% of } \\
\text { Identified }\end{array}$} & $\begin{array}{c}\text { Weight } \\
(\mathrm{g})\end{array}$ & $\begin{array}{c}\text { \% of } \\
\text { Identified }\end{array}$ \\
\hline Bos taurus & 3 & 37.50 & 31.98 & 68.45 \\
\hline Capra/Ovis & 1 & 12.50 & 0.54 & 1.16 \\
\hline Felis sp. & 1 & 12.50 & 4.29 & 9.18 \\
\hline Tammalia & 5 & $62.50 \%$ & 36.81 & $\mathbf{7 8 . 7 9 \%}$ \\
\hline Total Identified Mammalia & 84 & & 153.17 & \\
\hline Total Mammalia & 94 & & 189.98 & \\
\hline Gallus domesticus & 1 & 12.50 & 2.58 & 5.52 \\
\hline Meleagris gallopavo & 2 & 25.00 & 7.33 & 15.69 \\
\hline Total Identified Aves & 3 & $37.50 \%$ & 9.91 & $21.21 \%$ \\
\hline UID Aves & 30 & & 13.11 & \\
\hline Total Aves & 33 & & 23.02 & \\
\hline Total Identified & 8 & & 46.72 & \\
\hline UID Vertebrata & 6 & & 1.32 & \\
\hline Total Vertebrata & 128 & & 214.32 & \\
\hline
\end{tabular}

Table 12-25. Faunal Remains from Site 41BX938

\begin{tabular}{|c|c|c|c|c|}
\hline & $\#$ & $\begin{array}{c}\% \text { of } \\
\text { Identified }\end{array}$ & $\begin{array}{l}\text { Weight } \\
\text { (g) }\end{array}$ & $\begin{array}{c}\% \text { of } \\
\text { Identified }\end{array}$ \\
\hline \multicolumn{5}{|l|}{ Mammalia } \\
\hline Bos taurus & 24 & 52.17 & 661.68 & 83.49 \\
\hline Capra/Ovis & 2 & 4.35 & 27.71 & 3.50 \\
\hline Ovis sp. & 1 & 2.17 & 1.88 & 0.24 \\
\hline Sus scrofa & 12 & 26.09 & 80.17 & 10.12 \\
\hline Total Identified Mammalia & 39 & $84.78 \%$ & 771.44 & $97.34 \%$ \\
\hline UID Mammalia & 98 & & 211.34 & \\
\hline Total Mammalia & 137 & & 982.78 & \\
\hline \multicolumn{5}{|l|}{ Aves } \\
\hline Anas sp. & 4 & 8.70 & 12.36 & 1.56 \\
\hline Gallus domesticus & 2 & 4.35 & 3.61 & 0.46 \\
\hline Meleagris gallopavo & 1 & 2.17 & 5.08 & 0.64 \\
\hline Total Identified Aves & 7 & $15.22 \%$ & 21.05 & $2.66 \%$ \\
\hline UID Aves & 5 & & 4.40 & \\
\hline Total Aves & 12 & & 25.45 & \\
\hline Total Identified & 46 & & 792.49 & \\
\hline Total Vertebrata & 149 & & 1008.23 & \\
\hline
\end{tabular}


Table 12-26. Faunal Remains from Site 41BX939

\begin{tabular}{|c|c|c|c|c|}
\hline & $\#$ & $\begin{array}{c}\% \text { of } \\
\text { Identified }\end{array}$ & $\begin{array}{l}\text { Weight } \\
\text { (g) }\end{array}$ & $\begin{array}{c}\% \text { of } \\
\text { Identified }\end{array}$ \\
\hline \multicolumn{5}{|l|}{ Mammalia } \\
\hline Bos taurus & 34 & 42.50 & 336.89 & 58.00 \\
\hline Capra/Ovis & 7 & 8.75 & 63.60 & 10.95 \\
\hline Equid & 6 & 7.50 & 13.00 & 2.24 \\
\hline Lepus califomicus & 1 & 1.25 & 0.80 & 0.14 \\
\hline Sus scrofa & 27 & 33.75 & 140.68 & 24.22 \\
\hline Total Identified Mammalia & 75 & 93.75\% & $\mathbf{5 5 4 . 9 7}$ & 95.55\% \\
\hline UID Mammalia & 163 & & 250.34 & \\
\hline Total Mammalia & 238 & & 805.31 & \\
\hline \multicolumn{5}{|l|}{ Aves } \\
\hline Gallus domesticus & 2 & 2.50 & 2.35 & 0.40 \\
\hline Meleagris gallopavo & 1 & 1.25 & 21.79 & 3.75 \\
\hline Total Identified Aves & 3 & $3.75 \%$ & 24.14 & $4.16 \%$ \\
\hline UID Aves & 15 & & 17.67 & \\
\hline Total Aves & 18 & & 41.81 & \\
\hline \multicolumn{5}{|l|}{ Osteichthyes } \\
\hline Ictalurus sp. & 1 & 1.25 & 0.77 & 0.13 \\
\hline $\begin{array}{r}\text { Perca sp. } \\
\end{array}$ & 1 & 1.25 & 0.94 & 0.16 \\
\hline Total Identified Osteichthyes & 2 & $2.50 \%$ & 1.71 & $0.29 \%$ \\
\hline Total Identified & 80 & & 580.82 & \\
\hline Total Vertebrata & 258 & & 848.83 & \\
\hline
\end{tabular}

Table 12-27. Faunal Remains from Site 41BX940

\begin{tabular}{|r|r|r|r|r|r||}
\hline & \multicolumn{1}{|c|}{$\# \begin{array}{r}\text { \% of } \\
\text { Identified }\end{array}$} & $\begin{array}{c}\text { Weight } \\
\text { (g) }\end{array}$ & $\begin{array}{c}\text { \% of } \\
\text { Identified }\end{array}$ \\
\hline Bos taurus & 9 & 47.37 & 104.00 & 70.46 \\
\hline Sus scrofa & 6 & 31.58 & 35.52 & 24.07 \\
\hline Total Identified Mammalia & 15 & $\mathbf{7 8 . 9 5 \%}$ & 139.52 & $94.53 \%$ \\
\hline UID Mammalia & 19 & & 62.26 & \\
\hline Total Mammalia & 34 & & 201.78 & \\
\hline Gallus domesticus & 4 & 21.05 & 8.08 & 5.47 \\
\hline Total Identified Aves & 4 & $21.05 \%$ & $\mathbf{8 . 0 8}$ & $5.47 \%$ \\
\hline UID Aves & 3 & & 2.56 & \\
\hline Total Aves & 7 & & 10.64 & \\
\hline Total Identified & 19 & & 147.60 & \\
\hline Total Vertebrata & 41 & & 212.42 & \\
\hline
\end{tabular}




\section{BX941 (Houston Site)}

Seventy-nine bones were recovered, 31 (39.24 percent) of which were identified (Table 12-28). The identified bones were 13 cow, 2 house cat (Felis domesticus), 3 sheep, 4 pig, 2 chicken, 3 turkey, 1 possible quail (Phasianidae), and 1 catfish. Unidentified remains consist of 47 (97.92 percent) mammal and 1 (2.08 percent) bones. None of the bone was burned.

\section{BX942 (Harris Site)}

A total of 169 bones was recovered from this site. The identified bones, 20 (11.83 percent) in all, consist of 6 cow, 2 cotton rat, 1 rabbit, 9 pig, 1 chicken, and 1 turkey (Table 12-29). The unidentified remains consist of 131 ( 87.92 percent) mammal, 15 (10.07 percent) bird, and 3 (2.01 percent) fish. A total of 7.1 percent $(n=12)$ of the bone was burned.
$41 B X 943$ (Grant Site)

Only 16 bones were recovered from this site, $1(6.25$ percent) was identified (Table 12-30). The single identified bone is pig. The unidentified bone consists of 15 (93.33 percent) mammal and 1 (6.67 percent) bird. None of the bone was burned.

\section{BX945 (Pauly Site)}

This property was purchased in 1855 by a German immigrant, Peter Pauly. Pauly, an architect and stonemason, constructed a limestone house on the property soon after acquiring it. The property was sold to William Mueller in 1898. Mueller, a butcher, resided at the house until his death in 1951. From 1971 to 1975 the house served as a rental unit. In 1921 a second residence was constructed on the site by Mueller's son. A limestone-lined privy vault

Table 12-28. Faunal Remains from Site 41BX941

\begin{tabular}{|c|c|c|c|c|}
\hline & $\#$ & $\begin{array}{c}\% \text { of } \\
\text { Identified }\end{array}$ & $\begin{array}{l}\text { Weight } \\
\text { (g) }\end{array}$ & $\begin{array}{c}\% \text { of } \\
\text { Identified }\end{array}$ \\
\hline \multicolumn{5}{|l|}{ Mammalia } \\
\hline Bos taurus & 13 & 41.94 & 213.34 & 55.73 \\
\hline Felis domesticus & 2 & 6.45 & 7.58 & 1.98 \\
\hline Ovis sp. & 3 & 9.68 & 78.86 & 20.60 \\
\hline Sus scrofa & 4 & 12.90 & 42.23 & 11.03 \\
\hline Total Identified Mammalia & 22 & $70.97 \%$ & 342.01 & $89.35 \%$ \\
\hline UID Mammalia & 47 & & 185.70 & \\
\hline Total Mammalia & 69 & & 527.71 & \\
\hline \multicolumn{5}{|l|}{ Aves } \\
\hline Anas sp. & 2 & 6.45 & 4.80 & 1.25 \\
\hline Gallus domesticus & 2 & 6.45 & 4.08 & 1.07 \\
\hline Meleagris gallopavo & 3 & 9.68 & 28.54 & 7.46 \\
\hline Phasianidae & 1 & 3.23 & 2.66 & 0.69 \\
\hline Total Identified Aves & 8 & $25.81 \%$ & 40.08 & $10.47 \%$ \\
\hline UID Aves & 1 & & 0.10 & \\
\hline Total Aves & 9 & & 40.18 & \\
\hline \multicolumn{5}{|l|}{ Osteichthyes } \\
\hline Ictalurus sp. & 1 & 3.23 & 0.69 & 0.18 \\
\hline Total Identified Osteichthyes & 1 & & 0.69 & \\
\hline Total Identified & 31 & & 382.78 & \\
\hline Total Vertebrata & 79 & & 568.58 & \\
\hline
\end{tabular}


Table 12-29. Faunal Remains from Site 41BX942

\begin{tabular}{|c|c|c|c|c|}
\hline & $\#$ & $\begin{array}{c}\% \text { of } \\
\text { Identified }\end{array}$ & $\begin{array}{c}\text { Weight } \\
\text { (g) }\end{array}$ & $\begin{array}{c}\% \text { of } \\
\text { Identified }\end{array}$ \\
\hline \multicolumn{5}{|l|}{ Mammalia } \\
\hline Bos taurus & 6 & 30.00 & 200.73 & 67.81 \\
\hline Sigmodon hispidus & 2 & 10.00 & 0.66 & 0.22 \\
\hline Sus scrofa & 9 & 45.00 & 89.13 & 30.11 \\
\hline Sylvilagus sp. & 1 & 5.00 & 0.67 & 0.23 \\
\hline Total Identified Mammalia & 18 & $90.00 \%$ & 291.19 & $98.37 \%$ \\
\hline UID Mammalia & 131 & & 298.51 & \\
\hline Total Mammalia & 149 & & 589.70 & \\
\hline \multicolumn{5}{|l|}{ Aves } \\
\hline Gallus domesticus & 1 & 5.00 & 0.12 & 0.04 \\
\hline Meleagris gallopavo & 1 & 5.00 & 4.71 & 1.59 \\
\hline Total Identified Aves & 2 & $10.00 \%$ & 4.83 & $1.63 \%$ \\
\hline UID Aves & 15 & & 8.33 & \\
\hline Total Aves & 17 & & 13.16 & \\
\hline \multicolumn{5}{|l|}{ Osteichthyes } \\
\hline UID Osteichthyes & 3 & & 2.38 & \\
\hline Total Osteichthyes & 3 & & 2.38 & \\
\hline Total Identified & 20 & & 296.02 & \\
\hline Total Vertebrata & 169 & & 605.24 & \\
\hline
\end{tabular}

Table 12-30. Faunal Remains from Site 41BX943

\begin{tabular}{|c|c|c|c|c|}
\hline & $\#$ & $\begin{array}{c}\% \text { of } \\
\text { Identified }\end{array}$ & $\begin{array}{c}\text { Weight } \\
\text { (g) }\end{array}$ & $\begin{array}{c}\text { \% of } \\
\text { Identified }\end{array}$ \\
\hline \multicolumn{5}{|l|}{ Mammalia } \\
\hline Sus scrofa & 1 & 100.00 & 9.68 & 100.00 \\
\hline Total Identified Mammalia & 1 & $100.00 \%$ & 9.68 & $100.00 \%$ \\
\hline UID Mammalia & 14 & & 64.02 & \\
\hline Total Mammalia & 15 & & 73.70 & \\
\hline \multicolumn{5}{|l|}{ Aves } \\
\hline UID Aves & 1 & & 2.58 & \\
\hline Total Aves & 1 & & 2.58 & \\
\hline Total Identified & 1 & & 9.68 & \\
\hline Total Vertebrata & 16 & & 76.28 & \\
\hline
\end{tabular}


(Privy \#12) was uncovered and excavated down to sterile soil. The upper deposit in the privy dates to just after the turn of the century. A total of 7,154 pieces, more than $25 \mathrm{~kg}$, of bone was recovered from the privy deposits, constituting 83.63 percent of the bone recovered from the site. The bone material from this privy was included in the meat cut analysis discussed in the following section.

A total of 8,554 pieces of bone was recovered from this site (Table 12-31). From this assemblage, 3,099 (36.23 percent) pieces were identified. The identified bone has been broken down into mammal, bird, and fish taxa. The identified mammal remains consist of 1,619 cow, 1 canid, 8 goat, 30 goat/sheep, 6 opossum, 73 house cat (72 of which are the remains of a single individual recovered from the privy), 64 blacktail jackrabbit, 1 sheep, 1 black rat, 8 unknown rodent, 20 fox squirrel, 49 cotton rat, 397 pig, and 101 rabbit. Domesticated food animals make up 86.41 percent of the identified mammal remains. The identified bird remains consist of 159 mallard duck, 19 duck, 1 goose, 21 goose/duck, 12 Canada goose, 155 dove/ pigeon, 262 chicken, and 77 turkey. The fish remains consist of 3 drum fish (Aplodinotuys grunnieus), and 9 catfish bones. The unidentified bone remains include 4,691 (86.10 percent) mammal, 714 (13.11 percent) bird, 43 ( 0.79 percent) fish, and 7 ( 0.13 percent) unknown vertebrate. A total of $2.87(n=245)$ percent of the bone was burned.

\section{$41 B \times 946$}

Six bones were recovered from this site, 4 (66.67 percent) of which were identified (Table 12-32). The identified specimens consist of 1 cow and 3 turkey. The remaining 3 unidentified bones were mammal. None of the bone was burned.

\section{BX956 (W. Hoefgen Site)}

This site dates to around the 1880 s to 1890 s. Table 12-33 shows that five bones were recovered, two of which ( 40.00 percent) were identified as cow. The unidentified remains, 3 pieces, were all mammal. None of the bone was burned.

\section{Discussion}

Most of the excavation units from which this collection was recovered were test units scattered around the site, especially in the area that would have been back yards. It is no surprise, then, that the impression left by the bone counts, the low percentage of burned bone, and the species lists from most of the sites is that of scattered trash. The exceptions, of course, are sites where specific areas-privies and trash dumps-were excavated. Comparisons of the faunal assemblages between sites is difficult because of the difference in size of the assemblages and collection methodologies. However, a few general observations can be made.

Table 12-31. Faunal Remains from Site 41BX945

\begin{tabular}{|r|r|r|r|r||}
\hline \multicolumn{1}{||}{} & \multicolumn{1}{|c|}{$\#$} & $\begin{array}{c}\text { \% of } \\
\text { Identified }\end{array}$ & \multicolumn{1}{|c|}{$\begin{array}{c}\text { Weight } \\
\text { (g) }\end{array}$} & $\begin{array}{c}\text { \% of } \\
\text { Identified }\end{array}$ \\
\hline Mammalia & \multicolumn{4}{|c|}{} \\
\hline Bos taurus & 1,619 & 52.24 & $17,811.67$ & 84.884 \\
\hline Canis sp. & 1 & 0.032 & 18.41 & 0.088 \\
\hline Capra sp. & 8 & 0.258 & 16.93 & 0.081 \\
\hline Capra/Ovis & 30 & 0.968 & 174.54 & 0.832 \\
\hline Didelphis marsupialis & 6 & 0.194 & 10.30 & 0.049 \\
\hline Equid & 2 & 0.065 & 24.02 & 0.114 \\
\hline Felis domesticus & 73 & 2.356 & 109.26 & 0.521 \\
\hline
\end{tabular}


Table 12-31. continued

\begin{tabular}{|c|c|c|c|c|}
\hline & $\#$ & $\begin{array}{c}\% \text { of } \\
\text { Identified } \\
\end{array}$ & $\begin{array}{c}\begin{array}{c}\text { Weight } \\
\text { (g) }\end{array} \\
\end{array}$ & $\begin{array}{c}\% \text { of } \\
\text { Identified }\end{array}$ \\
\hline Lepus californicus & 64 & 2.065 & 80.25 & 0.382 \\
\hline Ovis sp. & 1 & 0.032 & 16.94 & 0.081 \\
\hline Rattus rattus & 1 & 0.032 & 0.61 & 0.003 \\
\hline Rodentia & 8 & 0.258 & 1.30 & 0.006 \\
\hline Sciurus niger & 20 & 0.645 & 12.54 & 0.060 \\
\hline Sigmodon hispidus & 49 & 1.58 & 16.37 & 0.078 \\
\hline Sus scrofa & 397 & 12.81 & 1732.04 & 8.254 \\
\hline Sylvilagus sp. & 101 & 3.259 & 66.38 & 0.316 \\
\hline Total Identified Mammalia & 2,380 & 76.794\% & $20,091.56$ & $95.749 \%$ \\
\hline UID Mammalia & 4,691 & & $7,659.20$ & \\
\hline Total Mammalia & 7,071 & & $27,750.76$ & \\
\hline \multicolumn{5}{|l|}{ Aves } \\
\hline Anas platyrhynches & 159 & 5.131 & 79.29 & 0.378 \\
\hline Anas sp. & 19 & 0.613 & 9.03 & 0.043 \\
\hline Anser sp. & 1 & 0.032 & 3.27 & 0.016 \\
\hline Anas/Anser & 21 & 0.678 & 36.68 & 0.175 \\
\hline Branta sp. & 12 & 0.387 & 17.42 & 0.083 \\
\hline Colombidae & 155 & 5.002 & 56.75 & 0.270 \\
\hline Gallus domesticus & 262 & 8.454 & 391.79 & 1.867 \\
\hline Meleagris gallopavo & 77 & 2.485 & 285.01 & 1.358 \\
\hline Total Identified Aves & 706 & $22.787 \%$ & 879.24 & $4.190 \%$ \\
\hline UID Aves & 714 & & 301.22 & \\
\hline Total Aves & 1,420 & & $1,180.46$ & \\
\hline \multicolumn{5}{|l|}{ Reptilia } \\
\hline Testudinata & 1 & 0.032 & 0.17 & 0.001 \\
\hline Total Identified Reptilia & 1 & $0.032 \%$ & 0.17 & $0.001 \%$ \\
\hline \multicolumn{5}{|l|}{ Osteichthyes } \\
\hline Aplodinotuys grunnieus & 3 & 0.097 & 3.15 & 0.015 \\
\hline Ictalunus sp. & 9 & 0.290 & 9.49 & 0.045 \\
\hline Total Identified Osteichthyes & 12 & $0.387 \%$ & 12.64 & $0.060 \%$ \\
\hline UID Osteichthyes & 43 & & 31.54 & \\
\hline $\begin{array}{r}\text { Total Osteichthyes } \\
\end{array}$ & 55 & & 56.8 & \\
\hline Total Identified & 3,099 & $100.000 \%$ & $20,983.61$ & $100.000 \%$ \\
\hline UID Vertebrata & 7 & & 24.44 & \\
\hline Total Vertebrata & 8,554 & & $29,012.65$ & \\
\hline
\end{tabular}


Table 12-32. Faunal Remains from Site 41BX946

\begin{tabular}{|c|c|c|c|c|}
\hline & $\#$ & $\begin{array}{c}\% \text { of } \\
\text { Identified }\end{array}$ & $\begin{array}{l}\text { Weight } \\
\text { (g) }\end{array}$ & $\begin{array}{c}\% \text { of } \\
\text { Identified }\end{array}$ \\
\hline \multicolumn{5}{|l|}{ Mammalia } \\
\hline Bos taurus & 1 & 25.00 & 22.65 & 84.26 \\
\hline Total Identified Mammalia & 1 & $25.00 \%$ & 22.65 & $84.26 \%$ \\
\hline UID Mammalia & 2 & & 32.57 & \\
\hline Total Mammalia & 3 & & 55.22 & \\
\hline \multicolumn{5}{|l|}{ Aves } \\
\hline Meleagris gallopavo & 3 & 75.00 & 4.23 & 15.74 \\
\hline Total Aves & 3 & $75.00 \%$ & 4.23 & $15.75 \%$ \\
\hline Total Identified & 4 & & 26.88 & \\
\hline Total Vertebrata & 6 & & 59.45 & \\
\hline
\end{tabular}

Table 12-33. Faunal Remains from Site 41BX956

\begin{tabular}{|r|r|r|r|r||}
\hline & \multicolumn{1}{|c|}{$\#$} & $\begin{array}{c}\text { \% of } \\
\text { Identified }\end{array}$ & \multicolumn{1}{|c|}{$\begin{array}{c}\text { Weight } \\
(\mathrm{g})\end{array}$} & $\begin{array}{c}\text { \% of } \\
\text { Identified }\end{array}$ \\
\hline Mammalia & \multicolumn{5}{|c|}{} \\
\hline Bos taurus & 2 & 100.00 & 182.79 & 100.00 \\
\hline Total Identified Mammalia & 2 & $100.00 \%$ & 182.79 & $100.00 \%$ \\
\hline UID Mammalia & 3 & & 17.51 & \\
\hline Total Mammalia & 5 & & 200.30 & \\
\hline Total Identified & 2 & & 182.79 & \\
\hline Total Vertebrata & 5 & & 200.30 & \\
\hline
\end{tabular}

\section{Wild vs. Domestic}

The percentage of total Number of Identified Specimens (NISP) which were wild mammals was only 7.33 percent (551 of 7515 ). Of these, 474 (86.03 percent) were from animals commonly hunted for food. This group is completely dominated by rabbits. A total of 425 (77.13 percent) of the wild mammals identified were jackrabbit (Lepus californicus) or cottontail rabbit (Sylvilagus sp.). Privy \#1 (41BX883) contained 82 specimens of these two genera; Privy \#5, on 41BX896, had 128 rabbit bones; and Privy \#12, on the Pauly site (41BX945), contained another 165. Together these three privies contain 88.24 percent $(n=375)$ of all rabbit bones found.
Rodents other than squirrels were 14.52 percent $(n=80)$ of the wild mammals. Of these identified rodent bones, 72.50 percent $(n=58)$ percent were from Privy \#12. The small number of game animals is a surprise, especially in those sites which were occupied before 1880 , when the Alamodome area was still on the outskirts of town. The Webb site (41BX897) and the Wyoming Street sites (41BX890-892), all occupied before 1870, contained only 18 wild mammal bones, only 3.27 percent of the total. These four sites are 12.50 percent of the sites from which animal bone was recovered. Clearly there is much less wild animal bone on those four sites than would be expected if the distribution was random. The 
implication is that even early in its occupation, the inhabitants of this part of San Antonio were thoroughly urbanized, dependant on domestic food supplies, and not likely to spend much time hunting.

As mentioned above, three exceptions can be found: Privy \#5 on site 41BX896, in which 128 Sylvilagus sp. bones were found; Privy \#1 on site 41BX883, which was filled during the tenure of butcher Adolf Klar; and Privy \#12 on the Pauly site (41BX945) which was filled during the tenure of the Mueller family. Table 12-34 shows the bone of rabbits (both Lepus and Sylvilagus) found in these privies, divided into three categories: heads, feet, and other post cranial. Recall that these three privies contained 375 rabbit elements, forming 88.24 percent of all rabbits found and 68.06 percent of all wild mammals found.

The rabbit bone in the privies on sites 41BX883 and $41 \mathrm{BX} 896$ is almost entirely head and feet, probably the waste from butchering, but not the remains of actual meals, suggesting that though the animals were butchered on the site, either they were not eaten on the site or the bone from such meals was deposited elsewhere on the site and not recovered. The exception is the 17 Lepus post-cranial bones in the Privy \#1, which are the remains of edible parts of the rabbit. However, though the overall Minimum Number of Individuals (MNI) for Lepus in Privy \#1 was 13, only a single individual is needed to account for the postcranial bone other than foot bones. The privy on the Pauly site, on the other hand, has bone from at least 4 individuals, in all three categories, suggesting that animals were both butchered and eaten on the site.
Examination of the MNI of other commonly hunted animals and certain fauna which could be either domestic or wild (ducks and geese) in the three privies reinforces the image of the families using Privy \#1 and Privy \#5 as uninterested in wild animals other than rabbits and of the Mueller family (Privy \#12) as at least occasional hunters of game that is commonly hunted with a shotgun (Table 12-35).

\section{Beef vs. Pork}

The preference for beef displayed in this collection deserves consideration. If the percentage of identified bone from cattle is compared to that from pigs, this preference is marked. Table 12-36 compares the percentage of total identified bones in each site which were Bos and Sus, for all sites with more than 10 identified bones. The data from site $41 B \times 896$ are skewed by the presence on the site of 3 nearly complete skeletons, 2 dogs and a large fish. These three individuals were removed, the percentage of beef and pig recalculated, and the results listed in parentheses in Table 12-36.

In most cases cow bone outnumbers pig by at least two times, and usually three or more. The only exceptions are all Runge Street houses. Sites 41BX938-940 and 41BX942 (shaded gray in Table 12-36) have a much greater proportion of pig bone than the other sites. One (41BX942) actually has more pig than cow. In the others the pig bone is nearly equal in number to cow bone. These sites are all in the Runge Street area, where the houses were originally built in the mid-

Table 12-34. Rabbits from Three Privies, 41BX883, 41BX896, and 41BX945

\begin{tabular}{||c|c|c|c|c|c|c|c|c||}
\hline \multirow{2}{*}{ Privies } & \multicolumn{2}{|c|}{ Head Elements } & \multicolumn{2}{c|}{ Feet Elements } & \multicolumn{2}{c|}{$\begin{array}{c}\text { Other Post-cranial } \\
\text { Elements }\end{array}$} & \multicolumn{2}{c|}{ Totals } \\
\cline { 2 - 10 } & Lepus & Sylvilagus & Lepus & Sylvilagus & Lepus & Sylvilagus & Lepus & Sylvilagus \\
\hline $\begin{array}{c}\text { Privy \#1 } \\
\text { 41BX883 }\end{array}$ & 27 & 27 & 4 & 1 & 17 & 0 & 48 & 28 \\
\hline $\begin{array}{c}\text { Privy \#5 } \\
\text { 41BX896 }\end{array}$ & 0 & 85 & 0 & 43 & 0 & 0 & 0 & 128 \\
\hline $\begin{array}{c}\text { Privy \#12 } \\
\text { 41BX945 }\end{array}$ & 10 & 9 & 8 & 4 & 26 & 66 & 44 & 79 \\
\hline
\end{tabular}


Table 12-35. MNI of Commonly Hunted Animals (Excluding Rabbits) from Three Privies

\begin{tabular}{|l|c|c|c|}
\cline { 2 - 4 } \multicolumn{1}{c|}{} & $\begin{array}{c}\text { Privy \#1 } \\
\text { (41BX883) }\end{array}$ & $\begin{array}{c}\text { Privy \#5 } \\
\text { (41BX89) }\end{array}$ & $\begin{array}{c}\text { Privy \#12 } \\
\text { (41BX94) }\end{array}$ \\
\hline Odocoileus virginianus (deer) & 1 & 0 & 0 \\
\hline Didelphis marsupialis (opossum) & 0 & 0 & 1 \\
\hline Sciurus niger(squirrel) & 0 & 0 & 2 \\
\hline Branta sp.(Canada goose) & 0 & 0 & 1 \\
\hline Anas sp. (duck) & 1 & 0 & 3 \\
\hline Anser/Anas (geese and/or large ducks) & 2 & 0 & 1 \\
\hline Columbidae (pigeons and doves) & 0 & 0 & 11 \\
\hline & 7 & 0 & 25 \\
\hline Total MNI & 7 & 0 & 6 \\
\hline
\end{tabular}

Table 12-36. Percentage of Beef and Pork Bone From Sites with Greater than 10 Identified Bone Elements

\begin{tabular}{|c|c|c|}
\hline Site & Bos taurus & Sus scrofa \\
\hline 41BX881 & 54.84 & 16.13 \\
\hline 41BX882 & 44.44 & 11.11 \\
\hline $41 B \times 883$ & 59.39 & 19.14 \\
\hline $41 B X 884$ & 48.57 & 18.57 \\
\hline 41BX891 & 53.33 & 6.67 \\
\hline 41BX892 & 3.24 & 11.76 \\
\hline 41BX893 & 30.00 & 5.00 \\
\hline 41BX895 & 53.33 & 11.11 \\
\hline 41BX896 & $\begin{array}{c}9.83 \\
(31.83)\end{array}$ & $\begin{array}{c}3.06 \\
(9.89)\end{array}$ \\
\hline 41BX897 & 68.40 & 15.20 \\
\hline $41 \mathrm{BX} 900$ & 61.43 & 18.57 \\
\hline 41BX936 & 15.38 & 0.00 \\
\hline $4 \mathrm{~B} \times 938$ & $52.1 \%$ & 2609 \\
\hline $41 \mathrm{~B} \times 939$ & 4250 & 3315 \\
\hline $41 \mathrm{~B} \times 940$ & 4737 & 3158 \\
\hline 41BX941 & 41.94 & 12.90 \\
\hline $4 \mathrm{BB} \times 42$ & 30.00 & 45.00 \\
\hline 41BX945 & 52.24 & 12.81 \\
\hline
\end{tabular}

*Data in parentheses reflect changes described in text. 
1920 s as rental property and the inhabitants throughout their occupation were largely African-American. On the other hand, the Webb site, at which only AfricanAmericans lived until the last few years of its occupation, had the highest percentage of beef bone of any site with more than 10 identified bone. Most of the Alamodome area had a scattering of black families living there at various times. Examples are the Webbs at 41BX897, and the Meades at 219 Wyoming Street. This was not an uncommon pattern in the South after the Civil War. Segregation into "white" and "black" neighborhoods did not really begin until after the turn of the century (Woodward 1957). The grouping of African-Americans into the mini-neighborhood of Runge Street was an example of twentieth century segregation practices. However, whether the difference in utilization of beef and pork between the Runge Street area and the rest of the project area is a product of the ethnicity of the inhabitants, the difference in time, or in economic status is unknown.

The preference for beef displayed in the other sites is quite distinct from the pattern Hilliard (1972) found in his study of the diet prevalent in the American Southeast during the nineteenth century. He noted that "it is unlikely that beef was eaten regularly, especially among poorer whites" (Hilliard 1972:45), and that though larger plantations may have slaughtered cattle fairly frequently, especially in the more cattle-oriented Coastal Plain, "beef consumption by most southerners must have been sporadic and the total amount small relative to pork" (Hilliard 1972:45). This pattern has been confirmed in a number of archaeological studies from the Southeast (Warner 1995), though not at the Edgewood site, an early twentieth-century dump in Atlanta (Davidson 1982:384).

This preference for pork almost certainly extended to east Texas. Texas is listed as having the second highest count of pigs per capita in the South in both the 1850 and 1860 censuses (Hilliard 1972:94). Texas east of the Brazos River was, by 1860 , "Anglo-American and African, entirely Southern in origin" (Meinig 1975:51), and presumably Southern in diet as well. West of the river, however, the influence of a large influx of Europeans, especially Germans and French, could be felt, as could the Hispanic influence, which grew stronger as one approached the Rio Grande (Meinig 1975: 51). Perhaps most importantly, however, is the change in environmental conditions, especially rainfall. The sharp east to west gradient in average precipitation across Texas is a well-known phenomenon. San Antonio averages about $70 \mathrm{~cm}$ of rain a year, though this is highly variable (Norwine 1995:141), while east Texas gets between 100 and 140 cm per year (Bomar 1995:77).

Jordan (1966:192-203) has noted the ways in which German immigrants adapted their traditional farming methods to the specific needs they found in the part of Texas to which they moved. Those in the eastern part of Texas soon adopted most of the farming practices then in use in the area (Jordan 1966:196). In the western part of the state, including the area around San Antonio, there was little in the way of an established farming community to copy. Instead, by a process of trial and error, those traditional German methods which passed the test of environmental and economic feasibility were retained, while others were either modified to match the specific conditions in the west, or were abandoned altogether (Jordan 1966:196). Jordan's study dealt specifically with Germans in Texas, but we can infer that a similar process took place whenever anyone moved to western Texas.

It was in the west that cattle became the main source of wealth. That the plains and hills of western Texas were excellent cattle country can be demonstrated by the success of feral Spanish cattle in establishing themselves there in such numbers that they made a considerable impression on Athanase de Mézieres, traveling in 1778 (quoted by Bieber 1940: 20). After statehood, numerous men began using these wild Spanish cattle to build the cattle industry of Texas. In 1850 Texas had 1.5 cows per capita, the second largest number of cattle of any state in the Union (Hilliard 1972:114). By 1860 this number had increased to 5.9 per capita, while the next highest state, Florida, had only 2.8 cows per capita, which was, in turn, more than twice the number found in the next highest state (Hilliard 1972:114).

San Antonio was most certainly a part of this western version of Texas, enjoying the prosperity that cattle ranching brought both before and after the Civil War (McCoy 1940:46). After the war, high beef prices in the east coupled with the building of the railroads that made rapid transportation of the animals possible caused a boom in the industry (McCoy 1940:46). Icemaking machines began to arrive in San Antonio by 
1870, but ice availability remained extremely limited until the turn of the century (Steinfeldt 1978:76-78). Until then, the meat in the city was slaughtered, butchered, sold, and eaten on the same day (Freeman 1972:3).

In 1838 the slaughter of cattle within the city (which did not at the time include the Alamodome area) was prohibited (City Council Minutes, Volume A, p.9, Originals on file, Office of the City Secretary, City Hall, San Antonio). Throughout the nineteenth century, the central meat market of San Antonio, located at Alamo Plaza between the mid-1850s and 1870 s, was the source of beef, pork, mutton, and goat for the inhabitants of the city. Meat purchases had to be made daily, and the scene at the market was described as follows:

The market opened at two in the morning, the meat having been slaughtered earlier the same night, and brought down to be cut up for sale. Hotel cooks, restauranteurs, and household shoppers came before or soon after daylight to buy a one-day supply, and since there was no way to preserve the meat, the stalls were closed at 7 am and what remained was given away [Freeman 1972:3].

The coming of the railroad in 1877 (San Antonio Express, 20 February 1877) and the improvement in refrigeration availability after the turn of the century made San Antonio's importance as both cattle shipper and meat packer grow. By 1921, San Antonio had the twenty-fifth largest meat market in the country, larger than any market in the old Confederate states except Fort Worth (ranked fourth) and Abilene (ranked twenty-fourth) (Clemen 1923:258).

The prevalence of Bos taurus bone in the faunal collection from the Alamodome shows that the diet of the inhabitants of San Antonio, like their farming practices, was influenced primarily by the cultural and economic realities of their region, their connection to the traditions of the American Southeast, Germany, or to any other region. German farmers in the Hill Country northwest of San Antonio concentrated on cattle, as did farmers in the same area originally from the Southeast, though the Germans had a lower percentage of swine (Table 12-37). Thus, although those from the Southeast and from Germany both came from farming traditions in which pigs play a very important part (Jordan 1966:89), after their move to the west cattle dominated their livestock. The data from this study suggest that cattle dominated their diets as well. The Webbs, in particular, born in Virginia, show that the traditional Southern diet was not maintained when people were faced with the changes in climate, culture, and economics as they moved into the Southwest. The trash dump on the Webb site has the highest percentage of beef bone of any site with more than 10 identifiable bone, 68.40 percent, while the pork bone was only 15.20 percent of the identifiable bone.

Why do the faunal remains from Alamodome project show no sign of the preference for pork described by Hilliard (1972) and evidenced by the high count of pigs per capita in Texas? The answer appears to be that the preference for pork is a Southeastern phenomenon, and that San Antonio, though not all that far in distance from east Texas, is a Southwestern city, with Southwestern climate and Southwestern economics. Those who moved to San Antonio from elsewhere changed their traditional diets, at least to some extent, to match the necessities of their new homes.

\section{Faunal Remains from Two Privies And a Trash Dump}

As discussed in the previous section, three proveniences of the Alamodome-the privy on the King site (Privy \#1, 41BX883), the privy on the Pauly site (Privy \#12, 41BX945), and the trash dump associated with the Webb site (41BX897 and 41BX883)-produced 50.93 percent $(n=12,323)$ of the total bone recovered during the project. These areas were chosen for more detailed analysis for three reasons.

1) The bone in these areas is the result of deliberate disposal of trash.

2) The two privies were completely excavated. Although the trash dump area was excavated by backhoe, and the material was not screened, a large number of artifacts were recovered, and the large number of buttons (more than 75) which were recovered from this trash dump is an 
Table 12-37. Average Counts of Cattle and Pigs per Farm in 1870 and 1880 in Counties of West Texas with Large German Populations (data from Jordan 1966:145)

\begin{tabular}{|l|c|c|c|c|}
\cline { 2 - 5 } \multicolumn{1}{c|}{} & \multicolumn{4}{c|}{ Origin of Farmers } \\
\cline { 2 - 5 } \multicolumn{1}{c|}{} & \multicolumn{2}{c|}{ Germany } & \multicolumn{2}{c|}{ Southeast United States } \\
\cline { 2 - 5 } & $\#$ & $\%$ & $\#$ & $\%$ \\
\hline Cattle & 118.5 & 82.29 & 183.5 & 76.62 \\
\hline Pigs & 25.5 & 17.71 & 56 & 23.38 \\
\hline Total & 144 & $100.00 \%$ & 239.5 & $100.00 \%$ \\
\hline
\end{tabular}

indication of how carefully each backhoe bucket of dirt was examined.

3) The three areas range in estimated age from the 1870 s to the early twentieth century, and represent two ethnic groups, German and AfricanAmerican.

The bone from these three areas is discussed in more detail, with special attention to the identification of specific meat cuts in domestic food animals.

Analysis of the bone from these privies included notation of evidence of immature animals, evidence of burning, and butcher marks. Butcher marks were divided into six categories: 1) thin cut, superficial, from a knife; 2) thick cut, superficial, from a heavy knife or small cleaver; 3) chop, deep cut, through all or most of the thickness of the bone, from a cleaver or hatchet; 4) machine saw cut; 5) hand saw cut; 6) undetermined saw cut. Bone is identified as machine saw or hand saw cut on the basis of the nature of the striations visible on the cut surface of the bone. Machine saw cuts exhibit parallel striations that are regular in depth and spacing along the cut surface. Hand sawing bone leaves much more irregular striations and grooves across the cut surface (Gust 1983). When the cut surface is too badly damaged to determine the kind of saw cut, the bone is placed in category 6 . Hand saws were still in use, at least in small butchering operations, in the $1920 \mathrm{~s}$ in California (Gust 1983:344), but it is not known when power equipment was introduced to San Antonio butchers.

Chopping bone with a cleaver, ax, or hatchet tends to leave a $V$-shaped gouge that cuts through part of the bone, with the remaining uncut section of bone having been broken. Cleavers and other chopping tools were more commonly used on pig and sheep bones, which are softer than those of beef (Gust 1983). Cleavers were usually used on beef carcasses only to split them into sides and, before machine saws, occasionally to cut ribs into sections. Much of the chopped bone from this assemblage is either vertebra or rib, from both pig and cow.

\section{Privy \#1 (41BX883, C. King Site)}

Privy \#1 was lined with yellow brick, dating the construction of the privy to post-1877, since fired brick was not available in San Antonio until after the railroad arrived. The privy was completely excavated, using arbitrary 10-inch levels, and all material was screened through $1 / 4$-inch screens. Analysis of the artifacts from Privy \#1 indicate that it was last filled beginning around 1890 and continuing into the early twentieth century (see Brown and DeLaO, this volume). During this period, the property was owned by Adolf Klar, a butcher. A list of the faunal remains from Privy \#1 is given in Table 12-38.

Privy \#1 contained 747 pieces of burned bone, 39.42 percent of the total, of which 2.4 percent is Bos, 1.74 percent is Sus, 0.67 percent is Capra/Ovis, and the remainder is unidentifiable. This high percentage of burned bone, much of which is completely calcined, indicating a high burning temperature (Lyman 1994:385), is an indication that some of the privy was filled with residue from trash burning. A lack of smoke stains or other signs of burning on the privy walls indicates that the trash was burned elsewhere and the residue dumped into the privy. 
Table 12-38. Faunal Remains from Privy \#1, 41BX883

\begin{tabular}{|c|c|c|c|c|}
\hline & $\#$ & $\begin{array}{c}\% \text { of } \\
\text { Identified }\end{array}$ & $\begin{array}{l}\text { Weight } \\
\text { (g) }\end{array}$ & $\begin{array}{c}\% \text { of } \\
\text { Identified }\end{array}$ \\
\hline \multicolumn{5}{|l|}{ Mammalia } \\
\hline Bos taurus & 250 & 42.44 & $3,065.35$ & 75.21 \\
\hline Capra sp. & 2 & 0.34 & 1.58 & 0.04 \\
\hline Capra/Ovis & 19 & 3.23 & 79.98 & 1.96 \\
\hline Lepus califormicus & 47 & 7.98 & 71.55 & 1.76 \\
\hline Odocoileus virginianus & 1 & 0.17 & 0.42 & 0.01 \\
\hline Ovis sp. & 7 & 1.19 & 111.38 & 2.73 \\
\hline Sigmodon hispidus & 2 & 0.34 & 0.55 & 0.01 \\
\hline Sus scrofa & 134 & 22.75 & 605.92 & 14.87 \\
\hline Sylvilagus sp. & 28 & 4.75 & 13.88 & 0.34 \\
\hline Total Identified Mammalia & 490 & $83.19 \%$ & $3,950.61$ & $96.93 \%$ \\
\hline UID Mammalia & 1,236 & & $1,752.95$ & \\
\hline Total Mammalia & 1,726 & & $5,703.56$ & \\
\hline \multicolumn{5}{|l|}{ Aves } \\
\hline Anas sp. & 15 & 2.55 & 21.97 & 0.5 \\
\hline Anas/Anser & 20 & 3.40 & 51.04 & 1.25 \\
\hline Gallus domesticus & 37 & 6.28 & 19.44 & 0.48 \\
\hline Meleagris gallopavo & 14 & 2.38 & 19.56 & 0.48 \\
\hline Total Identified Aves & 86 & $14.60 \%$ & 112.01 & $2.75 \%$ \\
\hline UID Aves & 42 & & 42.32 & \\
\hline Total Aves & 128 & & 154.33 & \\
\hline \multicolumn{5}{|l|}{ Osteichthyes } \\
\hline Ictalurus $\mathrm{sp}$. & 2 & 0.34 & 2.23 & 0.05 \\
\hline Micropterus sp. & 1 & 0.17 & 1.27 & 0.03 \\
\hline Perca flavencens & 10 & 1.70 & 9.64 & 0.24 \\
\hline Total Identified Osteichthyes & 13 & $2.21 \%$ & 13.14 & $0.32 \%$ \\
\hline UID Osteichthyes & 26 & & 20.41 & \\
\hline Total Osteichthyes & 39 & & 33.55 & \\
\hline Total Identified & 589 & & $4,075.80$ & \\
\hline UID Vertebrata & 2 & & 18.78 & \\
\hline Total Vertebrata & 1,895 & & $5,910.22$ & \\
\hline
\end{tabular}


Numerous crania fragments from both Sylvilagus sp. (cottontail rabbits) and Lepus californicus (blacktailed jackrabbit) have holes caused by shotgun pellets, indicating they were hunted rather than being raised as domestic rabbits. The only other wild animals were rats and deer, the latter represented by one deciduous tooth.

Butcher marks are found only on bone from domestic stock-cattle, pigs, and goat/sheep (Table 12-39). All the butcher marks are standard cuts, commonly seen on domestic stock since the mid-nineteenth century (Clonts 1983; Schulz and Gust 1983). Hand-sawed bone was smoothly and professionally done. The relatively low percentage of machine-sawed bone suggests that, similar to other western cities (Gust 1983:344), power equipment was only sparsely available to San Antonio butchers until at least the 1920s. Seventy-three (17.72 percent) pieces of domestic stock bone exhibited juvenile characteristics, 42 cow, 28 pig, and 3 goat/sheep.

\section{Privy \#12 (41BX945, Pauly Site)}

Privy \#12 in the Pauly site (41BX945) was probably constructed at the time the house was built, about 1855 , and was lined with large blocks of cut limestone. The house was sold to William Mueller, a butcher, in 1898. Artifact analysis indicates that the bottom part of the privy was probably filled for the last time beginning in the $1890 \mathrm{~s}$, and the entire privy was used as a trash dump until the 1920s (see Brown and $\mathrm{DeLaO}$, this volume). The privy was completely excavated, using arbitrary six-inch levels and all material was screened through $1 / 4$-inch screens. Faunal material from Privy $\# 12$ is listed in Table $12-40$.

As mentioned in the general discussion, the Mueller family seems to have gone hunting at least occasionally, as Lepus, Sylvilagus, Didelphis, and the Columbidae are all commonly hunted in the San Antonio area.

A total of 187 bones (2.60 percent) from Privy \#12 is burned; of this 19.25 percent $(n=36)$ is Bos, 4.28 percent $(n=8)$ is Sus, 5.56 percent $(n=2)$ is Capra/Ovis, and the remaining 70.91 percent $(n=141)$ is unidentifiable. This is considerably less burned bone than was found in Privy \#1, which is especially surprising since some $50 \mathrm{~cm}$ or more of Privy \#12 was filled with a mixture of ash, charcoal, and bone, with only a few other artifacts, and almost no other matrix. The bone in this level was almost entirely unburned, though it was mixed with large amounts of other burned materials. Clearly the bone and the ashes were coming from different sources and were being dumped together into the privy.

All the butcher marks are found on bone from domestic stock animals (Table 12-41). The high percentage of hand sawed bone from all three groups of animals is not surprising, given the fill dates for this privy. As we saw in Privy \#1 (Table 12-39), machinesawed bone is a relatively small proportion of the saw marks.

Of the bones from domestic stock animals, 335 (16.88 percent) display evidence of immaturity. This includes 265 Bos, 64 Sus, and 51 Caprid/Ovis.

\section{The Webb Trash Dump (41BX897 and 41BX883)}

The excavation of the Webb trash dump has been described in the site description for 41BX897. The dump was found within a large area south of the well on the property, and extended into the property to the south, 41BX883. Though the dirt from the trash dump was not screened, Table $12-42$ clearly indicates a large amount of bone was present in the dump. In many ways the bone from the Webb trash dump is the most interesting of the faunal remains collected during the project. The high percentage of beef bone, the presence of bullet holes in some beef bones (see below), and butchering techniques and tools used are all quite different from the two privies under consideration. It is important to remember that the Webb trash dump was deposited at least 20 years earlier than the deposits in the privies, and that, while the privies were filled by German-Americans, the trash dump was made by African-Americans.

Eighty-nine bones ( 2.76 percent) from the Webb trash dump are burned. Of these, 33.71 percent $(n=30)$ is Bos, 10.11 percent $(n=9)$ is $S u s, 4.49$ percent $(n=4)$ is Capra/Ovis, and the remaining 51.69 percent $(n=46)$ is unidentifiable. The high percentage of 
Table 12-39. Butcher Marks on Bone from Domestic Stock in Privy \#1

\begin{tabular}{|c|c|c|c|c|c|c|}
\hline \multirow{2}{*}{ Marks } & \multicolumn{2}{|c|}{ Bos taurus } & \multicolumn{2}{|c|}{ Sus scrofa } & \multicolumn{2}{|c|}{ Capra/Ovis } \\
\hline & $\#$ & $\%$ & \# & $\%$ & $\#$ & $\%$ \\
\hline Thin Cut & 1 & 0.70 & 1 & 3.26 & 0 & 0 \\
\hline Thick Cut & 2 & 1.41 & 0 & 0 & 0 & 0 \\
\hline Chop & 34 & 23.94 & 11 & 35.48 & 0 & 0 \\
\hline Machine saw & 28 & 19.72 & 5 & 16.13 & 1 & 12.50 \\
\hline Hand saw & 43 & 30.28 & 6 & 19.35 & 4 & 50.00 \\
\hline Undetermined saw & 34 & 23.94 & 8 & 25.81 & 3 & 37.50 \\
\hline Total & 142 & $99.99 \%$ & 31 & $100.03 \%$ & 8 & $100.00 \%$ \\
\hline
\end{tabular}

burned bone which is identifiable was due to the relatively minor effects of burning in these bones. While most of the burned bone in Privy \#1 was calcined, most of the burned bone in the Webb trash dump was only partially charred. If the Webbs were burning any of their trash, they were not throwing the remains of that activity into the trash dump.

From domestic stock animals, 224 (19.56 percent) bone pieces show evidence of immaturity. This is only a slightly higher percentage than the other two areas. Butchering marks found on bone from the Webb trash dump are listed in Table 12-43. The very low number of machine saw cuts is probably a reflection of the earlier date of the trash accumulation, but another factor may also be involved. An unusually high percentage of all domestic stock bone show signs of chopping. In fact, many bone which professional butchers do not chop, including 12 fragments of humeri, and 5 fragments of femurs of Bos taurus, were chopped with a heavy hatchet or axe. The smaller animals show an even higher percentage of chop marks. These data suggest that a considerable number of the bones in the Webb trash dump were not professionally butchered. Bullet holes found in some bone are discussed in the following section. The Webb trash dump is distinctly different from the other privies in terms of butchering techniques, but whether this is the result in differences in socioeconomic class, time, ethnicity, or some unconsidered factor, is discussed further in the next section.

\section{Meat Cut Comparisons}

Attempts to determine socioeconomic status and/or ethnicity from the faunal remains of historic urban sites has been the focus of many recent publications on faunal analysis (Cheek and Friedlander 1990; Clonts 1983; Gust 1983; Huelsbeck 1991; Lyman 1977, 1979 , 1987; Mudar 1977; Schulz and Gust 1983; Warner 1995). We have divided the bones of Bos taurus recovered from the two privies and the trash dump into categories according to which of the standard cuts of meat each bone represents, and will attempt to determine if these faunal remains reflect the socioeconomic ranking of the three households under consideration.

Further evidence of non-professional butchering at the Webb site is the placement of cuts made on bones. Though no quantitative analysis of exact placement of meat cuts was made, the Webb trash dump did show numerous examples of non-standard cuts, including extremely thick chuck roasts, arm roasts, and round roasts, and 45 tibia fragments. The latter usually consist of large sections of the diaphysis and/or distal tibia, 14 of which weighed more than $100 \mathrm{~g}$, and three of which weighed more than $200 \mathrm{~g}$. These large pieces of hindshank were not seen in any of the other sites.

\section{Factors Considered During Analysis}

\section{Butchering Practices}

Butchering practices for beef and pork in the late nineteenth century were similar to those in use today 
Table 12-40. Faunal Remains from Privy \#12, 41BX945

\begin{tabular}{|c|c|c|c|c|}
\hline & $\#$ & $\begin{array}{c}\% \text { of } \\
\text { Identified }\end{array}$ & $\begin{array}{c}\text { Weight } \\
\text { (g) }\end{array}$ & $\begin{array}{c}\% \text { of } \\
\text { Identified }\end{array}$ \\
\hline \multicolumn{5}{|l|}{ Mammalia } \\
\hline Bos taurus & 1,539 & 58.83 & $15,932.38$ & 85.72 \\
\hline Capra sp. & 8 & 0.31 & 16.93 & 0.09 \\
\hline Capra/Ovis & 25 & 0.96 & 130.27 & 0.70 \\
\hline Didelphis marsupialis & 6 & 0.23 & 1.30 & 0.01 \\
\hline Equid & 2 & 0.08 & 24.02 & 0.13 \\
\hline Felis domesticus & 72 & 2.75 & 108.03 & 0.58 \\
\hline Lepus califormicus & 44 & 1.68 & 64.04 & 0.34 \\
\hline Ovis sp. & 1 & 0.04 & 16.94 & 0.09 \\
\hline Rattus rattus & 1 & 0.04 & 0.61 & 0.00 \\
\hline Rodentia & 8 & 0.31 & 1.30 & 0.01 \\
\hline Sciurus niger & 7 & 0.27 & 3.43 & 0.02 \\
\hline Sigmodon hispidus & 34 & 1.30 & 12.67 & 0.07 \\
\hline Sus scrofa & 392 & 14.98 & 1674.22 & 9.01 \\
\hline Sylvilagus sp. & 79 & 3.02 & 53.16 & 0.29 \\
\hline Total Identified Mammalia & 2,218 & $84.79 \%$ & $18,039.30$ & $97.06 \%$ \\
\hline UID Mammalia & 3,944 & & $6,275.34$ & \\
\hline Total Mammalia & 6,162 & & $24,314.64$ & \\
\hline \multicolumn{5}{|l|}{ Aves } \\
\hline Anas sp. & 11 & 0.42 & 5.62 & 0.03 \\
\hline Anas/Anser & 9 & 0.34 & 13.91 & 0.07 \\
\hline Anser sp. & 1 & 0.04 & 3.27 & 0.02 \\
\hline Branta canadensis. & 3 & 0.11 & 6.74 & 0.04 \\
\hline Colombidae & 126 & 4.82 & 46.25 & 0.25 \\
\hline Gallus domesticus & 188 & 7.19 & 298.91 & 1.61 \\
\hline Meleagris gallopavo & 48 & 1.83 & 160.26 & 0.86 \\
\hline Total Identified Aves & 386 & $14.76 \%$ & 534.96 & $2.88 \%$ \\
\hline UID Aves & 557 & & 212.12 & \\
\hline Total Aves & 943 & & 747.08 & \\
\hline \multicolumn{5}{|l|}{ Osteichthyes } \\
\hline Aplodinotuys grunnieus & 3 & 0.11 & 3.15 & 0.02 \\
\hline Ictalurus sp. & 8 & 0.31 & 8.97 & 0.05 \\
\hline Total Identified Osteichthyes & 11 & 0.42 & 12.12 & 0.07 \\
\hline UID Osteichthyes & 31 & & 25.65 & \\
\hline Total Osteichthyes & 42 & & 37.77 & \\
\hline
\end{tabular}


Table 12-40. continued

\begin{tabular}{|c|c|c|c|c|}
\hline & $\#$ & $\begin{array}{c}\% \text { of } \\
\text { Identified }\end{array}$ & $\begin{array}{c}\text { Weight } \\
\text { (g) }\end{array}$ & $\begin{array}{c}\% \text { of } \\
\text { Identified }\end{array}$ \\
\hline \multicolumn{5}{|l|}{ Reptilia } \\
\hline Testudinata & 1 & 0.04 & 0.17 & 0.00 \\
\hline Total Reptilia & 1 & 0.04 & 0.17 & 0.00 \\
\hline Total Identified & 2,616 & & $18,586.55$ & \\
\hline UID Vertebrata & 6 & & 23.95 & \\
\hline Total Vertebrata & 7,154 & & $25,123.61$ & \\
\hline
\end{tabular}

Table 12-41. Butcher Marks on Domestic Stock from Privy \#12

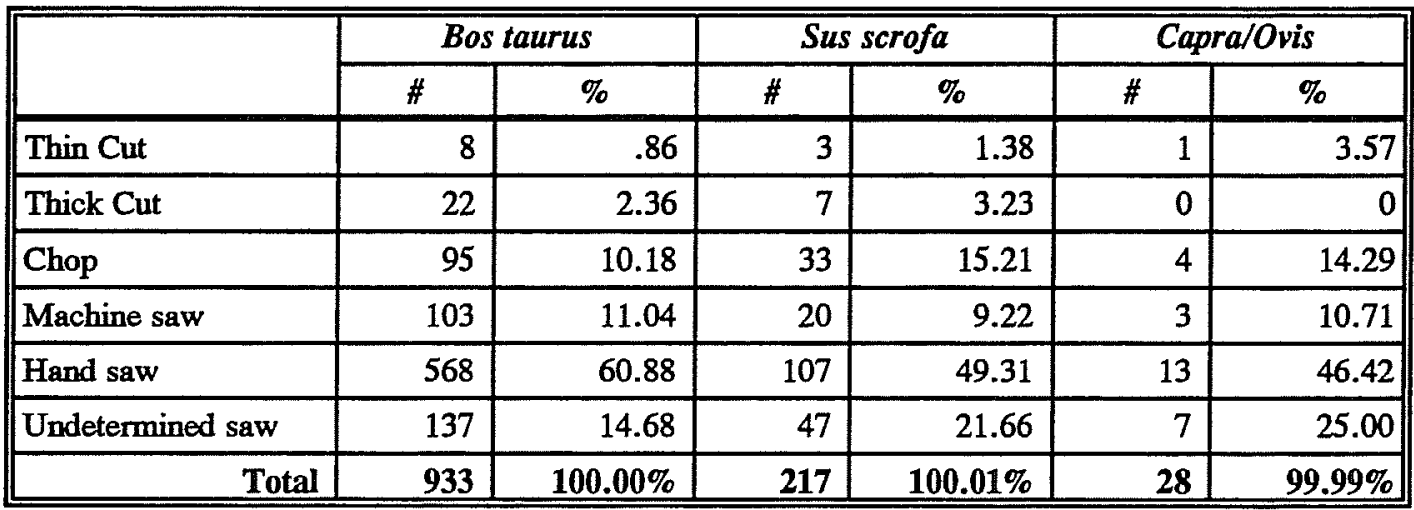


Table 12-42. Faunal Remains from the Webb Trash Dump

\begin{tabular}{|c|c|c|c|c|}
\hline & $\#$ & $\begin{array}{c}\% \text { of } \\
\text { Identified }\end{array}$ & $\begin{array}{l}\text { Weight } \\
\text { (g) }\end{array}$ & $\begin{array}{c}\% \text { of } \\
\text { Identified }\end{array}$ \\
\hline \multicolumn{5}{|l|}{ Mammalia } \\
\hline Bos taurus & 921 & 67.92 & $26,122.30$ & 87.61 \\
\hline Canis sp. & 1 & 0.07 & 0.92 & 0.00 \\
\hline Capra sp. & 1 & 0.07 & 16.93 & 0.06 \\
\hline Capra/Ovis & 87 & 6.42 & 834.02 & 2.80 \\
\hline Didelphis marsupialis & 1 & 0.07 & 0.85 & 0.00 \\
\hline Equid & 1 & 0.07 & 15.44 & 0.05 \\
\hline Lepus californicus & 5 & 0.37 & 7.59 & 0.03 \\
\hline Odocoileus virginianus & 1 & 0.07 & 18.52 & 0.06 \\
\hline Ovis sp. & 8 & 0.59 & 130.67 & 0.44 \\
\hline Sus scrofa & 179 & 13.20 & $2,497.28$ & 8.38 \\
\hline Sylvilagus sp. & 8 & 0.59 & 5.40 & 0.02 \\
\hline Tayassu tajacu & 1 & 0.07 & 10.70 & 0.04 \\
\hline Total Identified Mammalia & 1,214 & $89.53 \%$ & $29,660.62$ & $99.48 \%$ \\
\hline UID Mammalia & 1,908 & & $4,131.85$ & \\
\hline Total Mammalia & 3,122 & & $33,792.47$ & \\
\hline \multicolumn{5}{|l|}{ Aves } \\
\hline Anas sp. & 4 & 0.29 & 4.81 & 0.02 \\
\hline Colombidae & 1 & 0.07 & 0.31 & 0.00 \\
\hline Gallus domesticus & 26 & 1.92 & 29.99 & 0.10 \\
\hline Meleagris gallopavo & 8 & 0.59 & 22.29 & 0.07 \\
\hline Total Identified Aves & 39 & $2.88 \%$ & 57.40 & $0.19 \%$ \\
\hline UID Aves & 93 & & 89.81 & \\
\hline Total Aves & 132 & & 147.21 & \\
\hline \multicolumn{5}{|l|}{ Osteichthyes } \\
\hline Ictalurus sp. & 6 & 0.44 & 4.73 & 0.02 \\
\hline Perca flavencens & 4 & 0.29 & 3.25 & 0.01 \\
\hline Total Identified Osteichthyes & 10 & $0.74 \%$ & 7.98 & $0.03 \%$ \\
\hline UID Osteichthyes & 10 & & 5.84 & \\
\hline Total Osteichthyes & 20 & & 13.82 & \\
\hline Total Identified & 1,356 & & $29,815.81$ & \\
\hline Total Vertebrata & 3,274 & & $33,953.50$ & \\
\hline
\end{tabular}


Table 12-43. Butcher Marks on Bone from Domestic Stock Animal in the Webb Trash Dump

\begin{tabular}{|c|c|c|c|c|c|c|}
\hline \multirow{2}{*}{ Marks } & \multicolumn{2}{|c|}{ Bos taurus } & \multicolumn{2}{|c|}{ Sus scrofa } & \multicolumn{2}{|c|}{ Capra/Ovis } \\
\hline & $\#$ & $\%$ & $\#$ & $\%$ & \# & $\%$ \\
\hline Thin Cut & 30 & 3.49 & 9 & 8.18 & 4 & 5.71 \\
\hline Thick Cut & 30 & 3.49 & 4 & 3.64 & 1 & 1.43 \\
\hline Chop & 279 & 32.48 & 58 & 52.73 & 51 & 72.86 \\
\hline Machine saw & 21 & 2.44 & 4 & 3.63 & 2 & 2.86 \\
\hline Hand saw & 414 & 48.20 & 28 & 25.46 & 11 & 15.71 \\
\hline Undetermined saw & 85 & 9.90 & 7 & 6.36 & 1 & 1.43 \\
\hline Total & 859 & $100.00 \%$ & 110 & $100.00 \%$ & 70 & $100.00 \%$ \\
\hline
\end{tabular}

(Clonts 1983). The general sequence in processing cattle for consumption begins with the removal of the head and tail, and gutting of the animal. The carcass is then split along the vertebral column and each half is broken down into front and hind quarters. Each quarter is then cut into the smaller units most commonly purchased by the consumer. The meat cuts derived from the front quarter are the neck, chuck, rib, short rib, short plate, cross rib, brisket, arm, and foreshank (Schulz and Gust 1983). The meat cuts derived from the hind quarter are the short loin, sirloin, rump, round, hindshank, and flank. Any of these cuts may be, and most likely were, cut into smaller portions for retail sales and/or single meals. A very similar butchering technique was used for pigs and sheep (Clonts 1983:351).

\section{Socioeconomic Ranking}

Identification and analysis of meat cuts in historic faunal remains can be a useful way of looking at economic status, by themselves, or in addition to other artifact classes. Previous work using historic faunal remains to infer economic status has shown that faunal assemblages do reflect consumer behavior (Lyman 1977, 1987; Mudar 1977; Schulz and Gust 1983; Warner 1995), although there is still considerable concern about exactly how to use meat cut analysis to measure socioeconomic status (Huelsbeck 1991; Lyman 1987), and how to differentiate socioeconomic differences from ethnic differences (Cheek and Friedlander 1990; Mudar 1977). An economic ranking of meat cuts for beef in nineteenth-century Euroamerican sites was established by Schulz and Gust (1983:48), based on the price of each cut. Schulz and
Gust looked at meat cuts within the faunal remains recovered from the Sacramento City Jail, two saloons and an elite hotel. These sites all dated to the latter half of the nineteenth century. They found that the ranking that had been assigned to the different faunal assemblages matched the presumed socioeconomic rank of the four sites. The city jail site contained the highest percentage of lower ranking (low cost) meat cuts, such as the neck, chuck, and short rib. These are lower-priced cuts that would be used for soups, or roasts that would feed a large number of people. The hotel had a high percent of high ranking cuts. Over $\mathbf{5 0}$ percent of the identified meat cuts were of short loin, ranked number 1 , that was probably consumed as individual steaks. The two saloons fall in the middle with high percentages of middle ranking cuts, but had a more even distribution of all ranks of meat cuts (Schulz and Gust 1983:49).

This cost ranking may shift to some extent through time and in areas where there is a strong ethnic preference. Mudar (1977:369) found that although ethnicity and socioeconomic status was discernible from the faunal assemblages, the examination of the distribution of beef meat cuts alone did not provide clear delineation of these differences.

Lyman (1987) pointed out that ranking meat cuts by cost alone did not consider the fact that some cuts of beef provide more useable meat than others. He developed a ranking of meat cuts based on cost efficiency. The amount of useable meat per $\$ .10$ was calculated from a 1916 source to reflect cost efficiency (Lyman 1987:63). Table 12-44 shows a comparison of 
Schulz and Gust's (1985:48, Figure 1) ranking of meat cuts by cost, and Lyman's (1987:63) ranking of meat cuts by cost efficiency (Table 12-44).

Lyman's ranking does not take into consideration the nutrient value of the bone itself. Though cuts such as hind or foreshanks and neck do not contain a great deal of meat, the bone is not completely waste, as it is, say, in a T-bone steak. Such meats are prepared by boiling, with the bone. A number of food elements, including some protein and considerable fat, are added to the broth from the bone itself. This factor should be kept in mind in examining the data collected from the bone in the analysis below.

\section{Factors Affecting Consumer Choice}

Considerations that go into consumer choices of any product are complex (Henry 1987:360-363), and the cost-efficiency of meat is only one of the factors considered in purchasing decisions. The purchase, for instance, of T-bone steaks to serve a guest is less a matter of the cost (or cost efficiency) of the meat than of the social implications of the steaks. This is not to say that economic considerations are not a factor in such a purchase, for the buyer must actually have enough money to spend for his or her purchase. In this example, the buyer is purchasing prestige as well as a meal, and in some cases (say, if the guest is the buyer's boss), this may have direct economic results. Actual amount of cash available at any one time, maintenance of a traditional ethnic diet, purchase for every-day or special occasions, purchase of prestige items to define class membership (either real or hopedfor), and even the level of education of the consumer, may all be factors in making consumer decisions (Henry 1987:360-363). Cost efficiency, as defined by Lyman (1987) and in this report, does not take such other factors into consideration.

Table 12-44. Comparison of Ranking of Meat Cuts by Cost (Schulz and Gust 1985:48) and by Cost Efficiency (Lyman 1987:63)

\begin{tabular}{|c|c|c|}
\hline Meat Cuts Ranked by Cost & Rank & $\begin{array}{c}\text { Meat Cuts Ranked by Cost } \\
\text { Efficiency }\end{array}$ \\
\hline Short loin & 1 & Short plate \\
\hline Rib, Sirloin & 2 & Hindshank \\
\hline Round & 3 & Chuck \\
\hline Rump & 4 & Round \\
\hline Chuck & 5 & Arm \\
\hline Arm, Cross/Short ribs & 6 & Foreshank \\
\hline Brisket, Short plate & 7 & Rib \\
\hline Neck & 8 & Short loin \\
\hline Foreshank & 9 & Sirloin \\
\hline Hindshank & 10 & Short rib \\
\hline & 11 & Rump \\
\hline & 12 & Brisket \\
\hline & 13 & Neck* \\
\hline
\end{tabular}

* Note: Lyman's cost efficiency ranking did not include neck because price per pound was not available. However, he lists neck as last in the ranking of cuts by meat yield (Lyman 1987:62). Using his technique, and assuming that neck yields about 50 percent edible meat (Lyman 87:62) and costs $\$ .01$ per pound (as listed in Clemen 1923:352), then neck would yield only 5.0 lbs. of meat for $\$ .10$,
making it the least cost efficient. 


\section{Potential Problems}

Unfortunately, the faunal analyst is not always able to choose samples in which all or most extraneous variables have been eliminated. The ideal way to approach questions of socioeconomic and/or ethnic variations in meat cut purchases would be with samples that were very similar in space, time, sample size, sample origin, and procurement methods, both those used by the families in question to acquire the meat, and those used by the archaeologists to acquire the bone. The real world situation is not so generous. The three samples are from the same neighborhood, with Privy \#1 and the Webb site next door to each other and the Pauly site only two blocks away. However, they range in estimated time of deposition from the $1870 \mathrm{~s}$ (Webb trash dump) to a period between about 1890 and about 1920 for Privies \#1 and 12. The samples sizes also vary a great deal, from 234 identified $B o s$ taurus bones in Privy \#1, to 663 identified in Privy $\# 12$, and 871 identified in the Webb trash dump. The presence of the remains of at least 13 jackrabbit individuals in Privy \#1 (determined by the calculation of MNI), all but one of which are represented by heads and feet only, suggests that Klar was at least occasionally using the privy to dump waste from his butcher shop. That 68.65 percent of the pig remains, 19.60 percent of the cow bone, and 50.00 percent of the goat/sheep remains are from either the head or feet also suggests a considerable amount of butcher's waste. However, household waste is also present in the privy and the actual percentage of the bone that is waste from the Klar butcher shop is unknown. The waste in Privy \#12, however, though it too was filled by a butcher, seems to be entirely household waste, as is the Webb trash dump.

The methods used, at least by the Webbs, to acquire meat must also be taken into consideration. Though all the meat at Privy \#1 and Privy \#12 appeared professionally butchered and followed conventional meat cut lines, much of the Webb beef bone was cut in an unpracticed, unprofessional manner, with many non-standard cuts. Some of the bone was chopped where a professional butcher would saw. It seems likely that at least part of the meat at the Webb site was either purchased in wholesale cuts and the butchering finished at home, usually a highly wasteful way to purchase meat in the days before refrigeration, or it was acquired in some other fashion. The almost complete lack of head, tail, or feet bones in the Webb trash dump make it unlikely that actual slaughter and initial dressing of the carcass took place on the site.

The presence of bullet holes in two Bos taurus bones hint at less formal methods of procurement than purchase. Both bullet holes are roughly one centimeter in diameter, of approximately .44 caliber, a common caliber used in both handguns and rifles after the Civil War (Logan 1959:136-139). One bullet hole is in the transverse process of a lumbar vertebra (Figure 12-2). The angle of the hole suggests that the shot came from almost directly above, and somewhat behind the animal. The other bullet hole is in the scapula, at a point about two-thirds of the way distal of the glenoid fossa (Figure 12-3). Most surprising is the fact that the entrance wound is on the medial side of the bone, that is the inside, indicating the bullet originated on the other side of the animal, and had been on the way out of the body when it struck this bone. The position of the hole suggests that the bullet would have had to pass through the other scapula and possibly through the spinous process of the third or fourth thoracic vertebra (see drawing of articulated Bos taurus skeleton in Olsen 1969:Figure 4). This wound would not, by itself, have necessarily been fatal. Professional slaughtering, as early as 1848 , was (and still is) done with an axe or hammer blow between the eyes (Clemen 1923:125-126), not by shooting, and certainly not by shooting in the lower back or in the upper shoulder. While the Webbs may have chosen this highly unorthodox method of slaughter for a single cow kept on the site, the lack of evidence for the initial stages of dressing (head and foot bones), strongly suggests otherwise.

Examination of Koch's 1873 bird's-eye map (Figure 12-4) suggests another source. In the $1870 \mathrm{~s}$, the area of the future Alamodome was on the outskirts of town; only a few houses were standing at the time. The open range, shared by ranchers all over the area, was right there. Early in their tenure, the Webbs could have hunted for cows in the brush near their home much as they would hunt any wild animal. The position of the bullet holes in the bones from the Webb site is evidence that, at least in one case, they did.

It is not necessary to suppose that they were rustling. Texas stock laws at that time were explicit: an 

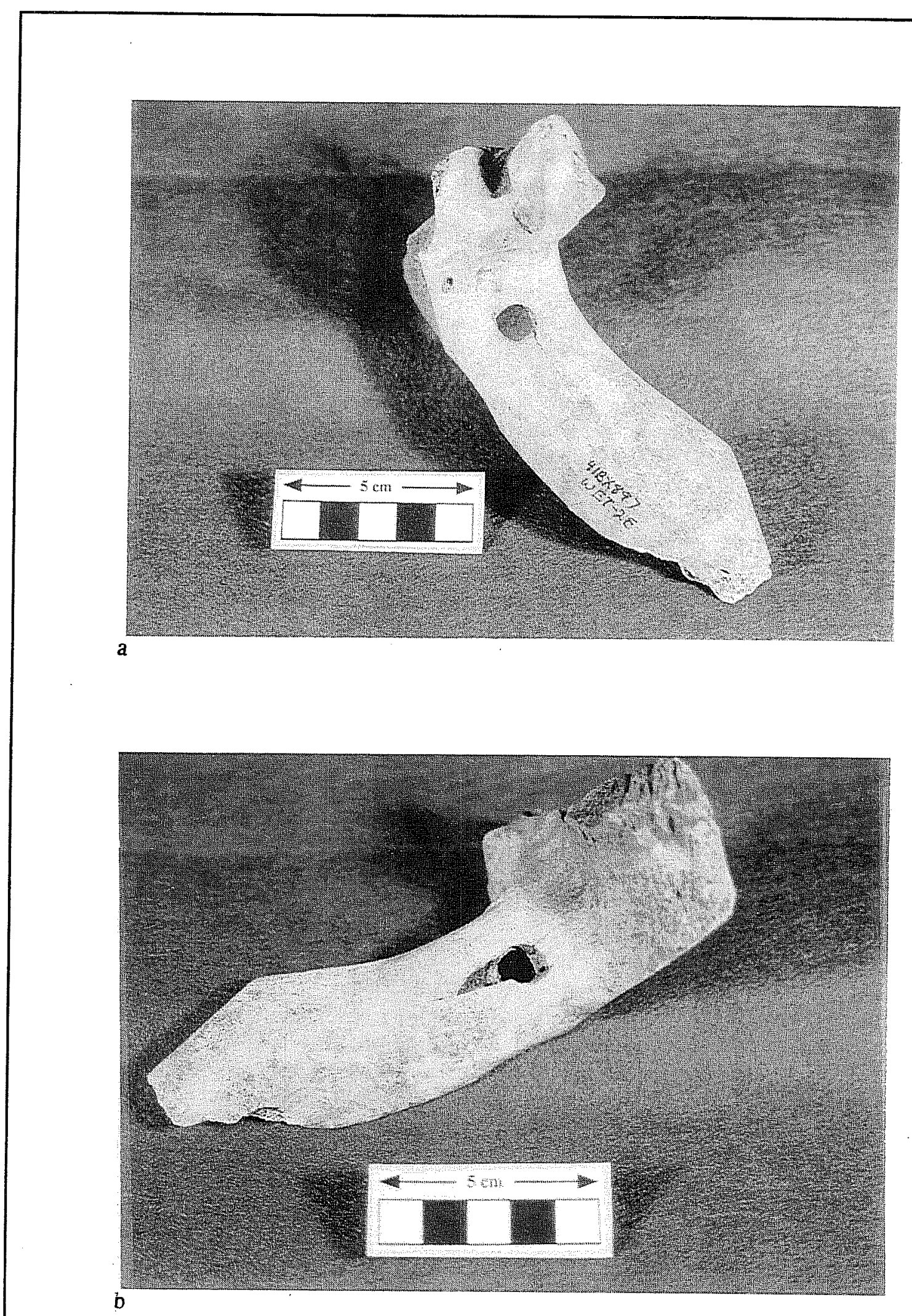

Figure 12-2. Photographs of a bullet hole in a lumbar vertebra of Bos taurus. a. dorsal view, showing entrance wound; b. ventral view, showing exit wound. 


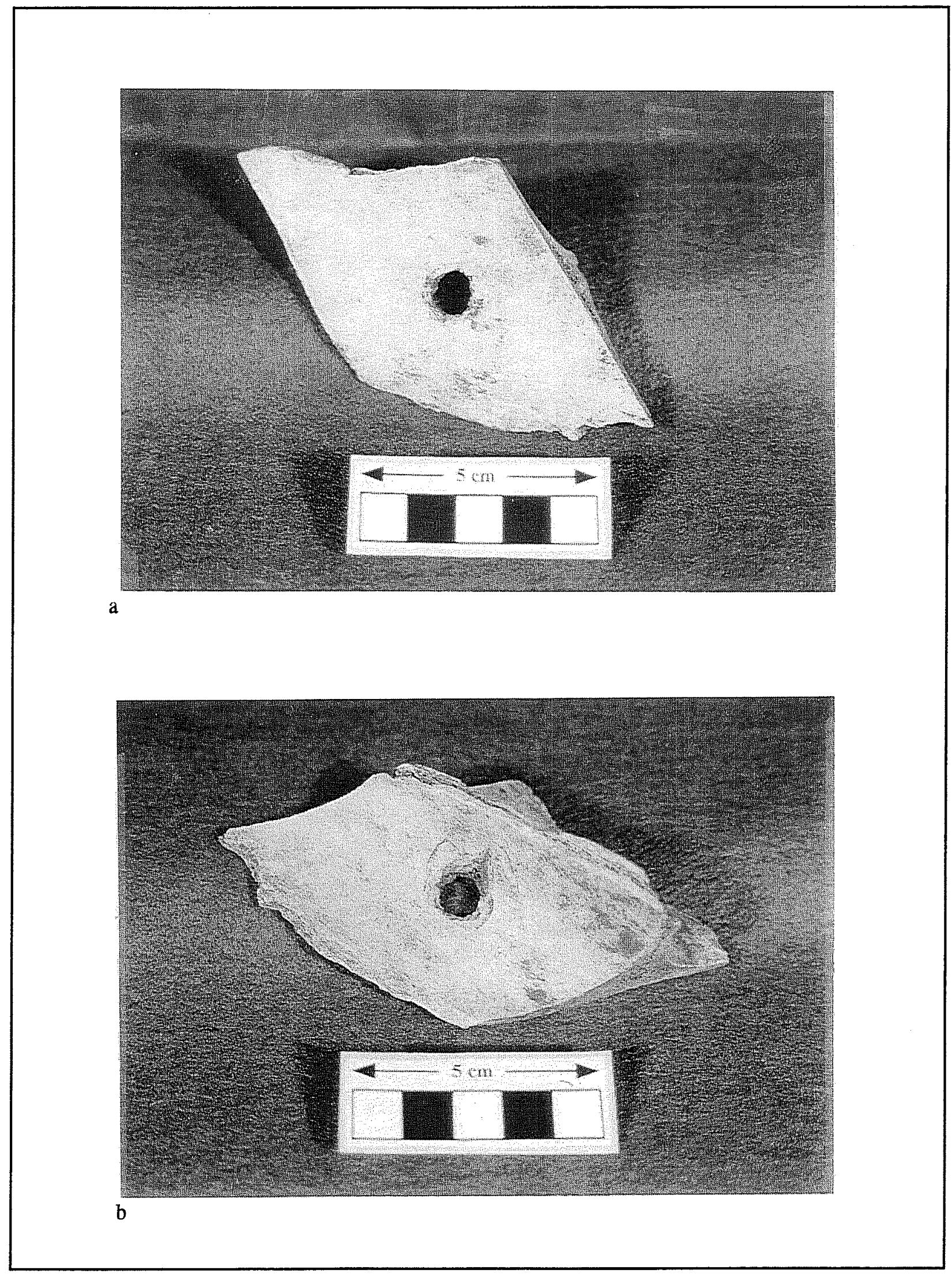

Figure 12-3. Photographs of bullet hole in scapula of Bos taurus. a. medial view, showing entrance wound; b. lateral view, showing exit wound 


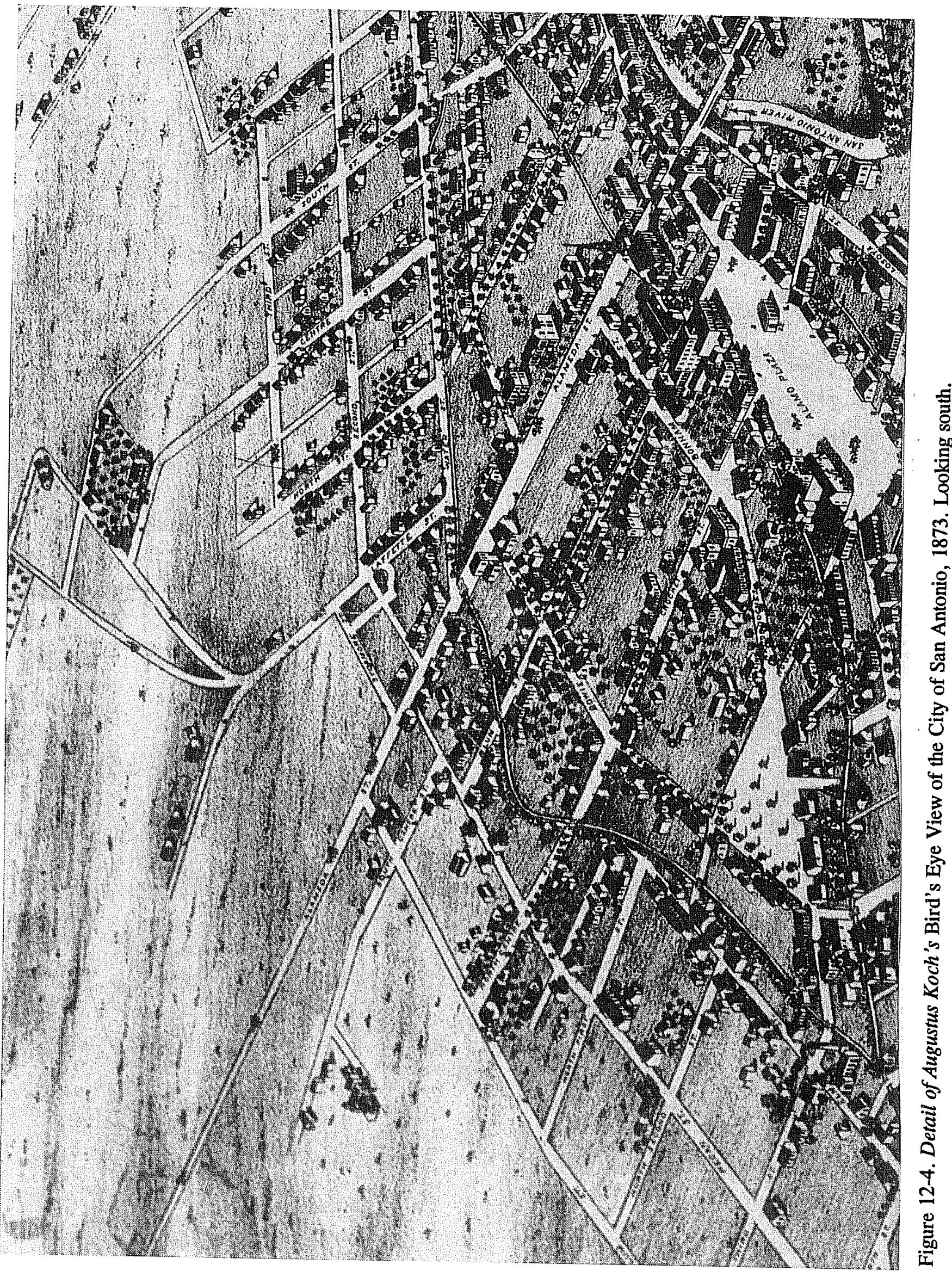


unbranded cow over the age of one year belonged to whoever caught it first (McCoy 1940:82). Killing such an animal in the open range and bringing parts back for meat was perfectly legal, and probably a common act by those of limited means living at the edge of town. It should be pointed out, however, that though the lumbar vertebra seems to be of adult size, the epiphysis of the centrum on the vertebra in Figure 12-3 is unsealed, suggesting the animal was immature and thus, at least possibly, less than a year old.

The point of the above discussion is that the Webbs seem to have been acquiring at least some of their beef by some means other than the purchase of retail cuts. This fact must be taken into consideration in the interpretation of the data.

Finally, recall that the three areas were not excavated in the same way. The two privies were completely excavated, in 6- to 10-inch levels, and all material was passed through $1 / 4$-inch screens. The Webb trash dump, as mentioned above, was excavated by backhoe, with crew members examining each bucketful carefully and all bone which could be seen collected. This dirt was not screened. This difference would probably have more effect on recovery of small animal bones, but should be kept in mind nonetheless.

\section{Meat Cut Analysis}

Do people with fewer means make cost-efficient purchases, or merely cheap purchases? In other words, do people realize that by spending $\$ .06$ a pound for short plate, they end up with more edible meat than by spending $\$ .03$ a pound for hindshank?

Lyman (1987) makes the assumption that this is the case. His model of economic strategies (Lyman, 1987:63, Figure 3) is based on this assumption. The assumption requires us to believe that : 1) people, even poorly educated people, understand the difference between cheap and cost efficient; 2) they are either able to make such calculations, or make use of a cultural tradition which has developed cost efficiency as a necessary strategy to deal with economic realities; and 3 ) other factors such as ethnic traditions, social prejudice, or individual preferences do not impact the choices made to such an extent that cost efficiency is noticeably affected. In other words, people know what is most economic and will make more use of that knowledge when they are poor than when they are rich, regardless of other factors.

This analysis proposes to test the hypothesis that the less income a family has, the more cost efficient they are in beef purchases. Were the meat purchases of the Mueller family, whom ceramic evidence suggests were the most affluent of the three (Meissner 1992), less cost efficient than the Klars or the Webbs? Did the lower-income families realize that cost efficient and cheap are not always the same thing? If Lyman's assumption and our hypothesis is correct, it could be a useful tool in understanding the socioeconomic ranking in neighborhoods such as the Alamodome area.

We feel that the data from these three sites is particularly suited to test the hypothesis. Common sense suggests that cost efficiency in meat purchases is vital when household income is barely sufficient (or not sufficient) to meet the food needs of the family; but in a very wealthy family, cost efficiency is probably the least important variable considered when making meat purchases. Thus, comparison of the cost efficiency of the very poor to the very wealthy is almost pointless. Such large class differentials are undoubtedly reflected in the kinds of meat purchased, but will be even more obvious in other artifact classes. It is in the more subtle variations of socioeconomic ranking, such as those found in a neighborhood like that of the Alamodome area, that analysis of relative cost efficiency of meat purchases promises to increase our understanding of the lives of the individuals in that neighborhood.

The three households which dumped their trash in the areas under construction were not poor. All owned land and had jobs. Examination of the ceramics from each of the areas indicated a rough economic ranking with the Muellers (Privy \#12) at the top and the Klars (Privy \#1) at the bottom (Meissner 1992). Socially, of course, the Webbs, as members of a racial minority, would have ranked at the bottom of the three families no matter what their economic standing. Cantrell (1990:333-335) has noted that the oppression of freed African-Americans during Reconstruction was especially violent in Texas. He quotes Inspector General W. E. Strong, who investigated the situation in 1865: Wherever the military was absent the exConfederates seem to take every opportunity to vent 
their rage and hatred upon the blacks" (Strong, quoted by Cantrell 1990:333, emphasis added).

Two factors in San Antonio, however, probably mitigated open violence committed against blacks: 1) there was a large United States military presence in San Antonio after the war which undoubtedly limited lawlessness in the area (Cox, Volume I): Paulus 1939:59); and 2) San Antonio had a large contingent of Union supporters, largely of German and French ethnicity, who would have been less tolerant of violence against blacks (Cox Volume I). This is not to say that African-Americans in San Antonio were treated as equals by their Anglo neighbors, but that the extremes of racial intolerance so prevalent in Texas after the war were largely avoided in San Antonio and that families like the Webbs could own land and make a reasonable living. The socioeconomic status of the Webbs, then, is ambiguous. Though the ceramics recovered from the Webb site indicate that they were economically equal or even somewhat richer than the Klars, their social status was low because of their ethnicity; therefore, roughly speaking, the socioeconomic ranking of the three families is Mueller, a butcher, at the top; followed by Klar, also a butcher; then Webb, a delivery man.

In the analysis that follows, modifications of the methods recommended by Schulz and Gust (1983), and Lyman (1987) will be used to examine the differences in beef purchases made by the three families. The questions being asked of the data are:

1) Do the beef remains from Privies \#1 and \#12 and the Webb trash dump exhibit differences in socioeconomic status, as defined by Schulz and Gust (1983)? Does the relative socioeconomic ranking of these households, as determined by meat cost, match the ranking as determined by archival and ceramics studies?

2) Can socioeconomic status be inferred from cost efficiency, i.e. are higher-status families less and lower-status families more cost efficient in their beef purchases?

For this analysis, the beef bone from the Privy \#1 (41BX883), Privy \#12 (41BX945) and the Webb trash dump (41BX897 and 41BX883) is classified by meat cut represented, when possible, using Schulz and Gust
(1983) and Lyman (1987) to define which elements would come from each cut. The cross-rib and short-rib cuts were combined due to the difficulty in identifying a specific rib from a portion of the medial section. Head, tail, and feet were added. Table 12-45 shows the meat cuts and the elements used to define them.

The meat cuts for Bos taurus bone recovered from each of the three areas are listed in Tables 12-46, $12-$ 47, and 12-48. Though Schulz and Gust (1983:49) used percentages of total NISP to compare socioeconomic rankings in the Sacramento City Jail, the two saloons and the elite hotel, we felt that bone weight was more closely related than NISP to the cost of the beef represented. Lyman $(1979,1987: 62)$ provides the percentage of each meat cut which is bone Table 12-46). Using these estimates and the bone weights from the identified beef bone, we estimated the total weight of meat purchased, which the bone weight represented. Of course, this is only a rough estimate. Lyman used Eakins (1924) to determine the percentage of bone in each meat cut. Eakins was concerned strictly with fresh meat and bone. The bone in archaeological context is dry, and all perishable components are gone. This bone weighs considerably less now than it did when the animal was recently slaughtered and the meat fresh. Since our calculations are intended strictly for comparative purposes, and not intended to calculate the actual weight of the meat, the fact that such calculations will underestimate the weight of meat represented by the bone is unimportant, provided that the underestimation is consistent for all cuts of meat. Strictly speaking, this is unlikely, as each skeletal element has different percentages of marrow, bone fat, etc., and thus lose a different percentage of total weight during drying and decomposition. However, this variation is unlikely to be a significant percentage of the total weight of the meat cut, and in any case, no method to reduce this potential bias has been developed. It should, however, be kept in mind. For the purpose of this report, then, we make the assumption that the bone weight of each meat cut is some (unknown) proportion of the fresh weight of the bone, and that proportion is roughly the same for each meat cut. Using the calculated total weight of meat (including bone) in pounds, we used the prices listed in Lyman (1987:63), which he obtained from a 1916 source, to calculate the estimated cost of the meat purchased. As has already been mentioned (see note in Table 12-44), Lyman's cost-efficiency ranking did not 
Table 12-45. Elements Used to Define Meat Cuts During Analysis

\begin{tabular}{||l|l||}
\hline \multicolumn{1}{|c||}{ Name } & \\
\hline Short Loin & Lumbar vertebra \\
\hline Rib & Dorsal ribs 6-13, thoracic vertebrae 6-13 \\
\hline Sirloin & llium, sacrum, femur head (if sawn through head) \\
\hline Round & Distal femur and diaphysis \\
\hline Rump & Acetabulum, pubis, ischium, proximal femur \\
\hline Chuck & Scapula, thoracic vertebrae 1-5, dorsal ribs 1-5 \\
\hline Arm & Proximal humerus and diaphysis, anterior portion of scapula (glenoid fossa only) \\
\hline Cross/Short Rib & Ventral ribs 1-13 \\
\hline Brisket & Sternebrae, costal cartilage (distal ribs 1-5) \\
\hline Short Plate & Costal cartilage (distal ribs 6-13) \\
\hline Neck & Axis, atlas, cervical vertebrae 3-7 \\
\hline Foreshank & Distal humerus, radius and ulna, carpals \\
\hline Hindshank & Tibia, tarsals \\
\hline Feet and Head & Cranium, metapodials, phalanges, tail \\
\hline
\end{tabular}

include neck, because price per pound was not available. However, using information in Clemen (1923:352), we were able to calculate that neck would yield only $5.0 \mathrm{lbs}$ of meat for $\$ .10$, making it the least cost efficient. This adjustment to Lyman's cost efficiency ranking was used in Tables 12-49-12-51.

Figure 12-5 shows a comparison of the estimated total meat purchased in Tables $12-49$ to $12-51$, with the meat cuts divided into three categories, according to the meat prices listed in Lyman (1987:62). Cuts costing more than $\$ .10$ per pound were short loin, sirloin, rib, round, and chuck; cuts costing from $\$ .05$ to $\$ .10$ per pound were rump, arm, short/cross rib, short plate, and brisket; and those costing less than $\$ .05$ per pound were neck, foreshank, hindshank.

Given what we know about the three families in question, Figure 12-5 is difficult to interpret. The Klar family purchased a higher percentage of cheap meats than either the Muellers or Webbs. The Muellers purchased mostly mid-priced meats, while the Webbs have a high percentage of the more expensive cuts of meat. If the estimated meat purchased for mid- and low-priced meats are combined (Table 12-52), there does not seem to be a great deal of difference between the three sites, though the Muellers and Klars appear to have purchased more of these cheaper meats than the Webbs. Either the socioeconomic ranking of these families, as estimated from archival and ceramic data, is in error, or the use of meat cost ranking, as least by the methodology described here, does not adequately reflect socioeconomic ranking.

We next made use of a modification of Lyman's technique of cost-efficiency ranking. Figure 12-6 shows the same information as Figure 12-5, but with the meat cuts grouped into three efficiency ranks. Short plate, hindshank, chuck and round are ranked high efficiency. Arm, foreshank, rib, and short loin are ranked moderate efficiency. Sirloin, cross/short ribs, rump, brisket, and neck are ranked low efficiency. These rankings are those of Lyman (1987), divided into three groups, with the addition of the neck, as discussed above. In Figure 12-6, we see that almost 39 percent of the meat bought by the Muellers was low efficiency cuts, and only about 24 percent were high efficiency cuts. This is what one would expect if higher-status families are less cost efficient than lower-status families, as our hypothesis supposes. 
Table 12-46. Bos taurus Bone from Privy \#1, Classified by Meat Cut Represented

\begin{tabular}{|l|r|r|r|r||}
\hline Name & $\#$ & \multicolumn{1}{|c|}{$\%$} & Weight (g) & $\%$ \\
\hline Short Loin & 8 & 3.42 & 49.57 & 1.62 \\
\hline Rib & 9 & 3.85 & 99.97 & 3.27 \\
\hline Sirloin & 8 & 3.42 & 65.36 & 2.14 \\
\hline Round & 0 & 0 & 0 & 0 \\
\hline Rump & 9 & 3.85 & 134.96 & 4.42 \\
\hline Chuck & 59 & 25.21 & 463.1 & 15.17 \\
\hline Arm & 9 & 3.85 & 142.59 & 4.67 \\
\hline Cross/Short & 33 & 14.1 & 278.03 & 9.11 \\
\hline Brisket & 1 & 0.43 & 11.34 & 0.37 \\
\hline Short Plate & 2 & 0.85 & 8.7 & 0.28 \\
\hline Neck & 34 & 14.53 & 527.48 & 17.28 \\
\hline Foreshank & 13 & 5.56 & 288.13 & 9.44 \\
\hline Hindshank & 15 & 6.41 & 556.76 & 18.24 \\
\hline Feet and Head & 34 & 14.53 & 427.05 & 13.99 \\
\hline Totals & 234 & $100.00 \%$ & 3053.04 & 100.00 \\
\hline \hline
\end{tabular}

Table 12-47. Bos taurus Bone from Privy \#12, Classified by Meat Cut Represented

\begin{tabular}{|l|r|r|r|r||}
\hline \multicolumn{1}{|c|}{ Name } & \multicolumn{1}{c|}{$\begin{array}{r}\text { \# } \\
\text { Short Loin }\end{array}$} & \multicolumn{1}{c|}{ \% } & Weight (g) & \multicolumn{1}{c|}{$\%$} \\
\hline Rib & 10 & 4.98 & 285.25 & 3.37 \\
\hline Sirloin & 34 & 1.51 & 109.03 & 1.29 \\
\hline Round & 50 & 7.54 & 764.56 & 9.03 \\
\hline Rump & 157 & 23.68 & 1341.33 & 15.85 \\
\hline Chuck & 37 & 5.58 & 444.63 & 5.25 \\
\hline Arm & 30 & 4.52 & 977.70 & 11.55 \\
\hline Cross/Short Rib & 108 & 16.29 & 1279.49 & 15.12 \\
\hline Brisket & 0 & 0.00 & 0.00 & 0.00 \\
\hline Short Plate & 0 & 0.00 & 0.00 & 0.00 \\
\hline Neck & 27 & 4.07 & 557.00 & 6.58 \\
\hline Foreshank & 72 & 10.86 & 1166.20 & 13.78 \\
\hline Hindshank & 49 & 7.39 & 765.78 & 9.05 \\
\hline Feet and Head & 56 & 8.45 & 326.59 & 3.86 \\
\hline \multicolumn{1}{|c|}{ Totals } & 663 & $100.00 \%$ & 8465.03 & $100.00 \%$ \\
\hline
\end{tabular}


Table 12-48. Bos taurus Bone from The Webb Trash Dump, Classified by Meat Cut Represented

\begin{tabular}{||l|r|r|r|r||}
\hline \multicolumn{1}{|c|}{ Name } & \multicolumn{1}{c|}{$\#$} & \multicolumn{1}{c|}{ \% } & Weight (g) & \multicolumn{1}{c|}{$\%$} \\
\hline Short Loin & 131 & 15.04 & 1967.22 & 8.95 \\
\hline Rib & 42 & 4.82 & 648.02 & 2.95 \\
\hline Sirloin & 45 & 5.17 & 962.67 & 4.38 \\
\hline Round & 37 & 4.25 & 1470.2 & 6.69 \\
\hline Rump & 43 & 4.94 & 897.76 & 4.09 \\
\hline Chuck & 185 & 21.24 & 2860.88 & 13.02 \\
\hline Arm & 39 & 4.48 & 2099.57 & 9.56 \\
\hline Cross/Short Lib & 129 & 14.81 & 1623.93 & 7.39 \\
\hline Brisket & 2 & 0.23 & 33.76 & 0.15 \\
\hline Short Plate & 3 & 0.34 & 25.94 & 0.12 \\
\hline Neck & 75 & 8.61 & 1419.24 & 6.46 \\
\hline Foreshank & 72 & 8.27 & 3562.79 & 16.22 \\
\hline Hindshank & 60 & 6.89 & 4308.45 & 19.61 \\
\hline Feet and Head & 8 & 0.92 & 89.14 & 0.41 \\
\hline Totals & 871 & $\mathbf{1 0 0 . 0 0 \%}$ & 21969.57 & $100.00 \%$ \\
\hline
\end{tabular}

Table 12-49. Calculations of Estimated Meat Represented by Bone Weight, Costs Per Pound, and Total Costs for Privy \#1

\begin{tabular}{|c|c|c|c|c|c|c|c|c|}
\hline $\begin{array}{c}\text { Cut } \\
\text { Code }\end{array}$ & $\begin{array}{l}\text { \% Bone } \\
\text { in Cut }\end{array}$ & $\begin{array}{c}\text { Bone } \\
\text { Weight (g) }\end{array}$ & $\begin{array}{c}\text { Est. Total Meat } \\
\text { Purchased (g) }\end{array}$ & $\begin{array}{c}\text { Est. Total } \\
\text { Meat } \\
\text { Purchased (lbs) }\end{array}$ & $\begin{array}{l}\text { Cost per } \\
\text { lb. } \\
\text { (\$) }\end{array}$ & $\begin{array}{c}\text { Est. Total } \\
\text { Cost } \\
(\$)\end{array}$ & $\begin{array}{l}\text { \% of Total } \\
\text { Cost }\end{array}$ & $\begin{array}{l}\text { \% of Total } \\
\text { Weight }\end{array}$ \\
\hline 1 & 33 & 49.57 & 150.21 & 0.34 & 0.20 & 0.067 & 7.20 & 2.46 \\
\hline 2 & 24 & 99.97 & 416.54 & 0.93 & 0.14 & 0.130 & 13.97 & 6.82 \\
\hline 3 & 43 & 65.36 & 152.00 & 0.34 & 0.13 & 0.044 & 4.73 & 2.49 \\
\hline 4 & 40 & 0.00 & 0.00 & 0.00 & 0.11 & 0.000 & 0.00 & 0.00 \\
\hline 5 & 48 & 134.96 & 281.17 & 0.63 & 0.07 & 0.044 & 4.72 & 4.61 \\
\hline 6 & 35 & 463.10 & 1323.14 & 2.95 & 0.11 & 0.325 & 34.87 & 21.67 \\
\hline 7 & 35 & 142.59 & 407.40 & 0.91 & 0.08 & 0.073 & 7.81 & 6.67 \\
\hline 8 & 50 & 278.03 & 556.06 & 1.24 & 0.08 & 0.099 & 10.66 & 9.11 \\
\hline 9 & 59 & 11.34 & 19.17 & 0.04 & 0.09 & 0.004 & 0.41 & 0.31 \\
\hline 0 & 24 & 8.70 & 36.25 & 0.08 & 0.06 & 0.005 & 0.52 & 0.59 \\
\hline 11 & 42 & 527.48 & 1255.90 & 2.80 & 0.01 & 0.028 & 3.01 & 20.57 \\
\hline 12 & 43 & 288.13 & 530.53 & 1.18 & 0.04 & 0.047 & 5.08 & 8.69 \\
\hline 13 & 57 & 556.76 & 976.77 & 2.18 & 0.03 & 0.065 & 7.02 & 16.00 \\
\hline Total & & 2.625 .99 & $6,105.14$ & 13.62 & & 0.931 & $100.00 \%$ & 99.99 \\
\hline
\end{tabular}


Table 12-50. Calculations of Estimated Meat Represented by Bone Weight, Costs Per Pound, and Total Costs for Privy \#12

\begin{tabular}{|c|c|c|c|c|c|c|c|c|}
\hline $\begin{array}{c}\text { Cut } \\
\text { Code }\end{array}$ & $\begin{array}{l}\text { \% Bone } \\
\text { in Cut }\end{array}$ & $\begin{array}{l}\text { Weight } \\
\text { (g) }\end{array}$ & $\begin{array}{c}\text { Est. Total Meat } \\
\text { Purchased (g) }\end{array}$ & $\begin{array}{l}\text { Est. Total Meat } \\
\text { Purchased (lbs) }\end{array}$ & $\begin{array}{c}\text { Cost per } \\
\text { lb. }\end{array}$ & $\begin{array}{c}\text { Est. Total } \\
\text { Cost }\end{array}$ & $\begin{array}{c}\text { \% of Total } \\
\text { Cost }\end{array}$ & $\begin{array}{c}\text { \% of Total } \\
\text { Weight }\end{array}$ \\
\hline 1 & 33 & 495.51 & $1,501.55$ & 3.35 & 0.20 & 0.670 & 10.77 & 4.47 \\
\hline 2 & 24 & 366.83 & $1,528.46$ & 3.41 & 0.14 & 0.478 & 7.68 & 4.55 \\
\hline 3 & 43 & 705.23 & $1,640.07$ & 3.66 & 0.13 & 0.476 & 7.65 & 4.88 \\
\hline 4 & 40 & $1,395.66$ & $3,489.15$ & 7.79 & 0.11 & 0.857 & 13.77 & 10.39 \\
\hline 5 & 48 & $2,211.06$ & $4,606.38$ & 10.28 & 0.07 & 0.720 & 11.57 & 13.72 \\
\hline 6 & 35 & 845.67 & $2,416.20$ & 5.39 & 0.11 & 0.593 & 9.53 & 7.19 \\
\hline 7 & 35 & $2,005.10$ & $5,728.86$ & 12.79 & 0.08 & 1.023 & 16.44 & 7.06 \\
\hline 8 & 50 & $2,463.10$ & $4,926.20$ & 11.00 & 0.08 & 0.880 & 14.14 & 14.67 \\
\hline 9 & 59 & 3.89 & 6.59 & 0.01 & 0.09 & 0.001 & 0.02 & 0.02 \\
\hline 10 & 24 & 15.61 & 65.04 & 0.15 & 0.06 & 0.009 & 0.14 & 0.19 \\
\hline 11 & 42 & 763.00 & $1,816.67$ & 4.06 & 0.01 & 0.041 & 0.65 & 5.41 \\
\hline 12 & 43 & $1,604.97$ & $3,732.49$ & 8.33 & 0.04 & 0.333 & 5.36 & 11.11 \\
\hline 13 & 57 & $12,11.73$ & $2,125.84$ & 4.75 & 0.03 & 0.142 & 2.29 & 6.33 \\
\hline Total & & $14,087.36$ & $33,583.49$ & 74.97 & & $\$ 6.222$ & $100.00 \%$ & $99.99 \%$ \\
\hline
\end{tabular}

Table 12-51. Calculations of Estimated Meat Represented by Bone Weight, Costs Per Pound, and Total Costs for Webb Trash Dump

\begin{tabular}{|c|c|c|c|c|c|c|c|c|}
\hline $\begin{array}{l}\text { Cut } \\
\text { Code }\end{array}$ & $\begin{array}{l}\text { \% Bone } \\
\text { in Cut }\end{array}$ & $\begin{array}{c}\text { Bone } \\
\text { Weight (g) }\end{array}$ & $\begin{array}{l}\text { Est. Total } \\
\text { Meat } \\
\text { Purchased } \\
\text { (g) }\end{array}$ & $\begin{array}{l}\text { Est. Total } \\
\text { Meat } \\
\text { Purchased } \\
\text { (lbs) }\end{array}$ & $\begin{array}{c}\text { Cost } \\
\text { per lb. }\end{array}$ & $\begin{array}{l}\text { Est. Total } \\
\text { Cost }\end{array}$ & $\begin{array}{c}\% \text { of Total } \\
\text { Cost }\end{array}$ & $\begin{array}{c}\text { \% of Total } \\
\text { Weight }\end{array}$ \\
\hline 1 & 33 & $1,967.22$ & $5,961.27$ & 13.31 & $\$ 0.20$ & $\$ 2.661$ & 21.17 & 9.48 \\
\hline 2 & 24 & 1,541 & $6,420.83$ & 14.33 & $\$ 0.14$ & $\$ 2.007$ & 15.96 & 10.21 \\
\hline 3 & 43 & 962.67 & $2,238.77$ & 5.00 & $\$ 0.13$ & $\$ 0.650$ & 5.17 & 3.56 \\
\hline 4 & 40 & $1,470.2$ & $3,675.50$ & 8.20 & $\$ 0.11$ & $\$ 0.90$ & 7.18 & 5.85 \\
\hline 5 & 48 & 897.76 & $1,870.33$ & 4.17 & $\$ 0.07$ & $\$ 0.292$ & 2.32 & 2.97 \\
\hline 6 & 35 & $2,860.88$ & $8,173.94$ & 18.25 & $\$ 0.11$ & $\$ 2.007$ & 15.96 & 13.00 \\
\hline 7 & 35 & $2,099.57$ & $5,998.77$ & 13.39 & $\$ 0.08$ & $\$ 1.071$ & 8.52 & 9.54 \\
\hline 8 & 50 & 4577.1 & $9,154.20$ & 20.43 & $\$ 0.08$ & $\$ 1.635$ & 13.00 & 14.56 \\
\hline 9 & 59 & 33.76 & 57.22 & 0.13 & $\$ 0.09$ & \$0.011 & 0.09 & 0.09 \\
\hline 10 & 24 & 25.94 & 108.08 & 0.24 & $\$ 0.06$ & $\$ 0.014$ & 0.12 & 0.17 \\
\hline 11 & 42 & $1,419.24$ & $3,379.14$ & 7.54 & $\$ 0.01$ & $\$ 0.075$ & 0.60 & 5.37 \\
\hline 12 & 43 & $3,562.79$ & $8,285.56$ & 18.49 & $\$ 0.04$ & $\$ 0.740$ & 5.88 & 13.18 \\
\hline 13 & 57 & $4,308.45$ & $7,558.68$ & 16.87 & $\$ 0.03$ & $\$ 0.506$ & 4.03 & 12.02 \\
\hline Total & & $25,726.58$ & $62,882.31$ & 140.35 & & $\$ 12.572$ & $100.00 \%$ & $100.00 \%$ \\
\hline
\end{tabular}


Table 12-52. Comparison of Percentages of Estimated Total Meat Purchased in the Mid- and Low-Priced Categories

\begin{tabular}{|l|r|r|c|}
\hline \hline \multirow{2}{*}{$\begin{array}{l}\text { \% of Estimated Total Meat } \\
\text { Purchased }\end{array}$} & Mueller & Klar & Webb \\
\cline { 2 - 4 } & 67.21 & 66.52 & 57.96 \\
\hline
\end{tabular}

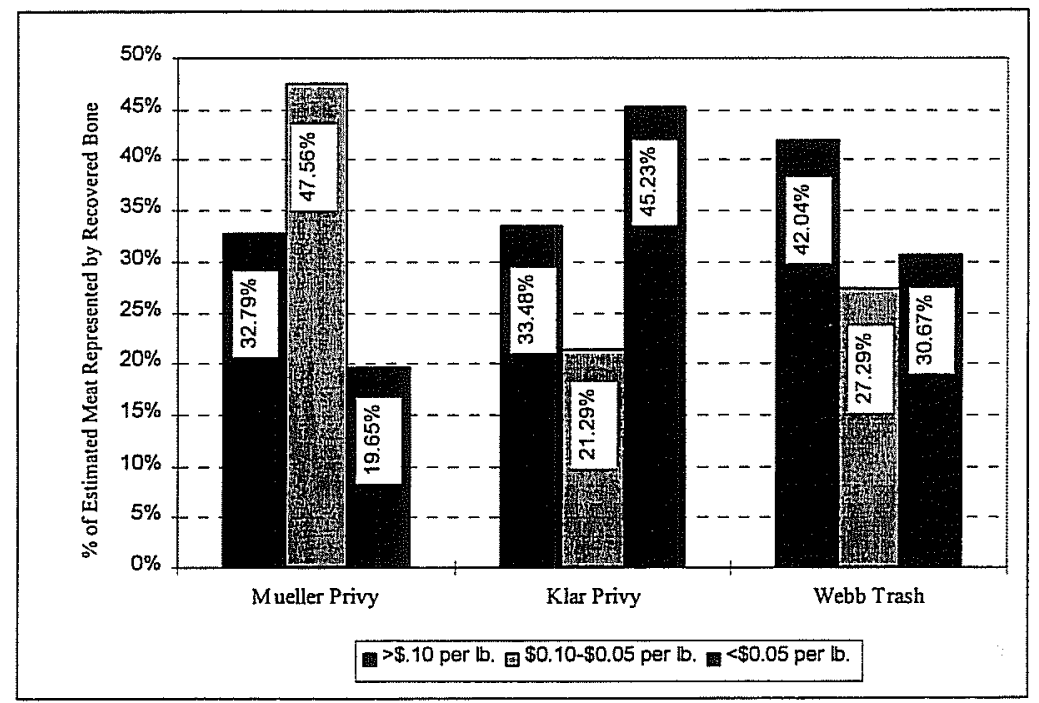

Figure 12-5. Comparison of expensive, mid-priced, and cheap meats, as a percentage of total weight purchased.

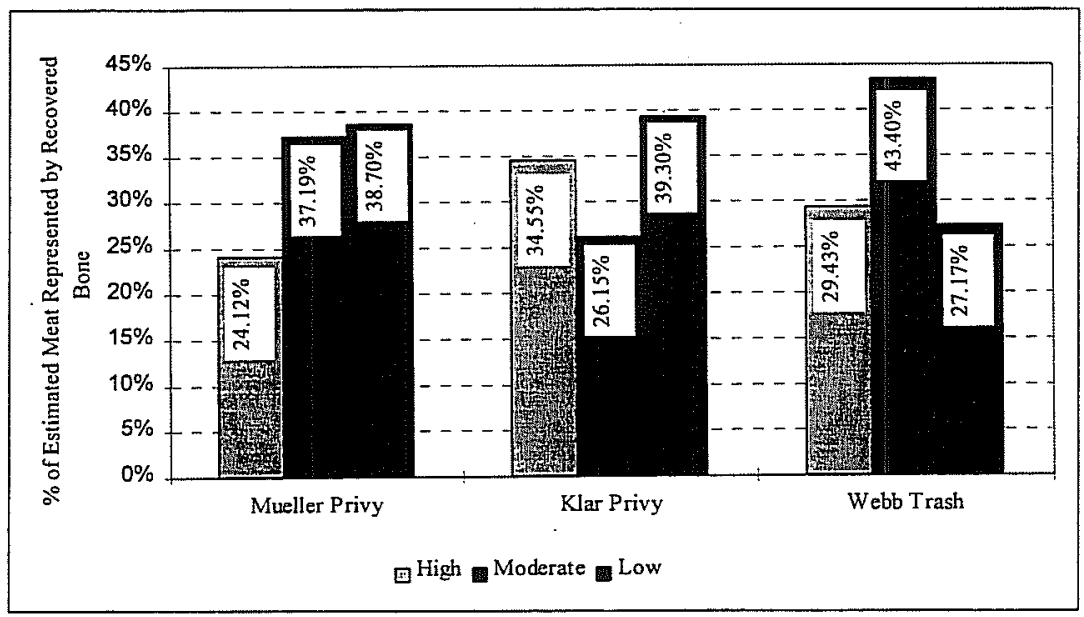

Figure 12-6. Comparison of cost efficiency (Lyman 1987) as a percentage of total weight purchased. 
However, the Klars bought more meat in the highefficiency category than either the Muellers or the Webbs. They also had the highest percentage of lowefficiency cuts. When the percentages of high and moderate-cost-efficient meats are combined, the Webbs (72.83 percent) are clearly more cost efficient than either the Muellers (61.3 percent) or the Klars ( 60.70 percent). The percentages of weight purchased also agrees with the socioeconomic ranking of the three families as expected from archival research and as seen in their ceramics, if it is indeed true that higher-status families are less cost efficient. However, distinction between the three families in this figure are more ambiguous.

Two observations are of particular interest. As seen in Figure $12-6$, the Webbs have a very high proportion of moderate efficiency cuts. This is due largely to the enormous number of lumbar vertebrae, representing short loin cuts, found in the trash dump, 131 of 871 , or 15.04 percent, of the Bos taurus bone identifiable to meat cut represented. Note that for the Klar and Mueller privies, lumbar vertebra constituted only 3.42 percent ( 8 of 234) and 4.98 percent (33 of 663), respectively, of the total beef which could be identified to meat cut. The short loin is the most expensive meat cut, ranking \#1 on Schulz and Gust's ranking by meat cost, but is listed as moderately efficient by Lyman (1987). Were the Webbs purchasing these large numbers of expensive cuts to impress the neighbors with their financial standing? Were they buying short loin because they understood that short loin cuts were fairly cost efficient despite their high cost, and were the most preferred of the moderately efficient cuts available? Or can the explanation be simply that, having killed a cow in the open range, the successful hunter would bring back only the very best parts of the cow, including the short loin? In that situation, the "cost" would not be the price per pound. It is this latter explanation which seems to make the most sense.

The other interesting observation is the very high percentage, by weight, of both high and low efficiency meat cuts in the Klar privy. Recall that the material considered butchers' waste, including head, foot and tail elements, are not included in the cost efficiency ranking. It is very tempting to suppose that the Klar family was eating whatever remained in the butcher shop at the end of the day. If their customers were purchasing mostly moderately cost-efficient meat cuts, as the Muellers did (Figure 12-6), then it would be the most and least efficient cuts which would tend to remain at the end of the day. Though this speculation cannot be confirmed, it would explain the data presented in Figure $12-6$.

\section{Discussion}

The answer to the first of the questions proposed above is, a qualified, yes, the remains of Bos taurus from the two privies and the trash dump do exhibit differences, however, the answer to the second part of the question is no. The socioeconomic ranking of the three households by analysis of meat cut costs does not match previous estimations of socioeconomic ranking by archival research and ceramic costs. In fact, it is just the opposite.

The difference in the three families does match archival and ceramic evidence concerning their relative socioeconomic status when looking at the meat cuts in terms of their cost efficiency (Lyman 1987), if: 1) the archival and ceramic evidence have accurately ranked the socioeconomic status of the three families; and 2) the hypothesis that lower-status families make more cost-efficient purchases is correct.

This cost-efficiency ranking must be taken with reservations, as it is based on the assumption that all beef was purchased at retail prices, and as we have shown, the Webbs may have been hunting some of their beef and the Klars may have been eating left-over meat from the butcher shop. However, the cost efficiency ranking does seem to match the estimated socioeconomic status of the three families, in spite of the variation in acquisition methods of the three families, though the data are ambiguous. While the difference in cost efficiency between the Muellers and the Webbs is clear, the position of the Klars is harder to estimate from the cost efficiency data.

Data from many more historic contexts concerning the cost efficiency of consumer meat purchases and the relationship of this cost efficiency to their socioeconomic ranking must be acquired in order to eliminate, as much as possible, such uncontrolled and uncontrollable variables as the effects of particular circumstances, and the eccentricity of individual human behaviors. In the mean time, we can say that the 
evidence of the meat cut analysis reported here suggests that cost efficiency in beef purchases is inversely proportional to economic standing. Further data is needed to confirm this suggestion.

\section{Conclusion}

This report is a preliminary and limited examination of the vertebrate faunal material from the Alamodome Project. We have listed the identified species for each site, and discussed some of the variations found. We have noted the unexpected near-absence of wild animal bone, even in sites which are known to have been inhabited during the years before 1880 , when the neighborhood stood at the very edge of town. We have also noted that the only signs of significant amounts of hunting occurred at the King site (41BX883, Privy \#1), the Demazieres site (41BX896, Privy \#5) and the Pauly site (41BX945, Privy \#12). Of these, only the deposits at the Pauly site indicate extensive hunting and use of the hunted animals for food on the same premises. However, the majority of the identified faunal remains, 62.30 percent $(4,682$ of 7,515$)$, are from domestic food animals, cattle, pigs, goats, and sheep.

We have also noted that beef was by far the most favored meat in the neighborhood. A total of 74.35 percent $(n=3,481)$ of domestic stock bone recovered was from Bos taurus. While noting that in the nineteenth century pigs were more favored in the Southeast, we have shown that newcomers to the San Antonio area adapted to the more western practice of raising cattle instead, a pattern which is probably ultimately related to environmental conditions.

The general impression of the portion of the vertebrate faunal remains found outside the two privies and the trash dump discussed above is that of scattered trash. In addition, we can add that most of it is probably more recent than the bone in the privies and trash dump. Our data show that 91.92 percent of the bone not from the two privies and the trash pit described above, which showed butcher marks, was machine saw cut. Of the bone in the two privies and trash dump which showed butcher marks only 7.80 percent $(187$ of 2,398$)$ were machine sawed. We suspect, therefore, that much of the bone not in the two privies or trash pit was deposited at a later date, after machine saws had become standard in San Antonio.
From the two privies and the trash dump, we were able to show that the ranking of the three families by the extent of their use of cost-efficient cuts of beef is roughly the inverse of their socioeconomic ranking, that is, the family with the lowest socioeconomic ranking, the Webbs, used the most cost-efficient meat cuts, while the Muellers, at the top of the socioeconomic ranking, used the least cost-efficient meat cuts. While this data seems to confirm the assumption made by Lyman (1987), there are enough extraneous variables which could effect this interpretation to make us cautious. We feel that more data from historic sites is necessary to prove that cost efficiency in meat purchases can be used as an indicator of socioeconomic ranking. We would also like to have more data from African-American families in the time period between 1870 and 1920, as it is at least possible that what we have interpreted as an inverse correlation between cost efficiency and socioeconomic status could in fact be strongly effected by difference in ethnicity. In other words, the Webbs may have been more cost efficient users of beef because of ethnic traditions instead of because of lower socioeconomic class. More data is needed to determine if ethnicity is a factor in cost-efficient consumer purchases or if it is entirely a matter of economics and/or social class. 


\section{References Cited}

Bieber, R. P.

1940 Introduction. In Historic Sketches of the Cattle Trade of the West and Southwest, by J. G. McCoy. The Southwest Historical Series, Vol. VIII, edited by R. P. Bieber. Arthur H. Clark Company, Glendale, California.

Bomar, G. W.

1995 The Climate of Central and East Texas. In The Changing Climate of Texas: Predictability and Implications for the Future, edited by J. Norwine, J. R. Giardino, G. R. North, and J. B. Valdéz, pp. 76cost-efficient91. Texas A\&M University Press, College Station.

Cantrell, G.

1990 Racial Violence and Reconstruction Politics in Texas, 1867-1868. Southwestern Historical Quarterly 93:333-355.

Cheek, C. B., and A. Friedlander

1990 Pottery and Pigs' Feet: Space, Ethnicity, and Neighborhood in Washington, D.C., 1880-1940. Historic Archaeology 24(1):34-60.

Clemen, R. A.

1923 The American Livestock and Meat Industry. Ronald Press, New York.

Clonts, J. B.

1983 Some Long Overdue Thoughts on Faunal Analysis. In Forgotten Places and Things: Archaeological Perspectives on American History, edited by A. E. Ward, pp. 349-354. Center for Anthropological Studies, Albuquerque.

Davis, W. B., and D. J. Schmidly

1994 The Mammals of Texas. Texas Parks and Wildlife, Austin.

Davidson, P. E.

1982 Patterns in Urban Food Ways: An Example from Early Twentieth Century Atlanta. In Archaeology of Urban America: The Search for Pattern and Process. Academic Press, New York.

Eakins, H. S.

1924 Military Meat and Dairy Hygiene. Williams and Wilkins, Baltimore.

Freeman, M. D.

1972 A History and Chronology: Public Markets in San Antonio. San Antonio Development Agency, San Antonio.

Gilbert, B. M.

1990 Mammalian Osteology. Missouri Archaeological Society, Columbia, Missouri.

Gust, S. M.

1983 Problems and Prospects in Nineteenth Century California Zooarchaeology. In Forgotten Places and Things: Archaeological Perspectives on American History, edited by A. E. Ward, pp. 341-348. Center for Anthropological Studies, Albuquerque. 
Henry, S. L.

1987 Factors Influencing Consumer Behavior in Turn-of-the-Century Phoenix, Arizona. In Consumer Choice in Historical Archaeology, edited by S.M. Spencer-Wood, pp. 359-381. Plenum, New York.

Hilliard, S. B.

1972 Hog Meat and Hoecake: Food Supply in the Old South, 1840-1860. Southern Illinois University Press, Carbondale.

Hillson, S.

1986 Teeth. Cambridge University Press, Cambridge.

Huelsbeck, D. R.

1991 Faunal Remains and Consumer Behavior: What $I s$ Being Measured? Historic Archaeology 25(2):62-76.

Jordan, T. G.

1966 German Seed in Texas Soil: Immigrant Farmers in Nineteenth-Century Texas. University of Texas Press, Austin.

Logan, H. C.

1959 Cartridges: A Pictorial Digest of Small Arms Ammunition. Bonanza Books, New York.

Lyman. R. L.

1977 Analysis of Historic Faunal Remains. Historic Archaeology 11:67-73.

1979 Available Meat from Faunal Remains: A Consideration of Techniques. American Antiquity 44(3): 536-546.

1987 On Zooarchaeological Measures of Socioeconomic Position and Cost-Efficient Meat Purchases. Historic Archaeology 21(1):58-66.

1994 Vertebrate Taphonomy. Cambridge University Press, Cambridge.

McCoy, J. G.

1940 Historic Sketches of the Cattle Trade of the West and Southwest. Arthur H. Clark, Glendale, California.

Meinig, D. W.

1975 Imperial Texas: An Interpretive Essay in Cultural Geography. University of Texas Press, Austin.

Meissner, B. A.

1992 Black and White: Evidence of Economic Parity in a Black Family in a White Neighborhood, 1866-1910 Paper presented at the annual meeting of the Society for Historical Archaeology, Kingston, Jamaica, January 9, 1992.

Mudar, $\mathbf{K}$.

1977 The Effects of Socio-Cultural Variables on Food Preferences in Early 19th Century Detroit. The Conference on Historic Archaeology Papers 12: 323-391.

Norwine, J.

1995 The Regional Climate of South Texas: Patterns and Trends. In The Changing Climate of Texas: Predictability and Implications for the Future, edited by J. Norwine, J. R. Giardino, G. R. North, and J. B. Valdéz, pp. 138-154. Texas A\&M University Press, College Station. 
Olsen, S. J.

1964 Mammal Remains from Archaeological Sites Part I; Southeastem and Southwestern United States. Peabody Museum, Cambridge.

1968 Fish, Amphibian, and Reptile Remains from Archaeological Sites Part I: Southeastern and Southwestern United States. Peabody Museum, Cambridge.

1969 Post-Cranial Skeletal Characters of Bison and Bos. Kraus Reprint, New York.

Page, L. M., and B. M. Burr

1991 A Field Guide to Freshwater Fishes: North America North of Mexico. The Peterson Field Guide Series, No. 42. Houghton Mifflin, Boston.

Paulus, $\mathrm{M}$.

1939 Fifteen Years in Old San Antonio, 1850-1865. Unpublished Master's thesis on file, Center for Archaeological Research, The University of Texas at San Antonio.

Robbins, C. S., B. Bruun, and H. S. Zim

1983 Birds of North America: A Guide to Field Identification. Golden, N.Y.

Schulz, P. and S. Gust

1983 Faunal Remains and Social Status in 19th Century Sacramento. Historical Archaeology 17:44-53.

Steinfeldt, C.

1978 San Antonio Was: Seen Through a Magic Lantern. San Antonio Museum Association, San Antonio.

Warner, M. S.

1995 From the Market and From the Water: An African-American Household's Changing Responses to a Commercial Marketplace. Paper presented at the Annual Meeting of the Society for Historical Archaeology, Washington D.C.

Wheeler, A., and A. K. G. Jones

1989 Fishes. Cambridge University Press, Cambridge.

Woodward, C. V.

1957 The Strange Career of Jim Crow: A Brief Account of Segregation. Oxford University Press, Oxford. 


\title{
Chapter 13 Summary
}

\author{
Anne A. Fox
}

\section{General Project History}

The archaeological investigations at the site of the Alamodome were done in response to the Antiquities Code of Texas that delegates to the Texas Antiquities Committee legal custody of "all cultural resources, historic and prehistoric, within the public domain of the State of Texas" (Texas Antiquities Code, Texas Antiquities Committee, Austin, 1983). The project was done under three successive permits issued by the Committee during the various phases of the work.

Acceptance of the underlying principle that the city is a complex, ever-evolving organism (Havlick 1974) and that the city's cultural and physical components are "interrelated in a dynamic system" (Dickens and Crimmins 1982:107) requires that no segment of the city's history go unrecorded if we are to understand what makes our city operate today. Driven by this realization, historical archaeologists have carried out projects in numerous urban areas of the United States as concern has grown over the tendency to reconstruct large areas of our cities with little regard for the unrecorded history that is being destroyed in the process. Projects in Tucson (Wilk and Schiffer 1979), New York (Rothschild 1990), Philadelphia (Cotter and Orr 1975), Detroit (Pilling 1982), Alexandria (Cressey and Stephens 1982), Atlanta (Dickens and Crimmins 1982), and most recently, in Houston (Klein 1986) and Austin, Texas (manuscript in preparation) have made important contributions to the historical background of these cities. Most of these studies have been done in the inner-city or "downtown" areas where lots have contained numerous specialized economic activities such as stores and other businesses. Changing uses dictated the building and rebuilding of structures on each lot (Rothschild and Rockman 1982:6). The confusion and complicated stratification caused by these activities has been avoided throughout much of the Alamodome site, which started as open farmland, was divided into suburban lots, and was gradually becoming an industrial section of the city when the Alamodome Project began.

The fact that numerous large downtown areas have been razed with no particular concern to capture the history of the neighborhoods being destroyed in the process has given added impetus to the planning of this project. Added to this was the growing realization as we examined the area to be affected that a large percentage of the lots involved had never been built over. These, therefore, held potential for preservation of original living surfaces, as well as undisturbed features such as outbuilding foundations, wells and cisterns, and privy vaults which should contain volumes of information about the living habits of several generations of San Antonio residents during the past 100 years. This information is particularly important because of the lack of interest until recently in urban dwellers during that time.

While it may seem at first that archaeological research about the 1900-plus time period is too recent to be significant, the gradual creep of the arbitrary 50-year point set by legislation as the line at which a cultural property is to be considered of historical importance makes the study of more "recent" history imperative. Before we know it, large sections of our cities and their suburbs have become historic sites which require archaeological investigations before construction projects are begun. 
The plans for this project were guided by preliminary examination of the area to be impacted by the Alamodome structure and parking areas, aided by previous knowledge of the general development of this part of the city. In addition we were goaded by the awareness of the time that has passed since the construction of Victoria Courts and the HemisFair and the probability that the opportunity for obtaining oral histories from people who remembered those areas before their demolition would soon be impossible. We anticipated that there would be an opportunity to learn a great deal about a San Antonio population never before studied: a working-class neighborhood of mixed ethnicity that was only sparsely occupied until after the Civil War.

Research advances were anticipated on many fronts. This would be an opportunity to relate the development of the east side of San Antonio to the city's general history, to apply various archaeological methods to an urban site and determine which were most advantageous, and for the first time to research the recent developmental history of twentieth-century artifacts in the hope of finding ways to use them to date archaeological deposits.

The project was planned to be done in phases, starting with archival, architectural, and historical research and oral history interviews. This phase was to be followed by a testing phase in which selected lots would be examined for determination of locations of privies, wells, and artifact deposits that would in turn require a mitigation phase before construction began. The choice of which lots to be investigated would be based on the findings of the Phase I research, looking for sites of distinct ethnic backgrounds that appeared to be relatively undisturbed, as well as examples of structures representative of different time periods and styles present in the area.

In actuality, the first, or research phase of the project went as planned, but the pressures of the construction schedule for the Alamodome caused some changes and compression of the later phases, as is often the case with large archaeological/construction projects. The testing phase was somewhat complicated by the need to coordinate with the demolition of the houses, particularly in the area where excavation for the Alamodome building was to be done, and the clearing of a "laydown" area for the storage of construction materials and the headquarters trailers. Because of the tight schedule for completion of the Alamodome, it was necessary to somewhat combine the testing and mitigation phases in this area, leaving some of the testing of other areas until we could get out of the way of the demolition and construction crews. Ideally, this could have been avoided by commencing the archaeological project farther in advance of the demolition/ construction work, but in this case that was apparently impossible.

\section{Results}

One basic objective of the project was not so much to determine ethnicity as to see if any pattern of artifact acquisition or disposal might serve as an ethnic indicator. Ethnic patterns appear to be less and less detectable in the second or third generation after immigration and in the post-World War I period of mass production and distribution. At this point in our research, social and economic levels appear to be the more important determining factors, rather than ethnicity.

One of the most interesting conclusions resulting from our research on this and other downtown San Antonio sites is that enclaves or suburbs surrounding the business district were not totally exclusive to one particular ethnic group. Thus, although an area might traditionally have earned an ethnic designation such as "the Irish Flats" or "the Little Rhein," there were actually mixtures of ethnic families within these areas. On the whole there was little apparent prejudice toward one group or another during the nineteenth century and the earliest years of the twentieth century. It was not until the early 1900 s that neighborhoods made up of one ethnic group or another began to form.

In the earlier period, residential groupings within the city tended to be more by family or close friends than by ethnicity (Mock 1994:2). Choice of home locations depended mostly on the place of employment or proximity to public transportation (Mock 1994:4). This was particularly true of the Alamodome area, where the early German homeowners were gradually joined by Polish immigrant families and African-Americans, and later by second and third-generation HispanicAmerican and Anglo-American families. The emphasis on home ownership among all of these people ensured 
the preservation of the housing stock, and the neat, well-kept appearance of the neighborhood reflected the pride of the residents and their consciousness of being a community where they looked out for each other and seldom locked their doors (Roger Garcia, Oral History Interview 1990).

\section{Architectural History And Evolution}

The fact that most of the houses in the Alamodome neighborhood were built within a limited time period (ca. 1870-1930) presented an opportunity to use changing architectural styles in San Antonio to reconstruct a neighborhood's development. Based on the complete photographic record of the existing buildings in the area provided by Andrew Perez Associates (Andrew Perez and Associates 1990) and expanding on their residential type descriptions, we have been able to draw up a time sequence of house types. Arranging the Alamodome houses in house-type groupings by address produces an interesting demonstration of the growth of the neighborhood through time. Comparison of the results of this type of analysis applied to two similar, but slightly different, San Antonio neighborhoods suggests a number of conclusions that can be drawn from this type of analysis in terms of ethnic and income differences of the homeowners.

\section{Site Layout}

Past experience in San Antonio urban sites and study of the Sanborn Insurance Maps of the Alamodome area prepared us to expect a rather dependably uniform lot layout. In the time period of this neighborhood, houses were set on rectangular lots, the pattern of which reflected the original division of the blocks into 16 lots each. Later lot line changes altered lot sizes somewhat, but nearly always kept most of the feeling of the original layout. A few alleys later divided the blocks, but were not part of the original plan. Remarkably few alterations were made in this pattern until the arrival of industries such as the Alamo Iron Works that gradually cleared whole blocks in the northern section and constructed buildings covering half or more of a block.
We anticipated that individual lots would all be laid out in a similar manner. The house would be centered on the lot, $10-15 \mathrm{ft}$ from the front lot line. Auxiliary buildings such as storage sheds, privies, and housing for chickens and other backyard animals and pets would be built against or adjacent to the side and back lot lines. By the time of the earliest Sanborn Map of this area (1904) the wells had been covered and filled and were no longer indicated.

Excavation during the project confirmed these expectations (Wright, Volume II). It was also obvious that when older storage sheds, etc., were replaced by new ones, the same arrangement was followed. This particular lot plan, independent of occupation or social stratum of the occupant, has been followed in San Antonio from the time the town was first laid out, and probably merely represents the most efficient use of a small city lot. Deagan (1982:198) found the same was true of eighteenth-century St. Augustine. The only noticeable difference between the appearance of the nineteenth- to twentieth-century neighborhood layout and that of the eighteenth-century settlement around the plazas is the Spanish custom of building the front walls of houses directly on the front lot line. The gradual development of the commercial downtown center meant that as commercial buildings replaced houses on the main streets, they also built directly on the street. However, in residential areas, even immediately adjacent to the business center, later houses were set back $10 \mathrm{ft}$ or more from the sidewalk (Fox et al. 1989; Nightengale et al. 1989).

The term suburbs today generally refers to promotions by land developers in areas outside the city core. Studies of the development of San Antonio reveal that suburban development by local entrepreneurs began in the mid-nineteenth century in areas directly north, east, and south of the plazas. Thus by the end of the Civil War, there were suburban areas of small houses, trees, and gardens within a few blocks of the commercial center of town. The Alamodome neighborhood was such a suburb.

\section{Artifacts}

Archaeological excavation of sites whose occupation extended so late into the present century produced a challenge to excavators and analysts alike. Knowledge 
of the dating of artifacts commonly found in sites of the mid- to late-nineteenth century had been well established by numerous earlier CAR projects. This knowledge made understanding nineteenth-century contexts relatively simple. However, the largest percentage of undisturbed deposits which merited controlled mitigative excavations consisted of materials of the 1910 to 1940 time period and in some cases, beyond this. Relatively little research has been done anywhere about artifacts of this period. New inventions, new materials, and new uses for familiar materials all combined to complicate the situation.

Carefully controlled excavations produced a body of artifacts with good relative provenience, wherever this was pertinent, but in most cases deposits appeared to have been accumulated within a short period of time. Individual staff members were then assigned particular artifact types with the intent of developing chronologies necessary for understanding what was happening in the neighborhood during the twentieth century. Mail order catalogs; bottle, button, and dollcollectors' books; and local newspaper advertisements were studied for clues. Numerous telephone calls were made to distributors and manufacturers asking for company histories, either written or verbal. In all, over a year of this kind of research has produced the contents of this volume. We hope it will be useful to others working in this time period, as it has been for us.

One of the hopes we had when planning this project was that we would find correlation between artifacts and ethnicity. Although we had the great good fortune to find a site first settled in the 1860 s by an AfricanAmerican family who continued to live there until the final house was demolished in the mid-twentieth century, it was not possible to determine that differences observed in artifact categories were any more likely to be the result of difference in ethnicity than of social and economic differences.

\section{Evolution of the Urban Infrastructure}

Two types of structures directly related to life in the Alamodome neighborhood dealt with the basic necessities of life: a water supply and the problems of garbage and waste disposal. When the area was first settled in the 1850 s, the town had become acquainted with the fact that polluted wells and the accumulated filth probably had something to do with the spread of disease, although the general public was slow to do anything about it. During Civil War times, kitchen waste continued to be thrown into the back yard where it attracted flies and rats (James 1938:133). Resistance to change among the homeowners meant that improvements in garbage and waste disposal were very slow to appear in San Antonio. However, by the mid1880 s city ordinances governing the collection of garbage and the location and cleaning of privies were in place.

The growing concern about cleanliness was reflected in the 12 privies investigated during this project. All of the privy vaults but one were lined in some fashion, probably to aid in cleaning them out and increasing their uselife. Linings consisted of brick, limestone, cedar posts, wooden crates, and a wooden trunk. The concern for control of privy deposits was only within the city limits, where the population was densest and the lots were comparatively small. People living in the country, where space was not at a premium and neighbors were some distance away, continued the custom of digging privy vaults, filling them, and digging another, moving the upper housing of the privy from one location to another.

Availability of water has been a concern of San Antonio citizens from the founding of the town. One of the first tasks of the inhabitants after they arrived was to build acequias to channel the water of the San Antonio River and San Pedro Creek through the town for irrigation and household use. When the first suburbs were laid out, care was taken to locate them within reach of the various acequias and their lateral ditches wherever possible. Before long, development began to outrun the surface water supply, and people turned to shallow wells and cisterns for their household needs. By this time, the main purpose of the acequias (by this time called ditches) was for irrigation and the disposal of storm waters. Thus, a branch of the old Alamo acequia built through the project area in 1874 was intended primarily for these purposes. The residents of the area at this time were dependent upon other sources for their water. A few dug shallow wells and cisterns and lined them with limestone, but most appear to have used wooden, above-ground cisterns, and water barrels (A. C. Sutton, oral history 1990). 
A public water system was installed in 1878 , but it was considered primarily for fire protection and sanitation. San Antonio residents were stubbornly resistant to the idea of piped water for a number of years thereafter. Water mains were not installed in the project area until after 1900 , and even then, the residents were reluctant to hook up to them. This was probably as much because of the cost of piping and plumbing fixtures as it was resistance to change.

The installation of water mains in the project area signaled the phasing out of privies and wells (cisterns may have lingered because of the advantages of "soft water" for washing purposes). The trash deposited in the resulting depressions in the back yards was found to date from the time the particular residence went on the water system. This limited the resulting artifact collections from the wells and privies to the time period between ca. 1890 and 1920. Careful studies of the excavated strata indicated that the artifacts in the fill had been deposited either all at once or within a very limited period of time. There seemed to be some difference of opinion as to whether to use these abandoned features for trash disposal or to fill them with soil, or in some cases to merely cover the hole with cedar poles and allow the grass to grow over it.

\section{Faunal Study}

The faunal analysis was intended not only to identify what the residents of the Alamodome Project were eating and how their preferences may have changed over time, but also who was eating which cuts of meat and what this might imply about family income, ethnicity, and the type of employment of the breadwinner. This is one place where the detailed historical research into individual homeowners was very helpful. Careful analysis of butchering patterns has yielded important information about both the butchering habits and the cuts of meat that are essential to determining individual family and group preferences.

\section{Future Work}

Laws governing historic resource preservation tend to stress the importance of a site's ability to contribute to future research. In the case of the city of San Antonio, future projects should be structured to fill in gaps in our present knowledge of the overall history of the city, including all population groups and social strata, rather than merely repeating work in the types of sites we have already examined.

The Alamodome Project, along with numerous smaller projects done by CAR within the past 10 or 15 years, has adequately sampled late-nineteenth- and early twentieth-century residential sites immediately surrounding the commercial district which were occupied by German, Anglo-American, and Hispanic citizens of the working class.

Working class sites yet to be studied are those settled by the Irish in the area immediately north of Alamo Plaza, called by San Antonians in the nineteenth century the Irish Flats. Another area so far unexamined is the small working class settlement directly south of Hemisfair Park which slightly predates the Alamodome area and contains settlement saltbox houses. Detailed archaeological investigations in these areas would provide data for comparison and contrast with the results of work at the Arciniega site in LaVillita (Katz 1978), the site of Rivercenter Mall (manuscript in preparation), and the Alamodome site.

Another aspect of San Antonio history as yet unstudied is the African-American population. This relatively small but important segment of the city's population has not been studied archaeologically, except for a few families at the Alamodome Project. Of particular interest would be a study of the few free black families present here before the Civil War, those newly freed families such as the Webbs, and their immediate descendants. Our concerns might include an attempt to determine the life styles of these various people and how they changed over the years. Comparisons would also be possible of these people with other ethnic groups when they first arrived in San Antonio and how their lives changed from one generation to the next.

Another group needing further study is the neighborhood in and around the missions. Many of these families are descendants of those who first moved onto the mission lands after secularization, built small houses on the mission ruins, and farmed the surrounding lands that had been cleared and cultivated by the Native Americans and irrigated by the Spanish acequias. Their wells and privies are time capsules of 
their lives, as demonstrated by a well/privy excavated at Mission San José by CAR in 1984 (Hafernik and Fox 1984).

Needed for study and comparison also are latenineteenth-century upper-class home sites such as those in the King William area and sites on Broadway just north of the business district. The difficulty would be to find one that was built before the public water system was installed in order to find a privy and/or well on the site that might contain household trash from the era before garbage collection. 


\section{References Cited}

Andrew Perez Associates

1990 Architectural Inventory and Assessment, Multi-Use Dome Stadium Site, VIA Transit Terminal Site. Interim Report prepared for the Center for Archaeological Research, The University of Texas at San Antonio.

Cotter, J. L. and D. Orr

1975 Historical Archaeology in Philadelphia, Historical Archaeology 9:1-10.

Cressey, P. J., and H. F. Stephens

1982 The City-Site Approach to Urban Archaeology. In Archaeology of Urban America, The Search for Pattern and Process, edited by R. S. Dickens, Jr., pp. 41-62. Academic, New York.

Deagan, $\mathrm{K}$.

1982 St. Augustine: First Urban Enclave in the United States. In North American Archaeologist 3(3):183--205.

Dickens, R. S., Jr., and T. J. Crimmins

1982 Environmental Impact Archaeology in the Urban Setting: A View from Arlants. In Archaeology of Urban America, The Search for Pattern and Process edited by R. S. Dickens, Jr., pp. 105-116. Academic, New York.

Fox, A. A., I, W. Cox, C. L. Highley, and D. Hafernik

1989 Archaeological and Historical Investigations at the Site of the New Bexar County Justice Center in Downtown San Antonio, Texas. Archaeological Survey Report, No. 184. Center for Archaeological Research, The University of Texas at San Antonio,

Hafernick, D, and A. A. Fox

1984 Archaeological Testing of Proposed Sewer Line Locations at Mission San José. Archaeological Survey Report, No. 138. Center for Archaeological Research, The University of Texas at San Antonio.

Havlik, S. W.

1974 The Urban Organism: The City's Natural Resources from an Environmental Perspective. Macmillan, New York.

James, V. L.

1938 Frontier and Pioneer Recollections of Early Days in San Antonio and West Texas. Artes Graficas, San Antonio.

Katz, P.

1978 Archaeological and Historical Investigations in the Arciniega Street Area, Downtown San Antonio, Texas. Archaeological Survey Report, No. 61. Center for Archaeological Research, The University of Texas at San Antonio.

Klein, J.

1986 Dig Reveals City's Past-18 Layers Thick. Houston Downtown Magazine, October 6. 


\section{Mock, S. B.}

1994 An Early African-American Community in San Antonio, Visions of a Good Life. In Historic Assessment Study for the Proposed Downtown Park and Ride Site Development, VIA Project No. 94114C. Prepared by Beaty Saunders Architects, San Antonio.

Nightengale, B. A., A. A. Fox, and I. W. Cox

1989 Archaeological and Historical Investigations a the West End of The Martin and Bowie Streets Connections, San Antonio, Bexar County, Texas. Archaeological Survey Report, No. 186. Center for Archaeological Research, The University of Texas at San Antonio.

Pilling, A. R.

982 Detroit: Urbanism Moves West: Palisaded Fur-Trade Center to Diversified Manufacturing City. North American Archaeologist 3(3):224-242.

Rothschild, N., A.

1990 New York City Neighborhoods, the 18th Century. Academic, New York.

Rothschild, N. A., and D. deZerega Rockman

1982 Method in Urban Archaeology: The Stadt Huys Block. In Archaeology in Urban America, The Search for Pattern and Process, edited by R. S. Dickens, Jr. pp 1-18. Academic, New York..

Wilk, R. and M. B. Schiffer

1979 The Archaeology of Vacant Lots in Tucson, Arizona. American Antiquity 44(3):530-536. 
